SAND79-2330

Unlimited Release

UC-60, 63a, 94c

\title{
SOLSTOR Description and User's Guide
}

Eugene A. Aronson, David L. Caskey, Bill C. Caskey

Prepared by Sandia National Laboratories, Albuquerque, New Mexico 87185

and Livermore, California 94550 for the United States Department

of Energy under Contract DE-ACO4-76DP00789

Printed March 1981 
Issued by Sandia National Laboratories, operated for the United States Department of Energy by Sandia Corporation

\section{NOTICE}

This report was prepared as an account of work sponsored by the United States Government. Neither the United States nor the Department of Energy, nor any of their employees, nor any of their contractors, subcontractors, or their employees, makes any warranty, express or implied, or assumes any legal liability or responsibility for the accuracy, completeness, or usefulness of any information, apparatus, product or process disclosed, or represents that its use would not infringe privately owned rights.

Printed in the United States of America

Available from

National Technical Information Service

U.S. Department of Commerce

5285 Port Royal Road

Springfield, VA 22161

Price: Printed Copy \$ ; Microfiche \$3 
SAND 79-2330

Unlimited Release

Printed March 1981

SOLSTOR DESCRIPTION AND USER'S GUIDE

E. A. Aronson

Applied Mathematics Division, 2646

D. L. Caskey

Systems Analysis Division, 4723

B. C. Caskey

Geo Energy Systems Analysis Division, 4744

\section{$\underline{\text { ABSTRACT }}$}

This report describes the computer simulation code SOLSTOR. The code simulates energy systems in which electricity is generated by either a photovoltaic (PV) system or a wind turbine generator (WTG). Storage may or may not be present. Backup electricity, if needed, is provided either from a utility grid or from a fuel-burning generator. SOLSTOR minimizes the life cycle cost of providing energy by choosing the optimal solar or wind system component sizes. Rates for electricity purchased from the grid can include time-of-day (TOD) energy charges as well as time-of-day peak demand changes. sell-back to the grid of excess collected energy is also considered. 


\section{Contents}

$\underline{\text { Page }}$

I. Introduction. . . . . . . . . . . . 8

II. Economic Analysis . . . . . . . . . . . . . 12

Assumptions . . . . . . . . . . . . . 12

Economic Parameters . . . . . . . . . . 14

Price-Year Present-Value Computation. . . . . . 16

Cost and Timing of Replacements and Overhauls . . . 19

System Annualized Cost in Base Year . . . . . . 20

III. Supply. . . . . . . . . . . . . . . . 22

PV Arrays . . . . . . . . . . . . . 22

Wind Turbines............... 24

IV. Demand. . . . . . . . . . . . . . . . . 27

Heating and Cooling Loads........... . 27

Hot Water Loads . . . . . . . . . . . 30

Lighting and Appliance (Miscellaneous) Loads. . . 33

V. Backup Energy . . . . . . . . . . . . . 35

Utility supplied . . . . . . . . . . . 35

Generator Supplied . . . . . . . . . . 36

VI. Energy Allocation Logic for Utility-Connected Simulation-UE. . . . . . . . . . . . . 37

The UEll System . . . . . . . . . . . . 37

Peak Pricing and Sell-Back Limits......... 43

Strategies

Strategy UEllA............... 44

Strategy UEllB. . . . . . . . . . . 48

Strategy UEllC. . . . . . . . . . . 50

Strategy UElID and Predictive Methods..... 54

Storage Replacement ............. 57

Price-Year and Replacement Costs. . . . . . . 58

VII. Energy Allocation Logic for Stand-Alone Simulation--GE 60

The GE11 System . . . . . . . . . . . 60

Generator Operation and Sizing. . . . . . . . 64 
StrategY GEllA. . . . . . . . . . . 66

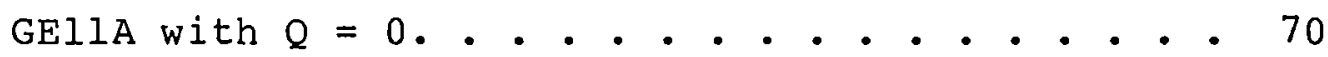

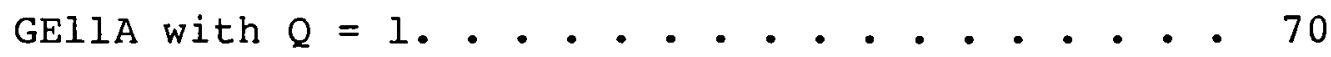

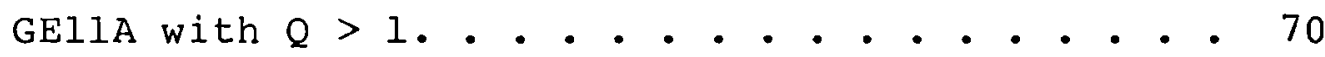

Storage and Generator Replacement and Overhaul. . • 71

Price-Year and Replacement Costs. . . . . . . 71

VIII. Optimization Algorithms . . . . . . . . . . 73

Optimization of UEll. •............ 73

Optimization of GEll. . . . . . . . . . . . 76

IX. SOLSTOR Input/Output. . . . . . . . . . . . 80

Introduction. . . . . . . . . . . . . 80

UEll and GEll Job Control Streams . . . . . . . . 81

TMY Data Input--TAPE 1............... 83

ASHRAE Data Tables-TAPE 2. . . . . . . . . . 84

Demand Data--TAPE 3 (Optional). . . . . . . . . 85

UEll Input Cards. . . . . . . . . . . . . 87

1. IDENT Card . . . . . . . . . . . 87

2. Demand Heat Card . . . . . . . . . 89

3. Demand Hot Water Card. . . . . . . . 91

4. Demand Miscellaneous Card.......... 92

5. Demand Season Card . . . . . . . . . 93

6. COLLECTOR Card .............. 95

7. StORAge Card . . . . . . . . . . 97

8. Transducer 3 Card. ............. 98

9. Transducer 4 Card. . . . . . . . . . 99

10. YEARS Card............... 100

11. AMORT Card............... 101

12. Price of Energy Card . . . . . . . . 102

13. LOGIC Card .............. 104 GEll Input Cards

1. IDENT Card.............. 105

2. DH Card.............. 105

3. DW Card............... 105

4. DM Card.............. 105 
$\underline{\text { Page }}$

5. DS Card............... 105

6. CO Card................ 105

7. ST Card. . . . . . . . . . . 105

8. YR Card................. 105

9. AMORT Card ............. 105

10. GENERATOR Card ............. 106

11. Generator Season Card. . . . . ... 107

12. Power Conditioning Card. . . . . . . 108

13. LOGIC Card . . . . . . . . . . . 109

UEll Output Listing Description and Samples . . . . 110

GEll Output Listing Description and Samples . . . • 117

Detailed Output--TAPE 9 (Optional). . . . . . . . 119 
Figure 1.1 SOLSTOR Model. . . . . . . . . . . . . 9

Figure 4.1 Air-to-Air Heat Pump Coefficient of Performance vs. Temperature............... 31

Figure 4.2 Default Hot Water Load Profile......... . 32

Figure 4.3 Default Miscellaneous Electrical Load Profile. •. 34

Figure 6.1 Block Diagram of UEll System . . . . . . . . . 38

Figure 6.2 Sample Spline Fit to Data. . . . . . . . . 56

Figure 7.1 Block Diagram of GEll system . . . . . . . . . 61

Figure 9.1 Sample Output--UEll with Collector . . . . . . 113

Figure 9.2 Sample Output--UEll with Wind Turbine. . . . . 115

Figure 9.3 Sample Output--GEll with Collector . . . . . 120

Figure 9.4 Sample Output--GEll with Wind Turbine. . . . . 122

\section{LIST OF TABLES}

Table 1.1 SOLSTOR Options................. 11

Table 4.1 Default Parameters Used in Heating/Cooling Load Calculations . . . . . . . . . . . 29

Table 9.1 Site Codes ................ 88 


\section{Chapter I. Introduction}

Several computer simulation codes exist which simulate or analyze photovoltaic (PV) and/or wind energy conversion systems (WECS) (Refs. 1. 2). In general, they accept as input a specified system configuration and analyze it using detailed performance simulation of the system components. SOLSTOR, on the other hand, uses fairly simple models of the components and is intended to generate the most economical system configuration, which can then be analyzed in detail by these other codes. SOLSTOR, then, is an effective tool for analyzing the economics of solar systems and for studying the effect of various economic parameters, including electricity rate structures (see Ref. 3). Electricity rates may include fixed service charges, time-of-day pricing, demand charges, and seasonal adjustments.

This document describes SOLSTOR as it is in late 1980. We intend the code to evolve as new problems arise, therefore, changes and improvements in SOLSTOR are expected in the future. A listing of current version of the SOLSTOR FORTRAN source code is in microfiche form at the end of this report.

SOLSTOR models a generalized solar system which can include wind turbines or PV arrays as energy sources and batteries or flywheels as system storage. Backup and/or storage charging power may be either purchased from the utility grid or obtained from an on-site fossil-fueled generator. A typical system configuration for the grid-connected case is shown in Figure 1.1 There are four major components (collector, storage, power conditioning, and utility-powered battery charger), each characterized by a "size" (physical or electrical), an efficiency, and a cost equation. In addition, the storage has a self-discharge rate parameter (leakage), and parameters limiting the rate of charge/discharge. As may be seen in Figure 1.1, all possible paths for energy flows are allowed. That is to say, array energy may flow to any or all of three destinations: (1) to the load (demand), (2) to storage, or (3) to the utility (sell-back mode). Likewise, stored energy may be (1) left in storage, (2) sent 


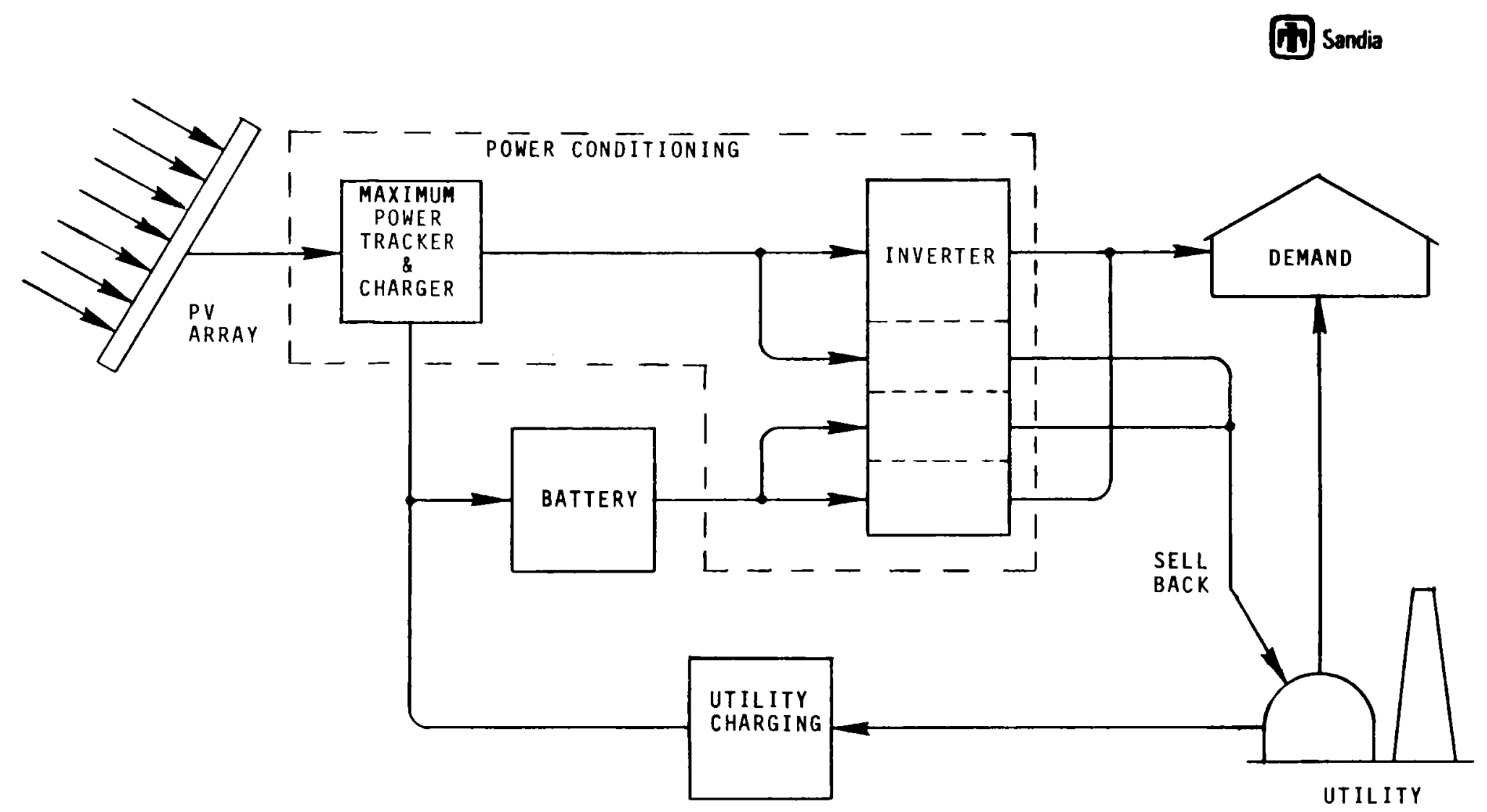

Figure 1.1 SOLSTOR Model 
to the load, or (3) sold to the utility; and finally, the battery may be charged from either the utility or the array. Decisions on all of these possibilities are made hourly, with a typical simulation run covering one year. Strategy algorithms, including predictive ones, for determining the choices are discussed later.

The version which provides backup energy from an on-site generator is somewhat simpler than the utility version since there is no "sell-back" option. The generator may be powered by gasoline, coal, natural gas, or diesel fuel. The generator model is discussed later in detail; the major parameters are the fuel cost, generator efficiency versus load, and start-up efficiency. The generator version of SOLSTOR has the capability of meeting only a user-specified fraction of the "desired" yearly demand. This allows the user to determine the cost effectiveness of insisting on meeting only 90 percent of the load versus 100 percent, for example.

The utility-connected model is referred to as the "UE" version (Utility Electric), while the generator version is known as "GE" (Generator Electric). A brief table of SOLSTOR options is given in Table 1.1. 
TABLE 1.1 SOLSTOR Options

Utility Connector, 1 Collector, 1 Storage Device

$\underline{\text { Identification }}$

Energy Allocation Strategy

UEIIA

Simple, based on storage level.

UEIIB

Simple, based on timing of price changes.

UEIIC

Complex, linear programming technique, assumes perfect knowledge of future supply and demand.

UEIID

Complex, moving linear programming technique, predicts future supply and demand. Spline and global average schemes implemented.

Stand-Alone, 1 Collector, 1 Storage Device

Identification

Generator Control Strategy

GEllA, $Q=0$ Simple, based on storage level and fixed times.

GEllA, $Q=1$ Simple, based on present supply, demand, and storage level.

GEllA, $Q>1$ Moderately complex, based on predictions of supply and demand for $Q$ hours. Spline, global averages and perfect knowledge schemes implemented. 
SOLSTOR economic analysis is based on the concept of life cycle cost, with methodologies appropriate to either personal (homeowner) or corporate (commercial, factory, etc.) entities. This chapter details the methodology.

\section{Assumptions}

The figure of merit for a system is the annualized cost for the life of the system referred to the base year. Cost is divided into capital cost, operation-maintenance cost (OM), and energy purchase cost. Increased property-tax costs, if any, due to capital investment are assigned to capital cost. It is possible that certain major system components require replacement during the system life. These items require depreciation rather than expensing, and their replacement cost is part of capital cost, not OM cost. For UE (Utility-Electric) systems, only the storage device may be replaced. For GE (Generator-Electric), only the storage device and back-up generator may be replaced. Also, the generator may require periodic overhauling, the cost of which is expensed as OM.

The economic computation considers events in whole year increments. These economics assume the following rules:

1. Initial capital investment is at the beginning of the first year of operation and includes all capital items, including items which may require replacement. Operation commences at the beginning of this year.

2. A loan, if any, is for the total initial investment only. All subsequent expenses and capital replacements are paid for in cash. The life of the loan is not greater than the life of the system. Principal plus interest on the unpaid balance are paid in equal yearly installments at the end of each year. 
3. All costs are constant over a year. Any cost escalation takes place as a step function at the beginning of each year. Escalation is absolute; i.e., not relative to inflation.

4. All OM, property tax, purchased energy, and overhaul expenses are priced at the beginning of the year and paid for and tax expensed at the end of the year.

5. Replacement items are purchased in cash at the beginning of the year in which they are required.

6. All capital items are depreciated at the end of the year in which they are purchased and subsequent years. Depreciation method is sum-of-years digits (SOYD).

7. The "true" life of nonreplaceable components is the system life. The "true" life of a replaceable component is the lesser of the life computed by the simulation and the system life. Depreciation life of each item is the lesser of its true life and the specified maximum allowed depreciation life. Replaceables with true life less than one year are expensed as capital items.

8. Investment tax credit is claimed at the end of the year of purchase, not carried forward or backward. The tax credit schedule is zero for life $<3,1 / 3$ for $3 \leq 1$ ife $<5,2 / 3$ for $5 \leq 1$ ife $<7$, and 1.0 for $7 \leq l i f e$. Here, life is depreciation life.

9. The effective tax rate is not affected by tax writeoffs.

10. Salvage value of components is constant (excluding escalation) after depreciation life. Income from salvaged items has no tax consequences. 
11. When a component is replaced, its out-of-pocket cost is escalated cost less escalated salvage. Both cost and salvage escalate at the same rate.

12. Generator overhaul costs escalate at the same rate as OM costs.

13. Escalation of $O M$ and property tax is considered only over the system life; that is, the ratio of $O M$ and property-tax annual cost to initial capital cost for the first year of operation is independent of the year specified.

\section{$\underline{\text { Economic Parameters }}$}

$\mathrm{y}_{\mathrm{p}} \quad=$ Price year. All input costs are quoted in this year.

$\mathrm{y}_{\mathrm{O}} \quad$ = Year of first operation.

$\mathrm{y}_{\mathrm{b}} \quad=$ Base year. All output costs are in base-year dollars.

$\mathrm{R} \quad=$ Discount rate

i $=$ Loan interest rate

D = Ratio of down payment to loan

$\tau=$ Effective income tax rate (federal plus state plus local marginal rate)

$\mathrm{f}_{\text {om }}=$ Ratio of annual $\mathrm{OM}$ cost to initial capital cost, assumed same for all components

$f_{p t}=$ Ratio of increased annual property tax to initial capital cost

g = General inflation rate 


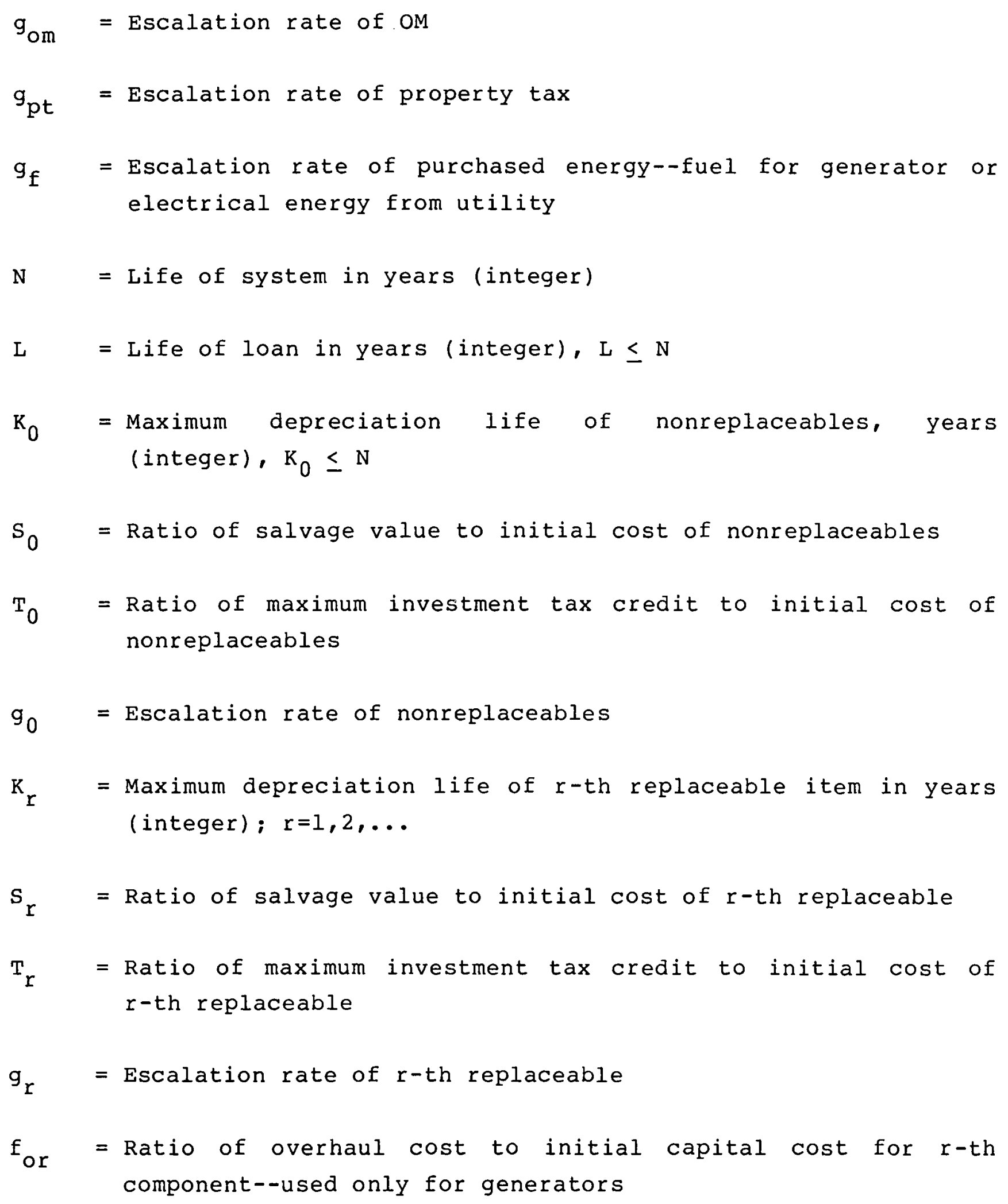


A dependent variable is $\hat{\tau}$, defined as

$$
\begin{aligned}
& \hat{\tau}=0 \text { if system is personal, } \\
& \hat{\tau}=\tau \text { if system is business-owned. }
\end{aligned}
$$

If the system is business owned, depreciation and certain expense items are tax deductable which are not tax deductable if personally owned.

\section{Price-Year Present-Value Computation}

Most of the formulas presented here are from References 4 and 5 . The annualized system cost is computed by summing the present value, $P V$, referenced to the base year, of all economic terms and finding the annualized cost, AC, from the PV over the system life. The PV of an annual one dollar payment discounted at rate $R$ and escalating at rate $g$ for $N$ years is

$$
\begin{aligned}
& p(R, g, N)=\frac{\left[1-\left(\frac{1+g}{1+R}\right)^{N}\right]}{R-g}, \\
& p(R, g=R, N)=N /(1+R),
\end{aligned}
$$

The assumption here is that cost is determined at the beginning of each year and paid at the end of the year; or, equivalently, there is no escalation in the first year--consistent with the rules above.

Let $C_{r}$ be the capital cost in price year dollars of the $r-t h$ component; where $r=0$ refers to the total of all nonreplaceables. The present-value capital cost associated with the initial investment in the $r$-th component in the price year is 


$$
\begin{aligned}
& \frac{P V I_{r}}{C_{r}}=D \\
& \text { down payment } \\
& +(I-D) p(R, 0, L) / p(i, 0, L) \\
& \text { loan payment } \\
& -\tau(1-D)\left\{p(R, i, L)\left[i-\frac{1}{p(i, 0, L)}\right]+\frac{p(R, 0, L)}{p(i, 0, L)}\left\{\begin{array}{l}
\text { interest tax } \\
\text { deduction }
\end{array}\right.\right. \\
& +(1-\tau) f_{p t^{p}} p\left(R, g_{p t^{\prime}}\right) \\
& \text { property tax } \\
& -s_{r}\left(\frac{1+g_{r}}{1+R}\right)^{N} \\
& -\theta\left(k_{r}\right) T_{r} /(I+R) \\
& \text { investment tax credit } \\
& -2 \hat{\tau} \frac{\left(1-S_{r}\right)\left[k_{r}-p\left(R, 0, k_{r}\right)\right]}{R k_{r}\left(k_{r}+1\right)} \text {, }
\end{aligned}
$$

where

$$
k_{r}=\max \left[1, \min \left(k_{r} \text {, integer part of true life of } r\right. \text {-th item)], }\right.
$$

and

$\theta\left(k_{r}\right)=0,1 / 3,2 / 3$, or 1 depending on $k_{r}$, according to the investment tax credit schedule.

The OM present value associated with the $r$-th component is

$$
\text { PVOM }_{r}=C_{r}(1-\hat{\tau}) f_{o m} p\left(R, g_{o m}, N\right) .
$$

Note that OM cost is associated only with initial capital cost. 
Let $t_{r j}$ be the year in which the $r-t h$ replaceable is replaced for the $j-t h$ time. Let this component be replaced exactly $J_{r}$ times during the system life such that the true life of the component is $N /\left(J_{r}+1\right)$, then

$$
t_{r j}=y_{0}+\text { integer part of }\left[j N /\left(J_{r}+1\right)\right] \text {. }
$$

Now, the price-year present value of all replacements (not initial purchase) of this item is

$$
\begin{aligned}
\operatorname{PVR}_{r}\left(J_{r}\right) & =c_{r}\left(1-S_{r}\right)\left\{1-\frac{\theta\left(k_{r}\right) T_{r}}{1+R}-\frac{2 \hat{\tau}\left[k_{r}-p\left(R, 0, k_{r}\right)\right]}{R k_{r}\left(k_{r}+1\right)}\right\} \sum_{j=1}^{J_{r}}\left(\frac{1+g_{r}}{1+R}\right)^{t_{r j}-y_{0}} \\
& =0 \text { if } J_{r}=0 \text { (Note } P^{\left.P V R_{0}=0\right)}
\end{aligned}
$$

Let $t_{r h}$ be the integer part of the years in which the $r-t h$ component is overhauled. For $\mathrm{H}_{r}$ overhauls, the price-year present value of the overhauls is

$$
\begin{aligned}
\operatorname{PVOH}_{r}\left(H_{r}\right) & =\frac{C_{r} f_{O r}(1-\hat{\tau})}{1+R} \sum_{h=1}^{H_{r}}\left(\frac{1+g_{o m}}{1+R}\right)^{t_{r h}-y_{O}} \\
& =0 \text { if } H_{r}=0 .
\end{aligned}
$$

If $C_{f}$ is the annual cost of purchased energy in price-year dollars, the price-year present value of purchased fuel for the system life is

$$
P V F=C_{f}(1-\hat{\tau}) p\left(R, g_{f}, N\right)
$$

All present value formulae given in this section are in priceyear dollars. 
For simplicity we temporarily drop the $r$ subscript. Let $Y \quad N$ be the true life in years of a replaceable component, as computed by the simulation. If $Y=N$, the number of replacements, $J$, is zero, and there are no replacements. Let $Y$ be less than $N$. The life $Y$ is not necessarily an integer, and the number of replacements

$$
\mathrm{J}=\mathrm{N} /(\mathrm{Y}+1)
$$

is also not necessarily an integer. Our economics now has the problem of coping with a partial life, with the attendant problem of defining salvage value for a life less than the depreciation life.

To circumvent these difficulties, the following approximation is used: Define

$$
\begin{aligned}
& \mathrm{J}_{1}=\text { integer part of }[\mathrm{N} /(\mathrm{Y}+\mathrm{I})] \geq 1 \\
& \mathrm{~J}_{2}=\mathrm{J}_{1}+1
\end{aligned}
$$

We compute the replacement present value for $\mathrm{J}=\mathrm{J}_{1}$ and $\mathrm{J}=\mathrm{J}_{2}$ and estimate the $\mathrm{PV}$ for $\mathrm{J}$ replacements by linear interpolation;

$$
\operatorname{PVR}(J)=\left[\operatorname{PVR}\left(J_{2}\right)-\operatorname{PVR}\left(J_{1}\right)\right]\left(J-J_{1}\right)+\operatorname{PVR}\left(J_{1}\right)
$$

The replacement times are

$$
\begin{aligned}
t_{i j} & =y_{0}+\text { integer part of }\left[j N /\left(J_{i}+1\right)\right] . \\
i & =1,2 .
\end{aligned}
$$


The criterion for overhaul is that an item is overhauled $Q$ times before it is replaced. We assume the overhauls are equispaced in time. For $J$ (integer) replacements, the overhaul times are

$$
\begin{aligned}
t_{j h} & =y_{0}+\text { integer part of }\left[\frac{N}{J+1} j+\frac{h N}{Q+1}\right], \\
j & =0,1, \ldots, J, \\
h & =1, \ldots, Q
\end{aligned}
$$

Note that overhaul of the initial purchase, $j=0$, is included.

Implicit in these schemes is that each replacement of a component has the identical life; and, if life depends on usage, wear occurs in a uniform way throughout each year.

System Annualized Cost in Base Year

The annualized costs in the base year for each economic term may now be computed. The annualized capital cost of the $r$-th component in the base year is

$$
A C C_{r}=(1+g)^{y_{b}-Y_{O}}\left(1+g_{r}\right)^{Y_{O}-y_{p}}\left(P V I_{r}+P V R_{r}\right) / P(R, 0, N),
$$

and the total AC of capital is

$$
\mathrm{ACC}=\sum_{r=0,1, \ldots} \mathrm{ACC}_{\mathrm{r}}
$$


The total $A C$ of $O M$ is

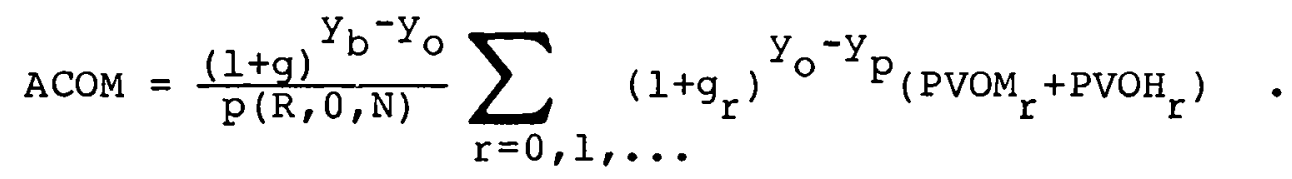

The annualized fuel cost in the base year is

$$
A C F=(1+g)^{Y_{b}-Y_{O}}\left(1+g_{f}\right)^{Y_{O}-Y_{P}} P_{P V F / p}(R, 0, N)
$$

The total system $A C$ is

$$
\mathrm{ACSYS}=\mathrm{ACC}+\mathrm{ACOM}+\mathrm{ACF}
$$

If required rate of revenue (see Ref. 6) is desired, the relationship is simply

$$
\text { Required rate of revenue }=\frac{\text { ACSYS }}{1-\tau} \text {. }
$$




\section{Chapter III. Supply}

SOLSTOR requires as supply inputs, hourly weather data for a year. Parameters required are: insolation (for calculating both PV output and heating or cooling loads), wind speed (required only for wind energy systems), and ambient temperatures (for heating and cooling load calculations). The file format required for this data is given in chapter IX. While any hourly data can be used, we prefer to use TMY (Typical Meteorological Year) data (Ref. 7), since it is specifically designed to provide "typical" or average year data. There would be little advantage in using sOLMET data for different years, since SOLSTOR simulates only one year of operation and extrapolates that performance to arrive at life cycle costs. It would, of course, be possible to run simulations on the same system using different year data in order to estimate the yearly performance variations to be expected in practice.

\section{$\underline{\text { PV Arrays }}$}

Hourly output of a flat plate PV array is calculated from the hourly insolation by computing the flux density on the array (assumed to be oriented due south, but at a user specified tilt angle) from the geometry of the sun's position relative to the array. A simple temperature-invariant overall array efficiency then is used to translate insolation to electrical output.

Let $I^{t}$ in $\mathrm{kWh} / \mathrm{m}^{2}$ be the total solar supply energy density at hour-of-the-year $t$. We assume this quantity is constant during each hour. The solar data for the chosen site contains the direct normal insolation $D_{N}^{t}$ and the total horizontal insolation $D_{H}^{t}$ for al1 $t, t=1, \ldots .8760$. The insolation for the various collectors are

1. Total tracking (two-axis) focused - CTTC

$$
I^{t}=D_{N}^{t}
$$


2. Flat plate total tracking--FPTT

$$
I^{t}=D_{N}^{t}+\left(.75+.25 \sin E^{t}\right)\left(D_{H}^{t}-D_{N}^{t} \sin E^{t}\right)
$$

where $E^{t}$ is the local elevation angle of the sun at time $t$.

3. Flat plate tilted--FPTI

$$
\begin{aligned}
I^{t}= & \left(\sin A_{t} \cos E^{t} \cos A^{t}+\cos A_{t} \sin E^{t}\right) D_{N}^{t} \\
& +\left(D_{H}^{t}-D_{N}^{t} \sin E^{t}\right)\left(.75+.25 \cos A_{t}\right)
\end{aligned}
$$

The tilt angle from the local horizon, positive southward, is $A_{t}$. The angle $A^{t}$ is the local azimuth of the sun measured positive westward from due south.

4. Flat plate tracking on east-west axis--FPEW

$$
\begin{aligned}
& I^{t}=q^{t} D_{N}^{t}+\left[.75+.25\left(\frac{\sin E^{t}}{q^{t}}\right)\right]\left(D_{H}^{t}-D_{N}^{t} \sin E^{t}\right), \\
& q^{t}=\left(1-\cos ^{2} E^{t} \sin ^{2} A^{t}\right)^{1 / 2}
\end{aligned}
$$

5. Flat plate tracking on a north-south axis--FPNS

$$
\begin{aligned}
I^{t}= & \sin \left(E^{t}+L+A_{t}\right) D_{N}^{t}+ \\
& {\left[.75+.23 \cos \left(L+A_{t}\right)\right]\left(D_{H}^{t}-D_{N}^{t} \sin E^{t}\right), }
\end{aligned}
$$

where $L$ is the latitude of the site, positive in the northern hemisphore. 
The $E^{t}$ and $A^{t}$ are computed from the hour angle $h^{t}$ and declination $d^{t}$ of the sun. For our purposes, a simple sinusoidal sun motion is suitable. The declination is taken as constant for each day. We use

$$
\sin d^{t}=0.410 \cos [0.01720(I-172)]
$$

where $I$ is the day of the year. The hour angle in radians is approximated by

$$
h^{t}=0.2618(J-13)
$$

where $\mathrm{J}$ is the hour of the day, $\mathrm{J}=13$ at noon. The formulas are then

$$
\begin{aligned}
& \sin A^{t} \cos E^{t}=\sin h^{t} \cos d^{t} \\
& \cos A^{t} \cos E^{t}=\sin L \cos d^{t} \cos h^{t}-\cos L \sin d^{t} \\
& \sin E^{t}=\cos L \cos d^{t} \cos h^{t}+\sin L \sin d^{t}
\end{aligned}
$$

With $x_{1}$ as the area of the collector and $e_{1}$ as its efficiency, then the output of the collector in hour $t$ is

$$
\mathrm{o}_{1}^{\mathrm{t}}=\mathrm{e}_{1} \mathrm{x}_{1} \mathrm{I}^{\mathrm{t}}, \mathrm{kWh}
$$

\section{Wind Turbines}

Wind turbines are necessarily more complex to describe. Only horizontal axis models (HAWT) are modeled currently. Factors in the function translating wind speed to electrical output are:

$$
\begin{aligned}
& v_{i} \text {, the "cut-in" wind speed of the turbine (i.e., output } \\
& \text { power is zero below } V_{i} \text { ) } \\
& v_{c^{\prime}} \text {, the "cut-out" wind speed of the turbine }
\end{aligned}
$$




$$
\begin{aligned}
& \mathrm{V}_{r^{\prime}} \text {, the reference wind speed at which rated power is } \\
& \text { obtained. Power out is constant at wind speeds } \\
& \text { from } v_{r} \text { up to } v_{C} \text {. } \\
& \left(0<v_{i}<v_{r}<v_{C}\right) \\
& x_{1} \text {, the desired rated power output of the wind turbine(s) } \\
& \mathrm{N}_{T} \text {, the number of turbines at the site }
\end{aligned}
$$

In addition, there are several parameters describing the site that must be read from the TMY data tapes. The most important is the height of the sensor where the data was read. This is used to obtain a "corrected" wind speed for the turbine at hub height. If

$$
\begin{aligned}
\mathrm{z}_{r}= & \begin{array}{l}
15 \cdot 2+\mathrm{D} / 2=\text { hub height }(\mathrm{D} \text { is diameter of turbine in } \\
\text { meters })
\end{array} \\
\mathrm{z}_{0}= & \text { reference data height, and } \\
v_{d}^{t}= & \text { wind speed at reference height as a function of } \\
& \text { time, then } \\
v^{t}= & \left(\frac{z_{r}}{z_{0}}\right) v_{d}^{t} \text { is the corrected wind speed function. }
\end{aligned}
$$

The average air density at the reference site, $\rho$, is also on the data tape. The wind power available to the turbine is:

$$
I_{1}=0.001226 \mathrm{~N}_{\mathrm{T}}\left(\mathrm{V}^{\mathrm{t}}\right)^{3} \mathrm{D}^{2} \text { in } \mathrm{kW}
$$

If the turbine efficiency is $e_{1}$ (typically $e_{1}=1.0$ ), then output power is: 


$$
\begin{array}{ll}
o_{1}^{t}=0 & 0 \leq v<v_{i} \text { and } v_{c}<v \\
o_{1}^{t}=x_{1} e_{1} & v_{r}<v \leq v_{c}
\end{array}
$$

For $V_{i}<V_{-} V_{r}, O_{1}^{t}$ varies linearly from 0 to $x_{l} e_{l}$. SOLSTOR uses as the input parameter the desired power output, $x_{1}$. Thus the necessary diameter, $D$, is solved for by the following relation:

$$
D=\left(\frac{259.7}{\rho v_{r}^{3}} x_{1}\right)^{\frac{1}{2}}
$$

But note that $D$ need not be the diameter of a single machine needed to achieve the desired power. Since $\mathrm{N}_{\mathrm{T}}$ turbines are permitted, $\mathrm{D}$ is the diameter for each of the $\mathrm{N}_{\mathrm{T}}$ turbines. 
Chapter IV. Demand

Electrical loads in SOLSTOR may be inputted in tabular form or computed from the TMY data. The computed residential electrical load is from three sources. These are (1) domestic hot water, (2) miscellaneous lighting and appliance loads (also called "diversified" loads), and (3) building heating and cooling, as supplied by an electric heat pump. The first two are input to sOLSTOR as separate schedules of 24 hourly values each. The same schedule, then, is used every day of the year. However, seasonal variations can be accommodated with a separate input parameter which applies various seasonal multipliers to the basic schedules. The heating and cooling loads are calculated by SOLSTOR, and some discussion of these procedures and assumptions is given next.

Heating and Cooling Loads

The driving force for calculating heating and cooling loads is weather data. Of course, any weather data could be used, but we have chosen to use the TMY (Typical Meteorological Year) derived from SOLMET data by Sandia (Ref. 7). These data have the advantage, compared to long-term-averaged data, of reflecting real weather. The TMYs are comprised of actual monthly data, with each month's data selected from the year that has the appropriate average statistics for insolation, degree days, runs of cloudy days, etc.

The insolation and temperature data then determine the calculated hourly heating or cooling load for the building. The heat loss/gain calculations follow the method outlined in the ASHRAE Handbook of Fundamentals, 1972 and updated in 1973 (Ref. 8). This method is intended for a dynamic hourly simulation such as this and is adequate for the needs of SOLSTOR. Heat flow totals in the ASHRAE model include the contributions due to conduction, air infiltration, gains due to appliances and lights, and gains due to occupants (we neglect the last in SOLSTOR). The conduction calculations use the "Sol-Air" temperature method of ASHRAE, which provides realistic outside surface temperatures by accounting for solar insolation. 
The residence simulated, for simplicity in calculation, was assumed to be a square, flat-roof, slab floor, windowless cubicle oriented east-west and north-south. The lack of windows eliminated the requirement for detailed calculations of direct solar gain. This "error" can be compensated for by using a composite wall conductance typical of a real wall with windows, and by appropriate solar absorptivity and thermal time lag for the walls.

Table 4.1 lists all of the input parameters pertinent to the heating and cooling load calculations. The parameters $\lambda$ and $\delta$, which vary with wall construction, have been empirically determined for many wall types. The 1972 ASHRAE Handbook of Fundamentals lists several. These parameters are used in the equation for the effective temperature difference between the inside and outside wall or roof surfaces as follows:

$\Delta T$ effective $(t)=\left[T_{I}-T_{E A}\right]+\left[T_{E A}-T_{E}(t-\delta)\right]$

where:

$$
\begin{aligned}
\mathrm{T}_{\mathrm{I}}= & \text { indoor air temperature }\left({ }^{\circ} \mathrm{F}\right) \\
\mathrm{T}_{\mathrm{EA}}= & \begin{array}{l}
\text { 24-hour average of } \mathrm{T}_{\mathrm{E}}(\mathrm{t}) \text { for the given day, } \\
\text { location and surface }\left({ }^{\circ} \mathrm{F}\right), \text { see Ref. } 8
\end{array} \\
\mathrm{~T}_{\mathrm{E}}(t)= & \text { effective outside air temperature (Sol-Air temp) } \\
& \text { at time } t\left({ }^{\circ} \mathrm{F}\right) \\
\mathrm{T}_{\mathrm{E}}(t-\delta)= & \mathrm{T}_{\mathrm{E}} \text { at time }(t-\delta)\left({ }^{\circ} \mathrm{F}\right) \\
\delta= & t \text { ime lag between a peak in the Sol-Air tempera- } \\
& \text { ture cycle and the corresponding peak of the } \\
& \text { inside wall surface temperature (hours) } \\
\lambda= & \text { an empirically determined constant known as the } \\
& \text { "decrement factor" }
\end{aligned}
$$


DEFAULT PARAMETERS USED IN HEATING/COOLING LOAD CALCULATIONS

Inside Air Temperature, heating $\left(\mathrm{T}_{\mathrm{HI}}\right)$
Inside Air Temperature, cooling $\left(\mathrm{T}_{\mathrm{LO}}\right)$
Underground Temperature and Cold Water Inlet Temperature $\left(\mathrm{T}_{\mathrm{DE}}\right)$

Absorptivity/Film Coefficient on

Outside Surfaces (R-value) $\left(\alpha / h_{0}\right)$

Time Lag for Sol-Air Temperature $(\delta)$

Decrement Factor $(\lambda)$

Conductance of Walls and Roof $\left(U_{w}\right)$

Conductance of Floor (Constant

built into SOLSTOR)

Air Infiltration, ( $\left.\rho_{\mathrm{vcp}}\right)$

Hours Size:

Roof and Floor $\left(A_{r}\right)$

walls, 4 each $\left(A_{W}\right)$

Hot Water Peak Load Multiplier

Heat Capacity of the House per square

foot of floor area $\left(c_{p}\right)$ $65^{\circ} \mathrm{F}$

$75^{\circ} \mathrm{F}$

$55^{\circ} \mathrm{F}$

$0.225 \frac{h-f t^{2}-o_{F}}{B t u}$

$4 \mathrm{~h}$

0.45

$58.6 \mathrm{~mW} / \mathrm{ft} \mathrm{t}^{2}-\mathrm{o}_{\mathrm{F}}$

one-half of $U_{w}$

$0.032 \mathrm{~kW} /{ }^{\circ} \mathrm{F}$

( 0.5 air changes per hour)

$1520 \mathrm{ft}^{2}$

$312 \mathrm{ft}^{2}$ ( $8 \mathrm{ft}$ by $39 \mathrm{ft}$ )

1.2

$3.52 \mathrm{Wh} / \mathrm{ft} \mathrm{t}^{2}-\mathrm{O}_{\mathrm{F}}$ 
A typical choice of 0.45 and 4 hours for $\lambda$ and $\delta$, respectively, is appropriate for a masonry wall consisting of 4-inch face brick over 4-inch concrete block and 1 inch of insulation.

Once the heating or cooling load has been determined for a particular hour, the electrical input energy required is obtained by dividing by the coefficient of Performance (COP) of the heat pump. The curve of heat pump COP versus ambient temperature is built into SOLSTOR and is shown in Figure 4.1 .

The building size and loss factors are entered by the user, although default values are available. Maximum summer and minimum winter interior temperatures are also specified. If the two differ, a "dead band" is created in which neither heating nor cooling is needed. The heat capacity of the building, per square foot of floor area, is used to determine the interior temperature changes in this dead band.

\section{Hot Water Loads}

A typical hot water load profile shown in Figure 4.2 represents an average based on metered tests of typical apartment buildings in Albuquerque, New Mexico, and is the default schedule used by SOLSTOR. The curve as shown is a normalized "load factor" curve. The actual consumption for an hour is given by the product of the load factor for that hour from Figure 4.2 and the "peak load multiplier." As shown in Table 4.1, the peak load multiplier used is 1.2. For example, the peak load between $9 \mathrm{a} . \mathrm{m}$. and $10 \mathrm{a} . \mathrm{m}$. would be $0.74 \times 1.2=0.89 \mathrm{~kW}$ and used for one hour in our simulations. A value of 1.522 was the peak load multiplier found in metered tests of electric hot water heaters in Albuquerque, but we have reduced this 20 percent to simulate some projected conservation efforts. The resulting daily load is about $12.5 \mathrm{kWh} / \mathrm{day}$, or $4.6 \mathrm{MWh} / \mathrm{year}$. We assume that this profile is invariant with respect to residence type, geographic location, and time of year. The typical hot water load profile and multiplier are stored in the code, but the user may use his own values. 


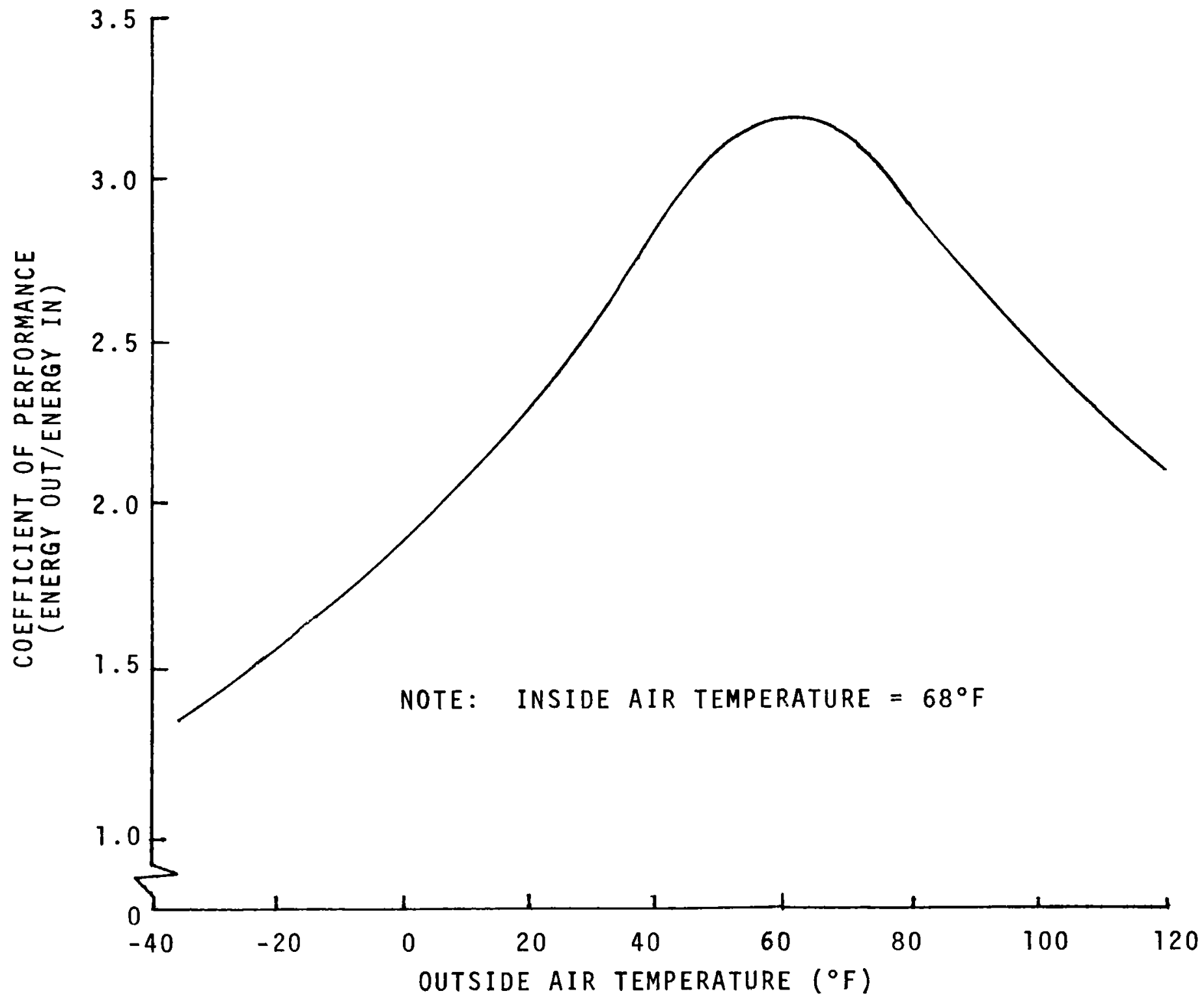

$\stackrel{\omega}{\omega}$

Figure 4.I Air-to-Air Heat Pump Coefficient of Performance Vs. Temperature 


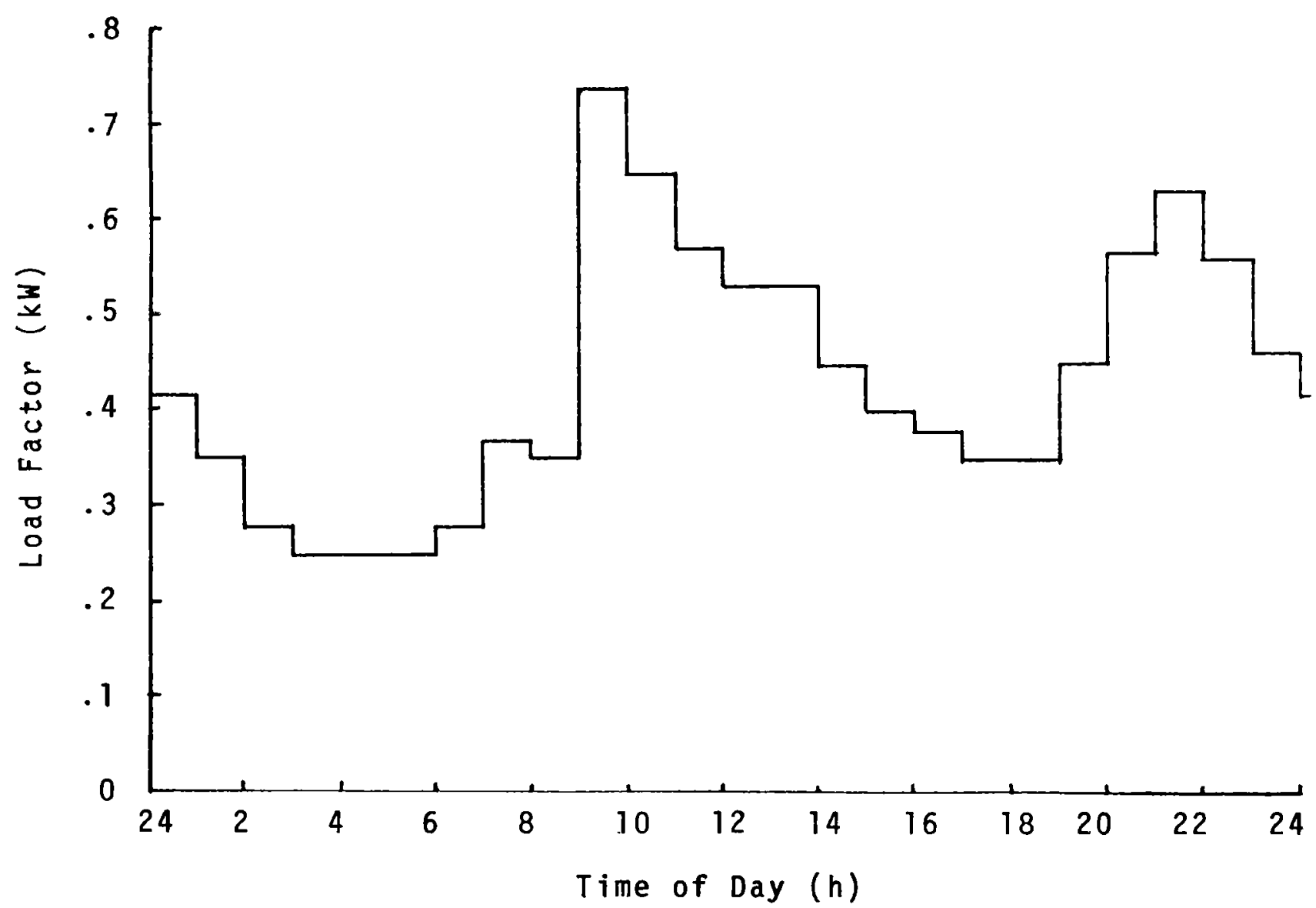

Figure 4.2 Default Hot Water Load Profile 
Lighting and Appliance (Miscellaneous) Load

The final contribution to the electrical load is that provided by appliances and lighting. Again, we use the same profile every day of the year and in all locations. The profile used, seen in Figure 4.3, was collected by the Public Service Company of New Mexico over the period November 1973 through January 1974. The data was from 127 individually monitored residential customers within the City of Albuquerque, New Mexico. The data in Figure 4.3 is a composite of those residences. 


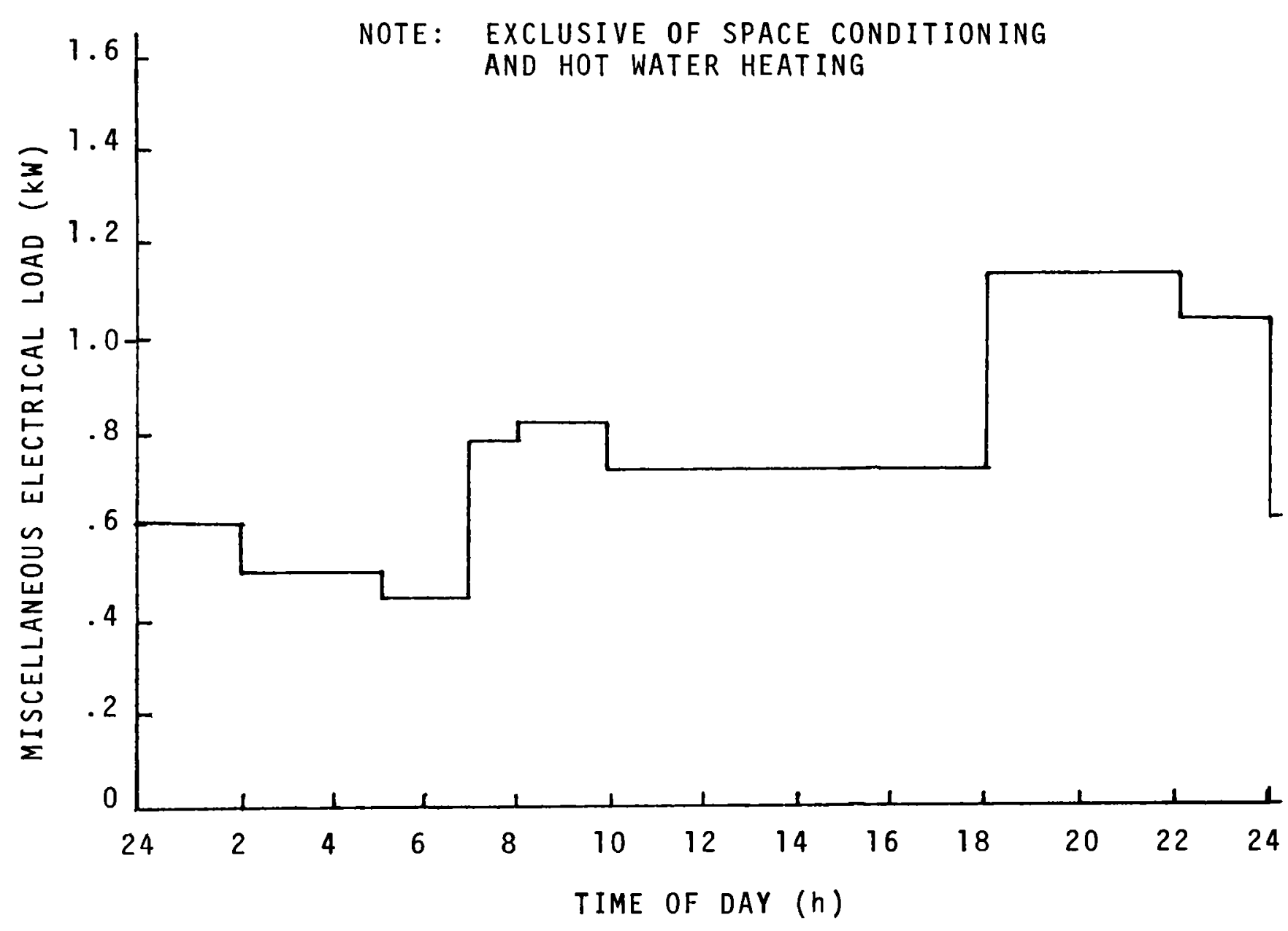

Figure 4.3 Default Miscellaneous Electrical Load Profile 
Utility Supplied

Assumptions about utility rates and policies are of critical importance in grid-connected systems since utility energy is used whenever there is an economic advantage in doing so. Moreover, there is the possibility of the system selling excess energy to the utility. SOLSTOR permits a large number of possible economic interfaces to be simulated. We permit any combination of the following rate attributes:

1. A fixed yearly "service" or "meter" charge.

2. Seasonal rates, with up to four seasons allowed.

3. Time-of-Day (TOD) energy charges with two rates in which the time period for the two rates is user specified.

4. Time-of-Day (TOD) peak demand charges. The specified demand charge is applicable for any period of the day, from 0 to 24 hours in length. The charge is applied to the highest hour demand in each month.

5. A "sell-back ratio" which specifies the rate paid by the utility for energy sold to them, as a fraction of the currently effective price of electricity.

6. A "sell-back limit" which specifies the maximum the utility will pay a customer in a year, expressed as a ratio of the amount sold to the total yearly bill for purchased electricity.

In the utility-backed model, the demand profile is always satisfied. Thus the utility is used either when the PV and/or battery cannot supply the full load, or when the allocation algorithms determine that utility energy is the least expensive alternative. 
Generator Supplied

The generator model has two major differences from the utility model. First, there is no "sellback" to consider, and second, the generator has a finite output power. That is, it may be sized such that at rated output, it cannot meet the peak demand. The latter characteristic means that we can either permit peak demand to go unsatisfied, or we must ensure that storage, if present, is charged sufficiently to meet the peak demand. This second alternative implies some sort of prediction, i.e., the generator must be operated such that the battery is able to meet demand. We accomplish this in any of several ways. One is to specify a fixed number of hours of daily generator operation for seasons of low insolation and/or high demand. This optional scheduled charging is in addition to other demand-sensitive charging schemes. The other major alternative is to use storage level as the determinant of generator operation. When storage declines to some lower bound, the generator is started and remains on until an upper bound is reached. We can prevent "oscillation", or one hour on, one hour off cycles by providing an optional "first hour penalty function" in which the generator operates at less than full output for the first hour of operation. These options and algorithms are discussed more fully in Chapter VII.

The generator model is quite different from the utility model in another way as well. Whereas the utility has only an operating cost, the generator has both operating costs and capital costs associated with its limited lifetime. We provide, as input data, information as to the total lifetime of the generator (in hours of operation) and number of overhauls allowed before replacement. These factors are also discussed more fully in chapter VII. 


\section{Chapter VI. Energy Allocation Logic for \\ Utility-Connected Simulation-UE}

\section{The UEll System}

The present SOLSTOR code can consider one solar or wind collector, one storage device, and associated components. Only electrical energy is considered. The energy user may be a residence, community (a group of more than one identical residences), or a large structure such as a factory or utility. The user may be connected to a utility or stand alone. We consider stand-alone systems in the next chapter.

The system described in this chapter is designated UEll. This acronym stands for Utility-connected, all-Electric, $\underline{1}$-collector, $\underline{1}$ storage-device system. Within the UEll scheme we have studied four different energy-distribution strategies, denoted UElIA, UEllB, UEIIC, and UEIID. These are described in detail below.

For simulation purposes UEll consists of eight components--see Figure 6.1. Component 1 is the collector, component 2 is the storage device, and the remaining six components are transducers. Each component is characterized by its size or capacity, whichever is appropriate, and its efficiency. We define $x_{i} \geq 0$ to be the size (or capacity) of the $i-t h$ component, and $0 \leq e_{i} \leq 1$ to be its efficiency. The collector area is $x_{1}$. The storage capacity is $x_{2}$. For the transducers $x_{i}, 3 \leq i \leq 8$, is the maximum power allowed at input; i.e., the input saturation level. The component efficiencies, except for $e_{2}$, specify that part of the input energy or power that appears at the output. The storage efficiency $e_{2}$ is the complement of hourly storage leakage; that is, if $E_{s}^{t}$ is the amount of energy in storage at the end of hour $t$, the amount of energy in storage at the end of hour $t+1$ is $e_{2} E_{s}^{t}$, provided no energy has been put into or drawn out of storage. In addition to $\mathrm{x}_{1}$ and $e_{1}$, the collector is described by its type (concentrating, flat plate, etc.) and any additional associated parameters (tilt angle, etc.) required to determine the energy density on the collector, as described in Chapter III. 
$\stackrel{\omega}{\infty}$

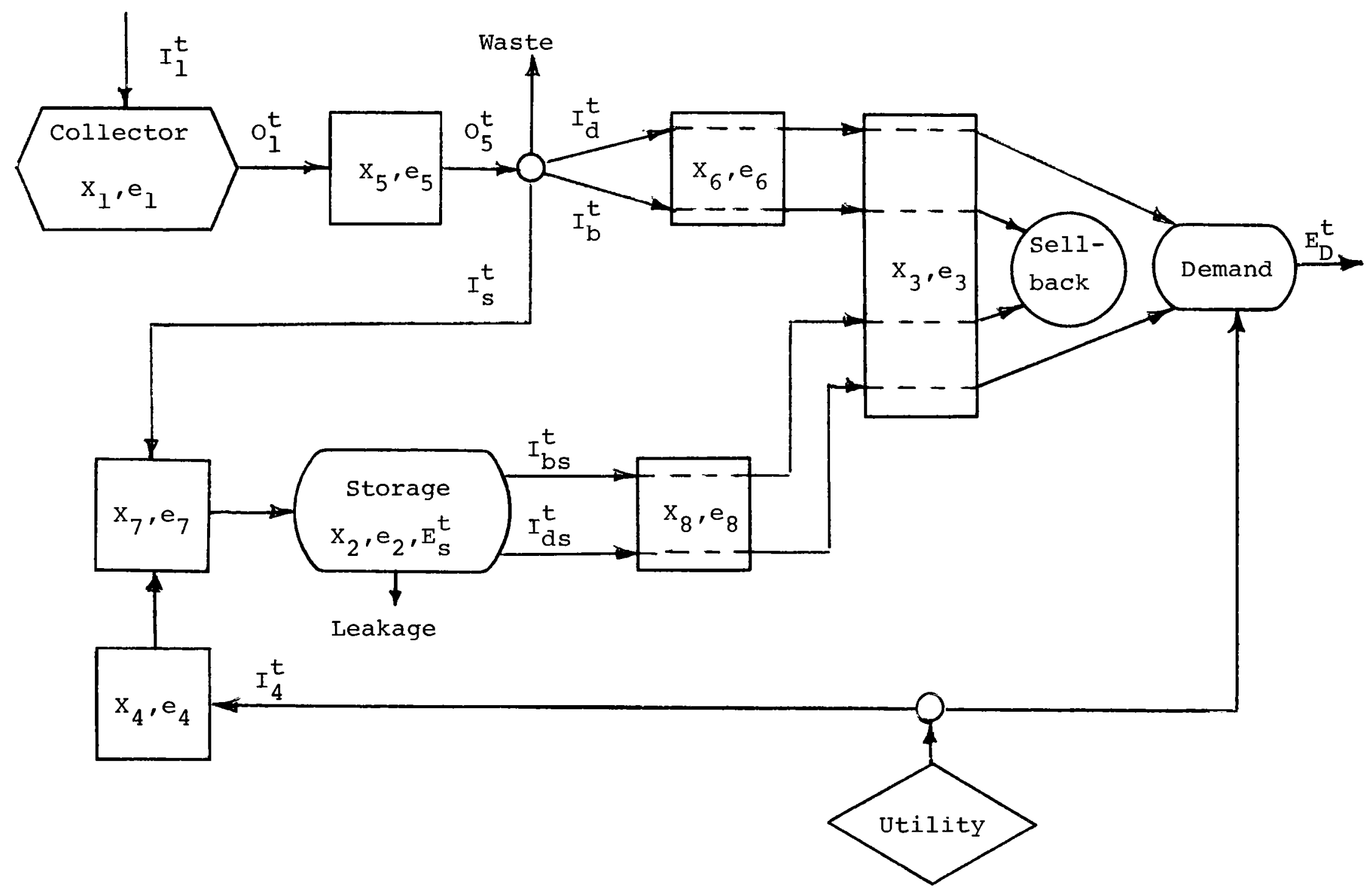

FIGURE 6.1 Block Diagram of UEll System. 
The simulation step is one hour. We assume that energy supply (insolation or wind velocity), demand, and prices are constant over each hour and that all changes occur instantaneously. For convenience we use a 364-day year with exactly 52 weeks and 8,736 hours. The basic problem time unit is hour-of-the-year. The year starts on January 1. There is no February 29 or December 31 considered. The time-of-day pricing structure, TOD, assumes that high-low pricing occurs on Monday through Friday, with only low pricing on Saturday and sunday. We uniformly assume January 1 is a saturday.

The insolation and ambient temperature information (as well as wind data, if needed) are given by the TMY (Typical Metrological Year) data. Having data for only one typical year for each site, we assume that each year in the life of a system is the same. Hence only 1 year need be simulated--at a great saving of computer-run time. The extension of the TMY results to include the total system life is achieved by proper use of the economic factors. For simplicity, storage is taken as empty at the beginning of the year. The cost anomaly due to storage not necessarily being empty at the end of the year is a trivial effect and is ignored. Given the system site and collection characteristics--excluding size and efficiency-the collector input energy density per unit area or wind turbine characteristics (supply) is determined for every hour of the year. The site and characteristics of the building(s) in which the system is used determine the energy demand. It is also possible to specify demand by an input file table (see chapter III).

The essence of the UEII simulation is that the hourly demand must be satisfied. If the collector/storage configuration cannot satisfy the demand, then the unsatisfied portion of the demand must be purchased from the utility at whatever rate exists at that hour. Energy may also be purchased for storage and use at a later time, and energy may be sold back to the utility. With supply, demand, economics, energy-pricing structure, and component efficiencies given, the code chooses a set of component sizes and runs a simulation to determine the net amount and cost of purchased energy. By 
net purchased energy, we mean energy purchased to satisfy demand and increase storage levels less energy sold back. With these results, the annualized system cost is computed. This cost consists of annualized capital cost, annualized operation-maintenance cost, and annualized net purchase cost, all of which depend only on component sizes and efficiencies, and the omnipresent economics, of course. That set of component sizes which minimizes the annualized system cost is taken as optimal. If purchase costs are cheap and component costs are expensive, the optimum solution may be $x_{i}=0$; that is, no system at all. We will describe the procedure for choosing component sizes in Chapter VIII.

Let superscript $t$ refer to the hour of the year. We use $I_{i}^{t}$ and $O_{i}^{t}$ to denote, respectively, the input and output of the $i-t h$ component at time (hour) $t$. Refer to Figure 6.1. The collector output is

$$
o_{1}^{t}=e_{1} x_{1} I_{1}^{t}
$$

where $I_{l}^{t}$ is the energy density supply to the collector at time $t$. Let $E_{s}^{t}$ be the energy level of storage at the end of time $t$. The storage balance is

$$
E_{s}^{t}=\min x_{2}, \max \left(0, e_{2} E_{s}^{t-1}+I_{2}^{t}-O{ }_{2}^{t}\right)
$$

This equation states that we cannot deplete storage below zero nor can we store more than $\mathrm{x}_{2}$. The input-output relation for the transducers is

$$
o_{i}^{t}=e_{i} \min \left(I_{i}^{t}, x_{i}\right) \quad ; \quad 3 \leq i \leq 8
$$

If a particular component does not exist in the sense that a path is not allowed, set the associated $x_{i}$ to zero. If a transducer does not exist in the sense that the path is nonsaturable and lossless, set $e_{i}=1$ and $x_{i}=\infty$. 
At each hour the simulation must decide how to allocate available energies. The available collected energy is the output of transducer $\# 5, O_{5}^{t}$. This energy can be allocated to satisfy demand $I_{d}^{t}$, to be sold back $I_{b}^{t}$, or to charge storage $I_{s}^{t}$, in any combination. Also, stored energy can be used to satisfy demand $I_{d s}^{t}$ or to be sold back $I_{b s^{*}}^{t}$ At the same time energy may be purchased to charge storage $I_{4}^{t}$. The total input to a component is the sum of all its inputs; i.e., $I_{6}^{t}=I_{d}^{t}+I_{b}^{t}$.

To simplify the computation and avoid excessive computer time usage, the number of variable component sizes has been reduced to four, without loss of generality. The size of components 5 and 6 is taken as infinity; i.e., $x_{5}=x_{6}=\infty$ (see Figure 6.1). These components may exist in the sense that they can have efficiency losses, but they do not saturate. This approximation is justified because these components are relatively inexpensive compared to the other components and because their outputs still can saturate due to finite $x_{7}$ and $x_{3}$. The cost of components 5 and 6 can be included in the collector or transducer costs in some fashion. Sizing of components 7 and 8 is accomplished by relating their sizes to the storage size $x_{2}$. We define parameters $r_{7}$ and ${ }^{r} 8$ as $x_{7}=r_{7} x_{2}$ and $\mathrm{x}_{8}=\mathrm{r}_{8} \mathrm{x}_{2} \cdot$ The $\mathrm{r}_{7}$ and $\mathrm{r}_{8}$ parameters specify the rate at which storage can be charged and discharged, respectively. The cost of $x_{7}$ and $\mathrm{x}_{8}$ is easily included in the storage component cost. Only four independent component sizes $x_{1}, x_{2}, x_{3}$, and $x_{4}$, are searched for the optimum configuration.

With $\mathrm{x}_{5}=\infty$, the available collected energy is

$$
\mathrm{O}_{5}^{t}=e_{5} e_{1} x_{1} I_{1}^{t}
$$

The constraint on collected energy allocation is

$$
I_{d}^{t}+I_{b}^{t}+I_{s}^{t} \leq O_{5}^{t}
$$


If $E_{D}^{t}$ is the demand at time $t$, the demand constraint is

$$
e_{3} e_{6} I_{d}^{t}+e_{3} e_{8} I_{d s}^{t} \leq E_{D}^{t}
$$

The storage balance and constraint equations are

$$
\begin{aligned}
& E_{s}^{t}=e_{2} E_{s}^{t-1}+e_{4} e_{7} I_{4}^{t}+e_{7} I_{s}^{t}-I_{d s}^{t}-I_{b s}^{t}, \\
& E_{s}^{t} \leq x_{2} .
\end{aligned}
$$

The component saturation constraints are

$$
\begin{array}{r}
e_{6} I_{d}^{t}+e_{6} I_{b}^{t}+e_{8} I_{d s}^{t}+e_{8} I_{b s}^{t} \leq x_{3}, \\
\quad I_{4}^{t} \leq x_{4}, \\
\\
I_{s}^{t}+e_{4} I_{4}^{t} \leq x_{7}, \text { and } \\
I_{d s}^{t}+I_{b s}^{t} \leq x_{8} .
\end{array}
$$

In addition, all quantities are nonnegative; i.e.,

$$
O_{5}^{t}, E_{s}^{t}, I_{d}^{t}, I_{b}^{t}, I_{s}^{t}, I_{d s}^{t}, I_{b s}^{t}, I_{4}^{t} \geq 0
$$

The quantities $I_{1}^{t}$ and $E_{D}^{t}$ are a fortiori nonnegative. Whatever distribution strategy is used, equations (6-1) to (6-13) must be satisfied.

At this time it is convenient to define $\mathrm{P}^{\mathrm{t}}$ as the annualized unit price of purchased energy and 0 R 1 as the sell-back ratio; that is, if at time $t$ the unit cost of energy is $P^{t}$, energy may be sold 
back for a dollar credit of $\mathrm{RP}^{\mathrm{t}}$ per unit. (Note: The sell-back ratio $R$ is not to be confused with the discount rate of the same symbol.)

Peak Pricing and Sell-back Limits

In addition to time-of-day pricing, peak demand usage pricing may also be considered (often called "demand" charge). Let $E_{P}\left(t_{m}\right)$ be the maximum energy purchased in month $m$. Let this purchase be at time (hour) $t_{m}$. If the peak usage cost at time $t_{m}$ is $P_{P}\left(t_{m}\right)$, then in addition to the fixed purchase cost (service charges) and costs associated with the amount of energy purchased, a premium cost of

$$
\sum_{m=1}^{12} P_{P}\left(t_{m}\right) E_{P}\left(t_{m}\right)
$$

is assumed. Here a year consists of four identical quarters of 3 months each of 31,30 , and 30 days.

Sell-back limitation is based on energy purchased costs. Let $c_{P}(t)$ be the total purchased energy cost for the year up to time $t$, less fixed or peak costs; that is, only the purchase cost associated with the hourly quantities purchased. Let ${ }_{C_{S}}(t)$ be the total dollar credit that the user has amassed up to time $t$ due to sell-back. Note that

$$
c_{P}(0)=c_{S}(0)=0
$$

Let $S_{L}$ be a given constant, then sell-back is allowed at time $t+1$ if

$$
S_{L} C_{p}(t)-C_{S}(t)>0
$$


Thus if $\mathrm{S}_{\mathrm{L}} \leq 0$, sell-back is never allowed, and if $\mathrm{S}_{\mathrm{L}}$ is very large, sell-back is essentially unlimited. For each hour in which sell-back is allowed, the amount is unlimited. Thus at each hour $I_{b}^{t}$ and $I_{b s}^{t}$ are either forced to zero or explicitly unlimited.

\section{$\underline{\text { Strategies }}$}

The essential problem of distribution strategy is with the storage. Without storage, the best strategy is simple: at each hour use all available energy to satisfy demand, and if any is left over, sell back all you can. Since R 1, sell-back never has a higher priority than demand. It is the storage linkage balance in time that requires strategical considerations.

Strategies can broadly be divided into two classes. A nonpredictive strategy assumes that all component characteristics and sizes are known, as well as the future price structure. It also "knows" the current available collected energy, demand, and storage level. However, the future supply and demand are not considered. A predictive strategy knows as much as a nonpredictive one, but also considers estimates of future supply and demand. Strategies UEllA and UEIIB are nonpredictive. Strategies UEllC and UEllD are predictive. None of these strategies explicitly use peak demand pricing in their decisions. The sell-back limitation is used only in a go-no-go fashion at each hour.

\section{Strategy UEllA}

In addition to the four optimizing size variables, this scheme uses a fifth optimizing variable, $0 \leq \mathrm{X}_{\mathrm{L}} \leq \mathrm{l}$. This new variable is the (relative) storage decision level. If the relative storage level, defined as $\mathrm{L}^{t}=\mathrm{E}_{\mathrm{S}}^{\mathrm{t}-1} / \mathrm{x}_{2}$, is greater than or equal to $\mathrm{x}_{L^{\prime}}$ the system tends to deplete storage, if $L^{t}<x_{L^{\prime}}$ the system tends to fill storage. For each simulation pass, $x_{L}$ is constant, like the sizes, however, no cost is associated with $\mathrm{x}_{\mathrm{L}}$. 
UEIIA makes decisions based on priorities having to do with the price structure, sell-back ratio $R$, component efficiencies and $x_{L}$. The TOD energy pricing structure is always such that for each week there is at most one high price and one low price for the whole week. Of course, these prices may be equal. Such a flat or average rate structure is typical today. Let $P^{t}$ be the price at time $t$ and $\mathrm{P}_{M}^{t}$ be the "high" price for the week in which $t$ occurs.

For simplicity, we drop the $t$ in the following equations when not needed for clarity. The priorities are demand D, utility sell-back $B$, and storage $S$. They are ordered by (see Figure 6.1):

A. If $L^{t} \geq x_{L^{\prime}}$ and

$$
\begin{aligned}
& \text { 1. } e_{6} \geq \operatorname{Re}_{6} \geq e_{2} e_{7} e_{8}+\text { DBS priority. } \\
& \text { (Demand, Seliback, Storage) }
\end{aligned}
$$

2. $\mathrm{e}_{6} \geq \mathrm{e}_{2} \mathrm{e}_{7} \mathrm{e}_{8}>\mathrm{Re}_{6} \rightarrow$ DSB priority

3. $e_{2} e_{7} e_{8}>e_{6} \geq \operatorname{Re}_{6} \rightarrow$ SDB priority.

B. $\quad \mathrm{It}^{t}<\mathrm{X}_{L}$ and

$$
\begin{aligned}
& \text { 1. } e_{6} \geq \operatorname{Re}_{6} \geq e_{2} e_{7} e_{8} P_{M}^{t} / P+D B S \\
& \text { 2. } e_{6} \geq e_{2} e_{7} e_{8} P_{M}^{t} / P{ }^{t}>R_{6}+D S B \\
& \text { 3. } e_{2} e_{7} e_{8} P_{M}^{t} / P{ }^{t}>e_{6} \geq R_{6}+S D B
\end{aligned}
$$

At each hour the quantities $I_{d^{\prime}} I_{b}, I_{s^{\prime}} I_{d s}, I_{b s}$ and $I_{4}$ are initially set to zero. The following equations are then solved in the order indicated by the priorities of the hour; i.e., if DSB, first solve equation "D", then equations "S", and finally equation "B". Let variable $B^{t}$ be the sell-back limit at time $t$. If sellback is allowed at this time, $B^{t}=\infty$, otherwise $B^{t}=0$. 
Equation "D"

$$
I_{d}=\min \left[\frac{E_{D}-e_{3} e_{8} I_{d s}}{e_{3} e_{6}}, o_{5}-I_{s}, \frac{x_{3}-e_{8}\left(I_{d s}+I_{b s}\right)}{e_{6}}\right]
$$

Equation "B"

$$
I_{b}=\min \left[\frac{B-e_{3} e_{8} I_{b s}}{e_{3} e_{6}}, o_{5}-I_{d}-I_{s}, \frac{x_{3}-e_{8}\left(I_{d s}+I_{b s}^{\prime}\right)}{e_{6}}-I_{d}\right]
$$

Equations "S"

1. $\mathrm{q}_{7}=\min \left(\mathrm{X}_{7}, \mathrm{O}_{5}-\mathrm{I}_{\mathrm{d}}-\mathrm{I}_{\mathrm{b}}\right)(6-17 \mathrm{a})$

2. $q_{2}=e_{2} E_{s}^{t-1}+e_{7} q_{7}(6-17 b)$

3a. $L \geq X_{L}$;

(1) $\mathrm{P}=\mathrm{P}_{\mathrm{M}}$; solve 4 (equation 6-17c); then, if $\mathrm{q}_{7}=0$ or $\mathrm{e}_{7} \mathrm{e}_{8} \geq \mathrm{e}_{6}$ solve 5 ; then solve 6 .

(2) $\mathrm{P} / \mathrm{P}_{\mathrm{M}} \geq \mathrm{R}$; solve 4 , then 6 .

(3) $P / P_{M}<R ;$ solve 6 .

3b. $L<\mathrm{X}_{\mathrm{L}}$;

(1) $\mathrm{P}=\mathrm{P}_{\mathrm{M}}$; solve 4 , then 6 .

(2) $\mathrm{P} \neq \mathrm{P}_{\mathrm{M}}$; solve 6 .

4. $I_{d s}=\min \left[\frac{E_{D}-e_{3} e_{6} I_{d}}{e_{3} e_{8}}, x_{8}, q_{2}, \frac{x_{3}-e_{6}\left(I_{d}+I_{b}\right)}{e_{8}}\right]$ 
5. $I_{b s}=\min \left[\frac{B-e_{3} e_{6} I_{b}}{e_{3} e_{8}}, x_{8}-I_{d s}, q_{2}-I_{d s^{\prime}}, \frac{X_{3}-e_{6}\left(I_{d}+I_{b}\right)}{e_{8}}-I_{d s}\right]$

6. $I_{s}=q_{7}-\max \left(0, q_{2}-I_{a s}-I_{b s}-X_{2}\right) / e_{7}$

After the three-step priorities are satisfied, the decision is made whether to buy for storage. If

$L<X_{L}$ and $e_{2} e_{3} e_{4}{ }^{e}{ }_{7}{ }^{e}{ }^{P}{ }_{M}>P$, then

$I_{4}=\min \left(e_{4} X_{4}, x_{7}-I_{s}, \frac{X_{2}-e_{2} E_{S}^{t-I}}{e_{7}}-I_{s}\right) / e_{4}$

Note that in order to buy for storage, $P \neq P_{M}$ and $I_{d s}=I_{b s}=0$.

The system is now updated for the next step. The new storage level is

$$
E_{s}^{t}=e_{2} E_{s}^{t-1}+e_{7}\left(e_{4} I_{4}^{t}+I_{s}^{t}-I_{d s}^{t}-I_{b s}^{t}\right)
$$

For each $t$ we get

$$
\begin{array}{ll}
\text { Purchase energy } & =\mathrm{E}_{\mathrm{D}}^{\mathrm{t}}-\mathrm{e}_{3} \mathrm{e}_{6} \mathrm{I}_{\mathrm{d}}^{\mathrm{t}}-\mathrm{e}_{3} \mathrm{e}_{8} \mathrm{I}_{\mathrm{ds}}^{\mathrm{t}}+\mathrm{I}_{4}^{\mathrm{t}} \\
\text { Sell-back energy } & =\mathrm{e}_{3} \mathrm{e}_{6} \mathrm{I}_{\mathrm{b}}^{\mathrm{t}}+\mathrm{e}_{3} \mathrm{e}_{8} \mathrm{I}_{\mathrm{bs}}^{\mathrm{t}} \\
\text { Leakage } & =\left(1-\mathrm{e}_{2}\right) \mathrm{E}_{\mathrm{s}}^{\mathrm{t}-1} \\
\text { Waste } & =O_{5}^{t}-I_{d}^{t}-I_{b}^{t}-I_{S}^{t}
\end{array}
$$

The maximum sell-back, $B^{t}$, is also updated at the end of each time step by the algorithm described above. 
Note that UEllA uses price information in the sense that it knows the high and low price for the week, but it ignores the timing of the price changes.

Strategy UEIIB

This strategy does not use $x_{L}$. Only the four size variables are used as optimizing variables. In UEllB the price change timing is used. Priorities are established by considering the value in cost savings of energy used for demand, for sell-back, for increasing storage, and for retaining in storage.

Define $m=m(t)$ to be the number of hours in the future when the purchase energy price next up-tics; i.e., the least number of hours we must wait, from time $t$, for the price to pass from a "low" to a "high" value. If the yearly price is constant, $m=\infty$. Let $P_{u}^{t}$ be the "high" price when the next up-tic occurs. Note, $P_{u}^{t}$ need not be the "high" price for the week in which $t$ occurs since the next up-tic may be in the next season.

The priorities are:

1. $e_{6} \geq \operatorname{Re}_{6} \geq \mathrm{e}_{7} \mathrm{e}_{8} \max \left(1, \mathrm{e}_{2}^{\left.\mathrm{m}_{\mathrm{u}} / \mathrm{P}\right) \rightarrow \mathrm{DBS}}\right.$

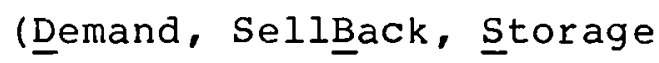

2. $e_{6} \geq e_{7} e_{8} \max \left(1, e_{2}^{m_{u}} / P\right)>\mathrm{Re}_{6} \rightarrow \mathrm{DSB}$

3. $e_{7} e_{8} \max \left(1, e_{2}^{m_{u}} / P\right)>e_{6} \geq \operatorname{Re}_{6} \rightarrow \mathrm{SDB}$

Again, at each hour the priorities are established, $I_{d^{\prime}} I_{b^{\prime}}$ $I_{s^{\prime}} I_{d s^{\prime}} I_{b s^{\prime}}$ and $I_{4}$ are initially set to zero and the following equations are evaluated according to the priorities.

Equation "D"--same as (6-15)

$$
I_{d}=\min \left[\frac{E_{D}-e_{3} e_{8} I_{d s}}{e_{3} e_{6}}, o_{5}-I_{s}, \frac{x_{3}-e_{8}\left(I_{d s}+I_{b s}\right)}{e_{6}}\right] \text {. }
$$


Equation "B"--same as (6-16)

$$
I_{b}=\min \left[\frac{B-e_{3} e_{8} I_{b s}}{e_{3} e_{6}}, o_{5}-I_{d}-I_{s}, x_{3}-\frac{e_{8}\left(I_{d s}+I_{b s}\right)}{e_{6}}-I_{d}\right]
$$

Equations "S"

1. $q_{7}=\min \left(X_{7}, O_{5}-I_{d}-I_{b}\right)(6-2 l a)$

2. $q_{2}=e_{2} E_{s}^{t-1}+e_{7} q_{7} \quad(6-21 b)$

3. $\mathrm{q}=\max \left(\mathrm{e}_{2}, \mathrm{e}_{2}^{\mathrm{m}} \mathrm{P} u / \mathrm{P}\right)$

(a) $1 \geq \mathrm{R} \geq \mathrm{q} \rightarrow$ solve 4 , then 5 , then 6 .

(b) $1 \geq q>R \rightarrow$ solve 4, then 6 .

(c) $q>1 \geq R \rightarrow$ solve 6 , then equations 7 .

4. $I_{d s}=\min \left[\frac{E_{D}-e_{3} e_{6} I_{d}}{e_{38}}, x_{8}, q_{2}, \frac{x_{3}-e_{6}\left(I_{d}+I_{b}\right)}{e_{8}}\right]$

5. If $q_{7}>0$ and $e_{7} e_{8} \leq e_{6}, I_{b s}=0$; otherwise

$$
I_{b s}=\min \left[\frac{B-e_{3} e_{6} I_{b}}{e_{38}}, x_{8}-I_{d s}, q_{2}-I_{d s^{\prime}} \frac{x_{3}-e_{6}\left(I_{d}+I_{b}\right)}{e_{8}}-I_{d s}\right]
$$

6. $I_{s}=q_{7}-\max \left(0, q_{2}-I_{d s}-I_{b s}-X_{2}\right) / e_{7}$

7. $q_{3}=e_{2} E_{s}^{t-1}+e_{7} I_{s}$.

If $e_{3} e_{4} e_{7} e_{8} e_{2}^{m_{P}} / P>1$ and 


$$
\begin{aligned}
& m \leq \frac{x_{2}-q_{3} e_{2}^{m}}{e_{7} \min \left(x_{7}, e_{4} x_{4}\right)} \text {, then } \\
& I_{4}=\min \left(e_{4} x_{4}, x_{7}-I_{s}, \frac{x_{2}-q_{3}}{e_{7}}\right) / e_{4}
\end{aligned}
$$

The system state is then updated as in equations (6-20a) through $(6-20 d)$, and the next hour is computed, etc.

\section{Strategy UEIIC}

This strategy utilizes ideal prediction of supply and demand; that is, the future supply and demand is known exactly for as far in the future as desired. Obviously it is not possible to implement such a scheme at any installation. However, UEllC is of great theoretical value for two reasons. First, the study of an ideal predictive scheme gives great heuristic insight into the development of truly predictive schemes. Second, the ideal scheme is a bound on how well any scheme can do; that is, we can measure how sub-optimal any scheme may be.

It turns out that the ideal predictive scheme is the solution of a linear program, LP. Given all system parameters, all system sizes, the initial storage condition, supply, demand, and purchase price structure, we desire to find $I_{d}, I_{b}, I_{s^{\prime}} I_{d s^{\prime}} I_{b s}$, and $I_{4}$ so as to minimize the net purchase cost over some period of time-hopefully over the whole TMY year. Attempting solution for the whole year creates an LP of hopelessly large size, so we must settle for some slightly sub-optimal scheme which pieces together a solution from smaller LP solutions in some fashion.

It should be pointed out here that if the capital costs of the variable components is directly proportional to their size--ignoring fixed costs associated with these components--then the optimal strategy and the optimal sizing is the solution of an LP. However, 
the LP must be solved over the whole year--an impossible task with today's computing technology. Therefore, we assume that for each simulation pass the sizes are given.

We wish to find the optimal energy allocations for a period of $T$ hours, starting at $t=t_{0}+1 ; i . e ., t_{0}+1 \leq t \leq t_{0}+T$. We assume the storage level at time $t_{0}, E_{s}^{t}{ }^{\prime}$ is known. The optimal allocations minimize the net purchased cost for the period. We wish to find

$$
\min \sum_{t=t_{0}+1}^{t_{0}+T} P^{t}\left(E_{D}^{t}-e_{3} e_{6} I_{d}^{t}-\operatorname{Re}_{3} e_{6} I_{b}^{t}-e_{3} e_{8} I_{d s}^{t}-R_{3} e_{3} e_{8} I_{b s}^{t}+I_{4}^{t}\right)
$$

subject to certain constraints. These constraints are equations (6-5) through (6-13) written in a slightly different form which is convenient to our purpose here. We have

$$
\begin{aligned}
& E_{s}^{t}+I_{d s}^{t}+I_{b s}^{t}-e_{4} e_{7} I_{4}^{t}-e_{7} I_{s}-e_{2} E_{s}^{t-1}=0 \\
& I_{d s}^{t}+I_{b s}^{t}+I_{d}^{t} e_{6} / e_{8}+I_{b}^{t} e_{6} / e_{8} \leq x_{3} / e_{8} \\
& I_{d s}^{t}+I_{b s}^{t} \leq x_{8} \\
& e_{4} I_{4}^{t}+I_{s}^{t} \leq x_{7} \\
& I_{d s}^{t}+I_{d}^{t} e_{6} / e_{8} \leq E_{D}^{t} / e_{3} e_{8} \\
& I_{d}^{t}+I_{b}^{t}+I_{s}^{t} \leq o_{5}^{t} \\
& I_{4}^{t} \leq x_{4}
\end{aligned}
$$




$$
E_{s}^{t} \leq x_{2}
$$

$(6-23 h)$

$$
\begin{aligned}
& I_{d}^{t}, I_{b}^{t}, I_{s}^{t}, I_{d s}^{t}, I_{b s}^{t}, I_{4}^{t}, E_{s}^{t} \geq 0 \\
& t=t_{0}+1, \ldots, t_{o}+T
\end{aligned}
$$

We see that this is an LP of 7 unknowns--the variables of equations (6-23i)--and 8 constraints for every $t ; i . e ., 7 T$ variables and $8 T$ constraints. The nonnegativity constraints of equations (6-23i) are automatically satisfied by the LP. Even for a period of one week, $\mathrm{T}=168$, solution is virtually impossible.

In actuality, the LP is not quite as large as it seems. The constraints $(6-23 \mathrm{~g})$ and $(6-23 \mathrm{~h})$ are simple upper bounds and can be implemented in the LP in such a way as to not be considered as explicit constraints (see Ref. 9). Also, if $O_{5}^{t}=0$, true for solar collectors at nighttime, then $I_{d}^{t}=I_{b}^{t}+I_{s}^{t}=0$, and only four variables need be considered. If $O_{5}^{t}=0$, the constraints are

$$
\begin{array}{ccc}
E_{s}^{t}+I_{d s}^{t} & +I_{b s}^{t}-e_{4} e_{7} I_{4}^{t}-e_{2} E_{s}^{t-1}=0, & (6-24 a) \\
I_{d s}^{t}+I_{b s}^{t} \leq \min \left(x_{3} / e_{8}, x_{8}\right), & (6-24 b) \\
I_{4}^{t} \leq \min \left(x_{4}, x_{7} / e_{4}\right), & (6-24 \mathrm{c}) \\
I_{d s}^{t} \leq E_{D}^{t} / e_{3} e_{8}, & (6-24 d) \\
E_{s}^{t} \leq X_{2}, \text { and } & (6-24 e) \\
I_{b s}^{t} \leq B^{t} . & (6-24 f)
\end{array}
$$

52 
Thus for each hour when there is no sunshine there are only four variables, two constraints, and at most four simple upper bounds. However, even with this problem-size reduction, solution of the LP over one week is still essentially prohibitive. The same thinking applies to wind systems. If sell-back is allowed, there is no explicit constraint on $I_{b}^{t}$ and $I_{b s}^{t}$. If sell-back is not allowed, $I_{b}^{t}=I_{b s}^{t}=0$.

Since solution of the LP for the whole year is impractical, we adopt the following sub-optimal scheme. Choose the integers $\mathrm{T}_{1}$ and $T$ so that $1 \leq T_{1}<T$. Starting at $t=0$, with $E_{S}^{0}=0$, solve the LP for $T$ hours. Implement the LP solution for $T_{1}$ hours. Using the storage level of the solution at $t=T_{1}$ as an initial condition, solve a new LP over $T_{1}+1 \leq t \leq T_{1}+T$. Then, implement the solution up to time $2 \mathrm{~T}_{1}$. Solve the next $L P$ over $2 \mathrm{~T}_{1}+1 \leq t \leq 2 \mathrm{~T}_{1}+\mathrm{T}$, etc. Hopefully, solutions very near optimal can be achieved for $T$ of the order of about half a day to a few days.

In this method, if sell-back is allowed at the first time step of an LP, it is allowed over that whole $\mathrm{T}$ interval. If sell-back is not allowed at the first step, it is not allowed over that whole $T$ interval.

To save computer time, we would like to choose $\mathrm{T}_{1}=\mathrm{T}$ and thus solve the least number of LPs per pass for any given T. Unfortunately this choice of $T_{1}$ yields a very poor solution. When any $L P$ is solved, the optimum solution does not consider the future beyond $t=n T_{1}+T$. Hence, since there is no reason to retain energy in storage for the future, the optimum solution dumps storage and $\mathrm{E}_{\mathrm{s}}^{\mathrm{nT}}{ }_{1}+\mathrm{T}_{\mathrm{T}}=0$. Actually, in some cases the optimum solution is not unique, but driving storage to zero at the end is always one of the optimal solutions. Indeed it is intuitively evident the $T_{1}=1$ is the best choice for any $T$.

We have conducted some preliminary studies concerning the choice of $T$. It appears that $T$ of about 12 to 24 hours gives good solutions. The implication here is that the system is loosely coupled 
from day to day, but quite tightly coupled on an intraday basis. This phenomenon is due to the diurnal nature of the supply, demand, and prices.

In the initial coding of UEllC, a packaged LP routine was used. A specialized LP tailored to this problem cut the computer running time by about one-third. Because the LP, is "block-angular," a Dantzig-Wolfe decomposition was then employed (see Ref. 9). This innovation further cut running time by one-half. For $\mathrm{T}=16$ hours and $\mathrm{T}_{1}=8$ hours, the CDC 7600 runs one pass (one set of sizes) in about 26 seconds. While this is excellent speed considering the computation involved, a fuli-blown optimization on four variables can be very time-consuming. The bag of LP tricks has not yet been exhausted, and we hope to achieve additional speed improvement in the future. In contrast, the computer time per pass for UEllA and UEIIB is only about a half second. In general, a few hundred pases may be required per optimization.

Strategy UElID and Predictive Methods

This scheme is a truly predictive strategy. A sliding LP is used as in UEllC with $T_{1}=1$ and $T$ chosen by the user.

Suppose the system is at $t=1$. It knows the state of the system, the current supply and demand (at $t=1$ ), the future price structure, the time of day, and the day of the year. With these data, a prediction is made of supply and demand for times $2 \leq t \leq T$. The LP is solved for $1 \leq t \leq T$, and the solution is implemented at $t=1$. Since supply and demand are known at $t=1$, the allocation chosen by the LP solution can be directly implemented for $t=1$. The scheme now steps to $t=2$, measures the new actual supply and demand, generates new predictions of future supply and demand to time $T+1$, and then implements its results for $t=2$, and so on.

The supply-and-demand-prediction method has not yet been studied per se. We envision eventually using something like a Box-Jenkins 
technique (see Ref. 10) with diurnal, and perhaps seasonal correlations. In an actual field implementation, it may be possible to include weather reports in some fashion. Additional control techniques such as load-leveling would aid the prediction of future demand.

For the present, three prediction schemes have been implemented in UEIID. None of these methods are truly predictive in the BoxJenkins sense, but are essentially global averaging techniques on the existing data.

The first method is merely ideal prediction. In this case UEIID is identical to UEllC with $\mathrm{T}_{1}=1$.

In the second method, both supply and demand are predicted by a spline fit to the data. Let $v_{d h}$ be the "true" computed supply or demand at day-of-the-year d and hour-of-the-day h. For each hour h, a least-squares cubic C2 spline is fit to the daily data (see Ref. 11). That is, 24 spline fits for supply and 24 spline fits for demand, each fitting 364 points. Each spline fit uses 16 equispaced knots, including the ends at $d=1$ and $d=364$. The only constraint imposed is that the endpoint values of the fit must be the same; that is, each fit must have yearly periodicity. Let the fitted data be $\mathrm{U}_{\mathrm{dh}}$. To account for the fact that we really know when the sun sets and rises and that the data cannot be negative, we adjust the fits so that

$$
\begin{aligned}
& \text { If } V_{d h}=0 \text {, set } U_{d h} \text { to zero, } \\
& \text { If } V_{d h}>0 \text { and } U_{d h} \leq 0 \text {, set } U_{d h}=0.001 \text {. }
\end{aligned}
$$

A value of 0.001 is negligibly positive for any supply or demand. A sample for a "typical" residence in Albuquerque at mid-day is shown in Figure 6-2. The collector is a "FPTI" tilted at $25^{\circ}$. We see that the basic seasonal character of the data is preserved, but daily variations are heavily smoothed. For later reference we denote this scheme as "spline prediction." 


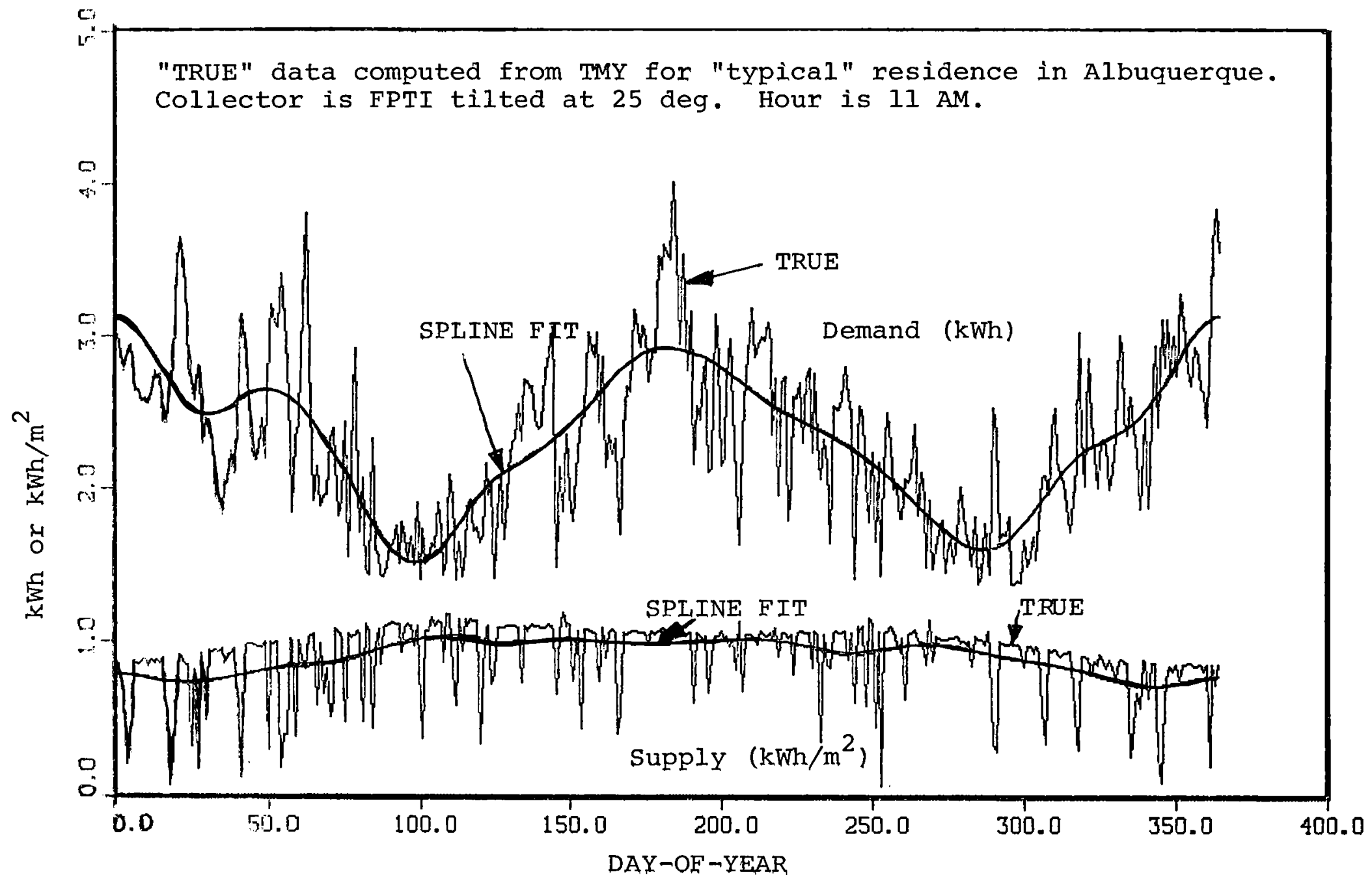

FIGURE 6.2 Sample Spline Fit to TMY Data. 
The third scheme is even cruder. For each h we take

$$
\mathrm{U}_{\mathrm{dh}}=\sum_{\mathrm{d}=1}^{364} \mathrm{v}_{\mathrm{dh}} / \mathrm{N}_{\mathrm{h}} \text {, }
$$

where $\mathrm{N}_{\mathrm{h}}$ is the number of nonzero values of $\mathrm{V}_{\mathrm{dh}}$ for each $\mathrm{h}$. The equation above is used for all $U_{d h}$ such that $V_{d h}>0$, and $U_{d h}$ is set to zero if $\mathrm{V}_{\mathrm{dh}}=0$. This scheme is denoted "global average prediction."

The latter two predictive methods are obviously inferior to Box-Jenkins type schemes, which weight recently measured data more heavily than data acquired far in the past. Also, they are extremely poor predictors for wind supply. For this reason, wind systems are not allowed in UEIID. However, wind can be used in UEllC.

\section{Storage Replacement}

In all UEll simulations, only the storage device, usually a battery, may require replacement. There are no overhauls. Replacement is based on the number of "storage cycles" experienced in the year. This quantity is computed as

$$
\begin{aligned}
S_{C y} & =\sum_{t=1}^{8736}\left(I_{b s}^{t}+I_{d s}^{t}\right) / x_{2}, \\
& =0 \text { if } x_{2}=0 ;
\end{aligned}
$$

that is, the total yearly output of the device divided by its size. The cycle life, $\mathrm{L}_{C y}$ ' is an input parameter. The storage device life is then

$$
\mathrm{Y}_{2}=\min \left(\mathrm{N}, \mathrm{L}_{\mathrm{Cy}} / \mathrm{S}_{\mathrm{Cy}}\right) \text {. }
$$


where $N$ is the system life. Of course, $Y_{2}$ is only a first order approximation to the characteristics of actual components.

\section{Price-Year and Replacement Costs}

The price-year cost of each component is described by the triplet $\left(\alpha_{i}, \beta_{i}, \gamma_{i}\right)$, where $i$ refers to the component. Given the price-year costs of components, the ACSYS, annualized cost of system, is computed as described in Chapter II. For a solar collector, the price-year cost is

$$
c_{1}=\alpha_{1} x_{1}^{\beta_{1}}+\gamma_{1}
$$

For a wind collector, the cost of $\mathrm{N}_{\mathrm{T}}$ turbines each with diameter $D$ is (see Chapter III),

$$
c_{1}=N_{T}\left(\alpha_{1}{ }^{B} I+\gamma_{1}\right)
$$

The costs of the other components are

$$
c_{i}=\alpha_{i}\left(e_{i} x_{i}\right)^{\beta}+\gamma_{i}, \quad i=2,3,4
$$

In all cases $c_{i}=0$ if $x_{i}=0$. Since only the storage device is replaceable, the cost of the nonreplaceables is

$$
\begin{aligned}
& c_{0}=c_{1} c_{3}+c_{4}, \\
& c_{1}=c_{2} \text { for the initial storage cost, and } \\
& c_{1}=c_{2}-\gamma_{2} \text { for storage replacement, }
\end{aligned}
$$

since the fixed cost is not repeated for replacement. 
The $\beta_{i}$ parameter offer economies of scale, $\beta_{i}<1$, or diseconomies of scale, $B_{i}>1$, as the user may choose. The $\gamma_{i}$ parameter represents fixed costs of purchase and installation.

The annual purchase energy cost is the total of the fixed purchase cost, the price per unit energy times the amount purchased totaled over the year, and the total monthly peak costs. 


\section{Chapter VII. Energy Allocation Logic for Stand Alone Simulation--GE}

\section{The GEll System}

The acronym GEll stands for Generator-connected, all-Electric, $\underline{1}$ collector, $\underline{l}$ storage-device system. Only one strategy has been devised for GEll--called GEllA. For the most part, GEll has the same component configuration as UEll (see Fig. 7.1), except that energy not supplied by a solar or wind collector is supplied by a fuelburning, on-site generator. Since a utility is not involved, sellback and time-of-day pricing are not considered. The rate of purchased energy costs in UEll is replaced by generator fuel costs. The time step is also 1 hour.

The GEll system consists of nine components--a collector, storage device, generator, and six transducers. For convenience, the notation has been changed somewhat. The generator size (maximum allowed power output) is denoted $x_{3}$. The transducer that feeds demand is $\mathrm{x}_{4}$, and the transducer that feeds generator output into the storage charger is $x_{9}$. The respective efficiencies are $e_{3}, e_{4}$, and $e_{9}$. As in UEll, all efficiencies are constant, except for the generator efficiency $e_{3}$, which depends on the type of fuel and power output versus rating (size) of the particular generator used. As before, we assume that certain transducers are inexpensive enough so that their size can be ignored and that the storage charge and discharge transducers depend on the storage size, viz,

$$
\begin{aligned}
& x_{5}=x_{6}=x_{9}=\infty, \\
& x_{7}=r_{7} x_{2}, x_{8}=r_{7} x_{2} .
\end{aligned}
$$

Additional quantities are the generator output to demand $G_{d^{\prime}}$ the generator output to storage $\mathrm{G}_{\mathrm{S}^{\prime}}$ and the generator starting level $g_{b}$, which allows for the fact that, in general, a generator should 


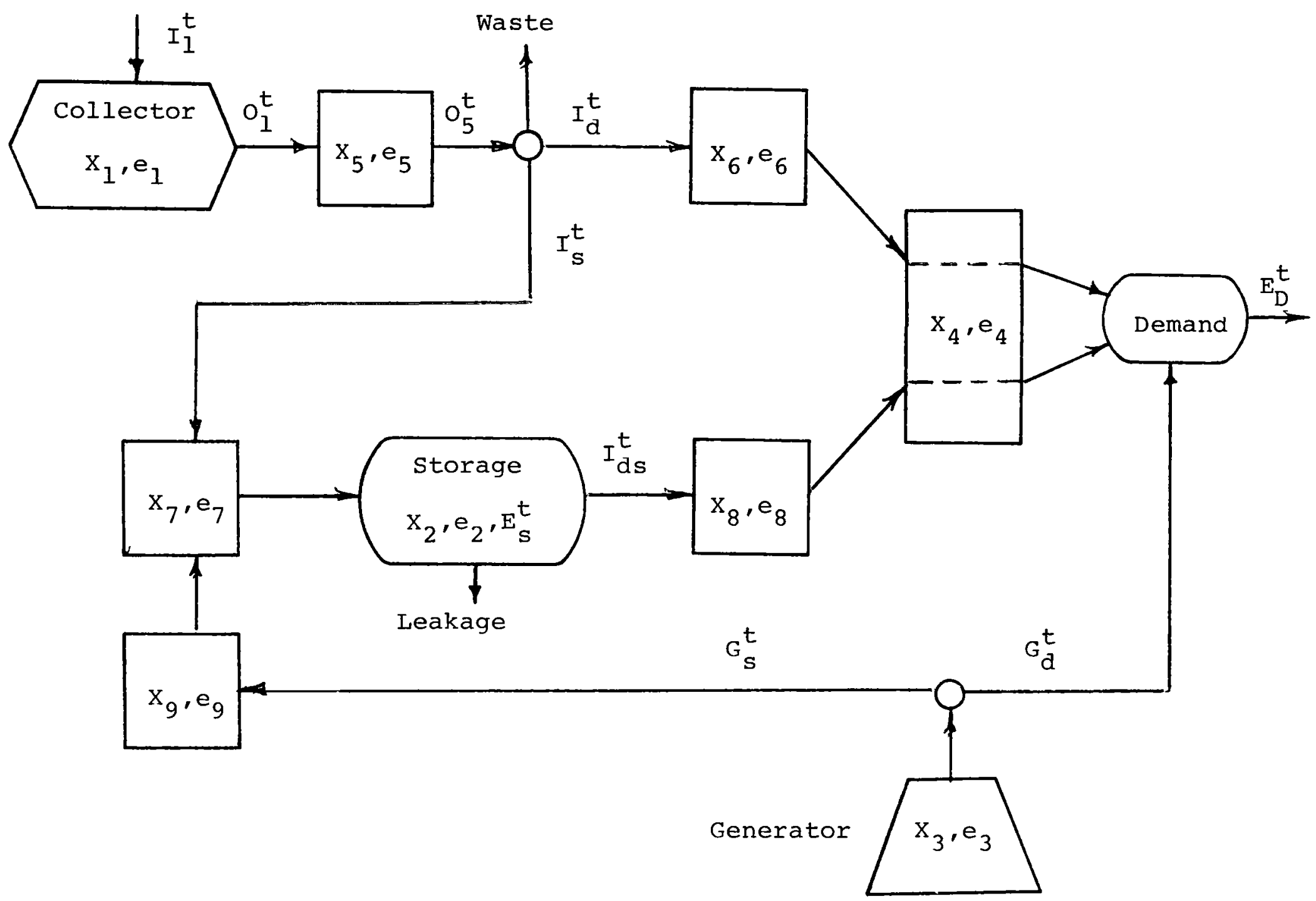

FIGURE 7.1 Block Diagram of GEll System. 
not be run at full throttle when it first starts. The parameter $0<g_{b} \leq 1$ is chosen by the user. The maximum generator output at time $t$ is $g_{b}^{t} x_{3}$ where $g_{b}^{t}=g_{b}$ if the generator was off at $t i m e t-l$, and $g_{b}^{t}=1$ if the generator was on at time $t-1$.

The system equations are

$$
\begin{aligned}
& \mathrm{o}_{1}^{\mathrm{t}}=\mathrm{e}_{1} \mathrm{x}_{1} \mathrm{I}_{1}^{\mathrm{t}} \\
& o_{5}^{t}=e_{5} o_{1}^{t} \\
& I_{d}^{t}+I_{s}^{t} \leq O_{5}^{t} \\
& e_{4} e_{6} I_{d}^{t}+e_{4} e_{8} I_{d s}^{t}+G_{d}^{t} \leq E_{D}^{t} \\
& e_{2} E_{s}^{t-1}-I_{d s}^{t}+e_{7} I_{s}^{t}+e_{7} e_{9} G_{s}^{t}=E_{s}^{t} \\
& E_{s}^{t} \leq x_{2} \\
& I_{s}^{t}+e_{9} G_{s}^{t} \leq x_{7} \\
& I_{d s}^{t} \leq x_{8} \\
& G_{d}^{t}+G_{s}^{t} \leq g_{b}^{t} x_{3} \\
& I_{l^{\prime}}^{t}, E_{s^{\prime}}^{t}, I_{d}^{t}, I_{d s}^{t}, I_{s}^{t}, G_{d}^{t}, G_{s}^{t} \geq 0
\end{aligned}
$$

These equations indicate two important distinctions between UEll and GE11. In GEIl it is not necessarily required that all the demand 
be satisfied and there is no constraint on $x_{4}$ (called $x_{3}$ in UEll). Because GEll is a stand-alone system, it cannot be assumed that an inexhaustible, unbounded source of energy like the utility exists at the site. While a suitably large generator could be used to meet all demand, such a value of $x_{3}$ may be impractical. We therefore permit the system to satisfy a demand goal which is some part of the total yearly demand. Let the unsatisfied demand at hour $t$ be

$$
D_{u}^{t}=E_{D}^{t}-e_{4} e_{6} I_{d}^{t}-e_{4} e_{8} I_{d s}^{t}-G_{d}^{t}
$$

then the system is required to satisfy the condition

$$
\sum_{t=1}^{8736} D_{u}^{t} \leq\left(1-d_{g}\right) \cdot \sum_{t=1}^{8736} E_{D}^{t}
$$

where $0<d_{g} \leq I$ is the input demand-goal parameter. If $d_{g}=1$, all demand must be satisfied. The simulation imposes this requirement by attempting to find $x_{1}, x_{2}$, and $x_{3}$ so as to minimize

$$
\begin{gathered}
\operatorname{ACSYS}+\lambda \min \left\{0, \sum_{t=1}^{8736}\left[D_{u}^{t}-\left(1-d_{g}\right) E_{D}^{t}\right]\right\} \\
\lambda \gg 1 .
\end{gathered}
$$

The term involving $\lambda$ in equation (7-12) is a penalty for not meeting the demand goal. As before, ACSYS is the annualized cost of the system.

Since the system must be allowed to satisfy equation (7-11) if it can, the second distinction is that no constraint is imposed on $\mathrm{x}_{4}$. However, $\mathrm{x}_{4}$ is dependently sized as 


$$
x_{4}=\max _{t}\left(e_{6} I_{d}^{t}+e_{8} I_{d s}^{t}\right)
$$

and its cost is included in ACSYS as a capital item. Thus only $\mathrm{x}_{1}, \mathrm{x}_{2}$, and $\mathrm{x}_{3}$ are independent variable sizes.

\section{Generator Operation and Sizing}

An important factor in generator operation is its fuel consumption versus power output. We call this relationship the generator consumption function, which depends on generator size, type of fuel, and instantaneous output relative to rated output $x_{3}$.

Define $G_{0}^{t}$ as the total generator output at time $t$,

$$
0 \leq G_{0}^{t}=G_{d}^{t}+G_{s}^{t} \leq g_{b}^{t} x_{3}
$$

The consumption function is of the form

$$
e_{3}^{t}=\left(e_{31}+e_{32} x_{3}\right)\left[e_{33}+e_{34}\left(\frac{G^{t}}{\bar{x}_{3}}\right)+e_{35}\left(\frac{G^{t}}{\bar{x}_{3}}\right)^{2}\right]
$$

The units of $e_{3}$ are $k W h$ output per unit fuel consumed. The $e_{3 i}$ are constant input parameters. The term $e_{31}+e_{31} x_{3}$ in (7-14) is an approximation to the economy of scale in that larger generators tend to be more efficient than smaller ones. We require

$$
e_{31}>0 \text { and } e_{32} \geq 0
$$

The second term in (7-14) is the relative efficiency which depends on the ratio of instantaneous output to rating. It is required that this term be a strictly positive nondecreasing function for $0 \leq G_{0}^{t} \leq x_{3}$. 
In particular

$$
0<e_{33} \leq 1 \text { and } e_{33}+e_{34}+e_{35}=1 \text {. }
$$

are required.

The fuel consumed at time $t$ is then

$$
F^{t}=G_{0}^{t} / e_{3}^{t}
$$

The parameters chosen for the $e_{3 i}$ and the unit price of fuel depend on the type of generator used. In particular, we allow gasoline, diesel fuel, coal, and natural gas with price units of dollars per gallon, gallon, ton, and MCF, respectively. A cursory, informal study indicates "typical" values of

$$
e_{31}=0.0836, e_{33}=0.327, e_{34}=1.293, e_{35}=-0.62
$$

for diesel and

$$
e_{31}=0.1495, e_{33}=0.136, e_{34}=1.664, e_{35}=-0.80
$$

for gasoline for generators of $x_{3} \leq 15 \mathrm{~kW}$. For both, $e_{32}=0$.

Because of the demand goal requirement, it is not possible to know what size generator will satisfy the demand goal in the absence of a collector and battery unless detailed knowledge of the demand profile is available. Therefore, generator size is specified on input as $0 \leq Z_{3} \leq 1$, which is the ratio of total yearly demand satisfied by a generator-only system. The simulation finds the value of $x_{3}$ associated with the demand profile for any value of $\mathrm{z}_{3}$. Of course, in the case where $\mathrm{z}_{3}=1$,

$$
x_{3}=\max _{t} E_{D}^{t}
$$


The constraint

$$
\mathrm{z}_{3} \leq \mathrm{d}_{\mathrm{g}}
$$

is always imposed on the generator size.

\section{Strategy GEllA}

In the absence of sell-back and time-of-day pricing, the distribution of collected energy is quite simple; namely, satisfy as much demand as possible and use any excess to increase storage. Also, use stored energy to help satisfy demand only if insufficient collected energy is available. Given that a solar or wind system has been built, the only strategical question is whether or not to have the generator running. If it is decided to turn on the generator, its fuel consumption function always indicates that it is best to run it at full output power if possible. In all cases we use the expression generator "ON" to mean turn it on if it is off, or leave it on if it is on. Generator "OFF" means to shut it off if it is on, or leave it off if it is off. If the generator is ON, its first priority is to help the collected energy satisfy demand before any stored energy is used. Excessive generator output can then be put to storage.

In addition to optimizing the sizes $x_{1}, x_{2}$, and $x_{3}$, this strategy uses two auxiliary optimizing variables $\mathrm{x}_{L}$ and $\mathrm{x}_{\mathrm{U}^{\prime}}$ constrained by

$$
0<\mathrm{x}_{\mathrm{L}} \leq \mathrm{x}_{\mathrm{U}}<1
$$

These variables represent, respectively, the lower and upper relative-storage decision levels. They are used only when $x_{2}>0$. If $E_{S}^{t-l} / X_{2}<X_{L}$, the generator will always be ON at time $t$. If $E_{S}^{t-1} / x_{2}>X_{U^{\prime}}$, the generator will always be OFF at time $t$. As usual, $x_{L}$ and/or $\mathrm{X}_{\mathrm{U}}$ may be fixed by the user or allowed to vary so as to optimize the system. The initial storage level is set to $\left(x_{L}+X_{U}\right) / 2$, at no cost. 
The user may also specify that the generator be ON for certain hours in certain weeks of the year. For example, in the dark, early morning hours of winter, a solar installation may arbitrarily turn on its generator to pump up storage because of the long absence of sunshine. The user can input a table of these "arbitrary ON" times. We define the input values

$$
\begin{aligned}
& g_{0}^{t}=0, \text { generator not necessarily on at } t \text { ime } t \\
& g_{0}^{t}=1 \text {, generator arbitrarily on at time } t .
\end{aligned}
$$

The $g_{0}^{t}=1$ condition is overridden if the relative storage level exceeds $x_{U}$.

There are three substrategies in GEllA depending on the degree of prediction and whether the values of supply and demand at the current time are used. In all cases the storage level is monitored. The strategies are defined by the value of the input parameter $Q$ :

$$
\begin{aligned}
& Q=0, \text { current time values not used, no prediction, } \\
& Q=1 \text {, current time values used, no prediction, } \\
& Q>1 \text {, current time values used, prediction for } Q-1 \text { hours ahead. }
\end{aligned}
$$

Whatever the value of $Q$ used, the following strategy and operating equations always hold:

1. If $E_{S}^{t-1} / X_{2}<x_{L}$, generator is ON.

2. If $E_{S}^{t-1} / x_{2} \leq x_{U}$ and $g_{O}^{t}=1$, generator is $O N$.

3. If $E_{S}^{t-1} / x_{2}>x_{U}$, generator is OFF. 
If the generator is $\mathrm{OFF}$, the operation equations are

$$
\begin{aligned}
& G_{S}^{t}+G_{d}^{t}=0 . \\
& I_{d}^{t}=\min \left(E_{D}^{t} / e_{4} e_{6}, O_{5}^{t}\right) .
\end{aligned}
$$

If $O_{5}^{t} \neq I_{d}^{t}$, then

$$
\begin{aligned}
& I_{d s}^{t}=0, \text { and } \\
& I_{S}^{t}=\min \left[O_{5}^{t}-I_{d}^{t}, x_{7},\left(x_{2}-e_{2} E_{S}^{t-1}\right) / e_{7}\right] .
\end{aligned}
$$

If $O_{5}^{t}=I_{d}^{t}$, then

$$
\begin{aligned}
& I_{s}^{t}=0, \text { and } \\
& I_{d s}^{t}=\min \left[E_{D}^{t}-e_{4} e_{6} I_{d}^{t} / e_{4} e_{8}, x_{8}, e_{2} E_{s}^{t-1}\right] .
\end{aligned}
$$

For the generator ON,

$$
I_{d}^{t}=\min \left(E_{D}^{t} / e_{4} e_{6}, O_{5}^{t}\right) .
$$

If $O_{5}^{t}>I_{d}^{t}$, then

$$
\begin{aligned}
I_{d s}^{t} & =G_{d}^{t}=0, \\
I_{s}^{t} & =\min \left[O_{5}^{t}-I_{d}^{t}, x_{7},\left(x_{2}-e_{2} E_{s}^{t-I}\right) / e_{7}\right], \\
G_{s}^{t} & =\min \left[g_{b}^{t} x_{3}, \frac{x_{7}-I_{s}^{t}}{e_{9}}, \frac{x_{2}-e_{2} E_{s}^{t-1}-e_{7} I_{s}^{t}}{e_{7} e_{9}}\right] .
\end{aligned}
$$


If $O_{5}^{t}=I_{d}^{t}$, then

$$
\begin{aligned}
& I_{s}^{t}=0, \\
& G_{d}^{t}=\min \left(g_{b}^{t} x_{3}, E_{D}^{t}-e_{4} e_{6} I_{d}^{t}\right)
\end{aligned}
$$

If $O_{5}^{t}=I_{d}^{t}$ and $G_{d}^{t}=g_{b}^{t} x_{3}$, then

$$
\begin{aligned}
& G_{s}^{t}=0, \\
& I_{d s}^{t}=\min \left[\frac{E_{D}^{t}-e_{4} e_{6} I_{d}^{t}-G_{d}^{t}}{e_{4} e_{8}}, x_{8}, e_{2} E_{s}^{t-I}\right] .
\end{aligned}
$$

If $O_{5}^{t}=I_{d}^{t}$ and $G_{d}^{t}<g_{b}^{t} x_{3}$, then

$$
\begin{aligned}
& I_{d s}^{t}=0, \\
& G_{s}^{t}=\min \left[g_{b}^{t} x_{3}-G_{d}^{t}, x_{7} / e_{7}, \frac{x_{2}-e_{2} E_{s}^{t-1}}{e_{7} e_{9}}\right] .
\end{aligned}
$$

The following equations apply whether the generator is ON or OFF.

$$
\begin{aligned}
& E_{s}^{t}=e_{2} E_{s}^{t-1}+e_{7} I_{s}^{t}+e_{7} e_{9} G_{s}^{t}-I_{d s}^{t} \\
& D_{u}^{t}=E_{D}^{t}-e_{4} e_{6} I_{d}^{t}-e_{4} e_{8} I_{d s}^{t}-G_{d}^{t} \\
& G_{O}^{t}=G_{d}^{t}+G_{s}^{t}
\end{aligned}
$$

$$
\text { Waste }=O_{5}^{t}-I_{d}^{t}-I_{s}^{t}
$$


Leakage $=e_{2} E_{s}^{t-1}$

GEllA with $Q=0$

This strategy does not use current time values of supply and demand, nor does it predict. Its decision is:

If $x_{L} \leq E_{S}^{t-1} / x_{2} \leq x_{U}$ and $g_{O}^{t}=0$, then leave generator ON if it is on, leave it OFF if it is off.

$$
\text { GEllA with } Q=1
$$

This strategy does not predict, but it monitors the current supply and demand. As usual we assume exact measurement of these quantities. The strategy is:

If $\mathrm{x}_{\mathrm{L}} \leq \mathrm{E}_{\mathrm{S}}^{\mathrm{t}-1} / \mathrm{x}_{2} \leq \mathrm{x}_{\mathrm{U}}$ and $\mathrm{g}_{\mathrm{O}}^{\mathrm{t}}=0$, then turn oN the generator if the demand for this hour cannot be satisfied by the collector and battery. Otherwise, turn it OFF.

\section{GEIIA with $Q>1$}

This strategy monitors the current demand and supply and also predicts them for $Q-1$ hours in the future. The strategy is:

If $\mathrm{x}_{\mathrm{L}} \leq \mathrm{E}_{\mathrm{S}}^{\mathrm{t}-1} / \mathrm{x}_{2} \leq \mathrm{x}_{\mathrm{u}}$ and $\mathrm{g}_{\mathrm{O}}^{t}=0$, turn the generator ON if the current demand or future demand, based on predicted supply and demand, is not satisfied in the present hour in any of the $Q-1$ hours in the future. Otherwise turn it OFF.

The implemented predictors are the same as described in Chapter VI for UEIID. 
Storage and Generator Replacement and Overhaul

In GEll, the storage may be replaced as described in Chapter VI. Also, the generator may be replaced according to its hours of operation. The generator life in hours, $0<\mathrm{L}_{g}$, is an input parameter that specifies the number of hours the generator may be on before it is replaced. If $\mathrm{H}_{\mathrm{y}}$ is the computed number of hours per year that the generator is $O N$, then the generator life in years of service is

$$
\mathrm{Y}_{3}=\min \left(\mathrm{N}, \mathrm{NH}_{\mathrm{Y}} / \mathrm{L}_{\mathrm{g}}\right)
$$

The generator may also require overhauls. The input parameter $N_{\text {og }} 0$ specifies the number of overhauls per generator life. If a generator is purchased at time (years) $Y_{p}$, it is overhauled every

$$
Y_{p}+j Y_{3} /\left(N_{o g}+1\right) ; j=1,2, \ldots, N_{o g}
$$

years.

Price Year and Replacement Costs

As with UEll, the cost of each component is described by the triplet $\left(\alpha_{i}, \beta_{i}, \gamma_{i}\right)$. The collector, storage, and transducer \#4 costs, $\left(\mathrm{c}_{1}, \mathrm{c}_{2}, \mathrm{c}_{4}\right)$, are as in Chapter VI. The generator price-year cost is

$$
c_{3}=\alpha_{3} x_{3}^{\beta_{3}}+\gamma_{3} ; c_{3}=0 \text { if } x_{3}=0
$$

The nonreplaceables are the collector and transducer, thus

$$
\begin{aligned}
& c_{0}=s_{1}+c_{4}, \\
& c_{1}=c_{2} \text { and } c_{2}=c_{3} \text { for initial storage and generator cost, } \\
& \text { and }
\end{aligned}
$$


$c_{1}=c_{2}-\gamma_{2}$ and $c_{2}=c_{3}-\gamma_{3}$ for replacement, since the fixed costs are not included for replacements.

Generator overhaul costs are imbedded in OM costs on output.

The annual energy purchase cost in UEll is replaced by the generator fuel cost. The yearly fuel consumed is, from Equation (7-15),

$$
\sum_{t=1}^{8736} F^{t}=\sum_{t=1}^{8736} G_{0}^{t} / e_{3}^{t}
$$

and its price year cost depends on the price per unit, which is an input parameter. 
Optimization of UEII

For given strategy, site, parameters, etc., the optimum system is that which minimizes the annualized cost of satisfying demand for the life of the system. For all UEll strategies there are up to four sizes to choose; $x_{1}, x_{2}, x_{3}, x_{4} \geq 0$. For UEllA, the additional variable $0 \leq \mathrm{X}_{\mathrm{L}} \leq 1$ must be found. Any or all of these variables may be held constant at the whim of the user.

Optimal sizing of the variables is accomplished by a pattern search procedure. Associated with each variable is a lower and upper bound, $0 \leq \mathrm{L}_{i} \leq \mathrm{U}_{i}$ specified by the code user. The upper bound of $x_{I}$ cannot exceed unity. If the specified upper and lower bounds are the same for a component, its size is fixed at that value.

Associated with the optimization is a relative mesh size and an iteration number. Let $0 \leq m_{k} \leq 0.333$ be the mesh size associated with the $k$-th iteration, $k=0,1, \ldots, k$, where $k \geq 0$ is the index of the final iteration. The $\mathrm{m}_{k}$ are interrelated by

$$
m_{k+1}=m_{k} / 10
$$

The quantities $m_{0}$ and $k$ can be specified by the user or left to the code as a default. The absolute mesh size associated with the $i-t h$ variable at the $k$-th iteration is

$$
d_{i k}=m_{k}\left(U_{i}-L_{i}\right)
$$

Let $G_{i k}$ be the estimate of the optimal value of the $i$-th variable at the beginning of the $k$-th iteration--here we view $x_{L}$ as a fifth variable. During the k-th iteration, the optimal value of $x_{i}$ will be selected from the monotonically nondecreasing set of points

$$
L_{i}, \ldots, G_{i k}-d_{i k}, G_{i k}, G_{i k}+d_{i k}, \ldots, U_{i}
$$


Because of the pattern search algorithm, not all grid points will necessarily be examined. The optimal value found at the end of the $k$-th iteration is the estimate for the $k+1$ iteration. The set of $G_{i K}$ at the end of the $k-t h$ iteration is taken as the optimal system size.

We will not discuss the pattern search algorithm here (see Ref. 12). Because of the special nature of our optimization, the algorithm has been somewhat modified. This modification was necessitated by the fact that the fixed cost terms in the components cause severe discontinuities in the capital cost as a size nears zero, because the collector and storage device, $x_{1}$ and $x_{2}$, are generally more expensive than the two variable-sized transducers $x_{3}$ and $x_{4}--x_{L}$ is free, of course--and because each value of $x_{1}$ and $x_{2}$ imposes an effective bound on $x_{3}$ and $x_{4}$.

If $x_{1}$ and $x_{2}$ are not both fixed, then sets of searches are performed, depending on the lower bounds. Assume $\mathrm{U}_{1}>0$ and $\mathrm{U}_{2}>0$ and let $\xi>0$ be an arbitrarily small number, if

1. $\mathrm{L}_{1}=0, \mathrm{~L}_{2}=0$;

Evaluate $\quad x_{1}=0, x_{2}=0$

Search $\mathrm{x}_{1}=0, \quad \xi \leq \mathrm{X}_{2} \leq \mathrm{U}_{2}$,

then $\quad \xi \leq \mathrm{X}_{1} \leq \mathrm{U}_{1}, \mathrm{x}_{2}=0$,

then $\quad \xi \leq \mathrm{X}_{1} \leq \mathrm{U}_{1}, \quad \xi \leq \mathrm{X}_{2} \leq \mathrm{U}_{2}$.

2. $\mathrm{L}_{1}>0, \mathrm{~L}_{2}=0$;

Search $\mathrm{L}_{1} \leq \mathrm{X}_{1} \leq \mathrm{U}_{1}, \mathrm{x}_{2}=0$ ，

then $\mathrm{L}_{1} \leq \mathrm{X}_{1} \leq \mathrm{U}_{1}, \quad \xi \leq \mathrm{X}_{2} \leq \mathrm{U}_{2}$.

3. $L_{1}=0, L_{2}>0$;

Search $\mathrm{x}_{1}=0, \quad \mathrm{~L}_{2} \leq \mathrm{X}_{2} \leq \mathrm{U}_{2}$,

then $\quad \xi \leq \mathrm{X}_{1} \leq \mathrm{U}_{1}, \mathrm{~L}_{2} \leq \mathrm{X}_{2} \leq \mathrm{U}_{2}$. 
4. $L_{1}>0, L_{2}>0$;

Search $\mathrm{L}_{1} \leq \mathrm{X}_{1} \leq \mathrm{U}_{1}, \quad \mathrm{~L}_{2} \leq \mathrm{X}_{2} \leq \mathrm{U}_{2}$.

Whatever the procedures, the optimum of the optimum of each search is retained as the solution. For each search $m_{0}=0.1$ and $k=1$ are the default values. The user can specify $0<m_{0} \leq 0.333$ and $0 \leq K \leq 9$.

The quantities $x_{3}, x_{4}$, and $x_{L}$ (if it exists) may be fixed or variable. If the input lower bound of any of these variables is equal to the input upper bound, that variable is fixed at its bound. If $x_{3}$ or $x_{4}$ are variable, then their search ranges depend on the values of $x_{1}$ and $x_{2}$ for any particular pass, and the actual input bounds are not used. Let $\mathrm{X}_{\mathrm{M} 3}$ and $\mathrm{X}_{\mathrm{M} 4}$ be upper bounds defined as

$$
\begin{aligned}
& x_{M 3}=e_{1} e_{5} e_{6} x_{1}+e_{8} r_{8} x_{2}, \\
& x_{M 4}=r_{7} x_{2} / e_{4} .
\end{aligned}
$$

Here we assume the maximum value of $I_{1}^{t}$ is $1.0 \mathrm{kWh} / \mathrm{m}^{2}$, which is nearly true. If $x_{3}$ or $x_{4}$ are variable, then the searched variables associated with these quantities have range $0.05 \leq x_{3} \leq 1.0$ and $0 \leq x_{4} \leq 1.0$. The values used in the simulation pass are $x_{3}=x_{3} x_{M 3}$ and $x_{4}=x_{4} x_{M 4}$. If $x_{2}$ is zero, then $x_{4}$ is fixed at zero. Note that no search on $x_{1}$ or $x_{2}$ includes zero in its range. Also, if $x_{2}$ is zero, $x_{L}$ is fixed at zero for that search.

To initialize the search estimates, a Latin hypercube random start is used if both $\mathrm{x}_{1}$ and $\mathrm{x}_{2}$ are allowed to vary during the search (see Ref. 13). If one of these variables is fixed, then the other variable is initialized at 20 percent of its range. For example, if $x_{1}$ is fixed (on a particular search, not necessarily for the whole optimization) and $\mathrm{L}_{2} \leq \mathrm{X}_{2} \leq \mathrm{U}_{2}$, then

$$
\mathrm{G}_{20}=0.2\left(\mathrm{U}_{2}-\mathrm{L}_{2}\right)+\mathrm{L}_{2}
$$


If both variables are allowed to vary, each range is broken into 15 equi-sized segments. A point is uniformly and randomly chosen within each segment. The points are randomly shuffled so that each point in the range of $x_{1}$ is randomly paired with a point in $x_{2}$ (no point is used twice). We now have 15 pairs of candidate sizes. An annualized cost is computed by a pass for each of the 15 pairs of $x_{1}, x_{2}$. At this stage $x_{3}$ and $x_{4}$ are set to their fixed values or effective maximums as in equations (8-3), and the cost of $x_{3}$ and $x_{4}$ is taken to be zero. The "best" pair is used to initialize the outer search. The uniform random number generator seed can be chosen by the user, or left to a "random" choice by the computer.

The cost of satisfying demand with no system is always computed. If all components are allowed to be zero; $i . e ., L_{i}=0$ for all $i$, then the nonsystem is a candidate for the optimum configuration. If, however, a nonsystem is not allowed, the nonsystem is not allowed to compete.

\section{Optimization of GElI}

Optimization is carried out for up to five variables, $x_{1}$, $\mathrm{x}_{2}, \mathrm{x}_{3}, \mathrm{x}_{\mathrm{L}}$, and $\mathrm{x}_{\mathrm{U}}$. As with UEll, any or all of these may be held constant if so desired. Optimization is achieved by a pattern search as above, with the modifications described below.

The "nonsystem"--no collector, storage, or transducers--must have a generator to satisfy the demand goal. Let $x_{3}(Z)$ denote the $\mathrm{kW}$ size of the generator for the satisfied demand ratio $Z$ (see Chapter VII). Then the stand-alone nonsystem generator is sized at

$$
x_{3}=x_{3}\left(z=d_{g}\right)
$$

Let the input bounds on $\mathrm{x}_{3}$ be $\mathrm{z}_{\mathrm{L}}$ and $\mathrm{z}_{\mathrm{U}^{\prime}}$, then if $\mathrm{Z}_{\mathrm{U}}=\mathrm{d}_{\mathrm{g}}$ and $\mathrm{L}_{1}=\mathrm{L}_{2}=0$, the nonsystem is a candidate for optimization. If it is not a candidate but is less expensive than the optimal system allowed under the input constraints, this fact is noted in the output of the code. 
In the input we do not allow $\mathrm{Z}_{U}>\mathrm{d}_{\mathrm{g}}$, nor do we allow the generator size to be fixed at zero; i.e., $\mathrm{Z}_{\mathrm{L}}=\mathrm{Z}_{U}=0$. If $\mathrm{z}_{U}<\mathrm{d}_{\mathrm{g}}$, then the generator alone cannot satisfy demand, and some collector-storage system must be built.

If $x_{1}$ or $x_{2}$ are not fixed, then sets of searches are performed, depending on their lower bounds. Assume $U_{1}, U_{2}$, and $U_{3}>0$ and $\xi>0$ is an arbitrary small number, where

$$
U_{3}=x_{3}\left(Z_{U}\right) \text { and } L_{3}=x_{3}\left(Z_{L}\right)
$$

that is, generator size in power units. Define

$$
\phi_{i}=\min \left(\xi, L_{i}\right)
$$

then the optimization candidates are:

1. $\mathrm{L}_{1}=0, \mathrm{~L}_{2}=0, \mathrm{~L}_{3}=0$

a. Evaluate $x_{1}=x_{2}=0$ and $x_{3}=U_{3}$

b. Search $\phi_{1} \leq x_{1} \leq U_{1}, x_{2}=0, x_{3}=0$

c. then $\phi_{1} \leq \mathrm{x}_{1} \leq \mathrm{U}_{1}, \mathrm{x}_{2}=0, \phi_{3} \leq \mathrm{x}_{3} \leq \mathrm{U}_{3}$

d. then $\phi_{1} \leq \mathrm{x}_{1} \leq \mathrm{U}_{1}, \phi_{2} \leq \mathrm{x}_{2} \leq \mathrm{U}_{2}, \mathrm{X}_{3}=0$

e. then $\phi_{1} \leq \mathrm{x}_{1} \leq \mathrm{U}_{1}, \phi_{2} \leq \mathrm{X}_{2} \leq \mathrm{U}_{2}, \phi_{3} \leq \mathrm{X}_{3} \leq \mathrm{U}_{3}$

In all these cases, $x_{L}$ and $x_{U}$ are also searched unless they are fixed on input or $x_{2}=0$.

2. $L_{1}=0, L_{2}=0, L_{3}>0$, do $1 a, 1 c$, and $1 e$.

3. $L_{1}=0, L_{2}>0, L_{3}=0$, do $1 d$ and le.

4. $L_{1}=0, L_{2}>0, L_{3}>0$, do le.

5. $L_{1}>0, L_{2}=0, L_{3}=0$, do $1 b, 1 c, 1 d$, and le. 


$$
\begin{aligned}
& \text { 6. } \mathrm{L}_{1}>0, \mathrm{~L}_{2}=0, \mathrm{~L}_{3}>0 \text {, do lc. } \\
& \text { 7. } \mathrm{L}_{1}>0, \mathrm{~L}_{2}>0, \mathrm{~L}_{3}=0 \text {, do ld and le. } \\
& \text { 8. } \mathrm{L}_{1}>0, \mathrm{~L}_{2}>0, \mathrm{~L}_{3}>0 \text {, do le. }
\end{aligned}
$$

In all cases where $x_{2}=0$, we set $x_{L}=X_{U}=0$, and these variables are not searched. The mesh sizes and iteration numbers are used exactly as in UEll above.

A problem arises in the bounding of $x_{U}$. Let $x_{L}$ be bound by $0 \leq L_{L} \leq X_{L} \leq L_{U}<1$. We always require that $x_{L} \leq X_{U}<1$. Suppose, for example, $\mathrm{L}_{\mathrm{L}}=0.1$ and $\mathrm{L}_{\mathrm{U}}=0.6$. We are forced to use $0.6 \mathrm{x}_{\mathrm{U}}$ to avoid $\mathrm{x}_{\mathrm{U}}$ becoming less than $x_{L}$ in the search. Now suppose the solution is $x_{L}=0.2$ and $x_{U}=0.6$. We cannot know if $x_{U}$ less than 0.6 would improve the solution unless we set up another optimization.

To avoid this difficulty while maintaining $x_{U} \geq X_{L}$, we use the bounds $\left(U_{\mathrm{L}}, \mathrm{U}_{\mathrm{U}}\right)$ to denote the relative range above $\mathrm{x}_{\mathrm{L}}$ that $\mathrm{x}_{\mathrm{U}}$ is allowed, where $0<\mathrm{U}_{\mathrm{L}}<\mathrm{U}_{\mathrm{U}}<\mathrm{I}$. Given a candidate value $\mathrm{x}_{\mathrm{L}^{\prime}} \mathrm{L}_{\mathrm{L}} \leq \mathrm{X}_{\mathrm{L}} \leq \mathrm{L}_{\mathrm{U}^{\prime}}$ and a candidate value $\mathrm{x}_{U^{\prime}}^{1} U_{L} \leq \mathrm{X}_{U}^{1} \leq \mathrm{U}_{U}$, the value of $\mathrm{X}_{U}$ used is

$$
x_{U}=x_{L}+\left(1-x_{L}\right) x_{U}^{1}
$$

Thus the bounds $\left(U_{L}, U_{U}\right)$ are bounds relative to $x_{L}$.

For each optimization search, for example le above, from one to five of the "variables" may be fixed. If all are fixed, the optimum cost is merely the cost associated with this fixed vector. If four are fixed, the search is initialized with the midpoint of the range of the variable one. If fewer than four are fixed, then the Latin hypercube random start technique described earlier is used on the variable quantities. In GEll, each range is broken into 20 segments instead of the 15 segments used in UEll. 
Optimization of UEll and GEll is a difficult procedure because the surface to be minimized is exceedingly complicated. The pattern search method was chosen because of its simplicity and since analytic derivatives are not available, and numerical derivatives are expensive to compute. Our experience indicates that the mimimums are quite broad in many cases, and thus moderate variations in sizes about the computed mimimum do not drastically change the annualized cost. As usual in these kinds of problems, the possibility of finding a local rather than global minimum always exists. 
Chapter IX. SOLSTOR Input/Output

\section{Introduction}

At this juncture, it is convenient to define some terms. By a "pass" we mean the simulation of one year's data for a fixed set of component sizes. By a "run" we mean a set of one or more passes resulting in the optimization of a particular configuration. By a "job" we mean a set of one or more runs presented to the computer to be processed at one time, i.e., with one object program loading.

Input data consists of an input card deck or 80-character coded records, TMY data for the various sets and the ASHRAE data. If the demand data is presented in tabular form rather than being internally computed, an additional input file is needed. In addition to the output listing, an output file is generated which gives detailed data about the system state for each hour of the year for each run, i.e., the detailed data for each optimal configuration. The TMY, ASHRAE, and demand data input files are identical for both UEll and GE11. The input card decks and output are somewhat dissimilar.

In the following, the symbol $\not b$ means blank. The default and override notation $a \sim^{b} \rightarrow c=d$ means that if $a$ is related to $b$ by $\sim$ in the input, then $c$ is set to $d$. The notation Error $=(a b$, etc.) means that if $a$ is related to $b$ by $\sim$ or input, a fatal input error has occurred.

Each type of card is identified by a code in columns 1 and 2 . Blank cards are used to separate runs within a job. Two successive blank cards terminate a job. Cards within a run may be in any order, except that the first card of a job must be an ID card. If two or more cards appear in a run with the same identification, the last card read is used. The first run deck of a job must contain at least one of each necessary type of card. Subsequent run decks require only those cards which are different from preceding cards of the 
same type. The configuration strategy field--UEllA, UEllB, etc.--of the first ID card of a job defines the configuration for the whole job. If subsequent ID cards appear in the job deck, their configuration field is ignored.

Both UEll and GEll require 13 cards per run. Many input cards are the same for both programs. These two simulations are actually in separate libraries. Their job control streams for the CDC 7600 are described below.

For residences, all component sizes are in $\mathrm{m}^{2}, \mathrm{~kW}$, or $\mathrm{kWh}$, and all costs are in dollars. For communities (multiple residences) and utilities as users, components sizes are $\mathrm{k}\left(\mathrm{m}^{2}\right), \mathrm{MW}$, and $\mathrm{MWh}$, and costs in $\$ \mathrm{~K}$. The electrical purchase prices per unit energy are in cents/kWh in UEll. Fuel purchase prices in GEll are in dollars per unit. Size and cost scaling is described in the "DH" card section.

\section{UEll and GEll Job Control Streams}

The UEll job control stream is shown here. The small driver program is in FORTRAN. The symbol o means the letter "O."

UEl1, etc. (JOB Card)

ACCOUNT Card

ATTACH (SOLLIBI, SOLLIBI)

ATTACH (SOLIIB2, SOLLIB2)

ATTACH (SOLLIB3, SOLLIB3)

LIBRARY (SOLLIBI, SOLLIB2, SOLLIB3)

FILE, TAPE1, RT=S.

ATTACH (TAPEl, PVBAT, $C Y=3)$

FILE, TAPE2, RT=S.

ATTACH (TAPE2, PVBAT, $C Y=2)$

* FILE, TAPE3, RT=S.

*ATTACH (TAPE3,...)

$\operatorname{FTN}(L=0, O P T=2)$ 


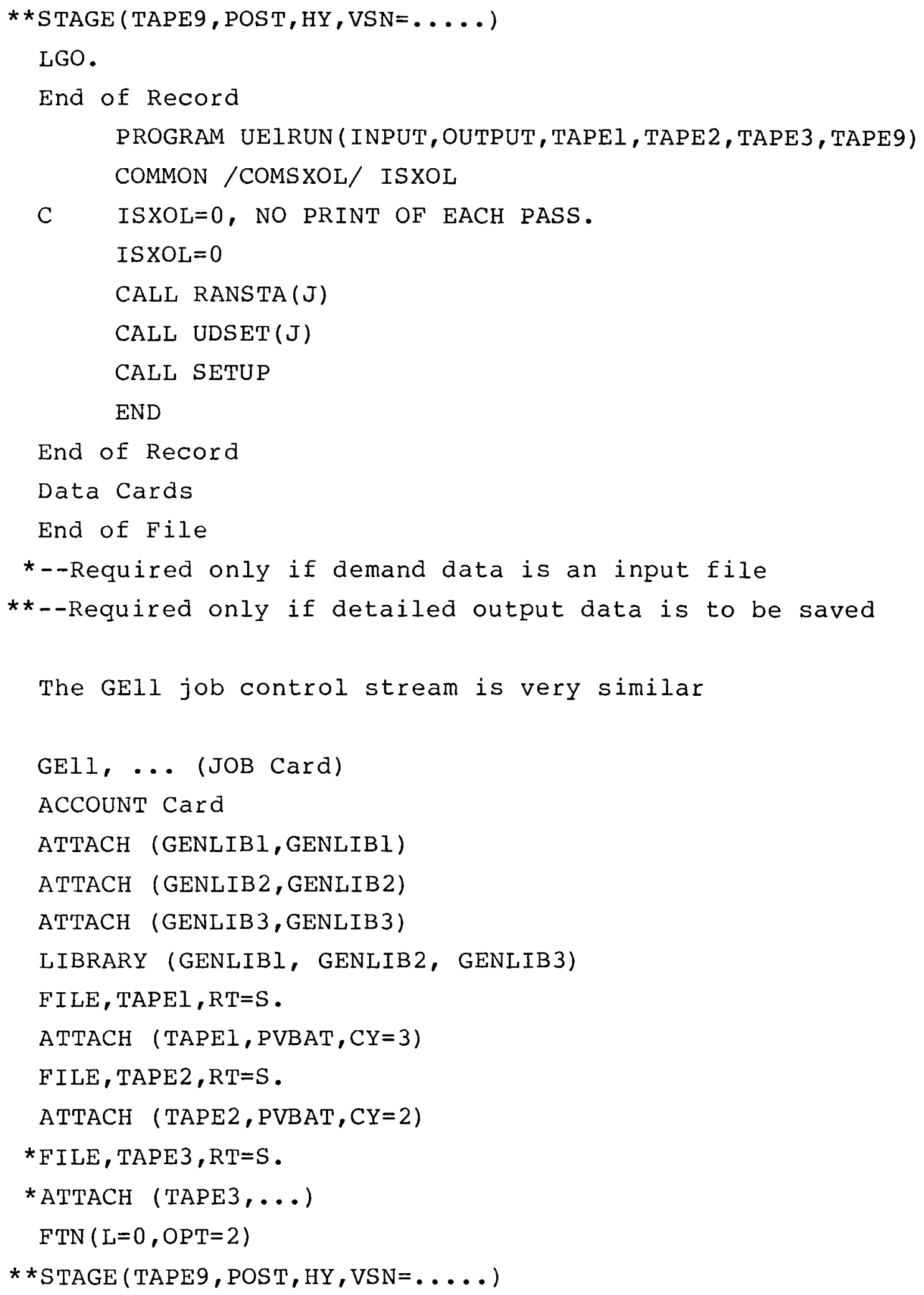


LGO.

End of Record

PROGRAM GElRUN (INPUT, OUTPUT, TAPE1, TAPE2, TAPE3, TAPE9)

COMMON /COMSXOL/ ISXOL

C ISXOL $=0$, NO PRINT OF EACH PASS.

ISXOL $=0$

CALL RANSTA ( $J)$

CALL UDSET $(J)$

CALL GSETUP

END

End of Record

Data Cards

End of File

The TMY data is on TAPEl. The ASHRAE data is on TAPE2. The file of demand data, if desired, is on TAPE3. The detailed output is written to TAPE9.

TMY Data Input--TAPE 1

The data on TAPE 1 contains the TMY information. These data are in binary (unformatted) mode. An END-OF-FILE mark separates data for various sites. Data for each site consists of 13 logical records.

First record - 7 words.

Word 1 Site Code (A10).

Word 2 Not used.

Word 3 Latitude of site in degrees (real).

Word 4 Median wind velocity in $\mathrm{m} / \mathrm{s}$ (real).

Word 5 Recording station height in $\mathrm{m}$ (real).

Word 6 Average air density in $\mathrm{kg-s} / \mathrm{m}^{4}$ (real).

Word 7 Not used.

words 4,5 , and 6 are used only in wind systems. 
Second through thirteenth records contain data for each month, January to December.

Word 1 Number of days in month, $\mathrm{N}$ (integer). February always has 28 days.

Word 2 Not used.

Words 3 through $24 \mathrm{~N}+2$ contain packed data at 60 bits/word. Each word is data for each hour of the month in hour order. The unpacked data is integer mode. Let $b_{i}$ ' $i=0, \ldots, 59$ be the $i-t h$ bit, with $b_{0}$ as the most significant (left-most) bit.

$\mathrm{b}_{0}-\mathrm{b}_{11} \quad$ Not used.

$b_{12}-b_{23}$ Ambient temperature, Kelvin.

$\mathrm{b}_{24}{ }^{-\mathrm{b}_{35}}$ Direct horizontal solar radiation $\left(\mathrm{kW} / \mathrm{m}^{2}\right)$

times 100 .

$\mathrm{b}_{36^{-\mathrm{b}}} 47$ Direct normal solar radiation $\left(\mathrm{kW} / \mathrm{m}^{2}\right)$

times 100 .

$\mathrm{b}_{48^{-}} \mathrm{b}_{59}$ Wind velocity $(\mathrm{m} / \mathrm{s})$ times 10 .

The last file on TAPE 1 is a terminator consisting of one record

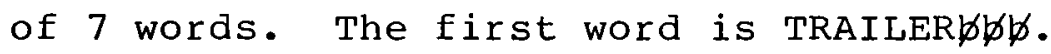

ASHRAE Data Tables--TAPE 2

This file contains the ASHRAE data for solar intensity and heat gain factors. The file has six logical records in binary (unformatted) mode. The first record is the one-word identifier "ASHRAETABL." The next five records each contain data for $24^{\circ}$, $32^{\circ}, 40^{\circ}, 48^{\circ}$, and $56^{\circ}$ north latitude in that order.

The first word of each data record is the latitude in degrees (real mode). The second word is the associated day-of-the-year (real mode). The next $9 \times 12=72$ words contain packed data for hours 5 
through 13 ( 9 hours) and the twenty-first day of each month, January to December. The data for hours 1 through 4 is always zero at these latitudes. Hour 14 data is the same as hour 12 data, hour 15 the same as hour 11, etc. The data word is integer mode when unpacked.

$\mathrm{b}_{0}{ }^{-b_{19}}$ Maximum direct normal radiation, BTUh/ft ${ }^{2}$.

$\mathrm{b}_{20^{-}} \mathrm{b}_{39}$ Sum of $\mathrm{N}, \mathrm{E}, \mathrm{S}$, and $\mathrm{W}$ solar heat gain factors, BTUh/ft ${ }^{2}$. Only the sum is required, since for residential demands the house is square, of homogeneous wall, and oriented north-south.

$\mathrm{b}_{40^{-\mathrm{b}}} 59$ Horizontal solar heat gain factor, BTUh/ft ${ }^{2}$.

Linear interpolation is used between latitudes and between days of the year.

Demand Data--TAPE 3 (optional)

If the demand is not residential (or community), the demand can be inputted as a table on TAPE 3. This file contains one logical record for each demand table in binary (unformatted) mode. There are 8739 words per record.

Word 1 Data identifier (Al0). The file is searched until a record whose first word agrees with column 3-12 of the DH card.

Word 2 Indicator of data types, left justified: "T" = thermal only; "E" = electrical only, "ET" = both. For both UEll and GEll, only "E" is allowed. The demand mix in the record must correspond to the demand mix indicated in columns 13-14 of the "DH" card.

Word 3 For input sites in $\mathrm{m}^{2}$ and $\mathrm{kW}$, use zero; for input sites in $k\left(\mathrm{~m}^{2}\right)$ and $M W$, use one (integer mode). 
Words 4 through 8739 give the demand for each hour of the 364-day year. When unpacked, the data is real mode.

$\mathrm{b}_{0}-\mathrm{b}_{29} \quad$ Electrical demand, kWh

$\mathrm{b}_{30}{ }^{-\mathrm{b}_{59}}$ Thermal demand, $\mathrm{kWh}-$-not used in UEIl and GEII 


\section{UEll Input Cards}

1. IDENT Card $(\mathrm{A} 2,8 \mathrm{X}, 2 \mathrm{~A} 10,1 \mathrm{X}, \mathrm{II}, \mathrm{F} 3.0)$

The first card of a job must be an ID card. The system configuration (strategy) is defined in this card along with other items. Subsequent ID cards may appear in a job deck, but their configuration field will be ignored.

Column symb.

\begin{tabular}{|c|c|c|}
\hline $1-2$ & -- & "ID" \\
\hline $3-10$ & -- & Not used \\
\hline $11-20$ & -- & Site code--T-ALBUQ, etc., left-justified \\
\hline $21-30$ & -- & $\begin{array}{l}\text { Configuration--UEllA, UEllB, UElIC, or } \\
\text { left-justified }\end{array}$ \\
\hline 31 & -- & Not used \\
\hline 32 & $\mathrm{~K}$ & Index of final iteration for search, $\mathrm{K}=\not 6 \mathrm{~K}=1$. \\
\hline $33-35$ & $\mathrm{M}_{0}$ & Initial relative mesh size for search, \\
\hline $36-80$ & -- & $\begin{array}{l}M_{0} \leq 0 \rightarrow M_{0}=0.1, M_{0}>0.333 \rightarrow M_{0}=0.333 . \\
\text { Not used }\end{array}$ \\
\hline
\end{tabular}




\begin{tabular}{|c|c|}
\hline T-MADISON & Madison, Wisconsin \\
\hline T-BISMAR & Bismarck, North Dakota \\
\hline T-APALACH & Apalachicola, Florida \\
\hline T-SEATTLE & Seattle, Washington \\
\hline 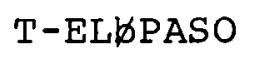 & El Paso, Texas \\
\hline T-FBWORTH & Fort Worth, Texas \\
\hline T-GBFFALLS & Great Falls, Montana \\
\hline T-FRESNO & Fresno, California \\
\hline 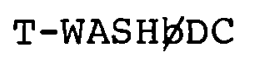 & Washington, D. C. \\
\hline T-OMAHA & Omaha, Nebraska \\
\hline$T-E L Y$ & Ely, Nevada \\
\hline T-MEDFORD & Medford, Oregon \\
\hline T-ALBUQ & Albuquerque, New Mexico \\
\hline T-BOSTON & Boston, Massachusetts \\
\hline T-BROWNSV & Brownsville, Texas \\
\hline T-CARIBOU & Caribou, Maine \\
\hline 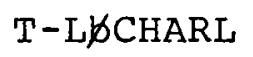 & Lake Charles, Louisiana \\
\hline Т-СДВНАТТ & Cape Hatteras, North Carolina \\
\hline $\mathrm{T}-\mathrm{N} \not 6 Y O R K$ & New York, New York \\
\hline T-CHARLES & Charleston, South Carolina \\
\hline T-COLUMB & Columbia, Missouri \\
\hline T-DODGE & Dodge City, Kansas \\
\hline T-MIAMI & Miami, Florida \\
\hline T-NASHV & Nashville, Tennessee \\
\hline T-PHOENIX & Phoenix, Arizona \\
\hline T-SßBMARIA & Santa Maria, California \\
\hline
\end{tabular}

Table 9-1 Site codes 
2. Demand Heat Card ( $\mathrm{A} 2, \mathrm{~A} 10, \mathrm{~A} 2, \mathrm{~F} 6.0,4 \mathrm{X}, \mathrm{I} 2, \mathrm{~F} 6.0,3 \mathrm{~F} 2.0,6 \mathrm{~F} 6.0)$

This card specifies parameters to compute residential electrical heat demand. If the demand is not residential, the identification code for the demand input on TAPE3 is given. The scaling parameter $f$ determines whether residential demand is a single residence or a community and also denotes the sale of component input sizes and certain fixed costs.

Column symb.

\begin{tabular}{|c|c|c|}
\hline $1-2$ & -- & "DH" \\
\hline $3-12$ & -- & $\begin{array}{l}\text { Identifier code of input demand file, if desired. } \\
\text { If column } 3 \text { is " } R \text {," the demand is internally com- } \\
\text { puted as residential }\end{array}$ \\
\hline $13-14$ & -- & 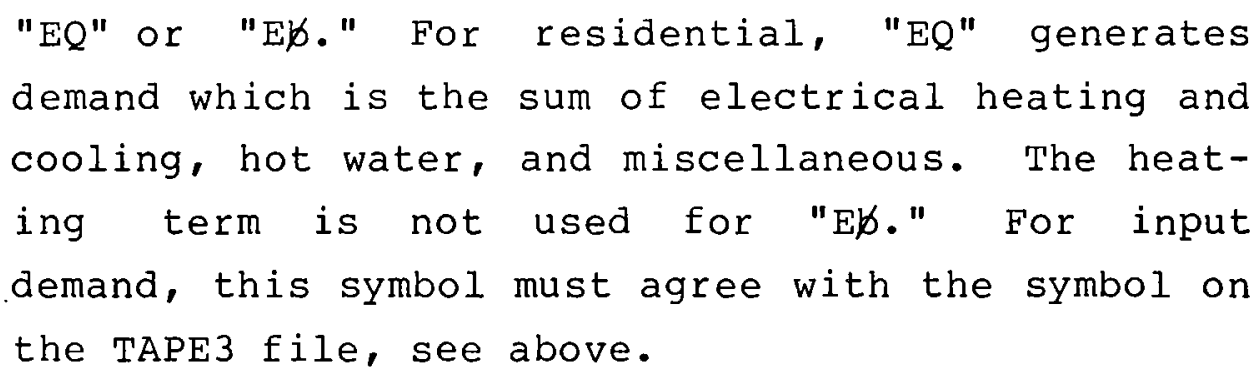 \\
\hline $15-20$ & $f$ & 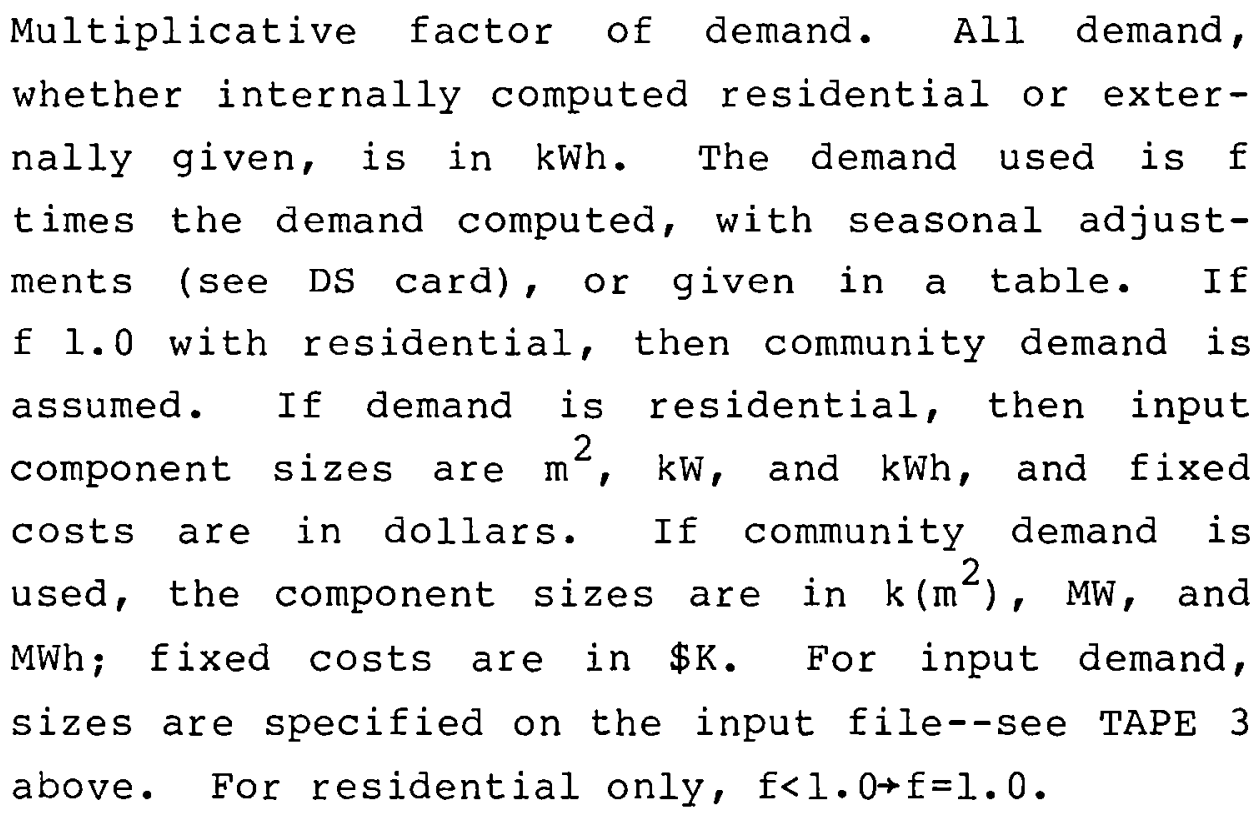 \\
\hline
\end{tabular}


Columns 21 through 74 give parameters for computing residential heating demand. If columns 21 through 30 are blank, "typical" residential default values are used for all these parameters. See Chapter IV for definition of these parameters.

\section{Default Values}

\begin{tabular}{|c|c|c|c|}
\hline $21-24$ & -- & Not used & \\
\hline $25-26$ & $\delta$ & Hours & 4 \\
\hline $27-32$ & $c_{p}$ & Wh/ft $t^{2}-\operatorname{deg} \cdot F$ & 3.52 \\
\hline $33-34$ & $\mathrm{~T}_{\mathrm{HI}}$ & Deg. F & 75 \\
\hline $35-36$ & $\mathrm{~T}_{\mathrm{LO}}$ & $\operatorname{Deg} \cdot \mathrm{F}$ & 65 \\
\hline $37-38$ & $\mathrm{~T}_{\mathrm{DE}}$ & Deg. $F$ & 55 \\
\hline $39-44$ & $\lambda$ & -- & 0.45 \\
\hline $45-50$ & $\alpha / h_{0}$ & Hours-ft ${ }^{2}-\mathrm{deg} \cdot \mathrm{F} /$ Btu & 0.225 \\
\hline $51-56$ & $\mathrm{U}_{\mathrm{W}}$ & Milliwatts/ft ${ }^{2}-\operatorname{deg} \cdot \mathrm{F}$ & 58.6 \\
\hline $57-62$ & $A_{r}$ & $f t^{2}$ & 520 \\
\hline $63-68$ & $A_{W}^{2}$ & $f t^{2}$ & 312 \\
\hline \multirow[t]{2}{*}{$69-74$} & $\rho_{\text {vcp }}$ & $\mathrm{kW} /$ deg. $\mathrm{F}$ (air infiltration & rate) \\
\hline & & & 0.032 \\
\hline $75-80$ & -- & Not used & \\
\hline
\end{tabular}


3. Demand Hot Water Card (A2,F6.0,24F3.2)

This card specifies the electrical hot water demand on an hour-of-the-day basis. Except for seasonal scaling, this demand is the same at the same hour of every day. The factor $f$ in the $\mathrm{DH}$ card also scales this demand. Although this card is not decoded if the demand is an input file, it must appear in the input deck. The hot water demand at hour-of-the-day $h$ is

$$
D_{W h}=Q_{W} W_{h}(k W h), h=1, \ldots, 24
$$

where $Q_{W}$ is the input hot water scale factor and the $W_{h}$ are from the input table on the card. A default which represents a "typical" residence is shown in Figure 4-2 and tabulated below.

\section{Column symb.}

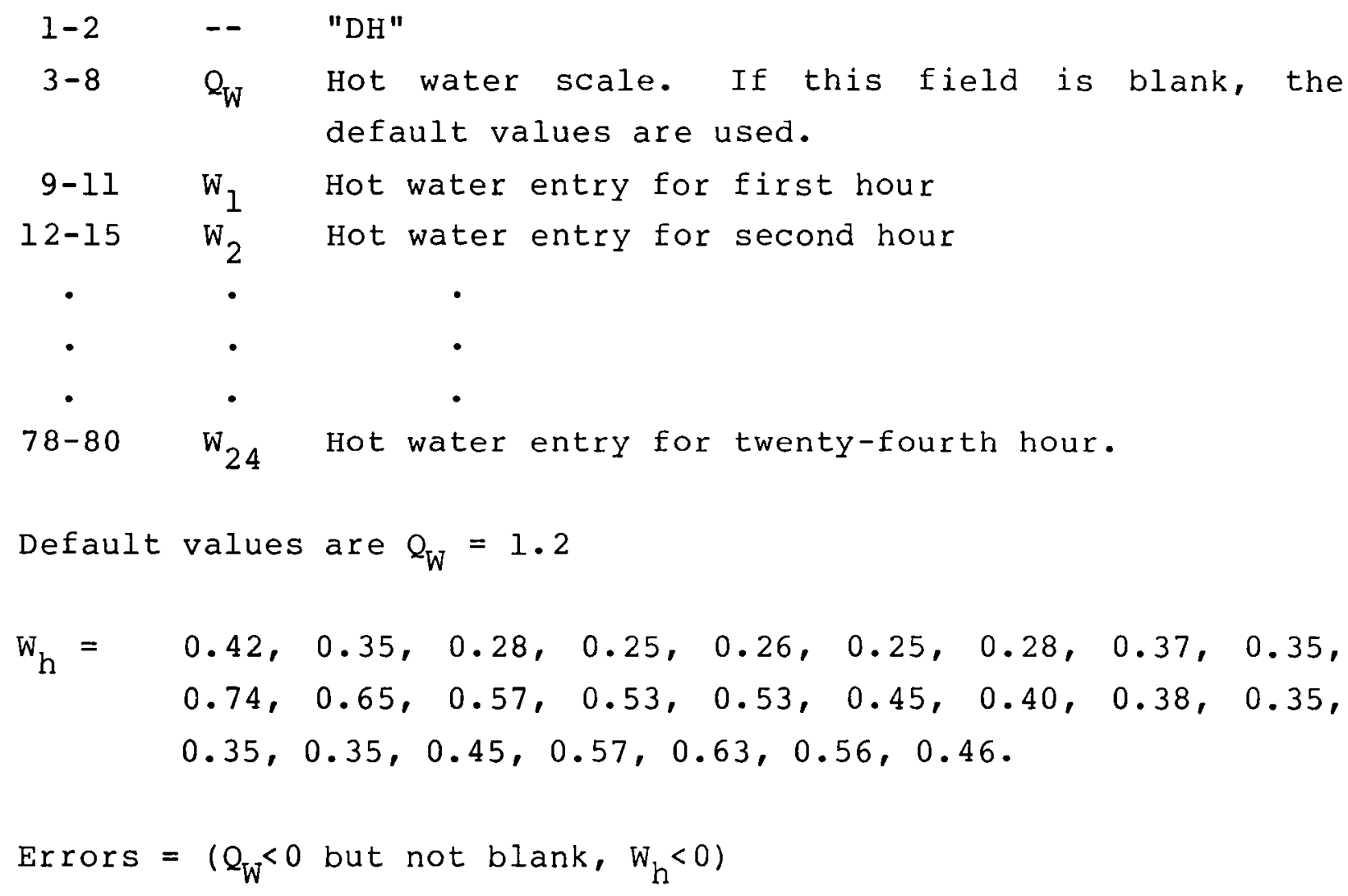


4. Demand Miscellaneous Card (A2,F6.0,24F3.2)

This card specifies the miscellaneous electrical demand on an hour-of-the-day basis. Except for seasonal scaling, this demand is the same at the same hour of every day. The factor $f$ in the DH card also scales this demand. Although this card is not decoded if the demand is an input file, it must appear in the input deck. The miscellaneous electrical demand at hour-of-theday $h$ is

$$
D_{M h}=Q_{M} M_{h}(k W h), h=1,2, \ldots, 24
$$

where $Q_{M}$ is the input miscellaneous scale factor and the $M_{h}$ are an input table. A default which represents a "typical" residence is shown in Figure $4-3$ and tabulated below.

\section{Column Symb.}

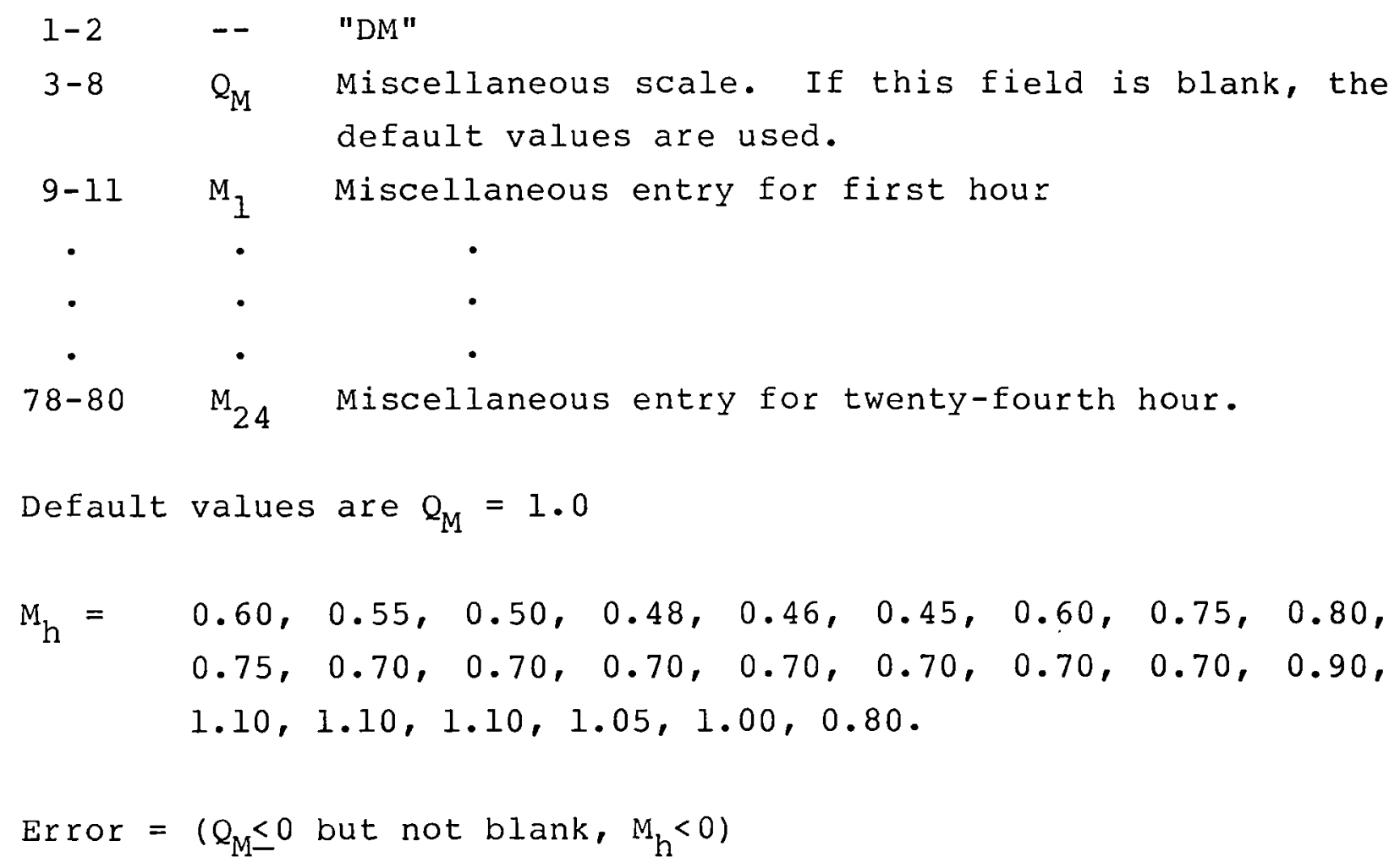


5. Demand Seasonal Card (A2,I2,4(F4.0,I2))

This card allows "seasonal" scaling of total demand by week-ofthe year (the first week starts January 1). By "season," we mean some set of contiguous weeks; for example, a season may be the whole year. The identification of weeks is sort of modulo 52 in that week 53 is week 1 , etc. If the second field of the card, $w_{0}$, is blank, the rest of the card is ignored and no seasonal scaling occurs. From one to four seasons can be scaled. The weeks given must span the year; that is, the last given week must be the initial given week plus 51 .

\section{Column symb.}

$\begin{array}{lll}\text { 1-2 } & -- & \text { "DS" } \\ 3-4 & \mathrm{w}_{0} & \text { Initial week. If blank, the card is ignored. } \\ 5-8 & \mathrm{f}_{1} & \text { Scale for first season } \\ 9-10 & \mathrm{w}_{1} & \text { End week of first season } \\ 11-14 & \mathrm{f}_{2} & \text { Scale for second season, if needed. } \\ 15-16 & \mathrm{w}_{2} & \text { End week for second season, if needed. } \\ 17-20 & \mathrm{f}_{3} & \text { Etc. } \\ 21-22 & \mathrm{w}_{3} & \text { Etc. } \\ 23-26 & \mathrm{f}_{4} & \text { Etc. } \\ 27-28 & \mathrm{w}_{4} & \text { End week for fourth season, if needed. } \\ 29-80 & -- & \text { Not used }\end{array}$

The total demand--heating/cooling (if used), plus hot water, plus miscellaneous for residential and input file otherwise--is scaled by $f_{i}$, depending on the week in which the demand occurs. Let $w$ be any week, then for

$$
\begin{aligned}
& w_{0} \leq w \leq w_{1} ; \text { use } f_{1} \\
& w_{i-1}<w \leq w_{i} ; \text { use } f_{i}, i=2,3,4 .
\end{aligned}
$$


The number of seasons terminates whenever $\mathrm{w}_{i}{ }^{-\mathrm{w}_{0}}=51$; for example, if $\mathrm{w}_{0}=5$ and $\mathrm{w}_{2}=56$, seasons three and four are not considered.

Error $=\left(w_{0} \leq 0\right.$ but not blank, $w_{0}>48, w_{i} \leq w_{i-1}, f_{i} \leq 0$, no $w_{i}$ such that $w_{i}-w_{0}=51$ ) 
6. COLLECTOR Card (A2,A4, A8,11F6.0)

Column Symb.

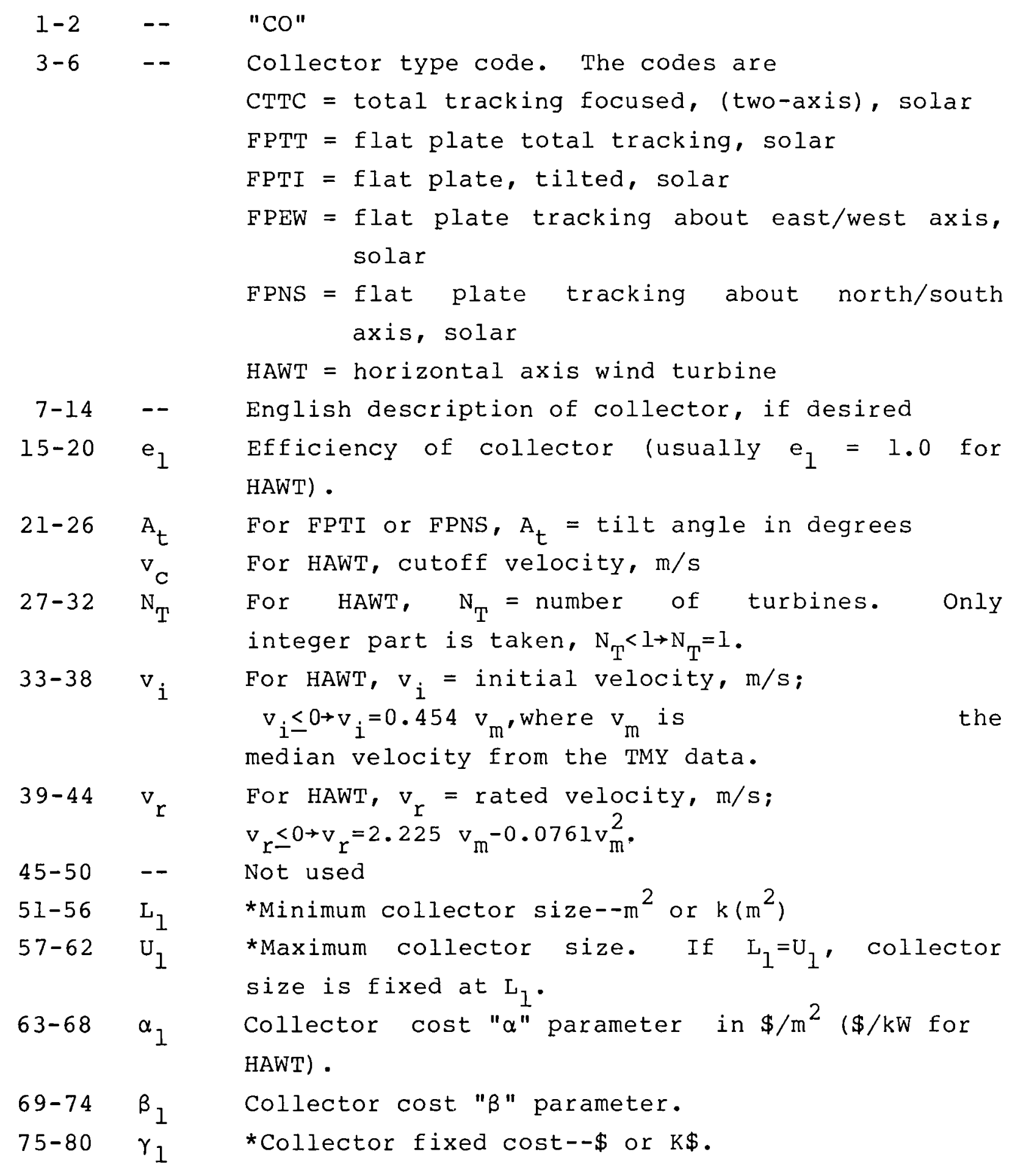


Errors = (Unacceptable collector type, $e_{1} \leq 0, e_{1}>1, A_{t}<0, A_{t} \geq 90$, $\left.v_{C} \leq v_{r} \leq v_{i}, L_{1}<0, U_{1}<I_{1}, \alpha_{1}<0, \beta_{1} \leq 0, \gamma_{1}<0\right)$

* See DH card for scale. 
7. STORAGE Card (A2, A4, A8, 11F6.0)

Column symb.

\begin{tabular}{|c|c|c|}
\hline $1-2$ & -- & "ST" \\
\hline $3-6$ & -- & Storage code, not used. \\
\hline $7-14$ & -- & English description of storage device, if desired \\
\hline $15-20$ & $e_{2}$ & Storage efficiency (one minus leakage per hour) \\
\hline $21-26$ & $e_{7}$ & Efficiency of transducer 7 \\
\hline $27-32$ & $e_{8}$ & Efficiency of transducer 8 \\
\hline $33-38$ & $r_{7}$ & Relative size of transducer 7 \\
\hline $39-44$ & $r_{8}$ & Relative size of transducer 8 \\
\hline $45-50$ & $L_{C Y}$ & $\begin{array}{l}\text { Storage cycles/life. To avoid storage } \\
\text { ment set } L_{c y}=999999 .\end{array}$ \\
\hline $51-56$ & $\mathrm{~L}_{2}$ & *Minimum storage size--kWh or MWh \\
\hline $57-62$ & $\mathrm{U}_{2}$ & $\begin{array}{l}\text { *Maximum storage size. If } \mathrm{L}_{2}=\mathrm{U}_{2} \text { ' } \\
\text { size is fixed at } \mathrm{L}_{2} \cdot\end{array}$ \\
\hline $63-68$ & $\alpha_{2}$ & Storage cost " $\alpha$ " parameter in $\$ / k W h$. \\
\hline $69-74$ & $\beta_{2}$ & Storage cost " $\beta$ " parameter. \\
\hline $75-80$ & $\gamma_{2}$ & *Storage fixed cost--\$ or $K \$$. \\
\hline Errors & $\begin{array}{l}=(\mathrm{e} \\
\mathrm{r}_{7}> \\
\beta_{2} \leq\end{array}$ & $\begin{array}{l}e_{2}>1, e_{7} \leq 0, e_{7}>1, e_{8} \leq 0, e_{8}>1, r_{7} \leq 0, \\
{ }_{8} \leq 0, r_{8}>1, L_{C Y} \leq 0, L_{2}<0, U_{2}<L_{2}, \alpha_{2}<0, \\
\left.r_{2}<0\right)\end{array}$ \\
\hline
\end{tabular}

* See DH card for scale. 
8. Transducer $\underline{3}$ Card (A2, A4, A8, 11F6.0)

Column symb.

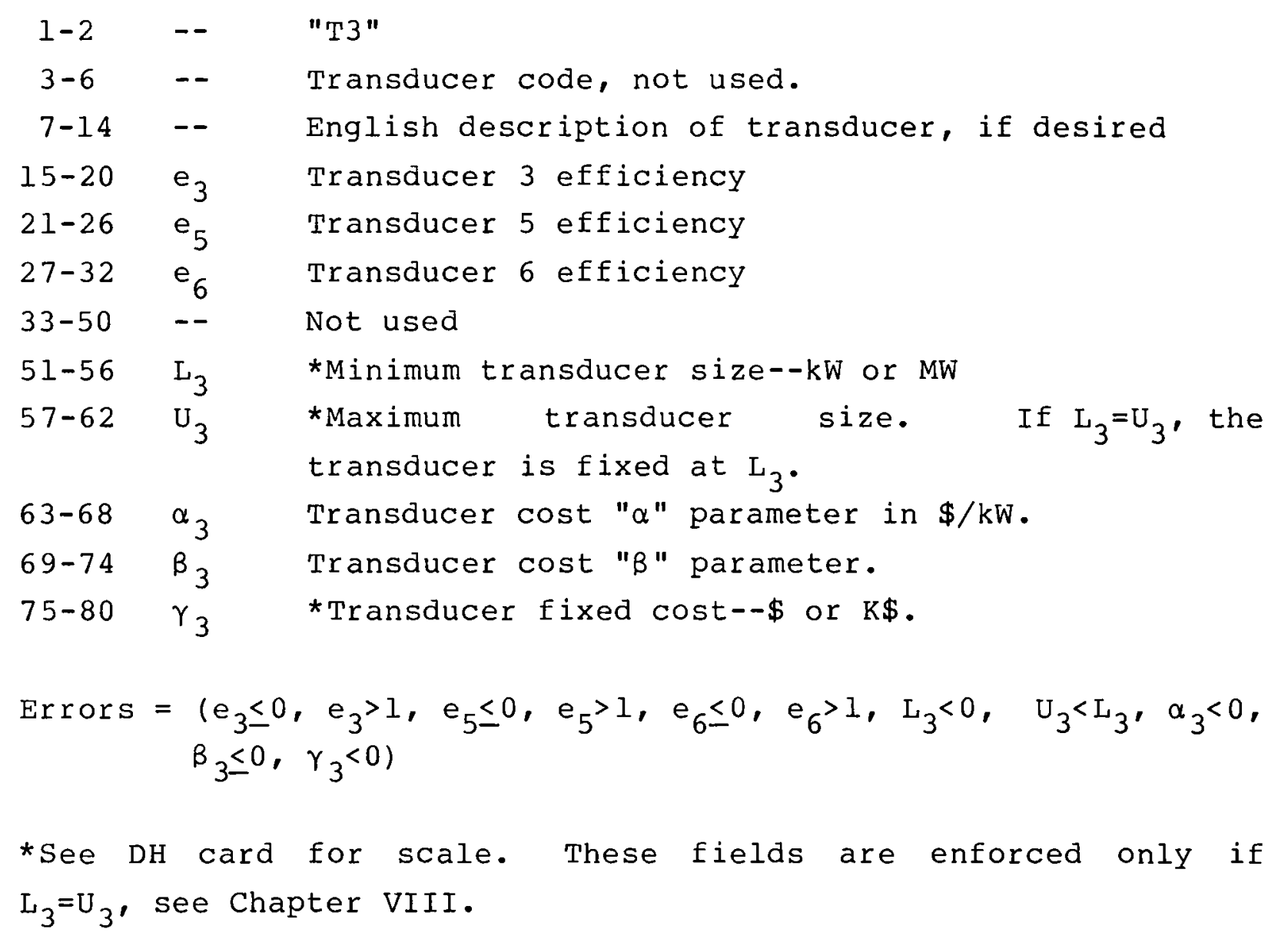


9. Transducer $\underline{4} \operatorname{Card}(\mathrm{A} 2, \mathrm{~A} 4, \mathrm{~A} 8, \mathrm{IIF} 6.0)$

Column Symb.

\begin{tabular}{|c|c|c|}
\hline $1-2$ & -- & "T4" \\
\hline $3-6$ & -- & Transducer code, not used. \\
\hline $7-14$ & -- & English description of transducer, if desired \\
\hline $15-20$ & $e_{4}$ & Transducer 4 efficiency \\
\hline $21-50$ & -- & Not used \\
\hline $51-56$ & $\mathrm{~L}_{4}$ & *Minimum transducer size--kW or MW \\
\hline $57-62$ & $\mathrm{U}_{4}$ & $\begin{array}{llll}\text { *Maximum transducer size. If } & \mathrm{L}_{4}=\mathrm{U}_{4} \\
\text { transducer } & \text { is fixed at } \mathrm{L}_{4} \cdot\end{array}$ \\
\hline $63-68$ & $\alpha_{4}$ & Transducer cost " $\alpha$ " parameter in $\$ / \mathrm{kW}$. \\
\hline $69-74$ & $B_{4}$ & Transducer cost " $\beta$ " parameter. \\
\hline $75-80$ & $\gamma_{4}$ & *Transducer fixed cost-- $\$$ or $\mathrm{K} \$$. \\
\hline Errors & $=\left(e_{4}\right.$ & $\left., \mathrm{e}_{4}>\mathrm{I}, \mathrm{L}_{4}<0, \mathrm{U}_{4}<\mathrm{L}_{4}, \alpha_{4}<0, \beta_{4} \leq 0, \alpha_{4}<0\right)$ \\
\hline
\end{tabular}


10. YEARS Card $(\mathrm{A} 2,3(2 \mathrm{X}, \mathrm{I} 4), 10 \mathrm{~F} 6.0)$

The YEARS and AMORT card give the economic parameters (see Chapter II).

Column symb.

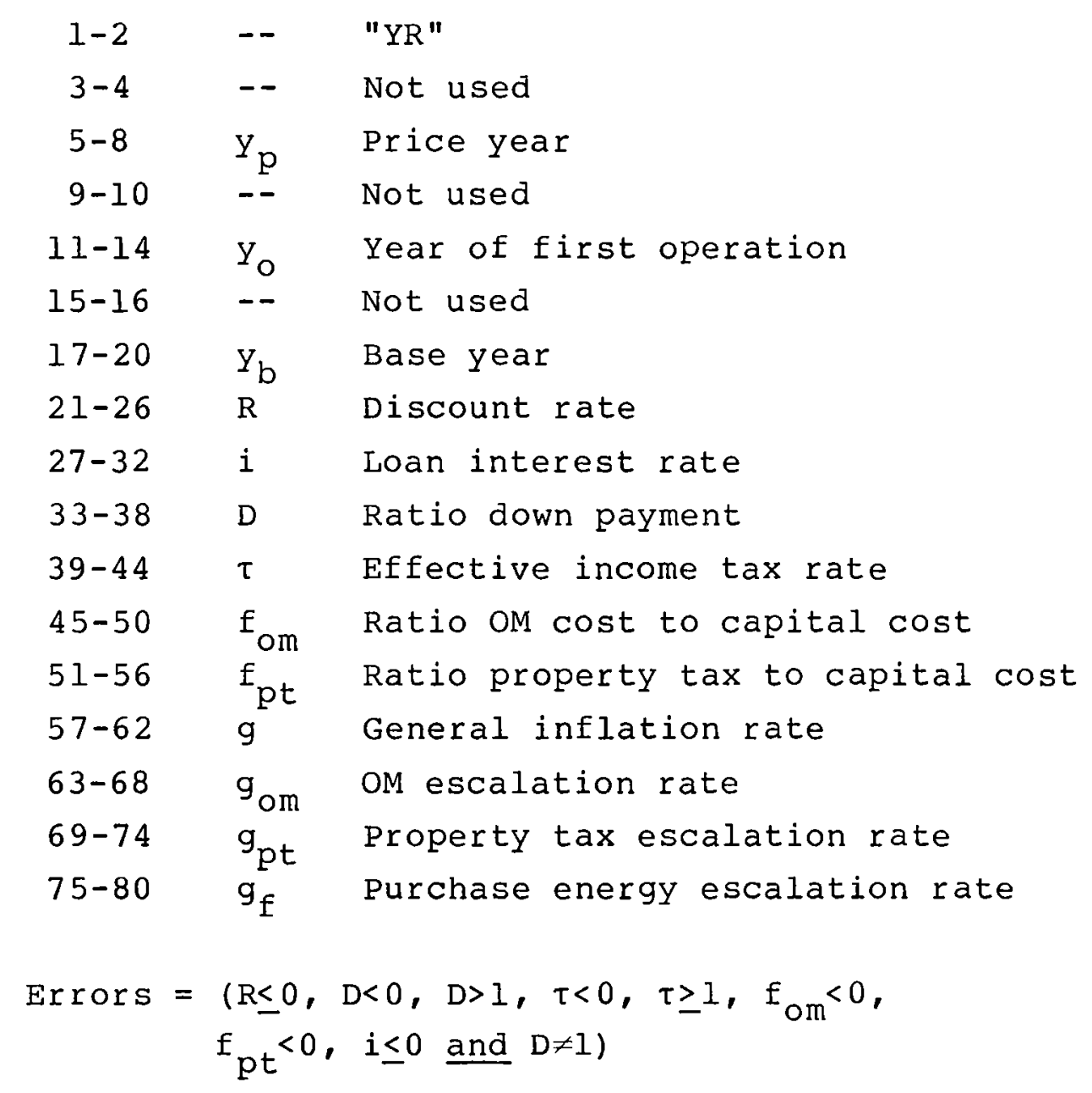


11. AMORT Card $(A 2, A 1, I 2,1 X, I 2,2(I 6,3 F 6.0))$

Column Symb.

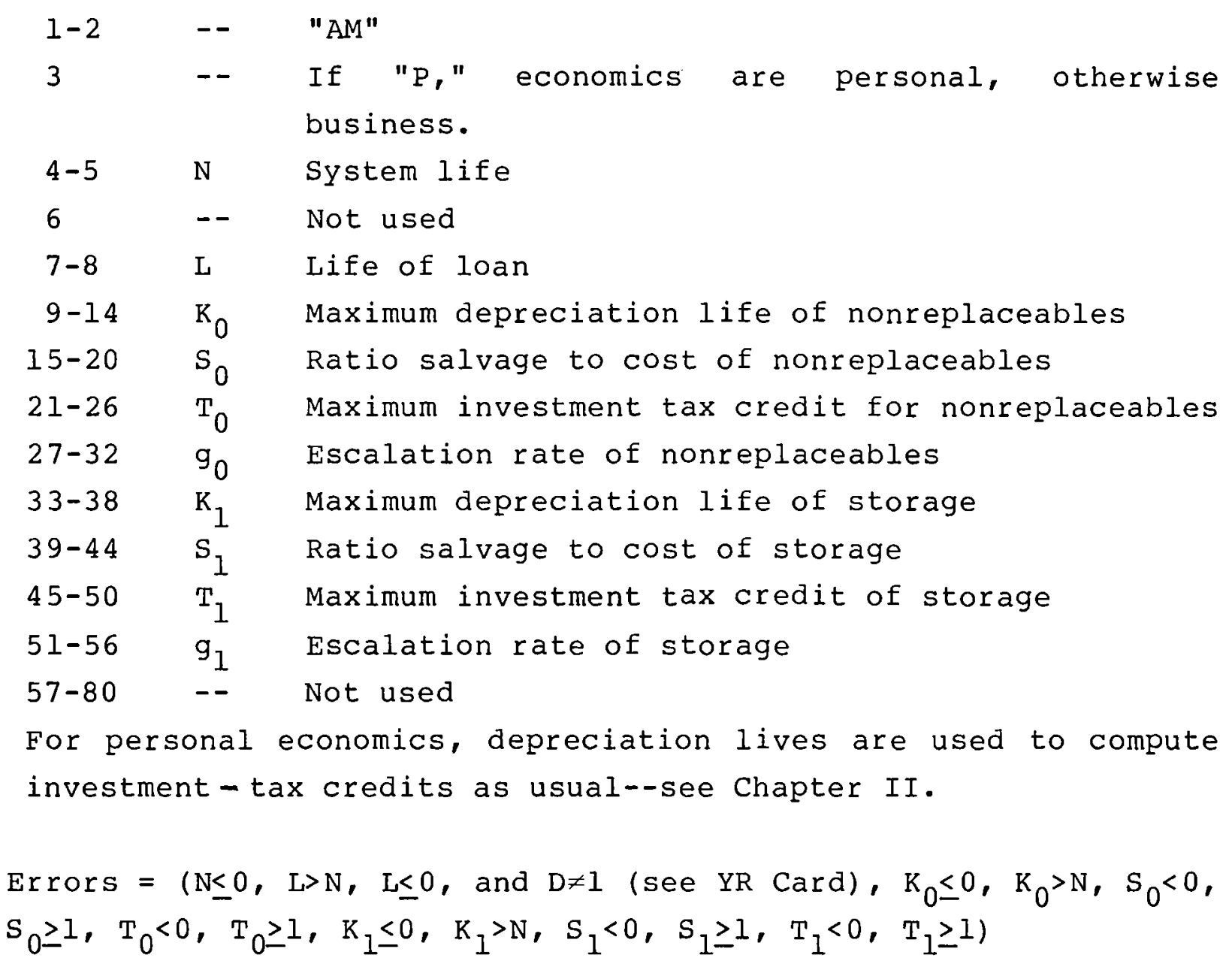


12. Price of Energy Card (A2,F4.0,I2,4(3F4.0,3I2))

This card describes the time-of-day pricing structure and the peak pricing structure "seasonally" by week-of-the-year. The basic format concept is like the DS card, except that at least one season must appear. If only one season, it must be the whole year. The purchase prices, $p_{i j}$, are in cents per kWh. Again, weeks are defined by a quasi-modulo 52 method (see 5 . Demand Seasonal (ard).

Column Symb.

\begin{tabular}{|c|c|c|}
\hline $1-2$ & -- & "PE" \\
\hline $3-6$ & $\mathrm{p}_{\mathrm{f}}$ & *Fixed yearly cost of purchased energy-- $\$$ or $\$ \mathrm{~K}$ \\
\hline $7-8$ & $w_{0}$ & Initial week \\
\hline $9-12$ & $\mathrm{p}_{11}$ & $\begin{array}{l}\text { "High" price of purchased energy--cents/kWh, for } \\
\text { first season }\end{array}$ \\
\hline $13-16$ & $\mathrm{p}_{21}$ & $\begin{array}{l}\text { "Low" price of purchased energy--cents/kWh, for } \\
\text { first season }\end{array}$ \\
\hline $17-20$ & $q_{1}$ & Monthly peak demand charge-- $\$ / k W$, for first season \\
\hline $21-22$ & $\mathrm{~h}_{11}$ & Start hour for first season \\
\hline $23-24$ & $\mathrm{~h}_{21}$ & End hour for first season \\
\hline $25-26$ & $w_{1}$ & End week of first season \\
\hline $27-30$ & $\mathrm{p}_{12}$ & $\begin{array}{l}\text { "High" price of purchased energy for second } \\
\text { season, if needed. }\end{array}$ \\
\hline $31-34$ & $\mathrm{p}_{22}$ & Etc. \\
\hline $35-38$ & $\mathrm{q}_{2}$ & Etc. \\
\hline $39-40$ & $\mathrm{~h}_{12}$ & Etc. \\
\hline $41-42$ & $h_{22}$ & Etc. \\
\hline $43-44$ & $\mathrm{w}_{2}$ & Etc. \\
\hline $45-48$ & $p_{13}$ & Etc. \\
\hline $49-52$ & $\mathrm{p}_{23}$ & Etc. \\
\hline $53-56$ & $q_{3}$ & Etc. \\
\hline $57-58$ & $\mathrm{~h}_{13}$ & Etc. \\
\hline $59-60$ & $h_{23}$ & Etc. \\
\hline $61-62$ & $w_{3}$ & Etc. \\
\hline
\end{tabular}


$\begin{array}{lll}63-66 & \mathrm{p}_{14} & \text { Etc. } \\ 67-70 & \mathrm{p}_{24} & \text { Etc. } \\ 71-74 & \mathrm{q}_{4} & \text { Etc. } \\ 75-76 & \mathrm{~h}_{14} & \text { Etc. } \\ 77-78 & \mathrm{~h}_{24} & \text { Etc. } \\ 79-80 & \mathrm{w}_{4} & \text { End week of fourth season, if needed. }\end{array}$

The seasons terminate whenever $w_{i}-w_{0}=51$. Let $w$ be any week, then

$$
\begin{aligned}
& w_{0} \leq w \leq w_{1} \text { use } p_{11}, p_{21}, q_{1}, h_{11}, \text { and } h_{21} \\
& w_{i-1}<w \leq w_{i} \text { use } p_{1 i}, p_{2 i}, q_{i}, h_{1 i} \text {, and } h_{2 i} ; i=2,3,4
\end{aligned}
$$

For the i-th season, the low price $p_{2 i}$ applies for the first 2 days of the week (weekends). For the remaining five "working" days, the high price applies for hours-of-the-day $h_{1 i}$ through $h_{2 i}$, inclusive, and the low price applies for the remaining hours, if any. If the high price and low price are not the same in any season, the peak price applies only at the same hours and days that the high price applies; that is, peaking is only measured during these hours. If the high price equals the low price, the peak demand charge applies at all hours and days in the season.

$$
\begin{aligned}
\text { Errors }= & \left(w_{0} \leq 0, \quad w_{0}>48, w_{i-l} \geq w_{i}, \quad p_{1 i} \leq 0, \quad p_{2 i} \leq 0, p_{1 i}<p_{2 i}, q_{i}<0,\right. \\
& \left.h_{1 i}<1, h_{2 i}>24, h_{2 i}<h_{1 i}, \text { no } w_{i} \text { such that } w_{i}-w_{0}=51, p_{f}<0\right)
\end{aligned}
$$




\section{LOGIC Card}

This LOGIC card depends on the strategy chosen.

Column Symb.

$\begin{array}{lll}1-2 & -- & \text { "LO" } \\ 3-8 & \mathrm{R} & \text { SIll-back ratio } \\ 9-14 & \mathrm{~S}_{L} & \text { Sell-back limit factor-see Chapter VI. }\end{array}$

UEI1A $\quad(\mathrm{A} 2,4 \mathrm{~F} 6.0)$

15-20 $\mathrm{L}_{\mathrm{L}} \quad$ Lower limit of decision variable $\mathrm{x}_{\mathrm{L}}$

21-26 $U_{L}$ upper limit of decision variable $x_{L}$. If $\mathrm{L}_{\mathrm{L}}=\mathrm{U}_{\mathrm{L}}, \mathrm{x}_{\mathrm{L}}$ is set equal to $\mathrm{L}_{\mathrm{L}}$.

27-80 -- Not used

UEI1B $\quad(A 2,2 \mathrm{~F} 6.0)$

15-80 -- Not used

UEIIC (A2, 2F6.0,2I3)

$\begin{array}{lll}15-17 & T_{1} & \text { LP step size } \\ 18-20 & \text { T } & \text { LP time span } \\ 21-80 & -- & \text { Not used }\end{array}$

UE1ID $\quad(A 2,2 \mathrm{~F} 6.0,2 \mathrm{I} 3)$

15-17 $Q_{P}$ Prediction indicator; $Q_{P}=0$, ideal prediction; $\mathrm{Q}_{\mathrm{P}}=1, \quad$ spline prediction; $\mathrm{Q}_{\mathrm{P}}=2$, average prediction--see Chapter VI

18-20 T LP time span

21-80 -- Not used

Errors $=\left(R<0, R \geq 1, L_{L} \leq 0, U_{L} \geq 1.0, U_{L}<L_{L}, T_{1} \leq 0, T_{1} \geq T, T<4, T>24\right.$, $Q_{\mathrm{P}}<0, \mathrm{Q}_{\mathrm{P}}>2$ ) 


\section{GEll Input Cards}

Many of the GEll cards are identical to the UEll cards. There is no "T3," "T4," or "PE" card.

1. IDENT Card (A2,F8.0,2A10,1X,II,F3.0)

This card is the same as the ID card in UEll, except:

The demand goal ratio parameter $d_{g}$ is in columns 3-10.

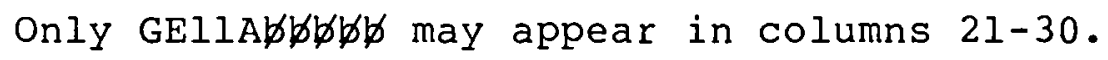

$$
\text { Errors }=\left(d_{g} \leq 0, d_{g}>1\right)
$$

2. DH Card--identical to UE1I.

3. DW Card--identical to UEll.

4. DM Card--identical to UELL.

5. DS Card--identical to UEll.

6. Co Card--identical to UEll.

7. ST Card--identical to UEll.

8. YR Card--identical to UEll.

9. AMORT Card (A2,AI,I2,IX,I2,3(I6,3F6.0))

This card is the same as the AM card in UEll except that the following additional data must be provided. 
Column symb.

\begin{tabular}{|c|c|c|}
\hline $57-62$ & $\mathrm{~K}_{2}$ & Maximum depreciation life of generator \\
\hline $63-68$ & $\mathrm{~S}_{2}$ & Ratio salvage to cost of generator \\
\hline $69-74$ & $\mathrm{~T}_{2}$ & Maximum investment tax credit of generator \\
\hline $75-80$ & $g_{2}$ & Escalation rate of generator \\
\hline
\end{tabular}

10. GENERATOR Card ( $\mathrm{A} 2, \mathrm{~A} 4, \mathrm{~A} 8,4 \mathrm{~F} 6.0,4 \mathrm{X}, \mathrm{I} 2,6 \mathrm{~F} 6.0)$

Column Symb.

\begin{tabular}{|c|c|c|}
\hline $1-2$ & -- & "GE" \\
\hline $3-6$ & -- & Fuel type--GAS 6, DIES, COAL, or NGAS \\
\hline $7-14$ & -- & English description of generator, if desired \\
\hline $15-20$ & $e_{9}$ & Efficiency of transducer 9 \\
\hline $21-26$ & $g_{b}$ & Generator turn-on loss factor \\
\hline $27-32$ & $p_{f}$ & Generator fuel cost, $\$$ /unit fuel \\
\hline $33-38$ & $\mathrm{f}_{\mathrm{or}}$ & Ratio overhaul cost to capital cost \\
\hline $39-42$ & -- & Not used \\
\hline $43-44$ & $\mathrm{~N}_{\mathrm{og}}$ & Number of overhauls per life \\
\hline $45-50$ & $\mathrm{~L}_{\mathrm{g}}$ & $\begin{array}{l}\text { Life of generator--hours. If it is desired to } \\
\text { never replace the generator, use } L_{g}=999999\end{array}$ \\
\hline $51-56$ & $\mathrm{Z}_{\mathrm{L}}$ & Minimum size of generator in demand goal units \\
\hline $57-62$ & $\mathrm{z}_{\mathrm{U}}$ & Maximum size of generator in demand goal units \\
\hline $63-68$ & $\alpha_{3}$ & Generator cost " $\alpha$ " parameter $--\$ / k W$ \\
\hline $69-74$ & $\beta_{3}$ & Generator cost " $B$ " parameter \\
\hline $75-80$ & $\gamma_{3}$ & *Generator $\mathrm{fixed}$ cost-- $\$$ or $\mathrm{K} \$$ \\
\hline
\end{tabular}

* See DH card for scale. 
11. Generator Season Card $(A 2, I 2,4(I 4, I 2), 4 X, 5 F 6.0)$

This card serves a dual function. It contains the seasonal data for arbitrary timing on the generator; that is, for producing the $g_{0}^{t}$ table. The card also gives the parameters to compute the generator fuel consumption function. The seasonal part of the card is just like the DS card. However, instead of giving a seasonal scaling, the GS card gives the number of hours daily that the generator is on for the season.

\section{Column symb.}

\begin{tabular}{|c|c|c|}
\hline $1-2$ & -- & "GS" \\
\hline $3-4$ & $\mathrm{w}_{0}$ & $\begin{array}{l}\text { Initial week. If blank, the rest of the card } \\
\text { is ignored up to column } 33 \text {. In this case, } \\
g_{0}^{t} \text { is set to zero for all t. }\end{array}$ \\
\hline $5-8$ & $\mathrm{H}_{1}$ & $\begin{array}{l}\text { Number of daily oN hours for first season, if } \\
\text { needed }\end{array}$ \\
\hline $9-10$ & $\mathrm{w}_{1}$ & End week of first season, if needed \\
\hline $11-14$ & $\mathrm{H}_{2}$ & Etc. \\
\hline $15-16$ & $\mathrm{w}_{2}$ & Etc. \\
\hline $17-20$ & $\mathrm{H}_{3}$ & Etc. \\
\hline $21-22$ & $w_{3}$ & Etc. \\
\hline $23-26$ & $\mathrm{H}_{4}$ & Number of ON hours for fourth season, if needed \\
\hline $27-28$ & $\mathrm{w}_{4}$ & End week of fourth season, if needed \\
\hline $29-32$ & -- & Not used \\
\hline $33-38$ & $e_{31}$ & Coefficient of generator \\
\hline $39-44$ & $e_{32}$ & $\begin{array}{l}\text { function--see Chapter VII } \\
\qquad "\end{array}$ \\
\hline $45-50$ & $e_{33}$ & " \\
\hline $51-56$ & $e_{34}$ & $"$ \\
\hline $57-62$ & $e_{35}$ & $"$ \\
\hline $63-80$ & -- & Not used \\
\hline
\end{tabular}


The same conventions concerning the $w_{i}$ are used as in the "DS" card. For any week w,

$$
\begin{aligned}
& w_{0} \leq w \leq w_{1}, \begin{array}{l}
\text { set } g_{0}^{t} \text { to one for the first } H_{1} \text { hours of every } \\
\text { day in all weeks } w .
\end{array} \\
& w_{i-1}<w \leq w_{i}, \begin{array}{l}
\text { set } g_{0}^{t} \text { to one for the first } H_{i} \text { hours of every } \\
\text { day in all weeks } w .
\end{array}
\end{aligned}
$$

A value of $\mathrm{H}_{i}=0$ is valid and merely means that $g_{0}^{t}=0$ for all weeks in the $i-t h$ season.

Errors $=\left(w_{0} \leq 0\right.$ but not blank, $w_{0}>48, w_{i} \leq w_{i-1}, H_{i}<0, H_{i}>24$, no $w_{i}$ such that $w_{i}{ }^{-w_{0}}=51, e_{31} \leq 0, e_{32}<0, e_{33} \leq 0, e_{33}>1$, $e_{33}+e_{34}+e_{35} 1 ;$ for any $0 \leq x<1$ max $\left.\left(e_{33}+e_{34} x+e_{35} x^{2}\right)>1\right)$

12. Power Conditioning Card (A2, A4, A8, 3F6.0,30X, 3F6.0)

This card is like the "T3" card in UEll, except that the component size is dependent, and hence size limits are not used.

\section{Column symb.}

$\begin{array}{lll}1-2 & -- & \text { "PC" } \\ 3-6 & -- & \text { Not used. } \\ 7-14 & -- & \begin{array}{l}\text { English description of power conditioner--if } \\ \text { desired } \\ \end{array} \\ \text { Efficiency of transducer } 4 \\ \text { 15-20 } & e_{4} & \text { Efficiency of transducer } 5 \\ 21-26 & e_{5} & \text { Efficiency of transducer } 6 \\ 27-32 & e_{6} & \text { Not used } \\ 33-62 & -- & \text { Transducer } 4 \text { cost " } \alpha " \text { parameter- } \$ / \mathrm{kW} \\ 63-68 & \alpha_{4} & \text { Transducer } 4 \text { cost " } \beta " \text { parameter } \\ 69-74 & \beta_{4} & \text { *Transducer } 4 \text { fixed cost- } \$ \text { or } \$ \mathrm{~K}\end{array}$


Errors $=\left(e_{4} \leq 0, e_{4}>1, e_{5} \leq 0, e_{5}>1, e_{6} \leq 0, e_{6}>1, \alpha_{4}<0, \beta_{4} \leq 0, \gamma_{4}<0\right)$

* See DH card for scale.

13. LOGIC Card $(\mathrm{A} 2,2(\mathrm{IX}, \mathrm{I} 2), 4 \mathrm{~F} 6.0)$

Column symb.

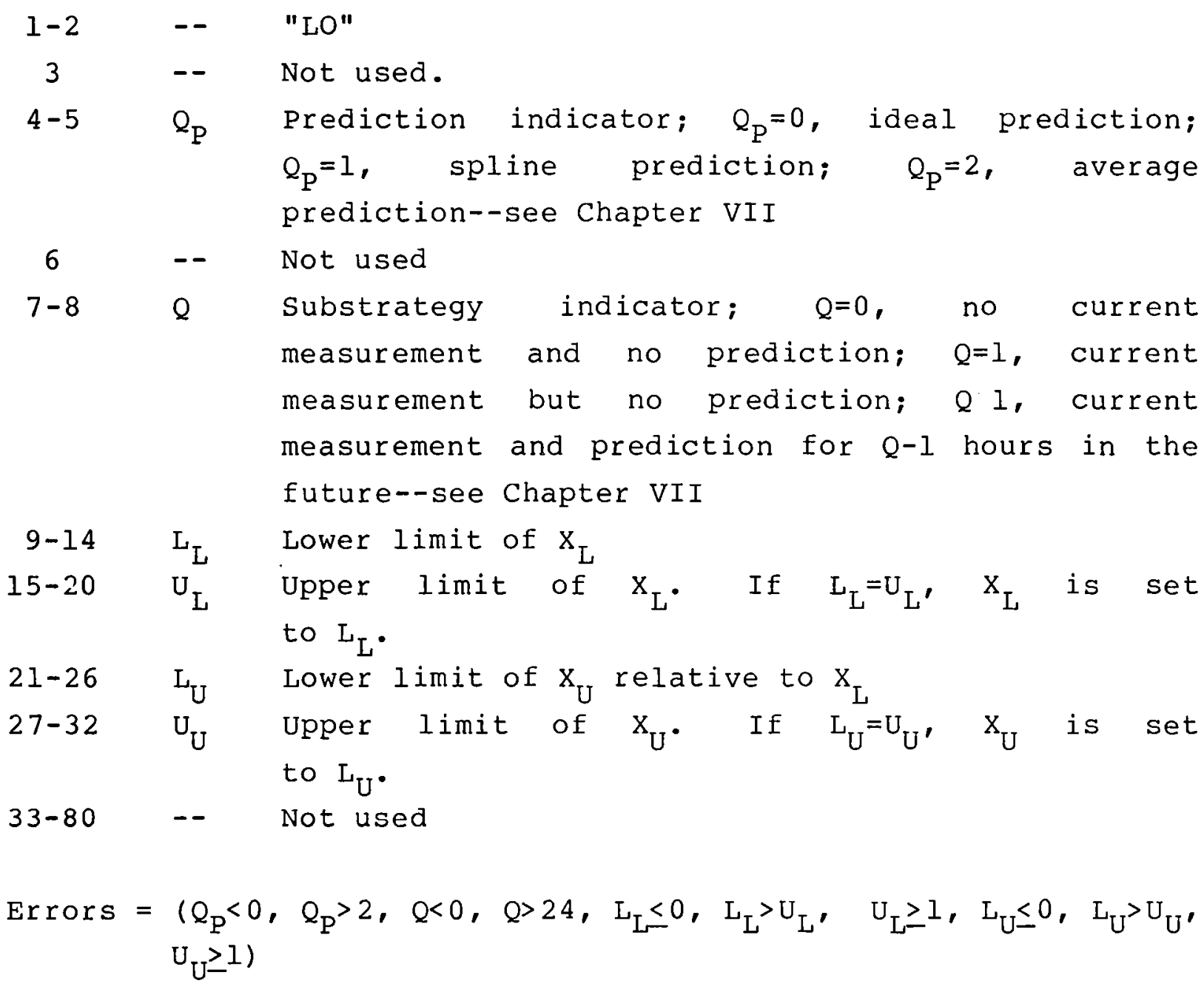




\section{UEll Output Listing Description and Samples}

The output for each run consists of two files, the OUTPUT listing and a detailed output written to TAPE 9 for further reference, if so desired. We discuss the TAPE 9 output later.

The OUTPUT listing consists of two pages (see Chapter $X$ ). The first page shows the input deck and certain quantities associated with the demand and optimization. The run identifier, run number, and random seed (in decimal) for the Latin hypercube are printed first. This identifier is the hour, minute, second, month, and day the job entered the computer. The run number is a counter of runs in the job. Each input card image is enclosed in parentheses and has slashes printed to separate fields. If a card has been changed from the previous run, an asterisk is printed to the right of the card image. A listing is also presented of the seasonal distribution of energy and costs for time-of-day prices and demand charges for the nonsystem--no collector, storage, or transducer. After the message "XMIN," the number of passes in the $r u n, k$, and $\mathrm{m}_{0}$ are listed.

The second output page gives the results. Fixed "optimal" sizes are denoted "F," variable ones by "V." The chosen size is under "SIZE." All costs are annualized unless otherwise noted. Under "PTC" is percent total capital cost. Percent capital cost assigned to variables is "PVC."

Let $D_{T}$ be the total yearly demand, then

TOTAL LEVEL COST $=\left(\right.$ TOTAL COST) $/ \mathrm{D}_{\mathrm{T}^{\prime}}$

CAPITAL LEVEL COST $=\frac{\text { CAPITAL plus OM COST }}{D_{T} \text { lesS NET E-PUR ENERGY }}$

NET E-PUR LEVEL COST $=\frac{\text { NET E-PUR COST }}{\text { NET E-PUR ENERGY }}$ 
$\operatorname{INIT} \operatorname{LEV} \operatorname{COST}(\mathrm{all})=(\operatorname{LEVEL} \operatorname{COST}) / \mathrm{p}(\mathrm{R}, 0, \mathrm{~N}) / \mathrm{p}(\mathrm{R}, \mathrm{g}, \mathrm{N})$,

where $\mathrm{p}$ is the $\mathrm{PV}$ function, $\mathrm{R}$ is the discount rate, $\mathrm{N}$ is the system life, and $g$ is the general inflation rate (see Chapter II).

The quantity BOD is an estimate of barrels of oil displaced by the system. We assume electrical energy provided by the system displaces oil consumption only during the "high-price" times. Thus

$$
\begin{aligned}
\text { BOD }=0.001667 \text { times (Demand plus total sold back less total } & \begin{array}{c}
\text { purchased energy, all in } \mathrm{kWh} \text { and at high } \\
\text { price time only). }
\end{array}
\end{aligned}
$$

The storage cycle estimate is

STO CYCLES/YR $\frac{8736 \text { (Average hourly storage output) }}{\text { storage capacity }}$

The "LIFE CYCLE COST RATIO" is the ratio of the optimal ACSYS to the annualized cost of the nonsystem (or "ZERO" system).

In the following equations, all sums are on $t$ from 1 to 8736 . other output quantities are:

PFD = percent fossil fuel displaced

$$
=100\left[e_{3} e_{6} \sum\left(I_{d}+I_{b}\right)+e_{3} e_{8} e_{7}\left[I_{s}-\frac{\left(I-e_{2}\right) \Sigma E s_{s} \Sigma I_{s}}{\sum I_{s}+e_{4} \sum I_{4}}\right] / D_{T}\right.
$$

$\mathrm{PFP}=$ percent fossil fuel purchased $=100-\mathrm{PFD}$

PSE = percent system efficiency

$$
=100 e_{3} e_{6}\left(I_{d}+I_{b}\right)+e_{8}\left(I_{d s}+I_{b s}\right) /\left(X_{1} I_{1}+I_{4}\right)
$$


$\mathrm{PDC}=$ percent demand from collector and storage

$=100 e_{3}\left(e_{6} I_{d}+e_{8} I_{d s}\right) / D_{T}$

PDS = percent demand from storage

$=100 e_{3} e_{8} I_{d s} / D_{T}$

$E-W A S T E=$ total waste $=\left(0_{5}-I_{d}-I_{b}-I_{s}\right)$

AES = average percent efficiency of storage

$=100 e_{8}\left(I_{d s}+I_{b s}\right) /\left(I_{s}+I_{4}\right)$

AVG STO = average storage level $=E_{S} / 8736$

LEAK = total leakage $=\left(1-e_{2}\right) E_{s}$

The "SELECTED CUMULANTS" give the percent of time that a particular component is at a certain level. For UEll, we only show storage cumulants. There are 20 numbers 1 isted across the page. The $i-t h$ number shows the percent of time that the storage level, $\mathrm{E}_{\mathrm{s}}^{\mathrm{t}}$, is at or below the level ix $2 / 20$. 


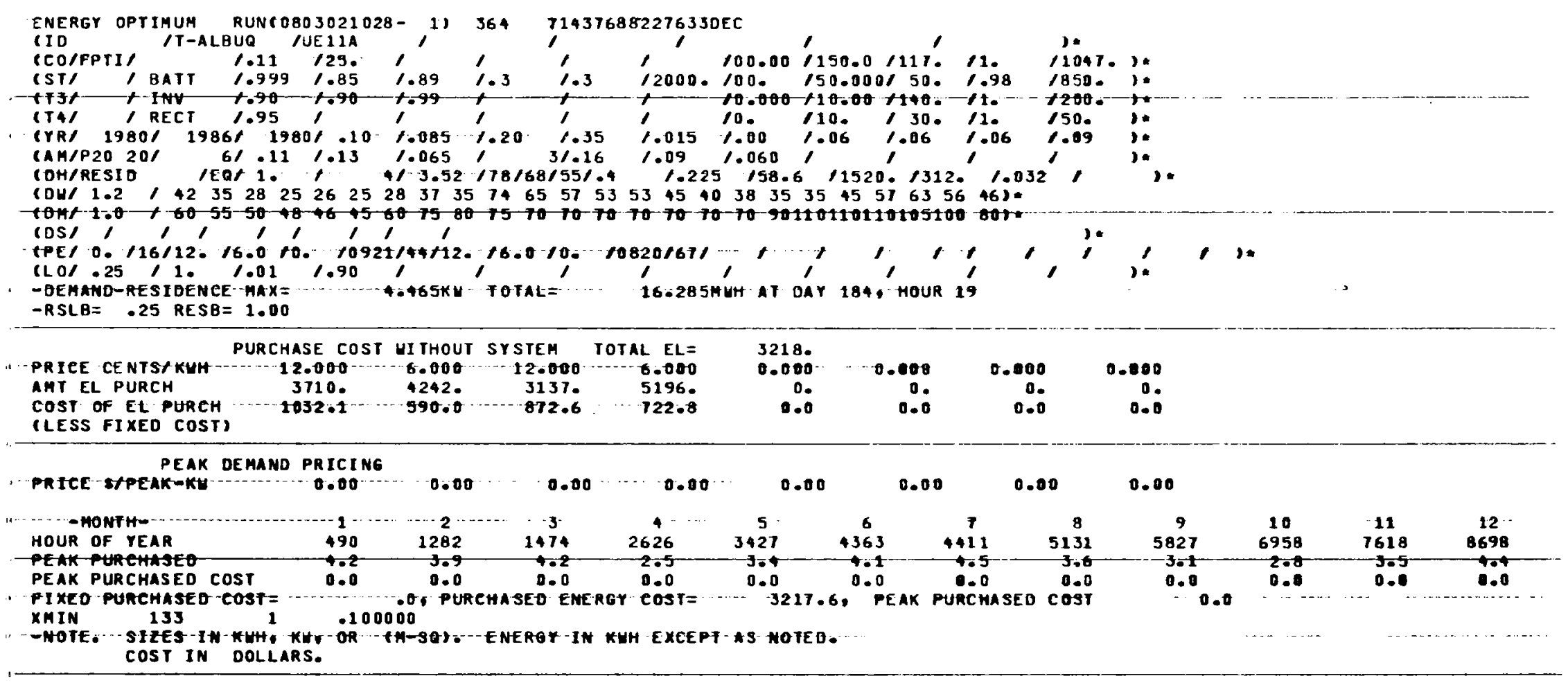


ENERGY OPTIMUM RUNCOBO302102B- 11

IID

-NOTE. SIZES IN KHA, KH, OR (M-SQ). ENERGY IN KHH EXCEPT AS NOTEO.

COST IN DOLLARS.

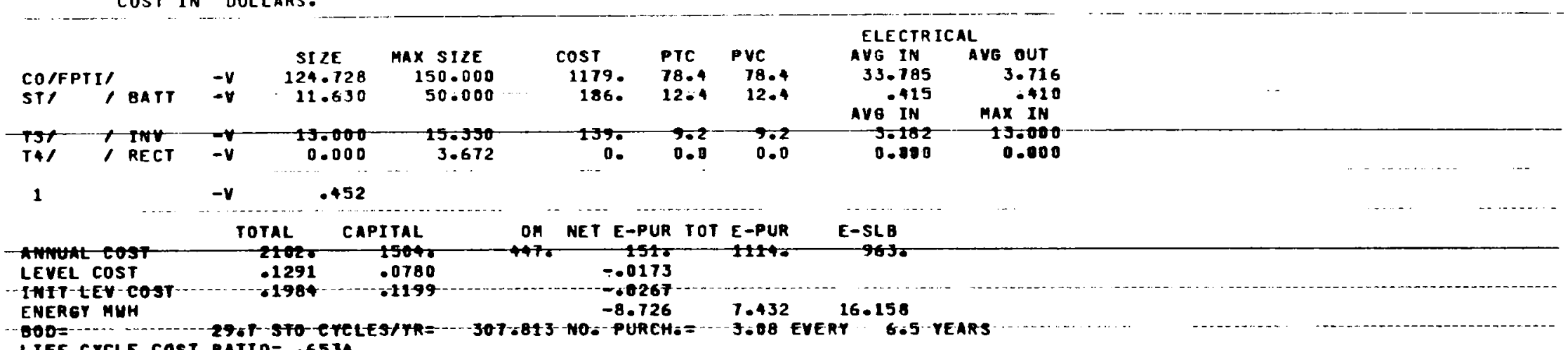

LOD=-
LIFE CYCLE COST RATIO $=.6534$

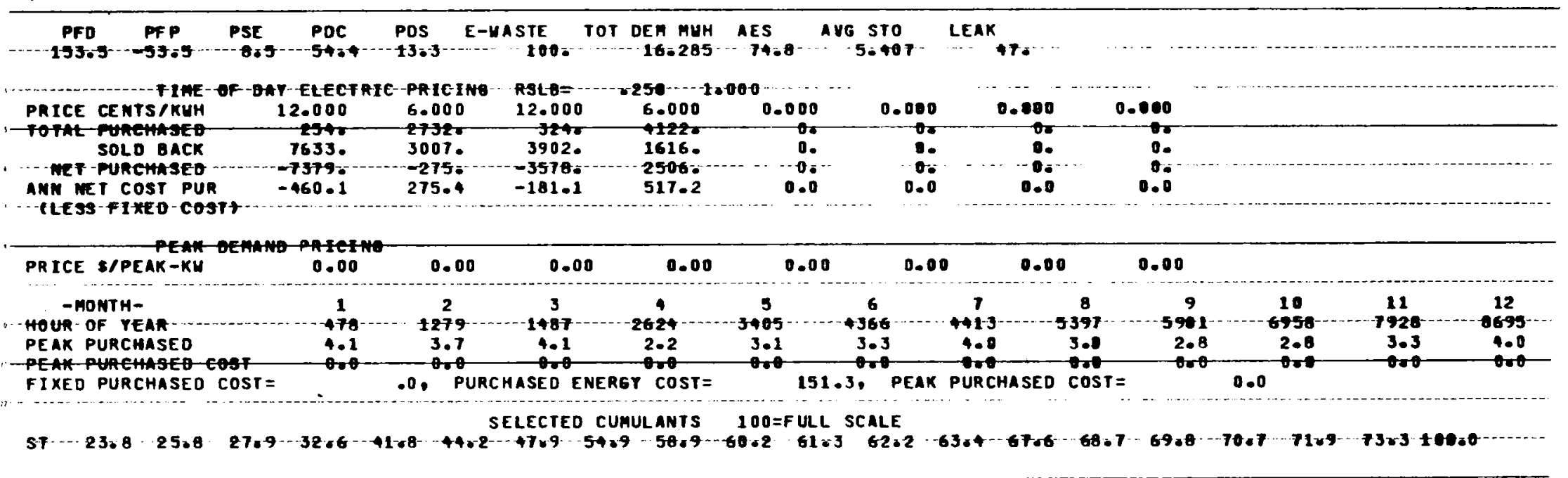




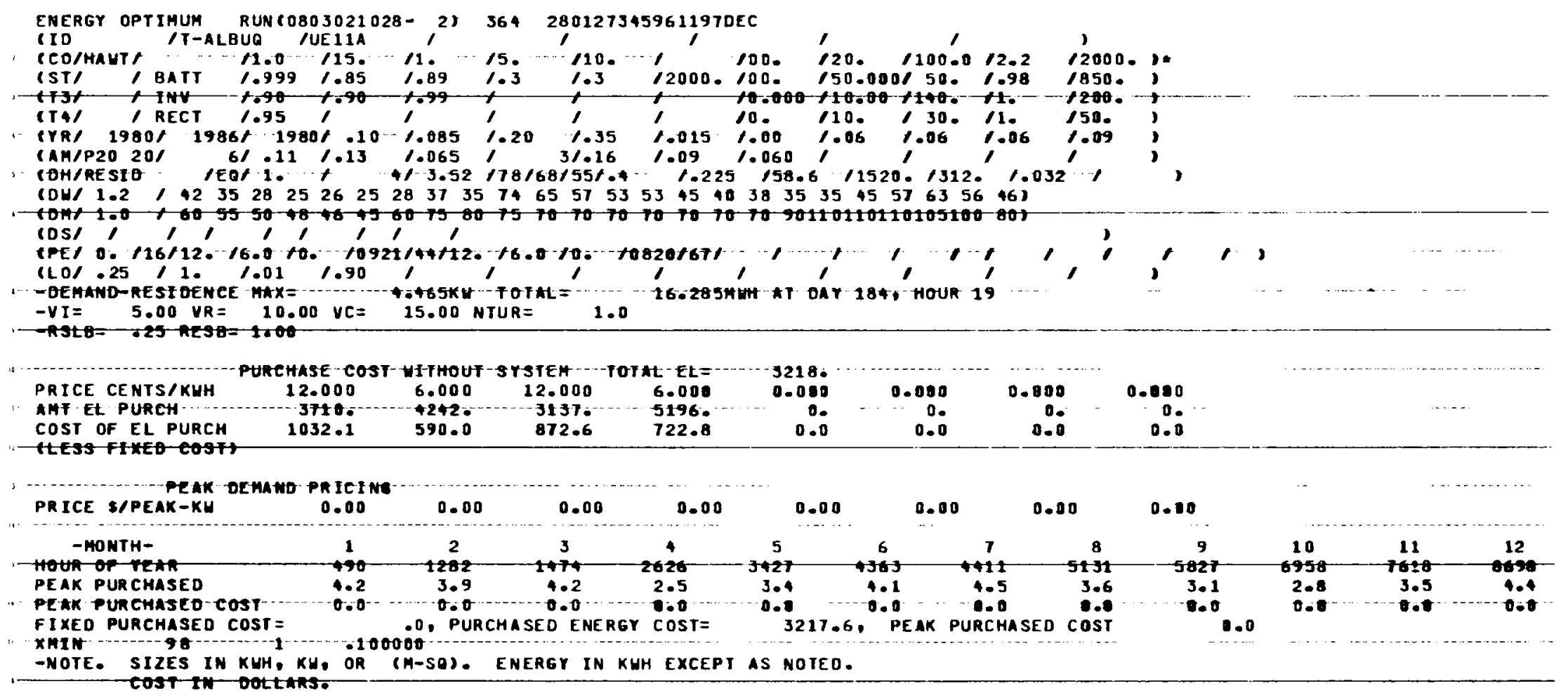


ENERGP OPTIMUM RUN $0803021028-{ }^{2)}$
IID
ONOTE. STZES IN KHH, KH, OR (M-SO). ENERGÝ IN KHH EXCEPT AS NOTED.

TOTE. SIZES IN KWH, KH,
COST IN DOLLARS.

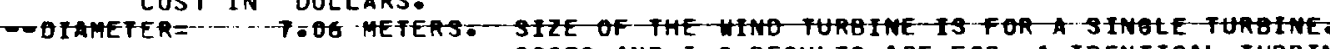

COSTS AND I-O RESULTS ARE FOR I IDENTICAL TURBINES.

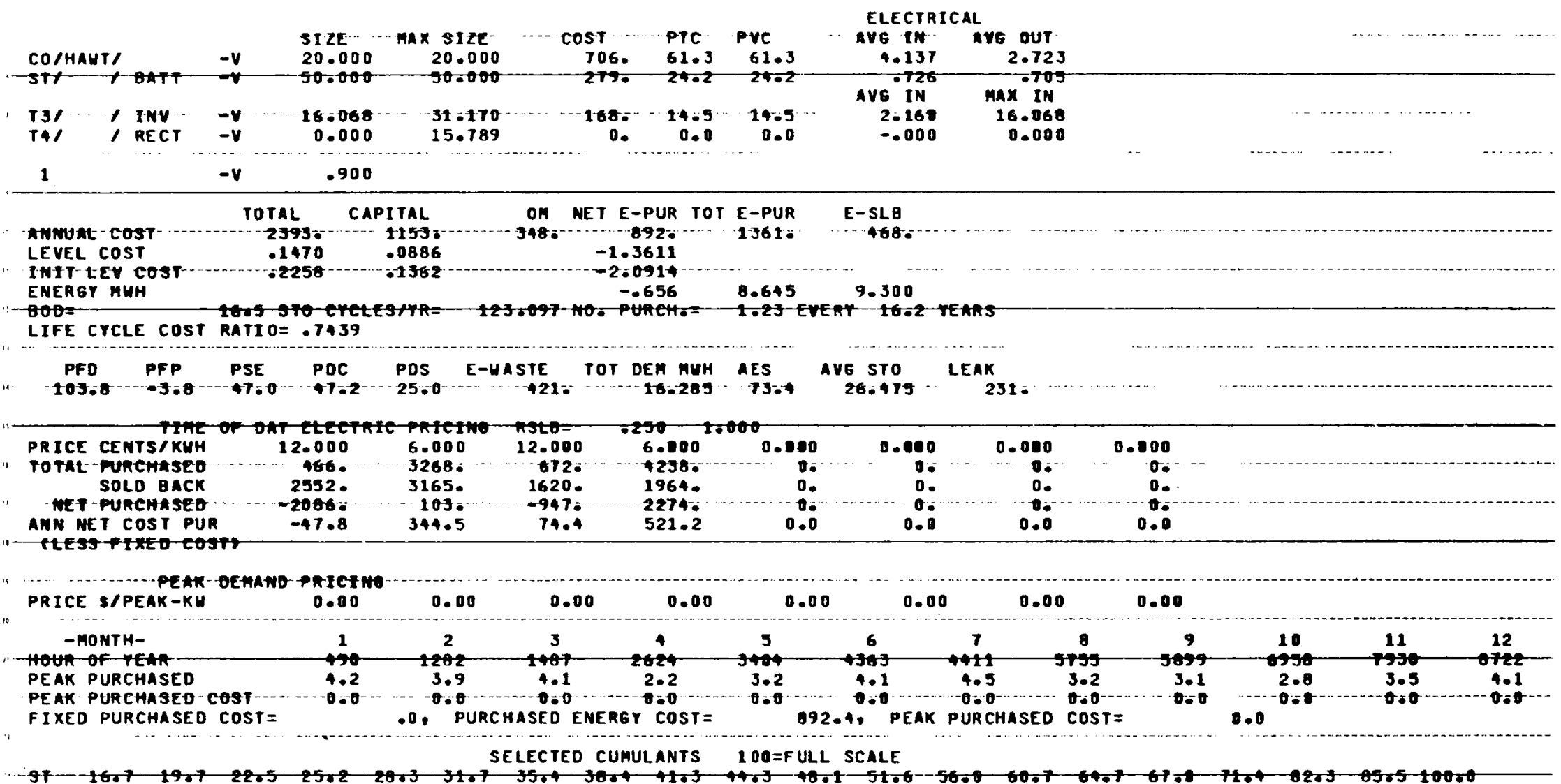


GEll Output Listing Description and Samples

The GEll output listing is much like the UEll listing. In addition to showing the input cards, data is given for the generator only system; that is, no collector, storage, or transducers. The generator size is that size which satisfies the demand goal, whether or not such a generator size is allowed by the limits on the GE card. Due to minor numerical errors, the actual demand goal satisfied may not be "exactly" the requested value of $d_{g}$ hence the "ACTUAL DEMAND SATISFACTION GOAL" printing. The "DEMAND NOT SATISFIED IN...HOURS" indicates how many hours in the year that the demand is not satisfied. The "GENERATOR CUMULANTS" show the percent of time that the generator output is at or below the level $i x_{3} / 20$, for the $i-t h$ number.

Most of the answer page is self-explanatory. Let $D_{S}$ be the total demand satisfied by the optimal system, then

TOTAL LEVEL COST $=($ TOTAL COST $) / \mathrm{D}_{\mathrm{S}}$

CAPITAL LEVEL COST $=($ CAPITAL $+O M \operatorname{COST}) /\left(D_{S}-\sum G_{d}\right)$

FUEL LEVEL COST $=($ FUEL COST $) /\left(\sum G_{d}+\sum G_{S}\right)$

$\operatorname{INIT} \operatorname{LEV} \cos T(a l l)=(\operatorname{LEVEL} \cos T) p(R, 0, N) / p(R, g, N)$

GENERATOR NO OVH = Number of overhauls

GENERATOR HOURS/YR = Number of hours generator is ON per year

GENERATOR DSIZE = Size of generator in ratio total-demandsatisfied units.

PDD = percent demand displaced

$=100\left(D_{S}-\Sigma G_{d}-\Sigma G_{S}\right) / D_{S}$ 


$$
\begin{aligned}
& \text { PDG }=\text { percent demanded generated }=100-\mathrm{PDD} \\
& \text { PSE = percent system efficiency } \\
& =100\left(D_{\mathrm{S}}-\Sigma \mathrm{G}_{\mathrm{d}}-\Sigma \mathrm{G}_{\mathrm{S}}\right) \\
& \text { = TOTAL COLLECTOR INPUT } \\
& \mathrm{PDC}=\text { percent demand from collector } \\
& =100\left(1-\sum G_{d} / D_{S}\right)-P D S \\
& \text { PDS = percent demand from storage } \\
& =100 e_{4} e_{8}^{\sum I_{d s}} / D_{S} \\
& \text { AES = average efficiency of storage } \\
& =100 e_{8} \sum I_{d s} /\left(\sum I_{s}+\sum G_{s}\right)
\end{aligned}
$$

All sums are on $t$ from 1 to 8736 .

The "ST" and "GE" CUMULANTS are respectively the storage and generator cumulants as explained above. 
Detailed Output--TAPE 9 (Optional)

For each run a file is written in binary (unformatted) mode to TAPE 9. Successive runs in a job are separated by END-OF-FILE marks. The file from each run consists of 366 records. 


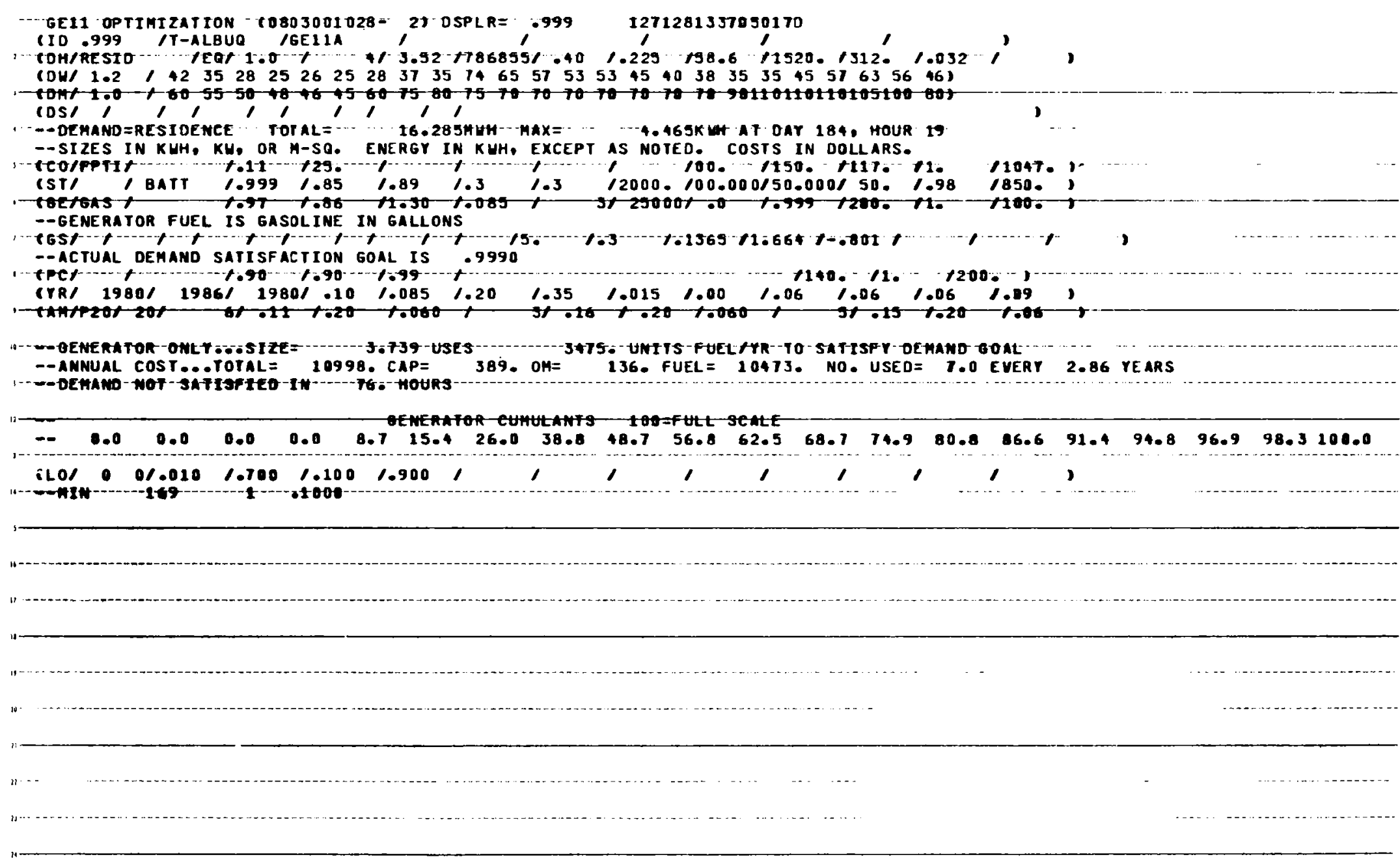

Figure 9.3 Sample Output GEll with Collector page 1 


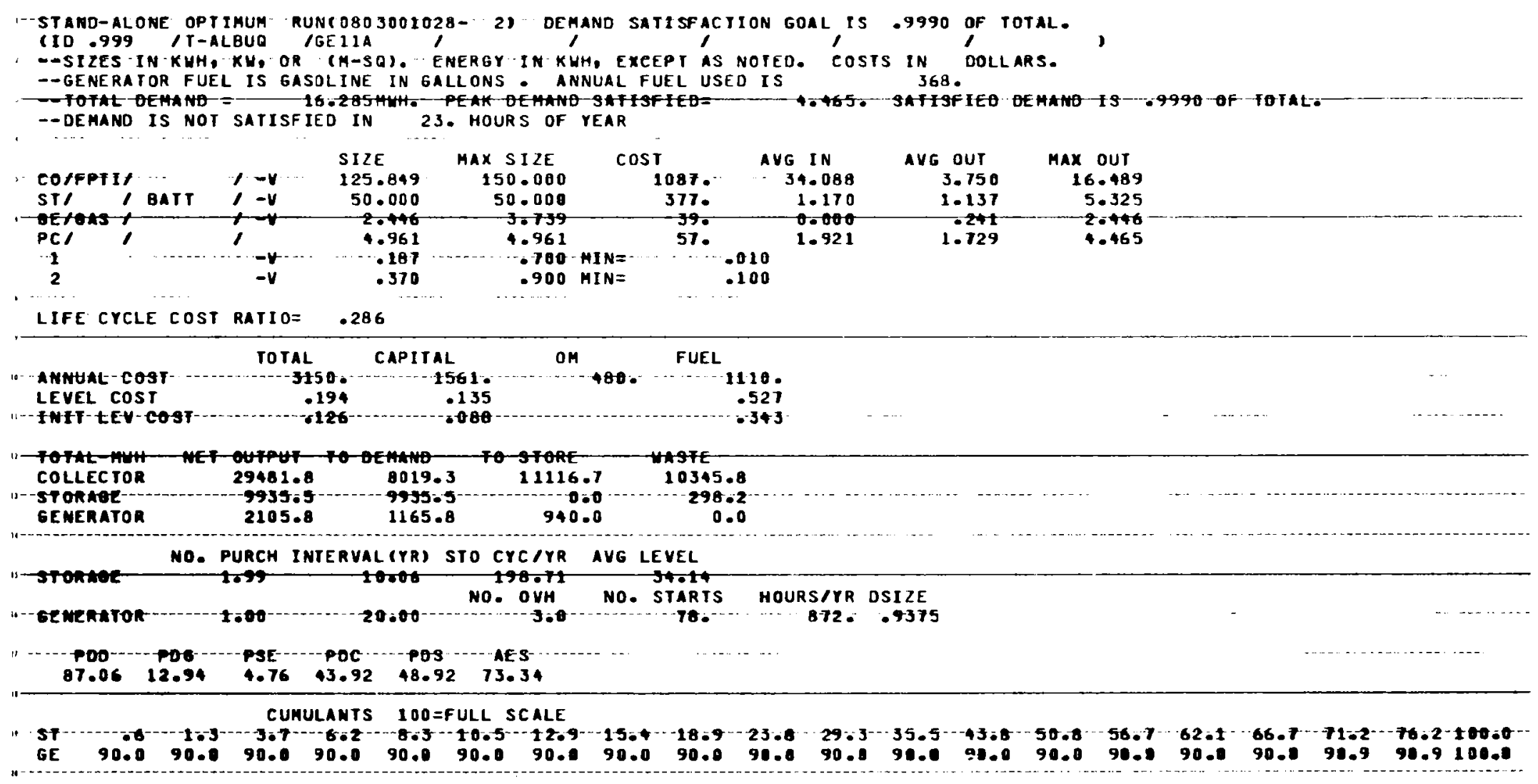




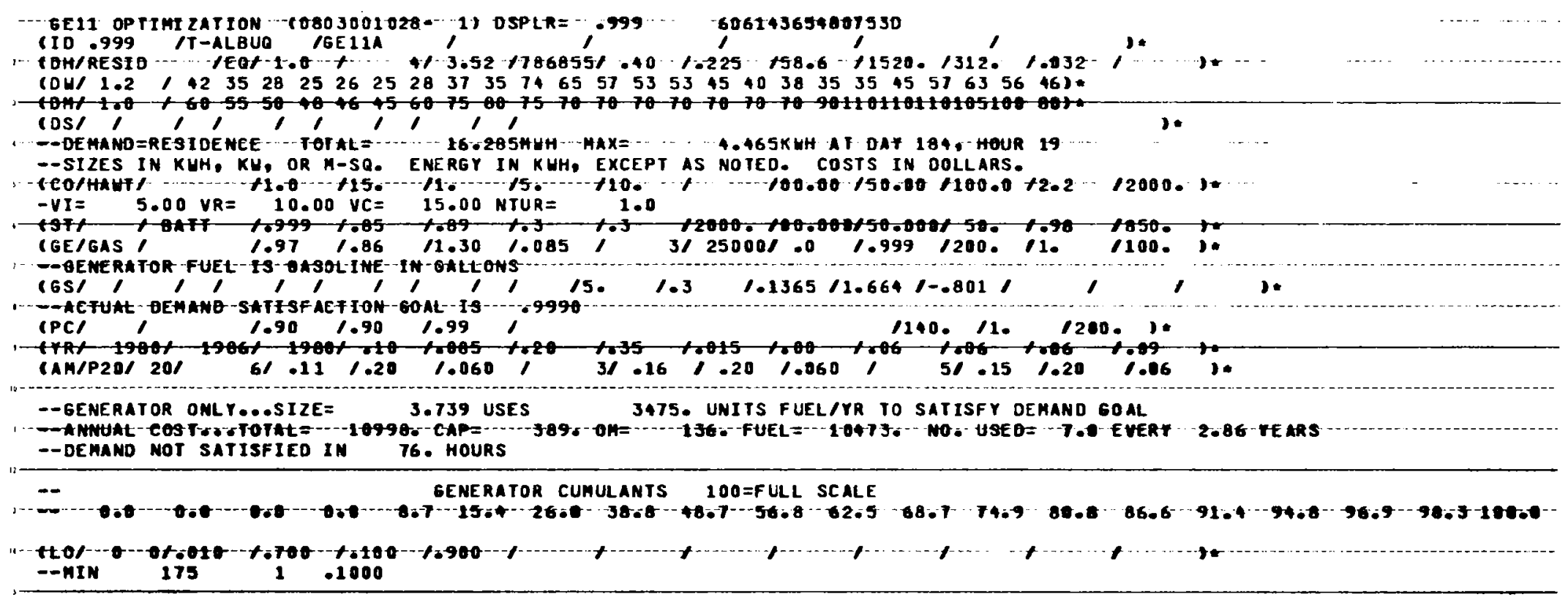


STAND-ALONE OPTIMUM RUNCOBOJ0O1028- 1) DEMAND SATISFACTION GOAL IS 9990 OF TOTAL.

--DIAMETER = 10.02 METERS. SIZE OF THE UIND TURBINE IS FOR A SINGLE TURBINE.

(ID .999 IT-ALBUG /GEIIA COSIS ANO I-O RESULTS ARE, FOR I SETS OF IDENTICAL TURBINES.

-SIZES IN KWH, KH, OR TH-SQT. ENERGY IN KWH, EXEEPT AS NOTEO- COSTS TH

--GENERATOR FUEL IS GASOLINE IN GALLONS - ANNUAL FUEL USED IS

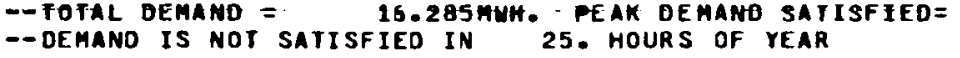

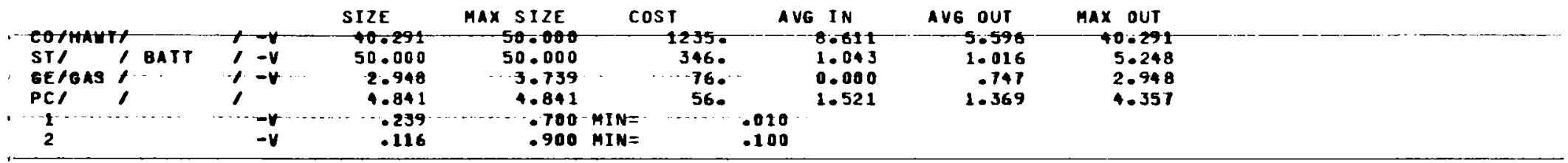

LIFE CYCLE COST RATIO= .511

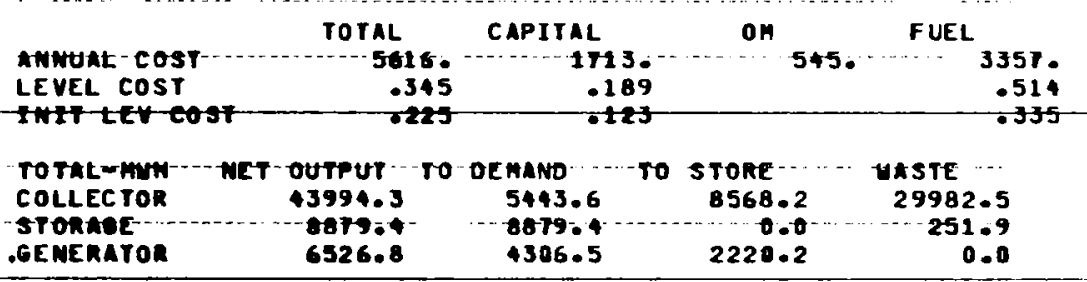

MO. PURCH INTERVAL(YR) STO CYC/YR AVG LEVEL

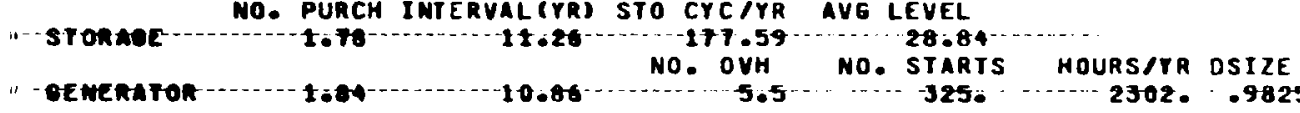

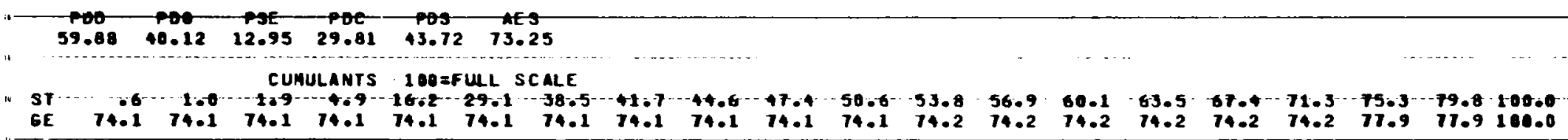


The first record gives the run identifier, run number, and input card images. It may be read by

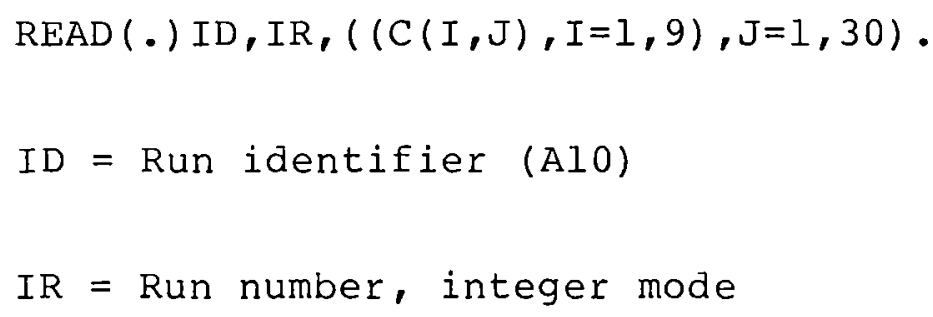

Word $C(I, J), I=1,8$ is the 10 character field of the $J$-th input card, ordered as in the OUTPUT listing. If $C(9, J)$ is an asterisk, the card is "new."

The second record contains 10 words; vis,

$$
\operatorname{READ}(.)(X(I), I=1,10) \text {. }
$$

The mode is real. The value of $X(I)$ is the optimum value of the I-th size. In UEll, only $I=1,4$ is meaningful, except for UEllA, where $x(5)$ is the value of $x_{L}$. In GEll, $x(4)=0, x(5)$ gives the optimal value of $x_{L}$, and $X(6)$ gives the optimal value of $X_{U}$.

The next 364 records contain detailed real-mode data for each of the 364 days. There are 240 words/record. Each record is read by

$\operatorname{READ}().((A(I, J), I=1,10), J=1,24)$.

Index $J$ is the hour of the day. 


$\begin{array}{lll}A(1, J)= & \frac{\text { UEIl }}{I_{d}} & I_{d} \\ A(2, J)= & I_{b} & G_{d} \\ A(3, J)= & I_{S} & I_{d s} \\ A(4, J)= & I_{d s} & I_{S} \\ A(5, J)= & I_{b s} & G_{S} \\ A(6, J)= & I_{4} & E_{S} \\ A(7, J)= & E_{S} & O_{5} \\ A(8, J)= & O_{5} & E_{D} \\ A(9, J)= & E_{D} & \text { Zero }\end{array}$

$E A A: p m l: 4632 A: 02 / 28 / 81$ 


\section{$\underline{\text { References }}$}

1. Hoover, E. R., "SOLCEL-II: An Improved Photovoltaic System Analysis Program," Sandia National Laboratories, Albuquerque, New Mexico, SAND79-1785, February 1980.

2. Burroughs, J. D., Warren, A. W., and Edsinger, R. W., "SIMWEST: A Simulation Model for Wind and Solar Photovoltaic Energy Storage Systems," Boeing Computer Services Company, NASA/LRC BCS-40262-1, MaY 1979.

3. Caskey, D. L., Caskey, B. C., and Aronson, E. A., "Parametric Analysis of Residential Grid-Connected Photovoltaic Systems with Storage," Sandia National Laboratories, Albuquerque, New Mexico, SAND 79-2331, March 1980.

4. Perino, Audrey, "A Methodology for Determining the Economic Feasibility of Residential or Commercial Solar Energy systems," Sandia National Laboratories, Albuquerque, NM, SAND78-0931, January 1979.

5. Stermole, F. J., Economic Evaluation and Investment Decision Methods, Investment Evaluations Corporation, Golden Colorado, 1974 .

6. Dickinson, W. C. and Brown, K. C., "Economic Analysis of Solar Industrial Process Heat Systems," Lawrence Livermore Laboratory, Livermore, CA, August 1979.

7. Hall, I. J., Prairie, R. R., Anderson, H. E., and Boes, E. C., Generation of TMY for 26 SOLMET Stations, Sandia National Laboratories, Albuquerque, NM, SAND78-1601, August 1978.

8. Hill, James, E., and Furlong, Richard R., "ASHRAE Cooling Load Calculation," ASHRAE Journal, May 1973. 
9. Lasdon, L. S., Optimization Theory for Large Systems, (New York, MacMillan Publishing Company, Inc., 1970).

10. Box, G. E. P. and Jenkins, G. M., Time Series Analysis: Forecasting and Control, (San Francisco, CA, Holden-Day, 1976).

11. Hanson, R. J., "Constrained Least Squares Curve Fitting to Discrete Data Using B-Splines--A User's Guide," Sandia National Laboratories, Albuquerque, NM, SAND78-1291, February 1979.

12. Haskell, K. H. and Jones R. E., "Brief Instructions for Using the Sandia Mathematical Subroutine Library (Version 7.2)," Sandia National Laboratories, Albuquerque, NM, SAND77-1441, June 1978 (see subroutine MINA).

13. McKay, M. D., Beckman, R. J., and Conover, W. J., "A Comparison of Three Methods for Selecting Values of Input Variables in the Analysis of Output from a Computer Code," TECHNOMETRICS, Vol 21, No. 2, pp 239-245 (May 1979). 
Distribution:

DOE/TIC-4500-R67

$\mathrm{UC}-60,63 \mathrm{a}, 94 \mathrm{C}$ (596)

U. S. Department of Energy

600 E. Street, N. W.

Washington, D. C. 20545

Attn: A. R. Landgrebe (50)

P. D. Maycock

J. W. Mayo

V. Rabl

A. S. Clorfeine

U. S. Department of Energy

P. O. Box 5400

Albuquerque, New Mexico 87115

Attn: D. L. Plymale

The Aerospace Corporation

20030 Century Blvd.

Germantown, MD 20767

Attn: T. Blanchard, Jr.

D. Edwards

Argonne National Laboratory 9700 South Cass Avenue

Argonne, IL 60439

Attn: J. G. Asbury

D. I. Barney

Bechtel National, Inc.

P. O. Box 3965

San Francisco, CA 94119

Attn: D. J. Rosen

W. J. Stolte

Bell Laboratories

600 Mountain Avenue

Murray Hill, NJ 07974

Attn: D. O. Feder

Best Battery Co.

4015 Fleet $\mathrm{St}$.

Baltimore, MD 21224

Attn: A. R. Best

F. Biondi, Consultant

74 Ridge Drive

Livingston, NJ 07039

Dr. Per Bro, Consultant

Rt. 7 Hyde Park Estates

Santa Fe, NM 87501
Brookhaven National Laboratory

Upton, NY 11973

Attn: J. McBreen

C \& D Batteries

3043 Walton Road

Plymouth Meeting, PA 19462

Attn: D. D. Delans

Brooklyn College

Dept. of Physics

Brooklyn, NY 11210

Attn: Prof. Misha Tomkiewicz

C. H. Guernsey Co.

$3555 \mathrm{NW} 58$ th St.

Oklahoma City, OK 73112

Attn: S. Collier

Dow Chemical Company

2800 Mitchell Road

Walnut Creek, CA 94598

Attn: C. A. Levine

Eagle Pitcher

P. O. Box 47

Joplin, MO 64801

Attn: E. Carr

Energy Development Associates

1100 Whitcomb Avenue

Madison Heights, MI 48701

Attn: B. D. Brummet

ESB Incorporated

$19 \mathrm{~W}$. College Avenue

Yardley, PA 19067

Attn: D. T. Ferrell, Jr.

F. P. Malaspina

EPRI

3412 Hillview Avenue

P. O. Box 10412

Palo Alto, CA 94303

Attn: T. M. Lechner

Exxon Research \& Engineering Co. P. O. Box 8

Linden, NJ 07036

Attn: P. Grimes 
GEL Incorporated 1511 Peace Street Durham, NC 27701 Attn: R. Zito, Jr.

General Electric Co. P. O. Box 8661

Philadelphia, PA 19101

Attn: R. L. McCarthy

E. Mehalick

Gilbert Associates

P. O. Box 1498

Reading, PA 19603

Attn: A. J. Sattolo

Globe-Union, Inc. 5757 Green Bay Avenue Milwaukee, WI 53201

Attn: C. K. Morehouse

Gould Laboratories

40 Gould Center

Rolling Meadows, IL 60008

Attn: B. W. Burrows

J. Oxley

P. Thomas, Jr.

Grumman Aerospace

MSB-29-35

Bethpage, NY 11714

Attn: Mike Malison

Hittman Associates, Inc.

9190 Red Branch Road

Columbia, MD 21045

Attn: L. D. Carter

Intertechnology Corporation

100 Main Street

Warrenton, VA 22186

Attn: D. G. Edelman

JBF Scientific Corporation

2 Jewel Drive

Wilmington, MA 01887

Attn: J. E. Soden

Jet Propulsion Laboratory

4800 Oak Grove Drive

Pasadena, CA 91103

Attn: R. G. Forney
Lawrence Berkeley Laboratory

University of California

Berkeley, CA 94720

Attn: E. J. Cairns

F. McLarnon

Lawrence Livermore Laboratory

P. O. Box 808

Livermore, CA 94550

Attn: D. King (L-3888)

Martin Marietta Corporation

P. O. Box 179

Denver, CO 80201

Attn: R. L. Donovan

Massachusetts Institute of Tech. Energy Laboratory

E3 3-400

Cambridge, MA 02139

Attn: R. Tabors

Massachusetts Institute of Tech. Lincoln Laboratory

P. O. Box 73

Lexington, MA 02173

Attn: M. D. Pope

Mobile Tyco Solar Energy Corp.

16 Hickory Drive

Waltham, MA 02154

Attn: J. R. Wood

Motorola Semiconductor Products, Inc.

Solar Operations Division

P. O. Box 2953

Phoenix, AZ 85062

Attn: W. Bailey

NASA Industrial Application Ctr. University of Southern Calif.

Denney Research Bldg., 3rd Floor Los Angeles, CA 90007

Attn: D. Maund

NASA/Lewis Research Center

21000 Brookpart Road

Cleveland, OH 44135

Attn: R. S. Palmer

A. W. Nice 
New York State Energy Research

and Development Authority

Rockefeller Plaza

Albany, NY 12223

Attn: R. S. Morette

Pennsylvania Power \& Light Co.

2 N. Ninth Street

Allentown, PA 18101

Attn: H. G. Pfeiffer

Research Triangle Institute

P. O. Box 12194

Research Triangle Park, NC 27709

Attn: R. Burger

R. A. Whisnant

Rocky Flats Plant

Energy Systems Group

P. O. Box 464

Golden, CO 80401

Attn: R. P. Cingo

Solar Energy Research

Institute

1536 Cole Boulevard

Golden, CO 80401

Attn: $F$. Baylin

J. I. Watkins

Solar Power Corporation

5 Executive Park Drive

North Billerica, MA 01862

Attn: E. Wald

Stonehart Associates, Inc.

34 Five Fields Road

Madison, CT 06443

Attn: T. B. Reddy

Dr. Philip C. Symons, Consultant

4544 Ottawa Lane

Birmingham, MI 48010

Team, Inc.

P. O. Box 672

Springfield, VA 22150

Attn: E. M. Henry

Texas Tech University

P. O. Box 4200

Lubbock, TX 79409

Attn: W. M. Marey
Tideland Signal Corporation

P. O. Box 52430

Houston, TX 77052

Attn: C. Kotilla

U. S. ArmY/MERADCOM

DRDME-E

Fort Belvoir, VA 22060

Attn: D. D. Faehn

U. S. Navy/Naval Sea System Command

Code 543

Washington, DC 20362

Attn: A. Himy

University of Houston

College of Engineering

Houston, $\mathrm{TX} 77004$

Attn: E. C. Tacker

Westinghouse Electric Corp. 1310 Beulak Road

Pittsburgh, PA 15235

Attn: R. Rosey

Westinghouse Electric Corp. Power Systems, AST

East Pittsburgh, PA 15112

Attn: J. T. Day

Yardney Electric Corp.

82 Mechanic St.

Pawcatuck, CN 02891

2000 E. D. Reed

2500 J. C. Crawford

2520 H. J. Saxton

2525 R. P. Clark

2525 J. L. Chamberlin

2525 J. D. Sealey (50)

2533 A. E. Verardo

2640 J. L. Tischhauser

2646 M. R. Scott

2646 E. A. Aronson (8)

4000 A. Narath

4700 J. H. Scott

4710 G. E. Brandvold

4719 D. G. Schueler

4719 G. J. Jones

4719 D. C. Browne

4720 V. L. Dugan

4723 W. P. Schimmel (5) 


$\begin{array}{ll}4723 & \text { D. L. Caskey (10) } \\ 4723 & \text { M. W. Edenburn } \\ 4740 & \text { R. K. Traeger } \\ 4744 & \text { H. M. Dodd } \\ 4744 & \text { B. C. Caskey (3) } \\ 3141 & \text { T. L. Werner (5) } \\ 3151 & \text { W. L. Garner (3) } \\ 8266 & \text { E. A. Aas } \\ 8452 & \text { A. C. Skinrood } \\ 8452 & \text { C. E. Hackett } \\ \text { For DOE/TIC (Unlimited Release) }\end{array}$





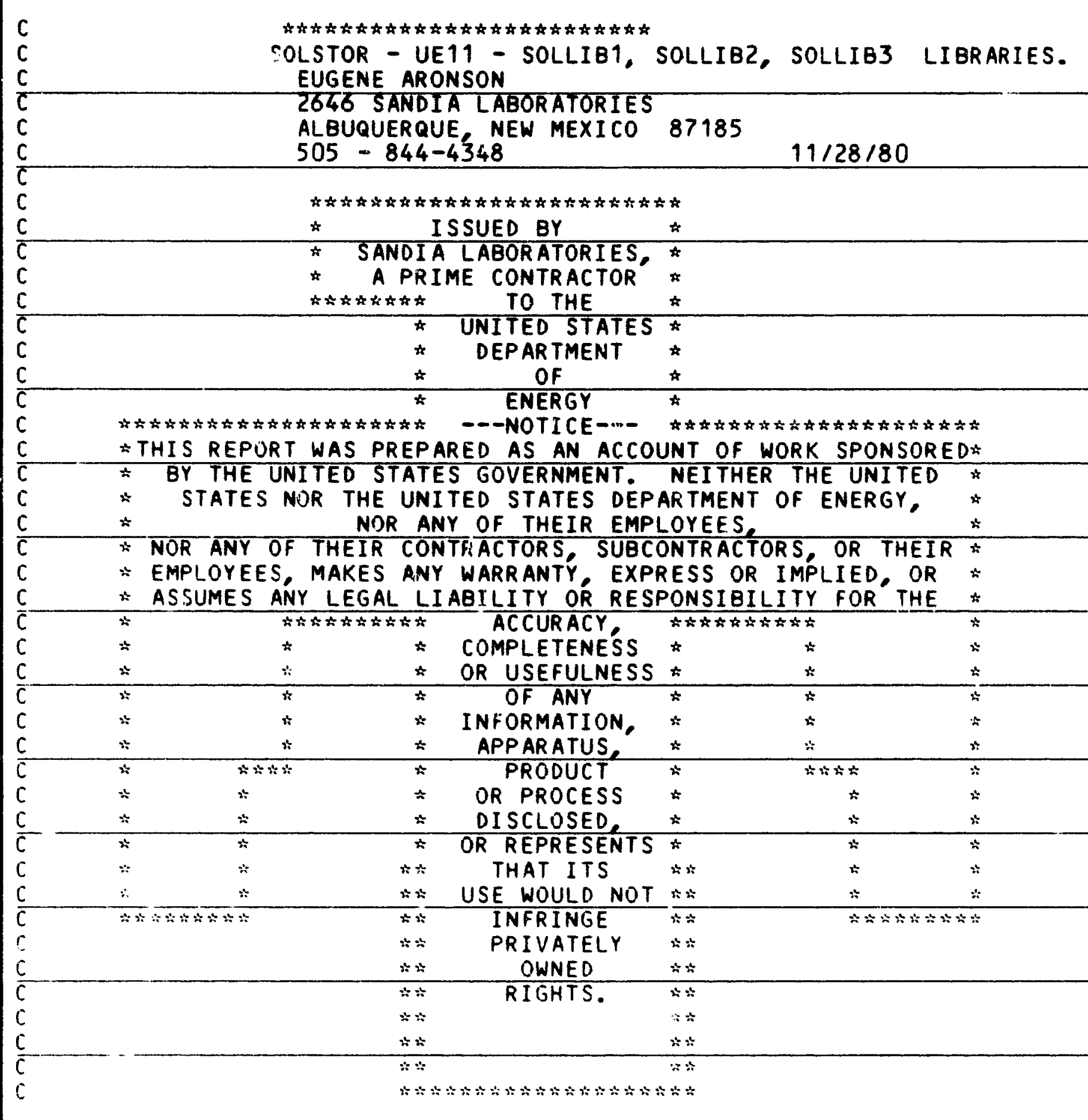




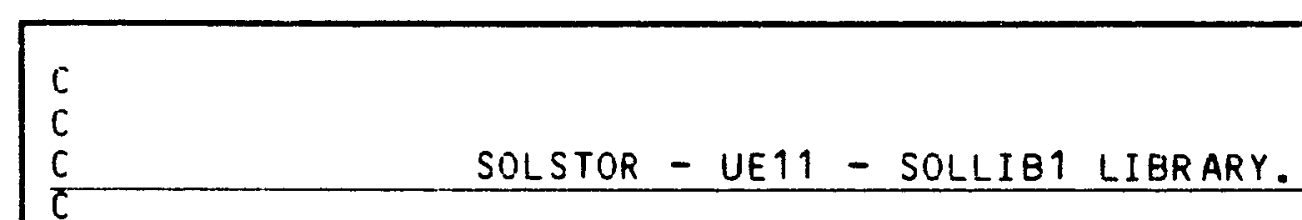




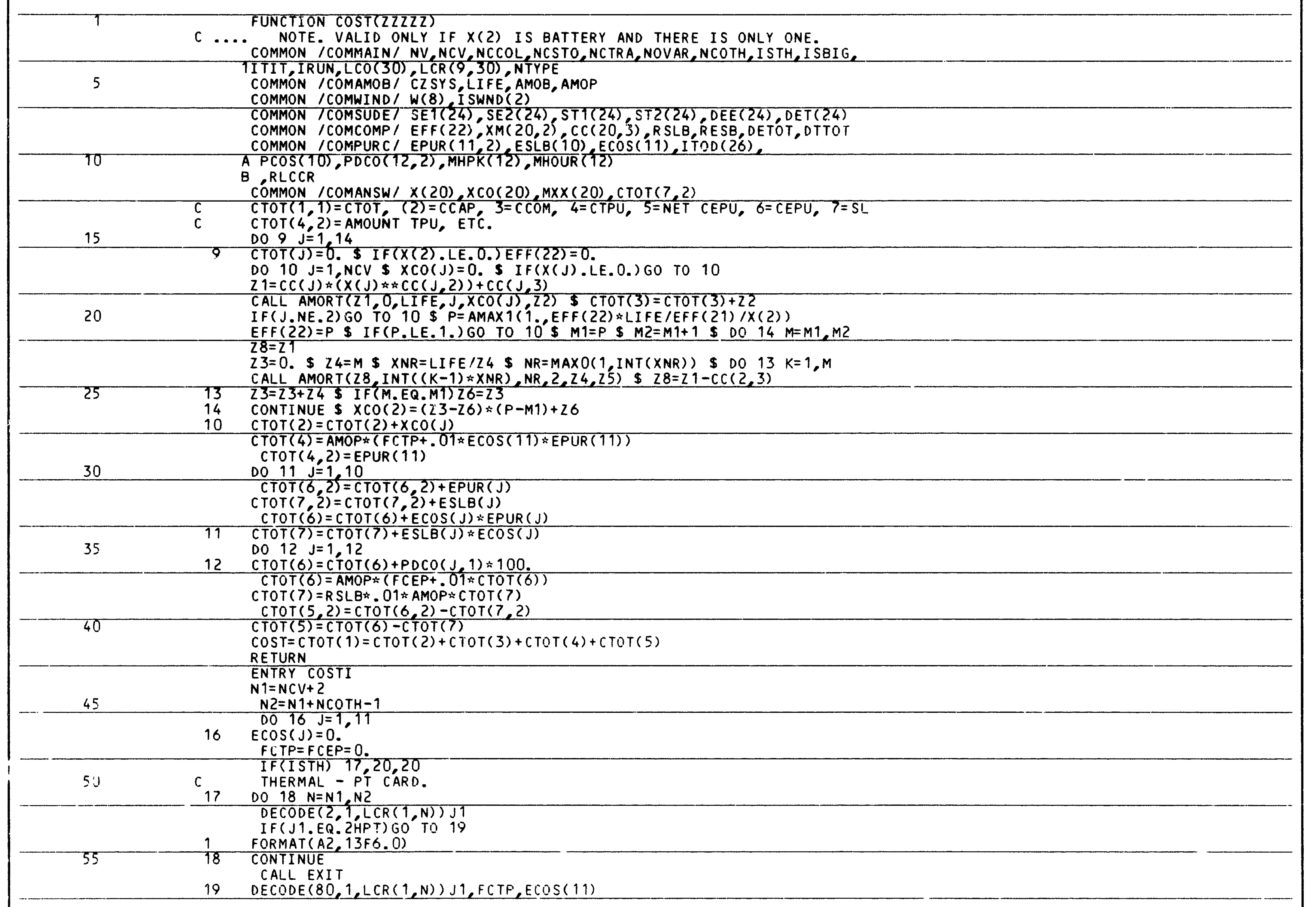




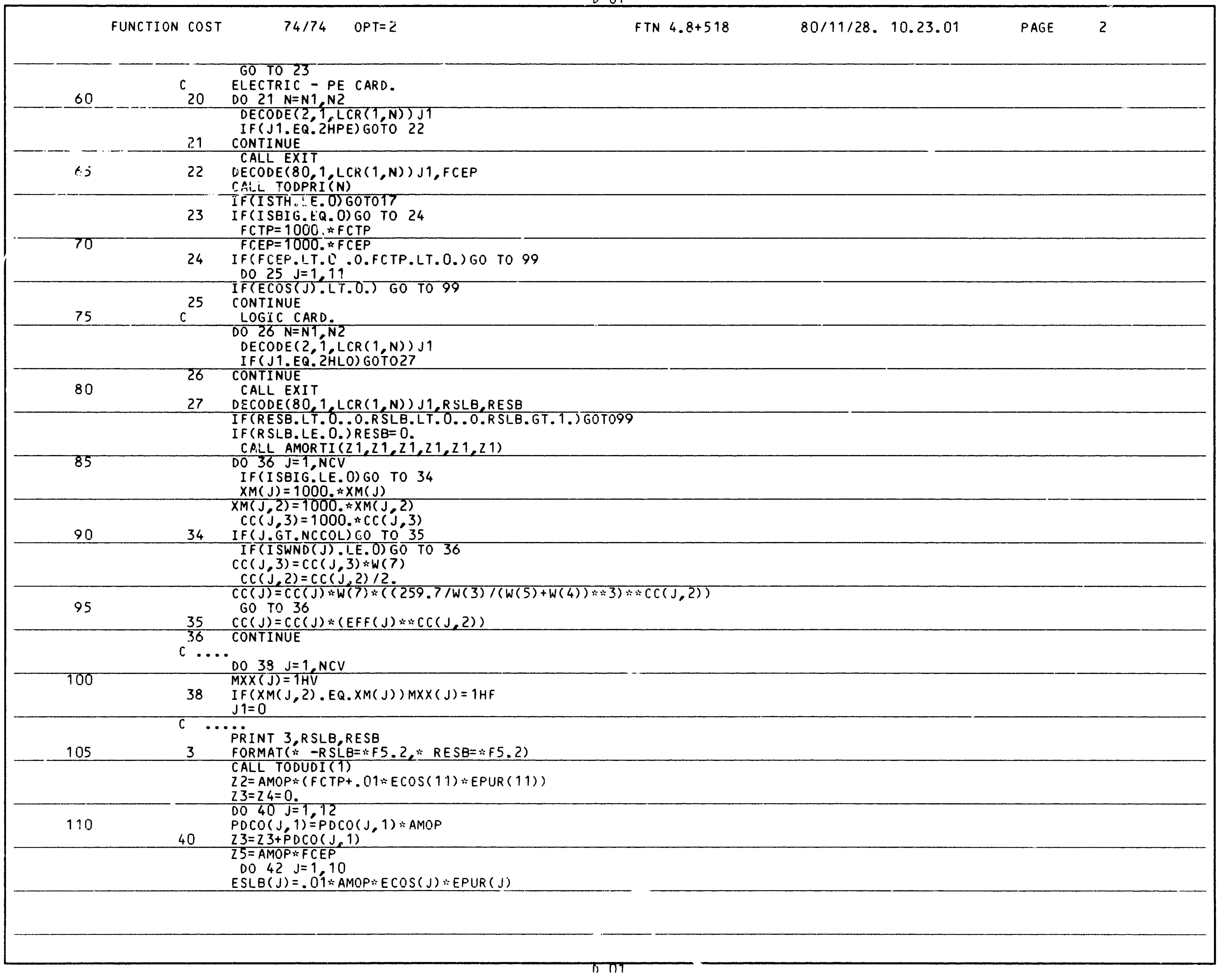




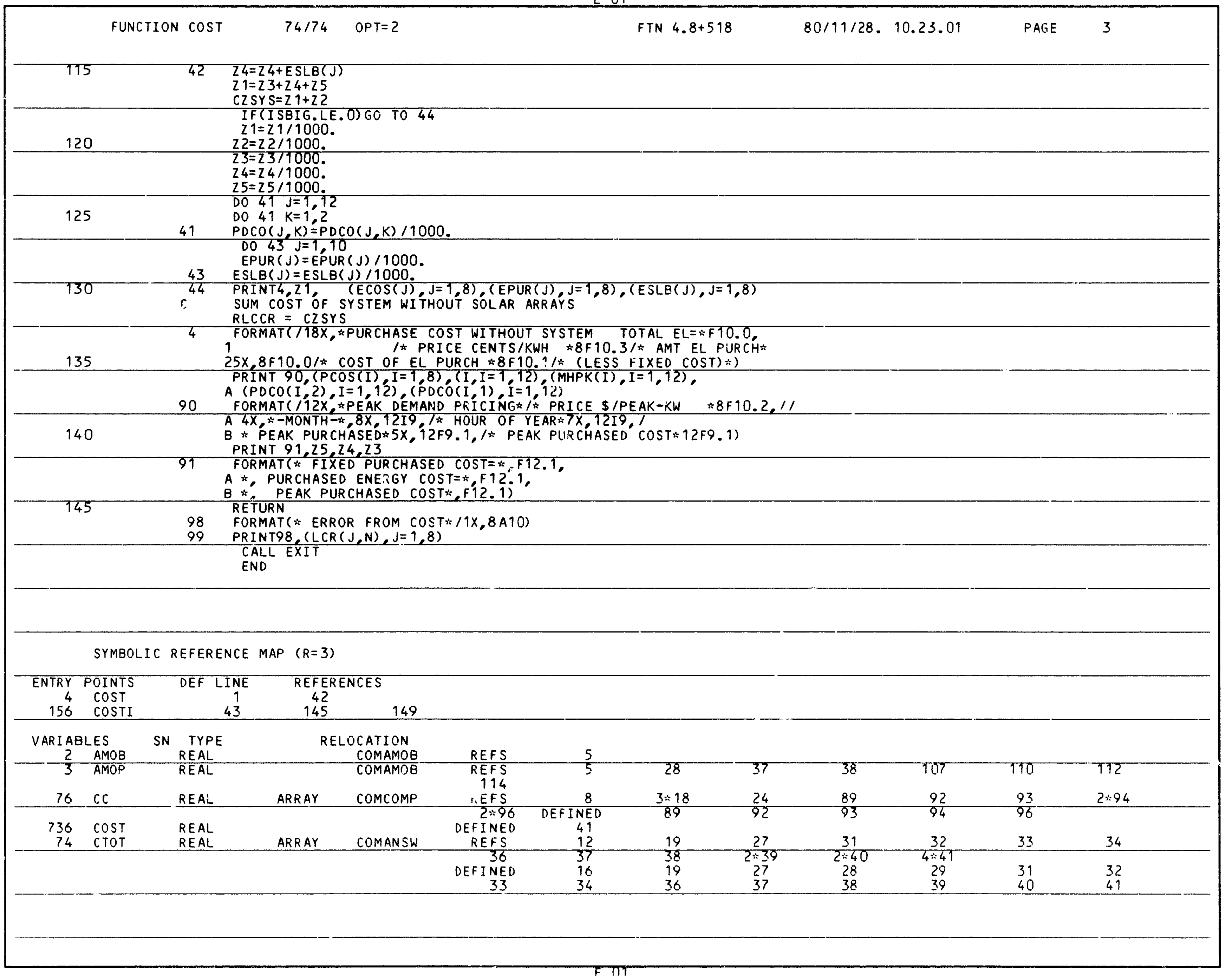




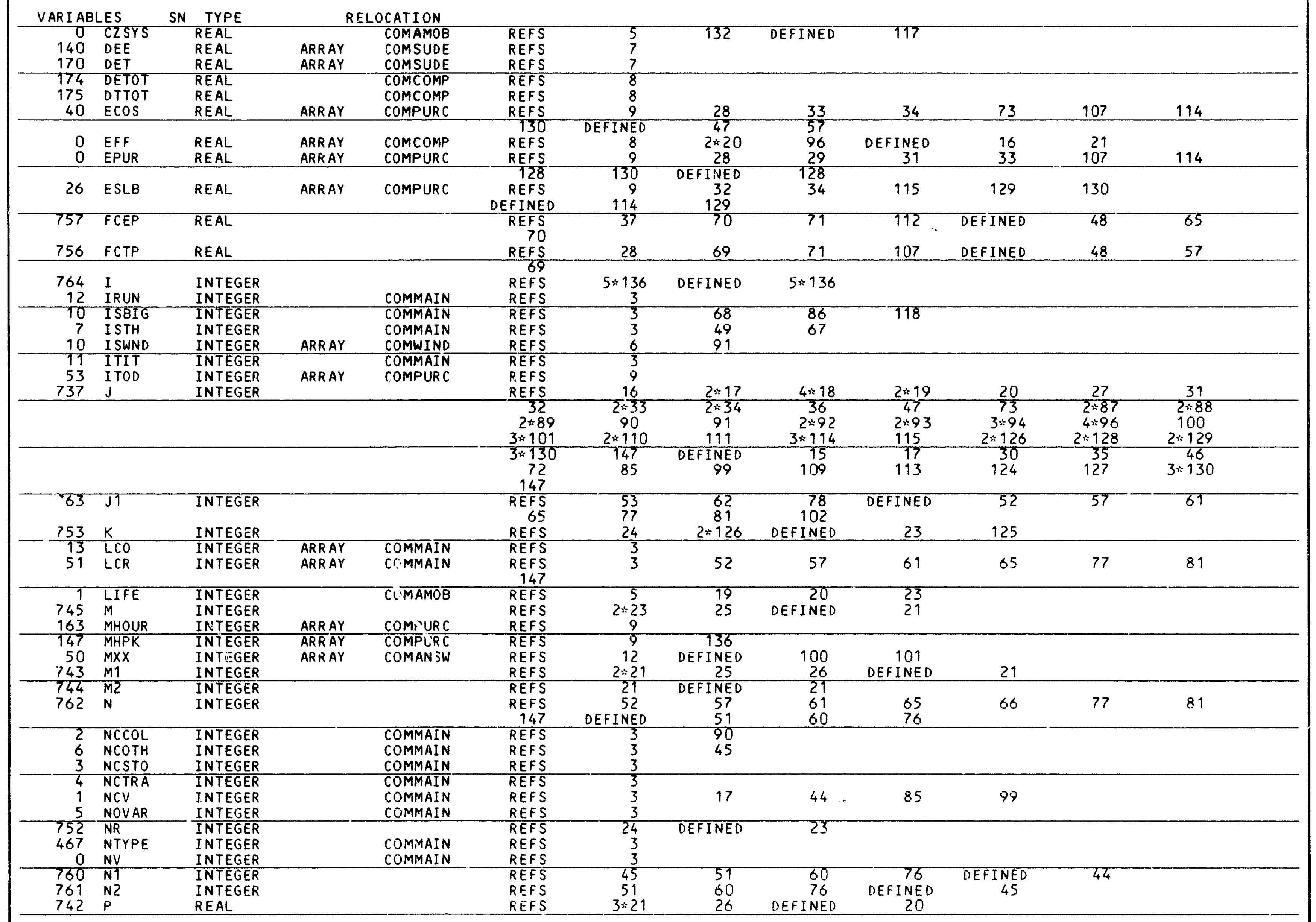




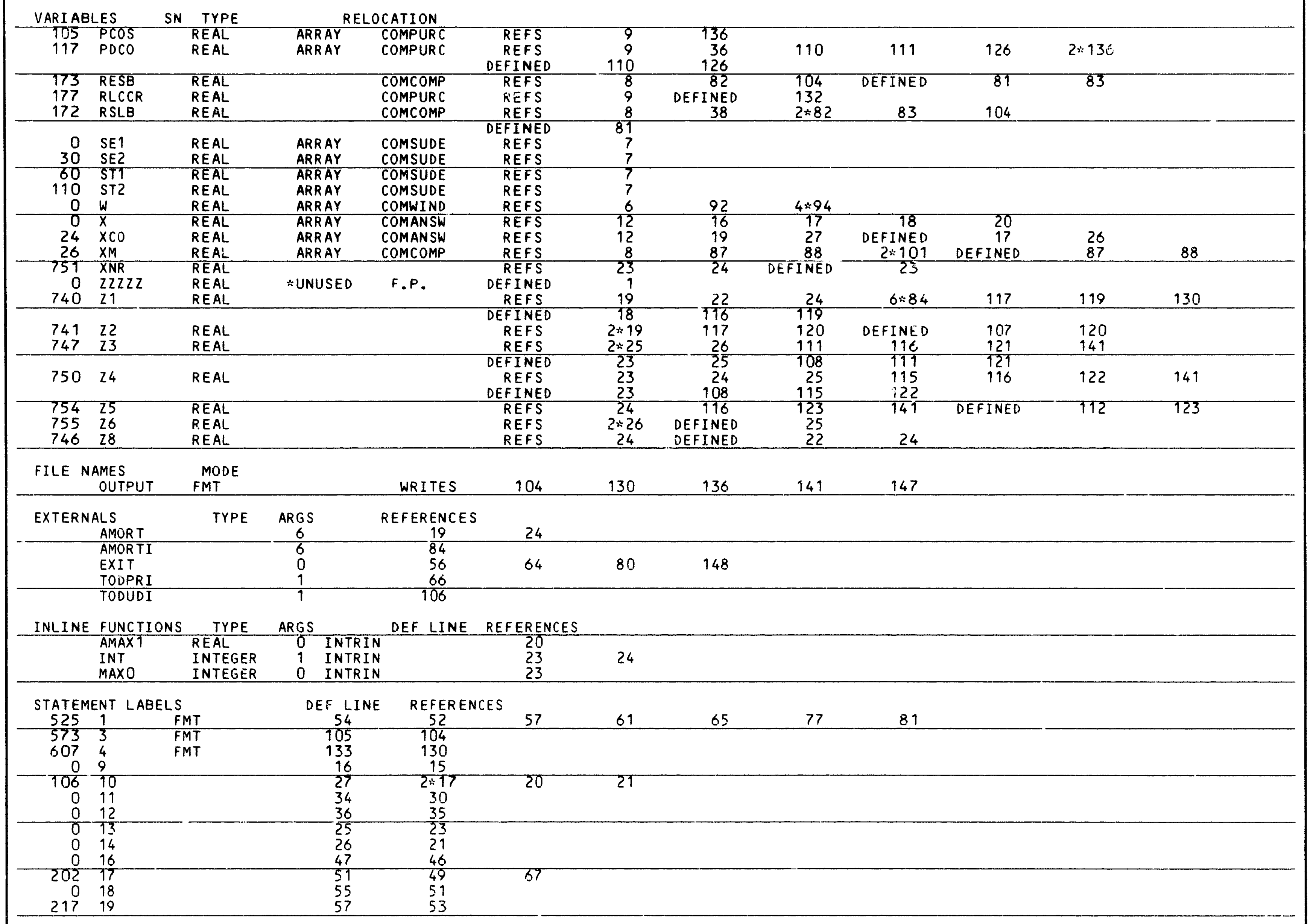




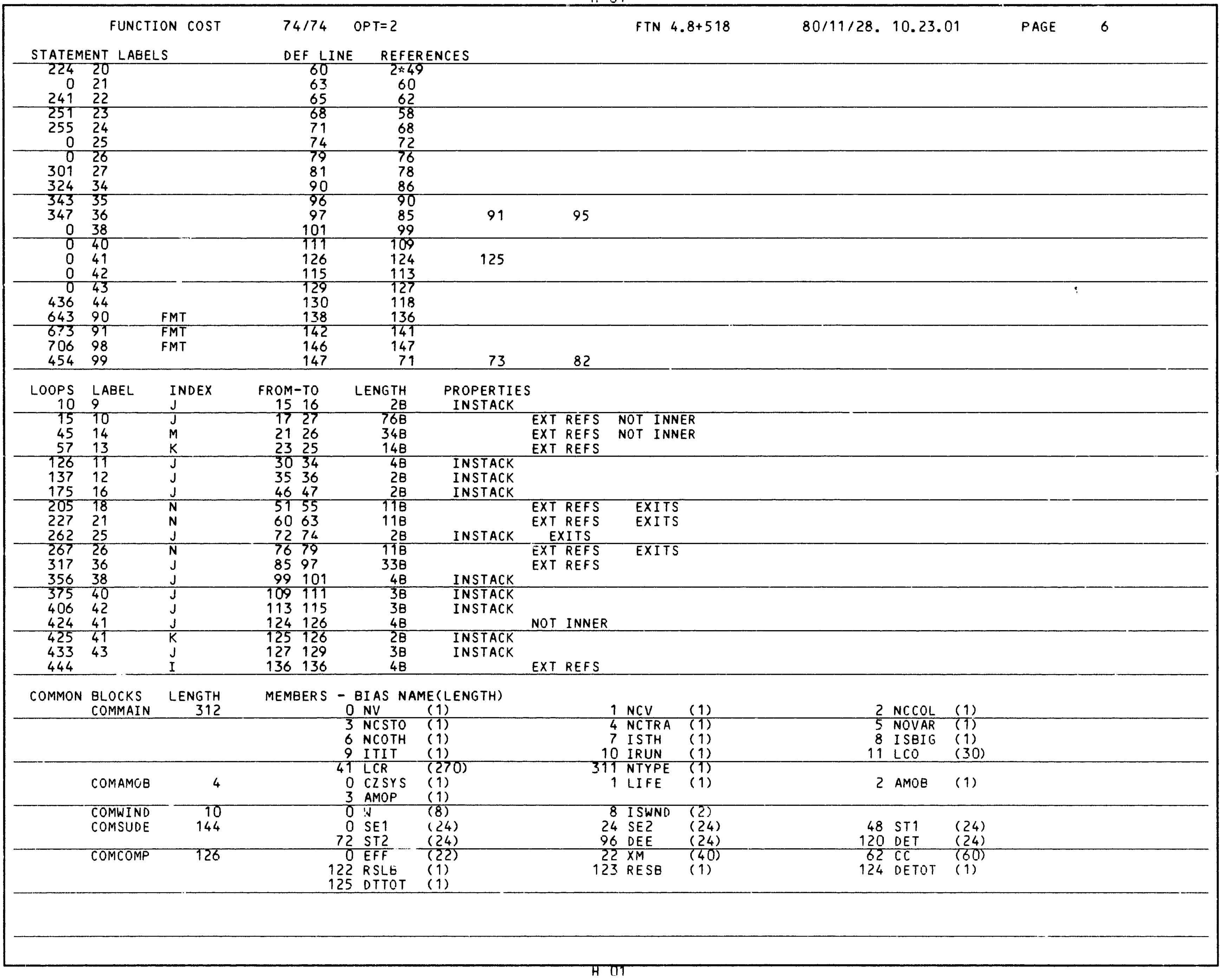




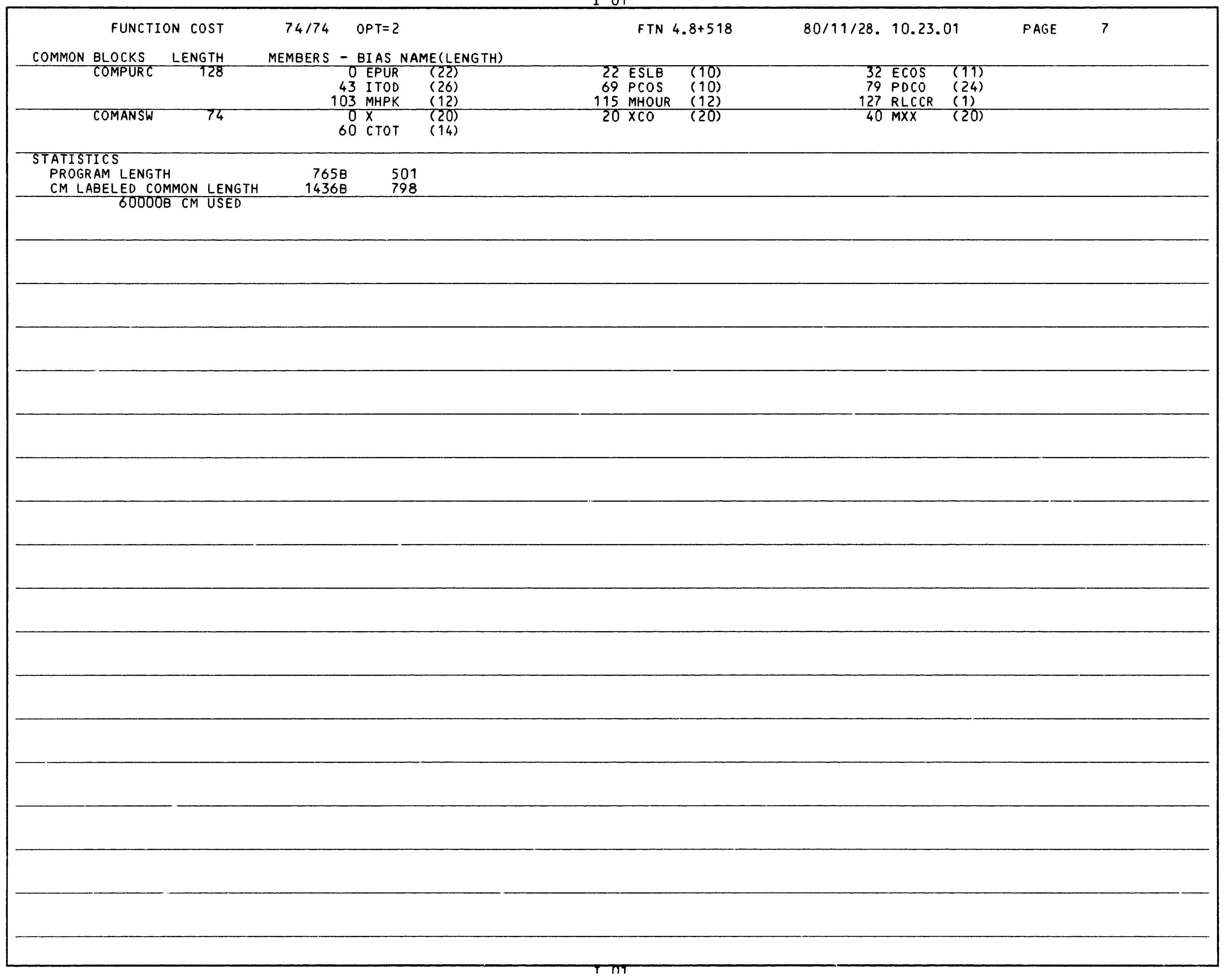




\begin{tabular}{|c|c|}
\hline 1 & 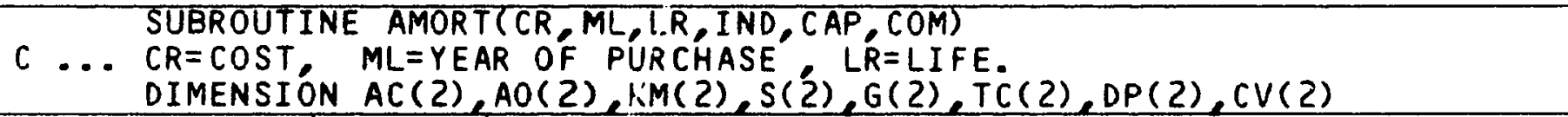 \\
\hline 5 & $\begin{array}{l}\text { COMMON ICOMMAIN/ NV, NCV, NCCOL, NCSTO, NCTRA, NOVAR, NCOTH, I STH, I SBIG, } \\
1 \text { ITIT, IRUN,LCO(30), LCR }, 30) \text {, NTYPE } \\
\text { COMMON /COMAMOB/ CZSYS, LIFE, AMOB, AMOP }\end{array}$ \\
\hline & 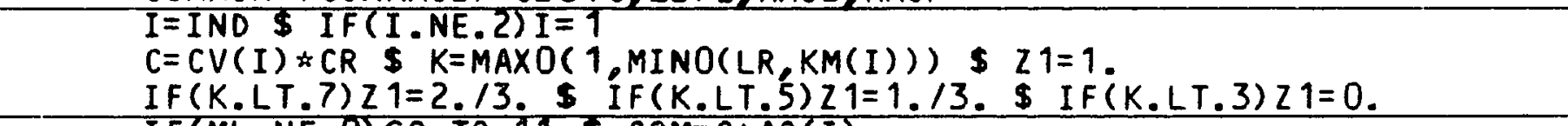 \\
\hline 10 & $\begin{array}{l}\text { IF (ML.NE.O) GO TO } 11 \text { S COM=C*AO(I) } \\
\text { CAP=C*(AC(I) }-Z 1 * T C(I)-D P(I) * S(I) *(K-Z M F(R, 0 ., K)) / K /(K+1)) \\
\text { RETURN }\end{array}$ \\
\hline 15 & $\begin{array}{l}C=C * S(I) *(G(I) * * M L) \quad \$ C O M=0 . \\
C A P=C *(1 .-Z 1 * T C(I)-D P(I) *(K-Z M F(R, 0 ., K)) / K /(K+1 .)) \\
\text { RETURN }\end{array}$ \\
\hline & $\begin{array}{l}\text { ENTRY AMORTI } \\
\text { DO } 20 \text { J } 1,30 \$ \text { DECODE }(10,1, L C R(1, J)) \text { J1 \$ IF (J1.EQ. 2HYR GO TO } 21 \\
20 \text { CONTINUE } \$ \text { GO TO } 99\end{array}$ \\
\hline 20 & 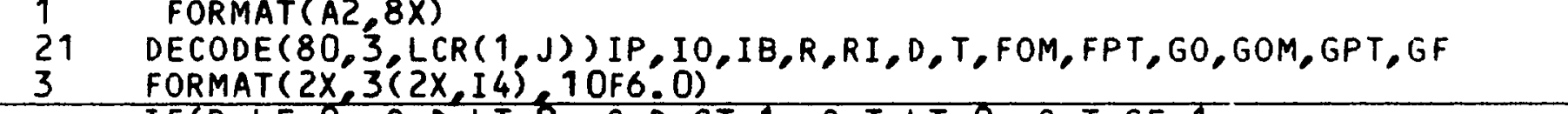 \\
\hline & 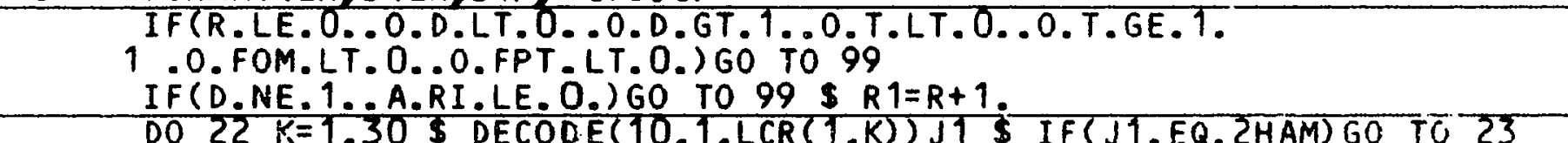 \\
\hline 23 & $\begin{array}{l}22 \text { DO } 22 K=1,30 \$ \text { DECOOE }(10,1, L C R(1, K)) J 1 \$ \text { IF (J1,EQ. } 2 H A M) G 0 \text { TO } 23 \\
23 \text { CONTINUE } \$ G 0 \text { TO } 99 \\
\text { DECOE }(80,6, L C R(1, K)) J P, N, L,(K M(J), S(J), T C(J), G(J), J=1,2)\end{array}$ \\
\hline 30 & 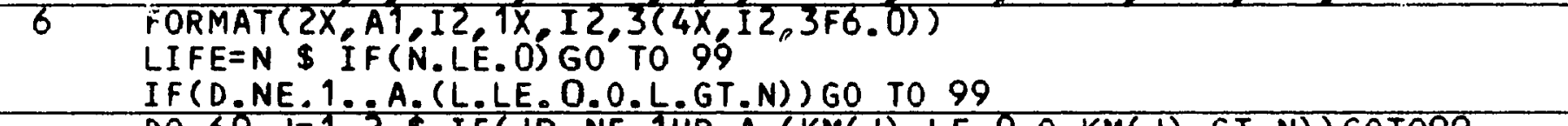 \\
\hline & 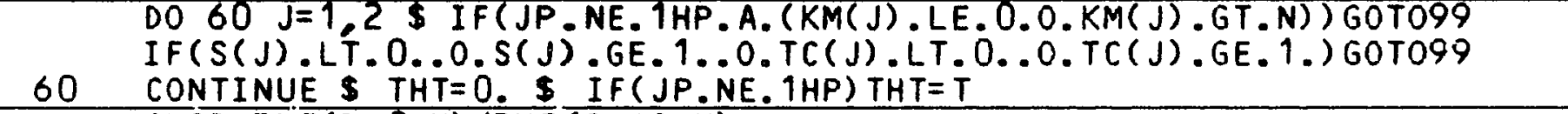 \\
\hline 35 & $\begin{array}{l}A M O B=Z M F(R, O, N) / Z M F(R, G O, N) \\
Z 1=D+(1 .-T) \approx F P T * Z M F(R, G P T, N) \\
I F(D, N E .1 .) Z 1=Z 1+(1,-D) *((1,-T) * Z M F(R, O ., L) / Z M F(R I, O ., L)-\end{array}$ \\
\hline & 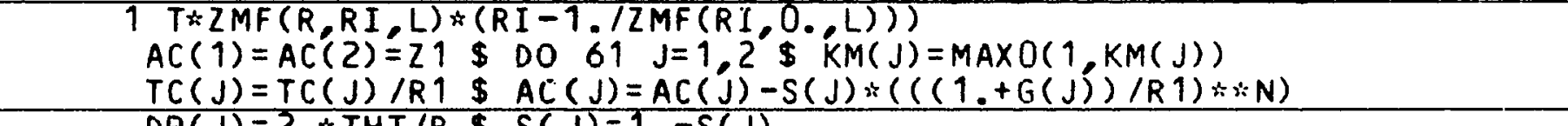 \\
\hline 40 & $\begin{array}{l}D P(J)=2 .{ }^{*} T H T / R \$ S(J)=1 .-S(J) \\
C O N T I N U E \\
A O(1)=A O(2)=(1 .-T H T) \div F O M=Z M F(R, G O M, N)\end{array}$ \\
\hline 45 & 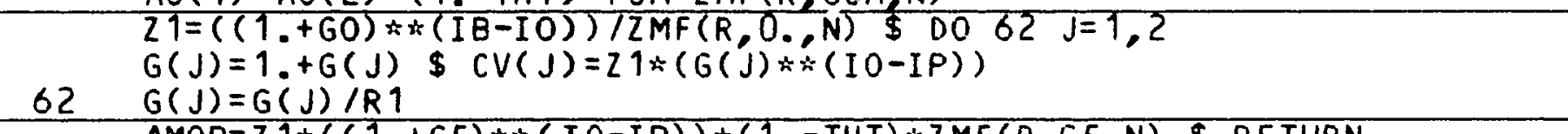 \\
\hline & $\begin{array}{l}\text { AMOP }=Z 1 *((1,+G F) *(I O-I P)) *(1,-T H T) * Z M F(R, G F, N) \$ R E T U R N \\
\text { FORMAT } * \text { ERROR IN AM OR YR CARD *) } \\
\text { PRINT98 \$CALL EXIT \$END }\end{array}$ \\
\hline
\end{tabular}




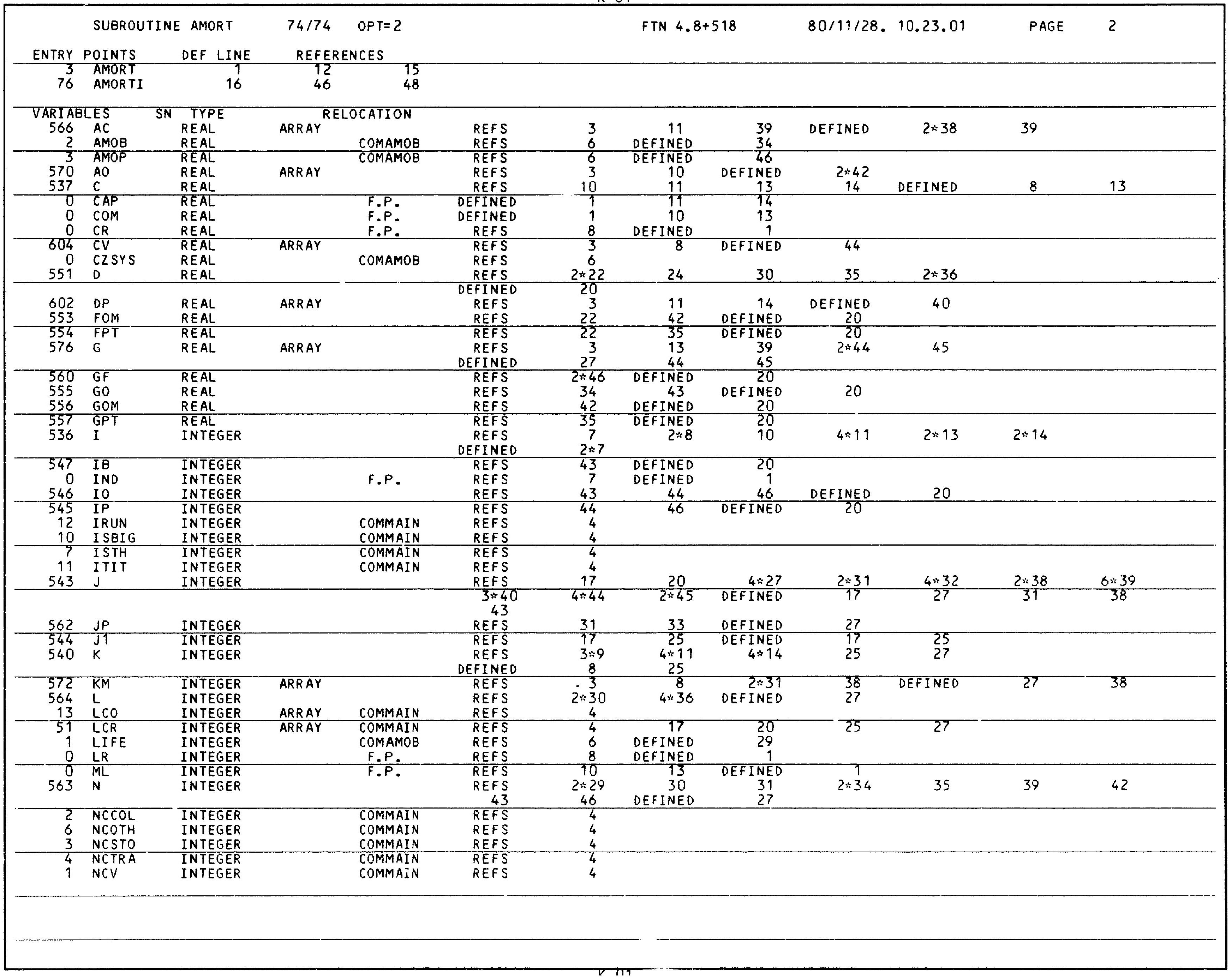




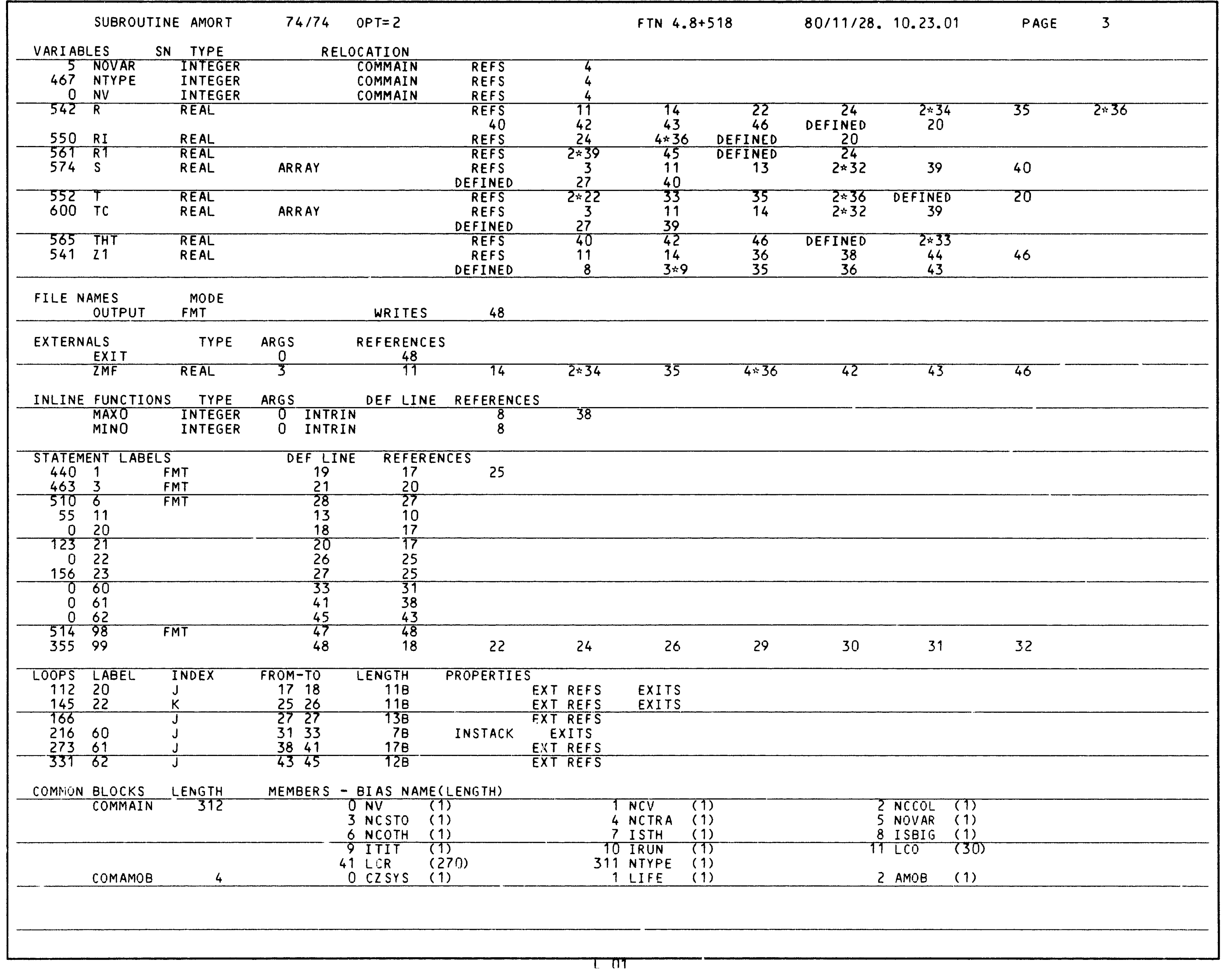


CM LABELED COMMON LENGTH 3 AMOP (1)

$60000 \mathrm{CN}$ H

$6068 \quad 390$




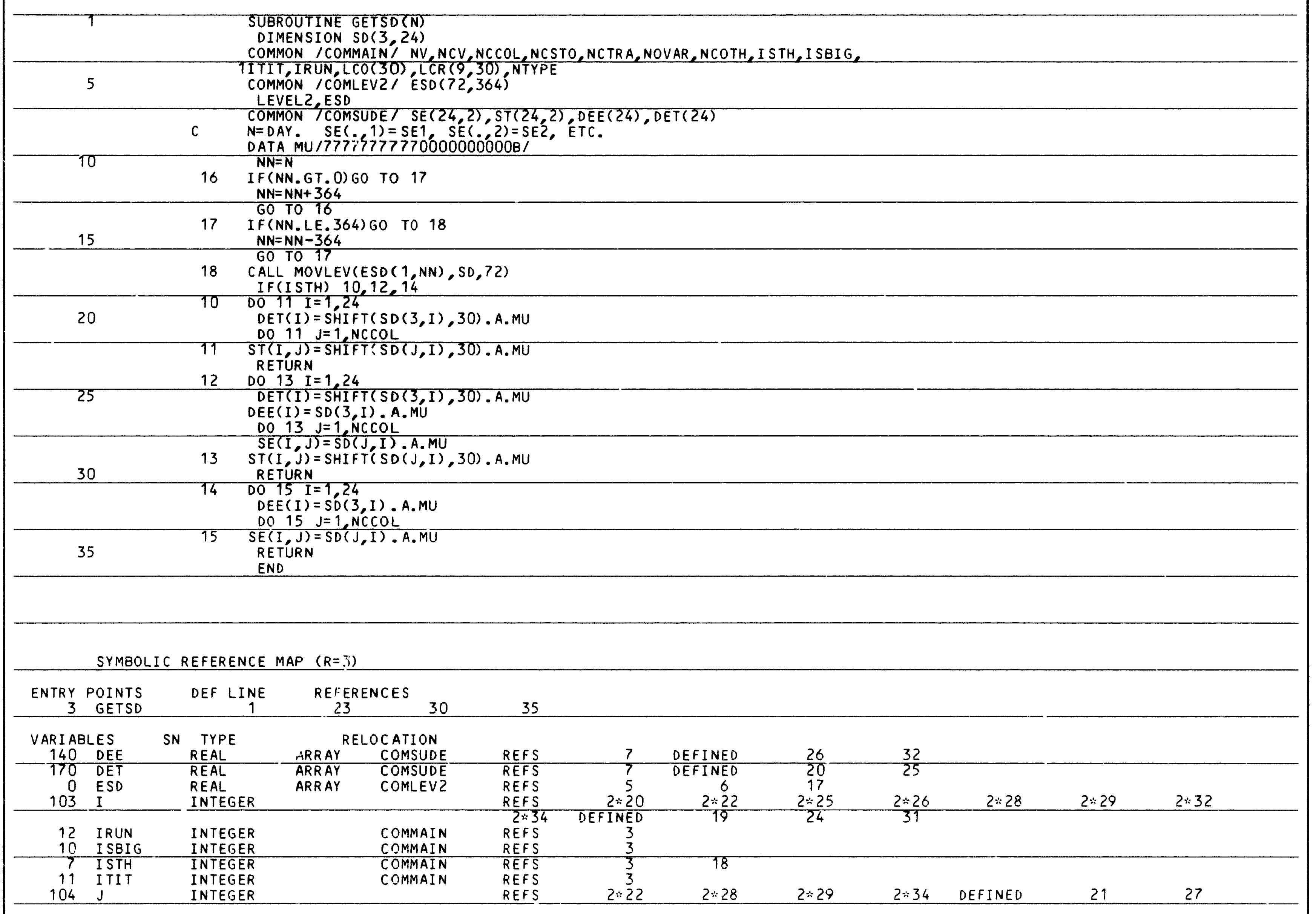




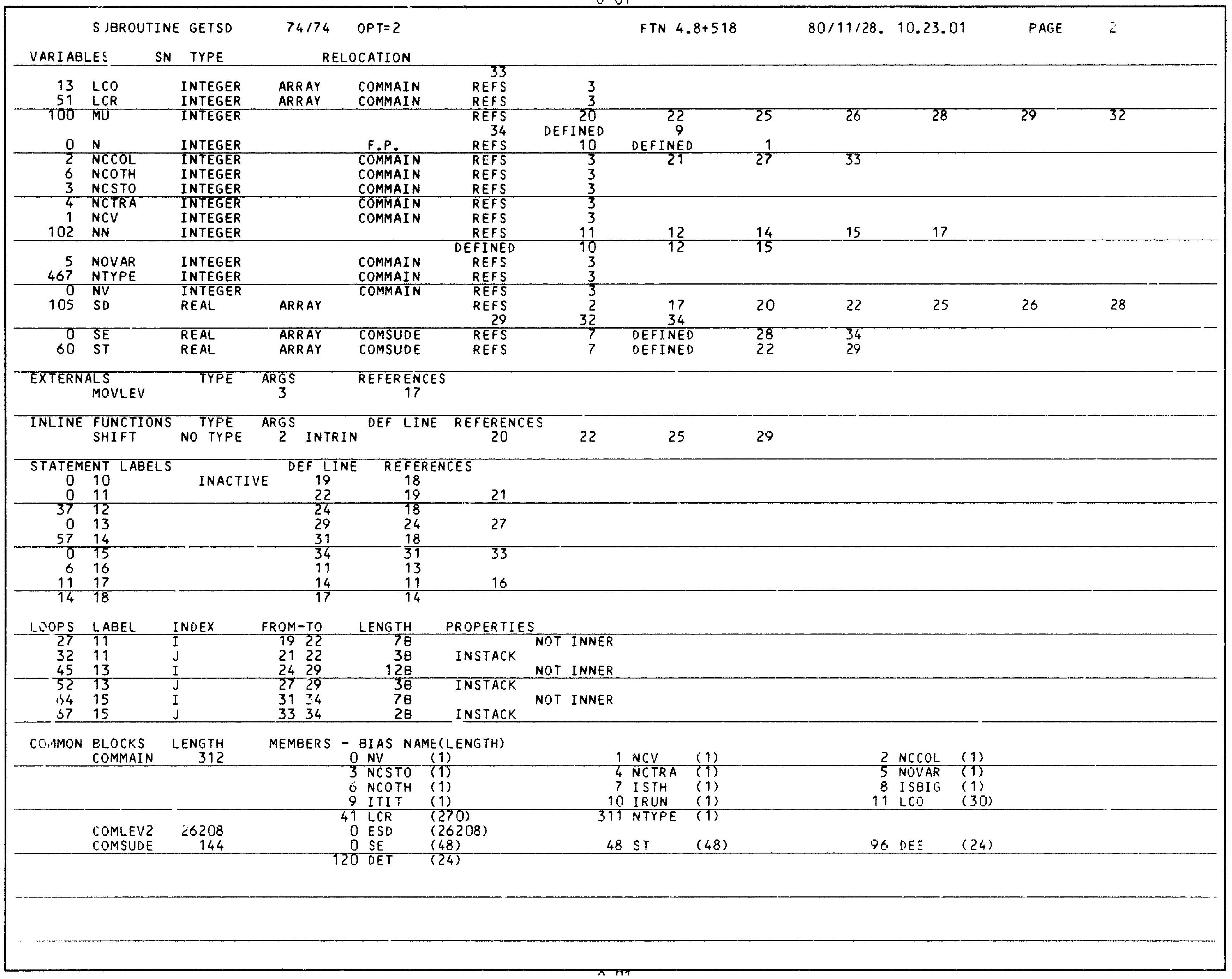




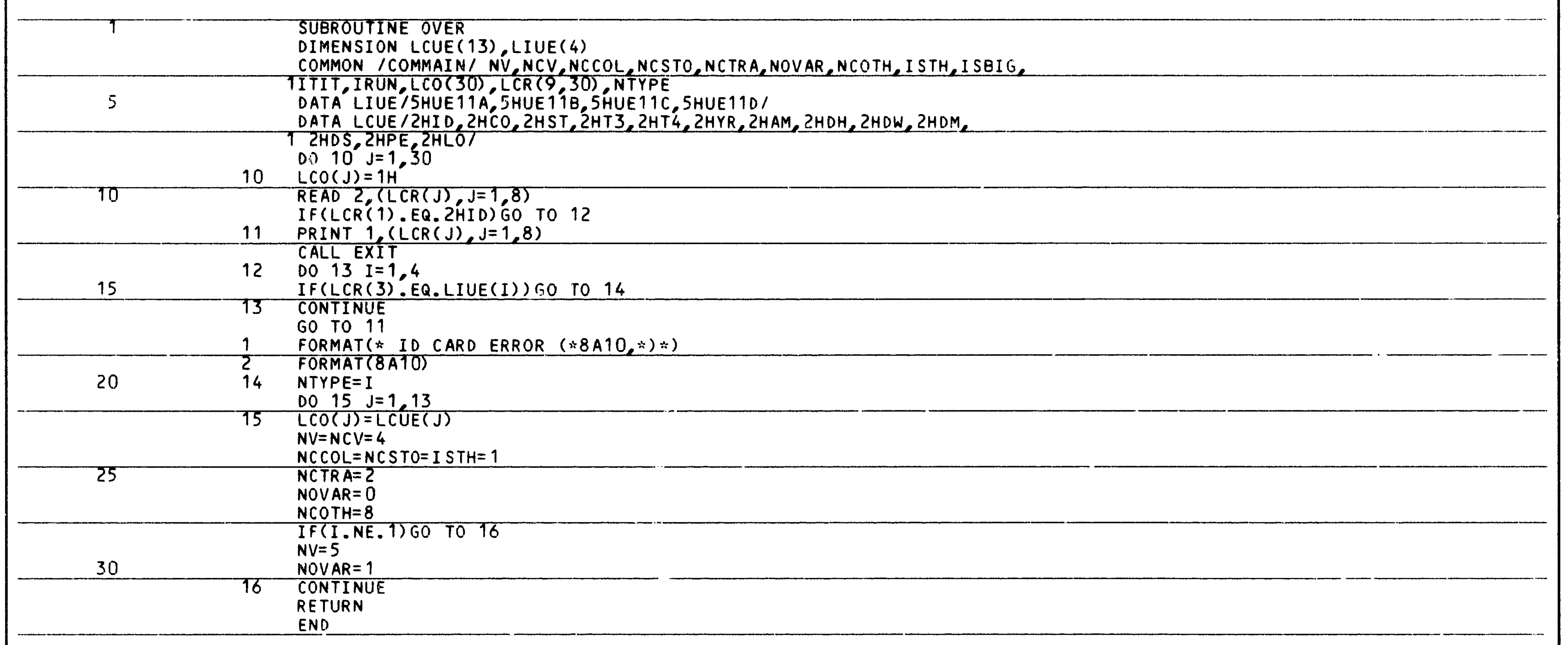

SYMBOLIC REFERENCE MAP $(R=3)$

\begin{tabular}{|c|c|c|c|c|c|c|c|c|c|c|c|c|c|}
\hline $\begin{array}{r}\text { ENTRY } \\
1\end{array}$ & $\begin{array}{l}\text { POINTS } \\
\text { OVER }\end{array}$ & & DEF LINE & $\begin{array}{r}R E F \\
3\end{array}$ & NCES & & & & & & & & \\
\hline \multirow{3}{*}{$\begin{array}{c}\text { VAR I AB } \\
65 \\
12 \\
10 \\
7 \\
71 \\
64\end{array}$} & \multirow{3}{*}{$\begin{array}{l}\text { BLES } \\
\text { I } \\
\text { IRUN } \\
\text { I SBIG } \\
\text { I STH } \\
\text { ITIT } \\
\text { J }\end{array}$} & \multirow{3}{*}{ SN } & \multirow{3}{*}{$\begin{array}{c}\text { TYPE } \\
\text { INTEGER } \\
\text { INTEGER } \\
\text { INTEGER } \\
\text { INTEGER } \\
\text { INTEGER } \\
\text { INTEGER }\end{array}$} & \multicolumn{2}{|c|}{ RELOCATION } & REFS & 15 & 20 & 28 & DEFINED & 14 & & \\
\hline & & & & & $\begin{array}{l}\text { COMMAIN } \\
\text { COMMAIN } \\
\text { COMMAIN }\end{array}$ & $\begin{array}{l}\text { REFS } \\
\text { REFS } \\
\text { REFS }\end{array}$ & $\begin{array}{l}3 \\
3 \\
3\end{array}$ & DEFINED & 24 & & & & \\
\hline & & & & & COMMAIN & $\begin{array}{l}\text { REFS } \\
\text { REFS } \\
12\end{array}$ & $\begin{array}{r}3 \\
9 \\
29\end{array}$ & 10 & 12 & $2 \div 22$ & DEFINEO & 8 & 10 \\
\hline $\begin{array}{l}13 \\
51 \\
66\end{array}$ & $\begin{array}{l}\text { LCO } \\
\text { LCR } \\
\text { LCUE }\end{array}$ & & $\begin{array}{l}\text { INTEGER } \\
\text { INTEGER } \\
\text { INTEGER }\end{array}$ & $\begin{array}{l}\text { ARRAY } \\
\text { ARR AY } \\
\text { ARR AY }\end{array}$ & $\begin{array}{l}\text { COMMAIN } \\
\text { COMMAIN }\end{array}$ & $\begin{array}{l}\text { REFS } \\
\text { REFS } \\
\text { REFS }\end{array}$ & $\frac{3}{3}$ & $\begin{array}{c}\text { DEFINED } \\
11 \\
22\end{array}$ & $\begin{array}{r}9 \\
12 \\
\text { DIFINEO }\end{array}$ & $\begin{array}{r}22 \\
15 \\
6\end{array}$ & DEFINEO & 10 & \\
\hline $\begin{array}{r}103 \\
2 \\
6\end{array}$ & $\begin{array}{l}\text { LIUE } \\
\text { NCCOL } \\
\text { NCOTH }\end{array}$ & & $\begin{array}{l}\text { INTEGER } \\
\text { INTEGER } \\
\text { INTEGER }\end{array}$ & ARRAY & $\begin{array}{l}\text { COMMAIN } \\
\text { COMMAIN }\end{array}$ & $\begin{array}{l}\text { REFS } \\
\text { REFS } \\
\text { REFS }\end{array}$ & $\begin{array}{l}\frac{c}{2} \\
\frac{3}{3}\end{array}$ & $\begin{array}{c}15 \\
\text { DEFINED } \\
\text { DEFINED }\end{array}$ & $\begin{array}{c}D E F \overline{N E S} \\
24 \\
27\end{array}$ & $\frac{0}{5}$ & & & \\
\hline
\end{tabular}




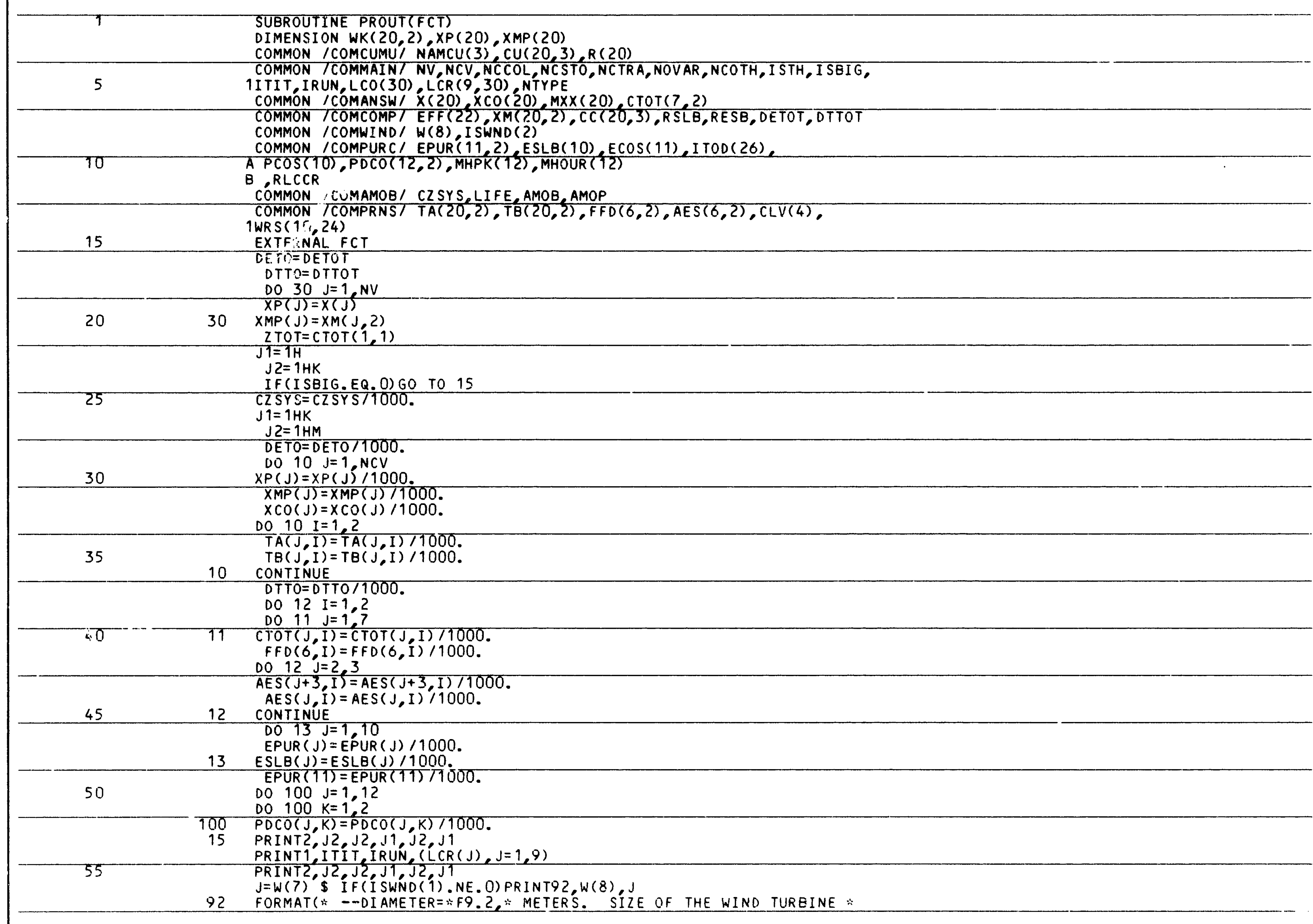




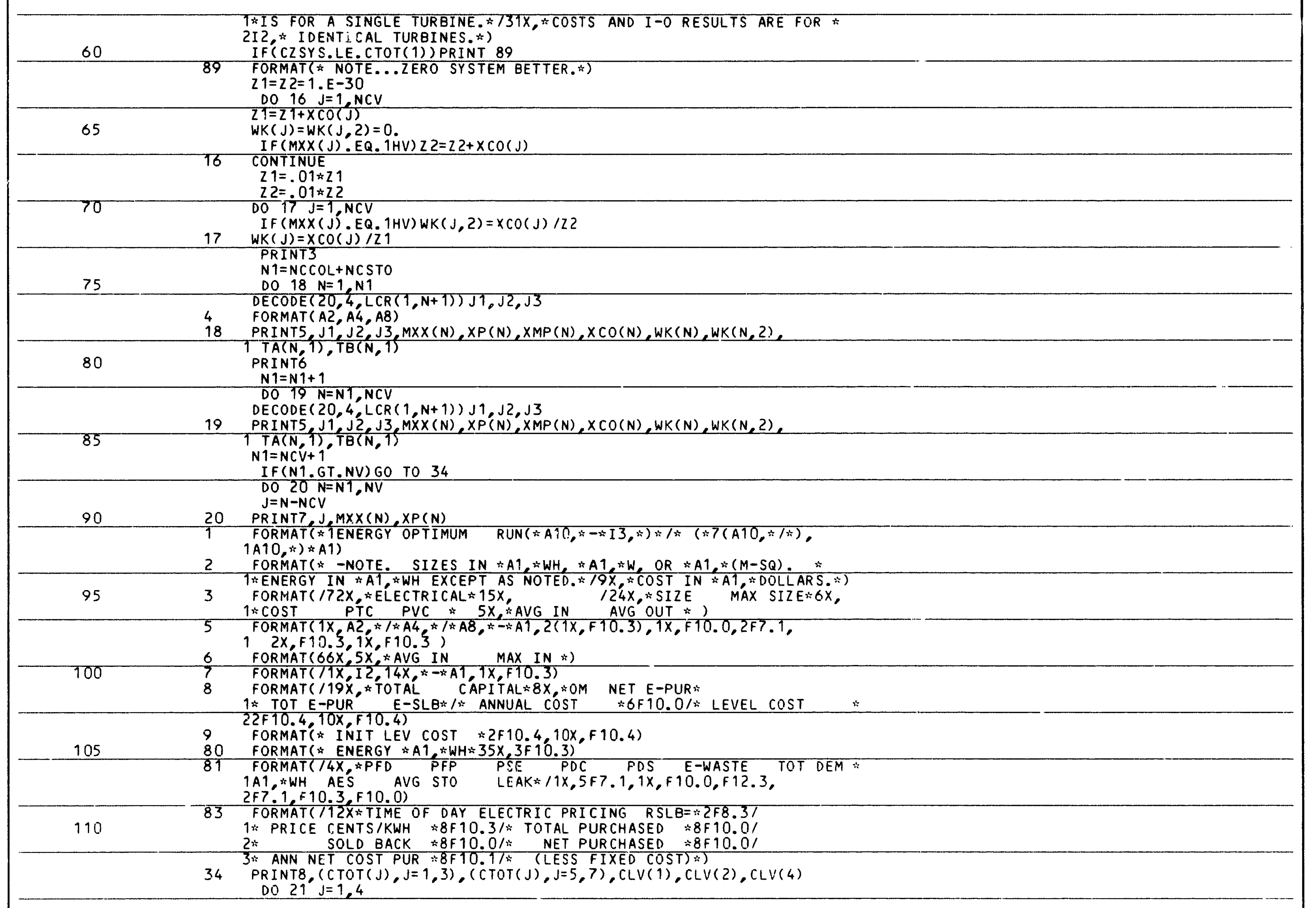


115 21 CLV(J)= ILVTJ)! . .

PRINT9, $\operatorname{LV}(1, \operatorname{CLV}(2), \operatorname{CLV}(4)$ JM= $1 \mathrm{HM}$

IF(IS!IG.NE.O) JM=1HG

120

DO $22 \mathrm{~J}=4,7$

$22 \quad \operatorname{CTOT}(J, 2)=$ CTOT $(J, 2) / 1000$.

DETO $=$ ETO/1000.

DTTO=)TTO $/ 1000$.

PRINT81), JM, (CTOT $(J, 2), J=5,7)$

$\begin{aligned} 21 & =0 \\ Z 2 & =1\end{aligned}$

IF (ISE IG.NE, O) ZZ=1000.

$0014,=9,10,2$

$I=J$

$130 \quad \frac{I F(E C O S: 1+1) \cdot G T \cdot E}{2 T=E P U R(I .0 S(J)) I=J+1}$

$Z 1=E P U R(1,2)+Z 2 * 21$
$Z 1=.00166667 * 21$

WK $(1)=W K(2)=0$. \$ DO $35 \mathrm{~J}=1, \mathrm{NCSTO}$

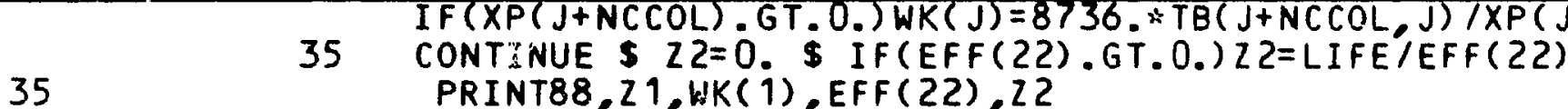

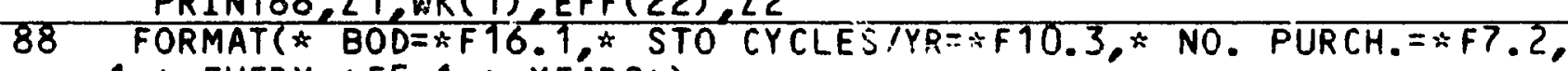

1 * EVERY *F5.1, * YEARS*)

C CALCULATE THE LIFE CYCLE COST RATIO OF SOLAR OVER NONSOLAR

RLCCR $=$ CTOT $(1,1) / R L C C R$

140 PRINT 220,RLCCR

220 FORMAT (* LIFE CYCLE COST RATIO=: G10.4)

PRINT81, JM, (FFD (J),J=1,6), DETO, $(\operatorname{AES}(J, 1), J=1,3)$ IF (ISTH. LE, O) PRINT84, ECOŚS(11)

IF (ISTH.LT.O) GO TO 29

14584 FORMAT $\left(/ *\right.$ THERMAL PURCHASED AT *F $8.3, *$ CENTS/KWH. $\left.{ }^{\circ}\right)$

DO $23 \mathrm{~J}=1,10$

WK $(J, 2)=.01 * A M O P * E \operatorname{COS}(1) *(\operatorname{EPUR}(1)-R S L B * E S L B(J))$

23 WK $(J)=E P U R(J)-E S L B(J)$

PRINT83,RSLB,RESB, $(\operatorname{ECOS}(J), J=1,8),(\operatorname{EPUR}(J), J=1,8)$

$150 \quad 1(E S L B(j), J=1,8)(($ WK $(I, J), j=1,8), j=1,2)$

SUM NET COST OF PURCHASED ENERGY

SNEC $=0$.

DO $200^{\circ} I=1,10$

$155200 \quad$ SNEC $=$ SNEC+WK(I, 2$)$

C SUM PEFK DEMAND COST

$S P D C=0$.

$D O 210 \quad I=1,12$

$P O C O(I, 1)=P O C O(I, 1) * A M O P$

$210 \quad S P D C=S P D C+P D C O(I, 1)$

GET FIXED COST
$F C=C T O T(5,1)-($ SNEC+ SPDC $)$

PRINT PEAK DEMAND PRICE ENERGY, AND COST

PRINT $90,(P \operatorname{COS}(I), I=1,8),(I, I=1,12),($ MHPK(I), I=1, 12),

165 A (PDCO $(I, 2), I=1,12),(P D C O(I, 1), I=1,12)$

FORMAT ( $/ 92 X^{\prime}$ *PÉAK DEMAND FRÍCING* / PRICE \$/PEAK-KW $\div 8 F 10.2 .11$

A $4 X, *-M O N T H-8 X, 12 I 9,1 *$ HOUR OF YEAR:7X, 12I9,'

$B$ * PEAK PURCHASED $5 X, 12 F 9.1$, / PEAK PURCHASEO COST:12F9.1)

C PRINT THE SUMS OF ENERGY COST, PEAK DEMAND COST AND FIXED COST

$170 \quad 91$ FORMAT ( FÍXED PUIJCHASED COST $=*, F 12.1$

$A$ i, PURCHASED ENERGY COST $=$, F $12.1,1$ 


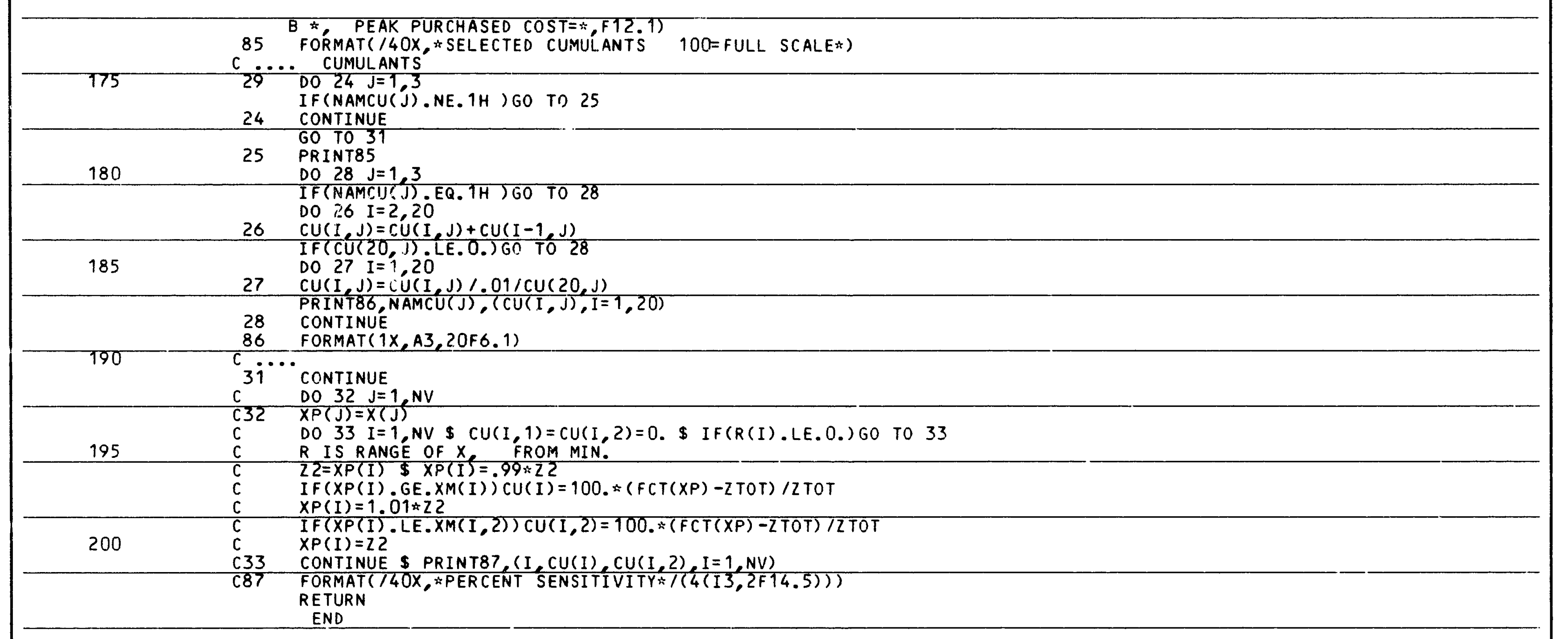

\section{SYMBOLIC REFERENCE MAP $(R=3)$}

\begin{tabular}{|c|c|c|c|c|c|c|c|c|c|c|c|c|c|}
\hline $\begin{array}{r}\text { ENTRY } \\
3 \\
\end{array}$ & $\begin{array}{l}\text { POINTS } \\
\text { PROUT }\end{array}$ & & $\begin{array}{c}\text { DEF LINE } \\
1 \\
\end{array}$ & $\begin{array}{r}\text { REF } \\
20 \\
\end{array}$ & NCES & & & & & & & & \\
\hline $\begin{array}{c}\text { VAR I AE } \\
134\end{array}$ & $\begin{array}{l}\text { LES } \\
\text { AES }\end{array}$ & SN & $\begin{array}{l}\text { TYPE } \\
\text { REAL }\end{array}$ & ARRAY' & $\begin{array}{l}\text { OCATION } \\
\text { COMPRNS }\end{array}$ & REFS & 13 & 43 & 44 & 142 & DEFINED & 43 & 44 \\
\hline $\begin{array}{r}2 \\
3 \\
76\end{array}$ & $\begin{array}{l}\text { AMOB } \\
\text { AMOP } \\
\text { CC }\end{array}$ & & $\begin{array}{l}R E A L \\
R E A L \\
R E A L\end{array}$ & ARRAY & $\begin{array}{l}\text { COMAMOB } \\
\text { COMAMOB } \\
\text { COMCOMP }\end{array}$ & $\begin{array}{l}\text { REFS } \\
\text { REFS } \\
\text { REFS }\end{array}$ & $\begin{array}{l}12 \\
12 \\
7\end{array}$ & $\begin{array}{l}115 \\
147\end{array}$ & 158 & & & & \\
\hline $\begin{array}{r}150 \\
74\end{array}$ & $\begin{array}{l}\text { CLV } \\
\text { CTOT }\end{array}$ & & $\begin{array}{l}\text { REAL } \\
\text { REAL }\end{array}$ & $\begin{array}{l}\text { ARRAY } \\
\text { ARRAY }\end{array}$ & $\begin{array}{l}\text { COMPRS } \\
\text { COMANSW }\end{array}$ & $\begin{array}{r}\text { REFS } \\
\text { REFS } \\
139\end{array}$ & $\begin{array}{r}13 \\
6 \\
161\end{array}$ & $\begin{array}{c}3: 113 \\
21 \\
\text { DEFINED }\end{array}$ & $\begin{array}{r}115 \\
40 \\
40\end{array}$ & $\begin{array}{c}3: 116 \\
60 \\
120\end{array}$ & $\begin{array}{r}\text { DEFINED } \\
2: 113\end{array}$ & $\begin{array}{l}115 \\
120\end{array}$ & 123 \\
\hline 3 & $\mathrm{CU}$ & & REAL & $\overline{A R R A Y}$ & COMCUMU & $\begin{array}{c}\text { REFS } \\
\text { DEFINED }\end{array}$ & $\begin{array}{r}3 \\
183\end{array}$ & $\begin{array}{c}2 \times 183 \\
186\end{array}$ & 184 & $2 \div 186$ & 187 & & \\
\hline $\begin{array}{r}1272 \\
174 \\
1273\end{array}$ & $\begin{array}{l}\text { DETO } \\
\text { DETOT } \\
\text { DTTO }\end{array}$ & & $\begin{array}{l}\text { REAL } \\
\text { REAL } \\
\text { REAL }\end{array}$ & & COMCOMP & $\begin{array}{l}\text { REFS } \\
\text { REFS } \\
\text { REFS }\end{array}$ & $\begin{array}{l}28 \\
7 \\
37\end{array}$ & $\begin{array}{r}121 \\
16 \\
122\end{array}$ & $\begin{array}{c}142 \\
\text { DEFINED }\end{array}$ & DEFINED & 16 & 28 & 121 \\
\hline
\end{tabular}




\begin{tabular}{|c|c|c|c|c|c|c|c|c|c|c|c|c|c|}
\hline \multirow{3}{*}{$\begin{array}{c}\text { VARIABL } \\
175 \\
40 \\
0 \\
\end{array}$} & \multicolumn{2}{|c|}{ SUBROUTINE } & \multirow{2}{*}{$\begin{array}{l}\text { E PROUT } \\
\text { TYPE }\end{array}$} & \multirow[t]{2}{*}{$74 / 74$} & $O P T=2$ & & \multicolumn{3}{|c|}{ FTN $4.8+518$} & \multirow[t]{2}{*}{$80 / 11 / 28$} & \multirow[t]{2}{*}{10.23 .01} & \multirow[t]{2}{*}{ PAGE } & \multirow[t]{2}{*}{5} \\
\hline & & SN & & & OCATION & & & & & & & & \\
\hline & $\begin{array}{l}\text { DTTOT } \\
\text { ECOS } \\
\text { EFF }\end{array}$ & & $\begin{array}{l}\text { REAL } \\
\text { REAL } \\
\text { REAL }\end{array}$ & $\begin{array}{l}\text { ARRAY } \\
\text { ARRAY }\end{array}$ & $\begin{array}{l}\text { COMCOMP } \\
\text { COMPURC } \\
\text { COMCOMP }\end{array}$ & $\begin{array}{l}\text { REFS } \\
\text { REFS } \\
\text { REFS }\end{array}$ & $\begin{array}{l}7 \\
9 \\
7\end{array}$ & $\begin{array}{c}17 \\
2 \approx 129 \\
2 \approx 134\end{array}$ & $\begin{array}{l}143 \\
135\end{array}$ & 147 & 149 & & \\
\hline & EPUR & & REAL & ARRAY & COMPURC & $\begin{array}{c}\text { REFS } \\
\text { DEFINED }\end{array}$ & $\begin{array}{r}9 \\
47\end{array}$ & $\begin{array}{l}47 \\
49\end{array}$ & 49 & $2 \div 130$ & 147 & 148 & 149 \\
\hline 26 & ESLB & & REAL & ARRAY & COMPURC & $\begin{array}{l}\text { REFS } \\
\end{array}$ & 9 & 48 & 130 & 147 & 148 & 149 & \\
\hline $\begin{array}{r}1312 \\
120\end{array}$ & $\begin{array}{l}\text { FC } \\
\text { FFD }\end{array}$ & & $\begin{array}{l}\text { REAL } \\
\text { REAL }\end{array}$ & ARRAY & COMPRNS & $\begin{array}{c}\text { DEFINED } \\
\text { REFS } \\
\text { REFS }\end{array}$ & $\begin{array}{r}48 \\
169 \\
13\end{array}$ & DEFINED & $\begin{array}{l}161 \\
142\end{array}$ & DEFINED & 41 & & \\
\hline 1300 & $I$ & & INTEGER & ANRAR & conir nove & $\begin{array}{c}\text { REFS } \\
149 \\
\text { DEFINED }\end{array}$ & $\begin{array}{l}2+34 \\
154 \\
33 \\
\end{array}$ & $\begin{array}{c}4 \div 35 \\
2 \div 158 \\
38 \\
\end{array}$ & $\begin{array}{l}14 c \\
2 \pi 40 \\
159 \\
128 \\
\end{array}$ & $\begin{array}{c}2 * 41 \\
5 * 163 \\
129\end{array}$ & $\begin{array}{c}2 \times 43 \\
2 \times 183 \\
149 \\
\end{array}$ & $\begin{array}{c}2 \times 44 \\
2 \times 186 \\
153\end{array}$ & $\begin{array}{c}3 \times 130 \\
187 \\
157\end{array}$ \\
\hline $\begin{array}{l}12 \\
10 \\
\end{array}$ & $\begin{array}{l}\text { IRUN } \\
\text { I SBIG }\end{array}$ & & $\begin{array}{l}\text { INTEGER } \\
\text { INTEGER }\end{array}$ & & $\begin{array}{l}\text { COMMAIN } \\
\text { COMMAIN }\end{array}$ & $\begin{array}{l}5 * 163 \\
\text { REFS } \\
\text { REFS }\end{array}$ & $\begin{array}{r}182 \\
4 \\
4\end{array}$ & $\begin{array}{r}185 \\
54 \\
24 \\
\end{array}$ & 187 & 126 & & & \\
\hline $\begin{array}{r}7 \\
10 \\
11\end{array}$ & $\begin{array}{l}\text { I STH } \\
\text { I SWND } \\
\text { I ITT }\end{array}$ & & $\begin{array}{l}\text { INTEGER } \\
\text { INTEGER } \\
\text { INTEGER }\end{array}$ & ARRAY & $\begin{array}{l}\text { COMMAIN } \\
\text { COMWIND } \\
\text { COMMAIN }\end{array}$ & $\begin{array}{l}\text { REFS } \\
\text { REFS } \\
\text { REFS }\end{array}$ & $\begin{array}{l}4 \\
8 \\
4\end{array}$ & $\begin{array}{r}143 \\
56 \\
54\end{array}$ & 144 & & & & \\
\hline $\begin{array}{r}53 \\
1274\end{array}$ & $\begin{array}{l}\text { ITOD } \\
\text { J }\end{array}$ & & $\begin{array}{l}\text { INTEGER } \\
\text { INTEGER }\end{array}$ & ARRAY & COMPURC & $\begin{array}{l}\text { REFS } \\
\text { REFS } \\
2 * 40\end{array}$ & $\begin{array}{c}9 \\
2 * 19 \\
2 * 43\end{array}$ & $\begin{array}{l}2 * 20 \\
2 * 44\end{array}$ & $\begin{array}{l}2 \div 30 \\
2 \div 47\end{array}$ & $\begin{array}{l}2 \div 31 \\
2 \div 48\end{array}$ & $\begin{array}{l}2 \times 32 \\
2 \times 52\end{array}$ & $\begin{array}{c}2 \times 34 \\
54\end{array}$ & $\begin{array}{c}2 \times 35 \\
56\end{array}$ \\
\hline & & & & & & $\begin{array}{c}64 \\
2 * 120 \\
4 * 149 \\
\end{array}$ & $\begin{array}{l}2 * 65 \\
123 \\
176 \\
\end{array}$ & $\begin{array}{l}2266 \\
128 \\
181 \\
\end{array}$ & $\begin{array}{r}3 \times 71 \\
3 \times 129 \\
3 \times 183 \\
\end{array}$ & $\begin{array}{r}2 * 72 \\
5 * 133 \\
184 \\
\end{array}$ & $\begin{array}{c}90 \\
2: 142 \\
3 \div 186 \\
\end{array}$ & $\begin{array}{l}2 * 113 \\
4: 147 \\
2: 187 \\
\end{array}$ & $\begin{array}{l}2 * 115 \\
3 * 148\end{array}$ \\
\hline & & & & & & $\begin{array}{c}\text { DEFINED } \\
56 \\
127\end{array}$ & $\begin{array}{r}18 \\
63 \\
132\end{array}$ & $\begin{array}{c}29 \\
70 \\
2 \times 142\end{array}$ & $\begin{array}{r}39 \\
89 \\
146\end{array}$ & $\begin{array}{c}42 \\
2 * 113 \\
4 * 149\end{array}$ & $\begin{array}{l}16 \\
114 \\
175\end{array}$ & $\begin{array}{r}50 \\
119 \\
180\end{array}$ & $\begin{array}{r}54 \\
123\end{array}$ \\
\hline $\begin{array}{l}1307 \\
1276\end{array}$ & $\begin{array}{l}J M \\
J 1\end{array}$ & & $\begin{array}{l}\text { INTEGER } \\
\text { INTEGER }\end{array}$ & & & $\begin{array}{l}\text { REFS } \\
\text { REFS } \\
76\end{array}$ & $\begin{array}{c}123 \\
2 * 53 \\
83\end{array}$ & $\begin{array}{l}142 \\
2 * 55\end{array}$ & $\begin{array}{c}\text { DEFINED } \\
78\end{array}$ & $\begin{array}{r}117 \\
84\end{array}$ & $\begin{array}{c}118 \\
\text { DEFINED }\end{array}$ & 22 & 26 \\
\hline 1277 & $\sqrt{2}$ & & INTEGER & & & $\begin{array}{l}\text { REFS } \\
76\end{array}$ & $\begin{array}{c}3 * 53 \\
83\end{array}$ & $3 \div 55$ & 78 & 84 & DEFINED & 23 & 27 \\
\hline 1306 & $\mathrm{J3}$ & & INTEGER & & & REFS & 78 & 84 & DEFINED & 76 & 83 & & \\
\hline 1301 & $\mathrm{~K}$ & & INTEGER & & & REFS & $2 \div 52$ & DEFINED & 51 & & & & \\
\hline 13 & LCO & & INTEGER & ARRAY & COMMAIN & REFS & 4 & & & & & & \\
\hline 51 & LCR & & INTEGER & ARRAY & COMMAIN & REFS & 4 & 54 & 76 & 83 & & & \\
\hline $163^{1}$ & $\begin{array}{l}\text { LIFE } \\
\text { MHOUR }\end{array}$ & & $\begin{array}{l}\text { INTEGER } \\
\text { INTEGER }\end{array}$ & ARRAY & $\begin{array}{l}\text { COMAMOB } \\
\text { COMPURC }\end{array}$ & $\begin{array}{l}\text { REFS } \\
\text { REFS }\end{array}$ & $\begin{array}{r}12 \\
9\end{array}$ & 134 & & & & & \\
\hline 147 & MHPK & & INTEGER & ARRAY & COMPURC & REFS & 9 & 163 & & & & & \\
\hline $\begin{array}{r}50 \\
1305\end{array}$ & $\begin{array}{l}M X X \\
N\end{array}$ & & $\begin{array}{l}\text { INTEGER } \\
\text { INTEGER }\end{array}$ & ARRAY & COMANSW & $\begin{array}{c}\text { REFS } \\
\text { REFS } \\
\text { DEFINED }\end{array}$ & $\begin{array}{l}6 \\
76 \\
75\end{array}$ & $\begin{array}{c}66 \\
8: 78 \\
82\end{array}$ & $\begin{array}{l}71 \\
83 \\
88\end{array}$ & $\begin{array}{c}78 \\
8: 84\end{array}$ & $\begin{array}{l}84 \\
89\end{array}$ & $\begin{array}{c}90 \\
2 * 90\end{array}$ & \\
\hline $\begin{array}{l}0 \\
2 \\
6\end{array}$ & $\begin{array}{l}\text { NAMCU } \\
\text { NCCOL } \\
\text { NCOTH }\end{array}$ & & $\begin{array}{l}\text { INTEGER } \\
\text { INTEGER } \\
\text { INTEGER }\end{array}$ & ARRAY & $\begin{array}{l}\text { COMCUMU } \\
\text { COMMAIN } \\
\text { COMMAIN }\end{array}$ & $\begin{array}{l}\text { REFS } \\
\text { REFS } \\
\text { REFS } \\
\end{array}$ & $\begin{array}{l}3 \\
4 \\
4 \\
\end{array}$ & $\begin{array}{r}176 \\
74\end{array}$ & $\begin{array}{c}181 \\
3: 133\end{array}$ & 187 & & & \\
\hline & NCSTO & & INTEGER & & COMMAIN & REFS & 4 & 74 & 132 & & & & \\
\hline 4 & NCTRA & & INTEGER & & COMMAIN & REFS & 4 & & & & & & \\
\hline & NCV & & INTEGER & & COMMAIN & REFS & 4 & 29 & 63 & 70 & 82 & 86 & 89 \\
\hline 5 & NOVAR & & INTEGER & & COMMAIN & REFS & 4 & & & & & & \\
\hline 467 & NTYPE & & INTEGER & & COMMAIN & REFS & 4 & & & 88 & & & \\
\hline$\frac{0}{1304}$ & $\frac{N V}{N 1}$ & & $\frac{\text { INTEGER }}{\text { INTEGER }}$ & & COMMAIN & $\begin{array}{l}\text { REFS } \\
\text { REFS }\end{array}$ & $\begin{array}{r}4 \\
75\end{array}$ & $\begin{array}{l}18 \\
81\end{array}$ & 82 & 87 & 88 & & \\
\hline 105 & Pros & & REAI & ARRAY & COMPUIR R & $\begin{array}{l}\text { DEFINED } \\
\text { RFFS }\end{array}$ & $\begin{array}{r}74 \\
8\end{array}$ & $\begin{array}{r}81 \\
163\end{array}$ & 86 & & & & \\
\hline 117 & PDCO & & $\frac{K E A L}{R E A L}$ & $\frac{\text { ARKRAY }}{\text { ARR AY }}$ & COMPURC & $\begin{array}{l}\text { KEFS } \\
\text { REF }\end{array}$ & $\frac{y}{9}$ & $\frac{103}{52}$ & 158 & 159 & $2: 163$ & & \\
\hline 77 & $R$ & & REAL & ARRAY & COMCUMU & $\begin{array}{l}\text { DEFINED } \\
\text { REFS }\end{array}$ & $\begin{array}{r}52 \\
3\end{array}$ & 158 & & & & & \\
\hline
\end{tabular}




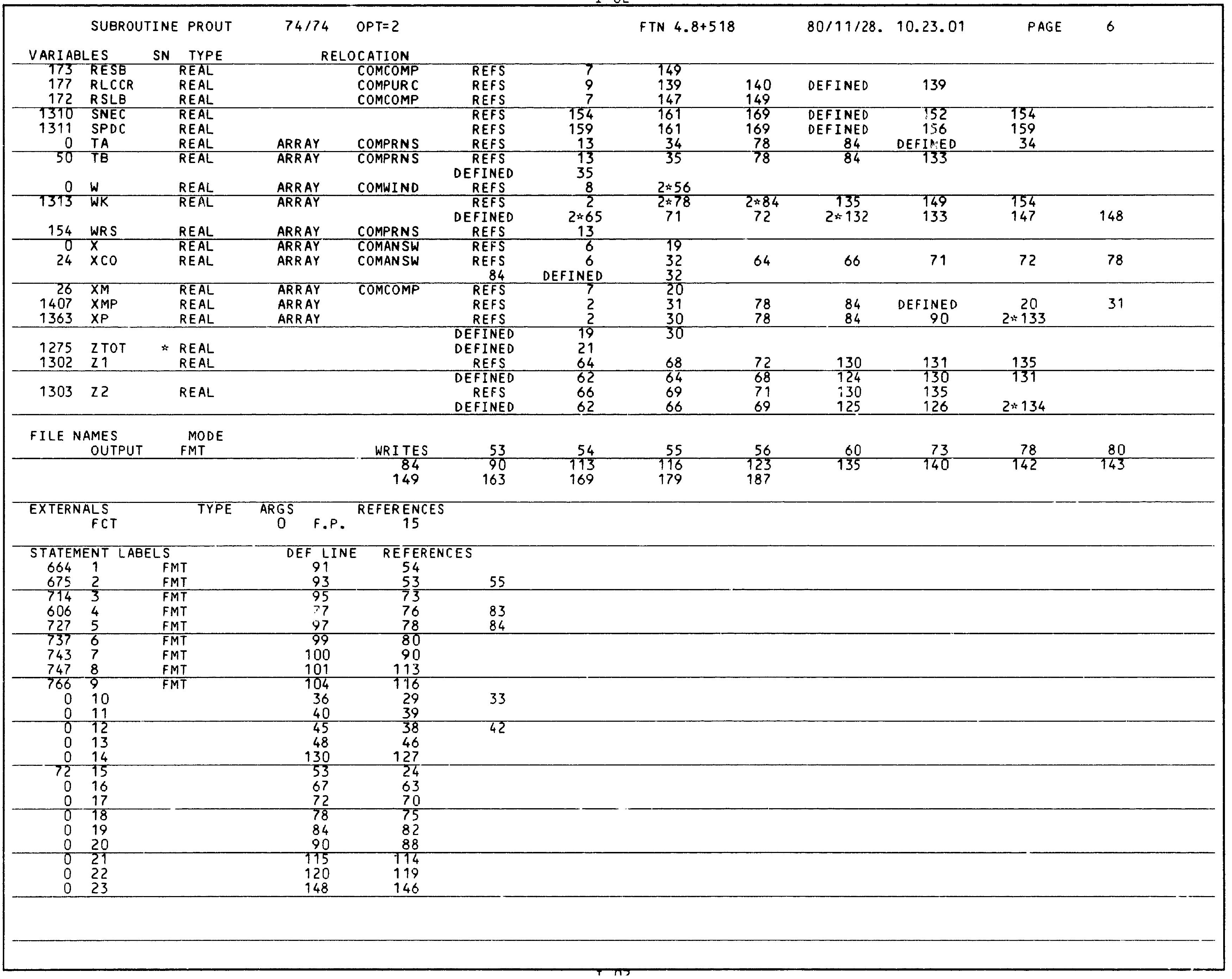




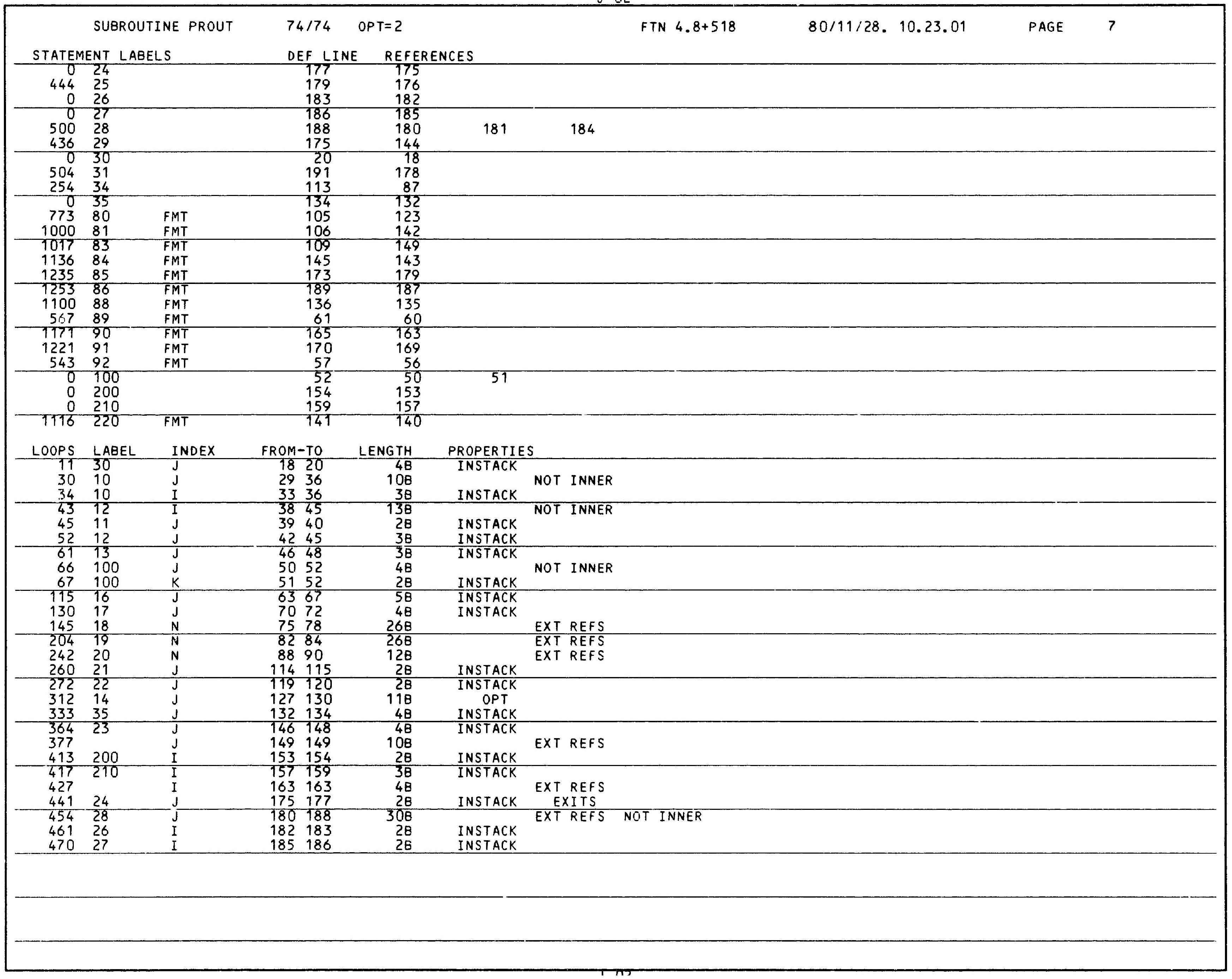




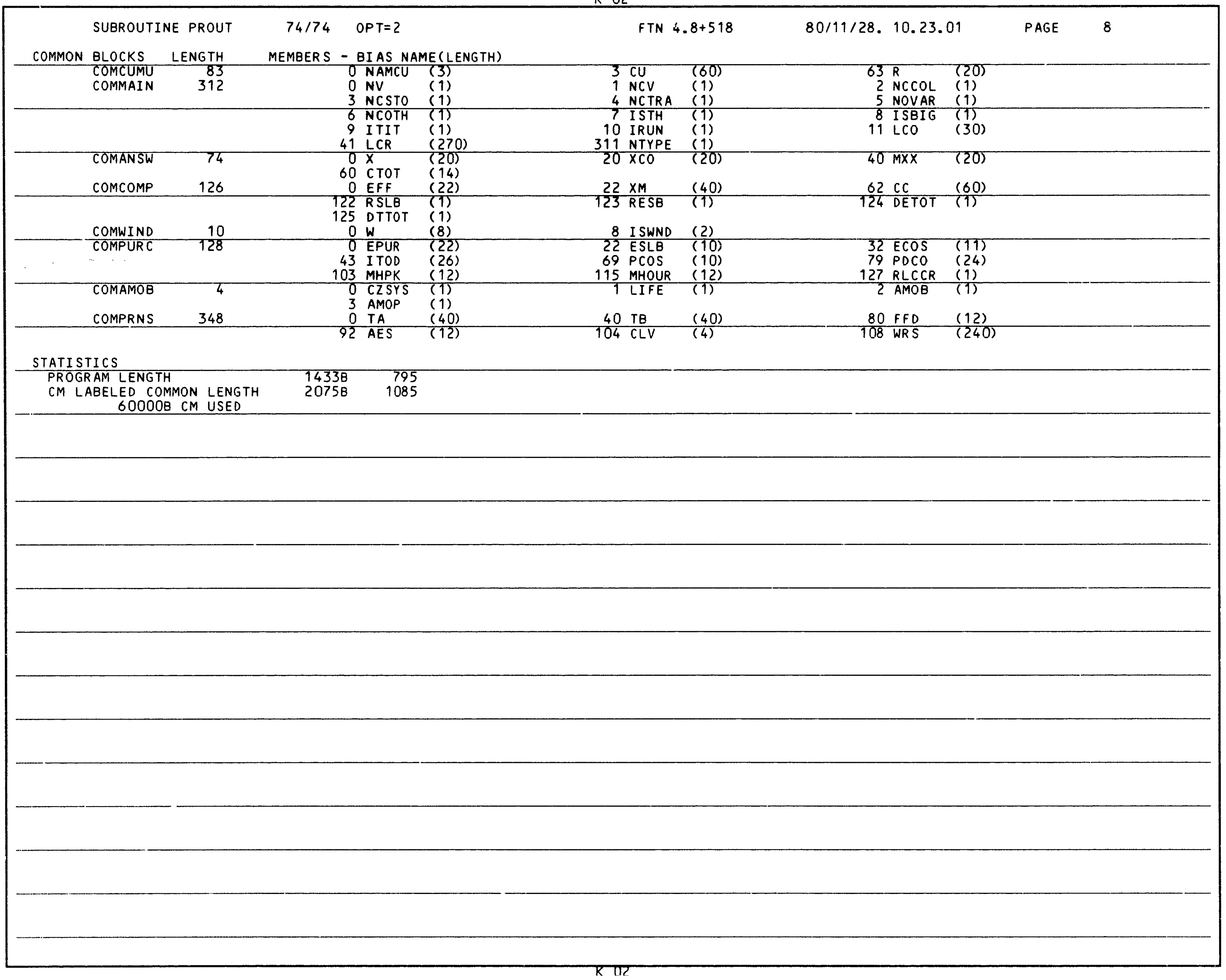




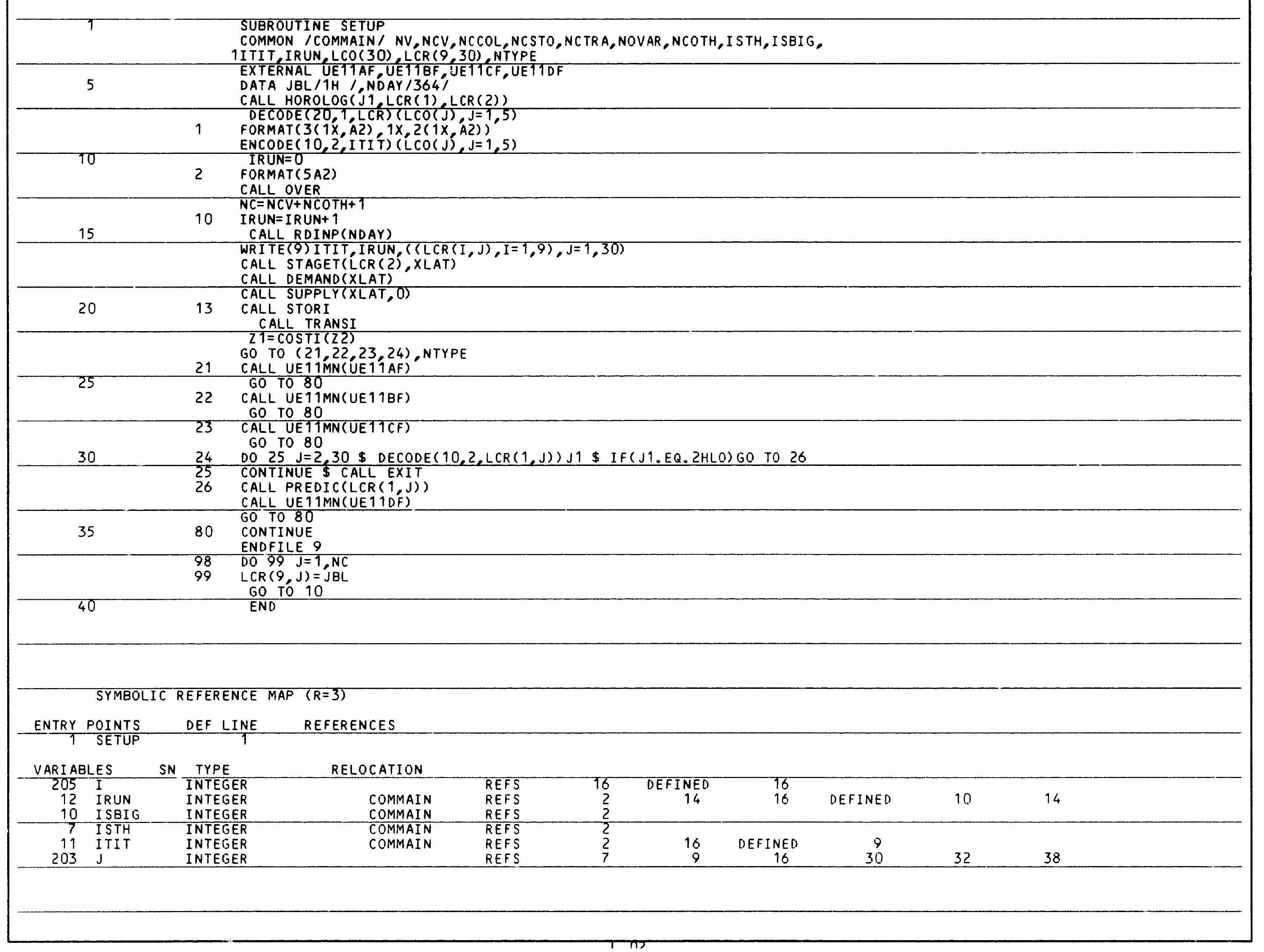




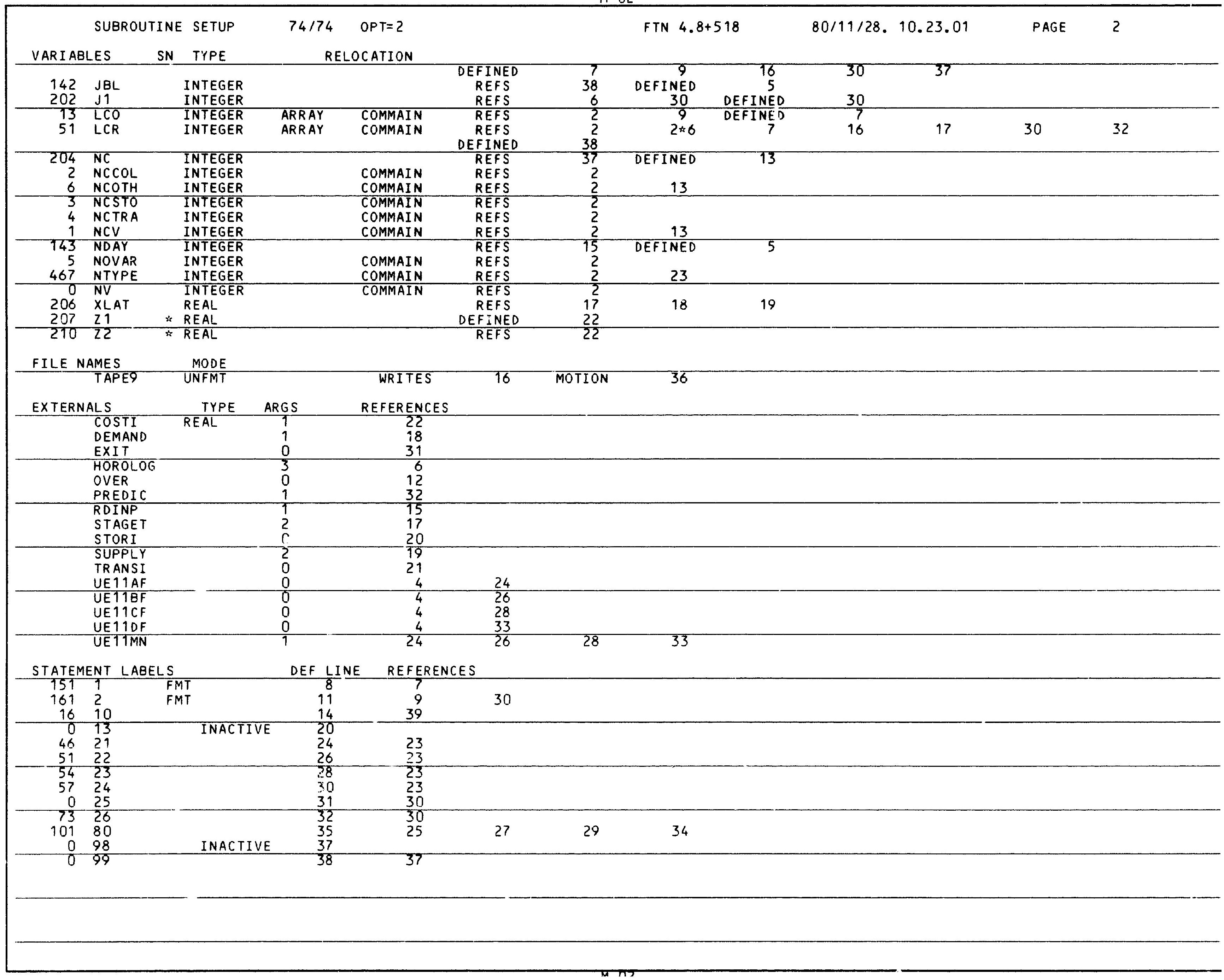




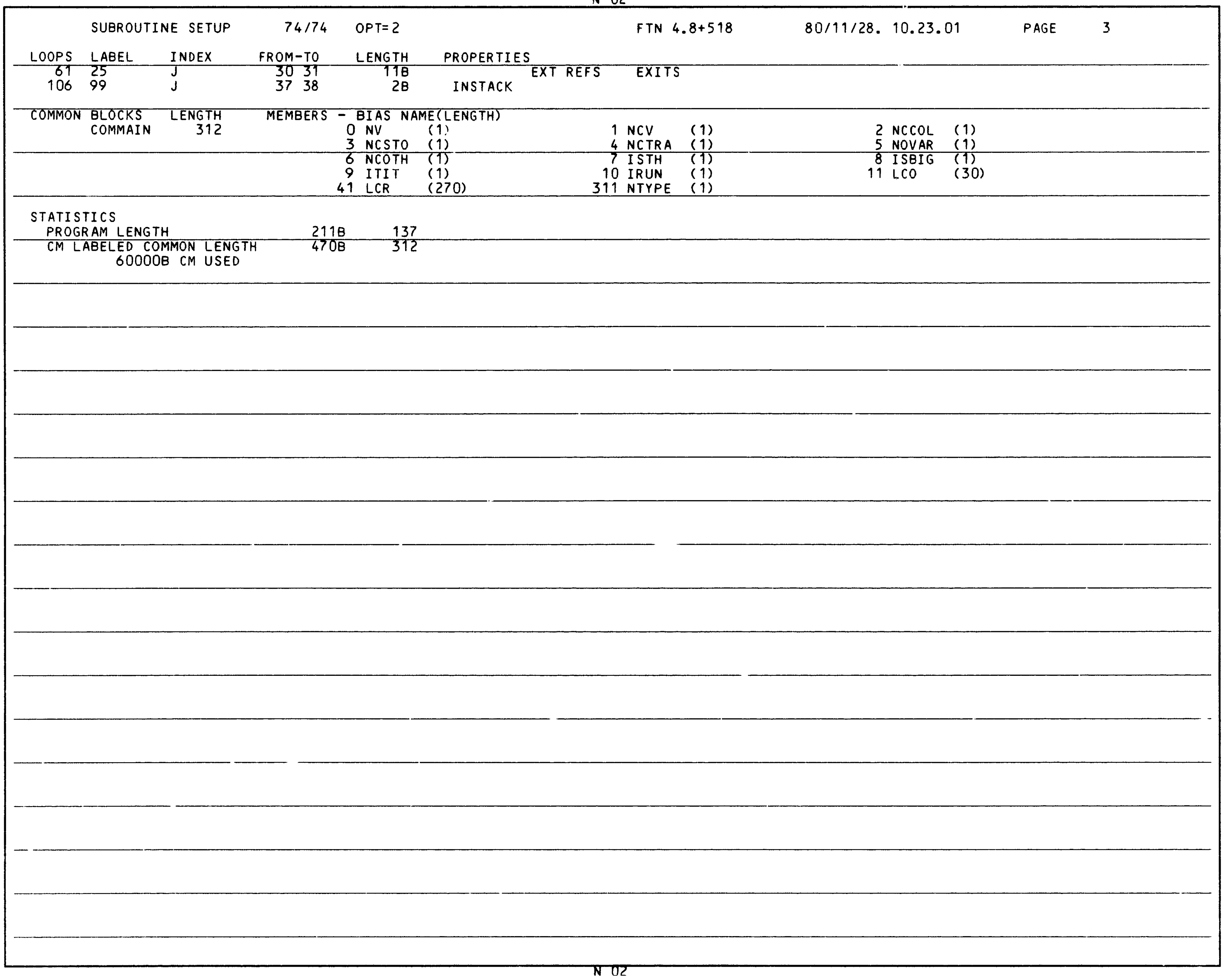




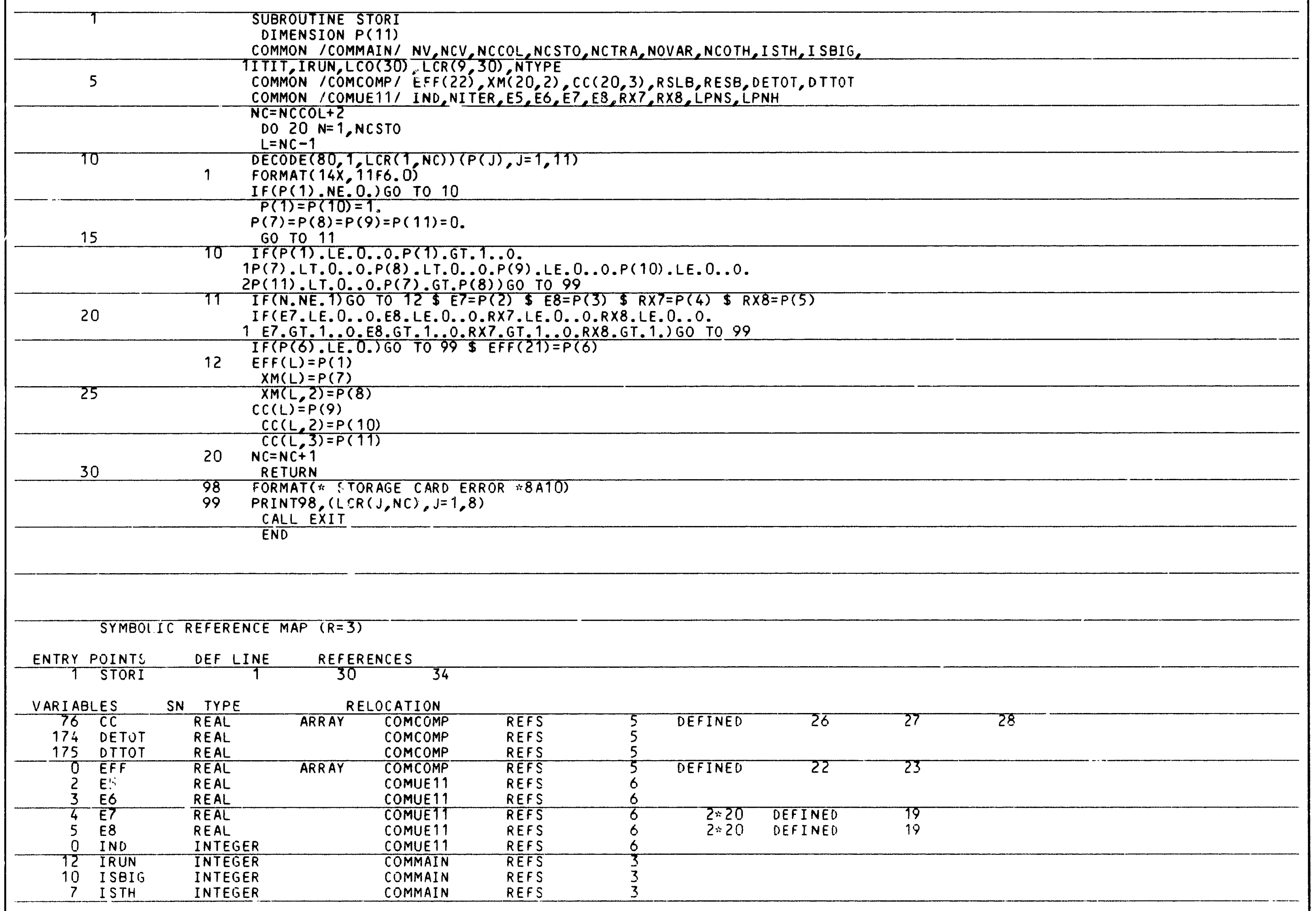




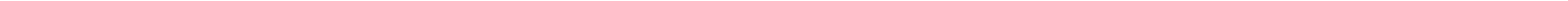





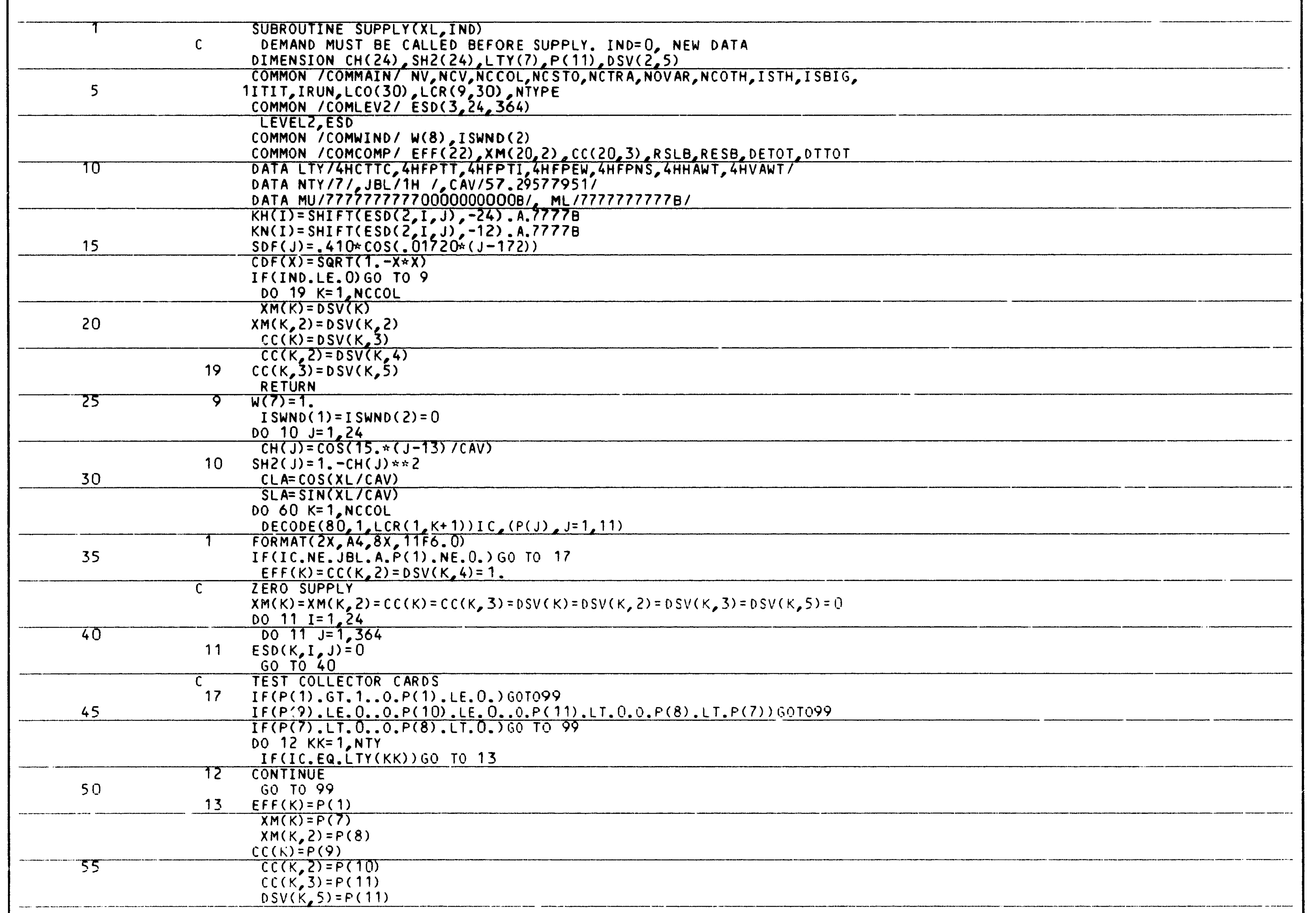


60

\section{$\operatorname{DSV}(K)=P(7)$}

$\operatorname{DSV}(K, 2)=P(8)$

$\operatorname{DSV}(K, 3)=P(9)$

$\operatorname{DSV}(K, 4)=P(10)$

GO TO $(16,16,14,16,14,15,32), \mathrm{KK}$

$14 \quad C T L=\cos (P(2) / C A V)$

$S T L=\operatorname{SIN}(P(2) / C A V)$

65

IF $(P(2) . G E .0$..A.P(2).LT.90.)GO TO 16

PRINT2

2 GO TO 99

FORMAT ( $*$ TILT ANGLE ERROR*)

15 IF (K.EQ.1) GO TO 18

IF(ISWND(1).EQ.0)GO TO 18

PRINT4

GO TO 99

4 FORMAT ( $*$ ONLY ONE WIND TURBINE ALLOWEO*)

$18 \quad \operatorname{IF}(P(5) . L E .0) P.(5)=W(1) *(2.225-.0761: W(1))$

$W(5)=P(5)$

IF $(P(4) . L E .0) P.(4)=.454 \pi W(5)$

$W(4)=P(4)$

$W(6)=P(2)$

$W(7)=$ MAXOC IN

$80 \quad$ I SWND $(K)=1$

PRINT3, $(W(J), J=4,7)$

IF (W(4).GE.W(5), O.W(5).GE.W(6)) G0T099

$W(5)=W(5)-W(4)$

$$
W(6)=W(6)-W(4)
$$

853 FORMAT $(*-V I=* F 8.2, * V R=* F 8.2, * V C=* F 8.2, * N T U R=* F 8.1)$

GO TO $(20,22,24,20,28,30,32), K K$

C 16 GTTC

20 DO $21 \quad I=1,24$

DO $21 \mathrm{~J}=1,24,364$

$90 \quad J 1=K N(I)$

$Z 1=.01 \div J 1$

$21 E S D(K, I, J)=21$. A. MU

GO TO 40

FPTT

$95 \quad 22 \quad$ DO $23 J=1,364$

$S D L=S D F(j)$

$C D L=C L A * C D F(S D L)$

$S D L=S L A * S D L$

$100 \quad \frac{D O 23 I=1,24}{21=C H(I) \div C D L+S D L}$

$22=.75+.25 \div 21$

$J 1=K H(I)$

$J 2=K N(I)$

105

$Z 3=.01 \div \operatorname{AMAX} 1(0 ., J 2+Z 2 *(J 1-J 2 * Z 1))$

$23 E S D(K, I, J)=23$. A. MU

60 TO 40

C FPTI

Q1 =STL:SLA

110

$Q 2=S T L: C L A$

$Q 3=.75+.25 * C T L$

DO $25 \mathrm{~J}=1,364$

SDL $=$ SDF( J)

$C D L=C D F(S D L)$

$Z 1=Q 1 \div C D L$ 
$2 Z=Q 2 * S D L$

$23=C L A * C D L$

$24=S L A * S D L$

DO $25 \quad I=1,24$

$25=23 * \mathrm{CH}($ I $)+24$

$26=21 * C H(I)-22+C T L * 25$

120

$\mathrm{J} 1=\mathrm{KH}(\mathrm{I})$

$27=.01 * \operatorname{AMAX} 1(0.26 * J 2+Q 3 *(J 1-J 2 * 25))$

125

$25 E S D(K, I, J)=Z 7$. A.MU

GO TO 40

C FPEW

$D O 27 \mathrm{~J}=1,364$

$S D L=S D F(j)$

$C D L=C D F(S D L)$

$130 \quad C D 2=C D L * 2$

$Z 1=C L A * C D L$

$Z 2=S L A * S D L$

DO $27 \quad I=1,24$

$23=\mathrm{Z} 1 * \mathrm{CH}(\mathrm{I})+\mathrm{Z2}$

135

$24=$ SQRT $(1-S H 2(1)$

$75=.75+.25 * \operatorname{COS}(23124)$

$J 1=K H(I)$

$J 2=K N(I)$

$Z 6=.01 \div A M A X T(0 ., 24 * J 2+Z 5 *(J 1-J 2 * Z 3))$

$140 \quad 27 \quad \operatorname{ESD}(K, I, J)=26$. A. MU

GO TO 40

FPNS

$28 Q 1=S L A * C T L+S T L * C L A$

$145 \quad \begin{aligned} & Q 2=C L A * C T L-S L A * S T L \\ & Q 3=.75+.25 * Q 2\end{aligned}$

DO $29 \mathrm{~J}=1,364$

SDL $=$ SDF $(J)$

$Z 1=C D F(S D L) * C I A$

$Z 2=S L A * S D L$

DO $29 \quad I=1,24$

$23=21 \div \mathrm{CH}(\mathrm{I})+\mathrm{ZZ}$

$24=Q 1 * \operatorname{CDF}(23)+Q 2 \div 23$

$\mathrm{J} 1=\mathrm{KH}(\mathrm{I})$

$155 \quad 25=.01 * \operatorname{AMAX} 1(0 ., 24 \div J 2+Q 3 *(J 1-J 2 * 23))$

$29 \quad E S D(K, I, J)=25 . A . M U$

GO TO 40

C HAWT

30 DO $31 \quad \mathrm{~J}=1,364$

160 DO $31 \mathrm{I}=1,34$

$J 1=E S D(2, I, J) . A .7777 B$

$Z 1=.1 \div J 1$

$31 \mathrm{ESD}(\mathrm{K}, \mathrm{I}, \mathrm{J})=Z 1 . \mathrm{A} . \mathrm{MU}$

GO TO 40

165

VAWT

32 PRINT33

GO TO 99

33 FORMAT(* NO VAWT YET*)

CONTINUE

$170 \quad$ C GO TO $(41,41,41,41,41,60,60), K K$ 


\begin{tabular}{|c|c|c|}
\hline & $\begin{array}{l}41 \\
60\end{array}$ & $\begin{array}{l}\text { CONTINUE } \\
\text { CONTINUE } \\
\text { RETURN }\end{array}$ \\
\hline 175 & $\begin{array}{l}98 \\
99\end{array}$ & $\begin{array}{l}\text { FORMAT (* COLLECTOR CARD ERROR * } 11 \times, 8 \text { A10) } \\
\text { PRINT98 }(L C R(J, K+1), J=1,8) \\
\text { CALL EXIT }\end{array}$ \\
\hline
\end{tabular}

SYMBOLIC REFERENCE MAP (R=3)

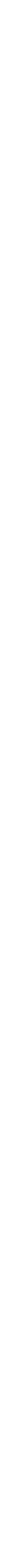




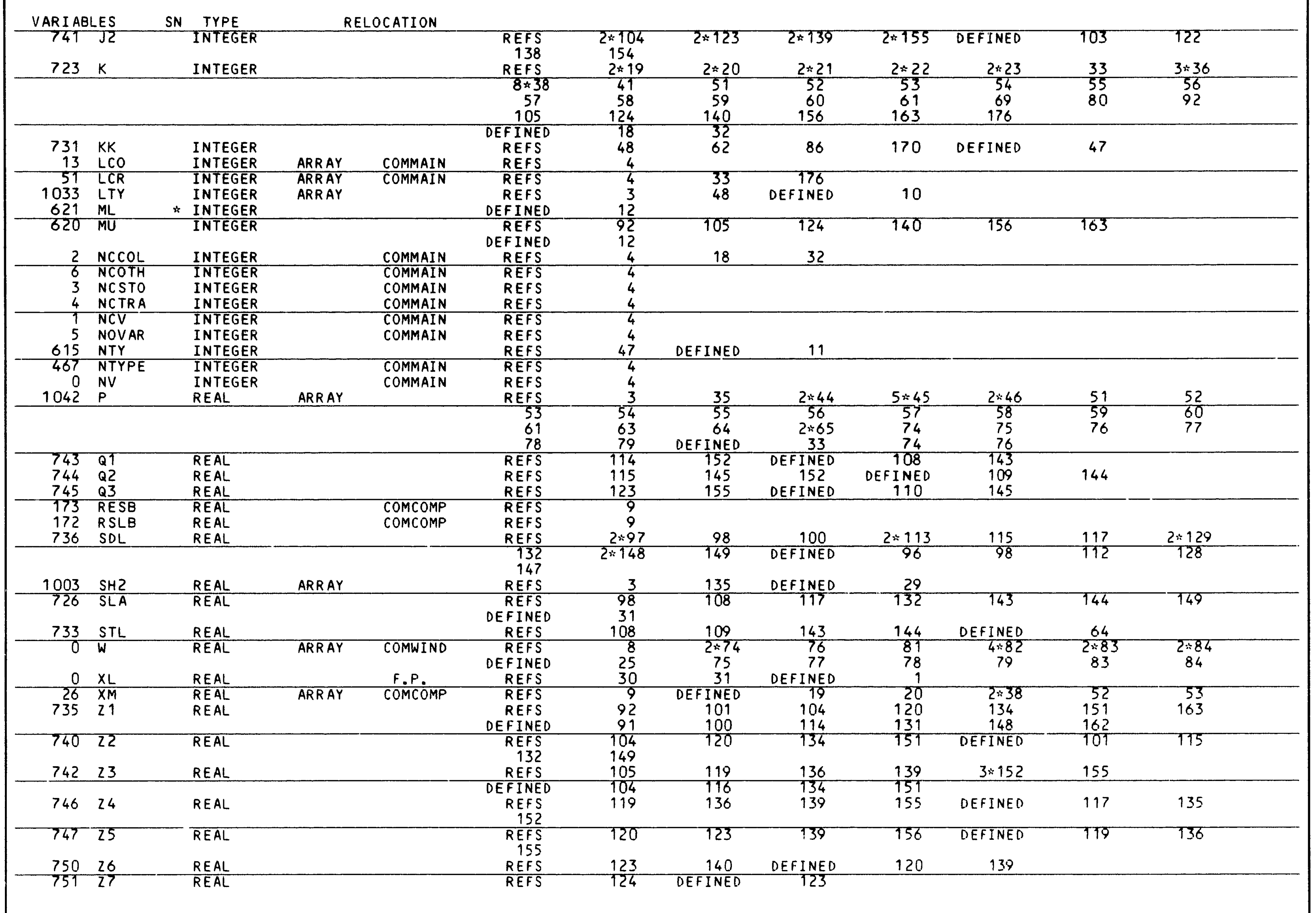




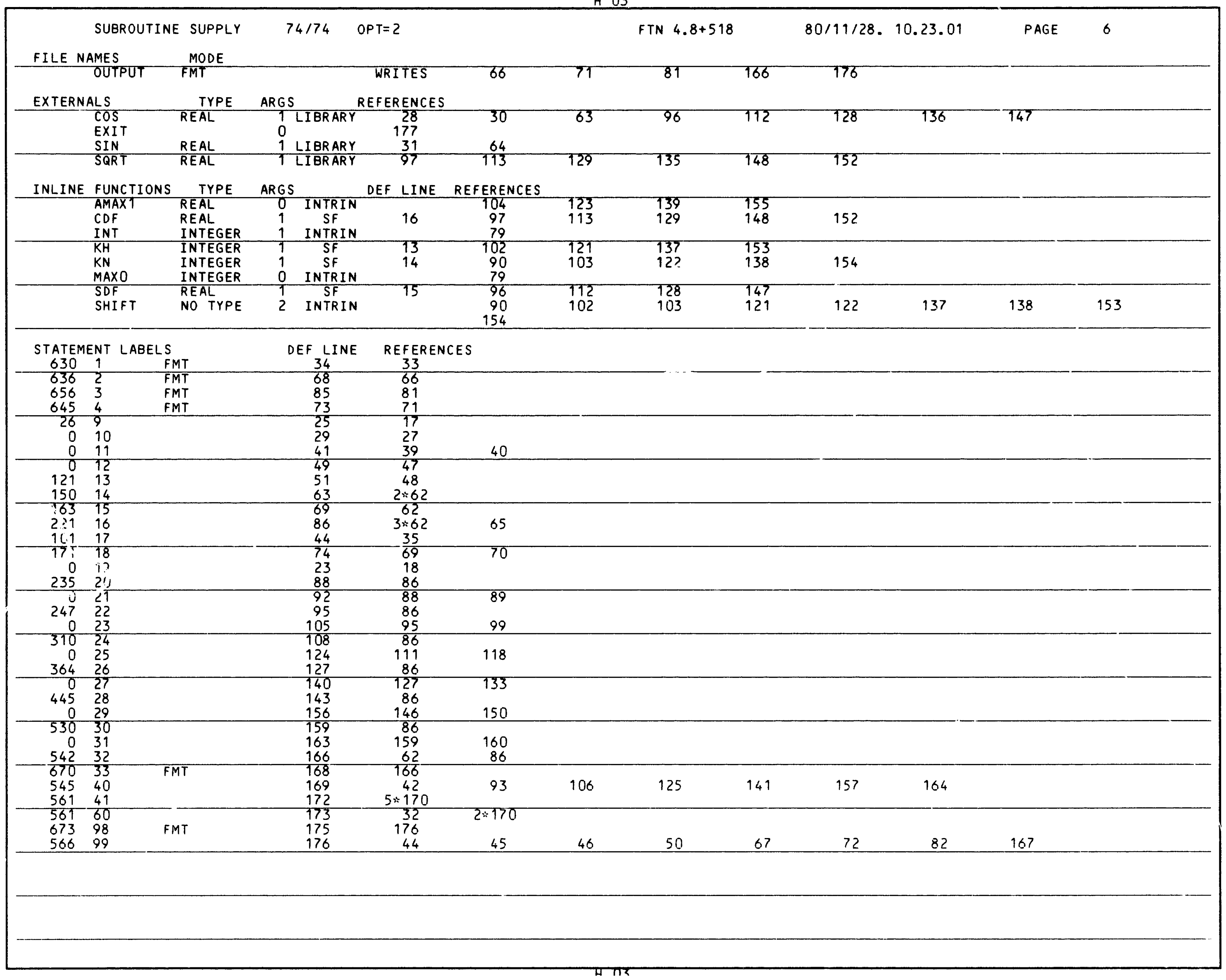




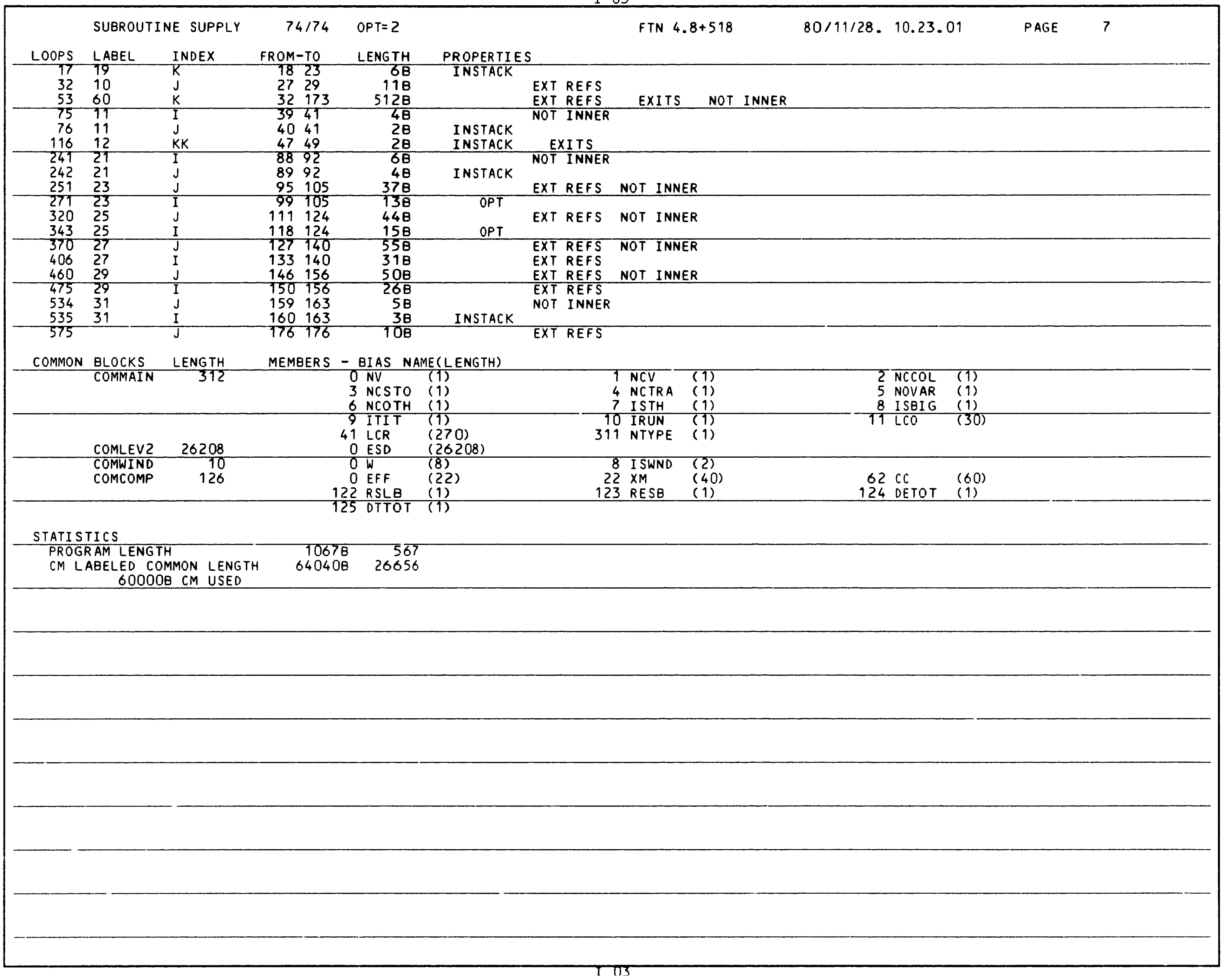




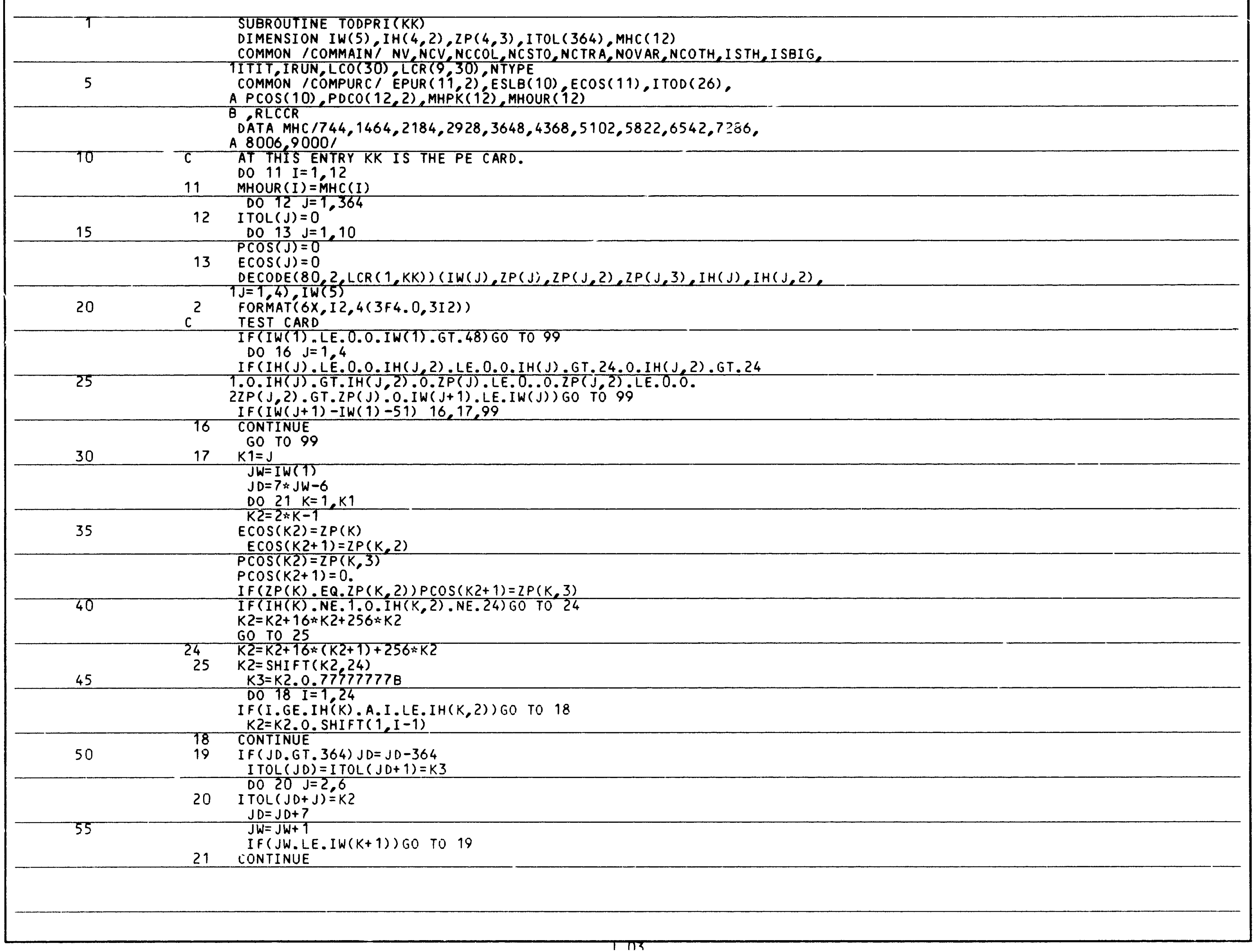




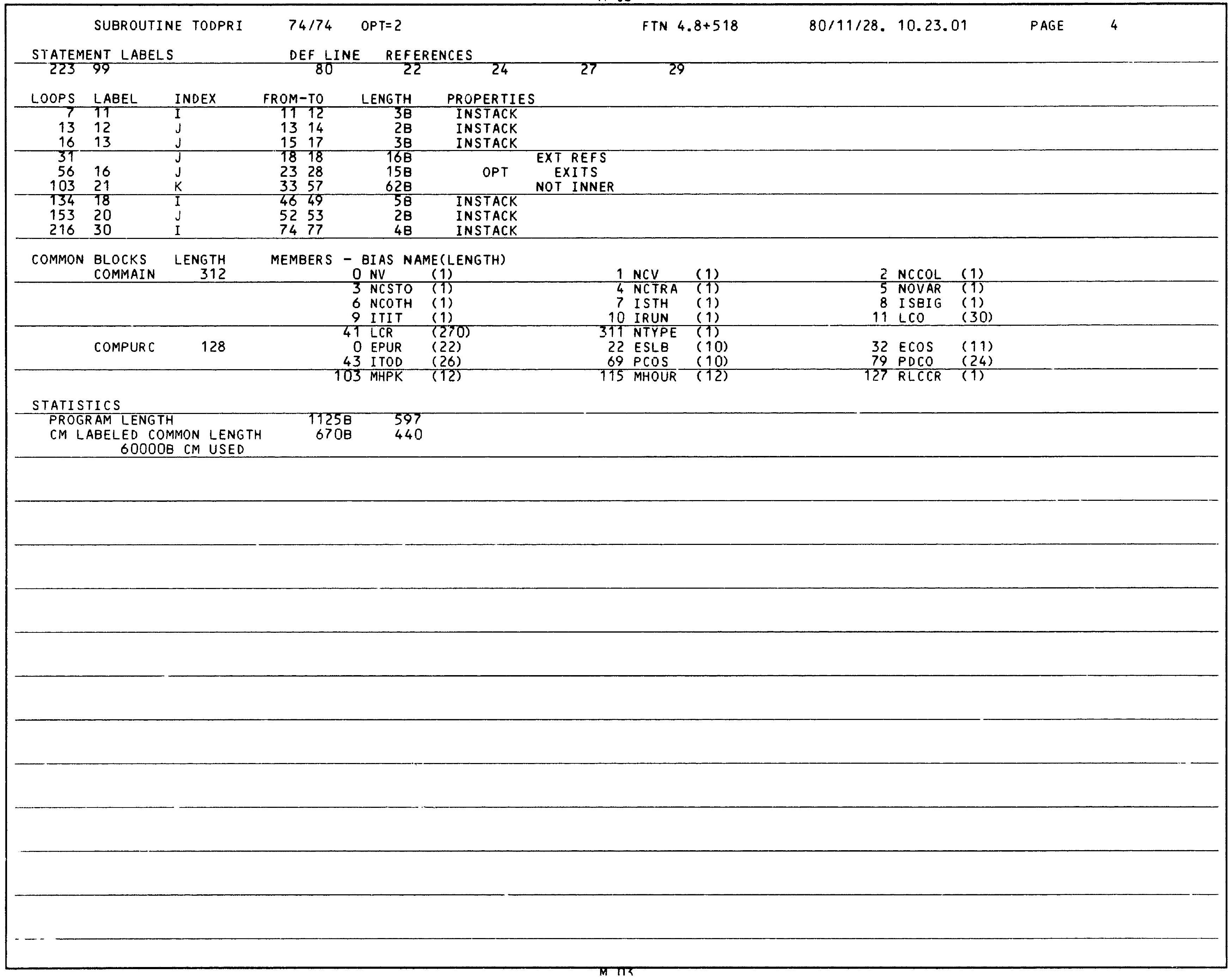


1

5

SUBROUTINE TODUP(NHR)

DIMENSION JUPT (365)

COMMON /COMPURC/ EPUR (11,2) ESLB(10),ECOS(11), ITOD(26)

$A P \operatorname{COS}(10), P D C O(12,2), \operatorname{MHPK}(12), \operatorname{MHOUR}(12)$

$B, R L C C R$

COMMON /COMUPDN/ IHUP PRUP IHDN PRDN

COMMON TCOMSUDE/ SET(24), SE2(24), ST1(24), ST2(24), DEE(24), DET(24)

I F (NHR . LT. NHRU) LU=1

NHRU $=$ NHR

$1010 \quad J=J U P T(L U)$. A.MS

IF (J.GT.NHRU) GO TO 11

$L U=L U+1$

GO TO 10

11 IHUP = J

$J=\operatorname{SHIFT}(J U P T(L U),-15) \cdot A \cdot 17 \mathrm{~B}$

15 PRUP $=E \operatorname{COS}(J)$

RETURN

ENTRY TODDN

IF (NHR . LT.NHRD) LD $=1$

20

$12 J=S H I F T$ (JUPT(LD), $-21 ; ;$. M5

IF(J.GT.NHRD)GO TO 13

$\angle D=L D+1$

GO TO 13

$2513 \quad$ IHDN $=J$

$J=\operatorname{SHIFT}(J U P T(L D),-36) \cdot A \cdot 17 \mathrm{~B}$

$P R D N=E \operatorname{COS}(J)$

RETURN

ENTRY TODUDI

$M 5=777778$

$\angle U=L D=1$

$N H R U=N H R D=M 5$

CALL TODPR (1)

$J=I T O D(1)$

$35 \quad 21=E \operatorname{COS}(\mathrm{J})$

$\mathrm{NH}=0$

$M O=1$

DO $19 \mathrm{~J}=1,11$

$19 \quad \operatorname{EPUR}(\jmath)=0$,

DO $20 \mathrm{~J}=1,12$

$\operatorname{MHPK}(J)=0$.

DO $20 \mathrm{~K}=1,2$

$20 \quad \operatorname{PDCO}(J, K)=0$

DO 23 ND $=1,364$

CALL GETSD'́(ND)

CALL TODPR (NO)

DO $23 \quad I=1,24$

EPUR (11) $=$ EPUR (11)+DET (I)

$J=I T O D(I)$

50

EPUR $(J)=E P$

$\mathrm{NH}=\mathrm{NH}+1$

IF (NH.GT.MHOUR (MO)) MO $=M O+1$

$Z Z=D E E(I) * P C O S(J)$

55 C FIND PEAK COST FOR EACH MONTH

IF $(22$. LE.PDCO $(M O, 1)) G O$ TO 18

$P D C O(M O, 1)=Z 2$ 


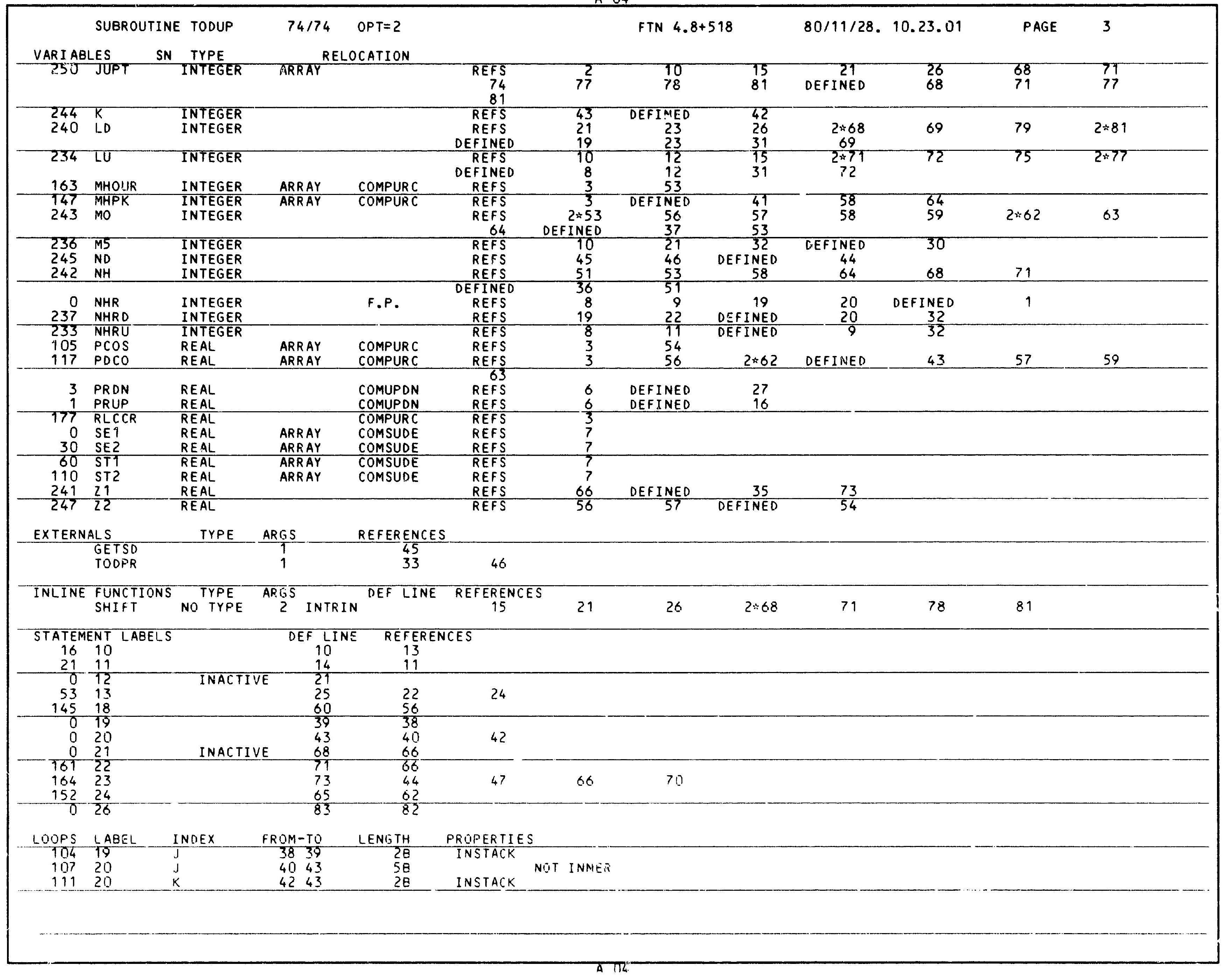


SUESROUTINE TODUP

$74 / 74 \quad O P T=2$

FTN $4.8+518$

$80 / 11 / 28.10 .23 .01$

PAGE

$\begin{array}{r}\text { LOOPS } \\ \hline 115 \\ 127 \\ 220 \\ 22 \\ \hline\end{array}$

\begin{tabular}{l} 
LABEL \\
23 \\
23 \\
26 \\
\hline
\end{tabular}

INDEX
ND
I

FROM-TO

LENGTH

PROPERTIES 4473 608 EXT REFS NOT INNER

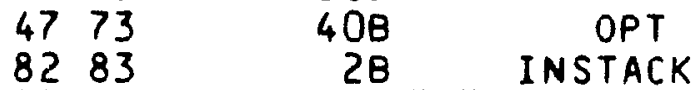

\section{COMMON BLOCKS LENGTH MEMBERS - BIAS NAME(LENGTH)}

COMPURC

128

0 EPUR (22)
43 ITOD (26)

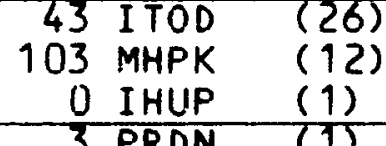

3 PRDN (1)

$\begin{array}{lll}0 & \text { SE } 1 & (24)\end{array}$

$(24)$

$\begin{array}{rll}22 & \text { ESLB } & (10) \\ 69 & \text { PCOS } & (10) \\ 115 & \text { MHOUR } & (12) \\ 1 & \text { PRUP } & (1) \\ 24 & \text { SE2 } & (24) \\ 96 & \text { DEE } & (24)\end{array}$

$\frac{32}{79}$ PIICO $\quad(11)$

127 RLCCR (1)

2 IHDN (1)

COMSUDE

144

$\frac{1025 B}{424 B}-\frac{533}{276}$

\section{TATISTICS
PROGRAM LENGTH}

CM LABELED COMMOH LENGTH

$60000 \mathrm{~B}$ CII USED

48 ST1 (24)

120 DET (24) 


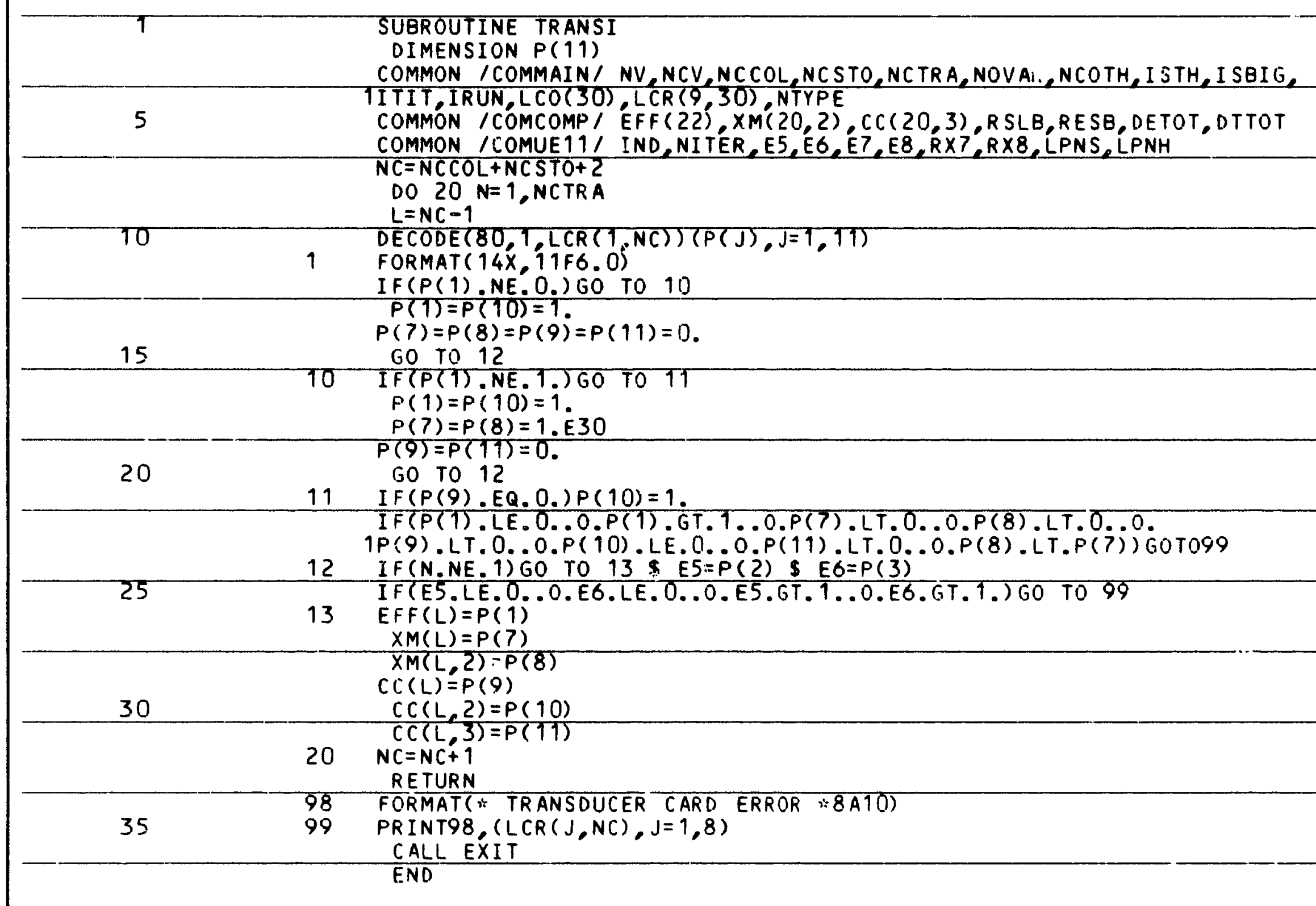

SYMBOLIC REFERENCE MAP $(R=3)$ ENTRY POINTS DEF LINE $\frac{\text { REF }}{1} \frac{3 K E N C E S}{3} 37$

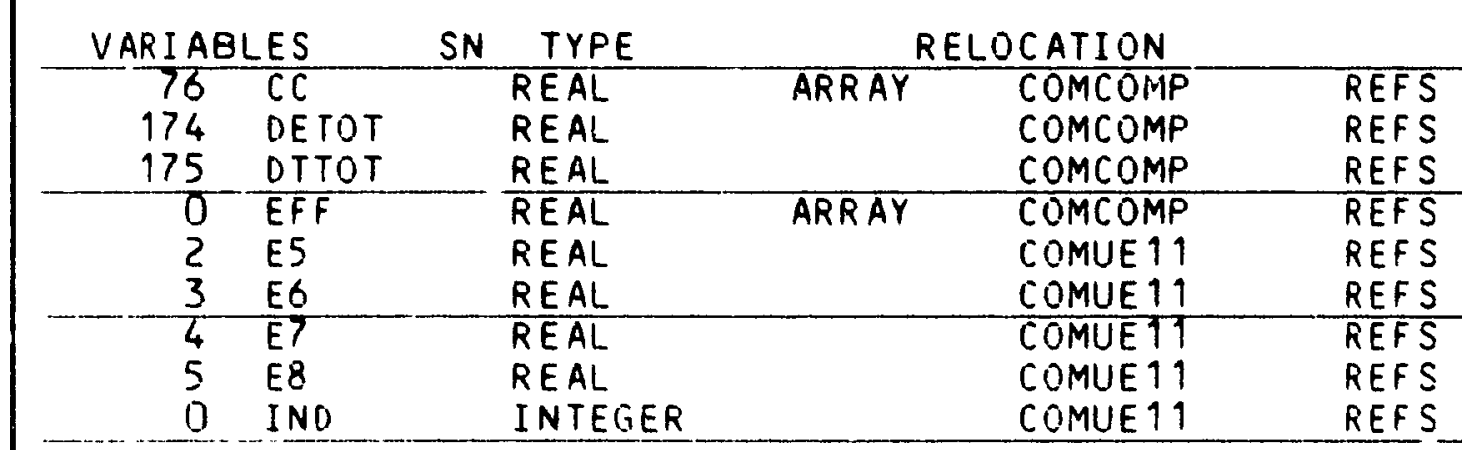

$\begin{array}{rrrr}5 & \text { DEFINED } & 29 & 30 \\ 5 & & & \\ 5 & & & \\ 5 & \text { DEFINED } & 26 & \\ 6 & 2=25 & \text { DEFINED } & 24 \\ 6 & 2 * 25 & \text { DEFINED } & 24 \\ 6 & & & \\ 6 & & & \\ 6 & & & \end{array}$




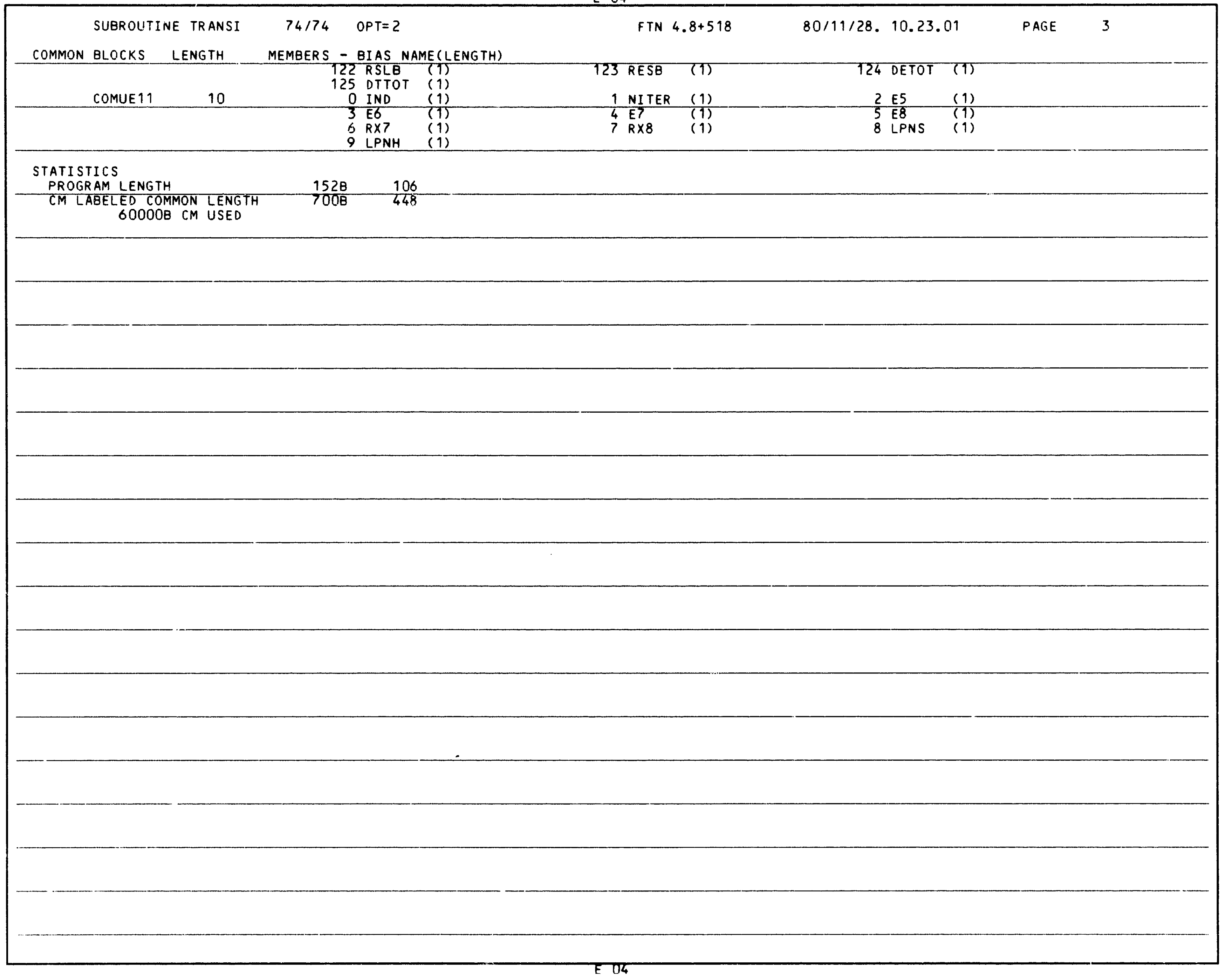




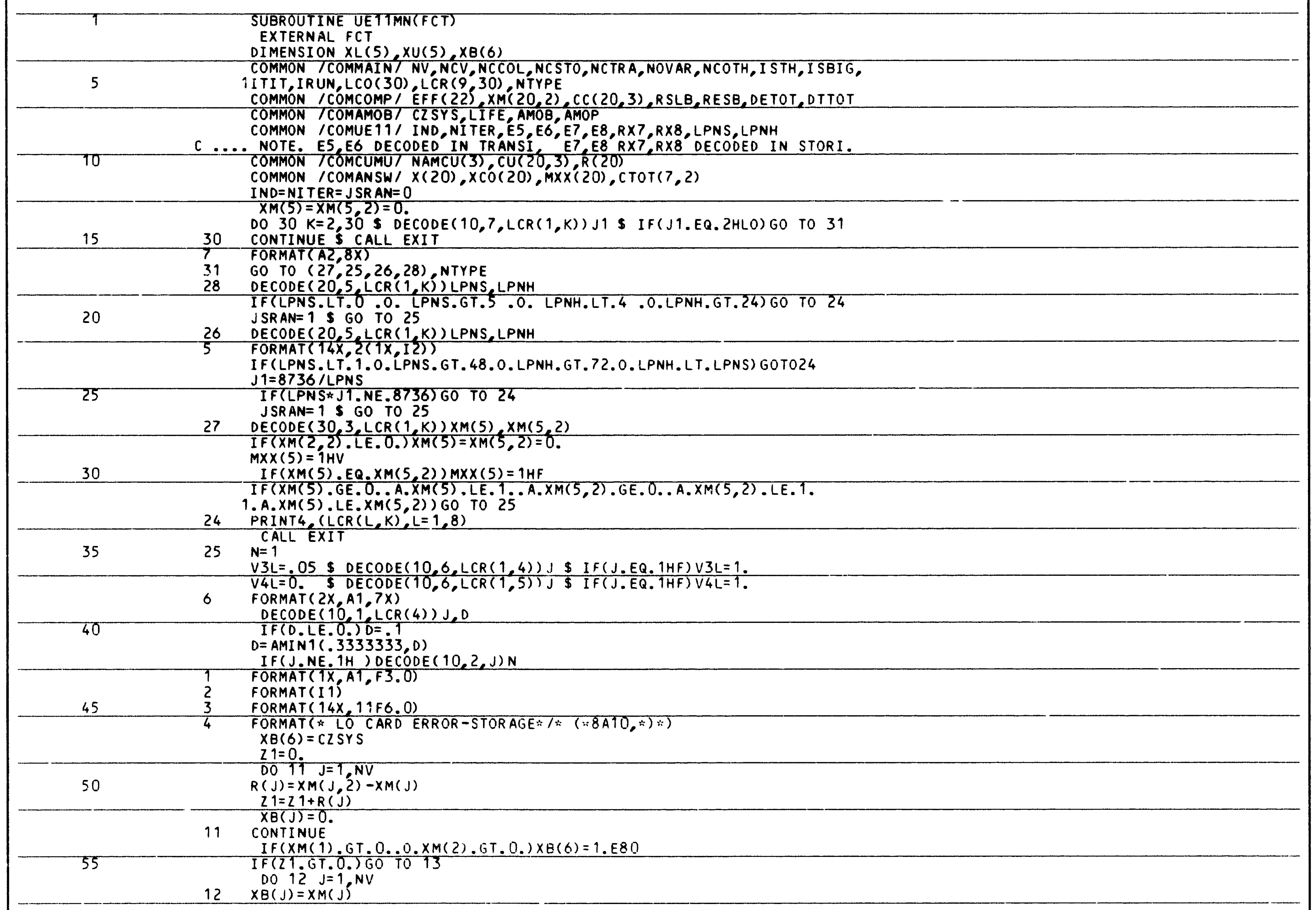




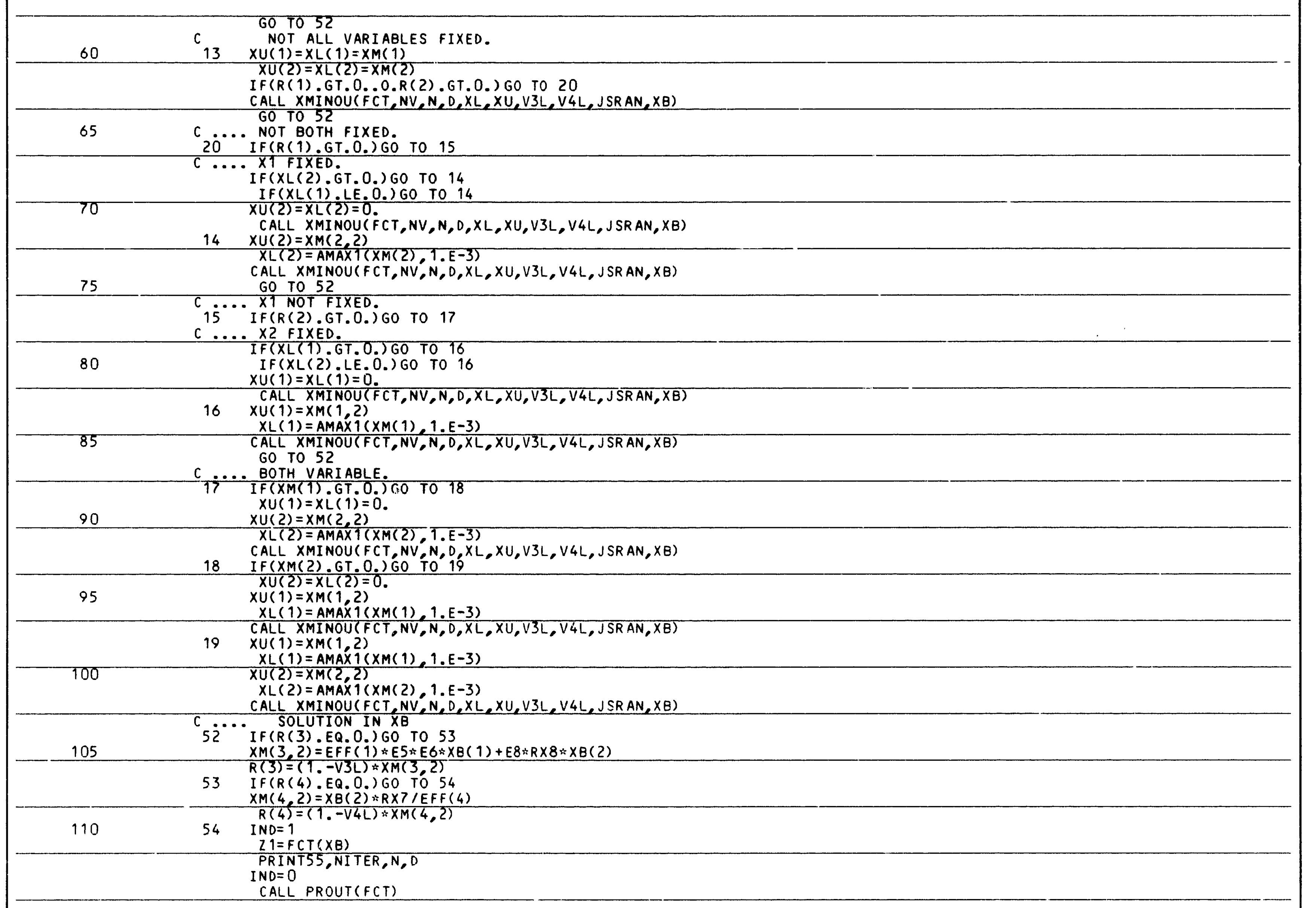



11555 FORMAT(* XMIN *2I8,F12.6) RETURN END

SYMBOLIC REFERENCE MAP $(R=3)$

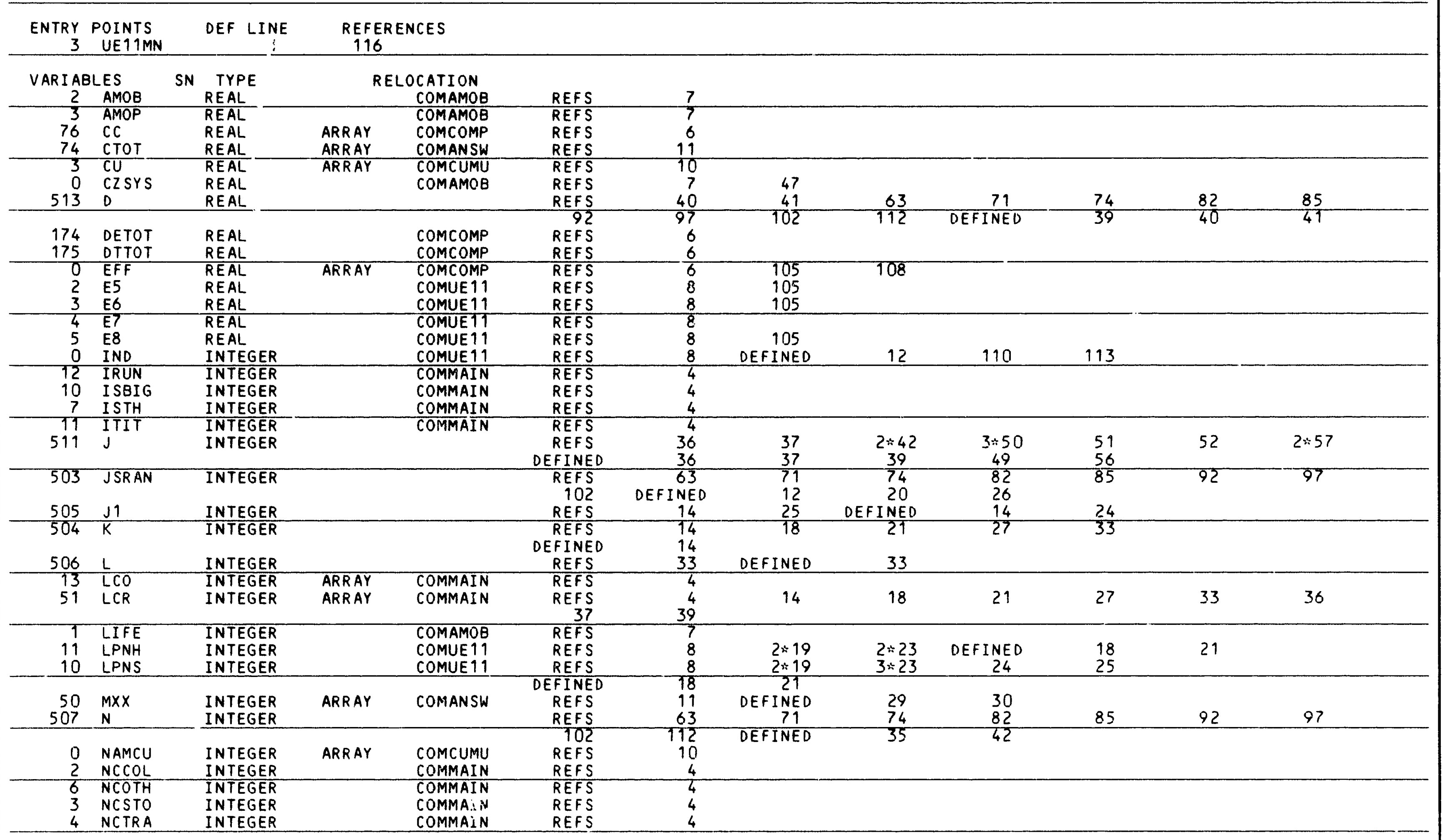




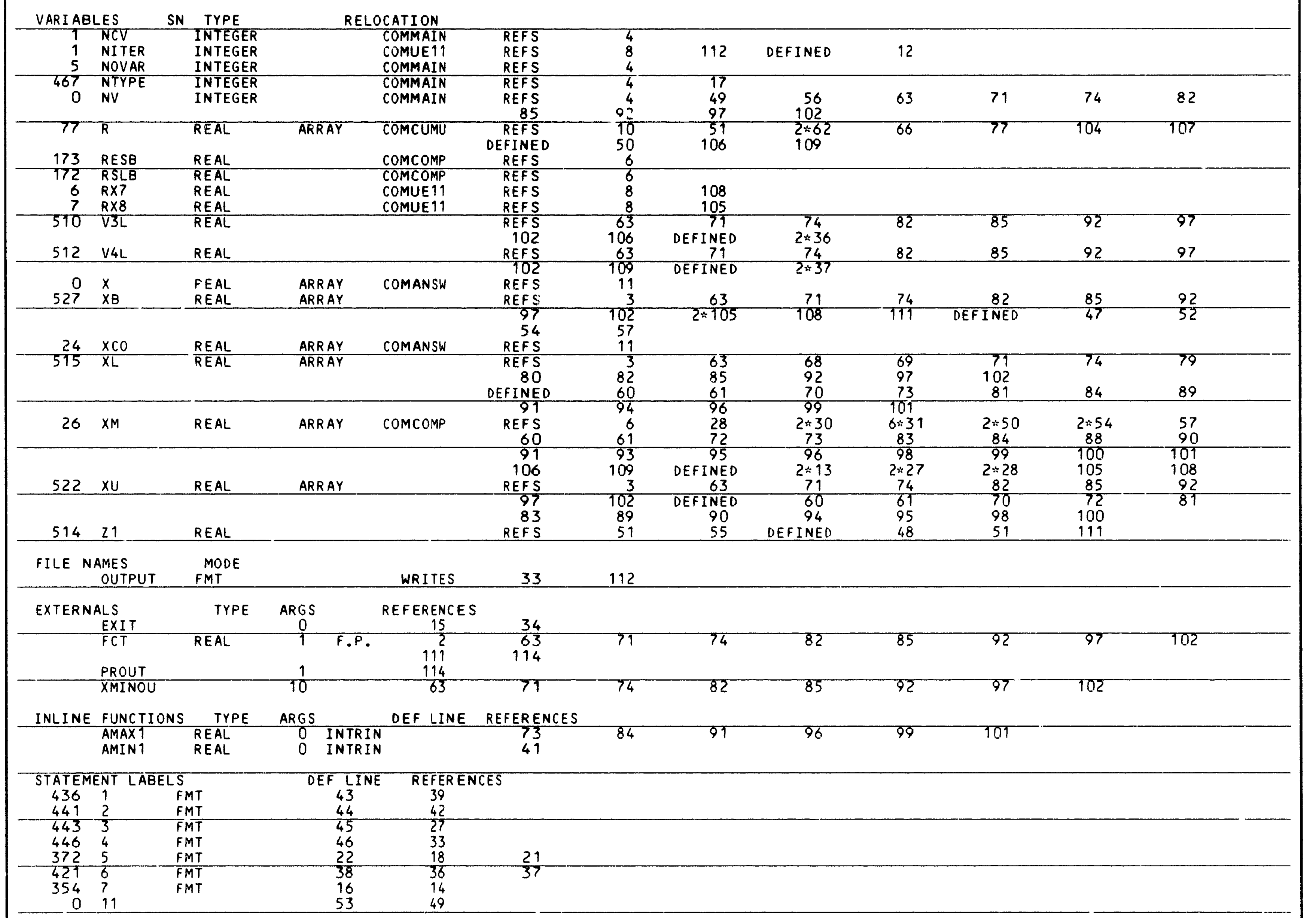




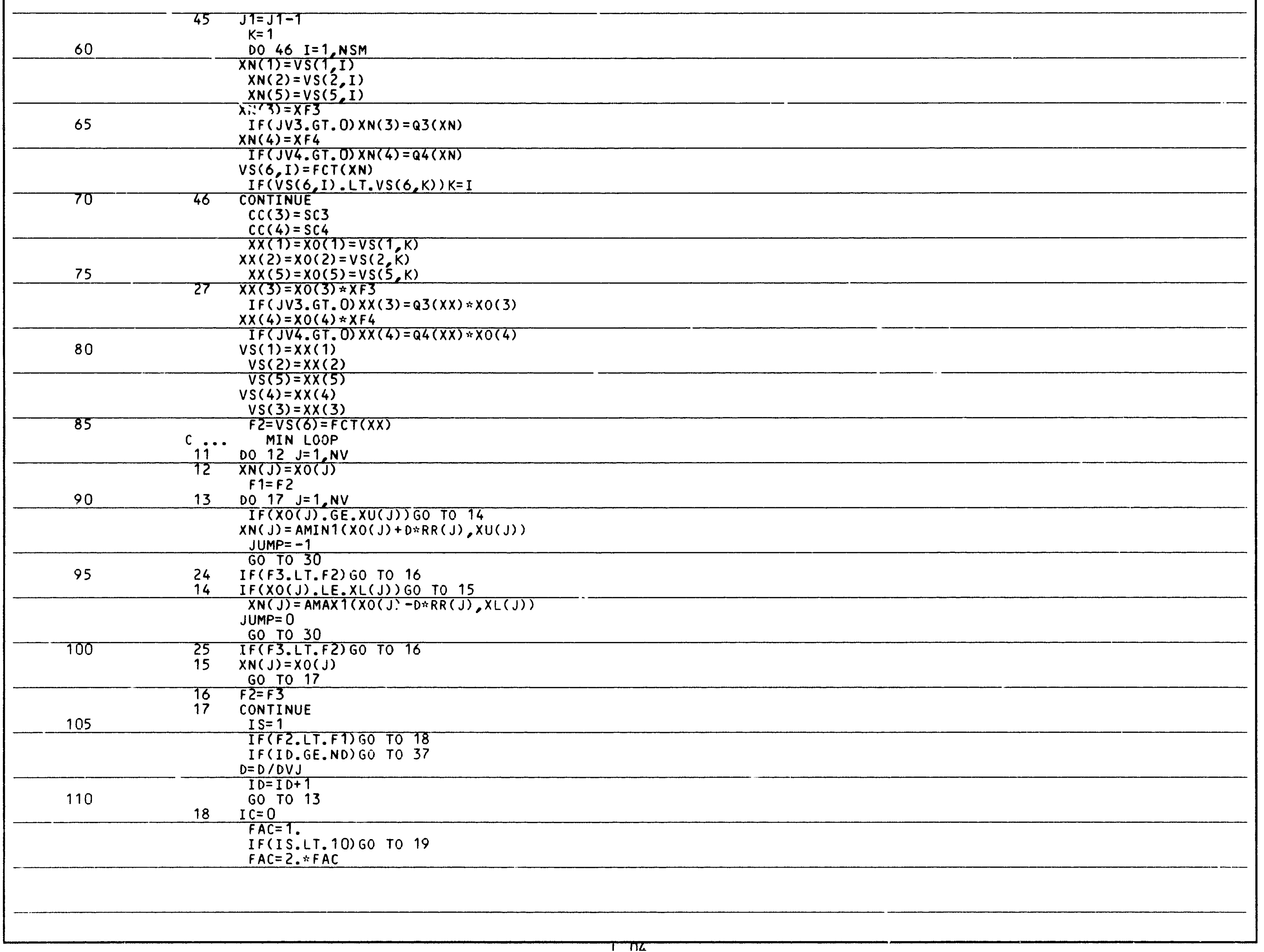


115

$$
I S=0
$$

19 I $S=I S+1$

DO $23 \mathrm{~J}=1, \mathrm{NV}$

$D X=(X N(J)-X O(J)) \div F A C$

120

$X O(J)=X N(J)$

IF (DX) $20,21,22$

$20 X N(J)=\operatorname{AMAX} 1(X O(J)+D X, X L(J))$

$\operatorname{IF}(X N(J) . L T . X O(J))$ I $C=1$

GO TO 23

$125 \quad 21 \quad X N(J)=X O(J)$

$22 \quad X N(J)=\operatorname{AMIN1}(X O(J)+D X X U(J))$

IF (XN(J).GT.XO(J)) IC $C=1$

23 CONTINUE

IF (IC.EQ.0) 60 TO 11

130

JUMP $=1$

GO TO 30

26 IF (F3.GE.F2)GO TO 11

$F 2=F 3$

135

GO TO 18

C 30 TEST LOOP

$X X(1)=X N(1)$

$X X(2)=X N(2)$

$X X(5)=X N(5)$

$140 \quad X X(3)=X N(3) * X F 3$

If

$X X(4)=X N(4) * X F 4$

IF (JV4.GT.0) XXX(4)=XN(4) $\approx Q 4(X X)$

DO $33 \mathrm{~K}=1, \mathrm{NS}$

$21=0$.

$145 \quad 0032 \mathrm{~L}=1$ NV

$32 \quad Z 1=Z 1+A B S(X X X(L)-V S(L, K))$

IF (Z1.LT.1.E-5)GO TO 35

33 CONTINUE

$F 3=F C T(X X)$

$150 \quad N S=$ MINO(NS+1, NSM)

$N R=N R+1$

IF (NR.GT.NSM) NR=1

VS $(6, N R)=F 3$

$155 \quad 34 \quad \begin{aligned} & D O \\ & V S(L, N R)=X X(L)\end{aligned}$

GO TO 36

$35 \quad F 3=V S(6 \quad K)$

36 IF ( JUMP) $24,25,26$

SOLUTION IN $X O$

$160 \quad 37 \because Z 1=X 0(3) * X F 3$

IF (JV3.GT.0) $Z 1=X 0(3) \div Q 3\left(X_{0}\right)$

$X O(3)=i 1$

$Z 1=X 0(4) * X F 4$

IF (JV4. FT. 0) Z1 $=X 0(4) * Q 4(X 0)$

$165 \quad \times 0(4)=\bar{i}$

$\frac{X 0(4)=21}{39 K=1, N S}$

in $38 \mathrm{~J}=1, \mathrm{NV}$

$\operatorname{IF}(A B S(X O(J)-V S(J, K))$.GT.1.E-5) GO TO 39

39 GO TO 5 


\begin{tabular}{|c|c|c|}
\hline & 50 & $\begin{array}{l}K=1 \\
D O 50 \mathrm{~J}=1, N V \\
V S(J)=X O(J)\end{array}$ \\
\hline 175 & 51 & $\begin{array}{l}\text { VS }(6)=F C T(V S) \\
\text { IF }(V S(6, K) \cdot G E \cdot \times B(6)) \text { PETURN } \\
\text { DO } 52 j=1,6\end{array}$ \\
\hline 180 & 52 & $\begin{array}{l}X B(J)=V S(J, K) \\
\text { RETURN } \\
\text { END }\end{array}$ \\
\hline
\end{tabular}

SYMBOLIC REFERENCE MAP $(R=3)$

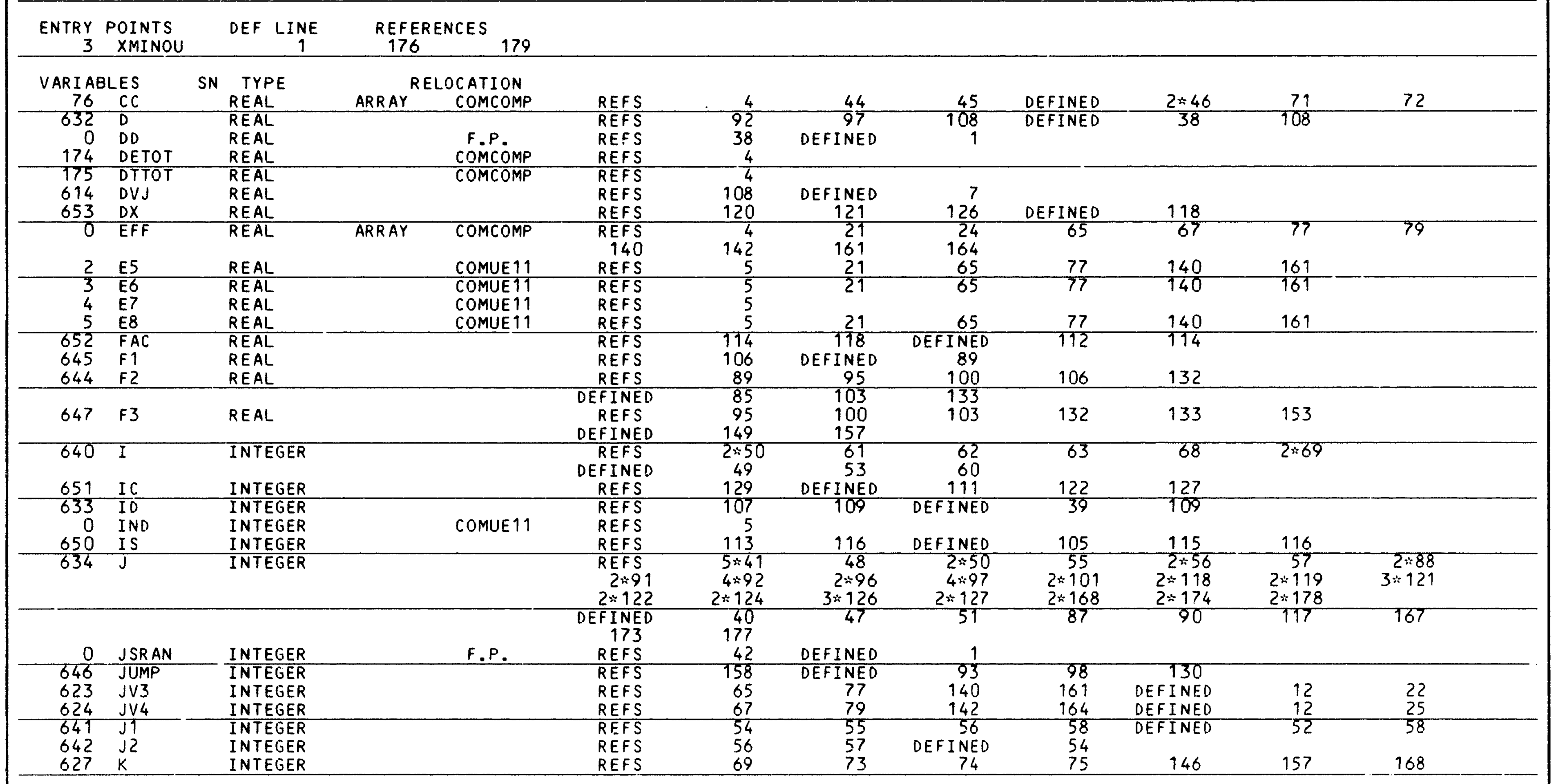




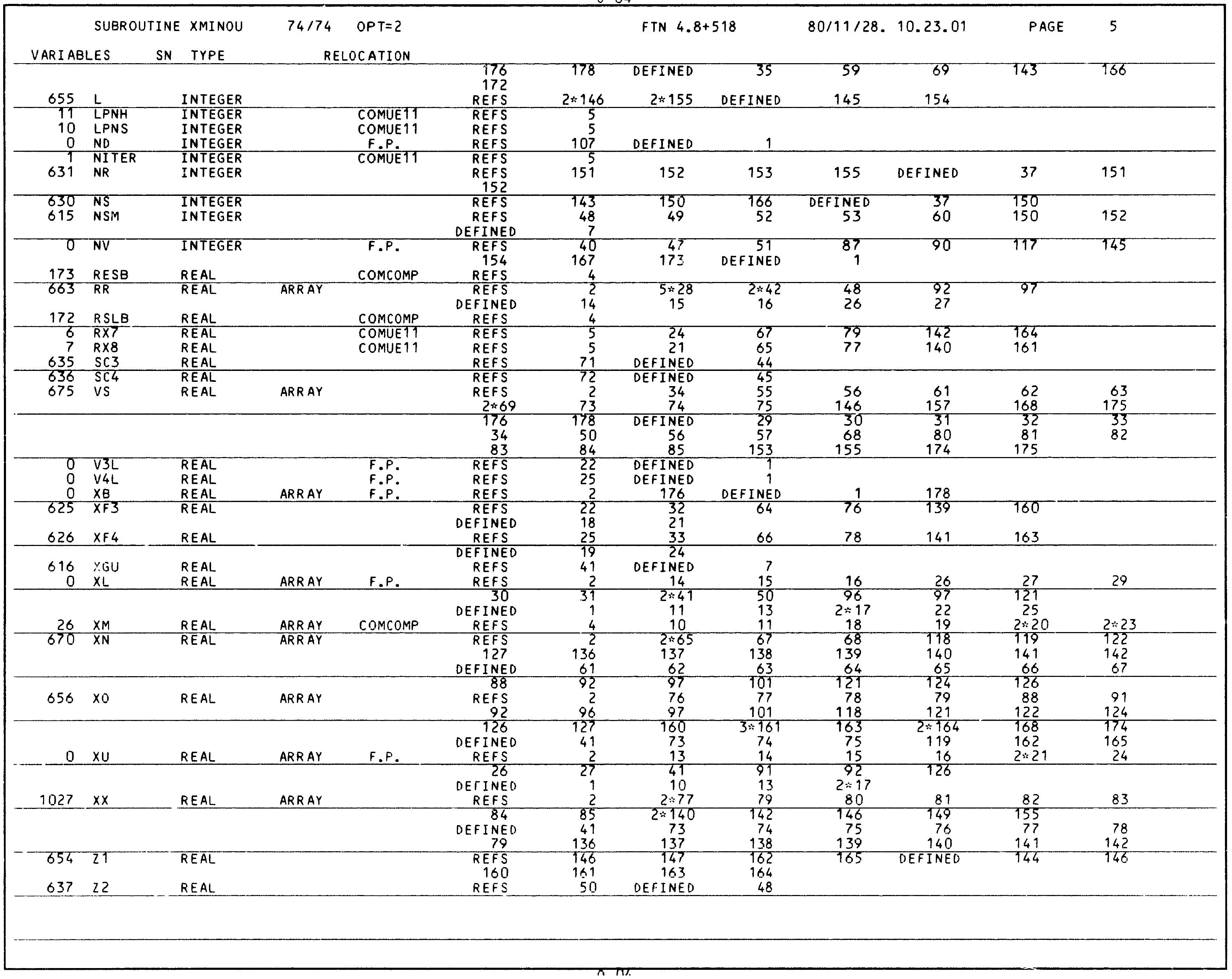




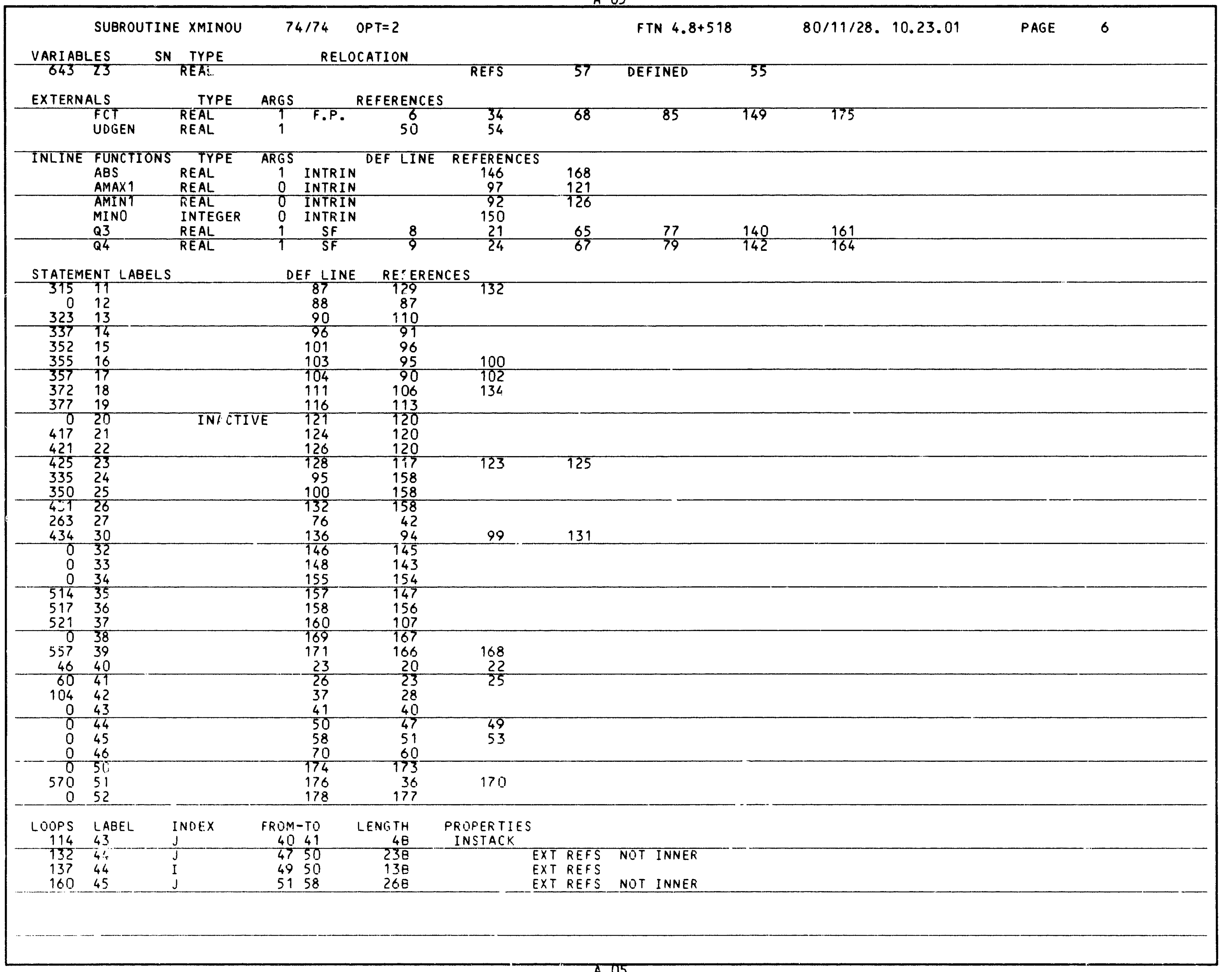




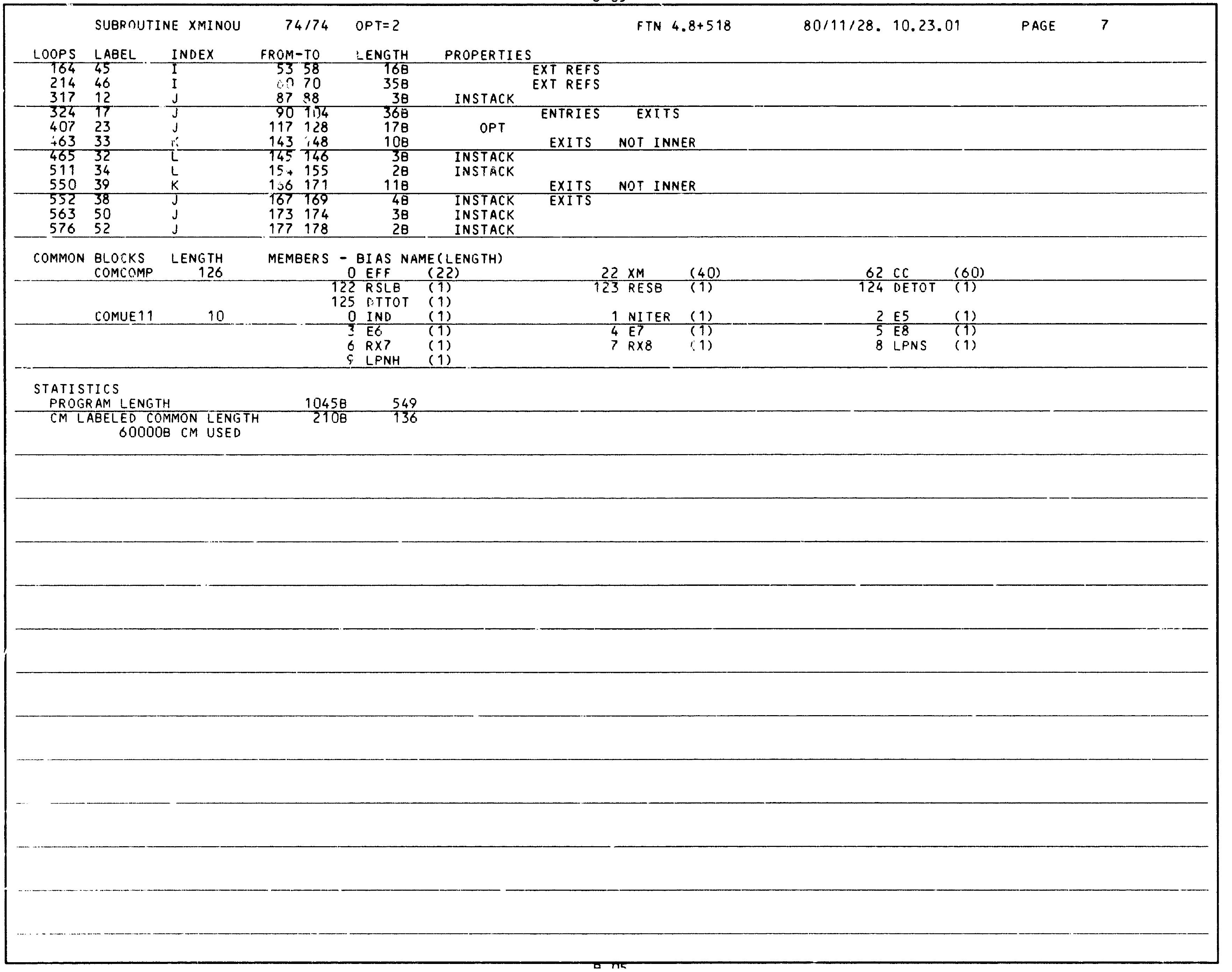




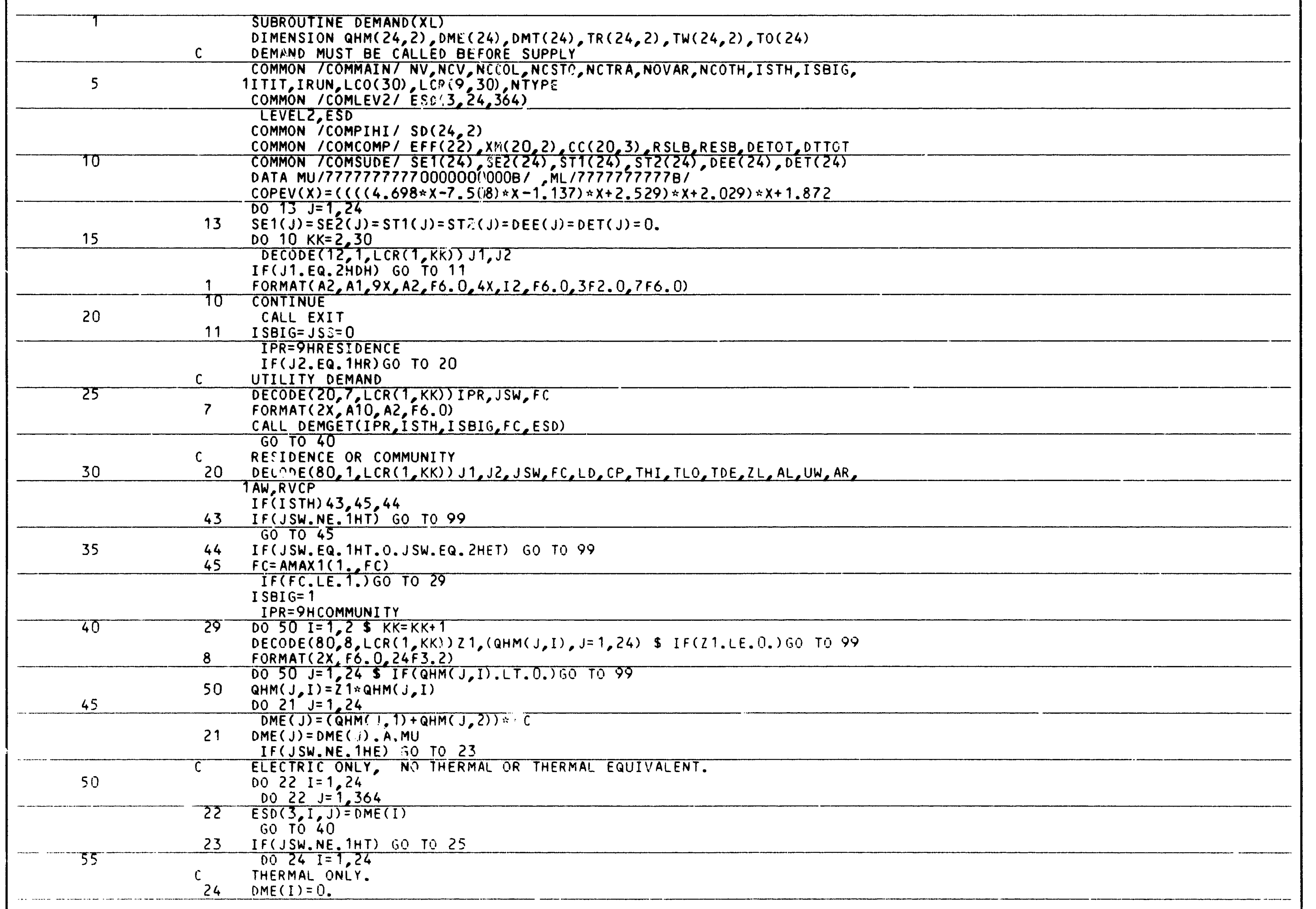


25 IF (JSW.EQ.2HEQ)GO TO 26

IF (JSW.EQ.2HET)GO TO 27

PRINT3, JSW

GO TO 99

3 FORMAT (* ELECTRIC -THERMAL DEMAND MIX ERROR *A10)

65

JSS $=1$

C COMPUTE THERMAL.

IF (LD.GE.O.A.LD.LE. 24)GO TO 28

PRINTY 90 TO 99

4 FORMAT ( * DELTA OUT OF RANGE *I6)

$70 \quad 28 \quad \begin{aligned} \text { SD(1) } & =X L \\ \text { CALL PIHI } & \end{aligned}$

CALL PIHI
$U W=1, E-6 * U W$

$U W=1 . E-6 * U W$

$A L=1.15 * .01 * 317.11 * A L$

$75 \quad$ TIN $=$ TLO

$C P=C P \div A R / 1000$

DO $35 \mathrm{~J}=1,364$

CALL PIH

$80 \quad \begin{array}{ll}21=22=0 . \\ \text { DO } 30\end{array}$

$J 1=\operatorname{SHIFT}(E S D(2, I, J),-36), A .7777 B$

$T O(I)=1.8+(J 1-243)+32$

$J Z=S H I F T(E S D(2, I, J),-12), A .77778$

$2=5 H I F T$

85

$T R(I, 2)=T O(I)+24 * S D(I, 2)$

$T W(I, 2)=T O(I)+24 * S D(I)$

$Z 1=Z 1+T W(1,2)$

$Z 2=22+T R(1,2)$

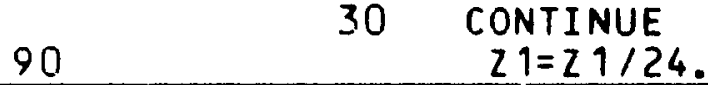

$21=21 / 24$.

IF (J.NE. i) GOTO 32

DO $31 \quad I=1,24$

$95 \quad 31 \quad \operatorname{TW}(\mathrm{I})=\operatorname{TW}(I, 2)$

$32 \quad J 2=L D$

$0033 \quad I=1,24$

$Z 6=F C *(U W * A W *((T I N-Z 1)+Z L *(Z 1-T W(J Z)))+U W * A R *((T I N-Z 2)+$

100

$T W(I)=T W(I D E)$

$T R(I)=T R(I, 2)$

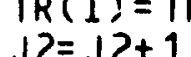

$27=T I N-Z \bar{Z} / \mathrm{CP}$

IF ( 27 . LE. THI ) GO TO 46

105

$26=($ THI -27$) * 26 /(27-$ TIN $)$

TIN $=$ THI

46 IF (27.GE.TLO) 60 TO 47

$\begin{array}{ll}26=(T L O \\ 110 & \text { TIN }=\text { TLO }\end{array}$

TIN $=$ TLO
$G 0$ TO 48

$47 \quad 26=0$.

48 $\quad$ IN $=27$

$48 \operatorname{DMT}(\mathrm{I})=26$ 


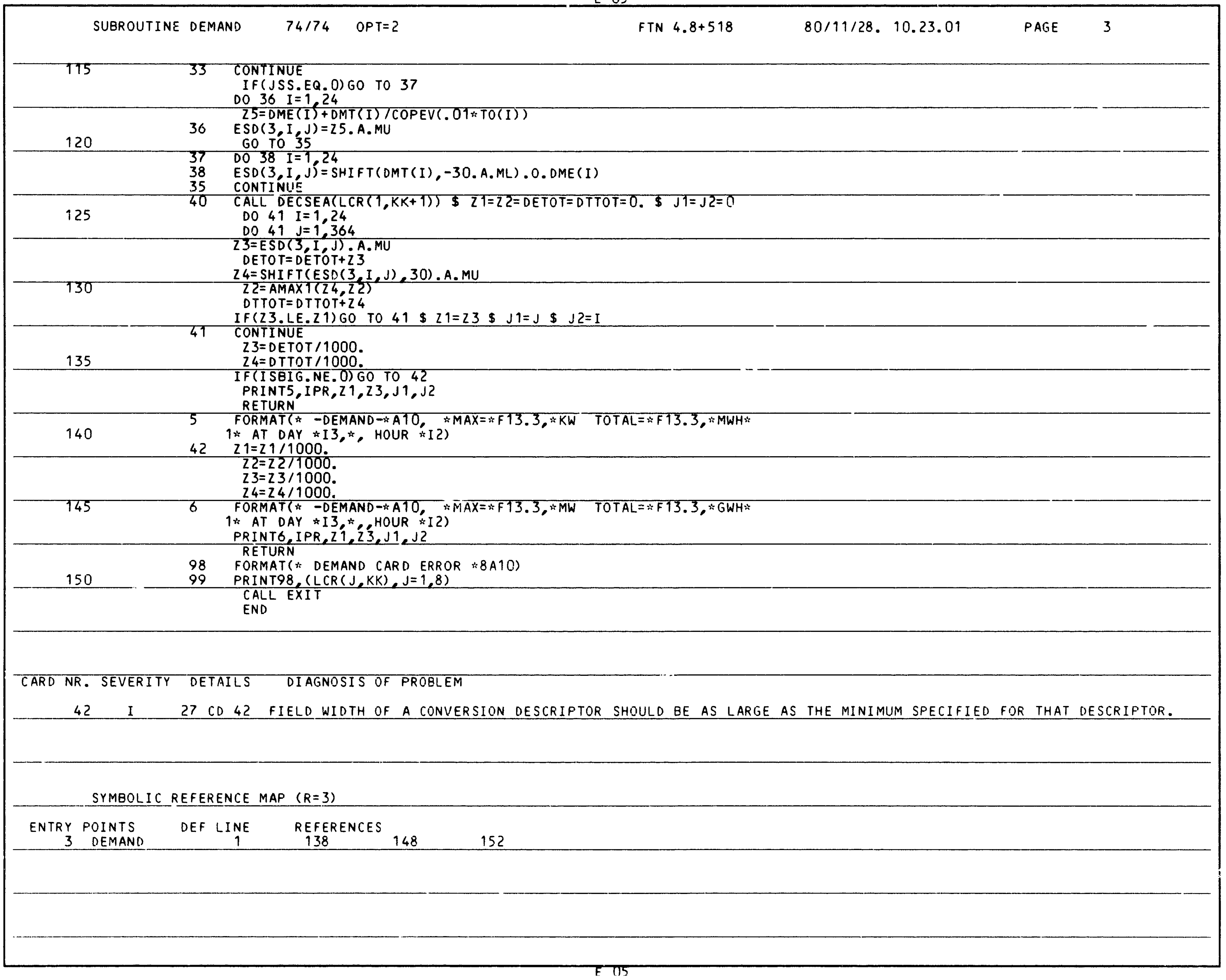




\begin{tabular}{|c|c|c|c|c|c|c|c|c|c|c|c|c|c|}
\hline \multirow{5}{*}{$\begin{array}{c}\text { VARI ABI } \\
672 \\
674 \\
675 \\
76 \\
665 \\
140 \\
170 \\
174 \\
770\end{array}$} & \multirow{2}{*}{\multicolumn{2}{|c|}{$\begin{array}{l}\text { SUBROUTI } \\
\text { LES }\end{array}$}} & \multirow{3}{*}{$\begin{array}{l}\text { E DEMAND } \\
\text { TYPE } \\
\text { REAL } \\
\text { REAL } \\
\text { REAL }\end{array}$} & \multirow{2}{*}{$\begin{array}{r}74 / 74 \\
\text { RE }\end{array}$} & \multirow{2}{*}{$\begin{array}{c}\text { OPT }=2 \\
\text { OCATION }\end{array}$} & \multicolumn{4}{|c|}{ FTN $4.8+518$} & \multirow[t]{2}{*}{$80 / 11 / 28$. } & \multirow[t]{2}{*}{10.23 .01} & \multirow[t]{2}{*}{ PAGE } & \multirow[t]{2}{*}{4} \\
\hline & & & & & & & & & & & & & \\
\hline & $\begin{array}{l}A L \\
A R \\
A W\end{array}$ & & & & & $\begin{array}{l}\text { REFS } \\
\text { REFS } \\
\text { REFS }\end{array}$ & $\begin{array}{l}74 \\
76 \\
98\end{array}$ & $\begin{array}{c}84 \\
98 \\
\text { DEFINED }\end{array}$ & $\begin{array}{c}\text { DEFINED } \\
\text { DEFINED } \\
30\end{array}$ & $\begin{array}{l}30 \\
30\end{array}$ & 74 & & \\
\hline & $\begin{array}{l}C C \\
C P \\
C F E\end{array}$ & & $\begin{array}{l}\text { REAL } \\
\text { REAL } \\
\text { REAl }\end{array}$ & $\begin{array}{l}\text { ARRAY } \\
\text { APRAY }\end{array}$ & COMCOMP & $\begin{array}{l}\text { REFS } \\
\text { REFS } \\
\text { PEFS }\end{array}$ & $\begin{array}{r}9 \\
76 \\
10\end{array}$ & $\begin{array}{c}103 \\
\text { DEF }\end{array}$ & DEFINED & 30 & 76 & & \\
\hline & $\begin{array}{l}\text { DET } \\
\text { DETOT } \\
\text { DME }\end{array}$ & & $\begin{array}{l}\text { REAL } \\
\text { REAL } \\
\text { REAL } \\
\text { REAL }\end{array}$ & $\begin{array}{l}\text { AKKAI } \\
\text { ARRAY } \\
\text { ARRAY }\end{array}$ & $\begin{array}{l}\text { COMSUDE } \\
\text { COMCOMP }\end{array}$ & $\begin{array}{l}\text { REFS } \\
\text { REFS } \\
\text { REFS }\end{array}$ & $\begin{array}{r}10 \\
10 \\
9 \\
2\end{array}$ & $\begin{array}{c}\text { DEFINED } \\
128 \\
47\end{array}$ & $\begin{array}{r}14 \\
14 \\
134 \\
52 \\
\end{array}$ & $\begin{array}{c}\text { DEF INED } \\
118 \\
\end{array}$ & $\begin{array}{l}124 \\
122\end{array}$ & 128 & \\
\hline $\begin{array}{r}1020 \\
175\end{array}$ & $\begin{array}{l}\text { DMT } \\
\text { DTTOT }\end{array}$ & & $\begin{array}{l}\text { REAL } \\
\text { REAL }\end{array}$ & ARRAY & COMCOMP & $\begin{array}{c}\text { DEFINED } \\
\text { REFS } \\
\text { REFS }\end{array}$ & $\begin{array}{r}46 \\
2 \\
9\end{array}$ & $\begin{array}{r}47 \\
118 \\
131\end{array}$ & $\begin{array}{r}57 \\
122 \\
135\end{array}$ & $\begin{array}{l}\text { DEF INED } \\
\text { DEFINED }\end{array}$ & $\begin{array}{l}114 \\
124\end{array}$ & 131 & \\
\hline $\begin{array}{l}0 \\
0\end{array}$ & $\begin{array}{l}\text { EFF } \\
\text { ESD }\end{array}$ & & $\begin{array}{l}\text { REAL } \\
\text { REAL }\end{array}$ & $\begin{array}{l}\text { ARRAY } \\
\text { ARRAY }\end{array}$ & $\begin{array}{l}\text { COMCOMP } \\
\text { COMLEVZ }\end{array}$ & $\begin{array}{c}\text { REFS } \\
\text { REFS } \\
\text { DEFINED }\end{array}$ & $\begin{array}{r}9 \\
6 \\
52\end{array}$ & $\begin{array}{r}7 \\
119\end{array}$ & $\begin{array}{r}27 \\
122\end{array}$ & OLI INE & 83 & 127 & 129 \\
\hline 663 & $F C$ & & REAL & & & $\begin{array}{c}\text { REFS } \\
\text { DEFINED }\end{array}$ & $\begin{array}{l}27 \\
25\end{array}$ & $\begin{array}{l}36 \\
30\end{array}$ & $\begin{array}{l}37 \\
36\end{array}$ & 46 & 98 & & \\
\hline 677 & I & & INTEGER & & & $\begin{array}{c}\text { REFS } \\
83 \\
2 * 100 \\
132\end{array}$ & $\begin{array}{r}41 \\
3 * 85 \\
2 * 101 \\
\text { DEFINED }\end{array}$ & $\begin{array}{l}43 \\
3 \times 86 \\
114 \\
40 \\
\end{array}$ & $\begin{array}{c}2 \times 44 \\
87 \\
7 * 118 \\
50 \\
\end{array}$ & $\begin{array}{c}2 \times 52 \\
88 \\
119 \\
55 \\
\end{array}$ & $\begin{array}{c}57 \\
2 * 94 \\
3 * 122 \\
80 \\
\end{array}$ & $\begin{array}{c}81 \\
2 \times 95 \\
127 \\
93 \\
\end{array}$ & $\begin{array}{c}82 \\
2298 \\
129 \\
97 \\
\end{array}$ \\
\hline $\begin{array}{r}661 \\
12\end{array}$ & $\begin{array}{l}\text { IPR } \\
\text { IRUN }\end{array}$ & & $\begin{array}{l}\text { INTEGER } \\
\text { INTEGER }\end{array}$ & & COMMAIN & $\begin{array}{l}117 \\
\text { REFS } \\
\text { REFS }\end{array}$ & $\begin{array}{r}121 \\
27 \\
4\end{array}$ & $\begin{array}{l}125 \\
137\end{array}$ & 147 & DEFINED & 22 & 25 & 39 \\
\hline $\begin{array}{r}10 \\
7 \\
11\end{array}$ & $\begin{array}{l}\text { I SBIG } \\
\text { I STH } \\
\text { ITIT }\end{array}$ & & $\begin{array}{l}\text { INTEGER } \\
\text { INTEGER } \\
\text { INTEGER }\end{array}$ & & $\begin{array}{l}\text { COMMAIN } \\
\text { COMMAIN } \\
\text { COMMAIN }\end{array}$ & $\begin{array}{l}\text { RLIS } \\
\text { REFS } \\
\text { REFS }\end{array}$ & $\begin{array}{r}7 \\
4 \\
4\end{array}$ & $\begin{array}{l}27 \\
27\end{array}$ & $\begin{array}{r}136 \\
32\end{array}$ & DEFINED & 21 & 38 & \\
\hline 654 & $j$ & & INTEGER & & & $\begin{array}{r}\text { REFS } \\
81 \\
150 \\
\end{array}$ & $\begin{array}{r}6 \div 14 \\
83 \\
\text { DEFINED }\end{array}$ & $\begin{array}{l}41 \\
92 \\
13 \\
\end{array}$ & $\begin{array}{r}43 \\
119 \\
41 \\
\end{array}$ & $\begin{array}{c}2: 44 \\
122 \\
43 \\
\end{array}$ & $\begin{array}{c}3 * 46 \\
127 \\
45 \\
\end{array}$ & $\begin{array}{c}2 \times 47 \\
129 \\
51 \\
\end{array}$ & $\begin{array}{r}52 \\
132 \\
77 \\
\end{array}$ \\
\hline $\begin{array}{l}660 \\
662\end{array}$ & $\begin{array}{l}\text { JSS } \\
\text { JSW }\end{array}$ & & $\begin{array}{l}\text { INTEGER } \\
\text { INTEGER }\end{array}$ & & & $\begin{array}{r}126 \\
\text { REFS } \\
\text { REFS }\end{array}$ & $\begin{array}{l}150 \\
116 \\
33\end{array}$ & $\begin{array}{r}\text { DEFINED } \\
2 * 35\end{array}$ & $\begin{array}{l}21 \\
48\end{array}$ & $\begin{array}{l}64 \\
54\end{array}$ & 59 & 60 & 61 \\
\hline 6.56 & J1 & & INTEGER & & & $\begin{array}{c}\text { DEFINED } \\
\text { REFS } \\
81\end{array}$ & $\begin{array}{r}25 \\
17 \\
124\end{array}$ & $\begin{array}{r}30 \\
82 \\
132\end{array}$ & 137 & 147 & DEFINED & 16 & 30 \\
\hline 657 & $\sqrt{2}$ & & $\begin{array}{l}\text { INTEGER } \\
\text { INTEGER }\end{array}$ & & & $\begin{array}{c}\text { REFS } \\
\text { DEFINED } \\
\text { REFS }\end{array}$ & $\begin{array}{l}23 \\
16 \\
16\end{array}$ & $\begin{array}{l}84 \\
30 \\
25\end{array}$ & $\begin{array}{c}2 \div 98 \\
83 \\
30\end{array}$ & $\begin{array}{r}102 \\
96 \\
40\end{array}$ & $\begin{array}{r}137 \\
102 \\
41\end{array}$ & $\begin{array}{l}147 \\
124 \\
124\end{array}$ & $\begin{array}{l}132 \\
150\end{array}$ \\
\hline $\begin{array}{l}13 \\
51\end{array}$ & $\begin{array}{l}\text { LCO } \\
\text { LCR }\end{array}$ & & $\begin{array}{l}\text { INTEGER } \\
\text { INTEGER }\end{array}$ & $\begin{array}{l}\text { ARRAY } \\
\text { ARRAY }\end{array}$ & $\begin{array}{l}\text { COMMAIN } \\
\text { COMMAIN }\end{array}$ & $\begin{array}{c}\text { DEFINED } \\
\text { REFS } \\
\text { REFS }\end{array}$ & $\begin{array}{r}15 \\
4 \\
4\end{array}$ & 16 & 25 & 30 & 41 & 124 & 150 \\
\hline $\begin{array}{l}664 \\
440 \\
437\end{array}$ & $\begin{array}{l}\text { LD } \\
M L\end{array}$ & & $\begin{array}{l}\text { INTEGER } \\
\text { INTEGER } \\
\text { INTEGER }\end{array}$ & & & $\begin{array}{l}\text { REFS } \\
\text { REFS } \\
\text { REFS }\end{array}$ & $\begin{array}{c}2: 66 \\
122 \\
47\end{array}$ & $\begin{array}{c}67 \\
D E F I N E D \\
119\end{array}$ & $\begin{array}{r}73 \\
11 \\
127\end{array}$ & $\begin{array}{r}96 \\
129\end{array}$ & $\begin{array}{l}\text { DEFINED } \\
\text { DEFINED }\end{array}$ & $\begin{array}{l}30 \\
11\end{array}$ & 73 \\
\hline $\begin{array}{r}451 \\
2 \\
6 \\
3\end{array}$ & $\begin{array}{l}\text { NCCOL } \\
\text { NCOTH } \\
\text { NCSTOO }\end{array}$ & & $\begin{array}{l}\text { INTEGER } \\
\text { INTEGER } \\
\text { INTEGER }\end{array}$ & & $\begin{array}{l}\text { COMMAIN } \\
\text { COMMAIN } \\
\text { COMMAIN }\end{array}$ & $\begin{array}{l}\text { REFS } \\
\text { REFS } \\
\text { REFS }\end{array}$ & $\begin{array}{r}41 \\
4 \\
4 \\
4\end{array}$ & & & & & & \\
\hline $\begin{array}{l}4 \\
1 \\
5\end{array}$ & $\begin{array}{l}\text { NCTRA } \\
\text { NCV }\end{array}$ & & $\begin{array}{l}\text { INTEGER } \\
\text { INTEGER }\end{array}$ & & $\begin{array}{l}\text { COMMAIN } \\
\text { COMMAIN }\end{array}$ & $\begin{array}{l}\text { REFS } \\
\text { REFS }\end{array}$ & $\begin{array}{l}4 \\
4\end{array}$ & & & & & & \\
\hline 5 & NOVAR & & INTEGER & & COMMAIN & REFS & 4 & & & & & & \\
\hline $\begin{array}{r}467 \\
0 \\
710\end{array}$ & $\begin{array}{l}\text { NTYPE } \\
\text { NV } \\
\text { OHM }\end{array}$ & & $\begin{array}{l}\text { INTEGER } \\
\text { INTEGER } \\
\text { REAI }\end{array}$ & & $\begin{array}{l}\text { COMMAIN } \\
\text { COMMAIN }\end{array}$ & $\begin{array}{l}\text { REFS } \\
\text { REFS } \\
\text { RFFS }\end{array}$ & $\begin{array}{l}4 \\
4 \\
7\end{array}$ & & 44 & $2 \because 46$ & 98 & & \\
\hline 173 & RESB & & REAL & ARRAY & COMCOMP & $\begin{array}{l}\text { REFS } \\
\text { DEFINED } \\
\text { REFS }\end{array}$ & 41 & $\frac{43}{44}$ & 44 & & & & \\
\hline
\end{tabular}




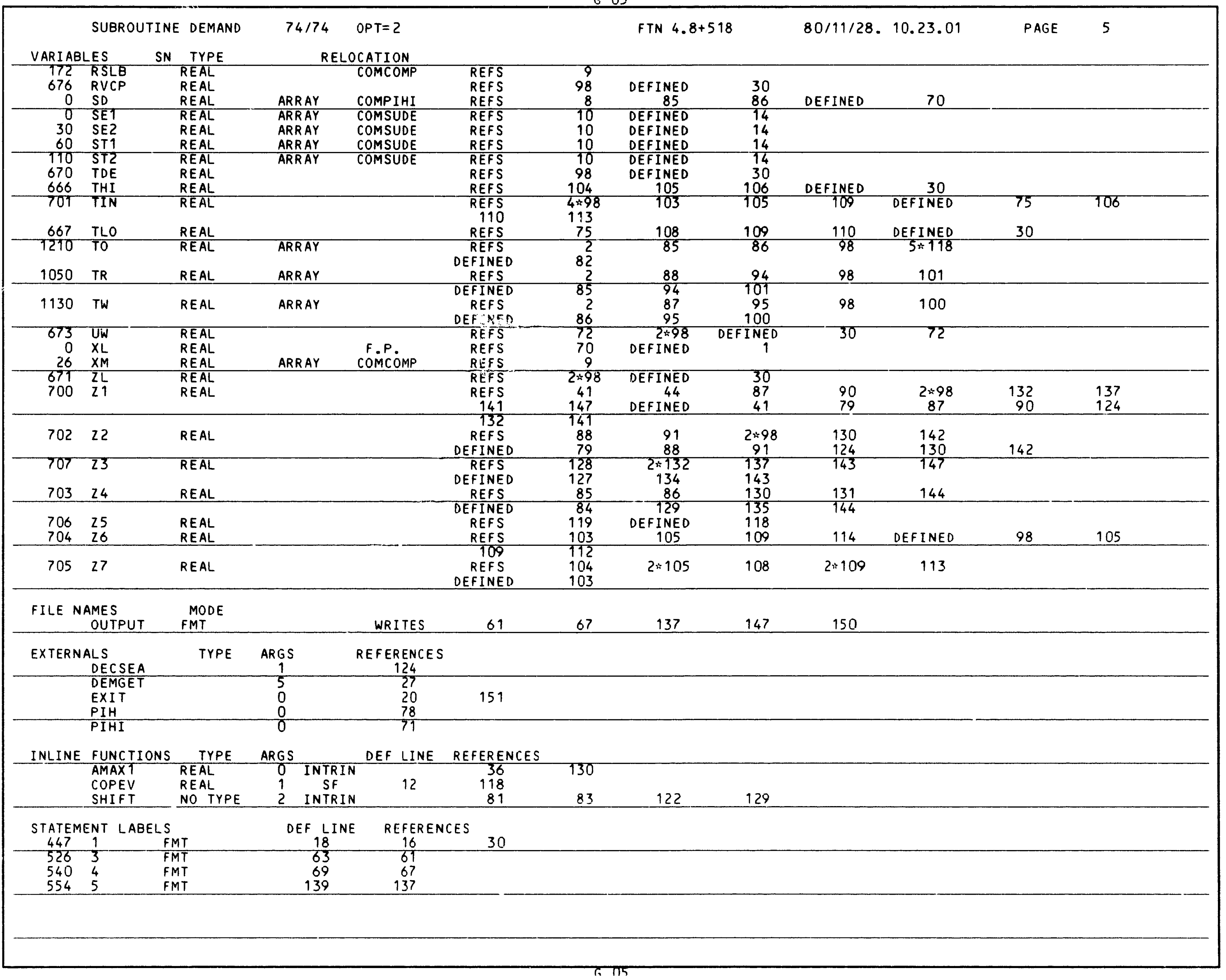




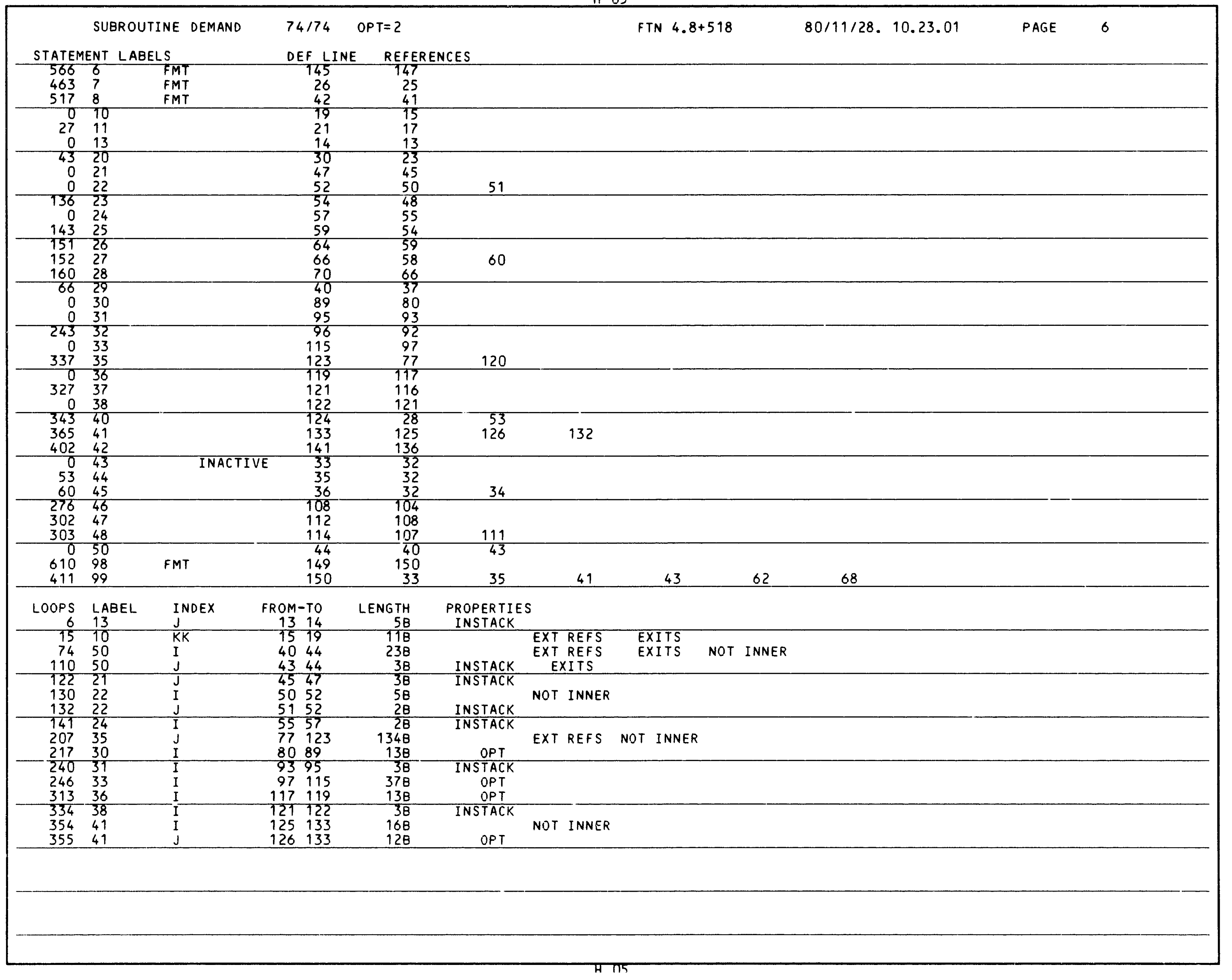




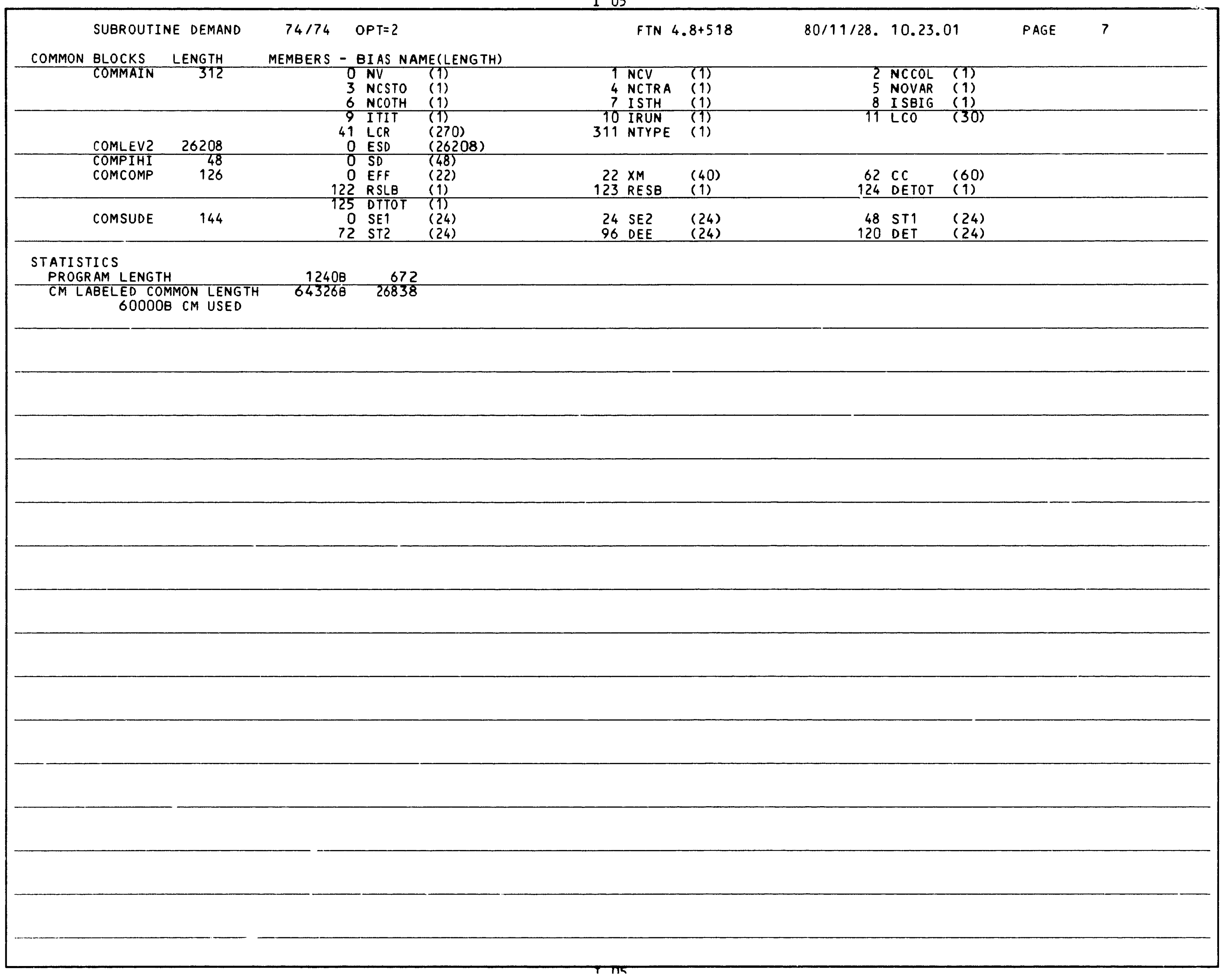


1 SUBROUTINE RDINP(NDAY)

DIMENSION LTYC (9), JWK( 30), LDO(6), LDW(8), LDM(8)

COMMON / COMMAIN/ NV, NCV, NCCOL,NCSTT, NCTRA, NOVAR, NCOTH, ISTH, I SBIG,

5

IITIT, IRUN, LCO(3O),LCR $(9,30)$, NTYPE

DATA ISW/Ö\%, JBL/1H /, JST/1H\&/,NTYC/9/

DATA LTYC/2HDH, 2HYR ZHAM 2HPE 2HPT 2HLO 2HDW 2HDM 2HCS/

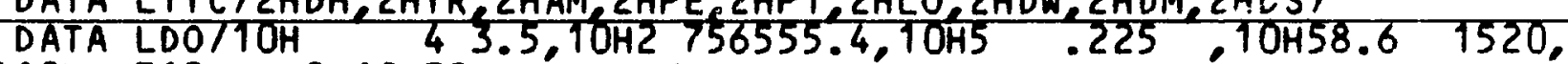

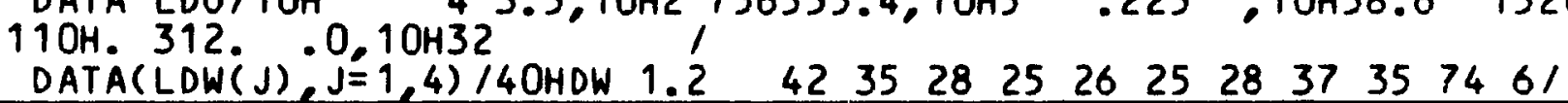

10

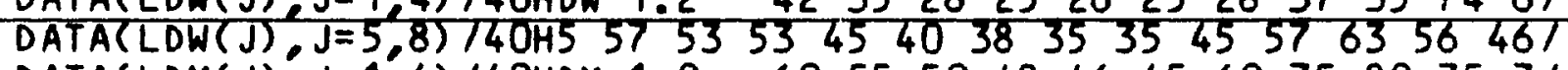

$\operatorname{DATA}(\operatorname{LDM}(J), J=1,4) / 40 \mathrm{HDM} 1.0 \quad 6055 \quad 5048 \quad 46 \quad 456075 \quad 80757 /$

DATA(LDM(J) J=5,8)/4OHO $7070707070709011011011010510080 /$

DO $17 \mathrm{~J}=1,30$

$15 \quad 17 \quad \operatorname{LCR}(9, J)=J B L$

IF (ISW.GT.O) GO TO 11

JSW = I SW=1

$\begin{array}{lll}\text { DO } & 10 & J=1,9 \\ \text { DO } & 10 & I=2,30\end{array}$

$2010 \quad$ LCR $(J, I)=J B L$

$N C=N C V+N C O T H+1$
$\operatorname{LCR}(9,1)=J S T$

11 READT,J1, (JWK (J), J = 1,8)

IF (J\}.EQ́.JBL) GÓ TO 16

$J S W=J S W+1$

25 FORMAT(A2 A8,7A10)

IF (J1.NE. $2 H I D)$ GO TO 12

JWK $(\dot{3})=\operatorname{LCR}(3)$

$J=1$

GO TO 15

$30 \quad 12 \quad 0013 \mathrm{~J}=2, \mathrm{NC}$

IF (JT.EQ.LCO(J))GOTO 15

13 CONTINUE

PRINT14,J1, (JWK(J),J=1,8)

CALL EXIT

3514 FORMAT(* INVALID INPUT CARD* $11 \mathrm{X}, A 2, A 8,7 A 10)$

$15 \quad \operatorname{ENCODE}(80,1, \operatorname{LCR}(1, \mathrm{~J})) \mathrm{J} 1,(\mathrm{JWK}(\mathrm{I}), I=1,8)$

$\operatorname{LCR}(9, J)=J S T$

GO TO 11

$40 \quad 16 \quad$ IF (JSW.EQ. 1) CALL EXIT

CALL UDGET( I 1)

C PRINT CARDS.

PRINT2, ITIT IRUN NDAY I1, (LCR (J) J=19)

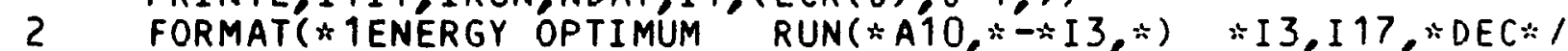
$1 *(* 7(A 10, * / *), A 10 *) * A 1)$

$45 \quad 1 *(* 7(A 10 *)$

CHECK THAT ALL CARDS ARE THERE.

DO $18 \mathrm{~J}=1, N C$ \& DECODE $(10,1, L C R(i, j)) \mathrm{J}$

50

18 IF(JT.EQ.LCO(J))GO TO 18

DECODE $(80,3, L C R(1, I)\}$ (JWK (J), J=1,14)

20 PRINT4, (JWK $(j), j=1,14), \operatorname{LCR}(9, I)$

$I 1=I 1+1$

FORMAT(* (*A2, *1*A4,*1:A8, 11(:1:A6,),:):AT)

DO $50 \mathrm{I}=\mathrm{I} 1, \mathrm{NC}$

$\operatorname{DECODE}(10,1, \operatorname{LCR}(1, I)) J 1$ 


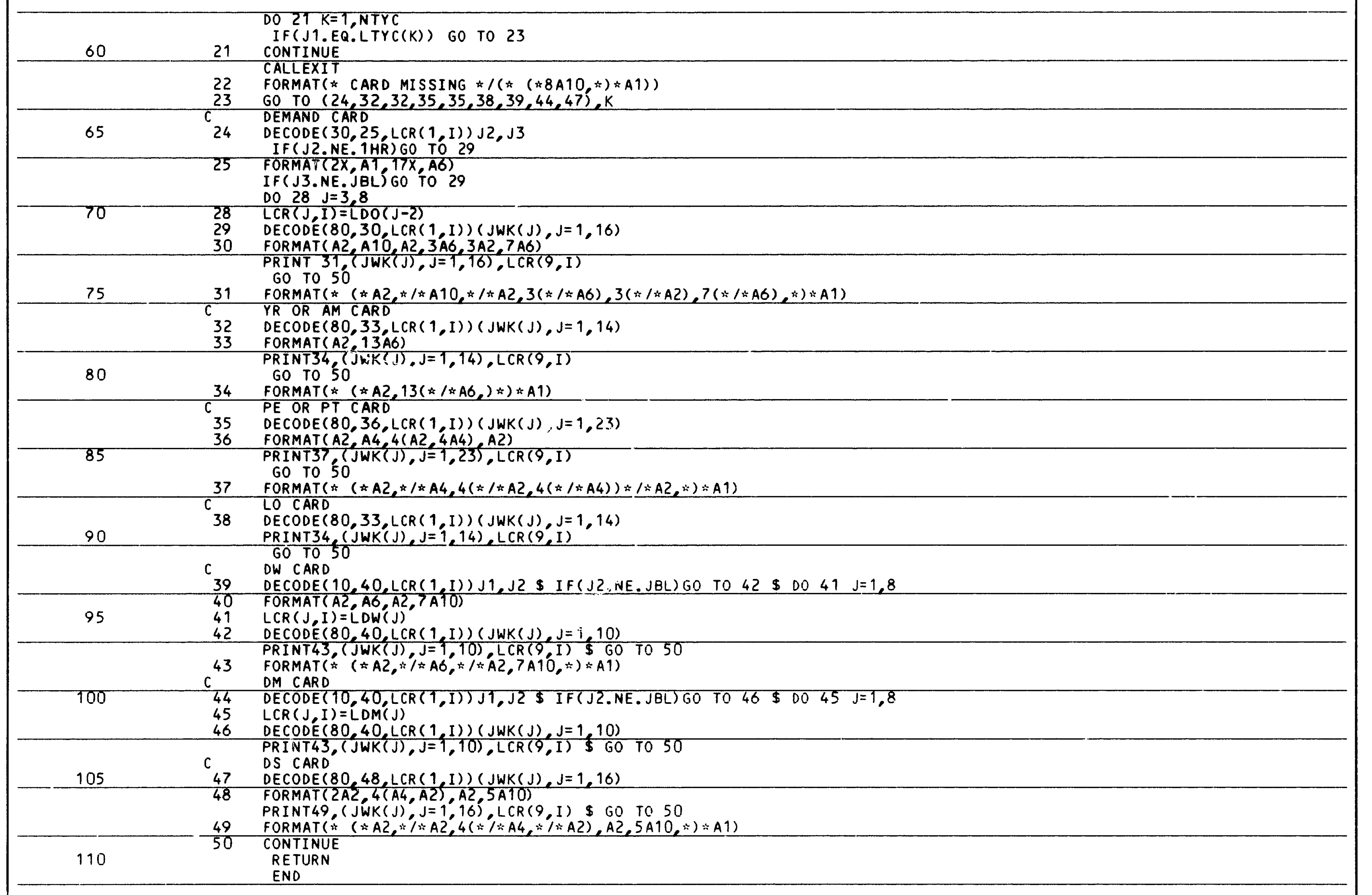


CARD NR. SEVERITY DETAILS DIAGNOSIS OF PROBLEM

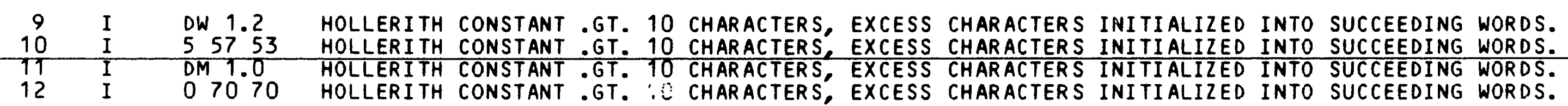

SYMBOLIC REFERENCE MAP $(R=3)$

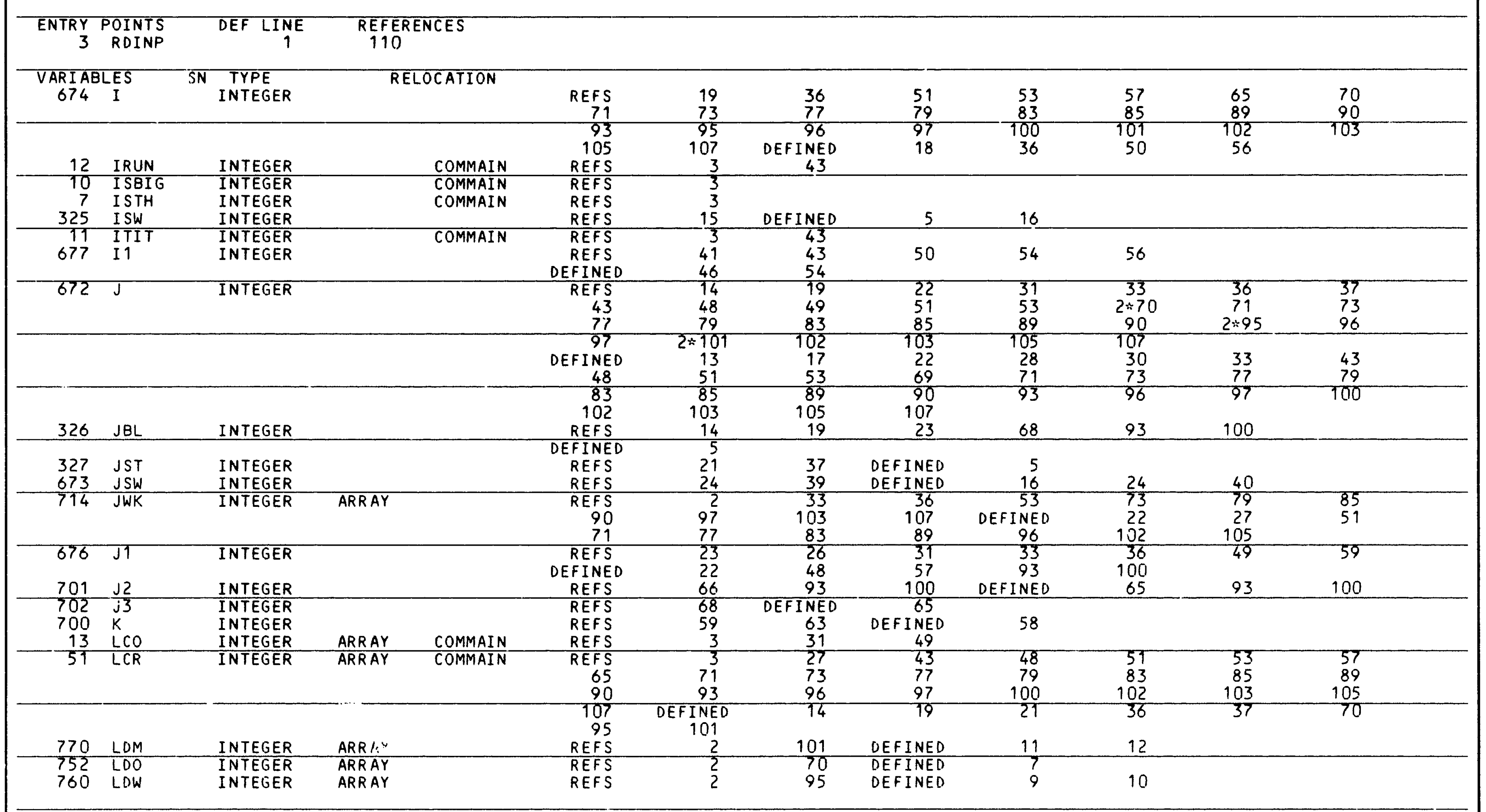




\begin{tabular}{rlrl}
\multicolumn{2}{c}{ VARI ABLES } & SN & TYPE \\
\cline { 1 - 2 } 703 & LTYC & & INTEGER \\
675 & NC & INTEGER \\
2 & NCCOL & INTEGER \\
\hline 6 & NCOTH & INTEGER \\
3 & NCSTO & INTEGER \\
4 & NCTRA & INTEGER \\
\hline 1 & NCV & INTEGER \\
0 & NDAY & INTEGER \\
5 & NOVAR & INTEGER \\
330 & NTYC & INTEGER \\
467 & NTYPE & INTEGER \\
0 & NV & INTEGER \\
\hline
\end{tabular}

RELOCATION ARRAY RELOCATION

COMMAIN
COMMAIN
COMMAIN
COMMAIN
COMMAIN
F.P.
COMMAIN
COMMAIN
COMMAIN

REFS
REFS
REFS
REFS
REFS
REFS
REFS
REFS
REFS
REFS
REFS

2
30
3
3
3
43
58
3

$\begin{aligned} 2 & \\ 30 & \\ 3 & \\ 3 & \\ 3 & \\ 3 & \\ 3 & \\ 43 & \text { DEF } \\ 3 & \\ 58 & \text { DEF } \\ 3 & \\ 3 & \end{aligned}$

$\begin{array}{cccc}59 & \text { DEFINED } & 6 & \text { NEINED }\end{array}$

\begin{tabular}{cc} 
FILE NAMES & MODE \\
INPUT & FMT \\
\hline OUTPUT & FMT
\end{tabular}

$\begin{array}{cr}\text { READS } & 22 \\ \text { WRITES } & 33 \\ 97 & 103\end{array}$

$\begin{array}{rr}22 & \\ 33 & 43 \\ 103 & 107\end{array}$

49

53

73

79

85

90

\begin{tabular}{ccc}
\hline EXTERNALS & TYPE & ARGS \\
EXIT & 0 \\
UDGET & & 1 \\
\hline
\end{tabular}

$G S$
0
1

REFERENCES

$\begin{array}{r}34 \\ 41 \\ \hline\end{array}$

39

49

61

STATEMENT LABELS

\begin{tabular}{rrr}
337 & 1 & FMT \\
\hline 372 & 2 & FMT \\
422 & 3 & FMT \\
432 & 4 & FMT \\
0 & 10 & \\
25 & 11 & \\
37 & 12 & \\
\hline 0 & 13 & \\
347 & 14 & FMT \\
50 & 15 & \\
57 & 16 & \\
0 & 17 & \\
103 & 18 & \\
0 & 20 & \\
0 & 21 & \\
445 & 22 & FMT \\
\hline 146 & 23 & \\
164 & 24 & \\
461 & 25 & FMT \\
\hline 0 & 28 & \\
200 & 29 & \\
471 & 30 & FMT \\
\hline 502 & 31 & FMT \\
210 & 32 & FMT \\
517 & 33 & FMT \\
526 & 34 & FMT \\
220 & 35 & FMT \\
537 & 36 & FMT \\
547 & 37 & \\
230 & 38 & \\
240 & 39 & \\
\hline 576 & 40 & FMT \\
0 & 41 & \\
252 & 42 & \\
\hline & &
\end{tabular}

DEF LINE REFERENCES

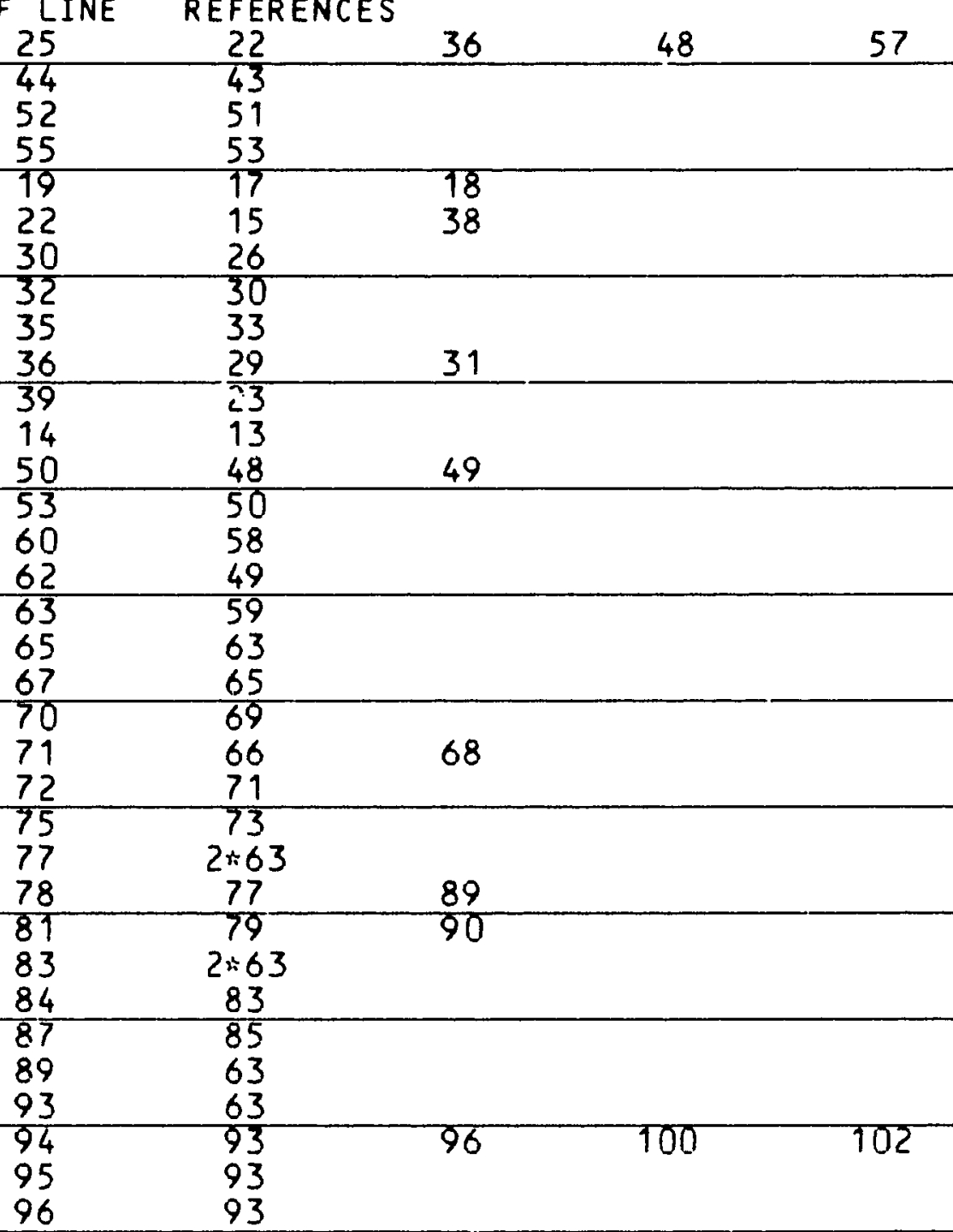




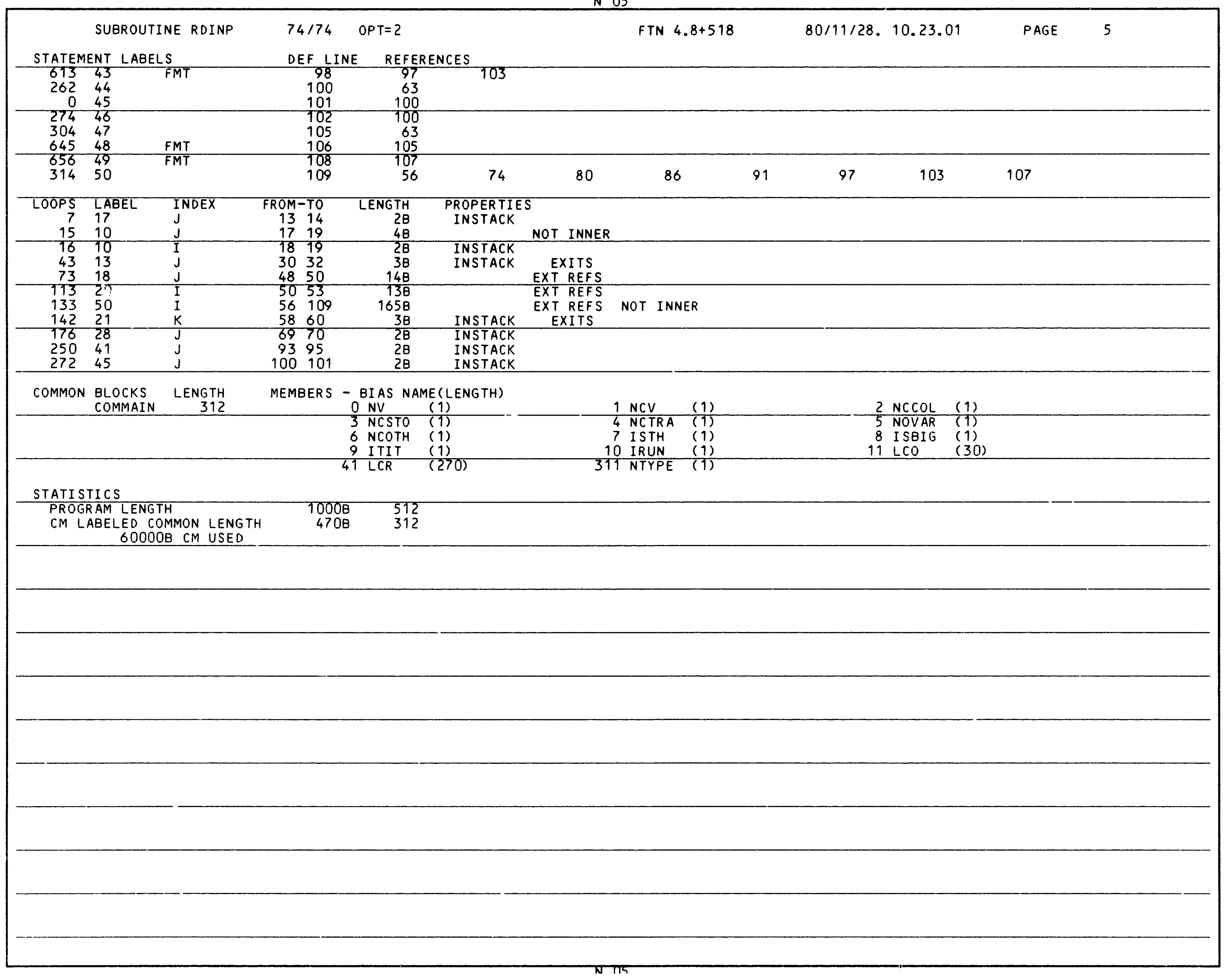


SOLSTOR - UE11 - SOLLIB2 LIBRARY. 
FUNCTION UETTDF $(X X X X)$

DIMENSION $X X X X(20), X O L(5), J \times O L(5), B 5(5,48)$

COMMON /COMCUMU/ NAMCU(3), CU(20,3), R(20)

COMMON TCOMWIND/ W(8) I SWND(2)

5 COMMON /COMCOMP/ EFF(22), XM(20,2), CC (20,3), RSLB,RESB, DETOT, DTTOT

COMMON /COMPURC/ EPUR (11,2), ESLE(10) ECOS(11), I TOD (26),

A PCOS (10), PDCO (12,2), MHPK (12), MHOUR(12)

B RLCCR
COMMON /COMANSW/ $x(20) \times C O(20), M X X(20), C T O T(7,2)$

10 COMMON TCOMSUDET SET(24), SEZ(24), STT(24), ST2(24), DEE(24), DET(24)

COMMON /COMPRNS/ TA(20,2), TB( 20,2$), F F D(6,2)$, AES $(6,2), \operatorname{CLV}(4)$

1WRS $(10,24)$

COMMON /COMUE $11 /$ IND, NITER,E5, E6,E7, E8,RX7,RX8, NSNS, NHNH

15

COMMON /COMLPRO/ NH,NS, SU (24), DE $(24), C T B(7,24), X T B(13), K S B W$

COMMON /COMSXOL/ ISXOL

DATA XOL $15(-1)$.

IF(I SWND(1).EQ.0)GO TO 22 \$PRINT2 \& CALL EXIT

2 FORMAT ( WIND NOT ALLOWED IN UE11D*)

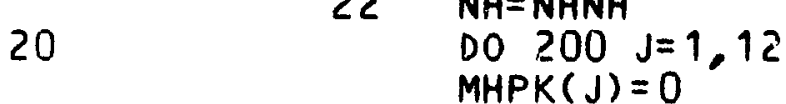

$200 \quad P D C O(J)=P D C O(J, 2)=75$

$M D=1$

$N H R=0$

$25 \quad$ EPUR(11) $=E F F(22)=0$

DO $10 \mathrm{~J}=1,10$

$10 \operatorname{EPUR}(J)=\operatorname{ESL}(J)=0$.

NI TER $=$ NI TER+

DO $11 \mathrm{~J}=1,4$

$30 \quad 11 \quad x(j)=X X X X(j)$

$X 7=R X 7 * X(2)$

$X 8=R \times 8 * X(2)$

$E 15 X=E F F(1) * E 5 * X(1)$

$35 \quad E 36=E F F(3) * E 6$

$R 36=R S L B * E 36$

$R 38=R S L B+E 38$

$E 47=E 7 * E F F(4)$

$E S T=E B M=0$

$40 \quad X T B(2)=X(2)$

$X T B(3)=X(3) / E 8$

$X T B(4)=x(4)$

$X T B(5)=E 7$

$X \operatorname{TB}(6)=\operatorname{AMIN} 1(X \operatorname{TP}(3), X 8)$

45

$X T B(7)=X 7$

$X T B(8)=X 8$

$X T B(9)=E F F(4)$

$X T B(10)=E F F(2)$

$X T B(11)=E 47$

$50 \quad X T B(12)=E 6 / E 8$

$X T B(13)=E F F(4) * X(4)$

12 IF(IND.LE.0) G0 TO 17

$\mathrm{NW}=0$

DO $13 \quad I=1,20$

55

DO $13 \mathrm{~J}=1,3$

$13 \quad \operatorname{CU}(I, J)=0$.

NAMCU(1) $=2 H S T$ 
NAMCU (2) $=2 \mathrm{H}$

60

$\operatorname{NAMCU}(3)=1 \mathrm{H}$

D015I $=1,2$

$0014 J=1,20$

$14 \quad T A(J, I)=T B(J, I)=0$.

65

$15 \quad F F D(J, I)=A E S(J, I)=0$.

DCU2 $=0$.

E15=EFF(1)*E5 I IF(E15.LE. O.)E15=1.

IF (X(2). GE.. 1) GO TO 16 \$ \$ PRINTA क CALL EXIT

1 FORMAT (* LESS THAN 0.1 KW STORAGE NOT ALLOWED IN UE110*)

16 DCUZ $=19.9999 / X(2)$

$70 \quad$ WRITE $(S)(X(J), J=1,10)$

17 CALL TODPR(1) \& CALL DGETSD(1) DO $18 \mathrm{~K}=1,24$

$B 5(1, K)=S E 1(K) * E 15 X \& B 5(4, K)=S E 2(K) * E 15 X \& \quad J P=I T O D(K)$

$18 \quad B(3, K)=(E \operatorname{COS}(J P)$. A. $(-17 B))$. $0 . J P \$ B 5(2, K)=D E E(K)$

$18 \quad B 5(5, K)=D E T(K)$

C.... SE $1=T R U E$ SU, SEZ $=S U$ PRED. DEE $=T R U E$ DE, DET=DE PRED.

C.... BEGIN LOOP

DO 59 ND $=1,364 \$$ CALL TODPR (ND+1) \$ CALL DGETSD(ND+1)

DO $19 \quad K=1,24 \$ L=K+24 \$ B 5(1, L)=S E 1(K) \times E 15 X \$ B 5(2, L)=D E E(K)$

$\begin{array}{lll}80 & B 5(4, L)=S E 2(K) * E 15 X \$ B 5(5, !)=D E \\ B 5(3, L)=(E C O S(J P) . A .(-17 B)) .0 . J P\end{array}$

DO 58 NHOU $=124 \$ \mathrm{KSOW}=1$ \$ IF (EBM 2 O $\mathrm{KSBW}=0$

$S U(1)=B 5(1) \& D E(1)=B 5(2) / E 38 \$ D O 21 \mathrm{~K}=2, \mathrm{NH} \& \mathrm{SU}(\mathrm{K})=B 5(4, \mathrm{~K})$

$21 \quad D E(K)=B 5(5, K) / E 38$

$D E(K)=B S(5, K)$
$X T B(1)=E F F(2) \approx E S T$

$85-\frac{X 1(1)=E K F, N H}{D O 20 K=1, N H}$

$21=\mathrm{CTB}(1, K)=\mathrm{B} 5(3, \mathrm{~K})$

$C T B(2, K)=-21 \div E 38^{\circ}$

$\operatorname{CTB}(3, K)=-21 \star R 38$

$\operatorname{CTB}(4, K)=-21 * E 36$

$C T B(5, K)=-21 * R 36$

90

CTB $(6, K)=\operatorname{AMIN1} 10 E($

(6)

20 CONTINÚE

CALL LPOUTR

95

$J P=B 5(3) \cdot A, 178$

$A 4=C T B(1)$

$A D S=C T B(2)$

$A B S S=C T B(3)$

$A D=C T B(4)$

$A B=C T B(5)$

$A S=C T B(6)$

EST $=C T B(7)$

$E F F(22)=E F F(22)+A D S+A B S S$

$26=A 4+B 5(2)-E 36 * A D-E 38 \div A D S$

EPUR $(J P)=E P U R(J P)+26$

105 $N H R=N H R+1$

C CHECK MONTH OF YEAR

IF (NHR GT. MHOUR (MO)) MO $=M O+1$

FIND MAXIMUM PEAK DEMANO COST FOR EACH MONTH

$27=26: P \operatorname{COS}(\mathrm{JP})$

IF(Z7. LE.POCO(MO)) $60 \quad$ TO 205

$P D C O(M O)=Z 7$

$\operatorname{MHPK}(M O)=N H R$

$\operatorname{POCO}(M O, 2)=26$ 
FIND PEAK DEMAND FOR EACH MONTH IF PEAK DEMAND PRICE IS ZERO

IF (PDCO (MO, 1).NE.0. .0. 26.LE.PDCO $(M 0,2))$ GO TO 210

PDCO $(M O, 2)=26$

MHPK $(M O)=$ NHR

120

210 CONTINUE

$25=E 36 * A B+E 38 * A B S S$

$E B M=E B M+E \operatorname{COS}(J P) *(R E S B * 26-R S L B * 25)$

$E S L B(J P)=E S L B(J P)+25$

IF(IND.EQ.O)GO TO 57

$A M S=A D S+A B S S$

$\operatorname{AES}(1)=A E S(1)+A M S$

AES(2) $=$ AES(2) +EST

$F F D(1)=F F D(1)+A D+A B$

130

$F F D(5)=F F D(5)+A D S$

$Z T=A S+A 4 * E F F(4)$

$T A(2)=T A(2)+Z 1$

$L=E S T * D C U 2+1$.

$\mathrm{CU}(\mathrm{L})=\mathrm{CU}(\mathrm{L})+1$.

$F F D(2)=F F D(2)+A S$

135

$T B(2)=T B(2)+A M S$

$Z 1=E 6 *(A D+A B)+E 8 * A M S$

$T A(3)=T A(3)+Z 1$

$T B(3)=A M A X 1(T B(3), Z 1)$

$T A(4)=T A(4)+A 4$

$140 \quad T B(4)=A M A X 1(T B(4), A 4)$

$T A(1)=T A(1)+B 5(1) / E 15$

$T B(1)=T B(1)+B 5(1)$

$N W=N W+1$

$W R S(1, N W)=A D$

$145 \quad W R S(2, N W)=A B$

$W R S(3, N W)=A S$

$W R S(4, N W)=A D S$

WRS $(5, N W)=A B S S$

$\begin{array}{ll}150 & \text { WR } S(6, N W)=A 4 \\ \text { WRS }(7, N W)=E S T\end{array}$

WR $S(7, N W)=E S T$

WRS $(8, N W)=B 5(1)$

WRS $(9, N W)=B 5(2)$

WR $S(10, N W)=B 5(3)$

155

IF (NW.LT.24)GO TO 57

$N W=0$

WRITE(9) ( (WRS $(I, J), I=1,10), J=1,24)$

5? CONTINUE

CALL MOVLEV(BS(6), B5, 235)

$\begin{array}{lll} & 58 & \text { CONTINUE } \\ 160 & 59 & \text { CONTINUE }\end{array}$

UE11DF $=\operatorname{COST}(7.2 Z Z Z)$

UE $11 D F=\operatorname{COST}(72 Z 2 Z)$
IF(I SXOL.EQ.0) GO TO 122

$00120 \mathrm{j}=1,4$

165

$X O L(J)=1 H$

I $F(X(J) . E Q \cdot X O L(J)) G O$ TO 120

$J X O L(J)=T H$

$120 \quad X O L(J)=X(J)$

CONTINUE

PRINTT2, UET1OF $(X O L(J), J X O L(J), J=1,4)$

170

121 FORMAT $(1 X, F 15.3,5(F 16.4, A 1))$

22 IF(IND.EQ.0)RETURN 
$Z 1=1 . E-30$

DO $61 \quad J=1,10$

$61 \quad 21=21+\operatorname{EPUR}(\mathrm{J})-\operatorname{ESLB}(\mathrm{J})$

CLV $(1)=$ CTOT(1) /DETOT

175

$\operatorname{CLV}(2)=0$.

$Z 2=D E T O T-21$

IF (22.NE.0.) CLV(2) $=($ CTOT(2) +CTOT (3)) /Z2

180

$\operatorname{CLV}(3)=\operatorname{CLV}(4)=0$

$\operatorname{IF}(Z 1 . N E .0.) \operatorname{CLV}(4)=\operatorname{CTOT}(5) / Z 1$

$21=F F D(2)+T A(4)$

$\operatorname{IF}(Z 1 . G T .0$.$) AES (1)=100 . * E 8 * \operatorname{AES}(1) / 21$

IF ( 21. LE. O.) AES $(1)=0$.

$\operatorname{AES}(3)=(1 .-E F F(2)) \div A E S(2)$

185

$F F D(6)=T B(1)-F F D(1)-F F D(2)$

IF (TA (2) GT.0.) FFD $(1)=100 *(E 36 * F F D(1)+E 38 * E 7 * F F D(2)-$

IFFD(2) AES(3) TTA(2)) IDETOT

IF (TA(2). LE. O.) FFD (1)=100.*E36*FFD(1)/DETOT

$Z 1=T A(1)+T A(4)$

$190 \quad$ IF $(Z 1 . G T .0$. FFD (3) $=100 . * E F F(3) * T A(3) / 21$

FFD (4) $=100 *(\operatorname{EFF}(3) * \operatorname{TA}(3)-\operatorname{CTOT}(7,2)) / D E T O T$

$F F D(5)=100 * 238 * F F D(5) / D E T O T$

FFD(2) $=100 .-F F D(1)$

$T B(1)=T B(1) / E 5$

195

(2) $=T A(2) * E 7$

$1=24.364$

$\operatorname{AES}(2)=\operatorname{AES}(2) / 21$

$T B(1)=T B(1) / 21$

200

$T B(?)=.T B(2) / 2$

$62 \quad T A(J)=T A(J) \% 1 / 21$

RETURN

END

SYMBOLIC REFERENCE MAP ( $R=3)$

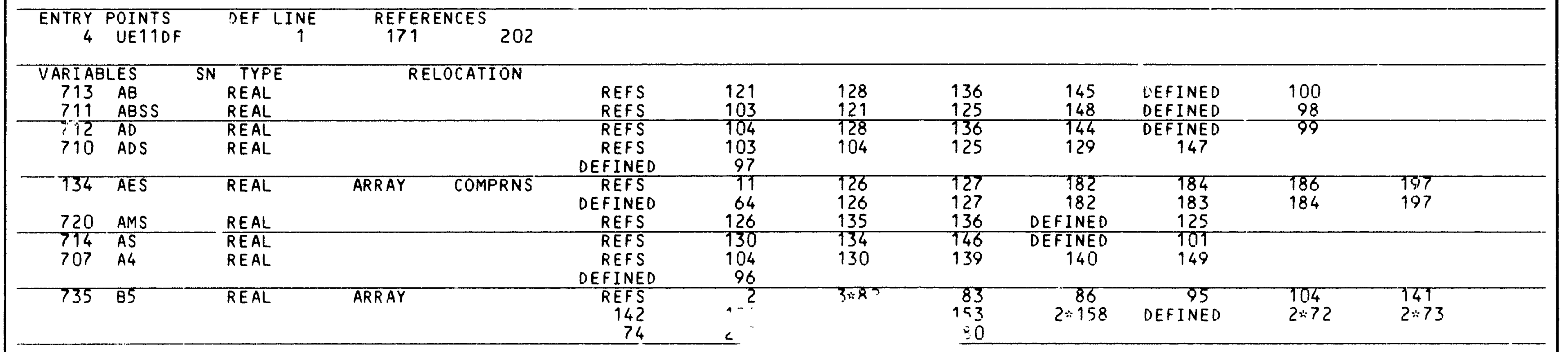




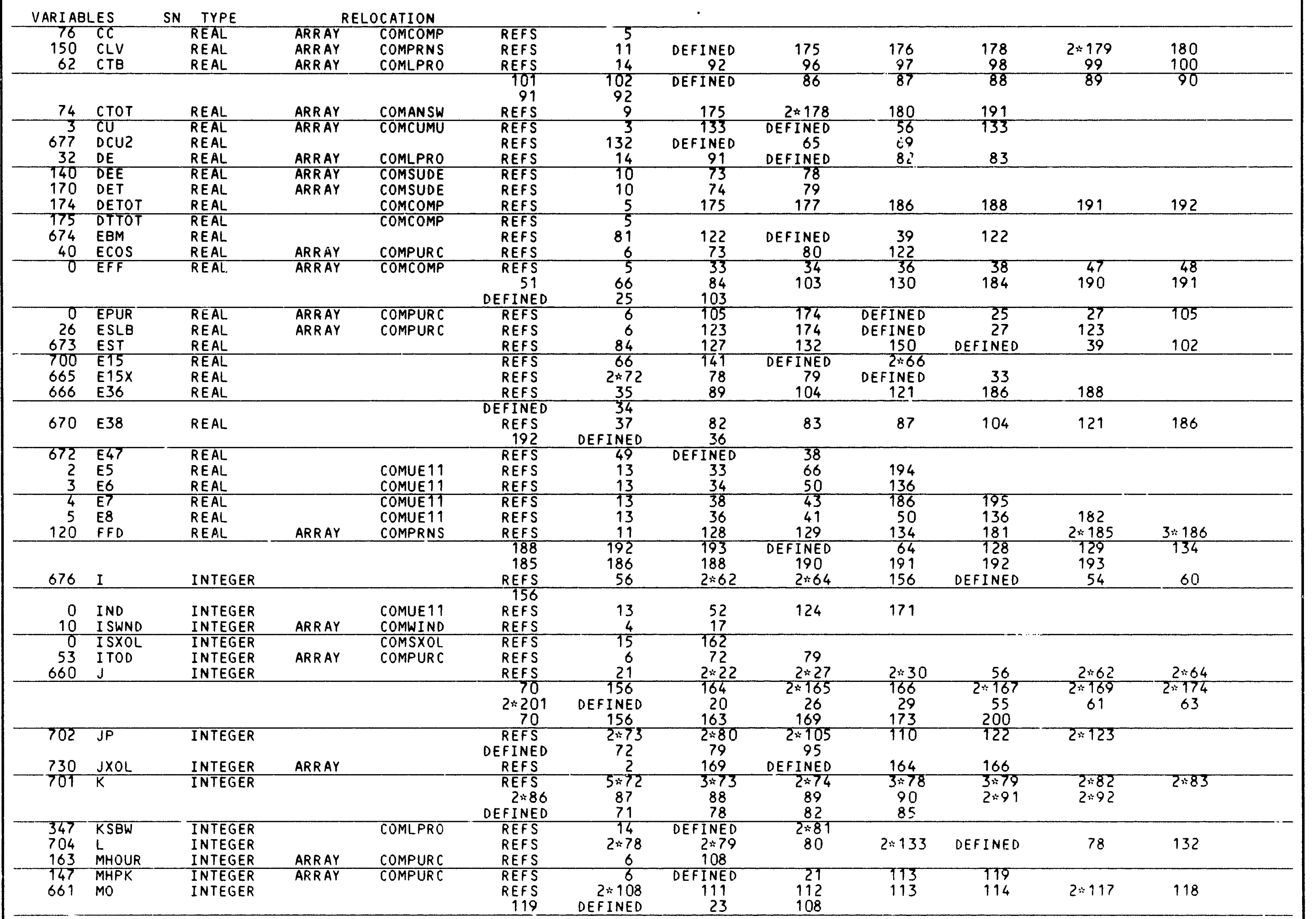




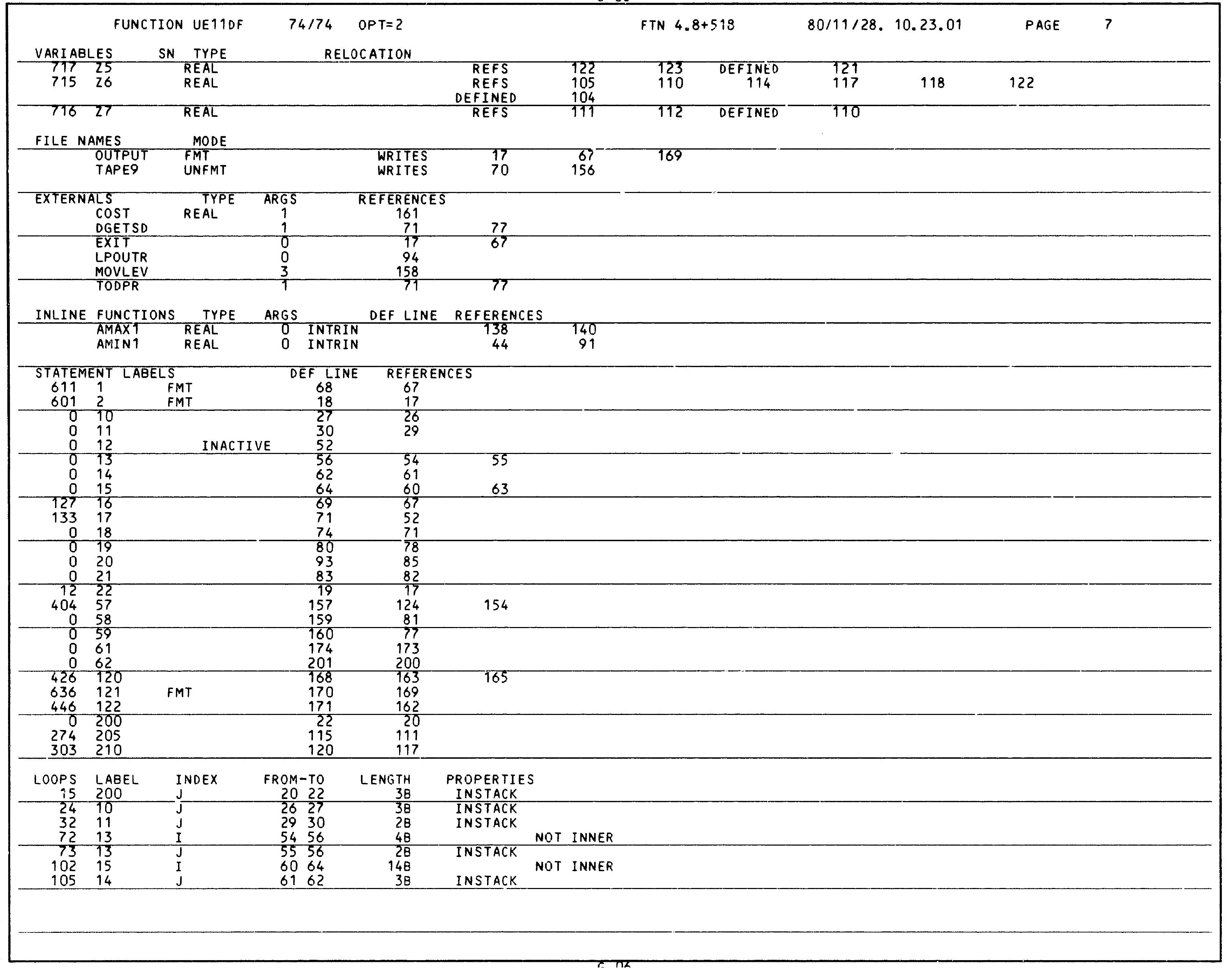




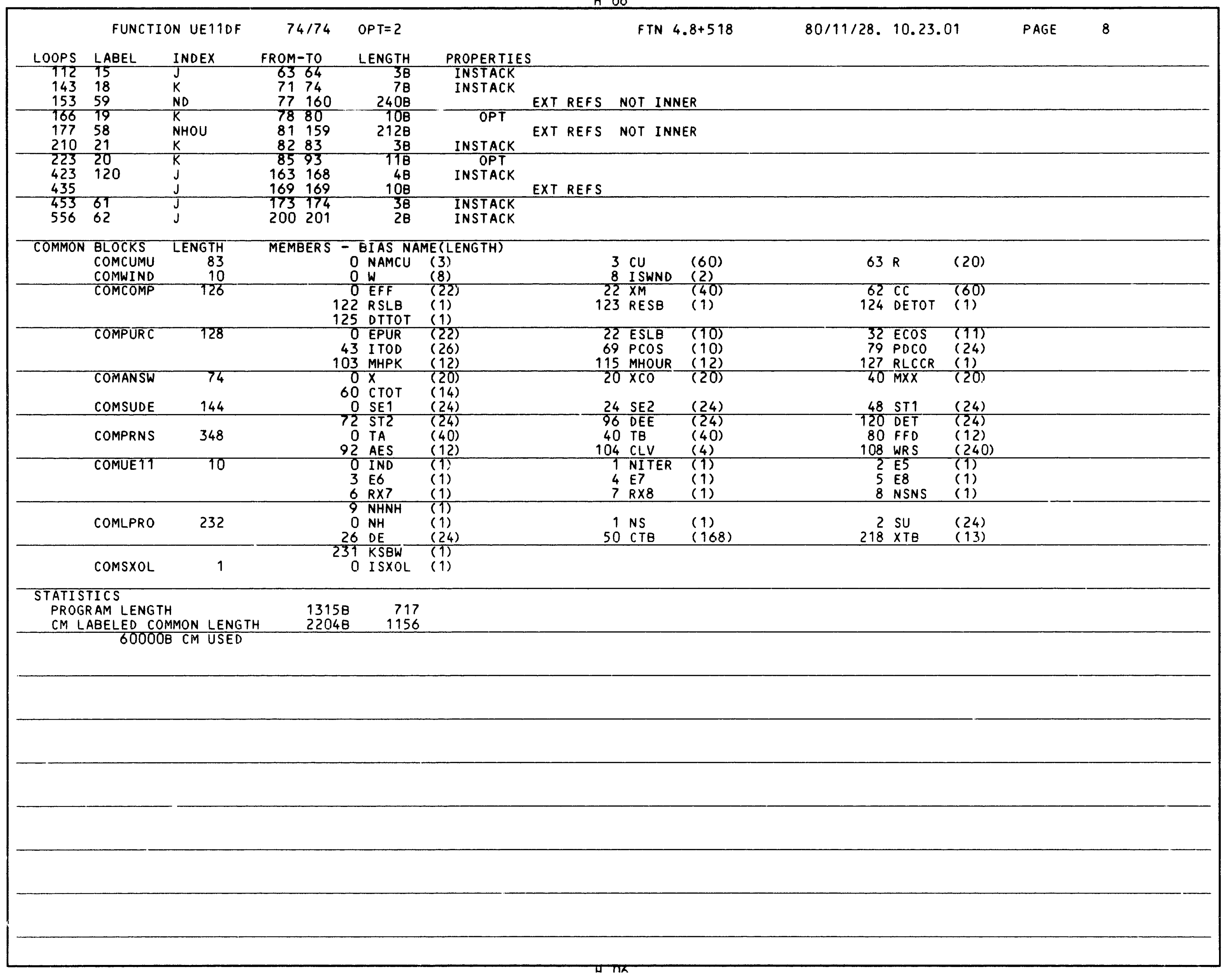


1 SUEROUTINE DGETSD(ND) \$ DIMENSION SD $(3,24)$

COPIMON /COMSUDEI SE $(24,2)$, ST ( 24,2$)$ DEE $(24), D E T(24)$
COMMON / COMLEV I I ESD $(72,364)$ \$ LEVEL2,ESD

COMMON /COMLEV2/ ESD $(72,364)$ \$ LEVEL2, ESD

5

$N=N D$

10 IF (N.GT, O)GO TO $11 \$ N=N+364 \$$ GO TO 10

11 IF(N.LE.364)GO TO $12 \$ N=N-364 \$$ SO TO 11

12 CALL MOVLEV $(E S D(1, N), S D, 72)$ \$ DO $13 \mathrm{~J}=1,24$

$\operatorname{SE}(J)=S D(1, J)$. A.MU $\$ D E E(J)=S D(3, J)$. A.MU

10

SE $(J, 2)=$ SHIFT(SD $(1, J) \cdot A \cdot M L, 30)$

$13 \operatorname{DET}(j)=\operatorname{SHIFT}(S D(3, j) . A . M L, 30)$ RETURN \$ END

SYMBOLIC REFERENCE MAP $(R=3)$

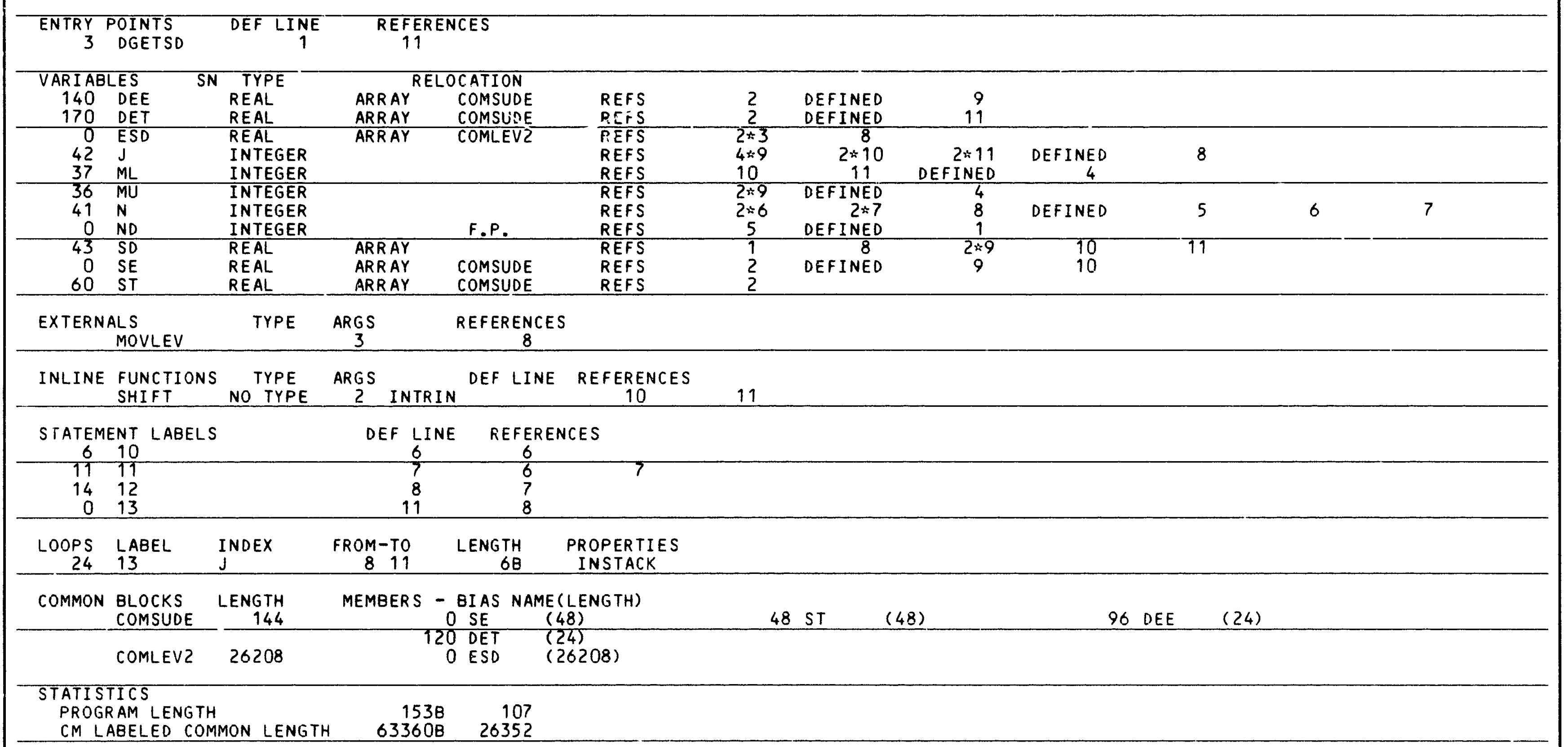




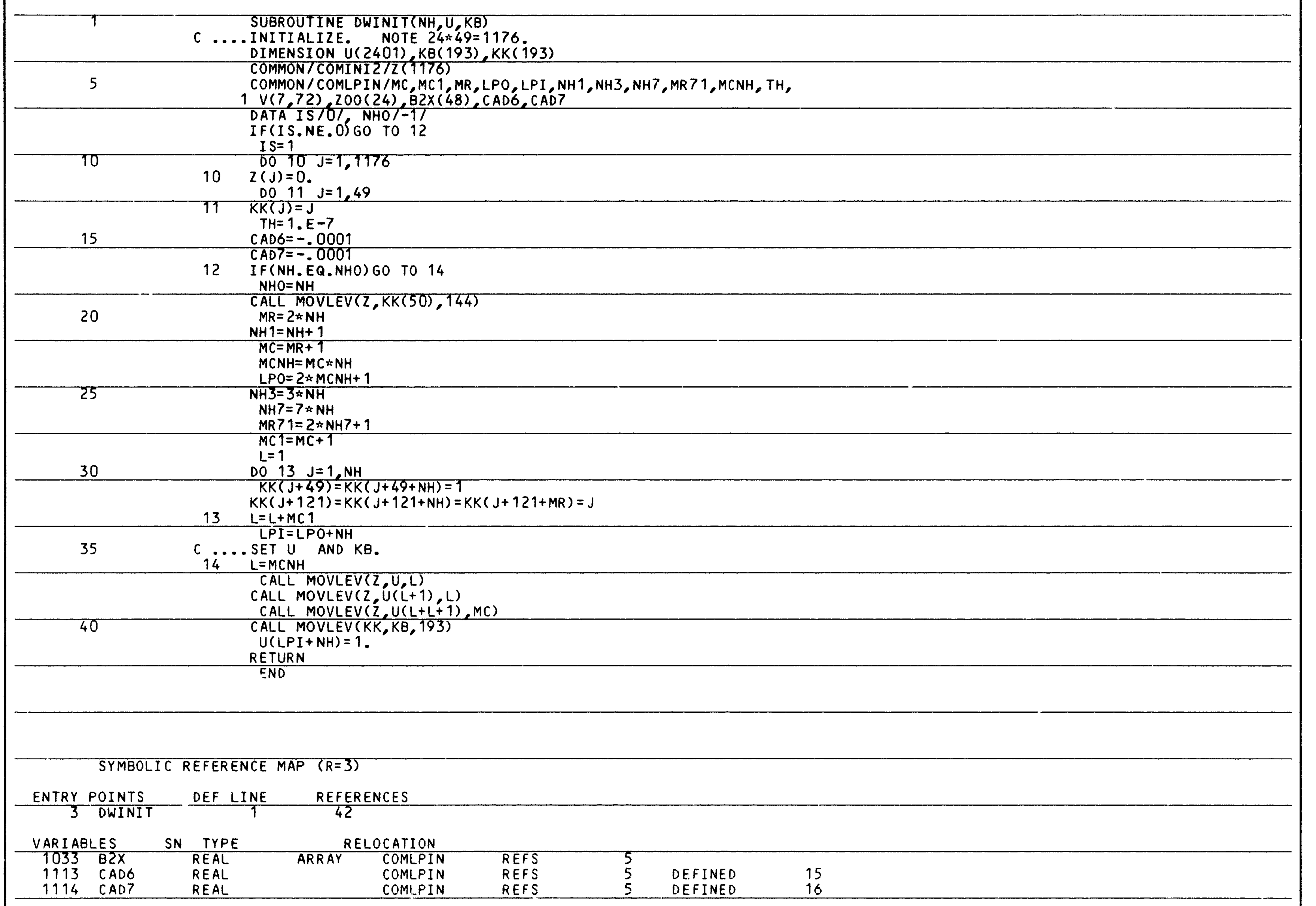




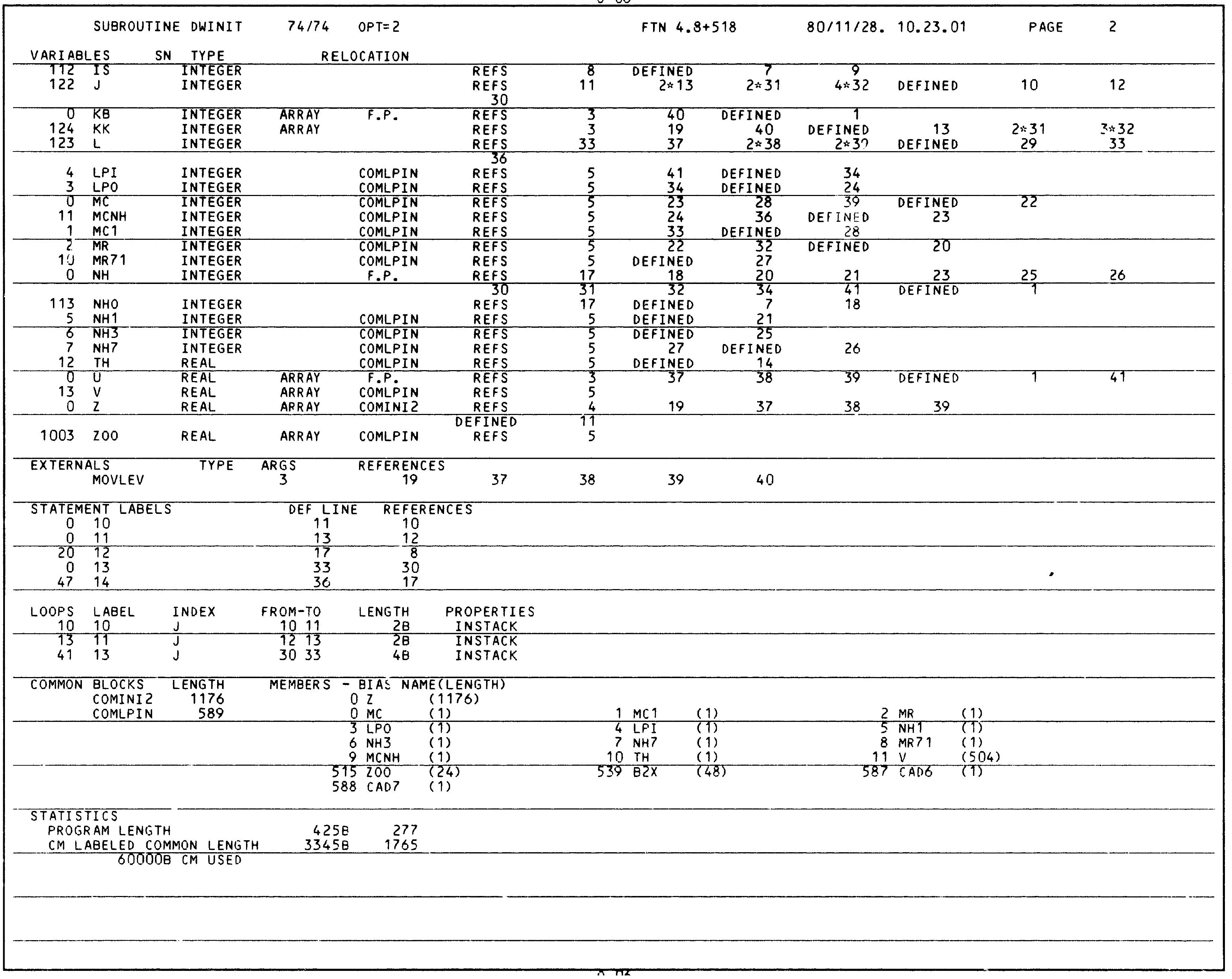




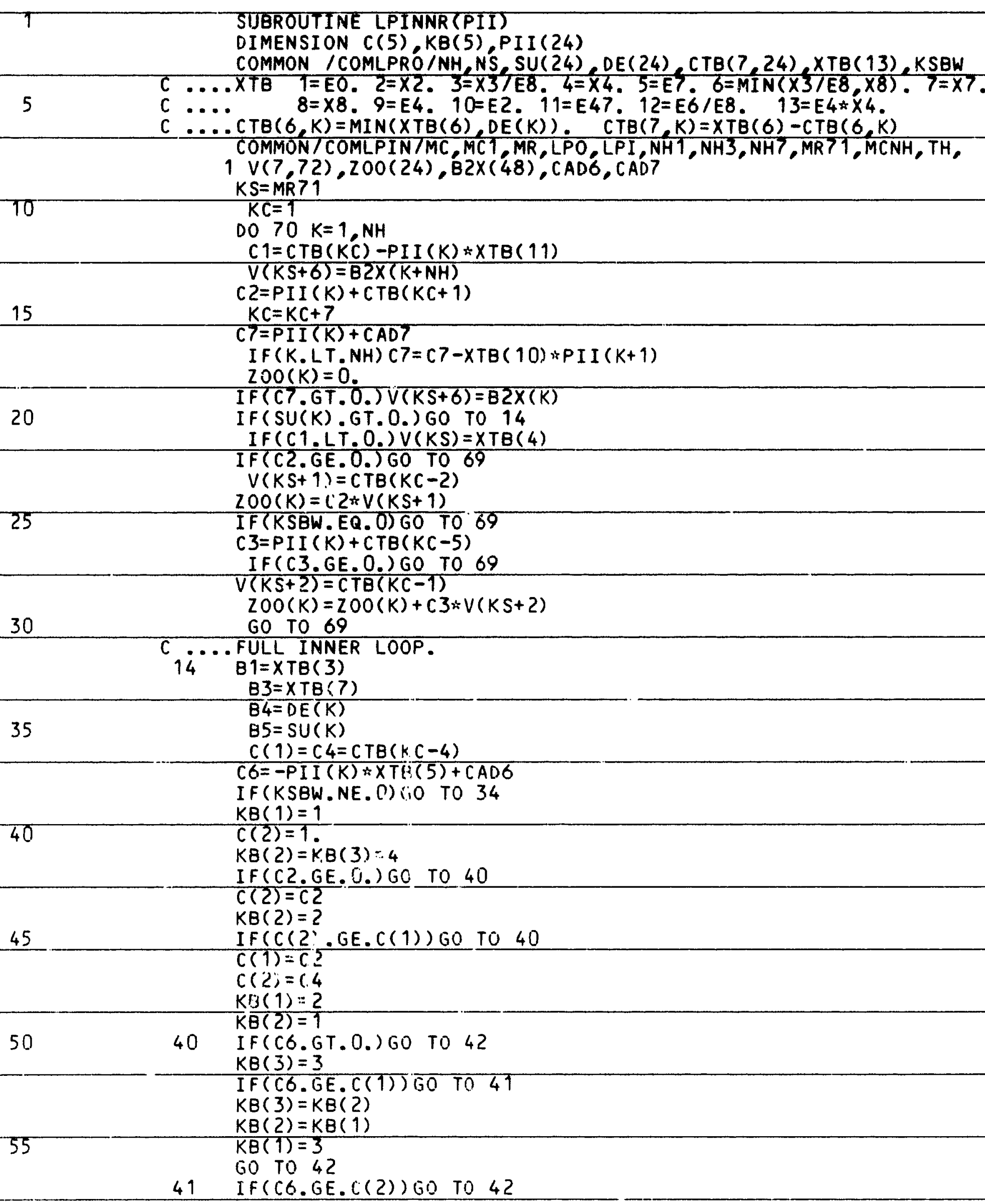


$K B(3)=K B(2)$

$K B(2)=3$

$K B(2)=3$
$D 0 \quad 46 \quad J=1,3$

60

GO TO $(43,44$

$33), K B(J)$

$=$ AMIN 1 (B1/XTB(12), B4/XTB(12),B5)

$B 5=85-21$

$65 \quad \begin{array}{ll}B 4=81-(21 * X T B(12)) \\ B 4=8(21 * X T B(12))\end{array}$

$200(K)=200(K)+C 4 * 21$

GO TO 46

$44 \quad 21=V(K S+1)=A M I N 1(B 1, X T B(8), B 4)$

$B 1=81-21$

$B Q=B 4-Z 1$

$200(K)=200(K)+C 2 * 21$

GO TO 46

$45 \quad Z 1=V(K S+5)=A M I N 1(B 3, B 5)$

$B 3=B 3-21$

$B 5=85-7$

$\mathrm{Z} 200(\mathrm{~K})=200(\mathrm{~K})+\mathrm{C} 6 * 21$

46 CONTINUE

GO TO 33

$34 \quad C(2)=C 5=C T B(K C-3)$

$\mathrm{KB}(1)=3$

$K B(3)=K B(4)=K B(5)=6$

IF (C2.GE.0.) GO TO 20

$B 2=X T B(8)$

85 IF(C2.GE.C4)GO TO 15

$K B(3)=4$

$K B(2)=3$

$\mathrm{KB}(1)=1$

$C(3)=c 5$

90

$C(2)=C 4$

$c(1)=C 2$

GO TO 17

15 IF (C2.GE.C5)GO TO 16

$\mathrm{KB}(2)=1$

$95 \quad$ KB(3) $=4$

$C(2)=C 2$

$C(3)=C 5$

( $(3)=C 5$

$16 \quad K B(3)=1$

$17 \quad C 3=P I I(K)+C T B(K C-5)$

IF (C3.GE.0.) 60 TO 20

IF (C3.GE, C(2)) GO TO 18

$K B(4)=K B(3)$

$105 \quad K B(3)=K B(2)$

$K B(2)=2$

$K B(2)=2$

$c(4)=c(3)$

$c(3)=c(2)$

110

$c(2)=c 3$

$18 \quad$ GO TO 20 (3) $(C 3, G E-C(3)) 60$ TO 19

$K B(4)=K B(3)$

$C(4)=C(3)$

$K B(3)=2$ 
115

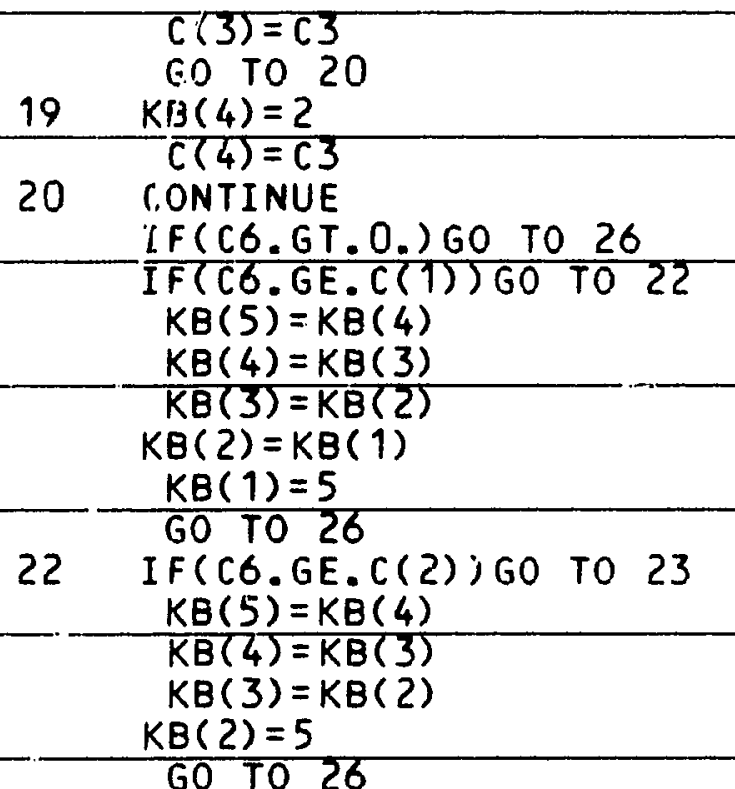

23 IF (C6.GE.C(3))GO TO 24

135

$K B(5)=K B(4)$

$K B(4)=K B(3)$

$K B(3)=5$

GO TO 26

$140 \quad 24 \quad \operatorname{IF}(\mathrm{C} 6 \cdot \mathrm{GE} \cdot \mathrm{C}(4))$

$K B(4)=5$

$\mathrm{KB}(4)=5$

$25 \quad K B(5)=5$

$145-\frac{26 \quad 0032 \mathrm{~J}=1,5}{60 \mathrm{TO}(29,28,29,30,31,33), \mathrm{KB}(\mathrm{J})}$

$27 \quad 21=V(K S+1)=A M I N 1(B 1, B 2, B 4)$

$B 1=B 1-21$

$82=82-21$
$84=84-21$

150

$200(K)=Z$ ZO

$28 \quad 21=V(K S+2)=\operatorname{AMIN} 1(B 1, B 2)$

$B 1=B 1-21$

$\begin{aligned} 200(K) & 200(K)+C 3 * 21 \\ 60 & \text { TO } 32\end{aligned}$

$29 \quad Z 1=V(K S+3)=A M I N 1(B 1 / X T B(12), B 4 / X T B(12), B 5)$

$B 5=85-21$

$B 1=B 1-21 * X T B(12)$

$84=84-21 \times \times T B(12)$

160

$200(K)=200(K)+C 4: Z 1$

GO TO 32

$50 \quad 21=V(K S+4)=A M I N T(B T / X T B(12), B 5)$

$B 1=81-21 * \times T B(12)$

165

$B 5=85-21$

$200(\mathrm{~K})=200(\mathrm{~K})+\mathrm{C} 5 * 21$

GO TO 32

$31 \quad 21=V(K S+5)=\operatorname{AMIN} 1(B 3, B 5)$ 


\begin{tabular}{|c|c|}
\hline 5 & 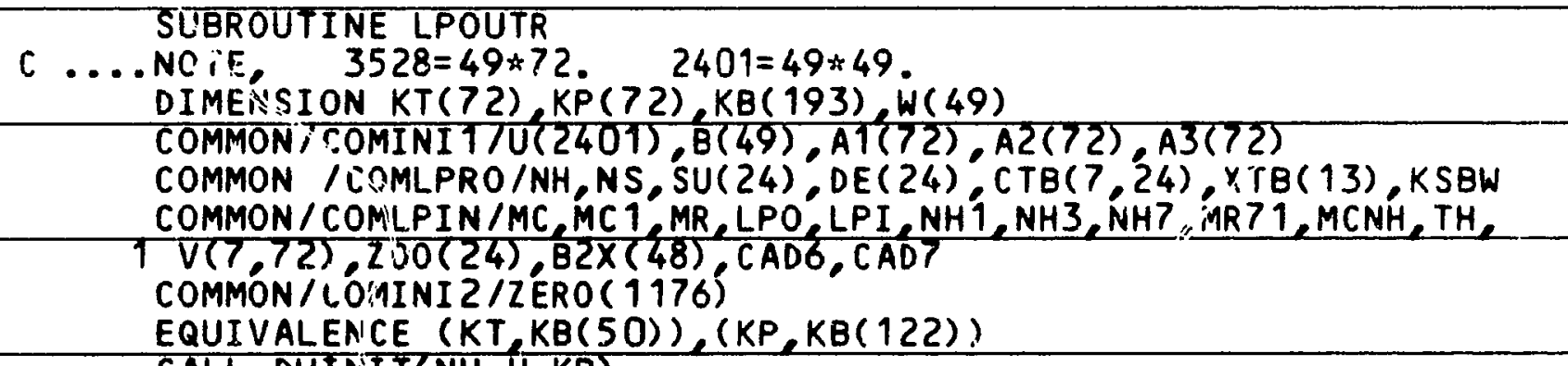 \\
\hline 15 & 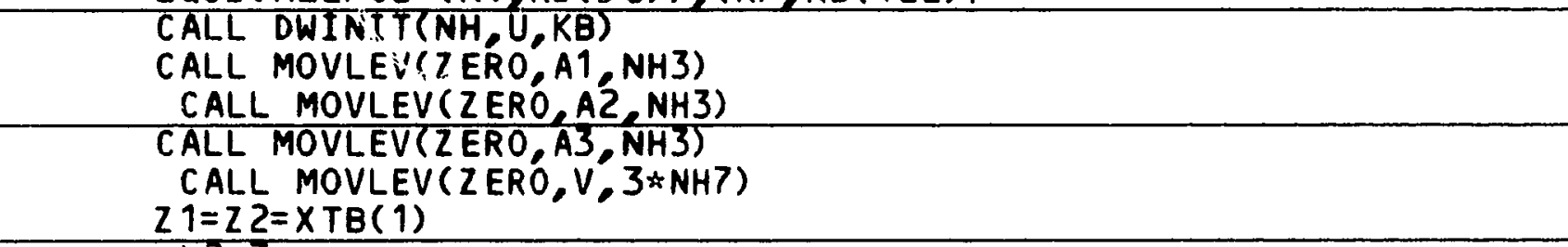 \\
\hline & $\begin{array}{l}L 2=7 \\
D 0 \quad 18 K=1, N H \\
B 2 X(K+N H)=A M I N 1(X T B(2), 22+X \operatorname{TB}(5) * A M I N 1(X T B(7), S U(K)+X T B(13)))\end{array}$ \\
\hline 20 & $\begin{array}{l}V(L 2)=A T(K)=B 2 X(K)=A M A X T(0 ., Z T-X T B(6)) \\
A 3(K)=C A D T * V(L 2) \\
Z 1=B 2 X(K) \approx X T B(10)\end{array}$ \\
\hline & $\begin{array}{l}Z 2=B 2 X(K+N H) * X T B(10) \\
A Z(K)=-Z 1 \\
18 \quad L Z=L Z+7\end{array}$ \\
\hline 25 & $\begin{array}{l}A 2(N H)=0 \\
L 1=M R \\
Z 1=0\end{array}$ \\
\hline 30 & $\begin{array}{rl}19 & B 2 \times(L 1)=21 \\
L 1 & =L 1-1 \\
Z 1 & =(Z 1+X T B(6)) / X T B(10)\end{array}$ \\
\hline & $\begin{array}{l}\text { IF(LI.GT.NHT. A.Z1.LT.BLX(L1))GO TO } 19 \\
\text { CALL LPINNRC(U) } \\
L \mathcal{L}=N H 7+1\end{array}$ \\
\hline 35 & $\begin{array}{l}\text { CALL MOVLEV (V(MRT1), } V(L 1), N H 7) \\
D O 13 I=N H 1=M R \\
A 1(I)=V(L 1+1)+V(L 1+2)+V(L 1+6)-X T B(5) \div V(L 1+5)\end{array}$ \\
\hline & $\begin{array}{l}I F((A B S(A 1(I)-A 1(I-N H)) . L E . .001) G 0 \text { TO } 14 \\
A 3(I)=Z O 0(I-N H) \\
A Z(I)=-X T B(10) * V(L 1+6)\end{array}$ \\
\hline 40 & $\begin{array}{ll}13 & L 1=L 1+7 \$ 60 T 016 \\
14 & D O 15 I=N H 1, M R \quad \$(1, I)=V(3, I)=V(4, I)=V(5, I)=V(6, I)=0 . \\
& V(2, I)=C T B(6, I-N H) \$ V(7, I)=B 2 \times(I) \$ A 1(I)=V(2, I)+V(7, I)\end{array}$ \\
\hline 45 & $\begin{array}{l}15 \text { A3 I I }=V(2, I) * C T B(2, I-N H)+V(7, I) * C A D T \$ A 2(I)=-X T B(10) * V(7, I) \\
16 \text { CONTINUE, } \\
162(M R)=0 .\end{array}$ \\
\hline & $\begin{array}{l}\text { CALL UINV } \\
\text { GO TO } 29 \\
\text { C.... LOOP }\end{array}$ \\
\hline 50 & 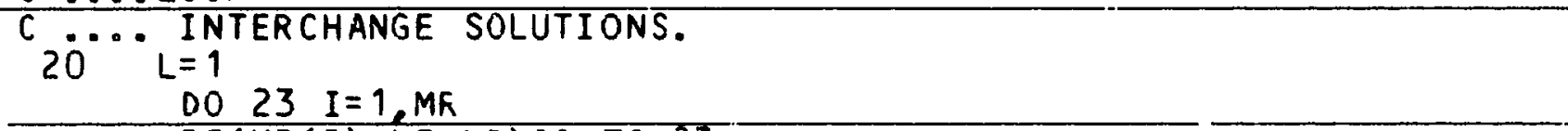 \\
\hline & 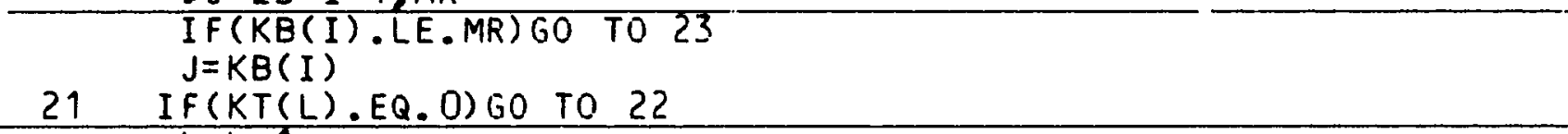 \\
\hline 55 & $\begin{array}{l}L=L+1 \\
22 \quad K O T(L)=1 \\
\end{array}$ \\
\hline
\end{tabular}




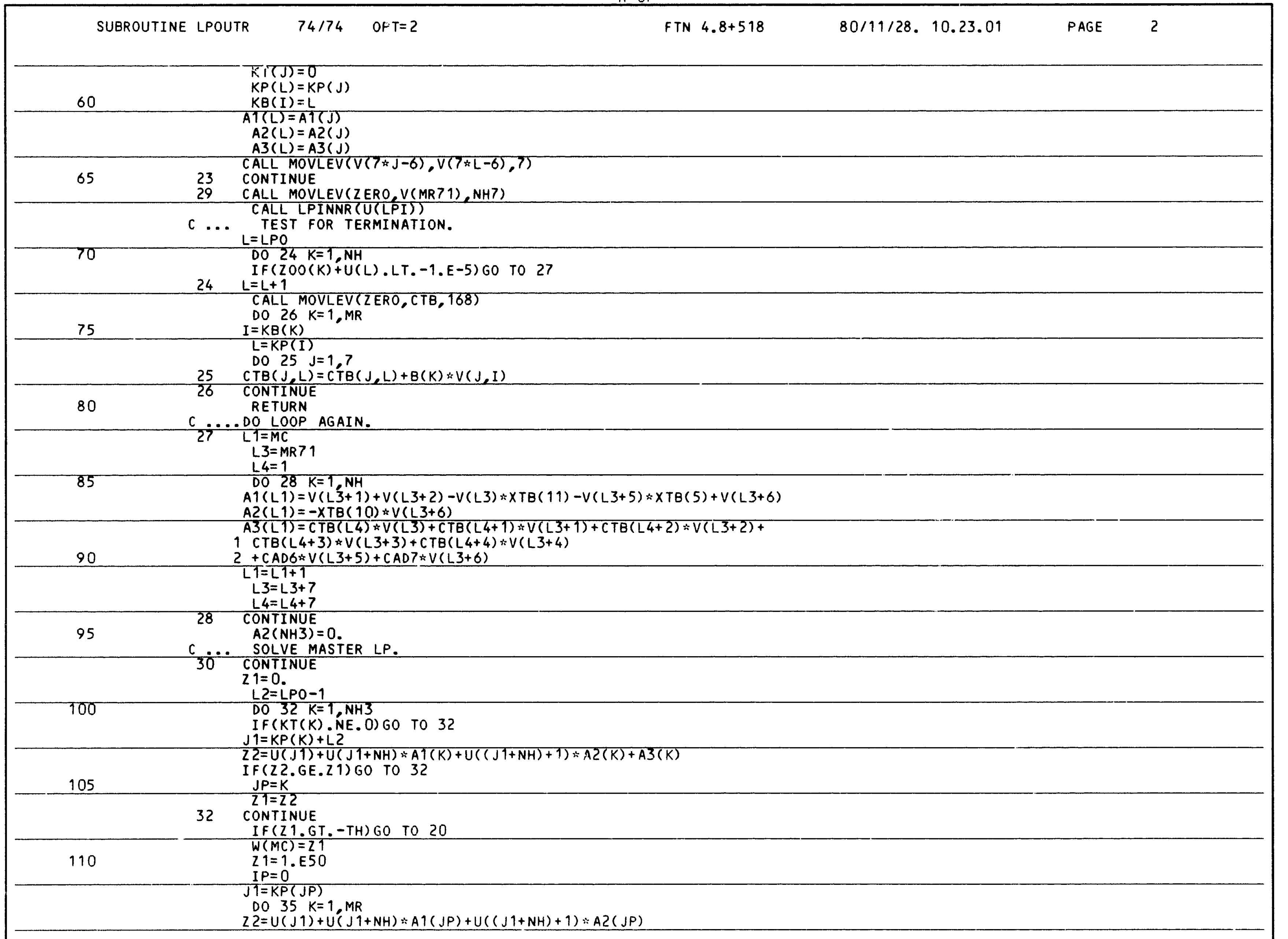




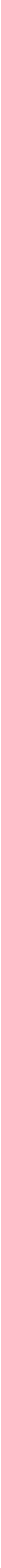




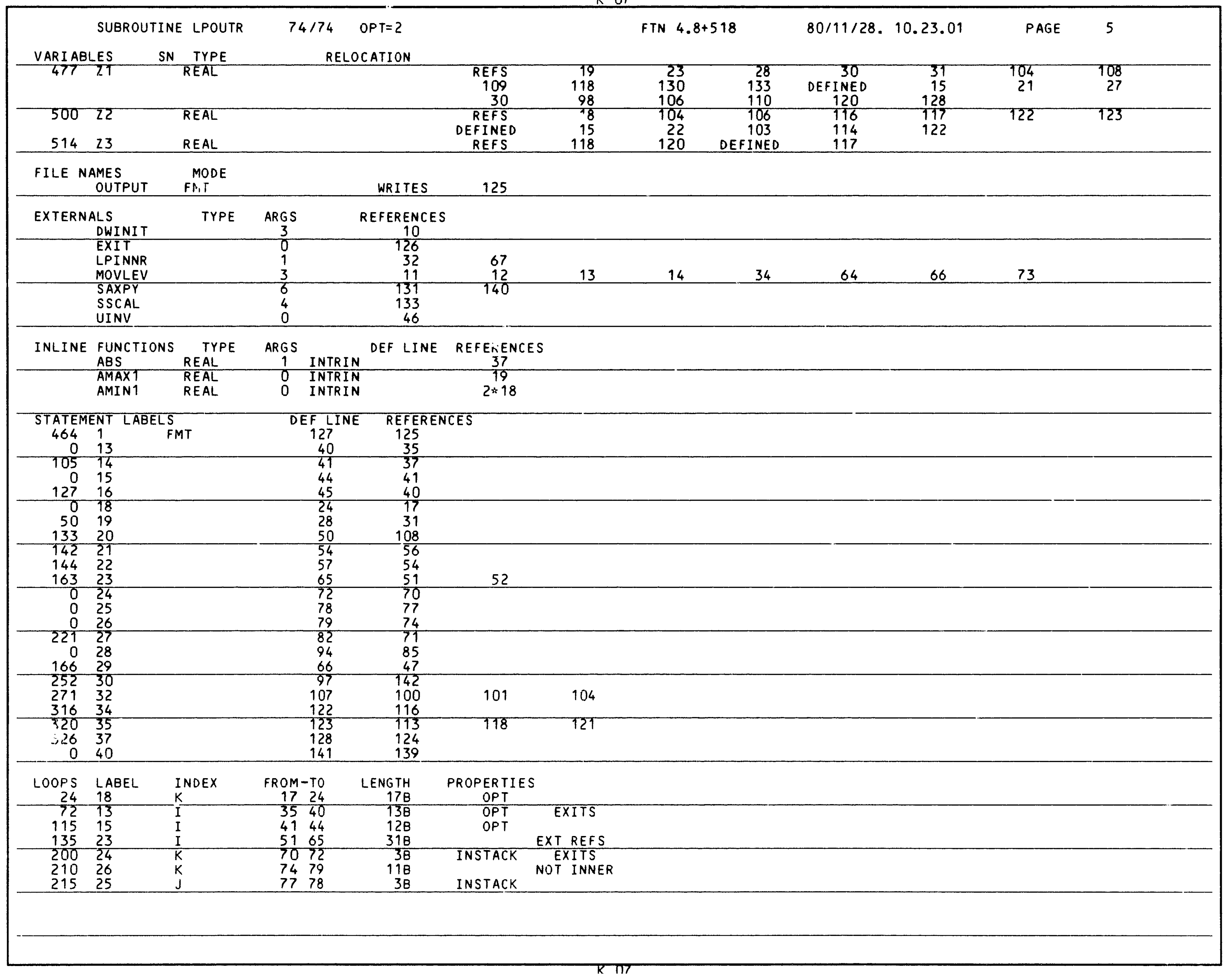


FUNCTION UETTAF $(X X X X)$

DIMENSION $X X X X(20), B 5(24), X O L(5), J X O L(5)$

COMMON / COMCUMU/ NAMCU(3), CU(20,3) R(20)

COMMON TCOMWIND/ W(8), ISWND(2)

COMMON / COMCOMP/ EFF(22) XM(20,2) CC (20,3) RSLB,RESB,DETOT, DTTOT

COMMON /COMPURC/ EPUR $(11,2)$ ESLB (10) ECOS (11) I TOD (26)

A PCOS(10),PDCO (12,2), MHPK(1 2$), M H O U R(12)$

B RLCCR

COMMON /COMANSW/ $\times(20) \times C O(20), M X X(20), C T O T(7,2)$

10 COMMON TCOMSUDEI SET(24),SE2(24),ST1(24), ST2(24), DEE(24),DET(24)

COMMON /COMPRNS/ TA $(20,2)$, TB $(20,2)$, FFD $(6,2)$, AES $(6,2), C L V(4)$,

1WRS (10,24)

COMMON /COMUETT/ IND,NITER, E5, E6, E7, E8, RX7, RX8, LPNS, LPNH

15

COMMON/COMSXOL/ I SXOL

DATA XOL/5(-1.)/, BIGW/1E30/

$A D F(I)=A M I N T((D E E(I)-E 38 * A D S) / E 36, B 5(I)-A S,(X(3)-E 8 * A M S) / E 6)$

$A B F(I)=A M I N 1((E B M-E 38 * A B S S) / E 36, B S(I)-A S-A D(X(3)-E 8 * A M S) / E 6-A D)$

$A D S F(I)=A M I N 1((D E E(I)-E 36 * A D) / E 38 \times 8, Q 2(X(3)-E 6 *(A D+A B)) / E 8)$

20

$A B S S F(I)=A M I N 1((E B M-E 36 * A B) / E 38, A M I N\{(X 8, Q 2,(X(3)-E 6 *(A D+A B)) / E 8$

1) -ADS)

$\operatorname{EPUR}(11)=E F F(22)=0$.

$A D=A B=A S=A D S=A B S S=A M S=B 4=0$

DO $10 \mathrm{~J}=1,10$

$10 \operatorname{EPUR}(J)=E S L B(J)=0$

25 C INITI ALIZE FOR PEAK DEMAND PRICING

DO $205 \mathrm{~J}=1,12$

$\operatorname{MHPK}(J)=0$

$205 \quad P D C O(J)=P D C O(J, \zeta)=0$.

$M O=1$

$30 \quad \mathrm{NH}=0$

NITER $=$ NI TER +1

11 DO $11 \mathrm{~J}=1,5$

$x(j)=x \times x \times(j)$

$\begin{aligned} & X 7=R \times 7 * X(2) \\ & X 8=R \times 8 * X(2) \\ X 3 E 6=X(3) & \end{aligned}$

E38=EFF(3)+ER

$R 38=R$ SLA* E38

$E 36=E F F(3) * E 6$

$40 \quad R 36=R S L B * E 36$

$E 78=E 7 * E 8$

$E 278=E F F(2) * E 78$

E23478=EFF (3)*EFF (4)*E278

$R E 6=R S L B * E 6$

$45 \quad E 4 \times 4=E F F(4) * \times(4)$

$E 4 \times 4 \times 7=$ AMIN $1(E 4 \times 4, \times 7)$

$X 8 \times 38=$ AMIN $1(X 8, X(3) / E 8)$

$E 15 X=E F F(1) \div E 5 * X(1)$

JUMP $=1$

IF (I SWND( 1$)$. LE. 0) GO TO 12

$W(8)=D I A=S Q R T(259.7 * X(1) / W(3) /(W(5)+W(4)) * * 3)$

$E 15 X=E 15 X \div W(7)$

JUMP $=2$

QHT $=((15.2+.5 * D I A) / W(2)) \div .142857$

55

12 IST $=-1$

I F (RE6.LT.E278) I S $1=0$

IF (E278.GT.E6) I $S 1=1$ 
$E 2=x(5) * x(2)$

$60 \quad E C=E F F(2) * E 2$

CALL TODPR (1)

JPI $=I T O D(1)$

$\operatorname{EPUR}(J P 1)=E 2$

$E B M T=R E S B * E P U R(J P 1) * E \operatorname{COS}(J P 1)$

65

$E B M=B I G W$

IF (EBMT . LE. O. ) EBM=0.

IF (IND.EQ.0) GO TO 17

IF (IND.EQ.
JUMP $=$ JUMP+
DO $13 \quad I=1,20$

DO $13 \mathrm{~J}=1,3$

CU(I, J) $=0$.

NAMCU $(1)=2 H S T$

NAMCU (2) $=2 H$

NAMCU( 2$)=2 H$

DO15I $=1,2$

$D 014 \mathrm{~J}=1,20$

75

TA $(J, I)=T B(J, I)=0$

DO $15 \mathrm{~J}=1,6$

$15 \quad F F D(J, I)=A E S(J, I)=0$.

DO $51 \quad I=1,10$

$80 \quad$ DO $51 \mathrm{~J}=1,24$

$51 \quad \operatorname{WRS}(I, J)=0$.

WRI TE $(9)(\dot{x}(J), J=1,10)$

$D C U 2=0$.

IF $(X(2) . L E .0) G$.0 TO 16

85 DCUZ $=19.9999 / X(2)$

16 IF (JUMP.NE. 4) GO TO 17

QW $1=0.00385159 * W(7) \div W(3) * D I A * D I A$

17 IF(X(1).GT.0.)GO TO 19

JUMP $=5$

DO $18 \quad I=1,24$

$18 \quad B 5(I)=0$

IF (IND.NE. O) JUMP $=6$

19 DO $60 \mathrm{ND}=1,364$

$D 0 \quad 60$ ND $=1,364$
CALL GETSD(ND)

$95 \quad \begin{gathered}\text { CALL TODPR (ND) } \\ \text { PMEECOS (ITOD (25)) }\end{gathered}$

$95 \quad \begin{gathered}\text { CALL TODPR (ND) } \\ \text { PMEECOS (ITOD (25)) }\end{gathered}$

20 GO TO $(20,22,24,26,74,70)$, JUMP

$21 \quad B 5(I)=E 15 X * S E 1(I)$

$100 \quad 21 \quad 65(I)=E 15 x * 5$

$22 \quad 0023 \quad I=1,24$

$B 5(I)=0$.

$Z 1=Q H T * S E T(I)-W(4)$

05

IF (Z1.GT.0..A.Z1.LE.W(6:.B5(I) $=$ E15X:AMIN1 $(1 \ldots Z 1 / W(5))$

24 DO 25 I $I=1,24$

$B 5(I)=E 15 X * S E 1$ (I)

110

$T B(1)=T B(1)+B 5(I)$

$25 \quad T A(1)=T A(1)+X(1) \div S E 1(I)$

GO TO 28
$26 \quad$ DO $27 \quad I=1,24$

$21=Q H T * S E 1(I)$

$T A(1)=T A(1)+Q W 1 *(21 * * 3)$ 
$175 \quad B 5(I)=0$.

$Z 1=Z 1-W(4)$

IF (Z1.LE.0.0.21.GT.W(6)) GO TO 27

$B 5(I)=E 15 X * A M I N 1(1.21 / W(5)$

$T B(1)=T B(1)+B 5(I)$

$120 \quad 27$ CONTINUE

GO TO 28

28 CONTINUE

If $(X(2)) 71,71,70$

125

$71 \quad X(2)=0$

DO $73 \quad I=1,24$

$\mathrm{NH}=\mathrm{NH}+1$

$J P=I T O D(I)$

I F (BS (I) .GT.0.) GO TO 72

$\operatorname{EPUR}(J P)=\operatorname{EPUR}(J P)+D E E(I)$

130 C CHECK MONTH

I F (NH, GT MHOUR (MO)) MO=MO+

C FIND PEAK DEMAND PURCHASED FOR EACH MONTH (MAX COST NOT MAX ENERGY)

$27=D E E(I) \div P \operatorname{COS}(J P)$

135

IF (Z7. LE.PDCO(MO)) GO TO 200

$P O C O(M O)=27$

$\operatorname{MHPK}(\mathrm{MO})=\mathrm{NH}$

PDCO $(M O, 2)=D E E(I)$

200 CONTINUE

FIND PEAK ENERGY FUR EACH MONTH IF PEAK DEMAND COST IS ZERO

140 IF (PDCO (MO,1).NE.O. .0. DEE (I).LE.PDCO $(M O, 2)) G O$ TO 206

PDCO $(M O, 2)=D E E(I)$

206 CONTINUE

IF (IND.EQ.O)GO TO 73

WR S $(1, I)=$ WRS $(2, I)=W R S(8, I)=0$

WRS $(q, I)=\operatorname{DEE}(I)$

WR $S\left(10^{\prime}, I\right)=E \operatorname{COS}(J P)$

60 TO 73

$150 \quad 72 \quad A D=A M I N 1$ (DEE (I) $/ E 36, \times 3 E 6, B 5(I))$

$A B=A M I N 1(E B M / E 36 \times 3 E 6-A D, B 5(I)-A D)$

EPUR (JP) $=E P U R(J P)+D E E(I)-E 36 * A D$

$E S L B(J P)=E S L B(J P)+E 36 * A B$

EBMT $=E B M T+E \operatorname{COS}(J P) *(R E S B *(D E E(I)-E 36 * A D)-R 36 * A B)$

EBMT $=E B M T+E$

155 IF (EBMT.LE.O.) EBMF 0.

IF (IND

$Z T=A D+A B$

$F F D(1)=F F D(1)+21$

$Z 1=21 * E 6$

$160 \quad$ TA $(3)=$ TA $(3)+21$

$\operatorname{TB}(3)=A M A X 1(T B(3), Z 1)$

WR $S(1, I)=A D$

WRS $(2, I)=A B$

WR $S(8, I)=B 5(I)$

$165 \quad$ WRS $(9, I)=\operatorname{DEE}(I)$

$73 W R S(10, I)=E \operatorname{COS}(J P)$

CONTINUEE

170

GO TO 59

$X 1=0$. AND IND $=0$

74 DO $78 \quad I=1,24$

$\mathrm{NH}=\mathrm{NH}+1$ 


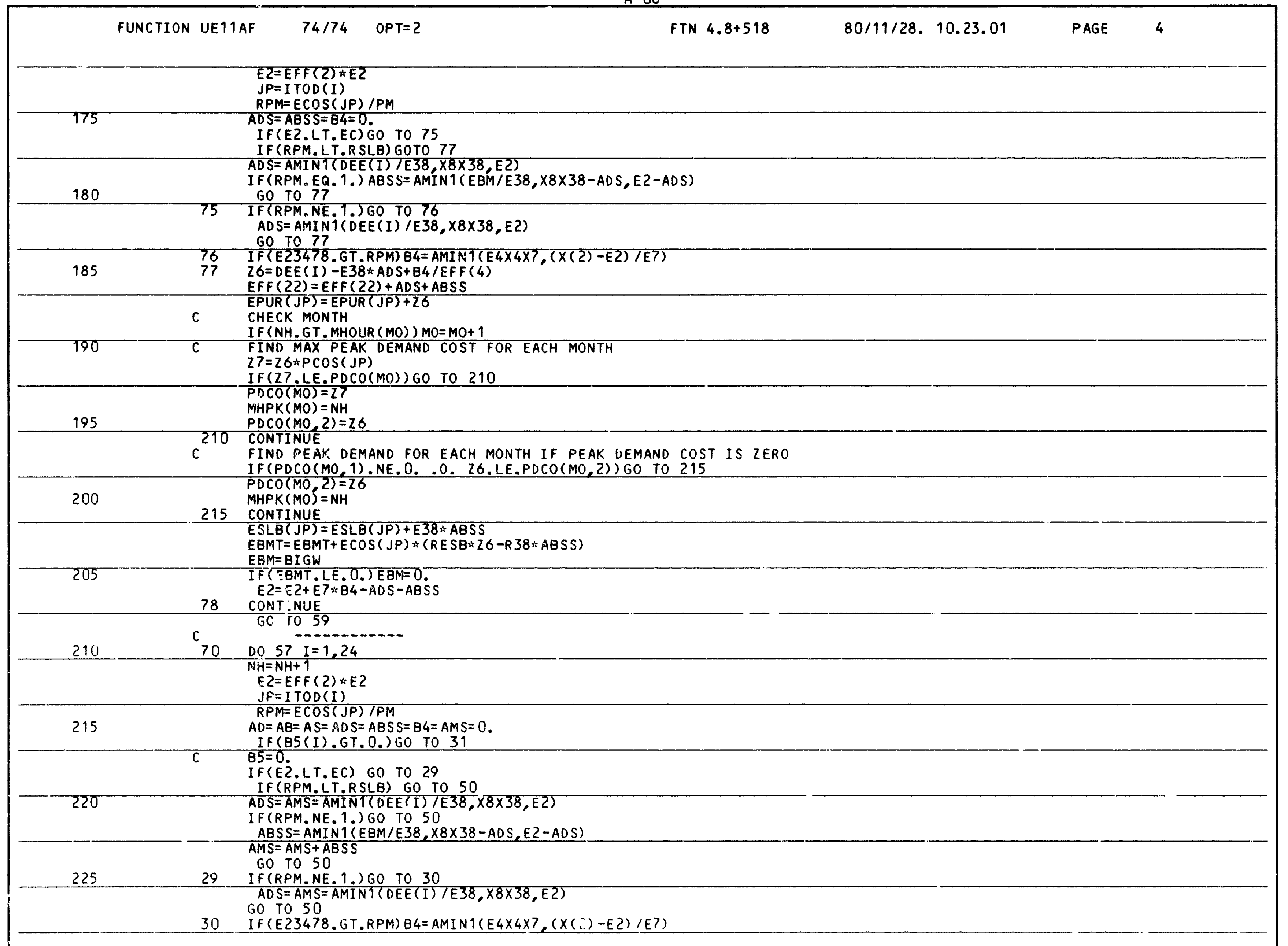




\section{0}

GO TO 50

C 31 BF.GT.0

IF (E2.LT.EC)GO TO 37

IF(ISI) $32,33,35$

$32 A D=A D F(I)$

$\begin{array}{rl} & \\ 235 & A B=A B F(I) \\ J U M G=-1 & \end{array}$

$33 \quad A D=A D F(I)$

JUMG $=0$

GO TO 46

$240 \quad 34 \quad \begin{array}{r}G 0 \text { TO } 46 \\ A B=A B F(I)\end{array}$

35 JUMG $=1$

$35 \quad$ GO TO 46

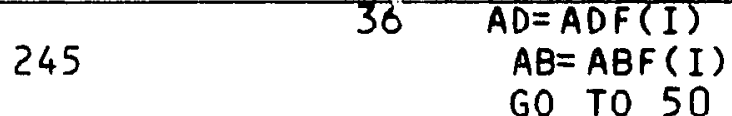

C E2.LT.EC

$37 \quad 21=E 278 / R P M$

IF (Z1.GT.RE6)GO TO 38

IF $251.6 T$
JUMG $=-1$
$A D=A D F(I)$

$A D=A D F(I)$
$A B=A B F(I)$

G0 TO 49

38 IF (Z1.GT.E6)GO TO 40

$A D=A D F(i)$

255

$A D=A D F(I)$
$J U M G=0$

GO TO 49

$39 \quad A B=A B F(I)$

$260 \quad 40 \quad$ GO TO

UMG $=1$

$41 \quad \mathrm{GO}$ TO $\mathrm{TDF}(\mathrm{I})$

$A D=A D F(I)$
$A B=A B F(I)$

$G O$ TO 50

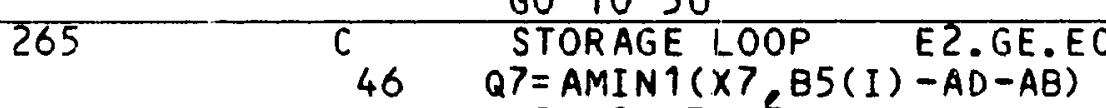

$Q 2=E 2+Q 7 * E\}$

Q $F(R P M . N E$. 1.) GO TO 47

ADS $=A D S F(I)$

$270 \quad I F(Q 7 . L E, 0.0 .078, G E . E 6) A B S S=A B S S F(I)$

GO TO 48

47 I F (RPM. GE.RSLB) ADS=ADSF (I)

$48 \quad A M S=A D S+A B S S$

$A S=Q 7-A M A X 1(0 ., Q 2-X(2)-A M S) / E ?$

$275 \quad$ IF (JUMG) $50,34,36$

C STORAGE E2 LT.EC

$49 \quad Q 7=A M I N T(X 7, \overline{B S(I)-A D-A B)}$

$Q 2=E 2+Q 7 \div E\}$

IF (RPM EO 1 ) AMS $=A D S=A D S F(I)$

$280-A S=Q 7-A M A X T\left(0 . Q^{2}-A M S-X(2)\right) / E 7$

IF $(E 23478 . G T . R P M)$ B $4=A M I N 1(E 4 \times 4, X 7-A S,(X(2)-E 2) / E 7-A S)$

IF (JUMG) $50,39,41$

50 CONTINUE

$26=84 / E F F(4)+D E E: I)-E 36: A D-E 38 \div A D S$

285

$\operatorname{EPUR}(J P)=\operatorname{EPUR}(J P)+Z 6$ 


\section{$E F F(22)=E F F(22)+A M S$}

C CHECK MONTH

IF (NH.GT.MHOUR (MO)) MO $=M O+1$

C FIND PEAK COST FOR EACH MONTH

$27=26 * P \operatorname{COS}(J P)$

IF (Z7.LE.PDCO(MO)) GO TO 220

290

$P D C O(M O)=Z 7$

$\operatorname{MHPK}(M O)=\mathrm{NH}$

$P D C O(M O, 2)=26$

295220 CONTINUE

C FIND PEAK DEMAND FOR EACH MONTH IF THE PEAK COST IS $Z$ ERO

IF (PDCO $(M O, 1)$. NE.0. .0. 26.LE.PDCO $(M 0,2)) G O$ TO 225

$P D C O(M O, 2)=Z 6$

$300 \quad 225$ CONTINUE

CONTINUE

$E B M T=E B M T+E \operatorname{COS}(J P) *(R E S B * Z 6-R S L B * Z 5)$

$E B M=B I G W$

305

IF (EBMT . LE. O. ) EBM $=0$.

$E S L B(J P)=E S L B(J P)+Z 5$

$E Z=E 2+E 7 *(A S+B 4)-A M$

IF(IND.EQ.0)GO TO 57

$\operatorname{AES}(1)=\operatorname{AES}(1)+\operatorname{AMS}$

$\operatorname{AES}(2)=\operatorname{AES}(2)+E 2$

$310 \quad \frac{A E S(2)=A E S(2)+E 2}{F F D(1)=F F D(1)+A D+A B}$

$F F D(5)=F F D(5)+A D S$

$Z 1=A S+B 4$

$T A(2)=T A(2)+Z 1$

$L=E 2 \div D C U 2+1$.

315

$C U(L)=C U(L)+1$

$F F D(2)=F F D(2)+A S$

$T B(2)=T B(2)+A M S$

$Z 1=E 6 *(A D+A B)+E 8 \div A M S$

$T A(3)=T A(3)+21$

320

$T B(3)=A M A X 1(T B(3), Z 1)$

$21=B 4 / E F F(4)$

$T A(4)=T A(4)+21$

TB(4) = AMAX 1 (TB(4), Z1)

WRS $(1, I)=A D$

WR $S(2, I)=A B$

WRS $(3, I)=A S$

WR $S(4, I)=A D S$

WR $S(5, I)=A B S S$

$\operatorname{WRS}(6, I)=21$

WR $S(7, I)=E 2$

WRS $(8, I)=85(I)$

WRS $(Q I I)=\operatorname{DEE}(I)$

$W R S(10, I)=E \operatorname{COS}(J P)$

WONT S 10,1$)$

335

IF (IND. NE.

60 CONTINUE

EPUR $(J P 1)=\operatorname{EPUR}(J P 1)-E Z$

UE 11AF $=\operatorname{COST}(Z Z Z Z Z)$

IF (I SXOL.EQ. 0) GO TO 102

$00100 \mathrm{~J}=1,5$

$\checkmark X O L(J)=1 \mathrm{H}$

IF $X(J) \cdot E Q . X O L(J)) G 0$ TO 100 


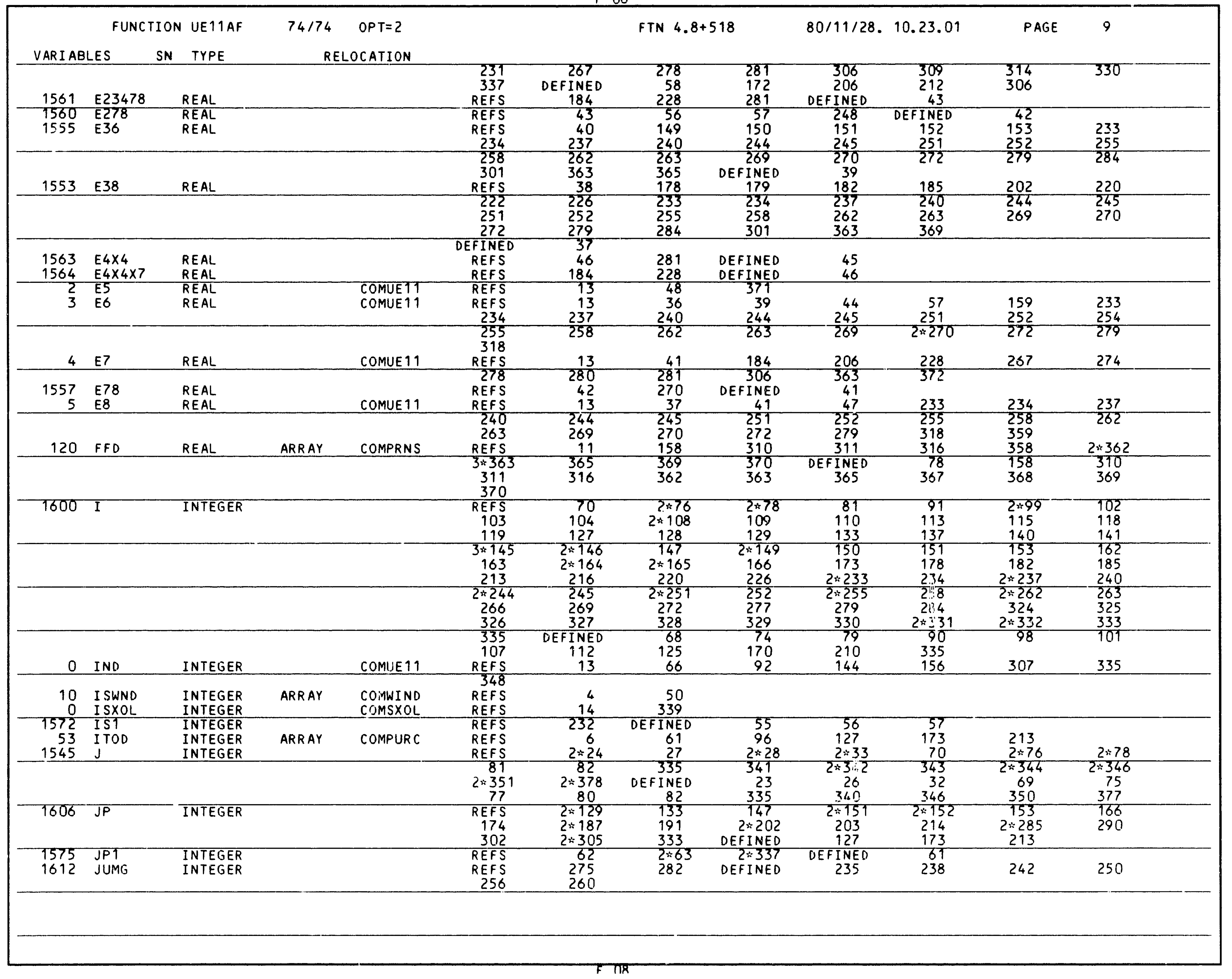




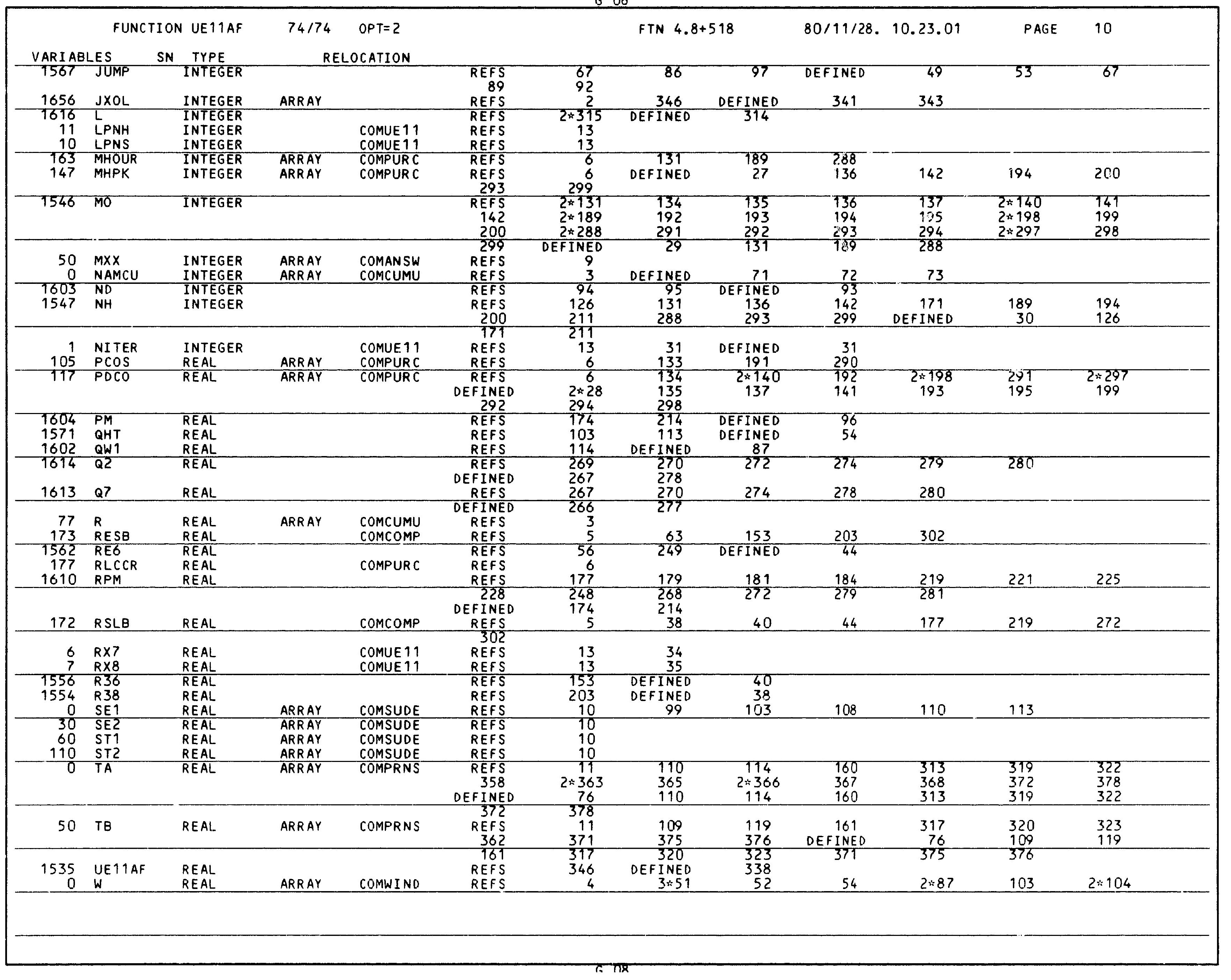




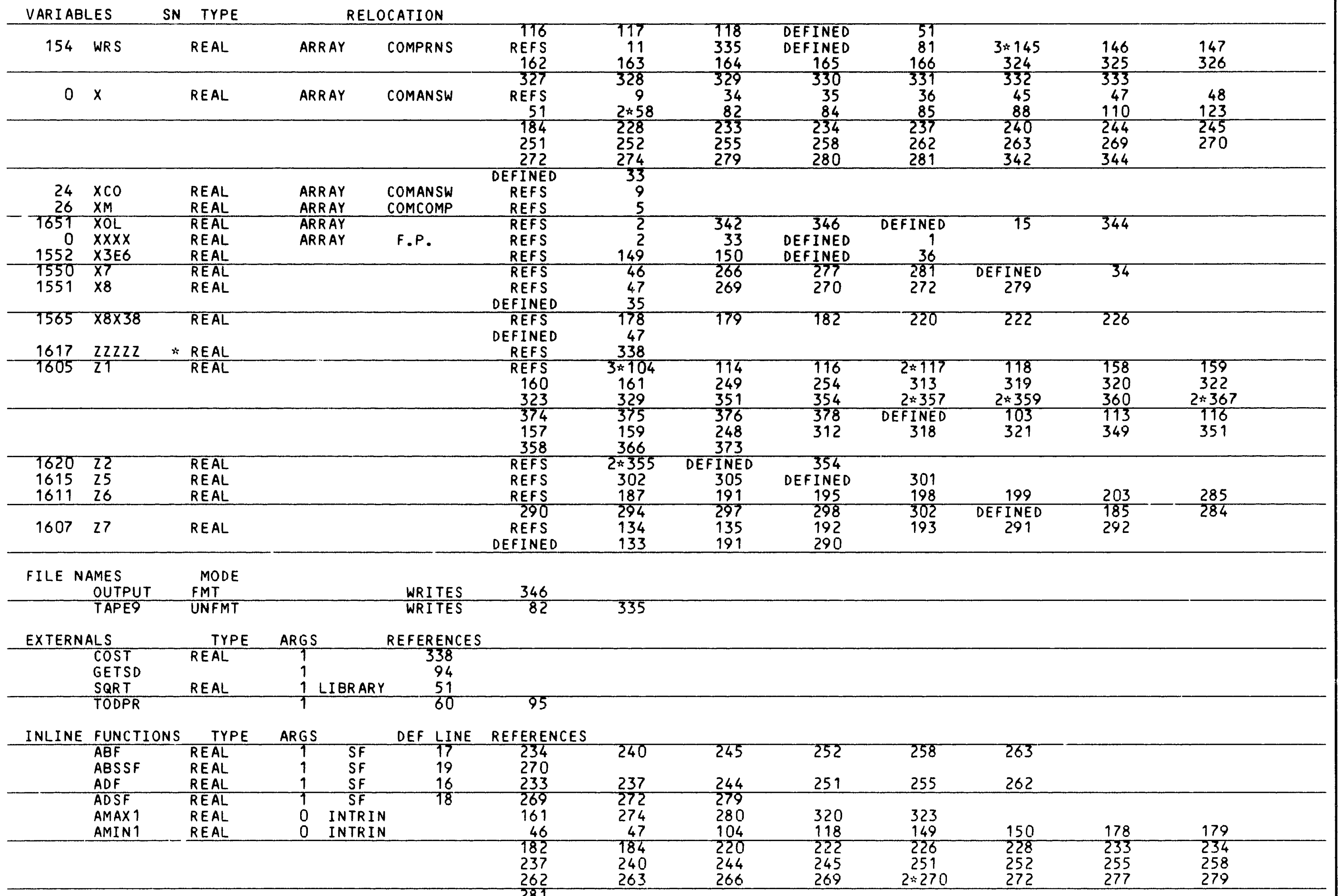




$\begin{array}{rrcc}\text { STATEMENT LABELS } & \text { DEF LINE } & \text { REFERENCE } \\ 323 & 200 & 138 & 134 \\ 0 & 205 & 28 & 26 \\ 330 & 206 & 143 & 140 \\ 477 & 210 & 196 & 192 \\ 504 & 215 & 201 & 198 \\ 1177 & 220 & 295 & 291 \\ 1204 & 225 & 300 & 297\end{array}$

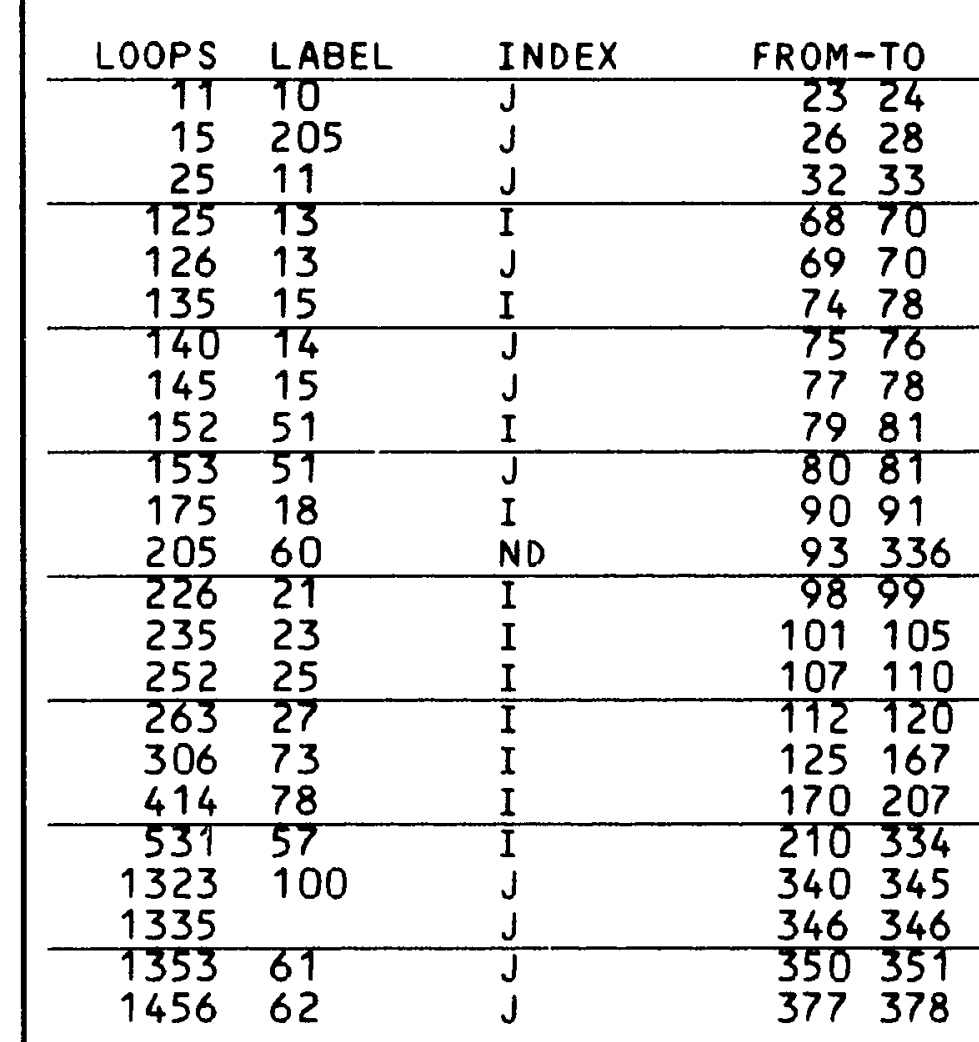

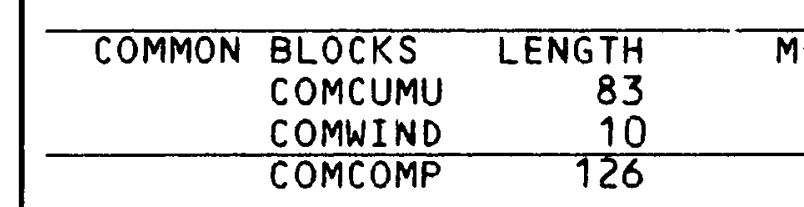

\begin{tabular}{r} 
LENGTH \\
$3 \mathrm{~B}$ \\
$3 \mathrm{~B}$ \\
$2 \mathrm{~B}$ \\
\hline $4 \mathrm{~B}$ \\
$2 \mathrm{~B}$ \\
$14 \mathrm{~B}$ \\
$3 \mathrm{~B}$ \\
$3 \mathrm{~B}$ \\
$4 \mathrm{~B}$ \\
$2 \mathrm{~B}$ \\
$2 \mathrm{~B}$ \\
$1104 \mathrm{~B}$ \\
$2 \mathrm{~B}$ \\
$7 \mathrm{~B}$ \\
$3 \mathrm{~B}$ \\
$13 \mathrm{~B}$ \\
$100 \mathrm{~B}$ \\
$107 \mathrm{~B}$ \\
$551 \mathrm{~B}$ \\
$4 \mathrm{~B}$ \\
$10 \mathrm{~B}$ \\
$3 \mathrm{~B}$ \\
$2 \mathrm{~B}$
\end{tabular}

PROPERTIES

INSTACK

INSTACK

INSTACK

INSTACK

INSTACK NOT INNER

INSTACK

NOT INNER

INSTACK

INSTACK EXT REFS NOT INNER

INSTACK

INSTACK

OPT

$O P T$

OPT

INSTACK EXT REFS

INSTACK

INSTACK

COMCOMP 126

- BIAS NAME (LENGTH)

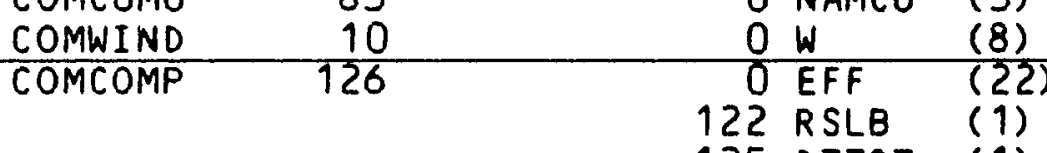

122 RSLB (1)

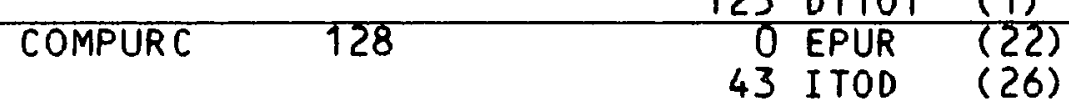

43 ITOD
103 MHPK (26)
0 (12)

$\begin{array}{cc}103 \text { MHPK } & (12) \\ 0 \times & (20)\end{array}$

COMANSW

60 CTO

COMSUDE $\quad 144$

0 SE 1

(14)

COMPRNS 348

COMUET1

72 ST2

92 TA

2 AES (40)

0 IND $-(1)$

3 E6

6 RX7

(1)

O LPNH (1)

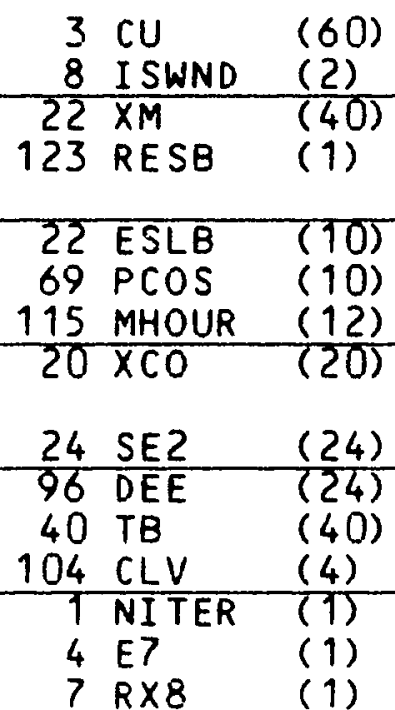

$63 R$

(20)

COMSXOL

1

0 ISXOL (1)

$\begin{aligned} 62 & \text { CC } \\ 124 & \text { DETOT }\end{aligned}$

32 ECOS (11)

79 PDCO (24)

$\begin{array}{ccc}127 & \text { RLCCR } & (1) \\ 40 \operatorname{MXX} & (20)\end{array}$

$\begin{array}{lll}48 & 5 T 1 & (24)\end{array}$

120 DET (24)

$\begin{array}{ll}80 \mathrm{FFD} & (12) \\ 108 \text { WRS } & (240)\end{array}$

2 ES (1)

5 E8 (1)

STATISTICS

PROGRAM LENGTH $16638 \quad 947$

$\begin{array}{lll}\text { CM LABELED COMMON LENGTH } & 16638 & 947 \\ & 1634 \mathrm{~B} & 924\end{array}$ 


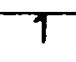

FUNCTION UETTBF $(X X X X)$

DIMENSION $X X X X(20), 85(24), X O L(5), J X O L(5)$

COMMON / COMUPDN/ IHUP PRUP, IHDN PRDN

COMMON TCOMCUMUI NAMCU $(3), C U(20,3), R(20)$

5

COMMON /COMWIND/ $W(8)$, I SWND(2)

COMMON /COMCOMP/ EFF (22) XM(20,2) CC (20,3) RSLB, RESB, DETOT, DTTOT

COMMON TCOMPURC I EPUR(11, 2$), E S L B(10), E C O S(11), I$ TOD(26).

A PCOS $(10), P D C O(12,2), \operatorname{MHPK}(12), \operatorname{MHOUR}(12)$

$B$ RLCCR

COMMON TCOMANSWI X(20),XCO(20), MXX(20), CTOT $(7,2)$

10

COMMON /COMSUDE/ SE1(24) SE2(24) ST1(24), ST2(24), DEE(24), DET(24)

COMMON / COMPRNS/ TA $(20,2)$, TB $(20,2)$, FFD $(6,2)$, AES $(6,2)$, CLV $(4)$

TWRS $(10,24)$

15

COMMON / COMUE11/ IND, NITER, E5, E6, E7, E8, RX7, RX8, LPNS, LPNH

COMMON / COMSYOL/ ISXOL

DATA XOL!S(-1.)T

DATA BIGW/1E30/

$A D F(I)=A M I N 1((D E E(I)-E 38 * A D S) / E 36$ B5 (I) - AS $(X(3)-E 8 * A M S) / E 6)$

20

$A B F(I)=A M I N T((E B M-E 38 * A B S S) / E 36$ BS(I)-AS-AD $(X(3)-E 8 * A M S) / E 6-A D)$

$A D S F(I)=A M I N 1((D E E(I)-E 36 * A D) / E 38, \times 8, Q 2,(X(3)-E 6 *(A D+A B)) / E 8)$

$A B S S F(I)=A M I N 1((E B M-E 36 * A B) / E 38, A M I N 1(X 8, Q 2,(X(3)-E 6 *(A D+A B)) / E 8$

1) - ADS)

$\operatorname{EPUR}(11)=\operatorname{EFF}(22)=0$

$A D=A B=A S=A D S=A B S S=A M S=B 4=0$

25

$10 \operatorname{EPUR}(\mathrm{J})=\operatorname{ESĹ} B(\mathrm{~J})=0$.

DO $200 \mathrm{~J}=1,12$

$200 \quad \operatorname{PDCO}(J, 1)=\operatorname{PDCO}(J, 2)=0$

$\mathrm{NH}=0$

NI TER $=N I T E R+1$

DO $11 \mathrm{~J}=1,4$

$X(j)=X X X X(j)$

$X 7=R \times 7 \div X(2)$

$X 8=R \times 8 * \times(2)$

$X 3 E 6=X(3) / E 6$

$E 15 X=E F F(1) \div E 5 * X(1)$

JUMP $=1$

$40-\operatorname{IF(ISWND(1).LE.0)GO~TO~} 12$

$W(8)=D$ I A= SQRT $(259.7 \div x(1) / W(3) /(W(5)+W(4)) \div \div 3)$

$E 15 X=E$ 15X*W(7)

JUMP $=2$

45

$Q H T=((15.2+.5 * D I A) / W(2)) * .142857$

$12 \quad E 2=0$

$E Z=0$.

$N H=I H \cup P=0$

CALL TODPR (1)

JPI $=I T O D(1)$

$E 36=E F F(3): E 6$

$R 36=R S I B \div E 36$

$E 38=E F F(3) * E 8$

$R 38=R S L B * E 38$

$E 4 \times 4=E F F(4) \div \times(4)$

55

EX7E4=E7

$\times 8 \times 38=A M I N 1(\times 8 \times(3) / E 8)$

IF $(E 7 \times 7 E 4$. LE. 0. S $7>>7 E 4=-1 . E 30$ 


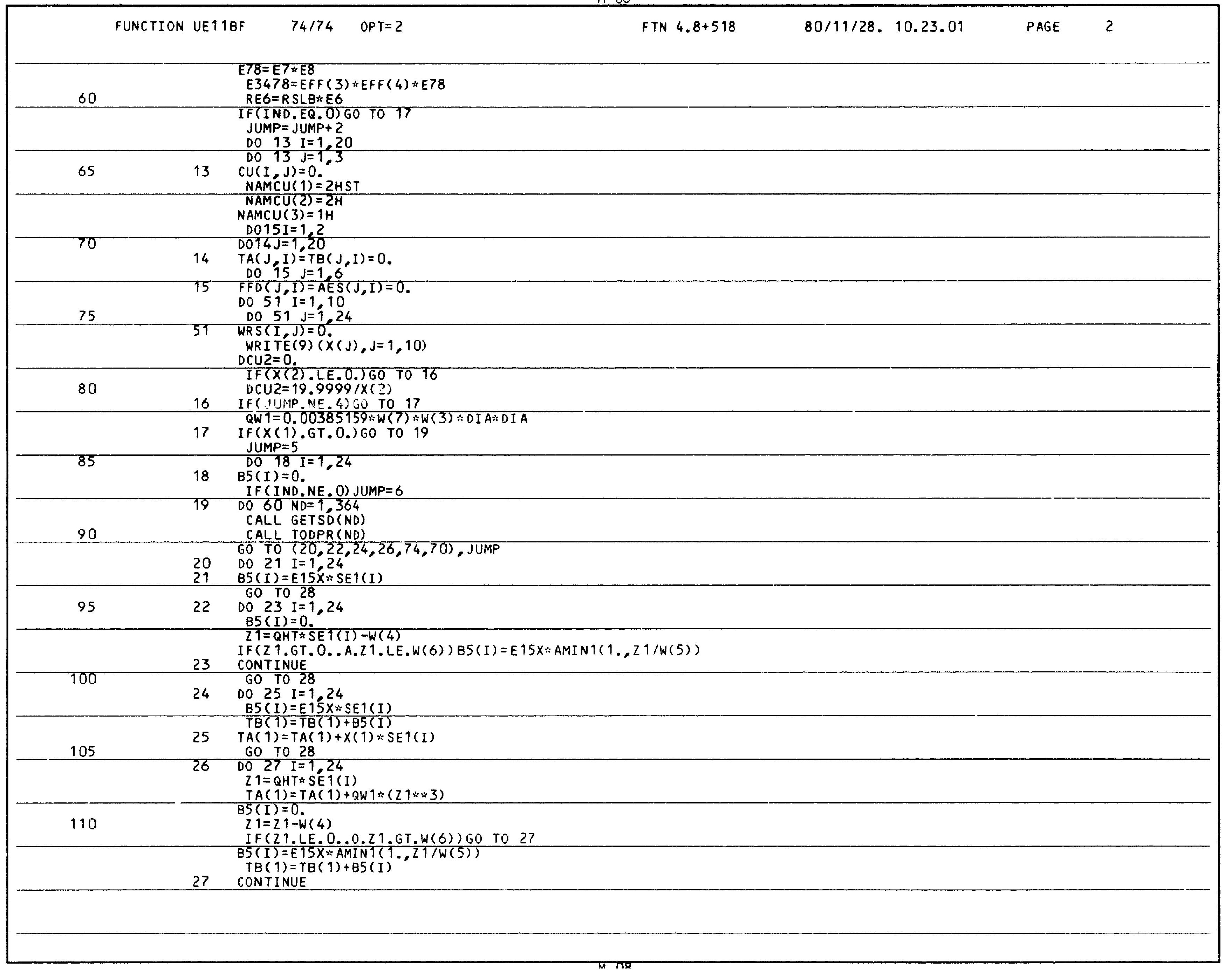


115

\begin{tabular}{cl}
\multirow{2}{*}{28} & GO TO 28 \\
& CONTINUE \\
& IF $(X(2)) 71,71,70$ \\
$C$ & X $=0$. \\
71 & DO 73 I I $=1,24$ \\
& $N H=N H+1$
\end{tabular}

$\mathrm{NH}=\mathrm{NH}+1$

$J P=I T O D(I)$

IF (BS(I).GT.0.) GO TO 72

$\operatorname{EPUR}(J P)=\operatorname{EPUR}(J P)+D E E(I)$

CHECK MONTH

125 C IF (NH.GT.MHOUR (MO)) MO $=M O+1$

C FIND MAXIMUM PEAK DEMAND COST FOR EACH MONTH

$Z 7=D E E(I) * P \operatorname{COS}(J P)$

$Z 7=D E E(I) * P C O S(J P)$
IF $(Z 7$. LE.PDCO $(M O, 1)) G O$ TO 300

$P D C O(M O)=Z 7$

MHPK $(M O)=N H$

$\operatorname{PDCO}(M 0,2)=D E E(I)$

300 CONTINUE

FIND PEAK POWER FOR MONTH IF PEAK DEMAND PRICE IS ZERO

IF $(P D C O(M O, 1)$. NE.0.. O.DEE(I). LE.PDCO $(M O, 2))$ GO TO 310

$\operatorname{PDCO}(M O, 2)=D E E(I)$

135

310 CONTINUE

IF (IND.EQ.0) GO TO 73

WRS $(1, I)=W R S(2, I)=W R S(8, I)=0$

$140 \quad$ WRS $(Q, I)=$ DEE (I)

$W R S(10, I)=E \operatorname{COS}(J P)$

WR $S(10, I)=$

$72 A D=A M I N 1(D E E(I) / E 36, \times 3 E 6, B 5(I))$

$A B=A M I N 1(E B M / E 36 \times 3 E 6-A D, B 5(I)-A D)$

$145 \quad$ EPUR $(J P)=E P U R(J P)+D E E(I)-E 36 * A D$

$E B M T=E B M T+E \operatorname{COS}(J P) *(R E S B *(D E E(I)-E 36 * A D)-R 36 * A B)$

$E B M T=E B M T+E$
$E B M=B I G W$

IF $(E B M T$ B . LE. O. $) E B M=0$.

$E S L B(J P)=E S L B(J P)+E 36 \div A B$

150 IF (IND.EQ.0) GO TO 73

$Z 1=A D+A B$

$F F D(1)=F F D(1)+Z 1$

$21=21 * E 6$
$T A(3)=T A(3)+Z 1$

$T B(3)=A M A X 1(T B(3), Z 1)$

WR $S(1, I)=A D$

WR $S\left(\sum, I\right)=A B$

WR $S(8, I)=B 5(I)$

WR $S(9, I)=\operatorname{DEE}(I)$

WRS $(10, I)=\operatorname{ECOS}(J P)$

16073 WRS(10, I)

GO TO 59

$X 1=0$. AND IND $=0$

165

$74 \quad D 079^{\circ}=1,24$

$\mathrm{NH}=\mathrm{NH}+1$

$N H=N H+1$
$E Z=E 2 \div E F F(2)$

IF (NH. LT. I HUP) GO TO 75

CALL TODUP(NH)

$M=I H U P-N H$

170

$75-J P=I T O D(1) \div M$

$J P=I T O D(I)$ 


\section{$E 2 M P=E 2 M \times P R U P / E \operatorname{COS}(J P)$}

\section{$A D S=A B S S=B 4=0$}

$175 \quad$ E2MPM $=A M A X 1(E F F(2), E 2 M P)$

IF (R SLB.GE.ELMPM) GO TO 77
IF $(1 .$. GE.E2MPM GO TO 76

IF (E2MP $\triangle E 3478$. LE. 1) GOTO 78

IF(INT( $(X(2)-E 2 * E 2 M) / E 7 X 7 E 4)$. LT.M)GO TO 78

180 $B 4=\operatorname{AMIN} 1((X(2)-E 2) / E 7, X 7, E 4 \times 4)$ GO TO 78 (

76 ADS $=$ AMIN1 (DEE(I) TE38,E2, X8×38) GO TO 78

77 ADS $=$ AMIN 1 (DEE(I) $/ E 38, E 2, \times 8 \times 38)$

ABSS $=$ AMIN T (EBM/E38, E2-ADS, $\times 8 \times 38-A D S)$

$185 \quad 78 \quad 26=D E E(I)-E 38 \times A D S+B 4 / E F F(4)$

$E F F(22)=E F F(22)+A D S+A B S S$

EPUR (JP) $=E P U R(J P)+26$

C CHEC.K MONTH

IF (NH.GT. MHOUR (MO)) MO $=M O+1$

190 C FIND MAXIMUM PEAK DEMAND COST FOR EACH MONTH

$Z 7=26 * P C O S(J P)$
IF $(27$. LE.PDCO $(M O, 1))$ GO TO 210

IF 27 . LE. PDCO

$\operatorname{MHPK}($ MOS $=\mathrm{NH}$

195

$P D C O(M O, 2)=26$

210 CONTINUE

FIND PEAK POWER FOR MONTH IF PEAK DEMAND PRICE IS ZERO

IF (PDCO (MO, 1).NE.0..0.26.LE.PDCO (MO, 2)) GO TO 230

$P D C O(M O, 2)=26$

$200 \quad$ MHPF $(M O)=N H$

230 CONTINUE

$E S L B(J P)=E S L B(J P)+E 38 \div A B S S$

$E B M T=E B M T+E C O S(J P) \approx(R E S B \approx 26-R 38 * A B S S)$

EBM $=B I G W$

205

F (EBMT.LE.O.) EBM $=0$.

$E Z=E 2+E 7 \approx B 4-A D S-A B S S$

$M=M-1$

E2M=E2M/EFF(2)

$210 \quad 79$ CONTINUE

GO TO 59

C 70 DO 57 I $=1,24$

$\mathrm{NH}=\mathrm{NH}+1$

$E Z=E 2 * E F F(2)$

215

I F (NH.LT. I HUP) GO TO 29

CALL TODUP(NH)

$M=I H U P-N H$

$E 2 M=E F F(2) \div \therefore M$

$29 \quad J P=I T O D(I)$

$E 2 M P=E 2 M \div P R U P / E \operatorname{COS}(J P)$

E2MPM $=A M A X 1$ (EFF (2), E2MP)

$A D=A B=A S=A D S=A B S S=B 4=A M S=0$.

225 IF (BS(I) . GT.0.) GO TO 32

C $\quad B 5=0$.

IF (RSLB. GE.EZMPM) GO TO 31

IF (1..GE.EZMPM) GO TO 30

IF (E2MP*E3478. LE. 1.) GO TO 50

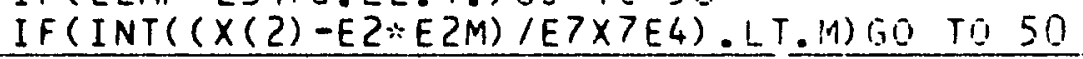




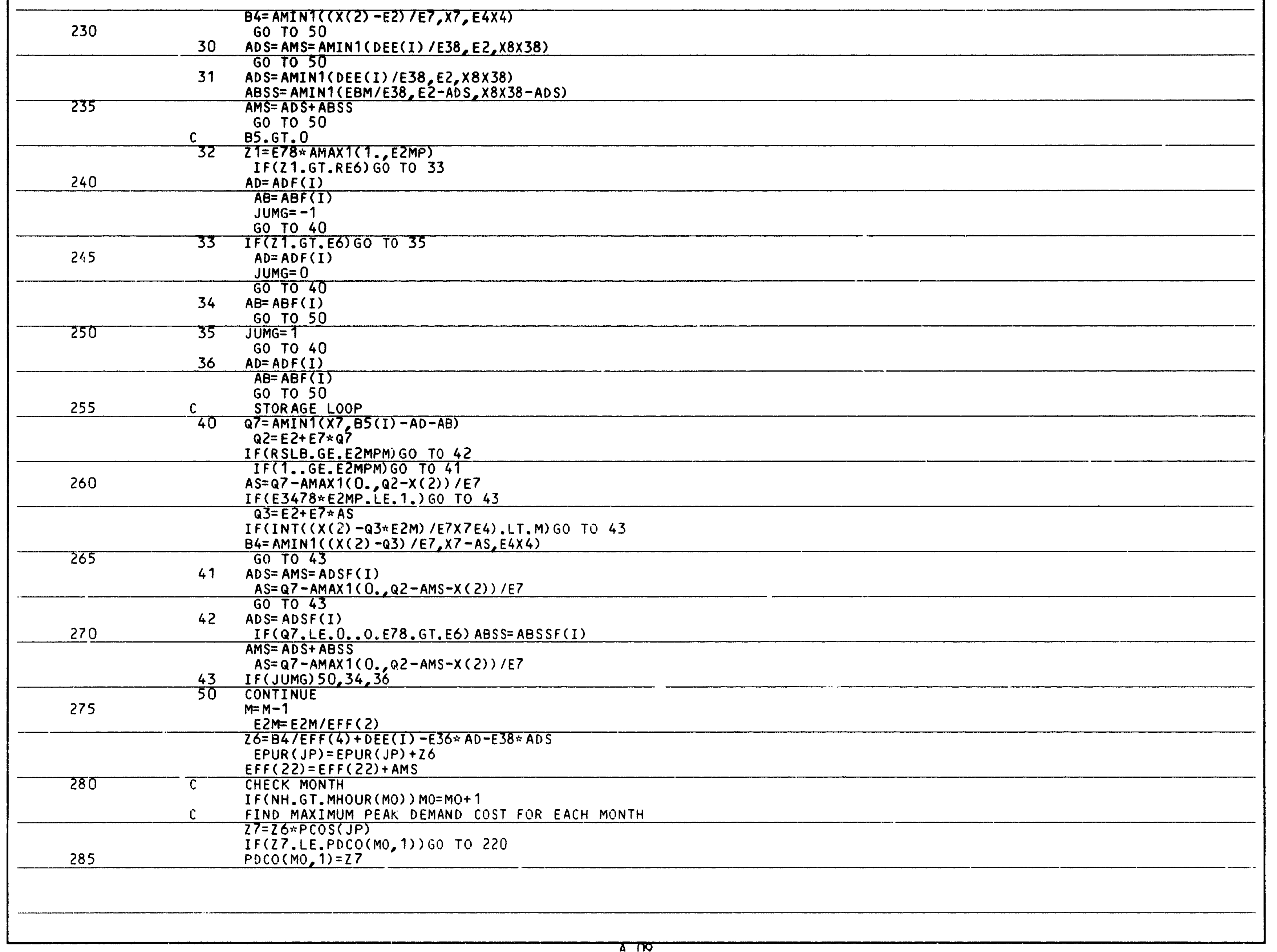


MHPK $(M O)=N H$

$P D C O(M O, 2)=26$

220 CONTINUE

290

FIND PEAK POWER FOR MONTH IF PEAK DEMAND PRICE IS ZERO

IF $(P D C O(M O, 1)$.NE.0.0.26.LE.PDCO $(M O, 2))$ GO TO 240

$P D C O(M O, 2)=26$

240 CONTIN!:

CONTIN:E
$25=E 36 * A B+E 38 * A B S S$

$295 \quad$ EBMT=EBMT+ECOS (JP)* (RESB*26-R SLB*25)

EBM $=B I G W$

IF (EBMT. LE. O.) EBM $=$ ก.

$E S L B(J P)=E S L B(J F, r \overline{Z 5}$

$\begin{aligned} & E 2=E 2+E 7 *(A S+B 4)-A M S \\ & 300 \quad \text { IF }(I N D . E Q .0) G 0 \text { TO } 57 \\ & \text { AES (1) }=\text { AES (1)+AMS }\end{aligned}$

$\operatorname{AES}(2)=\operatorname{AES}(2)+E 2$

$F F D(1)=F F D(1)+A D+A B$

$\begin{array}{rl}305 & F F D(5)=F F \\ 21=A S+B 4\end{array}$

$1=A S+B 4$

$T A(2)=T A(2)+Z 1$

$L=E 2 \times D C U 2+1$.

$\operatorname{CU}(L)=C U(L)+1$

$F F D(2)=F F D(2)+A S$

$310 \quad T B(2)=T B(2)+A M S$

$21=E 6 *(A D+A B)+E 8 * A M S$

$21=E 6 *(A D+A B)+E B$
$T A(3)=T A(3)+21$

$T A(3)=T A(3)+21$

$\mathrm{TB}(3)=\operatorname{AMAX1}(\mathrm{TB}(3), 21)$

$Z 1=B 4 /$ EFF (4)

$T A(4)=T A(4)+21$

TB(4) = AMAXT TTB(4), 21)

$W R S(1, I)=A D$

WR $(1, I)=A D$

WR $S(2, I)=A B$

$\begin{array}{ll}320 & \text { WRS }(3, I)=A S \\ & \text { WRS }(4, I)=A D S\end{array}$

WR $S(5, I)=A B S S$

WRS $(6, I)=71$

WR $S(7, I)=E 2$

WR $S(8, I)=B 5(1)$

WR $(8, I)=B 5(I)$

WRS $(9, I)=\operatorname{DEE}(\mathrm{I})$

WR $S(10, I)=E \operatorname{COS}(J P)$

$325 \quad \begin{aligned} & \text { WRS } \\ & \text { WRS }(10, \text { I } \\ & \\ & \text { CONTINUE }\end{aligned}$

59 IF(IND.NE. O)WRITE (9) ( (WRS $(I, J), I=1,10), J=1,24)$

330

$\operatorname{EPUR}(J P 1)=\operatorname{EPUR}(J P 1)-E 2$

EPUR $(J P 1)=E P U R(J P 1)-E 2$

UET1BF $=$ COST $(Z Z Z Z Z)$

F (ISXOL.EQ.O) GO TO 102

DO $100 j=1,4$

335

$X O L(J)=1 H$

IF $(X(J) . E Q . X O L(J)) G O$ TO 100

$J \times O L(J)=1 H^{*}$

$100-\operatorname{COLT}(J)=X(J)$

CONTINUE

PRINT101, UE 11BF $(X O L(J), J X O L(J), J=1,4)$

340

101 FORMAT $(1 X, F 15.3, f(F 16.4, A 1))$

102 IF(IND.EQ.0)RETURN

$Z 1=1 . E-30$ 


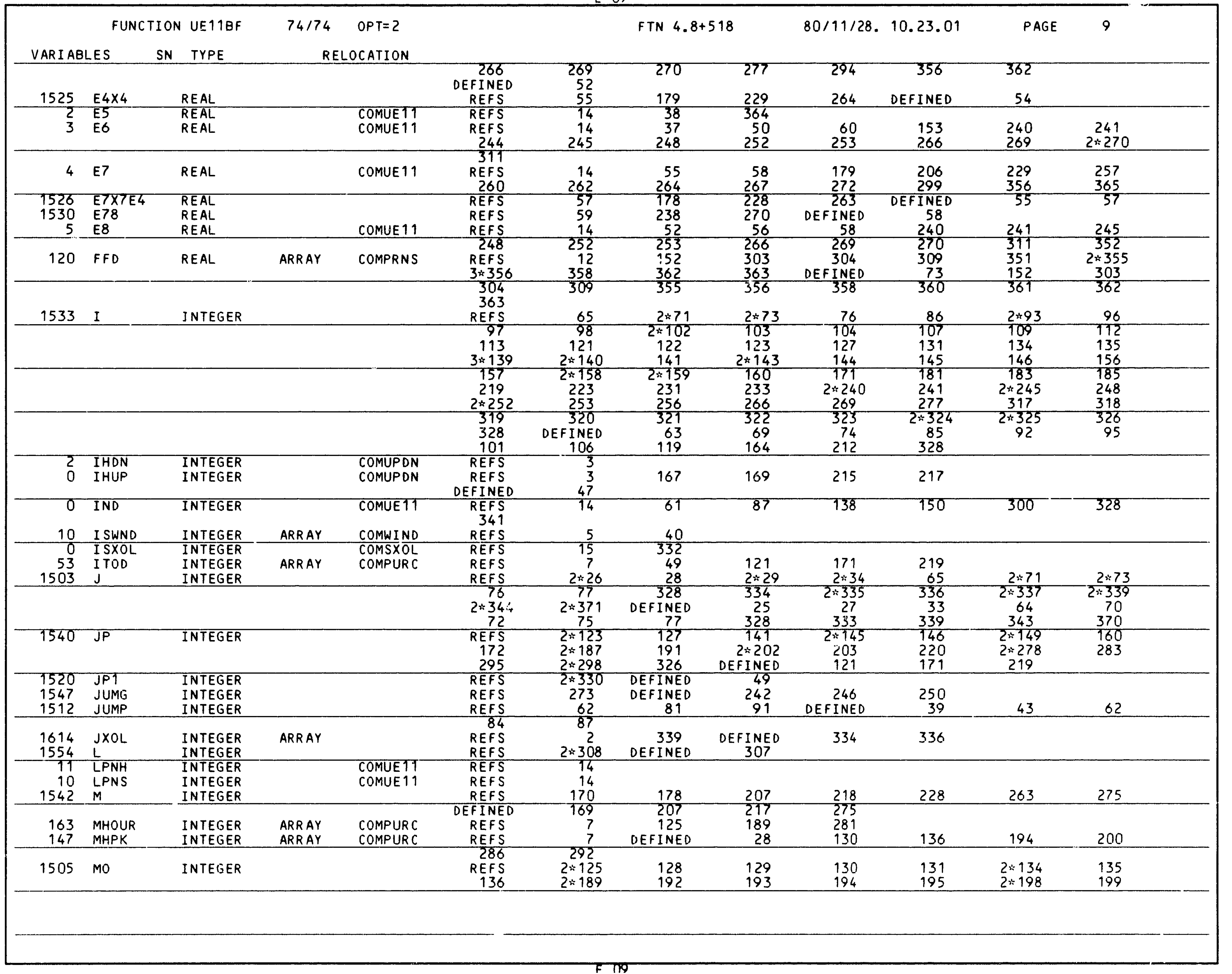




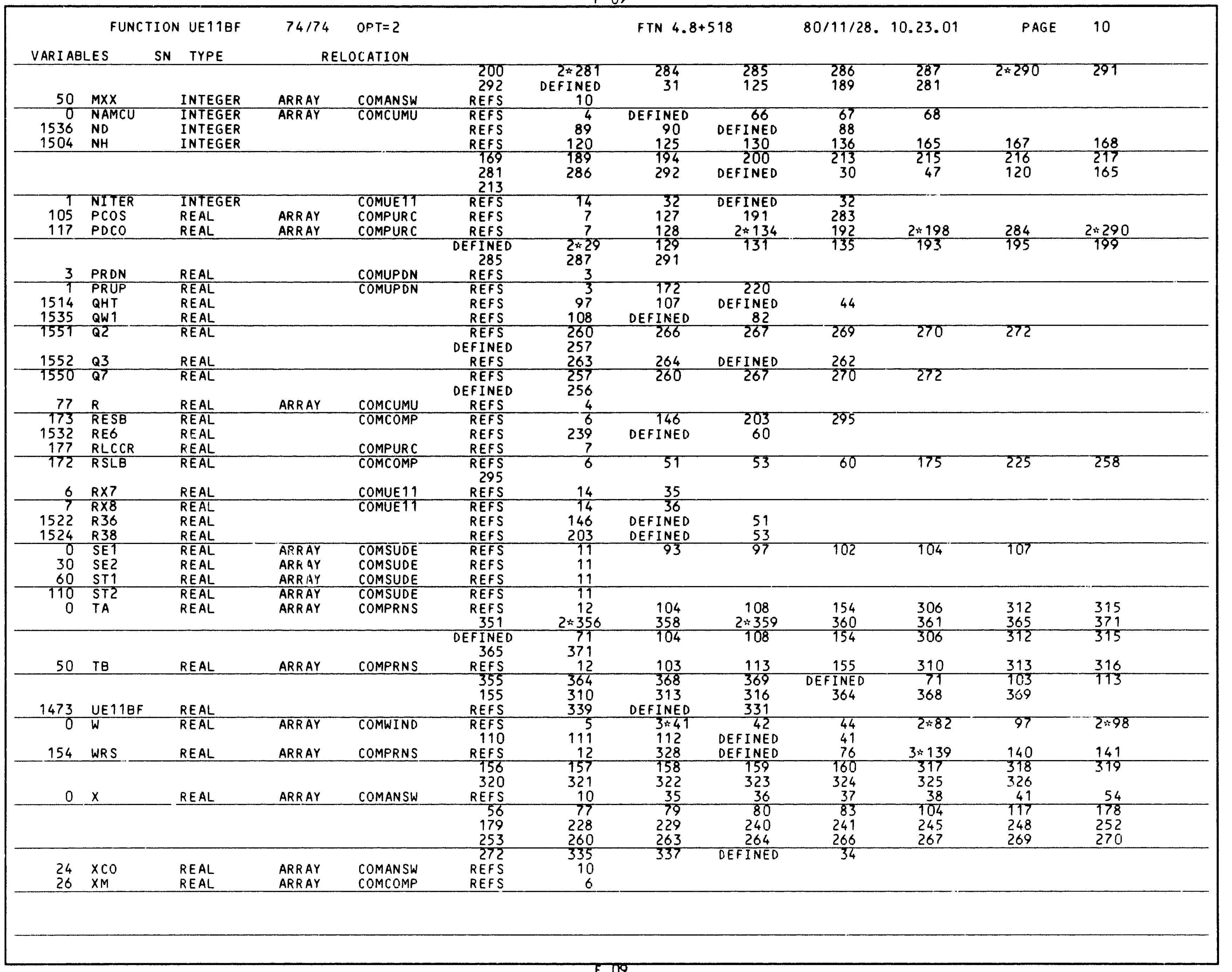




\begin{tabular}{rllll} 
VARI ABLES & SN & TYPE & \multicolumn{2}{c}{ RELOCATION } \\
\hline 1607 & XOL & REAL & ARRAY & \\
0 & $\times \times X X$ & REAL & ARRAY & F.P. \\
1510 & $\times 3 E 6$ & REAL & & \\
\hline 1506 & $\times 7$ & REAL & \\
1507 & $\times 8$ & REAL & & \\
1527 & $\times 8 \times 38$ & REAL & \\
1555 & 22222 & * REAL & & \\
1537 & 21 & REAL &
\end{tabular}

\begin{tabular}{cc} 
& \\
REFS & 2 \\
REFS & 2 \\
REFS & 143 \\
REFS & 55 \\
DEFINED & 35 \\
REFS & 56 \\
REFS & 181 \\
DEFINED & 56 \\
REFS & 331 \\
REFS & $3 \% 98$ \\
154 & 155 \\
316 & 322 \\
367 & 368 \\
151 & 153 \\
351 & 359 \\
REFS & $2 * 348$ \\
REFS & 295 \\
REFS & 187 \\
283 & 287 \\
REFS & 128 \\
DEFINED & 127 \\
\hline
\end{tabular}

\section{34}

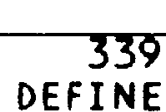

339
DEFINED

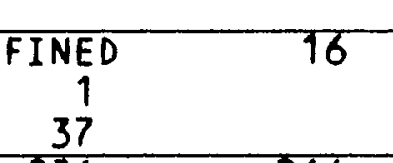

337

\begin{tabular}{lll} 
& & \\
& & \\
& & \\
\hline 1556 & 22 & REAL \\
1553 & 25 & REAL \\
1546 & 26 & REAL \\
\hline 1541 & 27 & REAL
\end{tabular}

FILE NAMES OUTPUT MODE UNFMT

\section{WR I TES}

WRITES

339 328

EXTERNALS COST GETSD
SQRT TODPR TYPE ARGS REFERENCES REAL 1131 REAL 1 LIBRARY TODUP

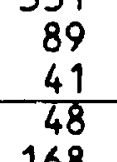

90
216

INLINE FUNCTIONS TYPE ARGS DEF LINE REFERENCES ABF ABSSF ADF ADSF REAL

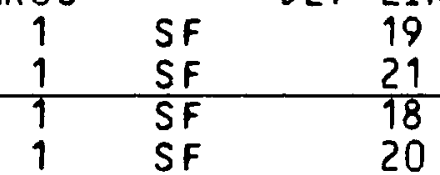

AMIN1 REAL 0 INTRIN 19
21
18
20 241
270 270
240
266 248 $\frac{144}{179}$ DEFINED $229 \quad 256$ 264 $\frac{266}{183}$ $\frac{269}{184}$ $\frac{270}{231}$

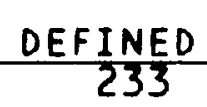
$\frac{36}{234}$

108
239
344
369
238
366
FINED
298
191
290
129
191

110
244
347
371
305
347
EFINED
195
291
192
283
$2 \times 11$
306
$2 \times 350$
DEFINE
311
294
198
295
193

$$
233
$$

498

$\begin{array}{ll}55 & 239\end{array}$

368
153

112
312
$2 \times 352$
97
314
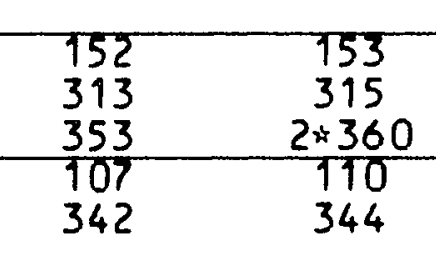

\begin{tabular}{llll} 
ABF & REAL & 1 & SF \\
ABSSF & REAL & 1 & SF \\
\hline ADF & REAL & 1 & SF \\
ADSF & REAL & 1 & SF \\
AMAX1 & REAL & 0 & INTRIN \\
\hline AMIN1 & REAL & 0 & INTRIN
\end{tabular}

INT INTEGER

1 INTRIN

$\begin{array}{lll}155 & 174 & 221\end{array}$

238

200

199
DEF INED
284

203
185
285

$\frac{278}{277}$

$\begin{array}{ll}284 & 285\end{array}$

$\begin{array}{rrr}55 & 56 & 98 \\ 183 & 184 & 229 \\ 245 & 248 & 252 \\ 24270 & & \end{array}$

112
231
253

143
233
256

267

272

313

178

228

263

\begin{tabular}{rrrrr}
\multicolumn{2}{c}{ STATEMENT LABELS } & DEF LINE & REFERENCES \\
0 & 10 & 26 & 25 & \\
\hline 0 & 11 & 34 & 33 & \\
56 & 12 & 45 & 40 & \\
0 & 13 & 65 & 63 & 64 \\
\hline 0 & 14 & 71 & 70 & 72 \\
0 & 15 & 73 & 69 & 71 \\
153 & 16 & 81 & 79 & \\
\hline 161 & 17 & 83 & 61 & 81 \\
0 & 18 & 86 & 85 & \\
171 & 19 & 88 & 83 & \\
\hline
\end{tabular}




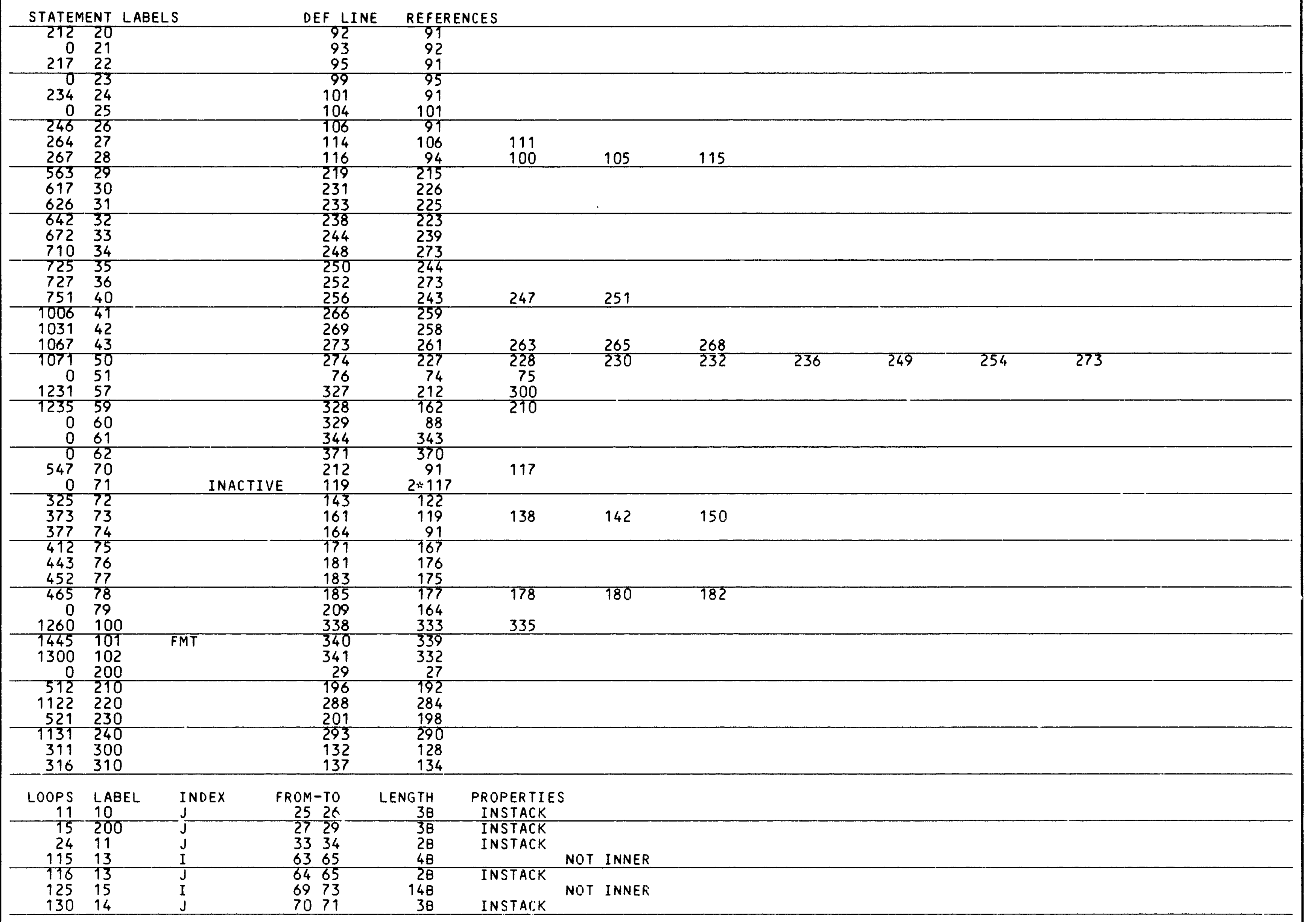




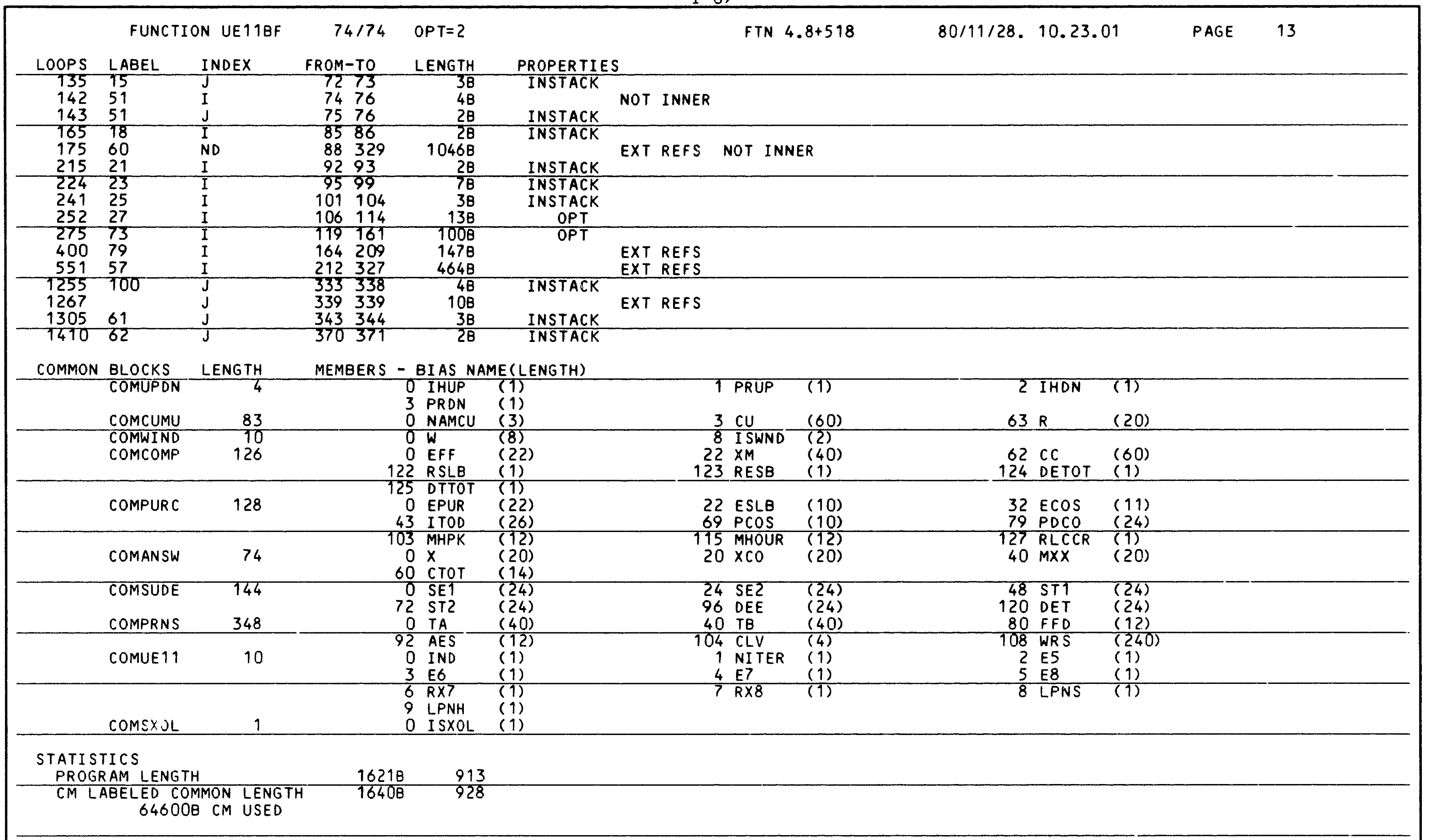


FUNCTION UETTCF(XXXX)

DIMENSION $X X X X(20), X O L(5), J X O L(5), B 5(4,72)$

COMMON /COMCUMU/ NAMCU(3) CU(20,3) R(20)

5 COMMON TCOMWIND/ W(8) I SWND(2)

COMMON /COMCOMP/ EFF(22),XM(20,2) CC $(20,3)$ RSLB,RESB, DETOT, DTTOT

COMMON /COMPURC/ EPUR $(11,2)$ ESLB(10) ECOS(11) I TOD(26)

A PCOS (10),PDCO (12,2),MHPK (12), MHOUR (12)

B.RLCCR

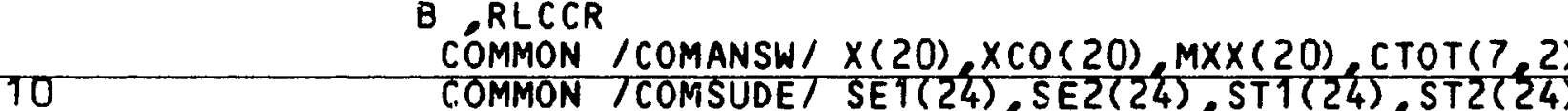

COMMON TCOMSUDE/ SET(24), SE2(24), ST (24), ST2(24), DEE(24), DET(24)

COMMON /COMPRNS/ TA $(20,2), T B(20,2), F F D(6,2), A E S(6,2), C L V(4)$,

1WRS $(10,24)$

COMMON TCOMUETT/ IND, NI TER,E5,E6,E7, E8,RX7 RX8, NSNS, NHNH

15

COMMON / COMLPRO/NH, NS, SU(24), DE (24), CTB $(7,24), X T B(13), K S B W$

COMMON / COMSXOL/ I SXOL

DATA XOL/5(-1.)T

NH=NHNH

NS=NSNS

20

DO $200 \mathrm{~J}=1,12$

$\operatorname{MHPK}(J)=0$

$200 \quad \operatorname{PDCO}(\mathrm{J})=\operatorname{PDCO}(\mathrm{J}, 2)=0$

$M O=1$

NHR $=0$

$\operatorname{EPUR}(11)=\operatorname{EFF}(22)=0$

$25 \quad \mathrm{NW}=0$

DO $10 \mathrm{~J}=1,10$

$10 \quad \operatorname{EPUR}(J)=\operatorname{ESL} B(J)=0$.

NI TER $=$ NI TER+1

DO $11 \mathrm{~J}=1,4$

$30 \quad 11 \quad x(j)=x \times x \times(j)$

$X 7=R X 7 \pm X(2)$

$X 8=R \times 8 * X(2)$

$E 15 X=E F F(1) * E 5 * X(1)$

35 $N D=0$

$N S 41=4 * N S+1$

NS42 $=289-N S 41$

36 $=E F F(3) * E 6$

$R 36=R S L B * E 36$

$E 38=E F F(3) * E 8$

40

$E 47=E 7 * E F F(4)$

$E S T=0$.

$E B M=0$.

$X \operatorname{TB}(2)=X(2)$

$45 \quad X T B(3)=X(3) / E 8$

$X T B(4)=X(4)$

$X T B(4)=X(4)$
$X T B(5)=E 7$

$\times$ XTB(5)=

$X T B(6)=A M I N 1(X T B(3), X 8)$

50

$X T B(7)=X 7$

$X T B(9)=E F F(4)$

$X T B(10)=E F F(2)$

$X T B(11)=E 47$

$X T B(12)=E 6 / E 8$ 
60

EPUR $(J P 1)=E S T$

NHOUR $=0$

JUMP $=1$

IF(I SWND(1) . LE. O) GO TO 12

$W(8)=D I A=S Q R T(259.7 * x(1) / W(3) /(W(5)+W(4)) * 3)$

$E 15 X=E 15 X * W(7)$

JUMP $=$

$Q H T=((15.2+.5 * D I A) / W(2)) * .142857$

65

12 IF(IND.LE O) GO TO 17

JUMP $=$ JUMP+2
DO $13 \quad I=1,20$

DO $13 \mathrm{~J}=1,3$

$70 \quad 13 \quad \operatorname{CU}(\mathrm{I}, \mathrm{J})=0$.

$\operatorname{NAMCU}(1)=2 \mathrm{HST}$

NAMCU (1) $=2 \mathrm{HST}$

$\operatorname{NAMCU}(2)=2$

NAMCU $(3)=1 \mathrm{H}$

DO $15 \mathrm{I}=1,2$

$75 \quad \frac{D 014 \mathrm{~J}=1,20}{14} \quad \operatorname{TA}(\mathrm{J}, \mathrm{I})=\operatorname{TB}(\mathrm{J}, \mathrm{I})=0$

$15 \quad$ DFD $(J, I)=A E S(J, I)=0$.

DCU2 $=0$

30 IF $(x(2) \cdot$ LE. O.)GO TO 16

DCU2 $=19.9999 / \times(2)$

WR I TE(9) $(X(J), J=1,10)$

16 IF (JUMP.NE. 4) GO TO 17

$85 \quad 17 \quad$ QW $1=0.00385159 * W(7) * W(3) \approx D$ I A*DI A

NDN $=1$

JUMG $=0$

DO $18 \quad K=1,3$

18 GO TO TOT

90 JUMG $=1$

JUMG $=1$

19 CONTINUE

$X T B(1)=E F F(2) * E S T$

$95 \quad$ DO $20 K=1$ NH

$O E(K)=85(2, K) / E 38$

ZT

$2 T=C T B(1, K)=B 5(3, K)$

$\operatorname{CTB}(2, K)=-21 * E 38$

$\operatorname{CTB}(3, K)=-21 * R 38$

$\operatorname{CTB}(4, K)=-21 * E 36$

$\operatorname{CTB}(5, K)=-21 * R 36$

CTB $(6, K)=A M I N 1(D E(K) \times T B(6))$

$C T B(Y, K)=X T B(6)-C T B(\sigma, K)$

$10520 \quad$ CONTINUE

$\mathrm{KSBW}=1$

IF(EBM. LE. O.) KSBW=0

CALL LPOUTR

DO $57 \mathrm{~K}=1 \mathrm{NS}$

$J P=B 5(3, K) \cdot A .17 B$

110

$A 4=C T B(1, K)$

$A D S=C T B(Z, K)$

$A B S S=C T B(3, K)$

$A D=C T B(4, K)$

$A B=C T B(5, K)$ 


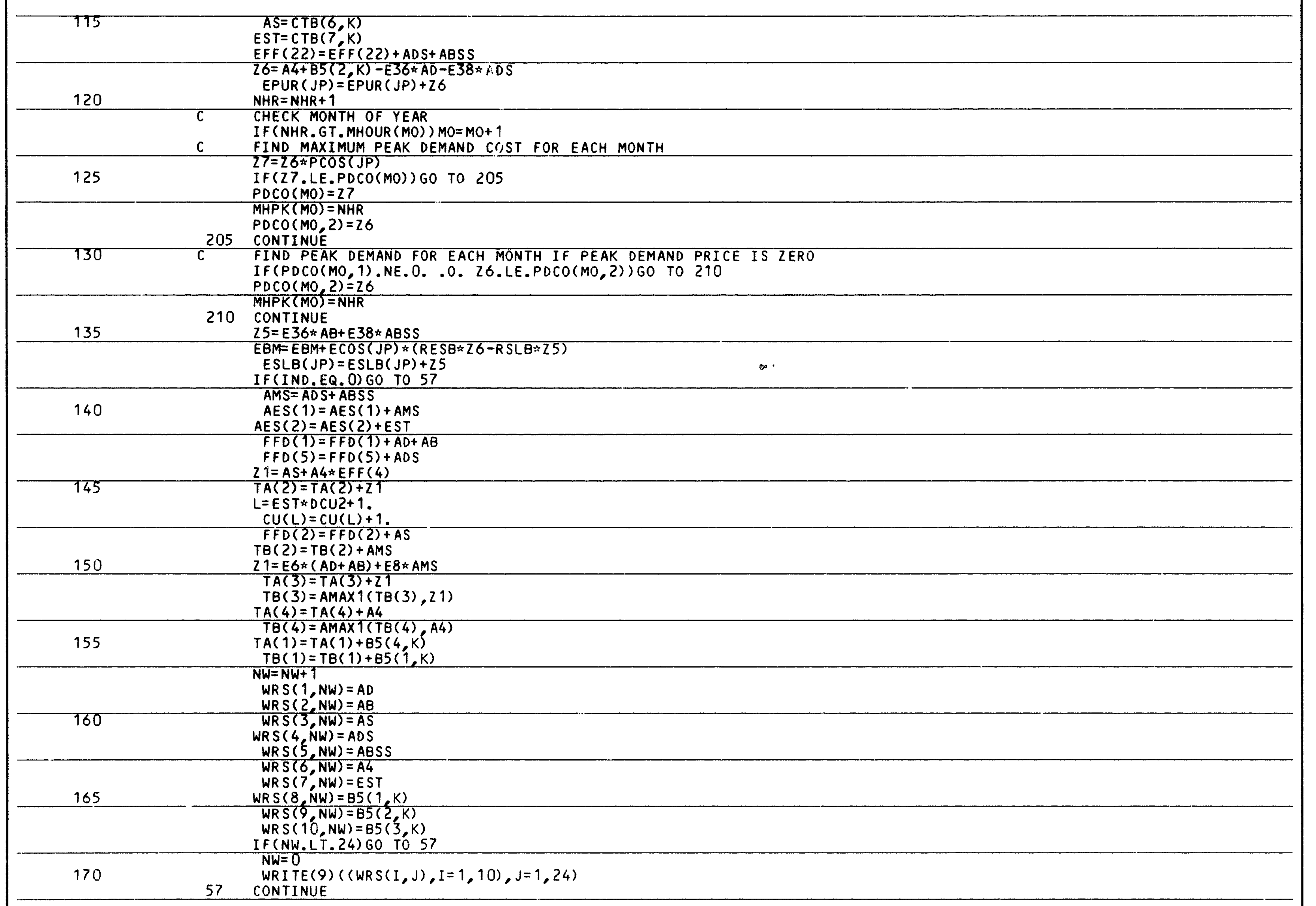


NHOUR $=$ NHOUR+NS

IF (NHOUR. LT.8736) GO TO 100

$\operatorname{EPUR}(J P 1)=\operatorname{EPUR}(J P 1)-E S T$

UET TCF $=\operatorname{COST}(2 Z Z Z Z)$

175

IF (I SXOL.EQ.0) GO TO 122

DO $120 \mathrm{~J}=1,4$

$J X O L(J)=1 H$

IF $(X(J) \cdot E Q \cdot X O L(J)) G O$ TO 120

$\mathrm{J} X O L(J)=1 \mathrm{H}^{*}$
$\mathrm{XOL}(J)=X(J)$

120 CONTINUE

PRINT121, UE11CF, $(X O L(J), J X O L(J), J=1,4)$

185

FORMAT $1 X, F 15.3,5(F 16.4, A 1)$

IF (IND.EQ. 0) RETURN

$21=1 . E-30$

$61 Z 1=21+\operatorname{EPUR}(j)-E S L B(J)$

$\operatorname{CLV}(1)=\operatorname{CTOT}(1) / D E T O T$

$190-\frac{C L V(2)=0 .}{2(12)}$

$22=D E T O T-21$

$\operatorname{IF}(22 . \operatorname{NE} .0.) \operatorname{CLV}(2)=(\operatorname{CTOT}(2)+\operatorname{CTOT}(3)) / Z 2$

$\operatorname{CLV}(3)=\mathrm{CLV}(4)=0$.

IF (Z1.NE.O.) CLV $(4)=C \operatorname{TOT}(5) / 21$

195

$Z 1=F F D(2)+T A(4)$

$\operatorname{IF}(21 . G T .0) A E S.(1)=100 . \approx E 8 * A E S(1) / Z 1$

IF (21.LE.0.) AES (1) $=0$.

$\operatorname{AES}(3)=(1 .-\operatorname{EFF}(2)) \div \operatorname{AES}(2)$

$200 \quad F F D(6)=T B(1)-F F D(1)-F F D(2)$

$I F(T A(2) . G T \cdot 0) F F D.(1)=100 * *(E 36 \approx F F D(1)+E 38 \approx E 7 * 1 F D(2)-$

1FFD(2) \& AES(3)/TA(2)) /DETOT

IF(TAC(2).LE.0.)FFD(1) $=100 . * E 36 * F F D(1) / D E T O T$

$Z 1=T A(1)+T A(4)$

$\operatorname{IF}(21 . G T$. 0.) FFD (3) $=100 . * E F F(3) * T A(3) / 21$

$205 \quad$ FFD $(4)=100 . *(E F F(3) * T A(3)-C T O T(7,2)) / D E T O T$

$F F D(5)=100 . \star E 38 * F F D(5) / D E T O T$

$F F D(2)=100 .-F F D(1)$

$T B(1)=T B(1) / E S$

$T A(2)=T A(2) * E ?$

$21=24 . * 364$.

$\operatorname{AES}(2)=\operatorname{AES}(2) / 21$

$T B(1)=T B(1) / 21$

$T B(2)=T B(2) / 21$

DO $62 \quad J=1,4$

$215 \quad 62 \quad \begin{aligned} & \text { TA }(J)=T A(J) \\ & \text { T } / 21\end{aligned}$

RETURN

DATA GETTER

100 CALATA GETTER

CALL MOVLEV(B5 (NS41), E5,NS42)

NDN=NDN-NS
$220 \quad 101 \quad$ IF(NDN.GT.49) G0 TO 111

$N D=N D+1$

CALL GETSD(ND)

CALL TODPR(ND)

225

DO $102 \quad \mathrm{I}=1,24$

$B 5(2, N D N)=D E E(I)$

$J P=I T O D(I)$

$B 5(3, N D N)=(E \operatorname{COS}(J P) . A .777777777777777777408)$.0.JP

102 NDN $=$ NDN+ 


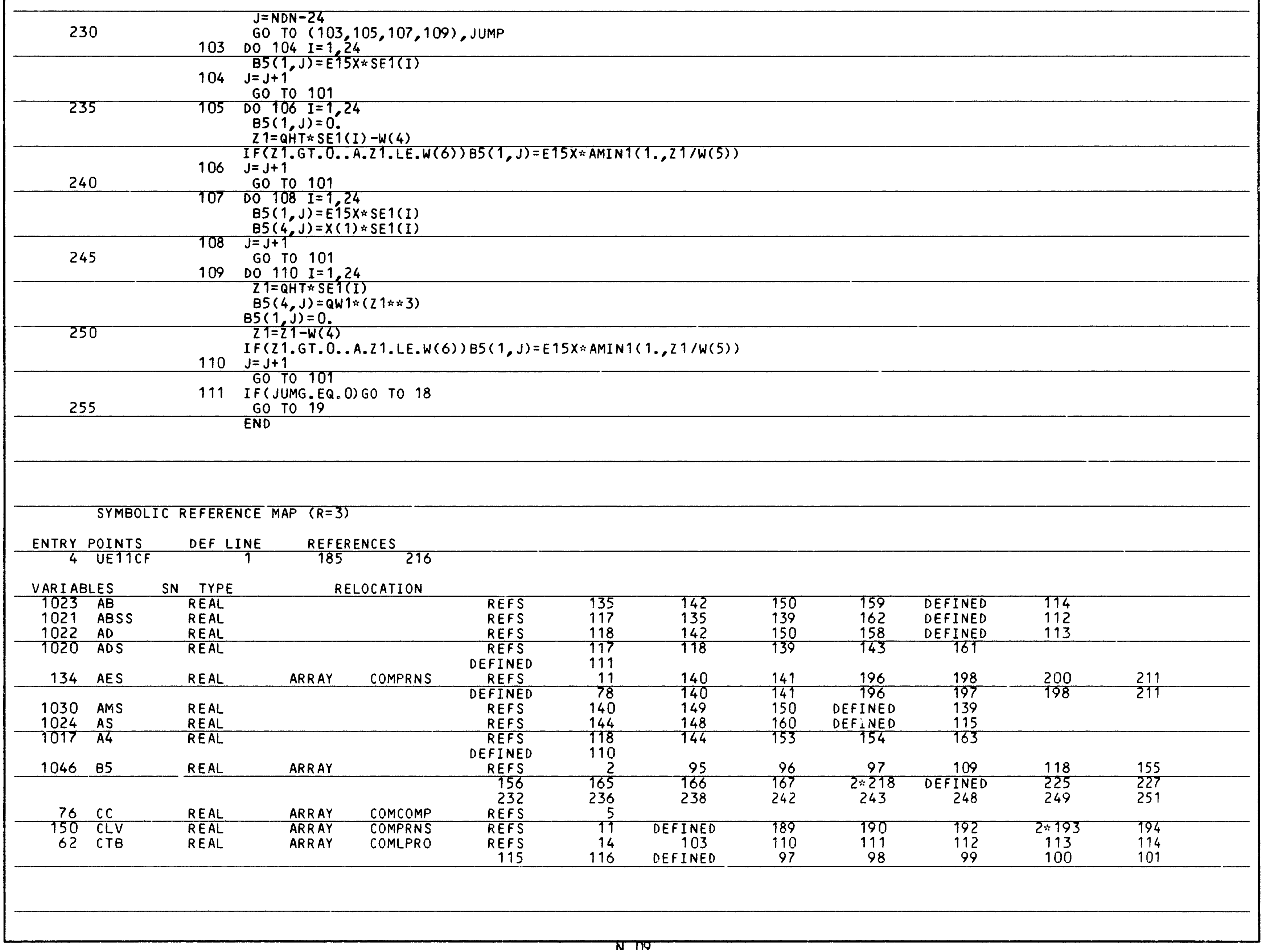


VARIABLES SN TYPE RELOCATION

\begin{tabular}{|c|c|c|c|c|c|c|c|c|c|c|c|c|}
\hline $\begin{array}{r}74 \\
3\end{array}$ & $\begin{array}{l}\text { CTOT } \\
\text { CU }\end{array}$ & $\begin{array}{l}\text { REAL } \\
\text { REAL }\end{array}$ & $\begin{array}{l}\text { ARRAY } \\
\text { ARRAY }\end{array}$ & $\begin{array}{l}\text { COMANSW } \\
\text { COMCUMU }\end{array}$ & $\begin{array}{r}102 \\
\text { REFS } \\
\text { REFS }\end{array}$ & $\begin{array}{r}103 \\
9 \\
3\end{array}$ & $\begin{array}{l}189 \\
147\end{array}$ & $\begin{array}{r}2 * 192 \\
\text { DEFINED }\end{array}$ & $\begin{array}{r}194 \\
70\end{array}$ & $\begin{array}{l}205 \\
147\end{array}$ & & \\
\hline $\begin{array}{r}1010 \\
32 \\
140\end{array}$ & $\begin{array}{l}\text { DCUL } \\
\text { SE } \\
D F E\end{array}$ & $\begin{array}{l}\text { REAL } \\
\text { REAL } \\
\text { RFAI }\end{array}$ & $\begin{array}{l}\text { ARRAY } \\
\text { ARRAY }\end{array}$ & COMLPRO & $\begin{array}{l}\text { REFS } \\
\text { REFS }\end{array}$ & $\begin{array}{r}146 \\
14 \\
10\end{array}$ & $\begin{array}{c}\text { DEFINED } \\
102 \\
275\end{array}$ & $\begin{array}{c}79 \\
\text { DEFINED }\end{array}$ & $\begin{array}{l}81 \\
96\end{array}$ & & & \\
\hline $\begin{array}{r}140 \\
170 \\
174 \\
1005\end{array}$ & $\begin{array}{l}\text { DET } \\
\text { DETOT } \\
\text { DIA }\end{array}$ & $\begin{array}{l}\text { KEAL } \\
\text { REAL } \\
\text { REAL } \\
\text { REAL }\end{array}$ & ARRAY & $\begin{array}{l}\text { COMSUDE } \\
\text { COMCOMP }\end{array}$ & $\begin{array}{l}\text { REFS } \\
\text { REFS } \\
\text { REFS } \\
\text { REFS }\end{array}$ & $\begin{array}{r}10 \\
10 \\
5 \\
65\end{array}$ & $\begin{array}{l}189 \\
2 \star 84\end{array}$ & $\begin{array}{c}191 \\
\text { DEFINED }\end{array}$ & $\begin{array}{r}200 \\
62\end{array}$ & 202 & 205 & 206 \\
\hline $\begin{array}{r}175 \\
1001 \\
40\end{array}$ & $\begin{array}{l}\text { DTTOT } \\
\text { EBM }\end{array}$ & $\begin{array}{l}\text { REAL } \\
\text { REAL } \\
\text { REAI }\end{array}$ & ARRAY & COMCOMP & $\begin{array}{l}\text { REFS } \\
\text { REFS } \\
\text { REFS }\end{array}$ & $\begin{array}{r}5 \\
106\end{array}$ & 136 & DEFINED & 43 & 136 & & \\
\hline & EFF & $\frac{n L A L}{R E A L}$ & ARRAY & COMCOMP & $\begin{array}{r}\text { REFS } \\
55 \\
\text { DEFINED }\end{array}$ & $\begin{array}{l}0 \\
5 \\
93 \\
24\end{array}$ & $\begin{array}{r}33 \\
117 \\
117\end{array}$ & $\begin{array}{r}37 \\
144\end{array}$ & $\begin{array}{r}39 \\
198\end{array}$ & $\begin{array}{r}41 \\
204\end{array}$ & $\begin{array}{r}51 \\
205\end{array}$ & 52 \\
\hline 26 & EPUR & REAL & ARRAY & COMPURC & $\begin{array}{r}\text { REFS } \\
58 \\
\text { REFS }\end{array}$ & $\begin{array}{r}6 \\
119 \\
6\end{array}$ & $\begin{array}{l}119 \\
174 \\
137\end{array}$ & 174 & DEFINED & DEFINED & 137 & 27 \\
\hline $\begin{array}{l}1000 \\
767\end{array}$ & $\begin{array}{l}\text { EST } \\
\text { E15X }\end{array}$ & REAL & & & $\begin{array}{c}\text { REFS } \\
\text { DEFINED } \\
\text { REFS }\end{array}$ & $\begin{array}{l}58 \\
42 \\
63\end{array}$ & $\begin{array}{r}93 \\
116 \\
232\end{array}$ & $\begin{array}{l}100 \\
141 \\
238\end{array}$ & $\begin{array}{l}146 \\
242\end{array}$ & $\begin{array}{l}164 \\
251\end{array}$ & 174 & \\
\hline 773 & E36 & REAL & & & $\begin{array}{c}\text { DEFINED } \\
\text { REFS } \\
\text { DEFINED }\end{array}$ & $\begin{array}{l}33 \\
38 \\
37\end{array}$ & $\begin{array}{r}63 \\
100\end{array}$ & 118 & 135 & 200 & 202 & \\
\hline $\begin{array}{l}775 \\
777\end{array}$ & E38 & REAL & & & $\begin{array}{c}\text { REFS } \\
\text { DEFINED } \\
\text { REFS }\end{array}$ & $\begin{array}{l}40 \\
39 \\
53\end{array}$ & 96 & $\begin{array}{l}98 \\
41\end{array}$ & 118 & 135 & 200 & 206 \\
\hline $\begin{array}{l}2 \\
3 \\
4\end{array}$ & $\begin{array}{l}\text { ES } \\
E 6 \\
E 7\end{array}$ & $\begin{array}{l}\text { REAL } \\
\text { REAL } \\
\text { REAL }\end{array}$ & & $\begin{array}{l}\text { COMUE } 11 \\
\text { COMUE } 11 \\
\text { COMUE } 11\end{array}$ & $\begin{array}{l}\text { REFS } \\
\text { REFS } \\
\text { REFS }\end{array}$ & $\begin{array}{l}13 \\
13 \\
13\end{array}$ & $\begin{array}{l}33 \\
37 \\
41\end{array}$ & $\begin{array}{r}408 \\
54 \\
47\end{array}$ & $\begin{array}{l}150 \\
200\end{array}$ & 209 & & \\
\hline $\begin{array}{r}4 \\
120\end{array}$ & $\begin{array}{l}\text { E8 } \\
\text { FFD }\end{array}$ & $\begin{array}{l}\text { REAL } \\
\text { REAL }\end{array}$ & ARRAY & $\begin{array}{l}\text { COMUE } 11 \\
\text { COMPRNS }\end{array}$ & $\begin{array}{l}\text { REFS } \\
\text { REFS } \\
202\end{array}$ & $\begin{array}{r}13 \\
11 \\
206\end{array}$ & $\begin{array}{r}41 \\
39 \\
142 \\
207\end{array}$ & $\begin{array}{r}47 \\
45 \\
143 \\
\text { DEFINED }\end{array}$ & $\begin{array}{r}200 \\
54 \\
148 \\
78\end{array}$ & $\begin{array}{l}20 y \\
150 \\
195 \\
142\end{array}$ & $\begin{array}{c}196 \\
2 * 199 \\
143\end{array}$ & $\begin{array}{c}3 * 200 \\
148\end{array}$ \\
\hline 1007 & I & INTEGER & & & $\begin{array}{r}199 \\
\text { REFS } \\
237\end{array}$ & $\begin{array}{r}200 \\
70 \\
242\end{array}$ & $\begin{array}{l}202 \\
2: 76 \\
243\end{array}$ & $\begin{array}{l}204 \\
2 \times 78 \\
247\end{array}$ & $\begin{array}{c}205 \\
170 \\
\text { DEFINED }\end{array}$ & $\begin{array}{r}146 \\
206 \\
225 \\
68\end{array}$ & $\begin{array}{l}207 \\
226 \\
74\end{array}$ & $\begin{array}{l}232 \\
170\end{array}$ \\
\hline $\begin{array}{r}0 \\
10\end{array}$ & $\begin{array}{l}\text { IND } \\
\text { I SWND }\end{array}$ & $\begin{array}{l}\text { INTEGER } \\
\text { INTEGER }\end{array}$ & ARRAY & $\begin{array}{l}\text { COMUE } 11 \\
\text { COMWIND }\end{array}$ & $\begin{array}{l}224 \\
R E F S \\
\text { REFS }\end{array}$ & $\begin{array}{r}231 \\
13 \\
4\end{array}$ & $\begin{array}{r}235 \\
66 \\
61\end{array}$ & $\begin{array}{l}241 \\
138\end{array}$ & $\begin{array}{l}246 \\
185\end{array}$ & & & \\
\hline $\begin{array}{r}0 \\
53 \\
761\end{array}$ & $\begin{array}{l}\text { I SXOL } \\
\text { I TOD }\end{array}$ & $\begin{array}{l}\text { INTEGER } \\
\text { INTEGER } \\
\text { INTEGER }\end{array}$ & ARRAY & $\begin{array}{l}\text { COMSXOL } \\
\text { COMPURC }\end{array}$ & $\begin{array}{l}\text { REFS } \\
\text { REFS } \\
\text { REFS }\end{array}$ & $\begin{array}{r}15 \\
6 \\
20\end{array}$ & $\begin{array}{c}176 \\
57 \\
2: 21\end{array}$ & $\begin{array}{l}226 \\
2 \geq 27\end{array}$ & $2: 30$ & 70 & $2 * 76$ & $2 * 78$ \\
\hline & & & & & $\begin{array}{r}82 \\
2 \times 215 \\
244\end{array}$ & $\begin{array}{l}170 \\
232 \\
248\end{array}$ & $\begin{array}{l}178 \\
233 \\
249\end{array}$ & $\begin{array}{c}24179 \\
236 \\
251\end{array}$ & $\begin{array}{l}180 \\
238 \\
252\end{array}$ & $\begin{array}{r}2 * 181 \\
239 \\
\text { DEFINED }\end{array}$ & $\begin{array}{c}2+183 \\
242 \\
19\end{array}$ & $\begin{array}{c}2: 188 \\
243 \\
26\end{array}$ \\
\hline 1016 & $J P$ & INTEGER & & & $\begin{array}{r}29 \\
187 \\
\text { REFS }\end{array}$ & $\begin{array}{r}69 \\
214 \\
2 \times 119\end{array}$ & 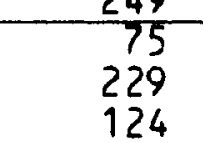 & $\begin{array}{l}291 \\
733 \\
236 \\
136\end{array}$ & $\begin{array}{r}82 \\
83 \\
239 \\
2 * 137\end{array}$ & $\begin{array}{c}170 \\
244 \\
2 \div 227\end{array}$ & $\begin{array}{l}177 \\
252\end{array}$ & 183 \\
\hline $\begin{array}{l}1002 \\
1013\end{array}$ & $\begin{array}{l}\text { JP1 } \\
\text { JUMG }\end{array}$ & $\begin{array}{l}\text { INTEGER } \\
\text { INTEGER }\end{array}$ & & & $\begin{array}{c}\text { DEFINED } \\
\text { REFS } \\
\text { REFS }\end{array}$ & $\begin{array}{r}109 \\
58 \\
254\end{array}$ & $\begin{array}{c}226 \\
2: 174 \\
\text { DEFINED }\end{array}$ & $\begin{array}{c}\text { DEFINED } \\
86\end{array}$ & $\begin{array}{l}57 \\
90\end{array}$ & & & \\
\hline 1004 & JUMP & INTEGER & & & REFS & 67 & 83 & 230 & DEFINED & 60 & 64 & BT \\
\hline $\begin{array}{l}1041 \\
1014\end{array}$ & $\mathrm{~K}_{\mathrm{K}} \times \mathrm{OL}$ & $\begin{array}{l}\text { INTEGER } \\
\text { INTEGER }\end{array}$ & ARRAY & & $\begin{array}{l}\text { REFS } \\
\text { REFS }\end{array}$ & $2 \div 2$ & $\begin{array}{l}183 \\
2: 96\end{array}$ & DEFINED & $\begin{array}{r}178 \\
98\end{array}$ & $\begin{array}{r}180 \\
99\end{array}$ & 100 & 101 \\
\hline & & & & & $\begin{array}{r}2 * 102 \\
115 \\
\text { DEFINED }\end{array}$ & $\begin{array}{c}2 * 103 \\
116 \\
87\end{array}$ & $\begin{array}{l}109 \\
198 \\
94\end{array}$ & $\begin{array}{l}110 \\
155 \\
108\end{array}$ & $\begin{array}{l}110 \\
156\end{array}$ & $\begin{array}{l}112 \\
165\end{array}$ & $\begin{array}{l}113 \\
16.6\end{array}$ & $\begin{array}{l}114 \\
167\end{array}$ \\
\hline
\end{tabular}




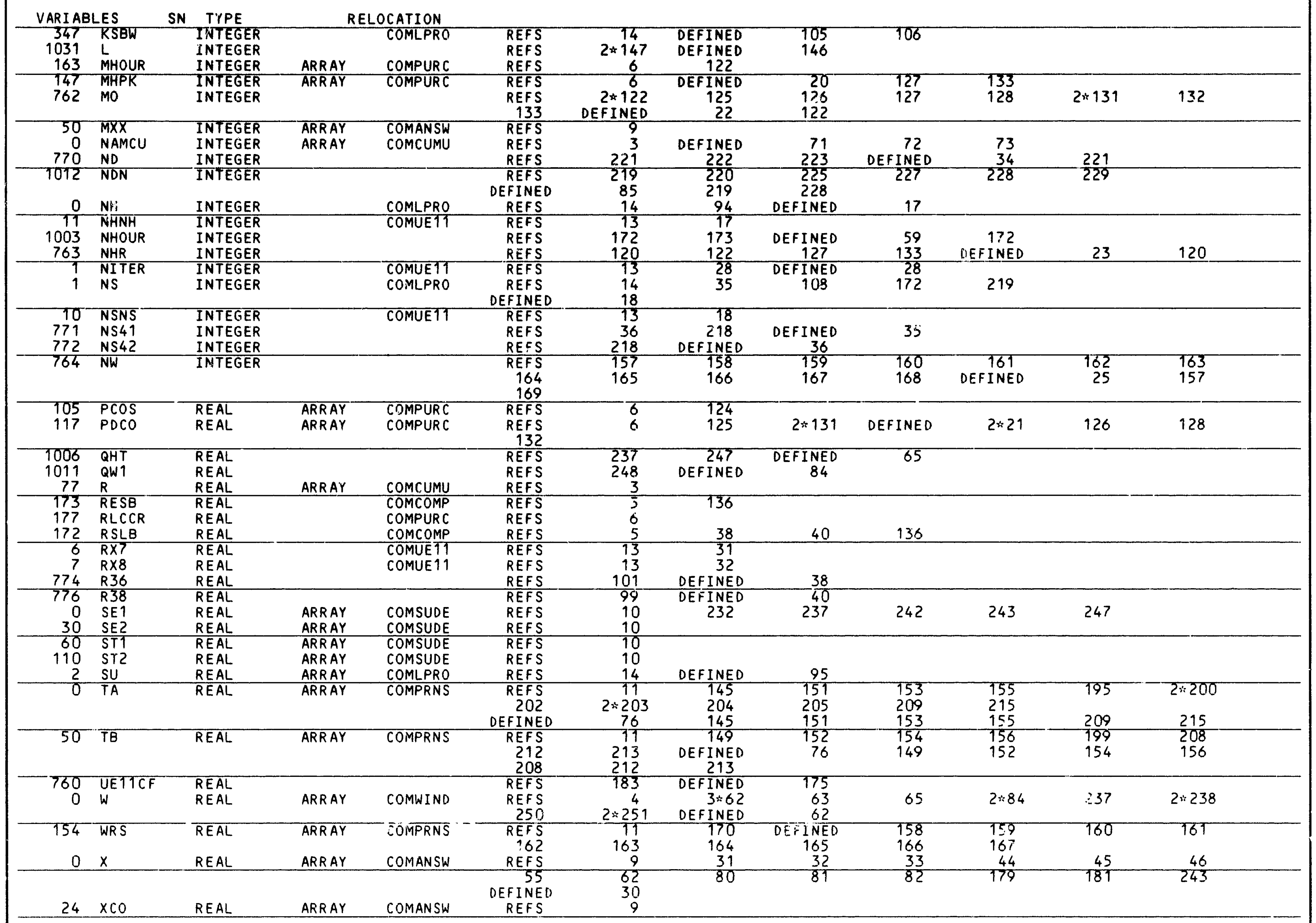




\begin{tabular}{|c|c|c|c|c|c|c|c|c|c|c|c|c|}
\hline & \multicolumn{2}{|c|}{ FUNCTION UE11CF } & $74 / 74$ & \multicolumn{2}{|l|}{$O P T=2$} & & \multicolumn{2}{|c|}{ FTN $4.8+518$} & \multicolumn{2}{|c|}{$80 / 11 / 28.10 .23 .01$} & \multirow[t]{2}{*}{ PAGE } & \multirow[t]{2}{*}{8} \\
\hline \multicolumn{2}{|c|}{ VARI ABLES } & TYPE & RELC & OCATION & & & & & & & & \\
\hline 26 & $X M$ & REAL & ARRAY & COMCOMP & REFS & 5 & & & & & & \\
\hline $\begin{array}{r}1034 \\
332\end{array}$ & $\begin{array}{l}\text { XOL } \\
X T B\end{array}$ & SEAL & ARR AY & & REFS & 2 & 179 & 183 & DEFINED & 16 & 181 & \\
\hline & & KEEAL & ARR AY & COMLPRO & $\frac{\text { REFS }}{46}$ & $\frac{14}{47}$ & $\frac{48}{48}$ & $\frac{102}{49}$ & $\begin{array}{r}103 \\
50\end{array}$ & $\frac{\text { DEF INED }}{51}$ & $\begin{array}{l}44 \\
52\end{array}$ & $\frac{45}{53}$ \\
\hline & $x x x x$ & REAL & ARR AY & F.P. & $\begin{array}{r}54 \\
R E F S\end{array}$ & 55 & $\begin{array}{l}93 \\
30\end{array}$ & DEFINED & 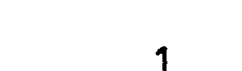 & & & \\
\hline 765 & 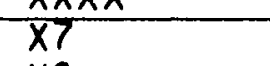 & REAL. & & 1.1. & REFS & 49 & DEFINED & 31 & & & & \\
\hline $\begin{array}{r}766 \\
1032\end{array}$ & $\begin{array}{l}x 8 \\
22222\end{array}$ & $\begin{array}{l}\text { REAL. } \\
\text { REAL }\end{array}$ & & & $\begin{array}{l}\text { REFS } \\
\text { REFS }\end{array}$ & $\begin{array}{r}48 \\
175\end{array}$ & $50^{\circ}$ & DEFINED & 32 & & & \\
\hline 1015 & 21 & REAL & & & $\begin{array}{r}\text { REFS } \\
188 \\
213\end{array}$ & $\begin{array}{l}98 \\
191 \\
215\end{array}$ & $\begin{array}{c}99 \\
2 * 194 \\
3 * 238\end{array}$ & $\begin{array}{c}100 \\
2 \div 196 \\
248\end{array}$ & $\begin{array}{l}101 \\
197 \\
250\end{array}$ & $\begin{array}{c}145 \\
2 * 204 \\
3 * 251\end{array}$ & $\begin{array}{l}159 \\
211\end{array}$ & $\begin{array}{l}152 \\
212\end{array}$ \\
\hline 1033 & $\mathrm{Z2}$ & REA'- & & & $\begin{array}{c}\text { DEFINED } \\
210 \\
\text { REFS }\end{array}$ & $\begin{array}{c}97 \\
237 \\
2 * 192\end{array}$ & $\begin{array}{c}144 \\
247 \\
\text { DEFINED }\end{array}$ & $\begin{array}{l}150 \\
250 \\
191\end{array}$ & 186 & 188 & 195 & 203 \\
\hline 1027 & 25 & $R=A L$ & & & REFS & 136 & 137 & DEFINED & 135 & & & \\
\hline 1025 & 26 & REAi. & & & $\begin{array}{c}\text { REFS } \\
\text { DEFINED }\end{array}$ & $\begin{array}{l}119 \\
118\end{array}$ & 124 & 128 & 131 & 132 & 136 & \\
\hline 1026 & 27 & REA $\bar{L}$ & & & REFS & 125 & 126 & DEFINED & 124 & & & \\
\hline FILE $N$ & AMES & MODE & & & & & & & & & & \\
\hline 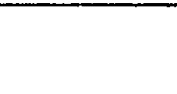 & $\begin{array}{l}\text { OUTPUT } \\
\text { TAPES }\end{array}$ & $\begin{array}{l}\text { FMT } \\
\text { UNFMT }\end{array}$ & & $\begin{array}{l}\text { WRITES } \\
\text { WRIYES }\end{array}$ & $\begin{array}{r}183 \\
82\end{array}$ & 170 & & & & & & \\
\hline EXTERN & $\begin{array}{l}\text { ALS } \\
\text { COST } \\
\text { GETSD }\end{array}$ & $\begin{array}{l}\text { TYPE } \\
\text { REAL }\end{array}$ & $\begin{array}{c}\text { ARGS } \\
1 \\
1\end{array}$ & $\begin{array}{c}\text { REFEREN } \\
175 \\
222\end{array}$ & & & & & & & & \\
\hline & $\begin{array}{l}\text { LPOUTR } \\
\text { MOVLEV } \\
\text { SQRT }\end{array}$ & PEAL & $\begin{array}{l}0 \\
3 \\
1 \text { LIBR ARY }\end{array}$ & $\begin{array}{r}107 \\
218 \\
\times \quad 62 \\
\end{array}$ & & & & & & & & \\
\hline & TODPR & & 1 & & 223 & & & & & & & \\
\hline INLINE & FUNCIIONS & TYPE & ARGS & DEF LINE & REFERENCES & & & & & & & \\
\hline & $\begin{array}{l}\text { AMAX1 } \\
\text { AMIN } 1\end{array}$ & $\begin{array}{l}\text { RE IL } \\
R E, M L\end{array}$ & $\begin{array}{ll}0 & \text { INTRIN } \\
0 & \text { INTRI }\end{array}$ & & $\begin{array}{r}152 \\
48\end{array}$ & $\begin{array}{l}154 \\
102\end{array}$ & 238 & 251 & & & & \\
\hline $\begin{array}{c}\text { STATEM } \\
0 \\
0\end{array}$ & $\begin{array}{l}\text { ENT LABELS } \\
10 \\
11\end{array}$ & & $\begin{array}{c}\text { DEF LINE } \\
27 \\
30\end{array}$ & $\begin{array}{cc}\text { E REFEREN } \\
26 \\
29\end{array}$ & & & & & & & & \\
\hline $\begin{array}{r}116 \\
0 \\
0\end{array}$ & $\begin{array}{l}12 \\
13 \\
14\end{array}$ & & $\begin{array}{l}66 \\
70 \\
76\end{array}$ & $\begin{array}{l}61 \\
68 \\
75\end{array}$ & 69 & & & & & & & \\
\hline 0 & 15 & & in & 74 & 77 & & & & & & & \\
\hline $\begin{array}{l}153 \\
161\end{array}$ & $\begin{array}{l}16 \\
17\end{array}$ & & 83 & $\begin{array}{l}80 \\
66\end{array}$ & 83 & & & & & & & \\
\hline $\begin{array}{l}171 \\
175\end{array}$ & $\begin{array}{l}18 \\
19\end{array}$ & & $\begin{array}{r}84 \\
92\end{array}$ & $\begin{array}{r}87 \\
255\end{array}$ & 254 & & & & & & & \\
\hline & 20 & & 104 & 94 & & & & & & & & \\
\hline $\begin{array}{r}402 \\
0 \\
0\end{array}$ & $\begin{array}{l}57 \\
61 \\
67\end{array}$ & & $\begin{array}{l}171 \\
188 \\
215\end{array}$ & $\begin{array}{l}108 \\
187\end{array}$ & 138 & 168 & & & & & & \\
\hline 561 & $\frac{0 c}{100}$ & & $\frac{215}{218}$ & $\frac{214}{173}$ & & & & & & & & \\
\hline 566 & $\begin{array}{l}101 \\
102\end{array}$ & & $\begin{array}{l}220 \\
228\end{array}$ & $\begin{array}{r}88 \\
724\end{array}$ & 234 & 240 & 245 & 253 & & & & \\
\hline 620 & $\frac{105}{103}$ & & 231 & $\frac{224}{230}$ & & & & & & & & \\
\hline 0 & 104 & & 233 & 231 & & & & & & & & \\
\hline 627 & 105 & & 235 & 230 & & & & & & & & \\
\hline
\end{tabular}




\section{STATEMENT LABELS}

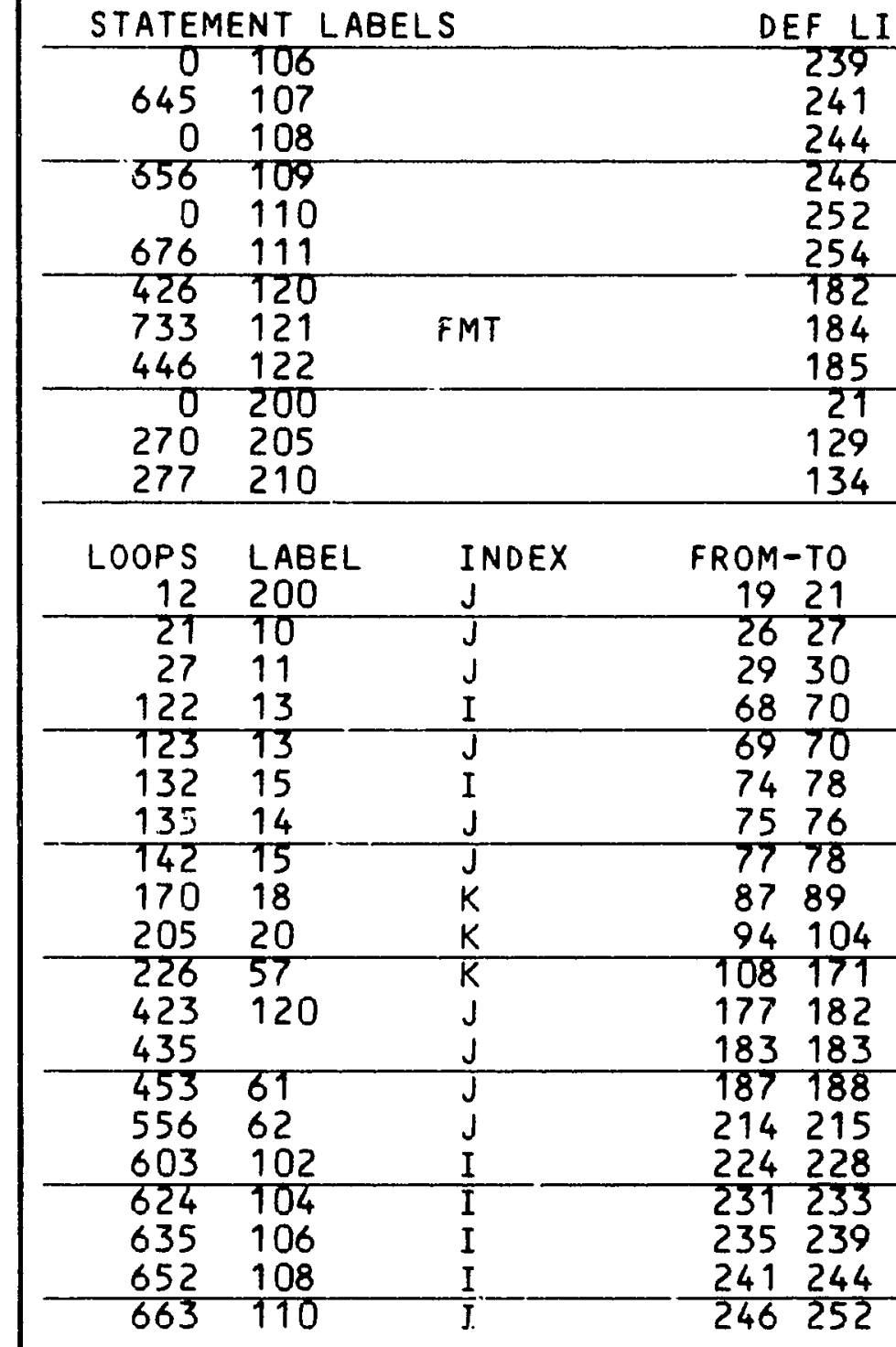

EF LINE REFERENCES
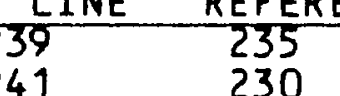

$\begin{array}{ll}231 & 230 \\ 244 & 241\end{array}$

$\begin{array}{ll}46 & 241 \\ 52 & 230 \\ 246\end{array}$

$252 \quad 246$

1827

179

COMMON BLOCKS LENGTH $\frac{\text { MEMBERS - BIAS NAME(LENGTH) }}{83}$

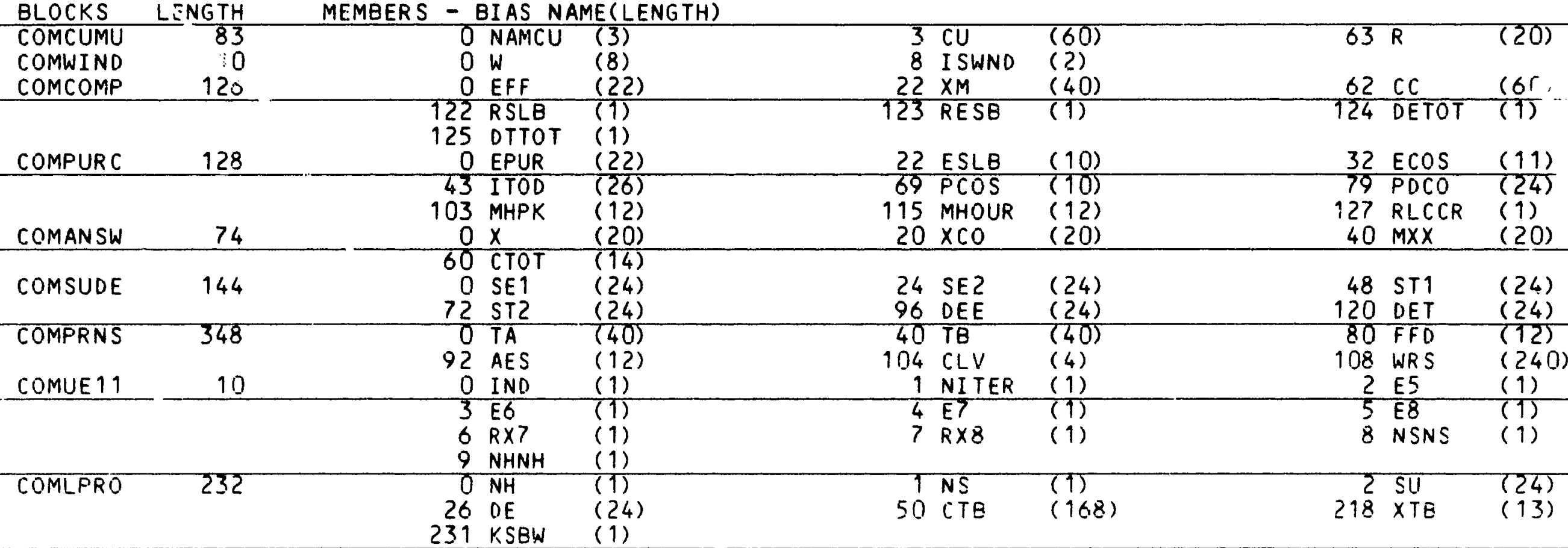




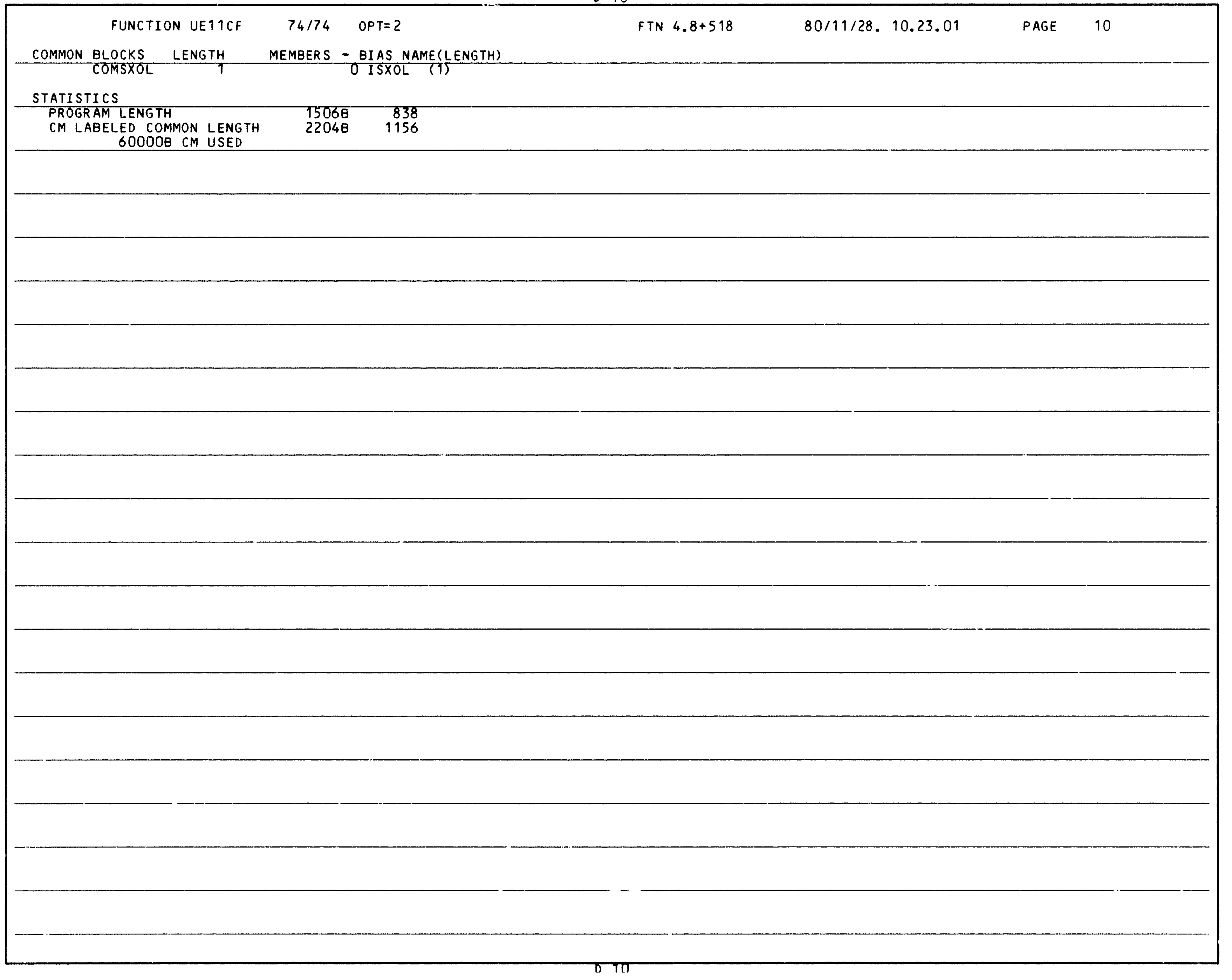


SUBROUTINE UINV

COMMON / CONLPIN/MC, MC1, MR, LPO, LPI, NH1,NH3, NH?, MR71, MCNH, TH,

$1 \vee(7,72), \angle 00(24), B 2 \times(48), C A D 6, C A D 7$

COMMON/CJMINI $1 / U(2401), B(49), A 1(72), A 2(? 2), A 3(72)$

5

COMMON COMLPRO/NH, NS, SU(24), DE(24), CTB (7, 24), XTB(13), KSBW

L1 $=\mathrm{NH} 1$

DO $10 \quad I=1, \mathrm{NH}$

$U(L 1)=1 . /(A 1(I)-A 1(I+N H))$

$U(L 1+!$ ! CNH $)=-U(L 1)$

$10 \quad 10 \quad L T=1+M C$

LONIINUE

$\mathrm{L} i=\mathrm{NH} 1$

D'J $11 \mathrm{I}=2, \mathrm{NH}$

15

$I 2=I-1$

$I 1=-(A 2(N H+I 2)-A 2(I 2)) * U(L 1+M C+I 2)$

L3:LI $=L 1+M C$

DO $19 \mathrm{~J}=1$ I 2

$U(1,3)=-21 \div U(L 3-M C)$

$20 \quad L 3=L 3+1$

11 CONTINUE

$4=1$

DO $13 \quad I=1, N H$

$L 1=L 4+N H$

$25-L 2=L 4+M C N H$

DO $12 \mathrm{~J}=\mathrm{I}, \mathrm{NH}$

$U(L 2)=U(L 1) * A 1(I)+U(L 1+1) * A 2(I)$

$U(L 2-M C N H)=-U(L 2)$

$L 1=L 1+M C$

$30 \quad L 2=L 2+M C$

12 CONTINUE

$U(L 4)=U(L 4)+1$.

$L 4=L 4+M C 1$

$35 \quad$ C.... CONTINUE

$L T=L P O-1$

DO $14 \quad I=1$ MR

$14 U(L 1+I)=-\operatorname{SDOT}(M R, U(I), M C, A 3,1)$

$40 \quad$ C.... $\quad$ FIND

DO $16 \quad I=1, N H$

$Z 1=X T B(1) \div U(L 1+N H 1)$

DO $15 \mathrm{~J}=1, \mathrm{I}$

$\begin{array}{ccc}15 & \begin{array}{r}Z 1=Z 1+U( \\ B(I)=Z 1\end{array} \\ & & B(I+N H)=1\end{array}$

$B(I+N H)=1 \cdot-Z$

$L 1=L 1+M C$

16 CONTINUE 


\section{SYMBOLIC REFERENCE MAP $(R=3)$}

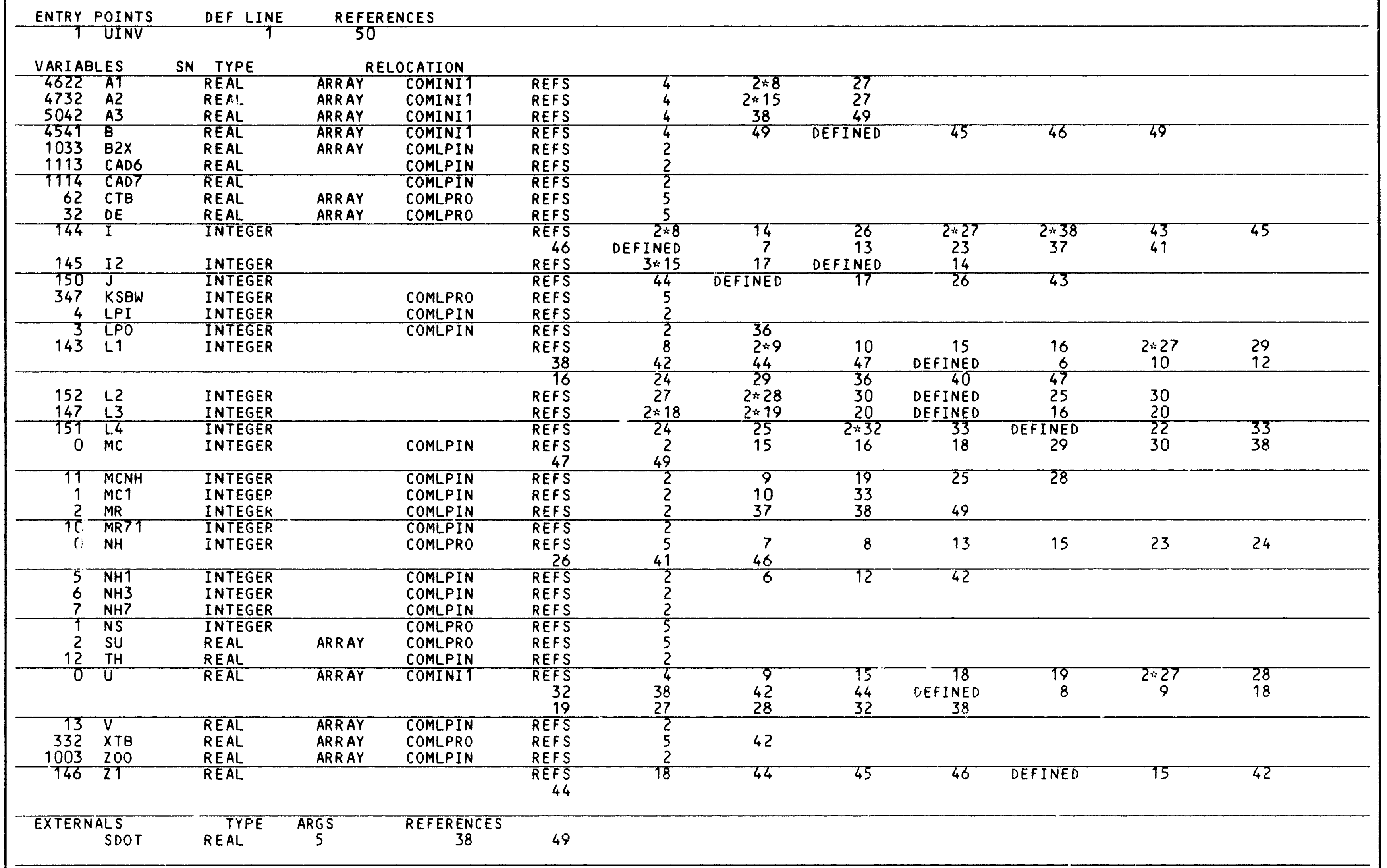


STATEMENT LABELS \begin{tabular}{ll} 
& 10 \\
0 & 11 \\
0 & 12 \\
0 & 13 \\
0 & 14 \\
0 & 15 \\
\hline 0 & 16
\end{tabular} DEF LINE REFERENCES

$\begin{array}{ll}11 & 7 \\ 21 & 13 \\ 31 & 26 \\ 34 & 23 \\ 38 & 37 \\ 44 & 43 \\ 48 & 41\end{array}$

\begin{tabular}{rllr} 
LOOPS & LABEL & INDEX & FROM-TO \\
\hline 11 & 10 & 1 & 71 \\
22 & 11 & $\mathrm{I}$ & 13 \\
33 & 11 & $\mathrm{~J}$ & 1721 \\
\hline 46 & 13 & $\mathrm{I}$ & 2334 \\
54 & 12 & $\mathrm{~J}$ & 26 \\
73 & 14 & $\mathrm{I}$ & 3738 \\
107 & 16 & $\mathrm{I}$ & 4148 \\
112 & 15 & $\mathrm{~J}$ & 4344
\end{tabular}
17

COMMON BLOCKS LENGTH MEMBERS - BIAS NAME(LENGTH)

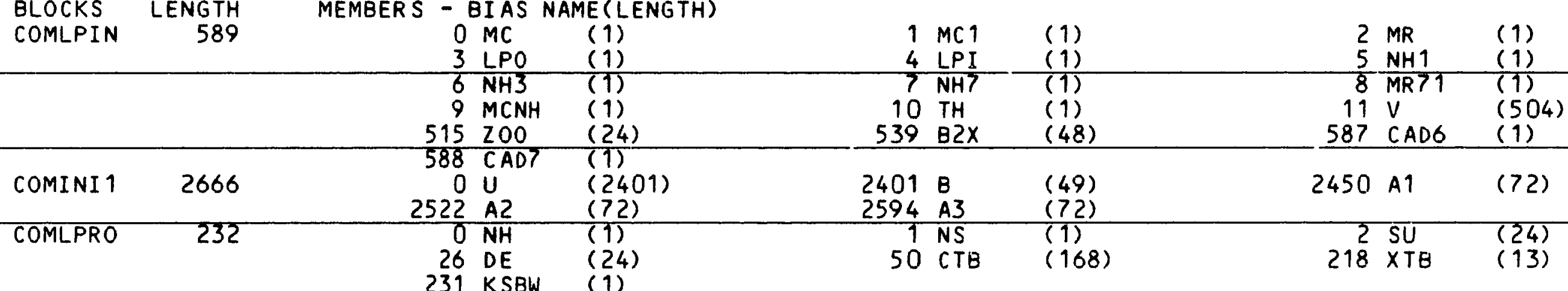

\section{STATISTICS}

\begin{tabular}{lrr} 
PROGR AM LENGTH & $153 E_{i}$ & 107 \\
\hline CM LABELED COMMON LENGTH & 66378 & 3487
\end{tabular} 



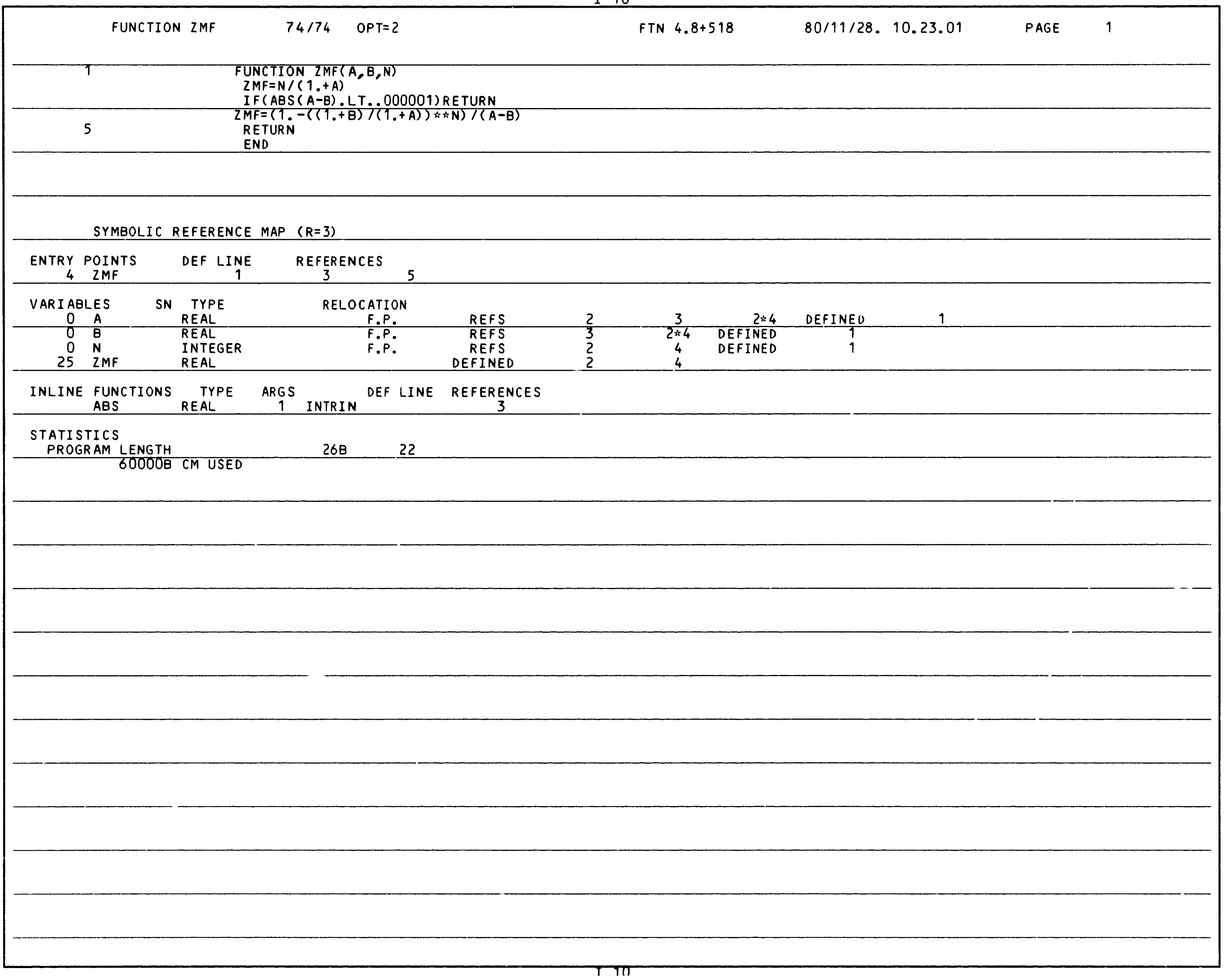




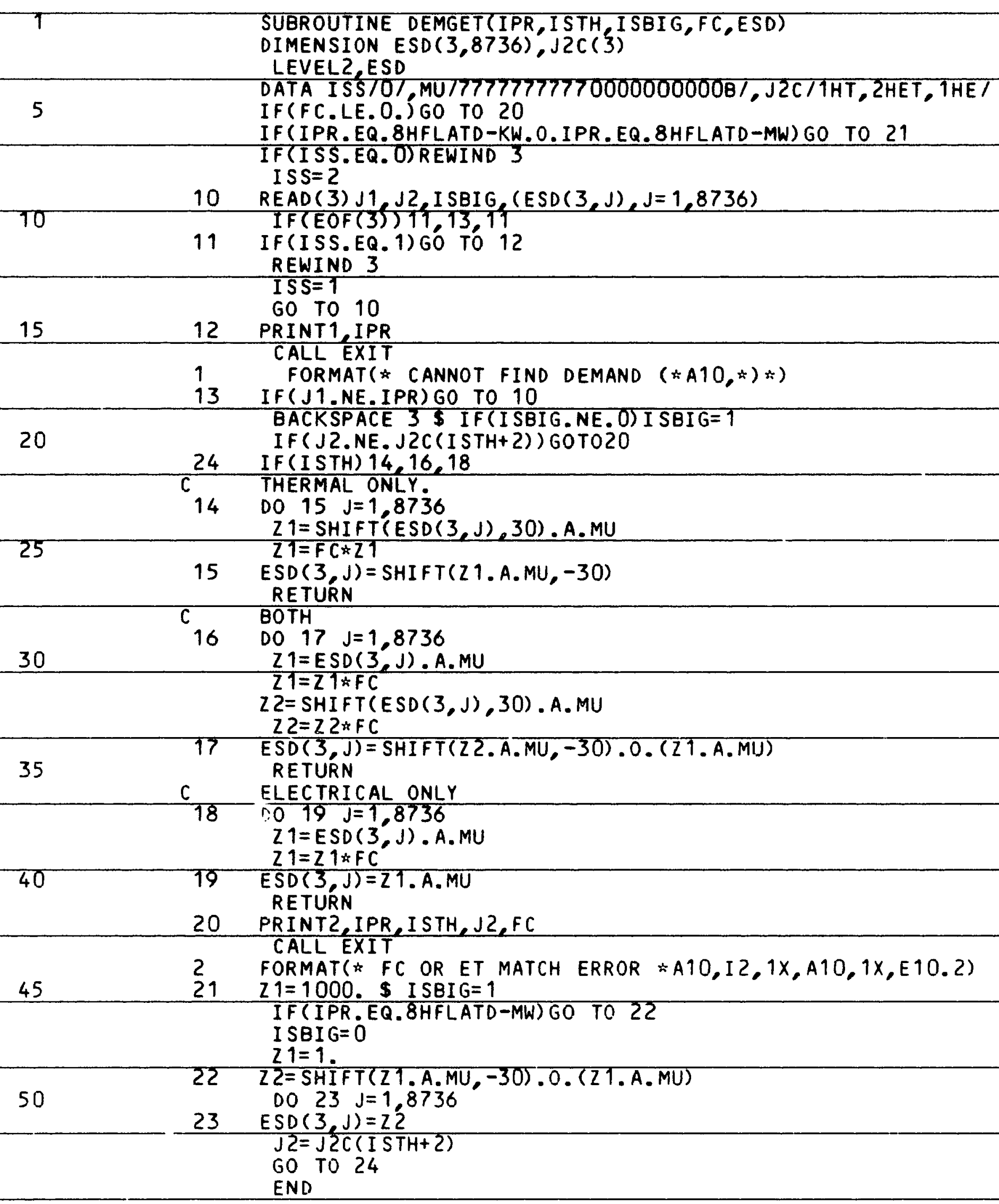




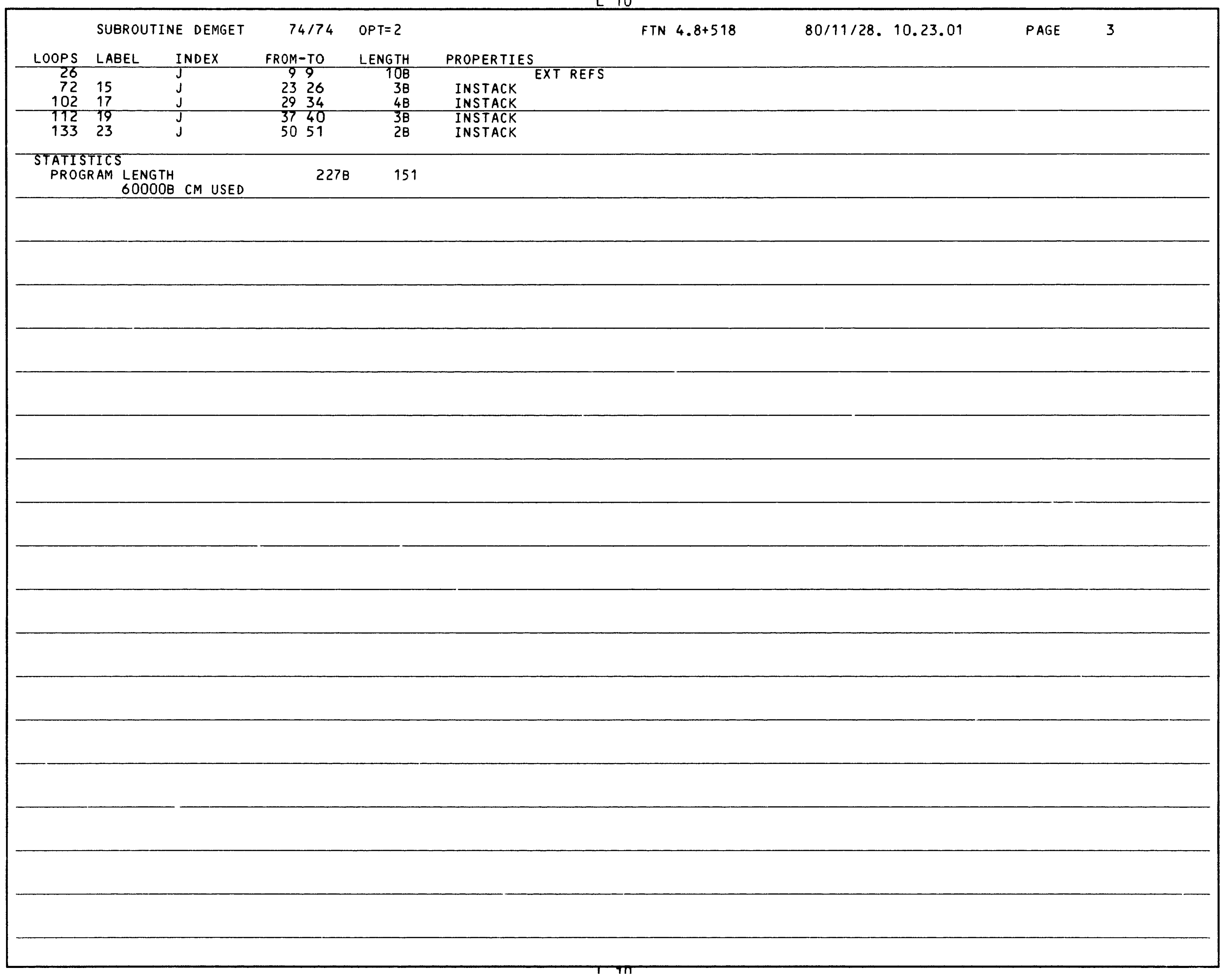


SUBROUTINE PIHI

DIMENSION $R(2,24,14), D(14), \operatorname{KF}(9,14), \operatorname{KE}(9,14)$

COMMON /COMPIHI/ SD $(24,2)$

$K A(I)=S H I F T(J 1, I) \cdot A .37977777 B$

5

$K B(I)=\operatorname{SHIFT}(J 2, I) \cdot A .3777777 B$

REWIND ?
READ(2) JT

IF (J1.EQ. 1OHASHRAETABL)GO TO 13

PRINT1, J1
CALL EXIT

13 FORMAT * NO ASHRAE DATA $\star A 10)$

$\operatorname{READ}(2) \times 2,(D(J),(\operatorname{KE}(I, J), I=1,9), J=2,13)$

IF(SD(1).LT.X2) GO TO 20 .

$10 \times 1=\times 2$

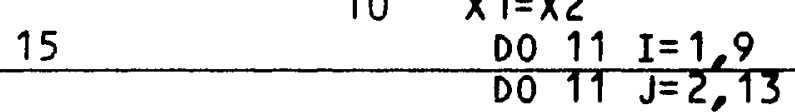

$11 K F(I, J)=K E(I, J)$

$\operatorname{READ}(2) \times 2(0(J)(K E(I, J), I=1,9), J=2,13)$

20

20 PRINT2, SD(1)

CALL EXIT
PONT

(1) $, 12,20$

2 FORMAT(* ASHRAE TABLE ERROR *F8.2)

GO

$25 \quad D(14)=386$

DO $14 \mathrm{~J}=1,9$

$K F(J, 1)=K F(J, 13)$

$K F(J, 14)=K F(J, 2)$

$30 \quad 14 \quad \operatorname{KEE}(J, 1)=\operatorname{KE}(J, 13)$

$\mathrm{z} 1=\mathrm{X}^{2} \mathrm{2}-\mathrm{X}^{1}$

$\times 2=(S D(1)-x 1) / 21$

$\times 2=($ so
$\times 1=1 .-x 2$

DO $23 \mathrm{~K}=1,14$

35

$\begin{array}{lll}\text { DO } & 21 & I=1,2 \\ \text { DO } & 21 & \mathrm{~J}=1,24\end{array}$

$21 \quad R(I, J, K)=0$.

$N 1=5$

$N 2=21$

40

DO $23 \mathrm{~J}=1,9$

$J 1=K F(J, K)$

$J Z=K E(J, K)$

$K 1=K A(-40)$

$K 2=K B(-40)$

$45 \quad \frac{21=x 1+K 1+X 2 * K 2}{\text { IF }(21 . L E .0 .) G 0 \text { TO } 22}$

$K 1=K A(-20)$

$K 2=K B(-20)$

50

$R(1, N 1, K)=R$
$K 1=K A(1,0)$

$\frac{K 2=K B(0)}{R(2, N 1, K)=R(2, N 2, K)=(X 1 \div K 1+X 2 * K 2) / Z 1}$

$22 \quad N 1=N 1+1$

$55 \quad 23 \quad$ CONTINUE

$x=1$

$K 1=1$ 


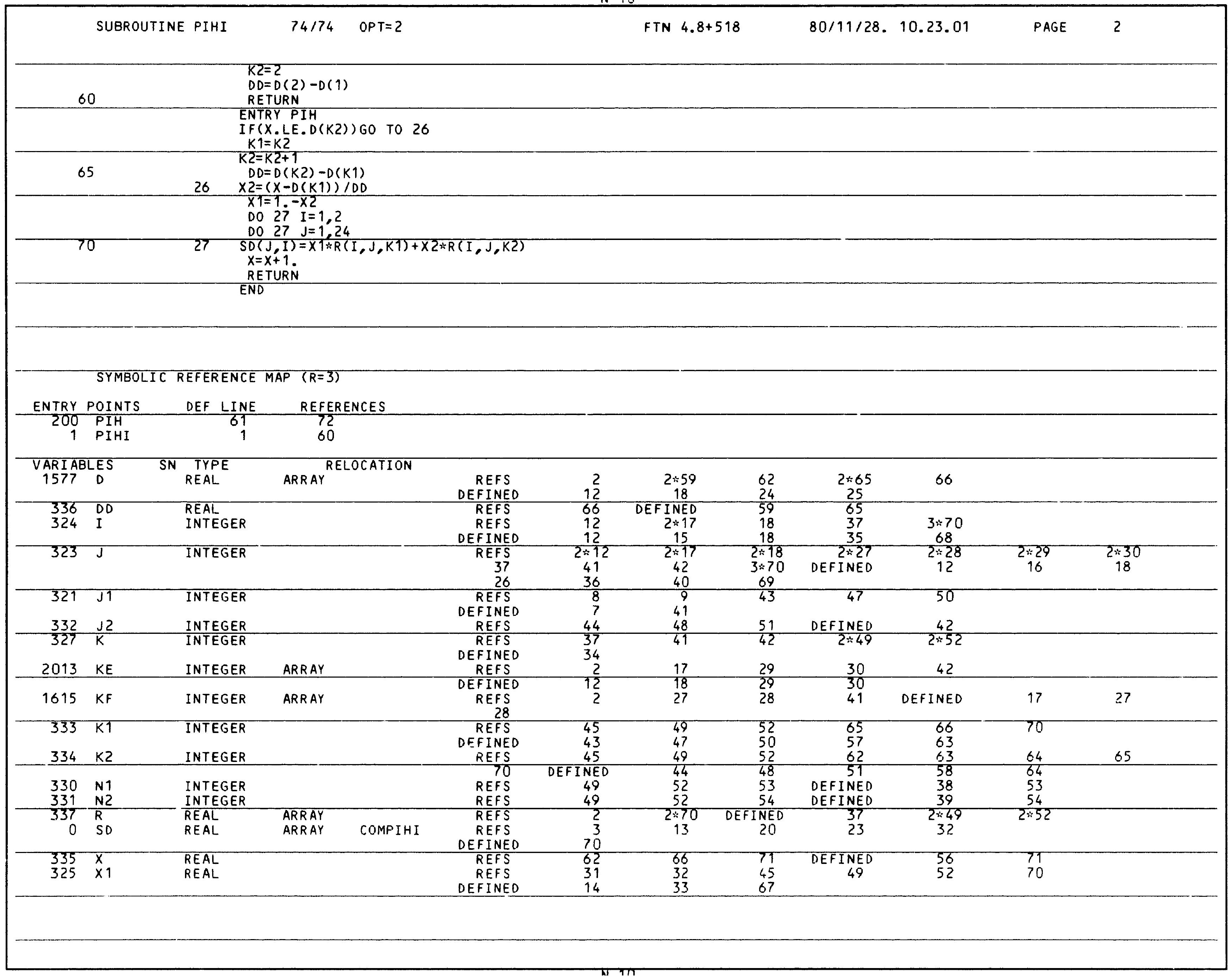




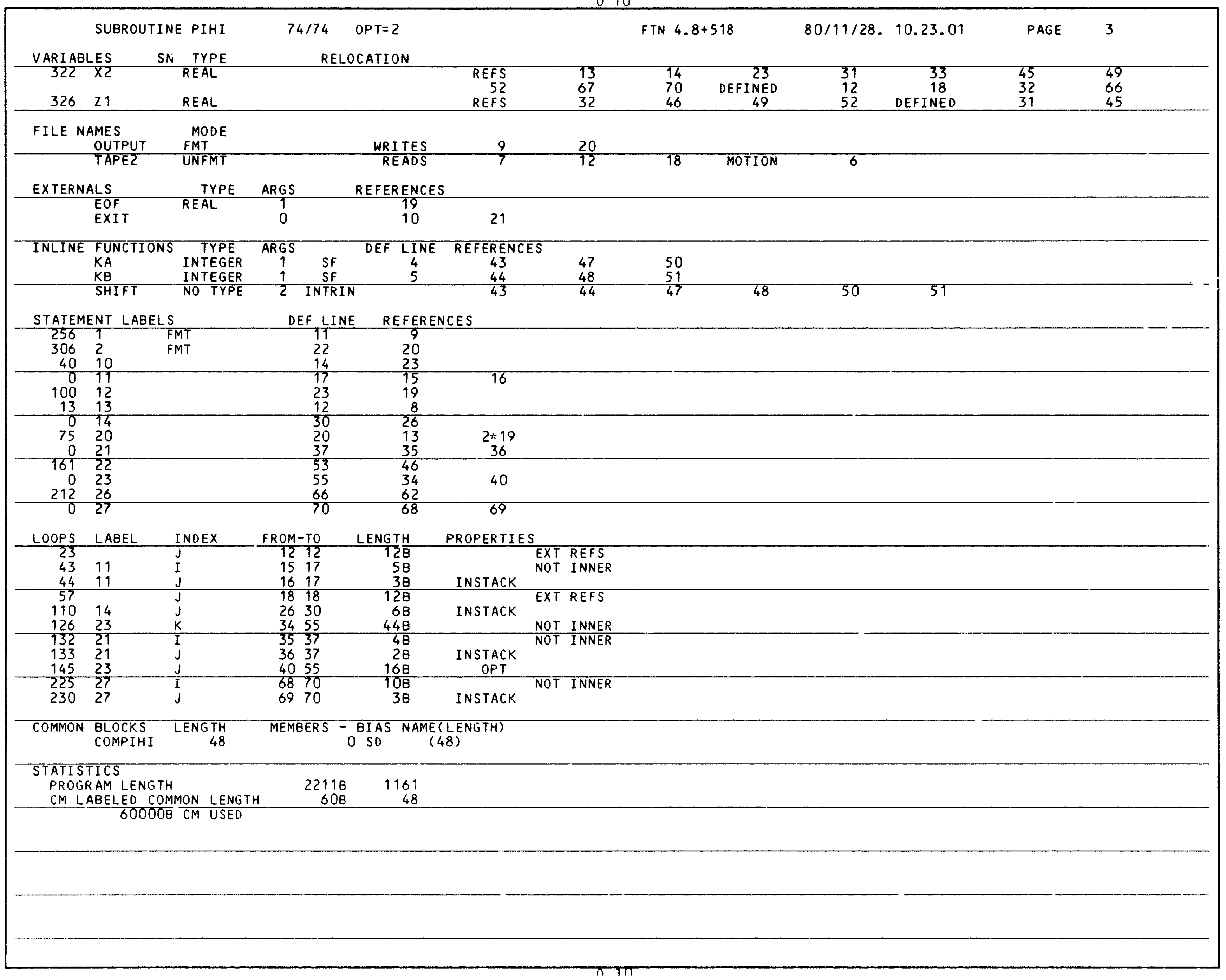




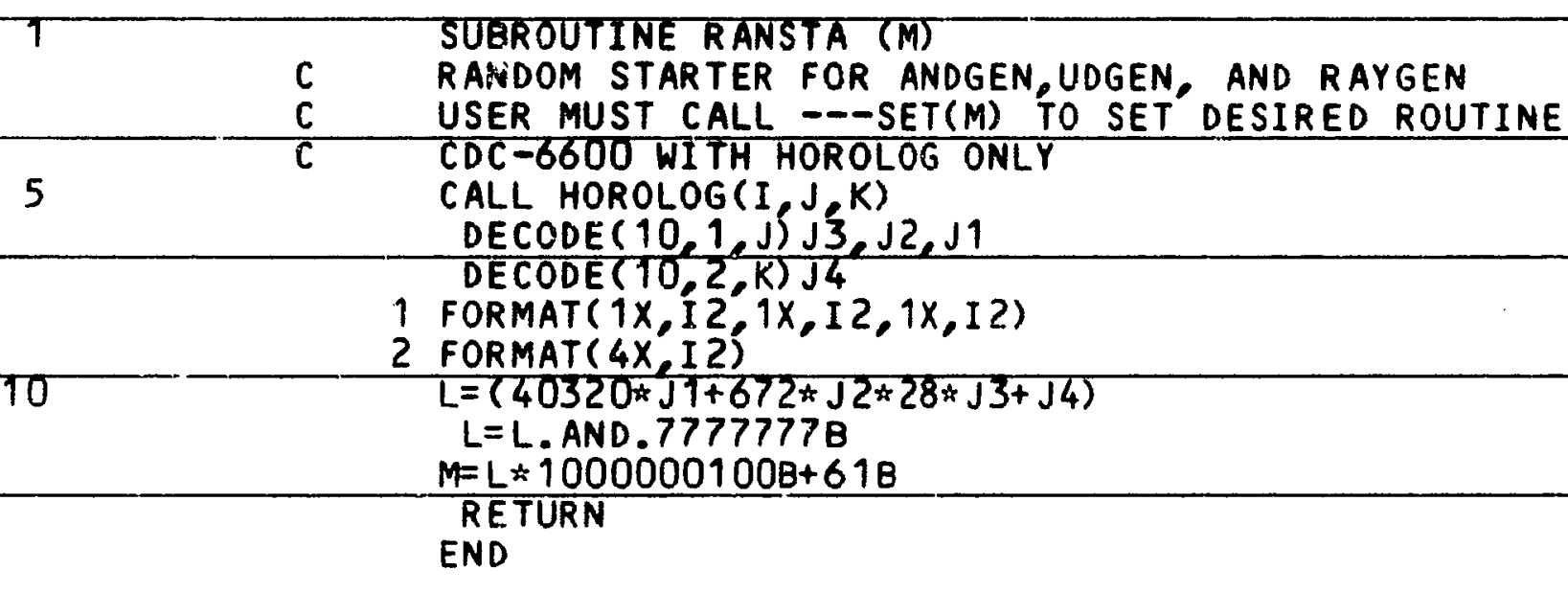

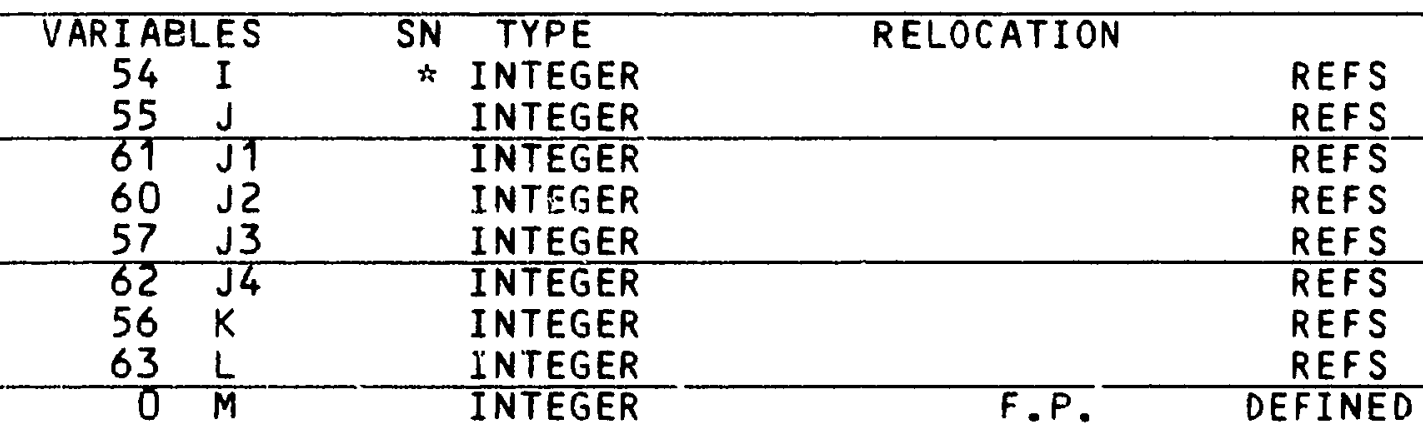

INTEGER

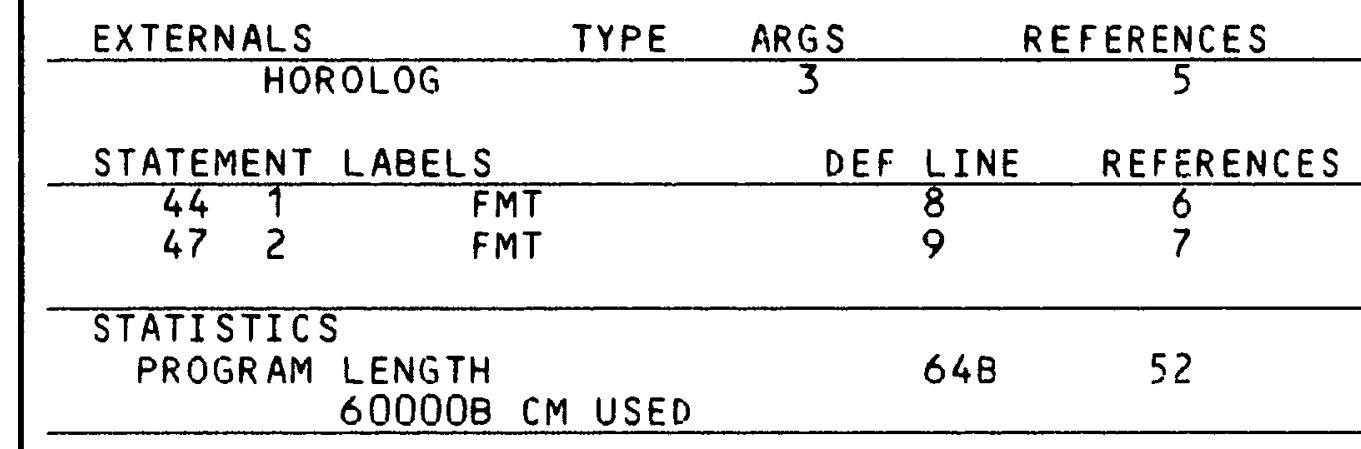




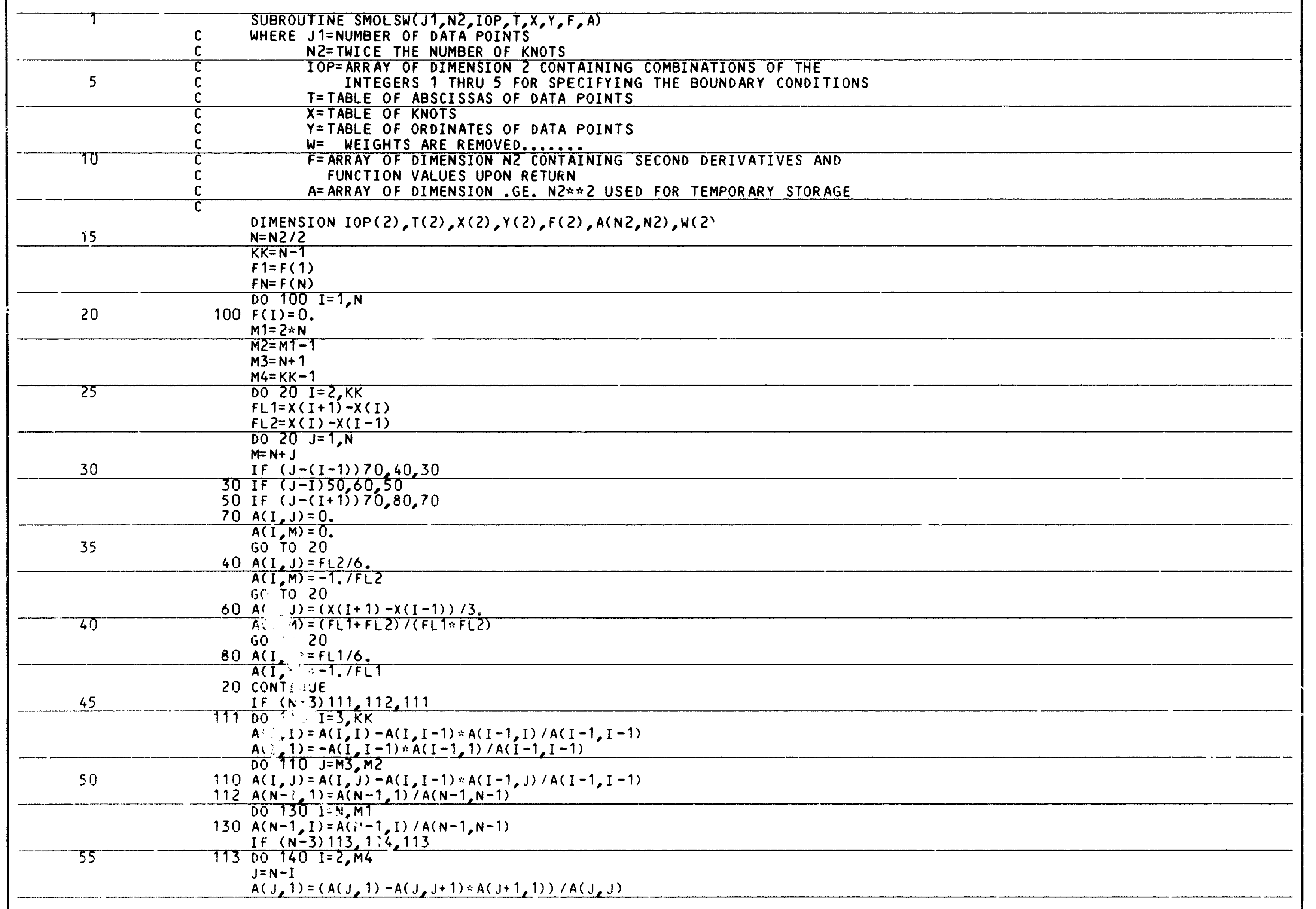


DO $140 \mathrm{~K}=\mathrm{N}, \mathrm{M1}$

$140 A(J, K)=(A(J, K)-A(J, J+1) \div A(J+1, K)) / A(J, J)$

$11400 \quad 141 \quad I=2, K K$

DO $141 \mathrm{~J}=2 \mathrm{KK}$

IF (I - J) 142, 143,142

$143 A(I, J)=1$

$A(I, J)=1$

65

$142 A(I, J)=0$.

141 CONTINUE

DO $150 \quad I=M 3, M$ ?

$F(I)=0$.

$D O^{\circ} 150^{\circ} \mathrm{J}=1, \mathrm{~N}_{1}$

$70 \quad 150 A(\mathrm{I}, \mathrm{J})=0$.

IF (IOP(i) -5) $151,152,151$

152 DO $153 \quad I=1, M 1$

$153 A(1, I)=0$.

75

151 DO $149 \quad I=N, M 1$

$149 A(1, I)=0$

DO $154 \mathrm{I}=1, \mathrm{KK}$

$160 \mathrm{MK}=\mathrm{IOP}(1)$

GO TO $(220,230,240,250), M K$

80

220 IF (I - 1) 221, 222, 221

$222 A(1,1)=1$.

$F(1)=F 1$

GO TO 155

85

$221 \mathrm{BOB}=0$

6070155

$230 \div$ I $(I-1) 231,232,231$

$23 \quad A(1,1)=1$

GO TO 155

231 IF $(I-2) 233,233,234$

90

$233 B 0 B=-F 1$

GO TO 155

$234 \mathrm{BOB}=0$.

240 IF $(\mathrm{I}-1) 241,242,241$

240 IF $(I-1) 241,242,241$
$242 A(1,1)=(x(2)-x(1)) / 3$.

$A(1, N+1)=1,1(x(2)-x(i)$

$A(1, N+2)=-A(1, N+1)$

$F(1)=-F 1$

GO TO 155

$100 \quad 241$ IF $(\mathrm{I}-2) 243,243,244$

$243 \mathrm{BOB}=\left(x(2)-x^{\prime}(1)\right) / 6$.

GO TO 155

$244 \mathrm{BOB}=0$

105

GO TO 155

250 IF (I - 1) $251,252,251$

$252 A(1,1)=1$.

$A(1, N)=-1$.

GO TO 155

$251 \mathrm{BOB}=0$

110

GO TO 155

155 If $(I-1) 156,154,156$

$156 \quad A(1,1)=A(1,1)-B 0 B * A(I, 1)$

$157 A(1, J)=A(1, J)-B 0 B \div A(I, J)$ 
$115 \quad 154$ CONTINUE

DO $158 \quad I=N, M 1$

$158 A(1, I)=A(1, I) / A(1,1)$
$F(T)=F(1) / A(1,1)$

$120 \quad$ DO $159 I=2, K K$

$F(I)=F(I)-A(I, 1) * F(1)$

$D O T 59 \mathrm{~J}=\mathrm{N}, \mathrm{MT}$

$159 A(I, J)=A(I, J)-A(I, 1) * A(1, j)$

$A(1,1)=1$.
$D O \quad 161$ I $=2, K K$

$125 \quad A(1, I)=0$.

$161 A(I, 1)=0$

200 IF (IOP(2)-5) 201,202,201

202 DO $203 \mathrm{I}=1, \mathrm{M} 1$

$130 \quad 203 A(N, I)=0$.

201 DO $204 \quad I=N, M 1$

$204 A(N-I)=0$.

$A(N, T)=0$.

$D O 205 I=1, K K$

135

$260 M K=I O P(2)$

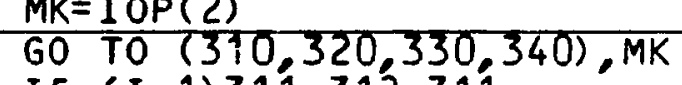

310 IF $(I-1) 311,312,311$

$312 A(N, N)=1$.

$140 \quad F(N)=F N$

$311 \mathrm{BOB}=0$.

$\mathrm{GO} \frac{\mathrm{B}=0 .}{\mathrm{TO}} 206$

320 IF $(I-1) 321,322,321$

$322 A(N, N)=1$.

GO TO 206

321 If $(I-(N-1)) 323,324,323$

$324 \mathrm{BOB}=-\mathrm{FN}$

GO $\frac{\text { TO } 206}{206}$

$323 \mathrm{BOB}=0$.

GO TO 206

150

330 If $(I-1) 331,332,331$

$332 A(N, N)=(X(N)-X(N-1)) / 3$

$A(N, M 2)=-1 . /(X(N)-X(N-1))$

$\begin{array}{ll}155 & A(N, M 1)= \\ & F(N)=F N \\ & G O T O 206\end{array}$

331 If $(I-(N-1)) 333,334,333$

$334 \mathrm{BOB}=(X(N)-X(N-1)) / 6$.

$160 \quad 333$ GO TO 206

GO TO 200

GO TO 206
340 If $(I-1) 341,342,341$

$342 A(N, N)=(X(2)-X(T)+X(N)-X(N-1) / 3$.

$\begin{array}{ll}165 & A(N, N+1)=1 . /(X(2)-X \\ A(N, N+2)=-A(N, N+1)\end{array}$

$A(N, M 2)=-1, /(X(N)-X(N-1))$

$A(N, M 1)=-A(N, M Z)$

$A(N, M 1)=-A(1)$
$G 0$ TO 206

\begin{tabular}{ll} 
GO & TO 206 \\
\hline 41 IF & $(I-2) 343,344,343$
\end{tabular}

343 IF $\left(I-(N-1) \int 345,346,345\right.$

170

$344 \mathrm{BOB}=(X(2)-X(1)) / 6$ 


\section{GO TO 206}

$346 B O B=(X(N)-X(N-1)) / 6$.

60 TO 206

175345 BOB=0.
GO TO 206

206 If (I - 1) $207,205,207$

$207 F(N)=F(N)-B 0 B \div F(I)$

$A(N, 1)=A(N, 1)-B O B \times A(I, 1)$

180

DO $208 \quad J=N, M 1$

$208 A(N, J)=A(N, J)-B 0 B * A(I, J)$

205 CONTINUE

DO 210 I $=M 3, M 1$

$\begin{array}{rl}210 & A(N, I)=A(N, I) / A(N, N) \\ F(N)=F(N) / A(N, N) & \\ A(N) I)=A(N, I) / A(N, N)\end{array}$

$A(N, 1)=A(N, 1) / A(N, N)$

DO $211 \mathrm{I}=1, \mathrm{KK}$

$F(I)=F(I)-A(I, N) * F(N)$

$A(I, 1)=A(I, 1)-A(I, N) * A(N, 1)$

$190-D O\{11 \mathrm{~J}=M\}, M 1$

$211 A(I, J)=A(I, J)-A(I, N) * A(N, J)$

$A(N, N)=1$.

DO $239 \quad I=2, K K$

195

$A(N, I)=0$.

$239 \quad A(I, N)=0$.

$A(1, N)=0$.

30060 To 400

$400 \quad A 1 N=A(1, N)$

$A N 1=A(N, 1)$

$200 \quad$ DO $1000^{\prime} \mathrm{J}=1, J 1$

IF $(T(J)-X(1)) 77,77,66$

$66 \operatorname{IF}(T(J)-X(N)) 68,69,69$

$69 \mathrm{I}=\mathrm{N}-1$

GO TO 212

205

68 CAL SMOLS2(T(J), $X, N, M, M F L A G)$

IF $(M-1) 76,77,76$

$77 \mathrm{I}=1$

60 TO 212

210

76 If (MFLAG) $78,79,78$

$I=M-i$

G0 TO 212

$78 \mathrm{I}=\mathrm{M}$

$212 A 1=X(I+1)-T(J)$

$215 \quad \begin{array}{ll}F L I=X(1+ \\ M B=N+I\end{array}$

$M B=N+I$

$A Z=T(J)-X(I)$

$A I J=-((A 1 \div 3) /(6 . \div F L I)-F L I * A 1 / 6$.

$B I J=-((A 2 * 3) /(6 . * F L I)-F L I * A 2 / 6$.

$C I J=A 1 / F L I$

DI J $=A 2 / F L I$
IF (I OP (I) -5$) 401,402,401$

220

402 IF $(I-1) 403,404,403$

403 IF $(I-(N-1)) 405,406,405$

$404 E I J=-A I J+A(2,1) \div B I J$

225

GO TO 410

$406 E I J=A(N-1,1) \div A I J+A N 1 \div B I J$

GO TO $410^{\circ}$

$405 E I J=A(I, 1) \div A I J+A(I+1,1) \div B I J$ 
$410 A(1, I)=A(1, I)-E I J * A I J$

$A(1, I+1)=A^{\prime}(1, I+1)-E I J * B I J$

$A(1, M B)=A(1, M B)+E I J * C I J$

$A(1, M B+1)=A(1, M B+1)+E I J * D I J$

$F(1)=F(1)+E I J * Y(J)$

235401 IF (IOP( 2) -5) $411,412,411$

413 If $(I-(N-1)\} 415,416,415$

414 GIJ $=A 1 N * A I J+A(2, N) * B I J$

GO TO 420

416 GI J $=A(N-1, N)$ *AIJ $-B I J$

GO TO $420^{\circ}$

415 GI $J=A(I, N) * A I J+A(I+1, N) * B I J$

$420 A(N, I)=A(N, I)-G I J * A I J$

$A(N, I+1)=A(N, I+1)-G I J * B I J$

$A(N, M B)=A(N, M B)+G I J * C I J$

$245 \quad A(N, M B+1)=A^{\prime}(N, M B+1)+G I J * D I J$

$F(N)=F(N)+G I J\{Y(J)$

$411001000 \mathrm{~K}=1, \mathrm{~N}$

$K 1=N+K$

250 IF $(I-1) 430,431,430$

430 IF $(I-(N-1)\} 432,433,432$

131 IF (IOP (1)-5) $43\{, 435,432$

$+35 P K J I=A(2, K 1) * B I J$

GO TO 450

255

433 IF (IOP ( 2) -5) 432,436,432

436 PKJI $=A(N-1, K 1) * A I J$

60 TO 450

432 PJI $=A(I, K 1) * A I J+A(I+1, K 1) * B I J$

450 It $(K-I) 451,452,453$

\begin{tabular}{l}
$460 \quad 452$ PKJI:PKJI+A1/FLI \\
\hline
\end{tabular}

GO TO 451

$454 \mathrm{PK} J \mathrm{I}=\mathrm{PKJI+A2/FLI}$

$451 A(K 1, I)=A(K 1, I)-P K J I * A I J$

$A(K 1, I+1)=A(K 1, I+1)-P K J I * B I J$

$\begin{array}{ll}265 & A(K 1, M B)=A(K 1, M B)+P K J I * C I J \\ & A(K 1, M B+1)=A(K 1, M B+1)+P K J I \\ 1000 \quad F(K 1)=F(K 1)+P K J I * Y(J)\end{array}$

$\begin{array}{rl}265 & A(K 1, M B)=A(K 1, M B)+P K J I * C I J \\ & A(K 1, M B+1)=A(K 1, M B+1)+P K J I * D I J \\ 1000 & F(K 1)=F(K 1)+P K J I * Y(J)\end{array}$

IF $(\operatorname{IOP}(1)-4) 601,602,601$

$\begin{array}{ll}670 & 602 D 0604 I=1, M 1 \\ 270 & 604 A(N+1, I)=0 .\end{array}$

$A(N+1, N+1)=1$.

$A(N+1, M 1)=-1$.

$F(N+1)=0$.

275

601 CALL SMOLST(N2, 1,N2, A, F, DET)

RETURN

END 


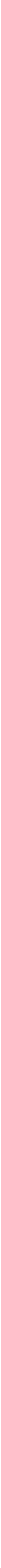




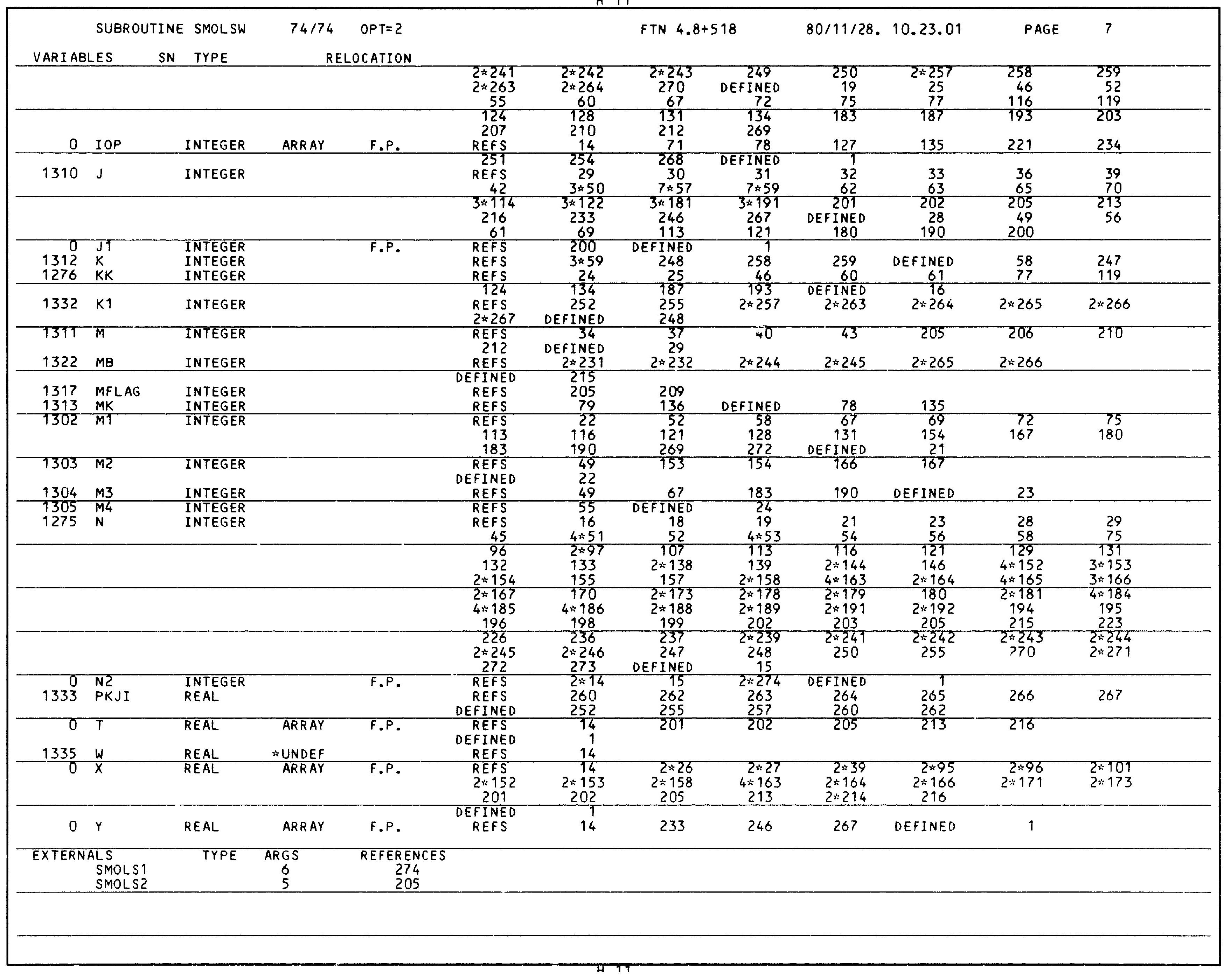




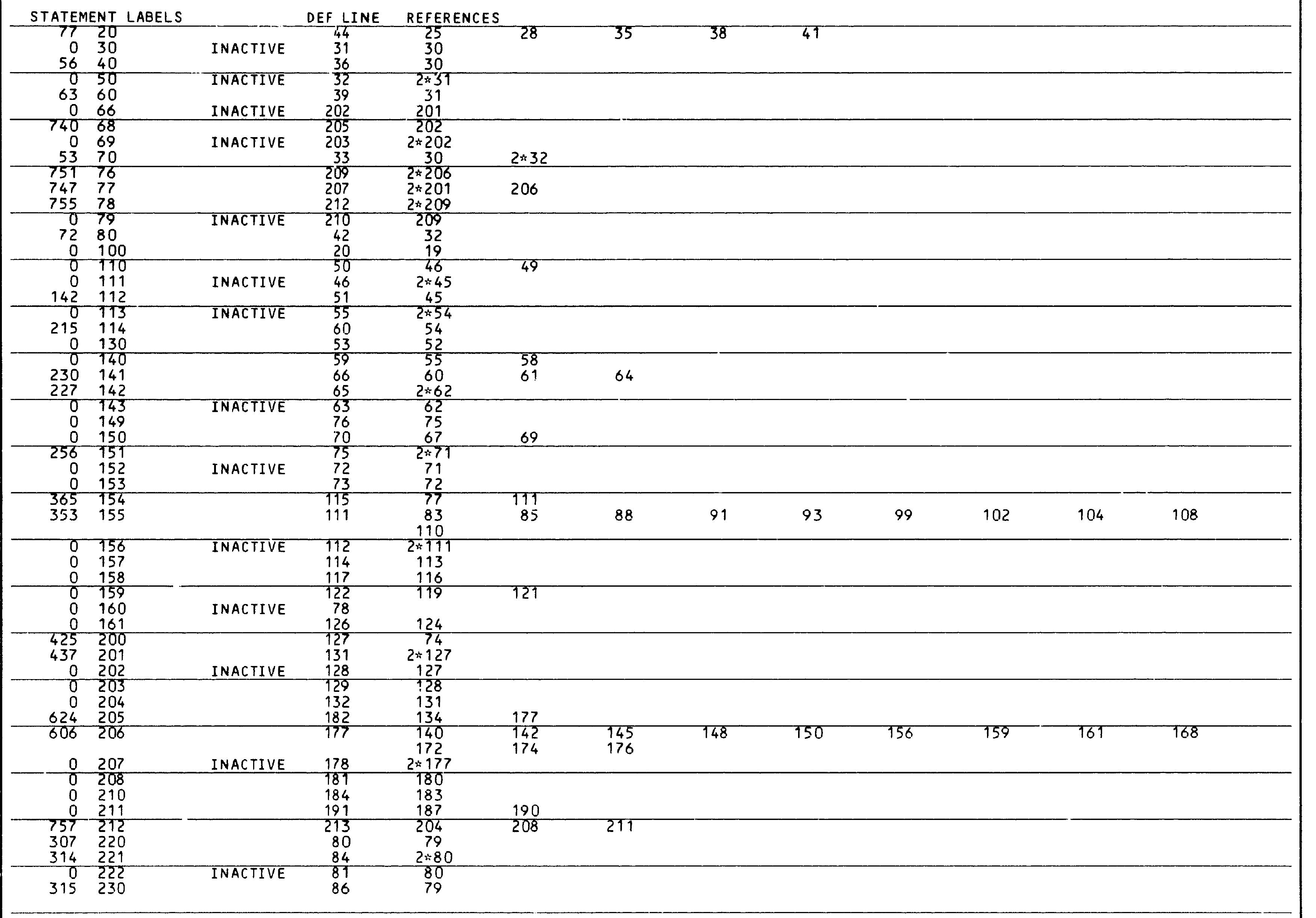




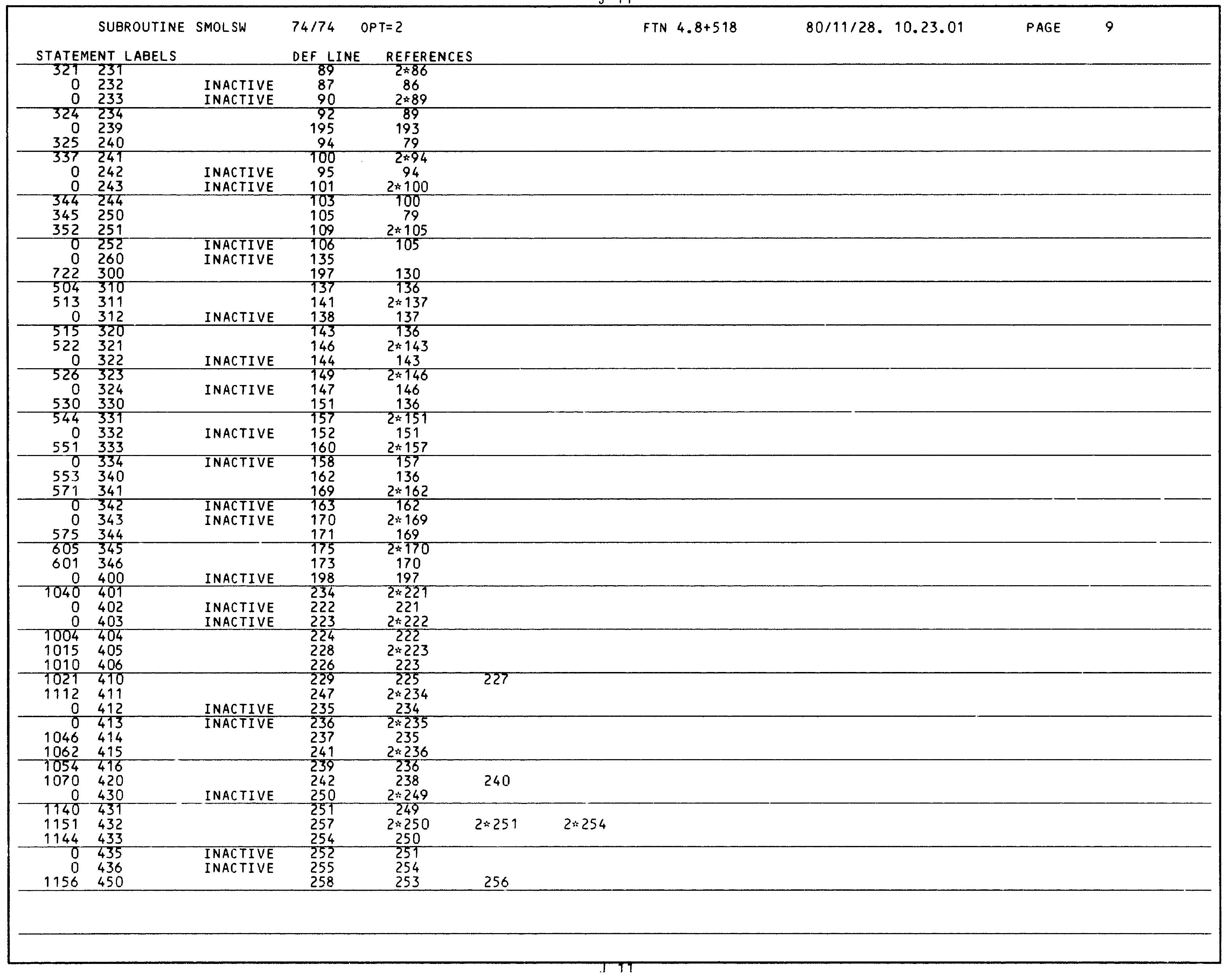




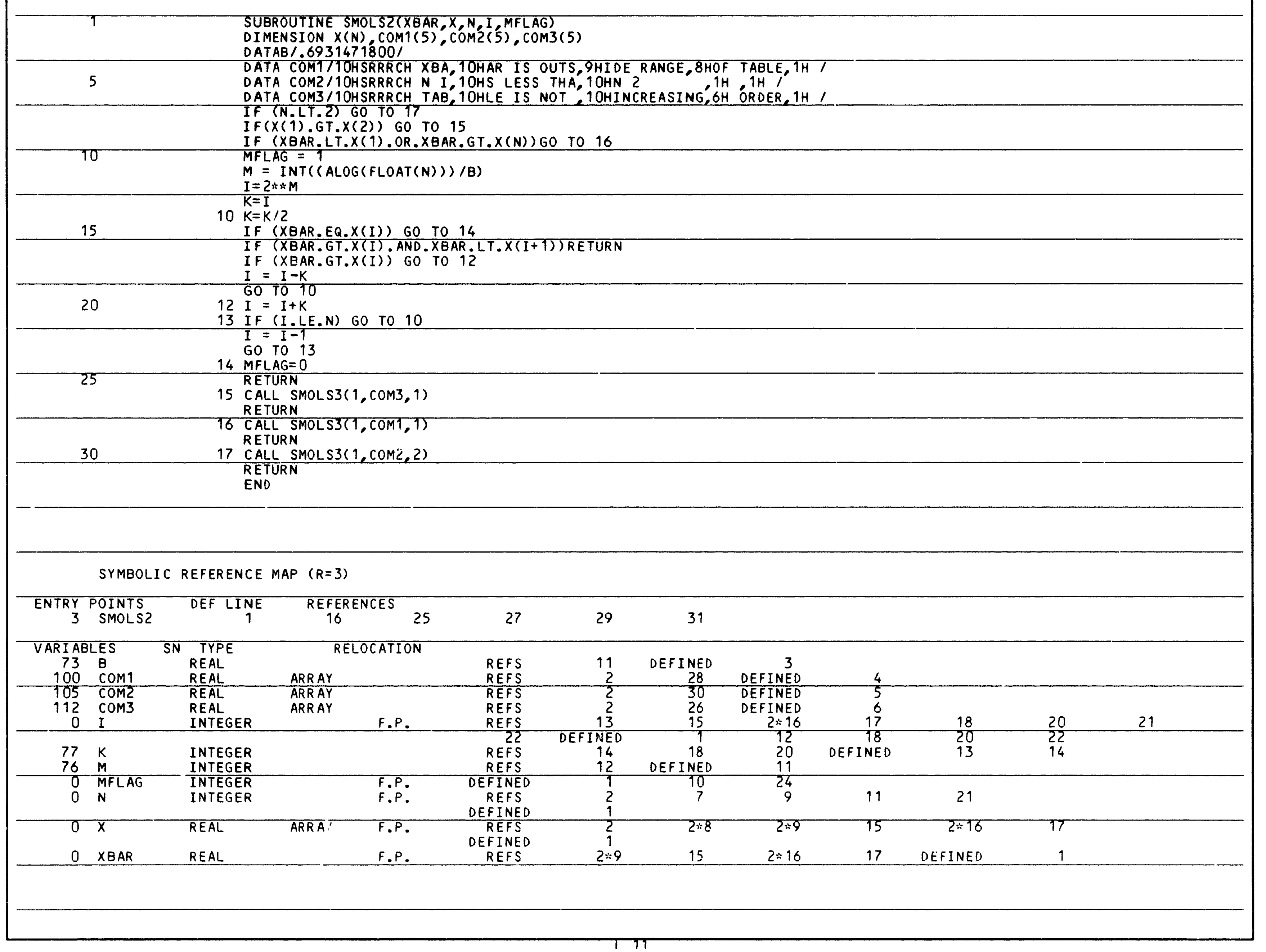




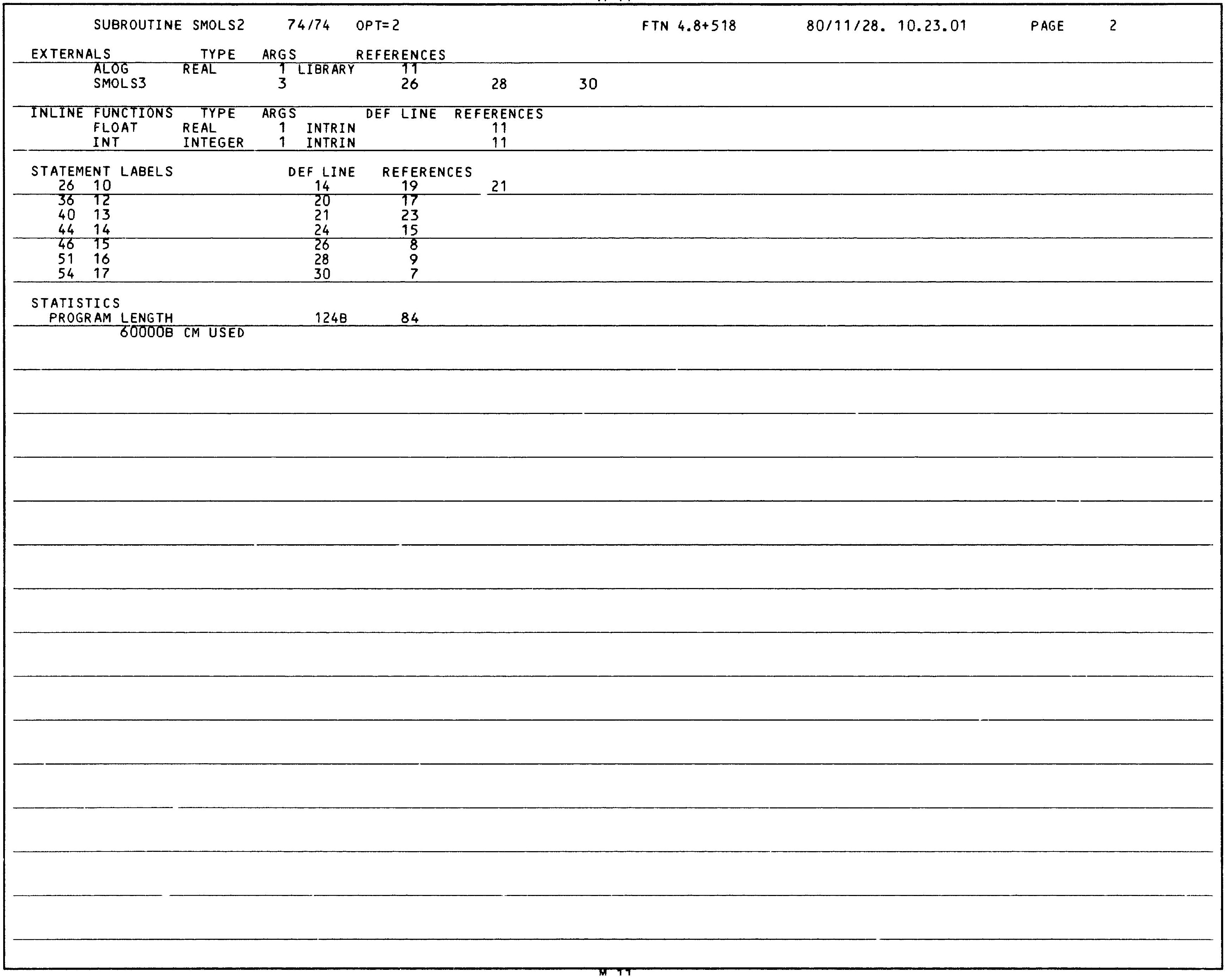


SUBROUTINE SMOLST(N,M, I, A, B, DET)

DIMENSION A(I,N), B(I, M), COMḾ (5), COM2(5), $\operatorname{COM} 3(5)$
DOUBLE PRECISION S1,S2, DSDOT

DATA COMT/1OHLSS NEAR S, 1OHINGULAR SY, 1OHSTEM, CALC, 1OHULATION CÓ,

11 OHNTINUED

DATA COM2/10HLSS SINGUL, 1OHAR SYSTEM., 10H NO RESULT, 10H. INPUT DE,

TTOHSTROYED

$N$ IS $2,10 H E R O$. NO IN, 1OHPUT DATA H, 10HAS BEEN DE,

DATA COMB/10HLSS N
11OHSTROYED

$\mathrm{NN}=\mathrm{N}$

IF (NN.EQ.0) G0 TO 20

$M M=M$

$M M=M$

$X=1$

15

$D D=1, N N$

DO $1 K=1, N N$

$T=A B S(A(K, J))$

IF (T.GT.X) $X=T$

1 CONTINUE

IF (X.EQ.O.) GO TO 19

IF (X.GT.1.E-15) GO TO 2

CALL SMOLS3 $(1$, COM1, 1)

2 SN $=1$.

DO $14 \mathrm{~J}=1, \mathrm{NN}$

25

IF (J.EQ.NN) GO TO 11

$T=A B S(A(J, J))$

$M 1=\mathrm{J}$

$M 2=J+1$

DO $3 K=M 2, N N$

$X=A B S(A(K, J))$

IF (X.LE.T) GO TO 3

$T=x$

$M 1=K$

353 CONTINUE

IF (M1.EQ.J) GO TO 6

DO $4 K=1, N N$

$T=A(J, K)$

$A(J, K)=A(M 1, K)$

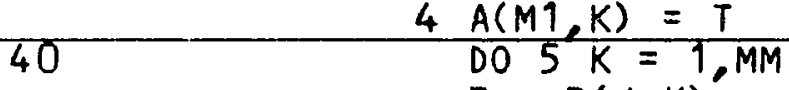

$T=B(J, K)$

$B(J, K)=B(M 1, K)$

$5 B(M 1, K)=$

45

6 IF $(A(J, J), E Q .0$.$) GO TO 19$

6 IF $(A(\mathrm{~J}, \mathrm{~J}) \cdot \mathrm{EQ} \cdot \mathrm{O}$.

s1 $=0$.

$s 2=0$.

IF (L.EQ.O) GO TO 8

$S 1=D S D O T(L, A(J, 1), I, A(1, K), 1)$
$8 A(J, K)=\left(A(J, K)-S, 1 A^{\prime}(j)\right.$

50

$8 A(J, K)=(A(J, K)-D S D T(J, A(K, 1), I, A(1, M Z), 1)$
$10 A(K, M 2)=A(K, M 2)-S 2$

11 DO $13 \mathrm{~K}=1$, MM

$S 1=0$.

IF (L.EQ.0) GO TO 13

$S 1=D S D O T(L, A(J, 1), I, B(1, K), 1)$ 
60

$13 B(J, K)=(B(J, K)-S T) / A(J, J)$
14 CONTINUE

$D E T=A(1,1) * S N$

IF (DET.EQ.O.) GO TO 19

IF (N.EQ.1) GO TO 21

DO $15 \mathrm{~J}=2, N N$

65

IF (DET.EQ.O.) GO TO 19

IF (MM.EQ.0) GO TO 21

$M 3=\mathrm{NN}-1$

DO $18 \mathrm{~J}=1, \mathrm{MM}$

DO $17 \mathrm{~L}=1, \mathrm{M3}$

$70 \quad M 1=N N-L$

$s 1=0$.

$M 2=M 1+1$

$S 1=D S D O T(K, A(M 1, M 2), I, B(M 2, J), 1)$

$75 \quad 17 B(M 1, J)=B(M 1, j)-S i$

18 CONTINUE

GO TO 21

19 CALL SMOLS3 $(1$, COM2, 2$)$

80

GO TO 21

20 CALL SMOLS3 $(1, \operatorname{COM} 3,3)$

21 RETURN SEND

SYMBOLIC REFERENCE MAP $(R=3)$

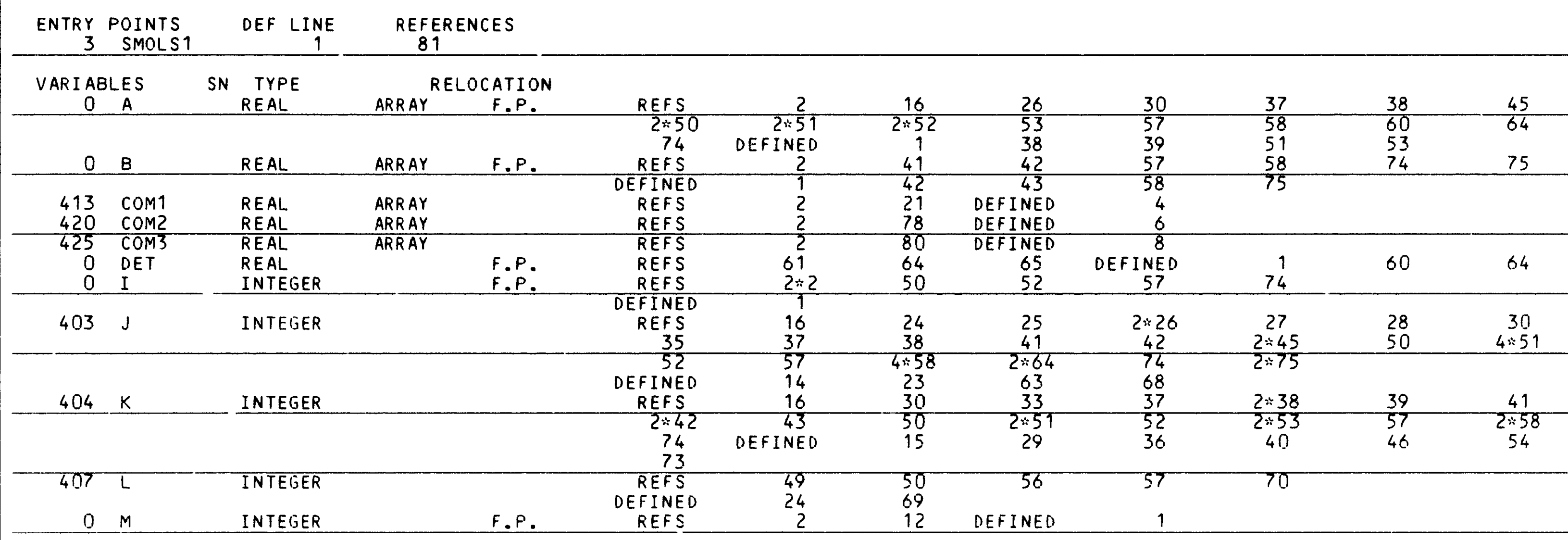




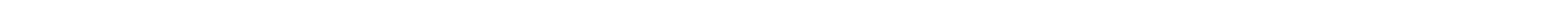


SUBROUTINE SMOLS3(I SW W LHOL, INX)

DIMENSION LHOL (5)

LOGICALPS, TS

DATA NP/TO/,PST.TRUE.1,TS/.FALSE. I

5

IF ( (I SW.EQ.0) . OR. (I SW.GT.5)) RETURN

GOTO $(1,2,3,4,5)$, I SW

1 IF(PS.AND. (NP.GT.O)) PRINT 27, LHOL, INX

27 FORMAT $(1 H 0,9 X, 5 A 10,3 X, 06)$ $N P=N P-1$

10 IF(TS) CALLEXIT

RETURN

$2 P S=. F A L S E$.

RETURN

15

3 PS $=$. TRUE.

NP = INX

RETURN

4 TS=.TRUE.

RETURN

20
5 TS $=$.FALSE
RETURN \$ END

SYMBOLIC REFERENCE MAP $(R=3)$

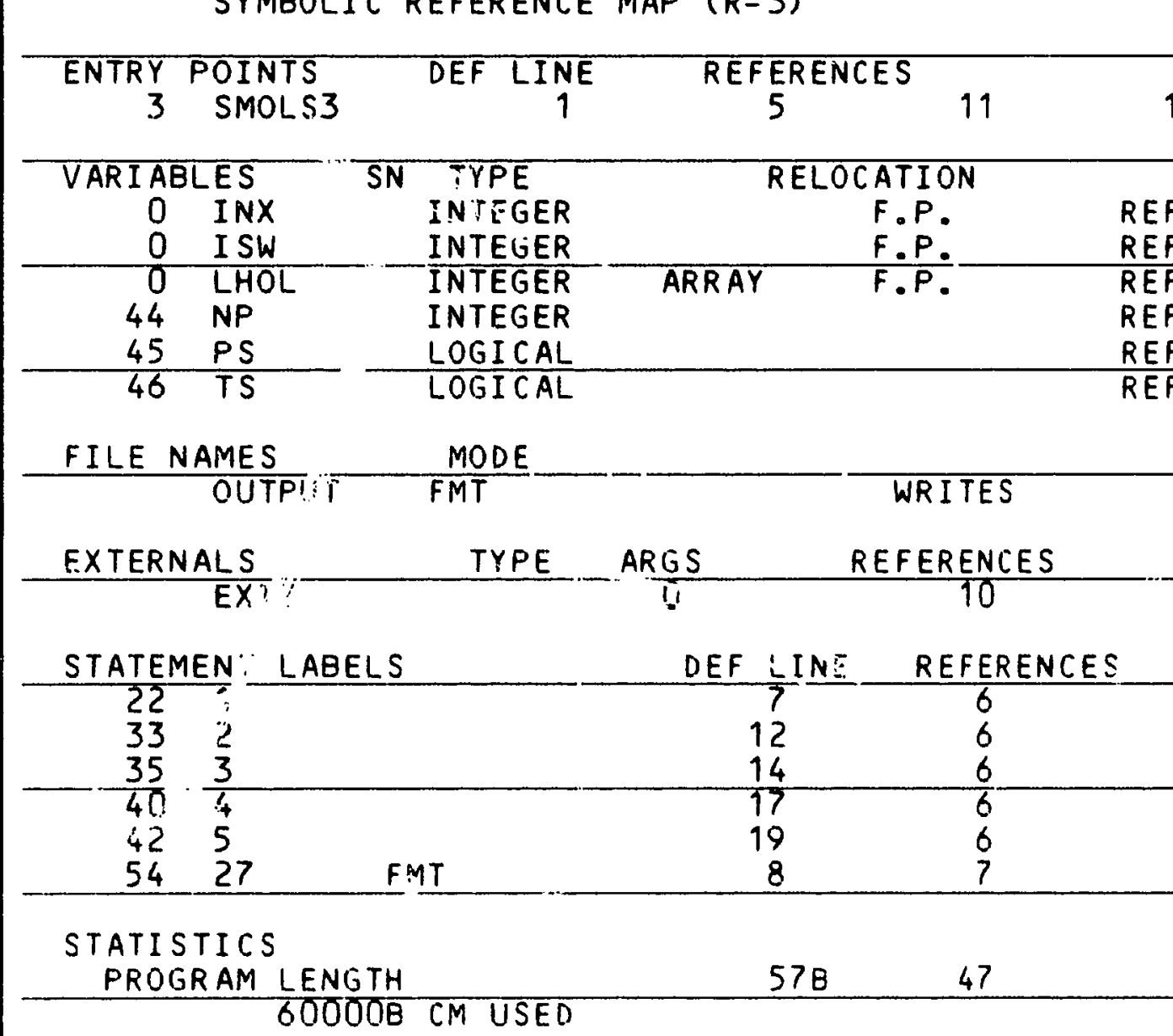




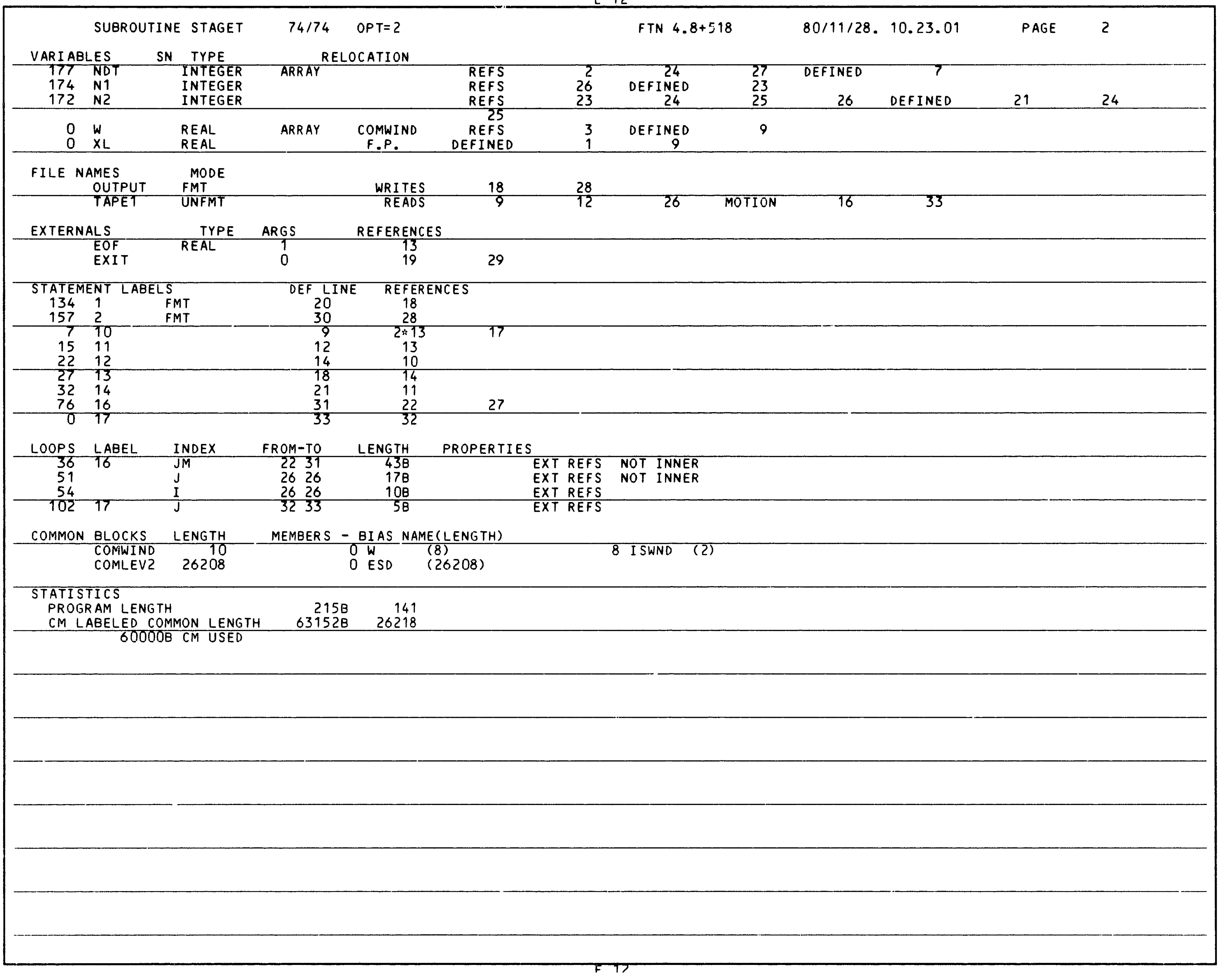




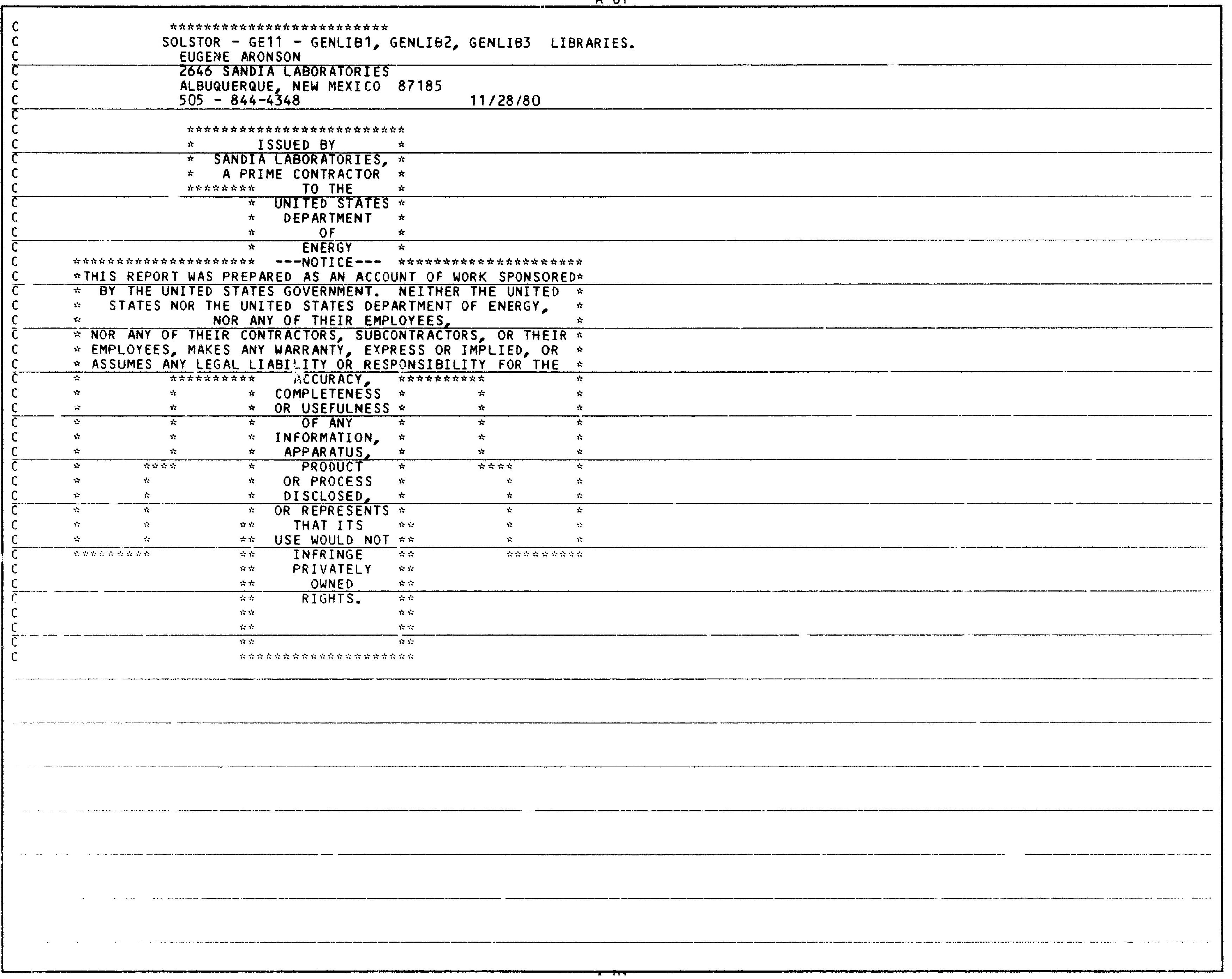




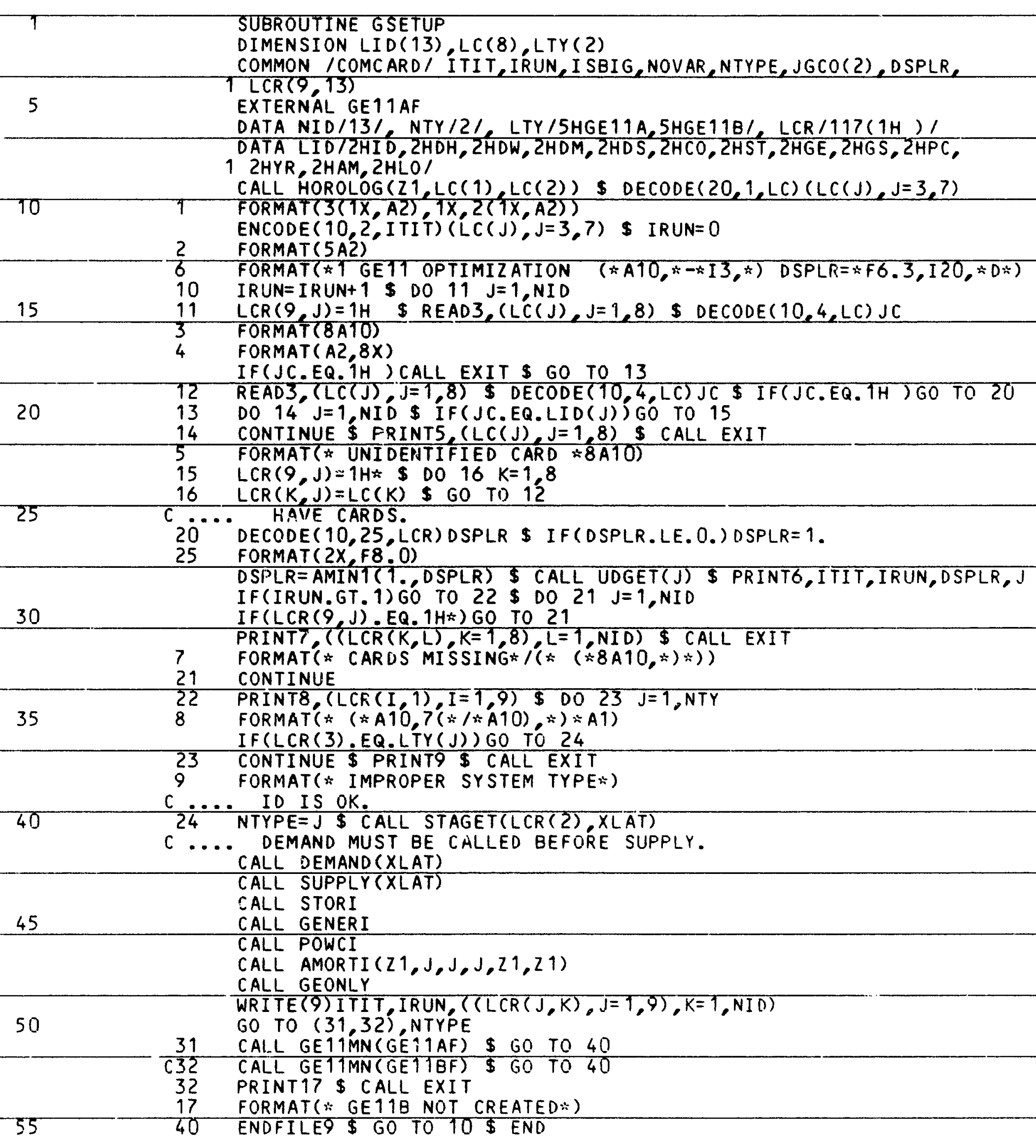


CARD NR. SEVERITY DETAILS DIAGNOSIS OF PROBLEM

50 I AN IF STATEMENT MAY BE MORE EFFICIENT THAN A 2 OR 3 BRANCH COMPUTED GO TO STATEMENT.

SYMBOLIC REFERENCE MAP $(R=3)$

\begin{tabular}{ccc}
\hline ENTRY POINTS & DEF LINE & REFERENCES \\
1 GSETUP & 1 &
\end{tabular}

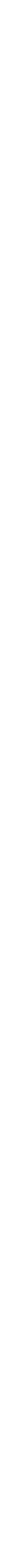




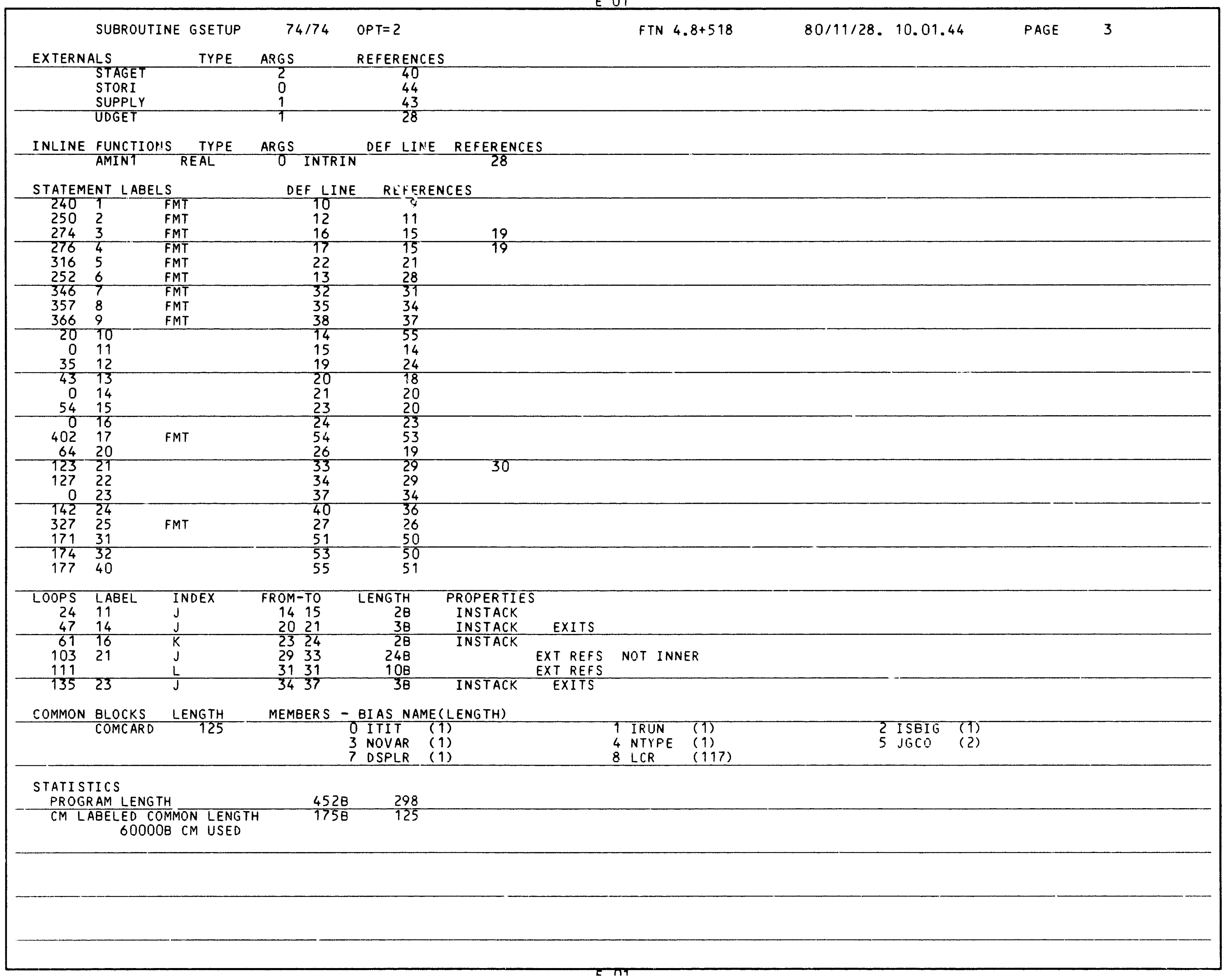




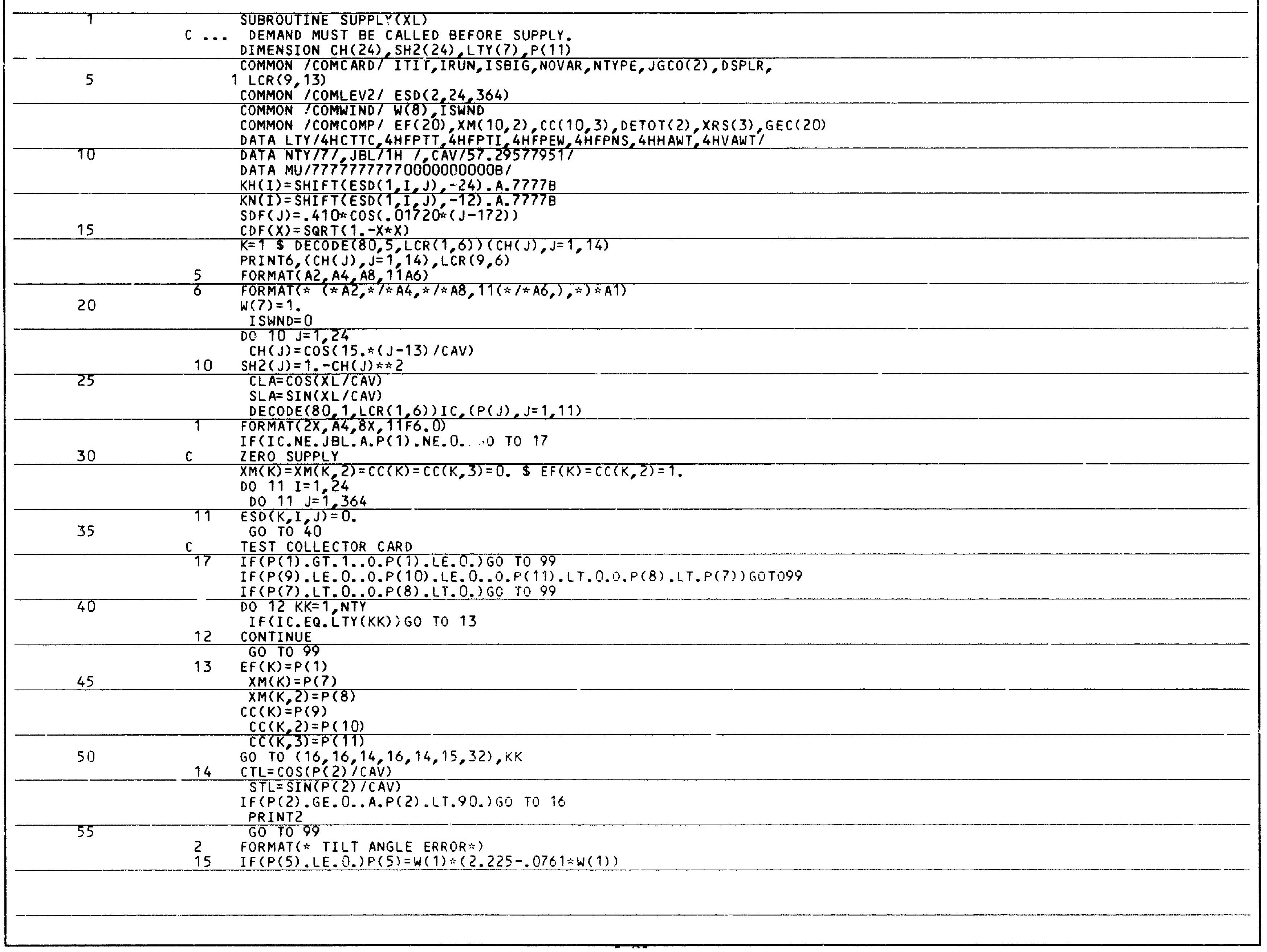


60

$W(5)=P(5)$

IF $(P(4)$.LE. 0.) $P(4)=.454 * W(5)$

$W(4)=P(4)$

$W(6)=P(2)$

$W(7)=\operatorname{MAXO}(\operatorname{INT}(P(3)), 1)$

I $S W N D=1$

PRINT3 (W(J) J=4,7)

IF (W(4).GE.W(5),0.W(5) . GE.W(6)) G0T099

$W(5)=W(5)-W(4)$

$W(5)=W(5)-W(4)$

3 FORMAT $(*-V I=* F 8.2 * V R=* F 8.2 * V C=* F 8.2$, *NTUR=*F8.1)

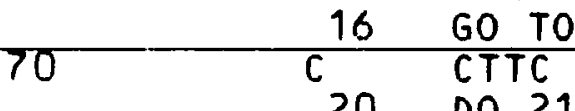

20 DO $21 \quad \mathrm{I}=1,24$

DO $21 \quad J=1,364$

$J 1=K N(\mathrm{I})$

$\mathrm{Z} 1=.01 \div \mathrm{J} 1$

$75 \quad 21 \quad E S D(K, I, J)=Z 1$.A.MU

C FPTT

DO $23 \mathrm{~J}=1,364$

CDL
SDL $=S L A * C D A C$ SL

DO $23 \mathrm{I}=1,24$

$Z 1=C H(I) \& C D L+S D L$

$\mathrm{Zz}=.75+.25 * 21$

$85-J 1=K H(I)$

$J 2=K N(I)$

$Z 3=.01 * \operatorname{AMAX} 1(0 ., J 2+Z 2 *(J 1-J 2 * 21))$

90

$23 \operatorname{ESD}(K, I, J)=Z 3$. A. MU

GO TO 40

FPT

$24 \quad Q T=S T L \approx S L A$

$Q 2=S T L * C L A$

$Q 3=.75+.25 * \mathrm{CTL}$

95

DO $25 \mathrm{~J}=1,364$

$S D L=S D F(J)$

$C D L=C D F(S D L)$

$Z 1=Q 1 \times C D L$

$22=Q 2 * S D L$

$100 \quad Z 3=C L A \div C D L$

DO 25 I $=1,24$

$25=73 * \mathrm{CH}(\mathrm{I})+74$

$26=21 \div C H(I)-22+C T L \div 25$

$105 \quad \begin{aligned} J 1=K H(I) \\ J Z=K N(I)\end{aligned}$

$25 \quad Z 7=.01 \div \operatorname{AMAX} 1(0 ., 26 \div J 2+Q 3 \div(J 1-J 2 \div 25))$

$E S D(K, I, J)=Z 7$. A. MU

GO TO 40

110

C 26 FPEW

DO $27 \mathrm{~J}=1,364$

$S D L=\operatorname{SDF}(\mathrm{J})$

CDL $=$ CDF (SDL)

$C D 2=C D L: \div 2$

$Z 1=C L A \div C D L$ 
$22=S L A \approx S D L$

DO $27 \quad I=1,24$

$Z 3=Z 1 \div \mathrm{CH}(\mathrm{I})+\mathrm{ZZ}$

$24=S Q R T(1 .-S H 2(I) * C D 2)$

$120 \quad 25=.75+.25 * \cos (23 / 24)$

$J 1=K H(I)$

$J 2=K N(I)$

$26=.01 * \operatorname{AMAX} 1(0 ., 24 * 12+25 *(11-12 * 23))$

$E S D(K, I, J)=26$. A. MU

$125 \quad C \quad$ FPNS

$28 \quad Q 1=S L A * C T L+S T L * C L A$

$Q 2=C L A * C T L-S L A * S T L$

$Q 3=.75+.25 * Q 2$

DO $2 \dot{9} \mathrm{~J}=i \mathrm{i}, 364$

$130 \quad$ SDL=SDF( $J)$

$S D L=S D F(J)$
$21=C D F(S D L) * C L A$

$Z 2=S L A * S D L$

DO $29 \quad I=1,24$

$135 \quad \begin{aligned} Z 3=21 * C H(I)+Z 2 \\ Z 4=Q 1 * C D F(Z 3)+Q 2 * Z 3\end{aligned}$

$J 1=K H(I)$

$J Z=K N(I)$

$Z 5=.01 \div \operatorname{AMAX} 1(0 ., 24 * J 2+Q 3 *(J 1-J 2 * 23))$

$29 \operatorname{ESD}(\mathrm{K}, \mathrm{I}, J)=Z 5$. A.MU

GO TO 40

GAWT

C HAWT

DO $31 \mathrm{~J}=1,364$

DO $31 \quad I=1,24$

$J 1=E S D(1, I, J) \cdot A .77778$

145

$21=.1 \% J 1$

$31 E S D(K, I, J)=21$. A.MI'

GO TO 40

C 32 PAWT

GO TO 99

150

33 FORMAT(* NO VAWT YET*)

40 CONTINUE \$IF(ISBIG.EQ. 0)RETURN \$ XM(1, 1)=1000. $\because X M(1,1)$

$X M(1,2)=1000 \div X M(1,2) \& C C(1,3)=1000 * \because C C(1,3)$ \& RETURN

$\begin{array}{lll} & 98 & \text { FORMAT } \\ 155 & 99 & \text { PRINT98 }\end{array}$

PAINT98

END

SYMBOLIC REFERENCE MAP ( $R=3)$

$\begin{array}{clllll}\text { ENTRY POINTS } & \text { DEF LINE } & \text { REFERENCES } & & \\ 3 & 152 & 153 & 157\end{array}$

\begin{tabular}{|c|c|c|c|c|c|c|c|c|c|c|c|}
\hline VAR I ABLES & SN TYPE & & DCATION & & & & & & & & \\
\hline $530 \mathrm{CAV}$ & REAL & & - & $\begin{array}{c}\text { REFS } \\
\text { DEFINED }\end{array}$ & $\begin{array}{l}23 \\
10\end{array}$ & & & & 52 & & \\
\hline 50 & REAL & ARRAY & COMCOMP & REFS & 8 & 153 & DEFINED & $3:: 31$ & 47 & 48 & 49 \\
\hline
\end{tabular}




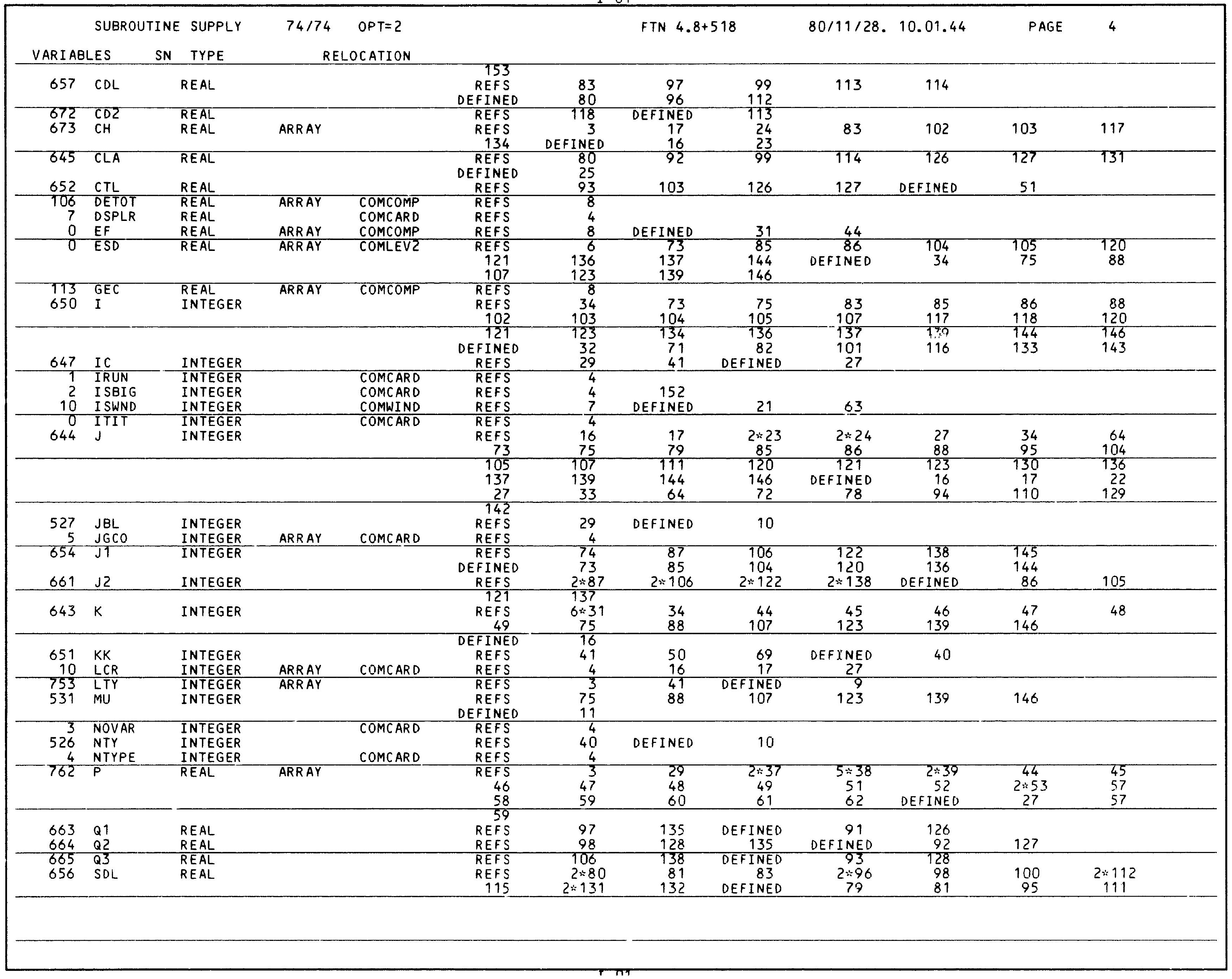


SUBROUTINE SUPPLY $\quad 74 / 74 \quad$ OPT $=2$

FTN $4.8+518$

$80 / 11 / 28 \cdot 10.01 .44$

PAGE 5

SN TYPE

RELOCATION

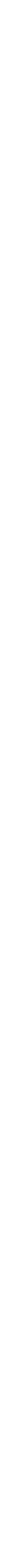


SUBROUTINE DEMAND(XL)

C ... DEMAND MUST BE CALLED BEFORE SUPPLY.

DIMENSION LHM(8,2), LHH (8), QHM(26,2), DME (24), TR(24,2), TW(24,2),

1 TO(24). WKF(52), SD 24,2$), I W(48)$

EQUI VALENCE (IW, SD) (WKF,QHM)

COMMON /COMCARD' I ITIT, IRUN, I SBIG, NOVAR, NTYPE, JGCO(2), DSPLR,

LCR $(9,13)$

COMMON /COMLEV2/ ESD $(2,24,364)$

COMMON / COMCOMP / EF (20), XM(10,2), CC(10,3), DETOT(2), XRS (3), GEC (20)

10

DATACLHM(J, 1), J $=1,4) / 40 H D W 1.2,42 \quad 352825262528 \quad 37 \quad 357461$

DATACLHM( $J, 1), J=5,8) / 40 H 5 \quad 57535345 \quad 4038 \quad 35 \quad 3545 \quad 5763 \quad 5646 /$

DATACLHM( $J, 2), J=1,4) / 40 H D M \quad 1.0 \quad 6055 \quad 5048 \quad 46 \quad 4560758075 \quad 7$ /

DATACLHM(J, 2$), J=5,8) / 40 H 070707070707090110110110105100801$

15

DATACLHH(J) $, J=1,4) \quad / 40 \mathrm{HDH} \quad 43.52756555$

DATACLHH(J) $J=5,8) \quad 140 \mathrm{H} .45 .225 \quad 58.6 \quad 1520.312 .032$ DATA MU/777 $477777770000000000 \mathrm{~B} /$

$\operatorname{COPEV}(X)=((((4.698 * x-7.508) * x-1.137) * x+2.529) * x+2.029) * x+1.872$

$50 \operatorname{DECODE}(80,51, \operatorname{CR}(1,2))(\operatorname{IW}(J), J=1,14)$ \$IF (IW(5) NE. 1H) GO TO 53

51 FORMAT (A2, A10, A2, 11A6)

DO $52 \mathrm{~J}=3,8$

$52 \operatorname{LCR}(J, 2)=\operatorname{LHH}(J) \$ 60$ TO 50

53 PRINTS4, (IW(J),J=1,14),LCR(9,2) $\$ 0058 K=1,2$

$\operatorname{DECODE}(80,56, L C R(1, K+2))(I W(J), j=1,10)$

25

IF(IW(2). NE. TH THO TO $58 \$ D 057 \mathrm{~J}=1,8$

56 FORMAT $(A 2, A 6,7 A 10, A 2)$

$57 \quad \operatorname{LCR}(J, K+2)=\operatorname{LHM}(J, K) \$ G 0$ TO 55

58 PRINT59, (IW(J), $J=1,10), \operatorname{LCR}(9, K+2)$

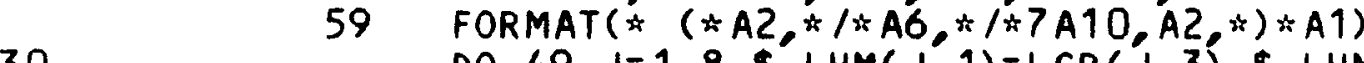

DO $49 \quad J=1,8 \$ \operatorname{LHM}(J, 1)=\operatorname{LCR}(J, 3) \$ \operatorname{LHM}(J, 2)=\operatorname{LCR}(J, 4)$

$49 \quad \operatorname{LHH}(J)=L C R(J, 2)$ \$ I SBIG $=0$

IPR=9HRESI DENCE \$ DECODE $(12,1, L C R(1,2)) J 2$

1 FORMAT $(2 X, A 1,9 X, A 2, F G, 0,4 X, I 2, F G .0,3 F 2,0,7 F 6.0)$

35 C UTILITY DEMAND

DECODE (20,7,LCR(1,2))IPR, JSW, FC

FORMAT( $X X, A 10$ A2, F6.0)

CALL DEMGET (IPR, I SBIG,FC,ESD)

GO TO 41

40 C RESIDENCE OR COMMUNITY

$20 \operatorname{DECODE}(80,1, L C R(1,2)) \mathrm{J} 2, \mathrm{JSW}, F C, L D, C P, T H I, T L O, T D E, Z L, A L, U W, A R$,

1 AW, RVCP

$\operatorname{DECODE}(80,60, \operatorname{LCR}(1,5))(\operatorname{IW}(J), J=1,16)$

45

PRINT61 (IW (J) J = 1, 16) LCR $(9,5)$ \& IWO $=$ IW(2)

60 FORMAT $(2 A 24$ (A' AZS AZ'5A10)

61 FORMAT( $(* A 2, * 1 * A 2,4(* 1 * A 4, * 1 * A 2), * 1 * A 2,5 A 10, *) * A 1)$

FORMAT $* 1 * A 2, *$ *
DO $69 K=1,2$ \$ DECODE $(80,65, L C R(1, K+2)) Z 1,(Q H M(J, K), J=1,24)$

65 FORMAT $\left(2 X_{1}, F 6.0,24 F 3.2\right)$

IF(ZT.GT.0.) GO TO 68

50

66 PRINT67 \& CALL EXIT

67 FORMAT(* NON-POSITIVE HW OR MISC. DEMAND VALUES*)

$680069 \mathrm{~J}=1,24 \$ \operatorname{IF}(\operatorname{QHM}(\mathrm{J}, \mathrm{K}) . \mathrm{LT} .0 . \mathrm{j}) \mathrm{GO}$ TO $66 \$ \operatorname{QHM}(\mathrm{J}, \mathrm{K})=21 \% \operatorname{QHM}(\mathrm{J}, \mathrm{K})$

CONTINUE \& $F C=A M A X 1(1 ., F C)$

IF (FC.LE.1.) GO TO 29

55

I SBI G=

IPR $=9 H$ COMMUNI TY

$29 \quad 0021 \quad \mathrm{~J}=1,24$ 
$\operatorname{DME}(J)=(Q H M(J, 1)+Q H M(J, 2)) \div F C$

$21 \operatorname{DME}(J)=\operatorname{DME}(J)$. A.MU IF (JSW. NE. 1 HE) GO TO 23
ELECTRIC ONLY, NO THERMA

60

DO $22 \quad I=1,24$

DO $22 \mathrm{~J}=1,364$

65

ESD $(2, I, J)=D M E(I)$

GO TO 40

IF ( JSW.EQ.2HEQ) GO TO 27

3 PRINT3 \$ CALL EXIT

3 FORMAT(* ELECTRIC-THERMAL DEMAND MIX ERROR *A10)

27 IF (LD.GE.0.A.LD.LE. 24)GO TO 28

70 PRINT4, LO

FORMAT $\because$ DELTA OUT OF RANGE $* 16)$

4 SD( 1 ) $=X$ L

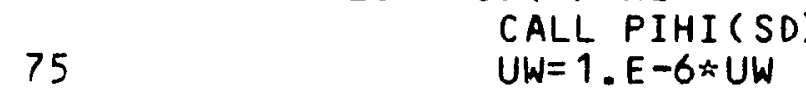

$U W=1 \cdot E-6 * U W$

$A L=1.15 * .01 * 317.11 * A L$

TIN $=$ TLO

DO $35 \mathrm{~J}=1,364$

CALL PIH (SD)

$Z 1=Z 2=0$.

DO $30 \quad I=1,24$

$J 1=\operatorname{SHIFT}(E S D(1, I, J),-36) \cdot A .7777 \mathrm{~B}$

$85 \quad$ TO(I) $=1.8 *(J 1-273)+32$

$J 2=S H I F T(E S D(1, I, J),-12)$. A. $7777 B$

$Z 4=A L \div J 2$

$\operatorname{TR}(I, 2)=T O(I)+Z 4 * S D(I, 2)$

$T W(I, 2)=T O(I)+Z 4 \div S D(I)$

$Z 1=Z 1+T W(I, 2)$

30 CONTINUE

$21=21 / 24$.

95

$22=22124$.

1) GOTO 32

DO $31 \quad I=1,24$

$31 \operatorname{TW}(I)=\operatorname{TW}(I, 2)$

$32 \quad \mathrm{~J} Z=L D$

$100 \quad 0033 \mathrm{I}=1,2_{4}$

$Z 6=F C *(U W * A W *((\operatorname{IIN}-Z 1)+Z L *(Z 1-T W(J 2)))+U W:=A R *((T I N-Z 2)+$

1.5*(TIN-TDE)+ZL*(ZZ-TR( J2))) +RVCP*(TIN-TO(I)) -QHM(I 2$))$

$T W(I)=T W(I, 2)$

105

$\operatorname{TR}(I)=\operatorname{TR}(1,2)$

$J 2=J 2+$

$27=T I N-26 / C P$

IF (27. LE. THI) 60 TO 46

$26=(T H I-27) * 26 /(27-$ TIN $)$

110

TIN= THI

46 IF (Z7.GE.TLO) GO TO 47

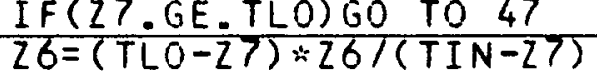

TIN $=$ TLO

GO TO 48 


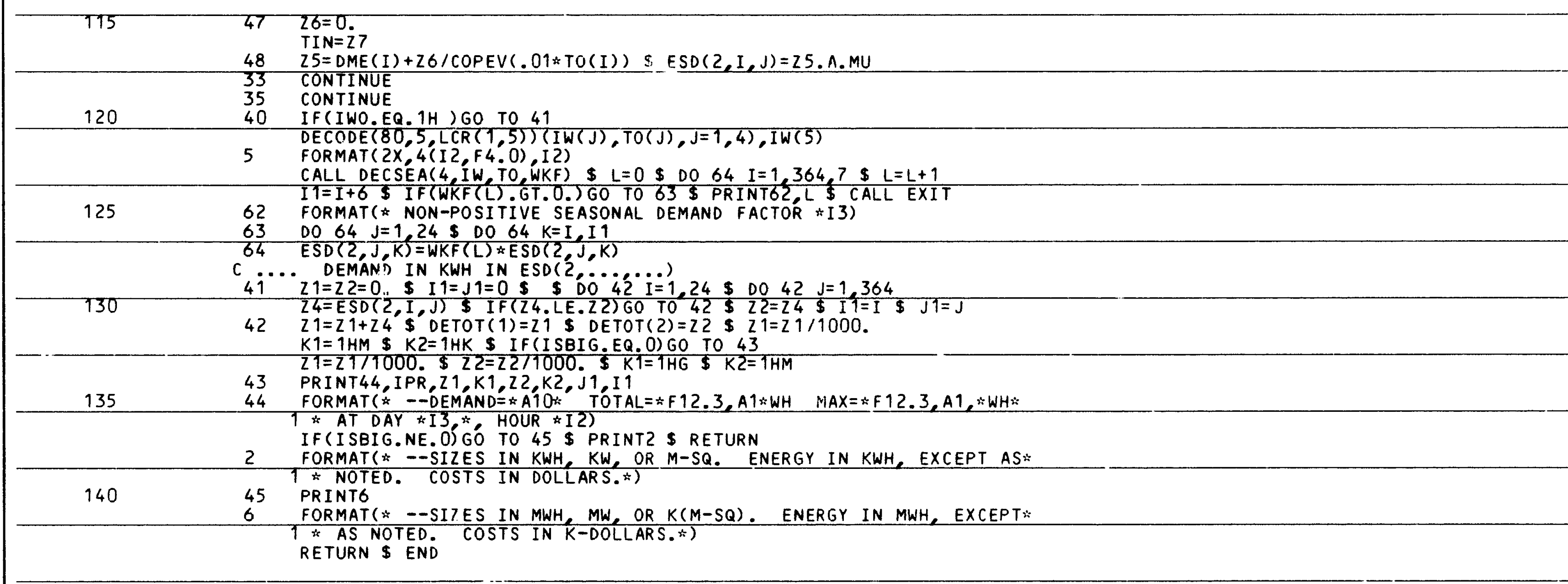

\section{CARD NR. SEVERITY DETAILS DIAGNOSIS OF PROBLEM}

$\begin{array}{lll}12 & \text { I } & \text { DW } 1.2 \\ 11 & \text { I } & 55753 \\ 12 & \text { I } & \text { DM } 1.0 \\ 13 & \text { I } & 07070 \\ 14 & \text { I } & \text { DH } \\ 15 & \text { I } & 45.225 \\ 48 & I & 27 C D 48\end{array}$

HOLLERITH CONSTANT.GT. 10 CHARACTERS, EXCESS CHARACTERS INITIALIZED INTO SUCCEEDING WORDS. HOLLERITH CONSTANT .GT. 10 CHARACTERS, EXCESS CHARACTERS INI TIALIZED INTO SUCCEEDING WORDS. HOLLERITH CONSTANT .GT. 10 CHARACTERS, EXCESS CHARACTERS INITIALIZED INTO SUCCEEDING WORDS. HOLLERITH CONSTANT .GT. 10 CHARACTERS, EXCESS CHARACTERS INITIALIZED INTO SUCCEEDING WORDS. HOLLER I TH CONSTANT . GT. 10 CHARACTERS, EXCESS CHARACTERS INITIALIZED INTO SUCCEEDING WORDS. HOLLERITH CONSTANT :GT. 10 CHARACTERS, EXCESS CHARACTERS INITIALIZED INTO SUCCEEDING WORDS FIELD WIDTH OF A CONVERSION DESCRIPTOR SHOULD BE AS LARGE AS THE MINIMUM SPECIFIED FOR THAT DESCRIPTOR.

SYMBOLIC REFERENCE MAP $(R=3)$

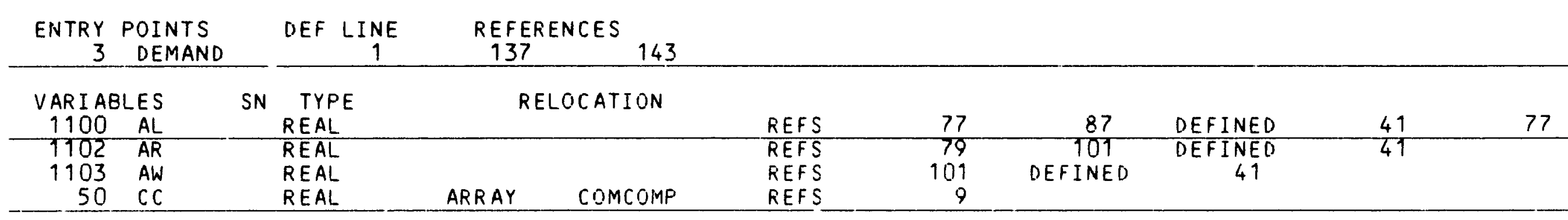




\begin{tabular}{|c|c|c|c|c|c|c|c|c|c|c|c|c|c|}
\hline & SUBROU & I INE & DEMAND & $74 / 74$ & $O P T=2$ & & & FTN 4.8 & 518 & $80 / 11 / 28$ & 10.01 .44 & PAGE & 4 \\
\hline VARI ABI & LES & SN & TYPE & & DCATION & & & & & & & & \\
\hline 1073 & & & REAL & & & REFS & 79 & 106 & DEFINED & 41 & 79 & & \\
\hline $\begin{array}{r}106 \\
1317\end{array}$ & $\begin{array}{l}\text { DETOT } \\
\text { DME }\end{array}$ & & $\begin{array}{l}\text { REAL } \\
\text { REAL }\end{array}$ & $\begin{array}{l}\text { ARR AY } \\
\text { ARRAY }\end{array}$ & COMCOMP & $\begin{array}{l}\text { REFS } \\
\text { REFS }\end{array}$ & $\begin{array}{l}9 \\
3\end{array}$ & $\begin{array}{c}\text { DEFINED } \\
59\end{array}$ & $\begin{array}{c}2 * 131 \\
64\end{array}$ & 117 & DEFINED & 58 & 59 \\
\hline$?$ & DSPLR & & REAL & & COMCARD & REFS & 5 & & & & & & \\
\hline 0 & $\begin{array}{l}\text { EF } \\
\text { ESD }\end{array}$ & & $\begin{array}{l}\text { REAL } \\
\text { REAL }\end{array}$ & $\begin{array}{l}\text { ARRAY } \\
\text { ARR AY }\end{array}$ & $\begin{array}{l}\text { COMCOMP } \\
\text { COMLEVZ }\end{array}$ & $\begin{array}{l}\text { REFS } \\
\text { REFS }\end{array}$ & $\begin{array}{l}9 \\
8\end{array}$ & 38 & 84 & 86 & 127 & 130 & \\
\hline 1071 & FC & & REAL & & & $\begin{array}{l}\text { DEFINED } \\
\text { REFS } \\
\text { DEFINED }\end{array}$ & $\begin{array}{l}64 \\
38 \\
36\end{array}$ & $\begin{array}{r}117 \\
53 \\
49\end{array}$ & $\begin{array}{r}127 \\
54 \\
53\end{array}$ & 58 & 101 & & \\
\hline 113 & GEC & & REAL & ARRAY & COMCOMP & REFS & 9 & & & & & & \\
\hline 1107 & & & INTEGER & & & $\begin{array}{r}\text { REFS } \\
91 \\
\end{array}$ & $\begin{array}{l}2 \div 64 \\
2 \div 97 \\
\end{array}$ & $\begin{array}{r}84 \\
2 \div 98 \\
\end{array}$ & $\begin{array}{r}85 \\
2 * 101 \\
\end{array}$ & $\begin{array}{r}86 \\
2 \div 103 \\
\end{array}$ & $\begin{array}{r}3 \times 88 \\
2 \div 104 \\
\end{array}$ & $\begin{array}{r}3 * 89 \\
7 \times 117\end{array}$ & $\begin{array}{r}90 \\
124\end{array}$ \\
\hline & & & & & & $\begin{array}{l}126 \\
130\end{array}$ & $2 * 130$ & DEFINED & 62 & 83 & 96 & 100 & 123 \\
\hline 1066 & IPR & & INTEGER & & & REFS & 38 & 134 & DEFINED & 32 & 36 & 56 & \\
\hline 1 & IRUN & & INTEGER & & COMCARD & REFS & 6 & & DLT LNOL & & & & \\
\hline 2 & I SBIG & & INTEGER & & COMCARD & REFS & 6 & 38 & 132 & 137 & DEFINED & 31 & 55 \\
\hline 1123 & $\frac{1111}{I W}$ & & INTEGER & ARRAY & COMLARD & $\frac{R E F S}{\text { REFS }}$ & $\frac{0}{3}$ & 5 & 18 & 22 & 25 & 28 & $2 \div 44$ \\
\hline & TWO & & INTEGFR & & & $\begin{array}{r}123 \\
E F C\end{array}$ & DEF INED & 18 & 24 & 43 & $2 * 121$ & & \\
\hline$\frac{1105}{1120}$ & $\frac{\text { I WO }}{\text { T1 }}$ & & & & & REFS & 120 & DEFINED & $\quad 44$ & & & & \\
\hline $\begin{array}{l}1120 \\
1064\end{array}$ & J & & INTEGER & & & $\begin{array}{l}\text { REFS } \\
\text { REFS } \\
2: 31\end{array}$ & $\begin{array}{r}126 \\
18 \\
43\end{array}$ & $\begin{array}{l}134 \\
2 * 21\end{array}$ & $\begin{array}{c}\text { DEFINED } \\
22 \\
47\end{array}$ & $\begin{array}{l}124 \\
24 \\
3 \times 57\end{array}$ & $\begin{array}{l}129 \\
2 * 27 \\
3+58\end{array}$ & $\begin{array}{c}130 \\
28 \\
7 \times 50\end{array}$ & $4 \div 30$ \\
\hline & & & & & & 84 & 86 & $\begin{array}{l}44 \\
95\end{array}$ & 117 & $2 * 121$ & $2 \times 127$ & $2 \div 130$ & \\
\hline & & & & & & DEFINED & 18 & 20 & 22 & 24 & $\begin{array}{l}25 \\
62\end{array}$ & 28 & 30 \\
\hline & & & & & & $\frac{45}{126}$ & $\frac{44}{129}$ & & & & & & \\
\hline 5 & $J G C O$ & & INTEGER & ARRAY & COMCARD & REFS & 6 & & & & & & \\
\hline$\frac{1070}{1112}$ & JSW & & INTEGER & & & REFS & 67 & 66 & DEFINED & 36 & 41 & & \\
\hline 1067 & J2 & & $\begin{array}{l}\text { INTEGER } \\
\text { INTEGER }\end{array}$ & & & $\begin{array}{l}\text { REFS } \\
\text { REFS }\end{array}$ & $\begin{array}{l}85 \\
34\end{array}$ & $\begin{array}{r}134 \\
87\end{array}$ & $\begin{array}{r}\text { DEFINED } \\
2 * 101\end{array}$ & $\begin{array}{r}84 \\
105\end{array}$ & $\begin{array}{c}129 \\
\text { DEFINED }\end{array}$ & $\begin{array}{r}130 \\
32\end{array}$ & 41 \\
\hline 1065 & K & & INTEGER & & & $\begin{array}{r}86 \\
\text { REFS }\end{array}$ & $\frac{99}{24}$ & $\frac{105}{2 * 27}$ & 28 & $2: 47$ & $3: 52$ & $2 \div 127$ & \\
\hline & & & 1) & & & DEFINED & 22 & 47 & 126 & & & & \\
\hline 1121 & K1 & & INTEGER & & & REFS & 134 & DEFINED & 132 & 133 & & & \\
\hline 1122 & $\mathrm{~K} 2$ & & INTEGER & & & REFS & 134 & DEFINED & 132 & 133 & & & \\
\hline 1117 & L & & INTEGER & & & REFS & 123 & $2 \div 124$ & 127 & DEFINED & $2 \div 123$ & & \\
\hline 10 & ICR & & INTEGER & ARRAY & COMCARD & REFS & 6 & 18 & 22 & 24 & 28 & $2 * 30$ & 31 \\
\hline & & & & & & 32 & 36 & 41 & 43 & 44 & 47 & 121 & \\
\hline 1072 & LO & & INTEGER & & & REFS & $2 \div 69$ & 70 & 76 & 99 & DEF INED & 41 & 76 \\
\hline 1307 & LHH & & INTEGER & $\overline{A R R A Y}$ & & REFS & $-\frac{3}{3}$ & 21 & DEFINED & 14 & 15 & 31 & \\
\hline 1267 & LHM & & INTEGER & ARRAY & & REFS & 3 & 27 & DEFINED & 10 & 11 & 12 & 13 \\
\hline 513 & MU & & INTEGER & & & REFS & 59 & 917 & DEFINED & 16 & & & \\
\hline 3 & NOV AR & & INTEGER & & COMCARD & REFS & 6 & & & & & & \\
\hline $\begin{array}{r}4 \\
1503\end{array}$ & NTYPE & & INTEGER & $000 A Y$ & COMCARD & REFS & 6 & 5 & 3.55 & 3.58 & 101 & & \\
\hline $1<03$ & QHM & & REAL & ARR AY & & $\begin{array}{c}\text { REFS } \\
\text { OEFINED }\end{array}$ & 47 & 52 & $2 \because 22$ & $\because 38$ & roi & & \\
\hline 1104 & $R \vee C P$ & & REAL & & & REFS & 101 & DEFINED & 41 & & & & \\
\hline 1123 & So & & REAL & $\overline{A R R A Y}$ & & REFS & $3 \frac{3}{3}$ & 5 & 74 & 81 & 88 & 89 & \\
\hline 1076 & TDE & & REAL & & & $\begin{array}{c}\text { DEFINED } \\
\text { REFS }\end{array}$ & 109 & $D E F I N E D$ & 41 & & & & \\
\hline 1074 & THI & & REAL & & & REFS & 107 & 108 & 109 & DEFINED & 41 & & \\
\hline 1110 & TIN & & REAL & & & REFS & $4: 101$ & 106 & 108 & 112 & DEFINEO & 78 & 109 \\
\hline
\end{tabular}




\begin{tabular}{|c|c|c|c|c|c|c|c|}
\hline \multirow{2}{*}{$\begin{array}{c}\text { VARI AB } \\
1075 \\
1507\end{array}$} & \multirow{2}{*}{$\begin{array}{l}\text { ES } \\
\text { TLO } \\
\text { TO }\end{array}$} & \multirow{2}{*}{ SN } & \multirow{2}{*}{$\begin{array}{l}\text { TYPE } \\
\text { REAL } \\
\text { REAL }\end{array}$} & \multicolumn{3}{|c|}{ RELOCATION } & \\
\hline & & & & ARRAY & & $\begin{array}{c}\text { REFS } \\
\text { REFS } \\
\text { DEFINED }\end{array}$ & \\
\hline 1347 & TR & & REAL & ARRAY & & $\begin{array}{c}\text { REFS } \\
\text { DEFINED }\end{array}$ & \\
\hline 1427 & TW & & REAL & ARRAY & & REFS & \\
\hline $\begin{array}{l}1101 \\
1203 \\
\end{array}$ & $\begin{array}{l}\text { UW } \\
\text { WKF }\end{array}$ & & $\begin{array}{l}\text { REAL } \\
\text { REAL }\end{array}$ & ARRAY & & $\begin{array}{c}\text { DEFINED } \\
\text { REFS } \\
\text { REFS }\end{array}$ & \\
\hline $\begin{array}{r}0 \\
24 \\
110 \\
\end{array}$ & $\begin{array}{l}X L \\
X M \\
X R S\end{array}$ & & $\begin{array}{l}\text { REAL } \\
\text { REAL } \\
\text { REAL }\end{array}$ & $\begin{array}{l}\text { ARRAY } \\
\text { ARRAY }\end{array}$ & $\begin{array}{l}\text { F.P. } \\
\text { COMCOMP } \\
\text { COMCOMP }\end{array}$ & $\begin{array}{l}\text { REFS } \\
\text { REFS } \\
\text { REFS }\end{array}$ & \\
\hline $\begin{array}{l}1077 \\
1106\end{array}$ & $\begin{array}{l}2 L \\
21\end{array}$ & & $\begin{array}{l}\text { REAL } \\
\text { REAL }\end{array}$ & & & $\begin{array}{r}\text { REFS } \\
\text { REFS } \\
134 \\
\end{array}$ & $\begin{array}{r}2 * 1 \\
\text { DEFIN }\end{array}$ \\
\hline 1111 & 22 & & REAL & & & $\begin{array}{c}\text { REFS } \\
\text { DEFINED }\end{array}$ & 8 \\
\hline $\begin{array}{l}1113 \\
1916 \\
1114 \\
\end{array}$ & $\begin{array}{l}24 \\
25 \\
26 \\
\end{array}$ & & $\begin{array}{l}\text { REAL } \\
\text { REAL } \\
\text { REAL }\end{array}$ & & & $\begin{array}{l}\text { REFS } \\
\text { REFS } \\
\text { REFS } \\
\end{array}$ & $\begin{array}{r}8 \\
11 \\
10\end{array}$ \\
\hline 1115 & 27 & & REAL & & & $\begin{array}{c}112 \\
\text { REFS } \\
\text { DEFINED } \\
\end{array}$ & $\begin{array}{l}17 \\
10 \\
10\end{array}$ \\
\hline
\end{tabular}

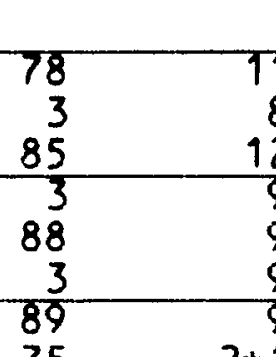

111
88
121
91
97
90
98
$2 \times 101$

\section{2}

112

$\begin{array}{llll}89 & 101 & 5 \times 117 & 123\end{array}$

FILE NAMES MODE

OUTPUT FMT

$\frac{22}{140}$

28

DEFINED

970104

$\begin{array}{r}104 \\ 98 \\ \hline\end{array}$

$101 \quad 103$

9

101 DEFINED

\begin{tabular}{rr}
49 & 5 \\
\hline
\end{tabular}

52
47

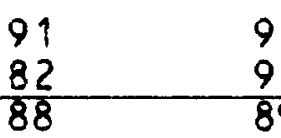

$\begin{array}{cc}94 & 2 * 101 \\ 91 & 94\end{array}$

DEFINED

$89 \quad 2 \div 130$

$130 \quad 131$

131
130

108

117

129

$2 \div 108$

111

117

DEFINED

87

$2 * 11 ? \quad 116$

101

44

50

67

70

124

$\begin{array}{rcccc}41 & 93 & 2 * 101 & 3 * 131 & 133 \\ 82 & 90 & 93 & 129 & 2 * 131\end{array}$

$\begin{array}{llll}129 & 130 & 133 & 134\end{array}$

134

108

EXTERNALS

TYPE ARGS 137

134

\begin{tabular}{lcc} 
& TYPE & ARGS \\
\hline DECSEA & 4 \\
DEMGET & 4 \\
EXIT & 0 \\
\hline PIH & 1 \\
PIHI & 1
\end{tabular}

REFERENCES

\begin{tabular}{rrr}
67 & 71 & 124 \\
\hline
\end{tabular}

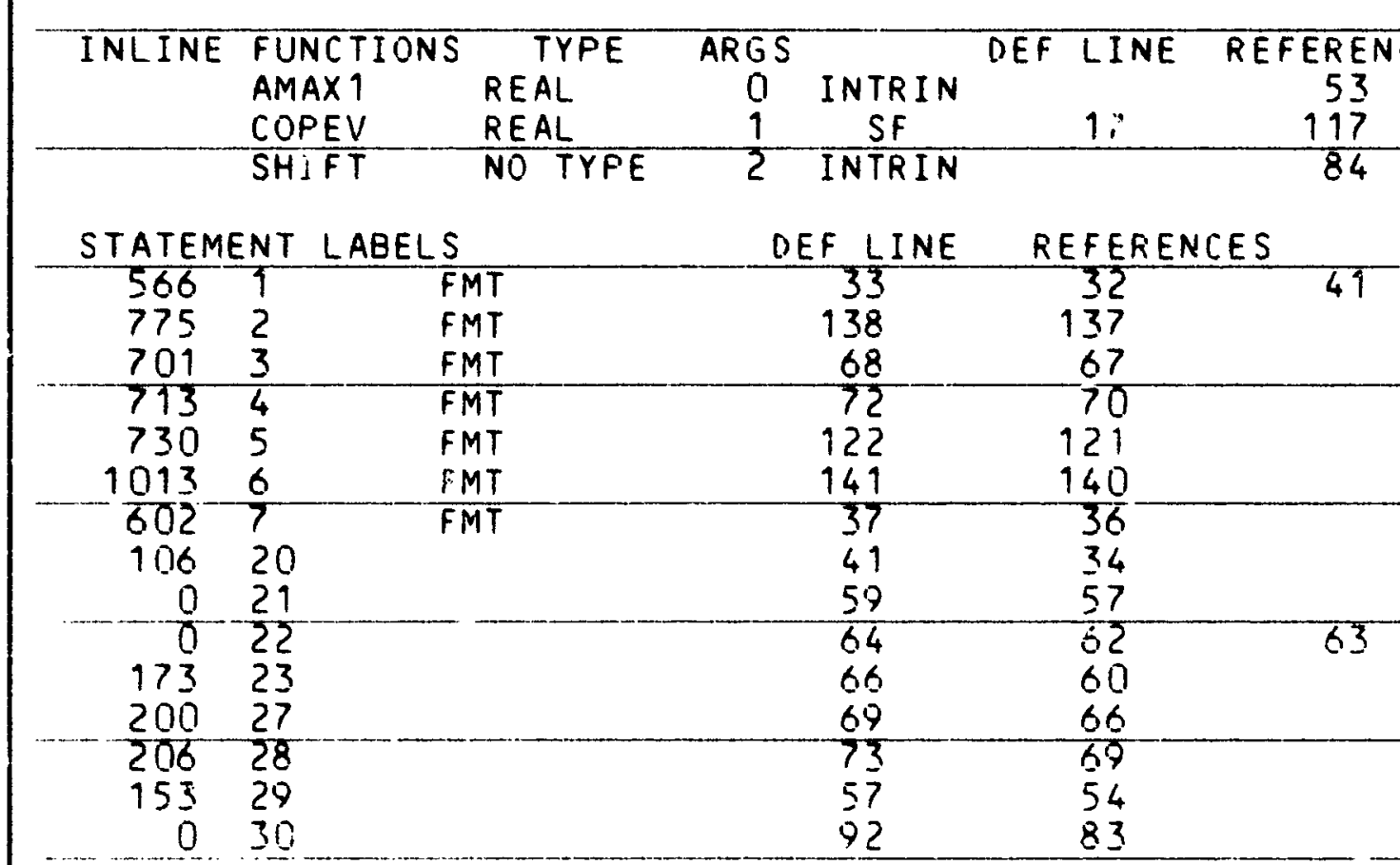




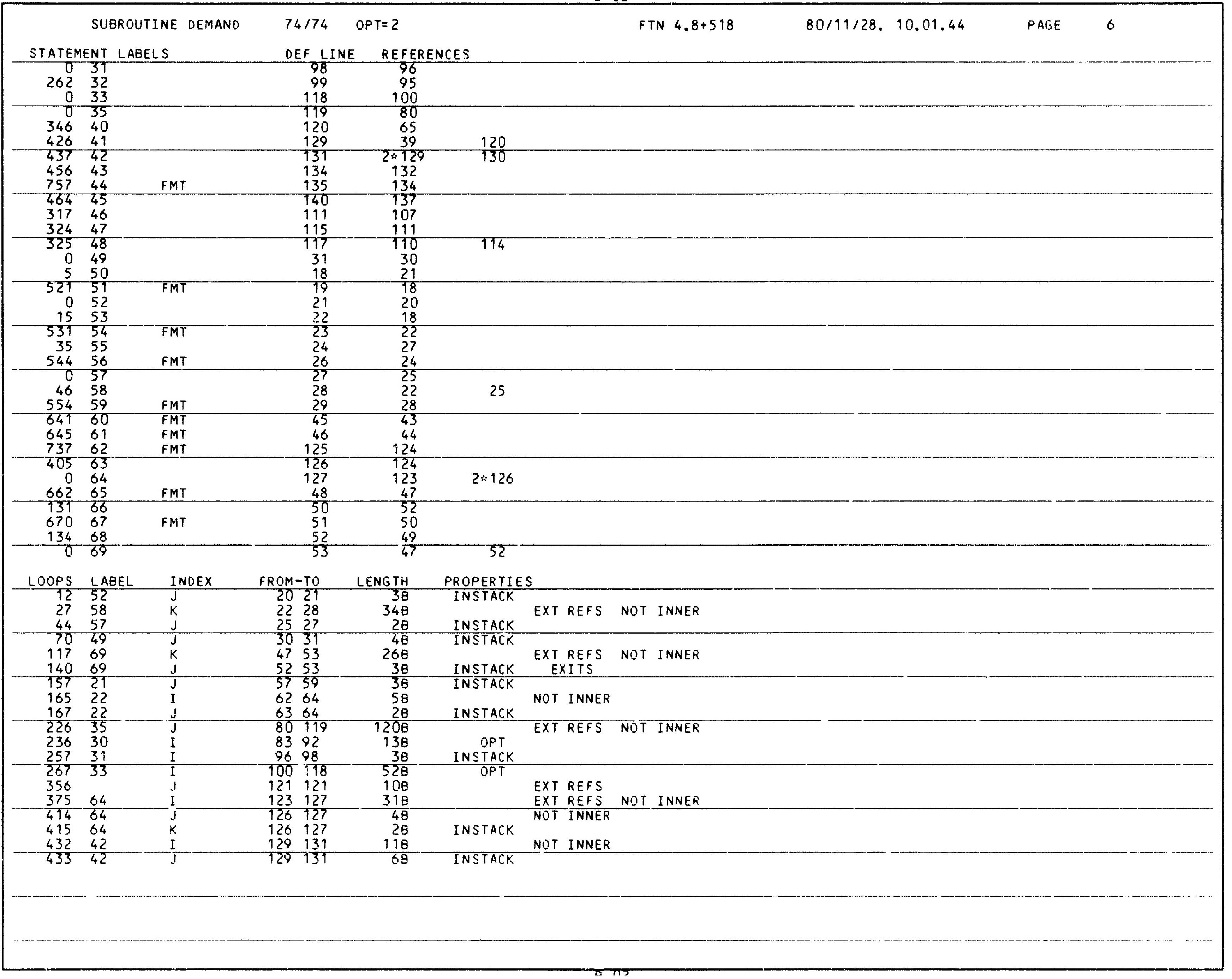


COMMON BLOCKS LENGTH MEMBERS - BIAS NAME(LENGTH) COMCARD

\section{COMLEV2}

COMCOMP

0 ITIT (1)

3 NOVAR (1)

7 DSPLR (1)

$O$ ESD $\quad(17472)$

$0 \mathrm{EF}$

70 DETOT (2)

1 IRUN (1)

4 NTYPE

8 LCR

$20 \times M$

$72 \times R S$

(1)

\section{EQUIV CLASSES LENGTH MEMBERS - BIAS NAME(LENGTH)}

IW

0 SD

$(48)$

WKF 52

$O$ QHM

(52)

STATISTICS

PROGR AM LENGTH

CM LABELED COMMON LENGTH $60000 B$ CM USED

$15378 \quad 863$

$424348 \quad 17692$ 


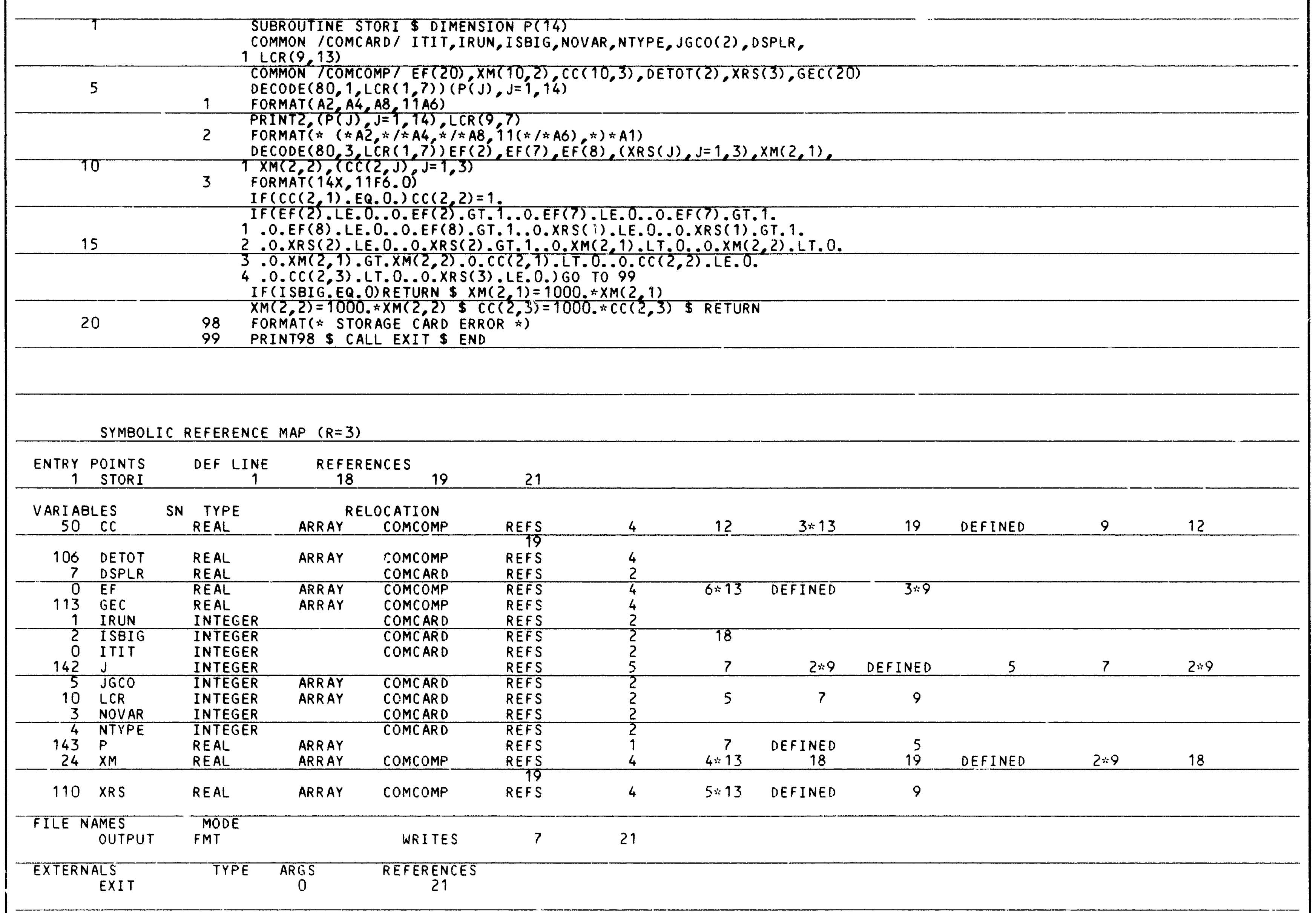


DEF LINE REFERENCES

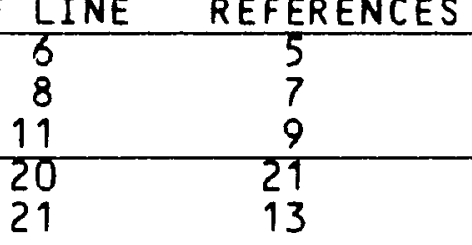

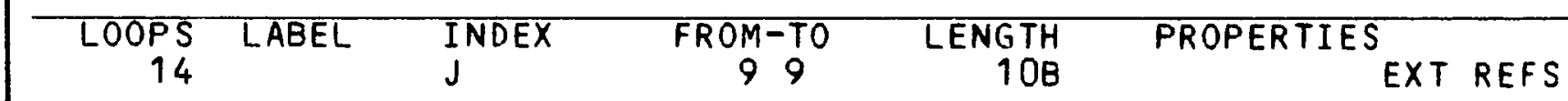

\begin{tabular}{cccc}
\hline COMMON BLOCKS & LENGTH & MEMBERS & - BIAS NAME (LENGTH) \\
COMCARD & 125 & ITIT & (1) \\
& 3 NOVAR & (1) \\
\hline \multirow{2}{*}{ COMCOMP } & \multirow{2}{*}{95} & 7 DSPLR & $(1)$ \\
& & 0 EF & (20) \\
& & 70 DETOT & $(2)$
\end{tabular}

1 IRUN

4 NTYPE (1)

8 LCR $(117)$

20 XM

$72 X R S$

$\begin{array}{lll}2 \text { I SBIG } & \text { (1) } \\ 5 \text { JGCO } & (2) \\ 40 \mathrm{CC} & (30) \\ 75 \mathrm{GEC} & (20)\end{array}$

STATISTICS

PROGRAM LENGTH

CM LABELED COMMON LENGTH 60000B CM USED

$161 \mathrm{~B}$

$\frac{113}{220}$ 


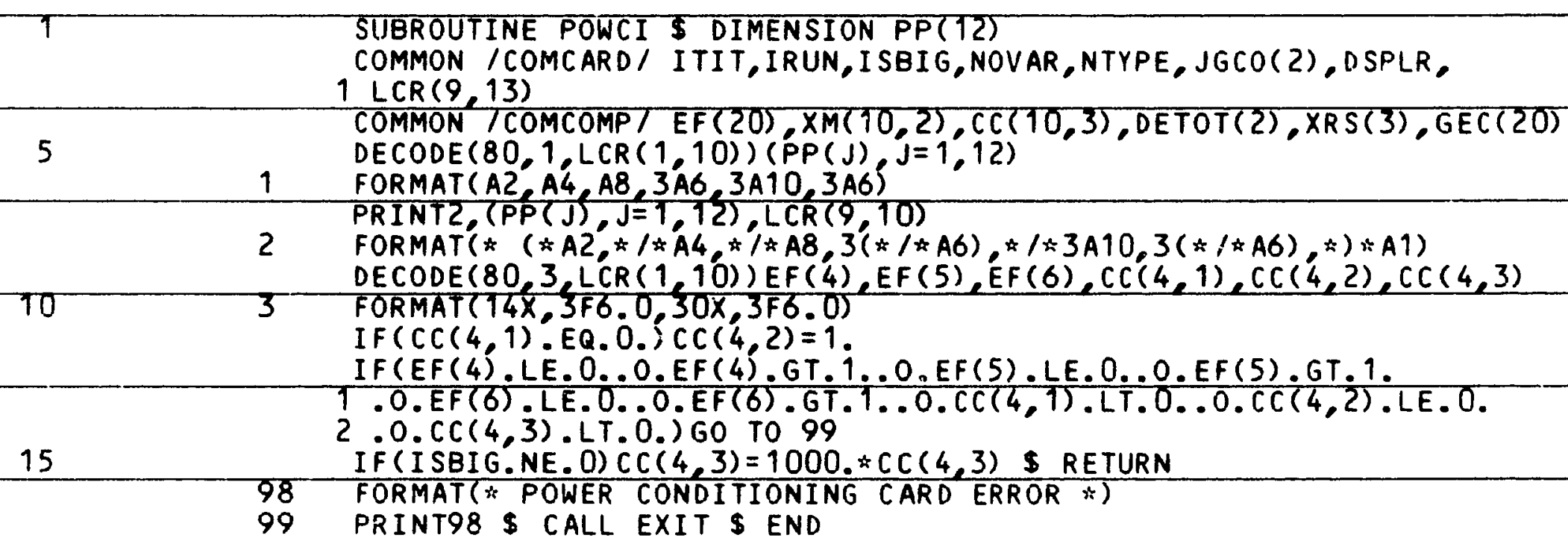

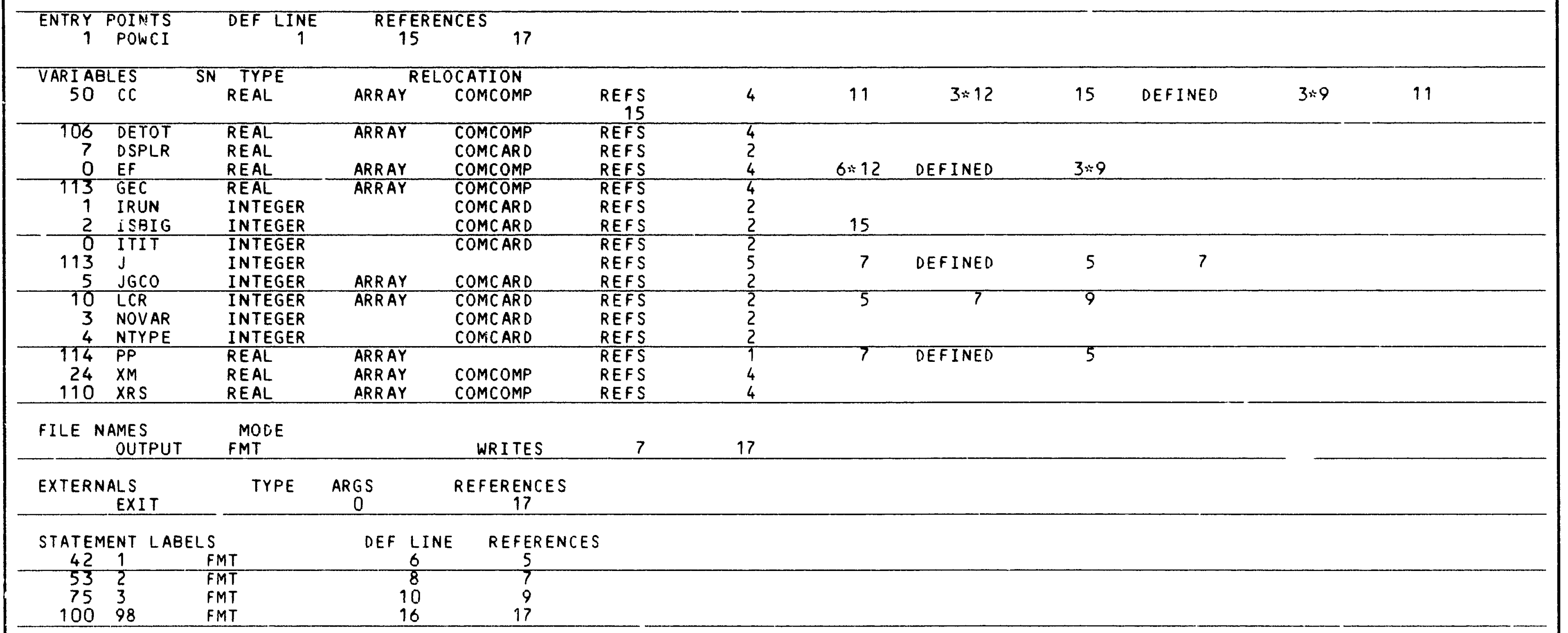


STATEMENT LABELS

3199

DEF LINE REFERENCES

COMMON BLOCKS LENGTH MEMBERS - BIAS NAME(LENGTH) COMCARD $\quad 125$

0 ITIT (1)

3 NOVAR (1)

7 DSPLR (1)

COMCOMP

95

7 EF (2O)

70 DETOT (2)

$\begin{array}{rll}1 & \text { IRUN } & (1) \\ 4 & \text { NTYPE } & (1) \\ 8 & \text { LCR } & (117) \\ 20 & \text { XM } & (20) \\ 72 & \text { XRS } & (3)\end{array}$

2 ISBIG (1)

5 JGCO (2)

$40 \mathrm{CC} \quad(30)$

75 GEC (20)

\section{STATISTICS}

$\begin{array}{llr}\text { PROGRAM LENGTH } & 130 \mathrm{~B} & 88 \\ \text { CM LABELED COMMON LENGTH } & 334 \mathrm{~B} & 220\end{array}$

60000B CM USED 
SUBROUTINE AMORT(CR, ML, LR, IND, CAP, COM)

C... CR COST, ML=YEAR OF PUKR CHASE (OR OVH), LR=LIFE, IND=0 IS OVH.

C... OVH ONLY ON I=3 ITEM (GENERATOR).

DIMENSION P(2O), ACC(3),AO(3), KM(3), S(3), G(3), TC(3), DP(3), CV (3)
COMMON /COMCARD' ITIT, IRUN, I SBIG, NOVAR, NTYPE, JGCO (2), DSPLR,

$1 \operatorname{LCR}(9,13)$

COMMON /COMCOMP/ EF(20), XM(10,2), CC(10,3), DETOT(2), XRS(3), GEC(20)

COMMON / COMAMOR/ LIFE, AMP, AMB

COMMON /COMWIND/W(8), I SWND

I=IND $\$$ IF (I.GT.O) GO TO $10 \$ C A P=0$.

COM $=A C O H * C R *($ SOMR $*$ \&L) \& RETURN

$10 \quad C=C V(I) * C R \$ K=\operatorname{MAXO}(1, \operatorname{MINO}(L R, K M(I))) \$ Z 1=1$

IF(K.LT.7)Z1=2.13. \$IF(K.LT.S)Z1=1.13. \$ IF(K.LT.3)Z1=0.

IF (ML.NE.0) GO TO $11 \$ C O M=C * A O(I)$

15

$C A P=C *(A C(I)-Z 1 * T C(I)-D P(I) * S(I) *(K-Z M F(R, 0 ., K)) / K /(K+1))$

RETURN

$11 C=C * S(I) *(G(I) * M L) \$ C O M=0$.

$C A P=C *(1 .-Z 1 * T C(I)-D P(I) *(K-Z M F(R, 0 ., K)) / K /(K+1)$.

RETURN

ENTRY AMORTI

ENTRY AMORTI
DECODE $(80,1, L C R(1,11))(P(J), J=1,14)$

20

FORMAT( A2, 13A6)

PRINT2, $(P(J), J=1,14), \operatorname{LCR}(9,11)$

2 FORMAT $\left.*\left(* A Z, 13^{\prime}(* / * A 6) * *\right) * A 1\right)$

25 DECODE (80,3,LCR(1,11))IP,IO,IB,R,RI,D,T,FOM, FPT, GO, GOM, GPT, GF

FORMAT $(2 X, 3(2 x, I 4), 10 F 6,0)$

IF R.LE.0..0.D.LT.0.0.0.GT.1..0.T.LT.0..0.T.GE.1.

1 .0.FOM.LT.O..O.FPT.LT.O.)GO TO 99

IF (D.NE.1..A.RI.LE.0.) GO TO $99 \$ R 1=R+1$.\$GOMR $=(1 .+G O M) / R 1$

$30 \quad \operatorname{DECODE}(80,4, L C R(1,12))(P(J), J=1,15)$

FORMAT (A2, 2A3,12AG)

PRINT5, $(P(J), j=1,15), \operatorname{LCR}(9,12)$

5 FORMAT $(* 2 * A 2 * / * A 3 * / * A 3,12(* / * A 6), *) * A 1)$

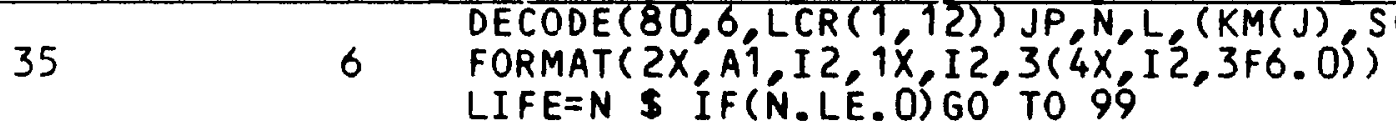

IF(D.NE.1..A. (L.LE.0.O.L.GT.N)) GO TO 99

DO $60 \mathrm{~J}=1,3$ \$ IF (JP.NE. IHP. A. (KM(J).LE.0.0.KM(J).GT.N)) G0T099

40

IF $(S(J) . L T .0 . .0 . S(J) . G E .1 . .0$.TC (J).LT.0..0.TC(J).GE.1.) GOTO99

60 CONTINUE \$ THT 0. S S IF (JP.NE. THP)THT $=T$

$A M B=Z M F(R, O, N) / Z M F(R, G O, N)$

$Z 1=D+(1 .-T): F P T \& Z M F(R, G P T, N)$

IF (D.NE.1.)Z1 $Z Z 1+(1 .-D) *((1 .-T) * Z M F(R, 0 ., L) / Z M F(R I, 0 ., L)-$

45

$1 \operatorname{T} \leftarrow \operatorname{MF}(R, R I, L) *(R I-1 . / Z M F(R I, 0, L)))$

$A C(1)=A C^{\prime}(2)=A C(3)=Z 1$ \& $D O 61, J=1,3 \& K M(J)=\operatorname{MAXO}(1 \mathrm{KM}(\mathrm{J}))$

$T C(J)=T C(J) / R 1 \$ A C(J)=A C(J)-S(J) *(((1,+G(J)) / R 1): * N)$

$D P(J)=2 . * T H T / R \& S(J)=1 .-S(J)$

61 CONTINUE

50

$A O(1)=A O(2)=A O(3)=(1,-T H T) * F O M * Z M F(R, G O M, N)$

$Z 1=((1 .+G 0)$ स $\pi(I B-I 0)) / Z M F(R, 0, N) \$ D 062 \mathrm{~J}=1,3$

$G(J)=1+G(J) \& C V(J)=Z 1 \div(G(J) \div 2(I O-I P))$

$62 G(J)=G(J) / R 1 \$ A C O H=C V(3) * G E C(3) \div(1 .-T H T) / R 1$

$A M P=Z 1 *((1 .+G F) \div \div(I 0-I P)) \div(1,-T H T) \div Z M F(R, G F, N)$

IF (I SWND.EQ.0)RETURN \$CC $(1,2)=C C(1,2) / 2$.

$55 \quad C C(1,1)=C C(1,1) * W(7) *((259.4 / W(3) /(W(5)+W(4)) * 3) * * C C(1,2))$

$C C(1,3)=W(7) \div C C(1,3) \$$ RETURN

98 FORMAT(* ERROR IN AM OR YR CARD *) 


\section{PRINT98 \$ CALL EXIT \$ END}

\section{SYMBOLIC REFERENCE MAP ( $R=3)$}

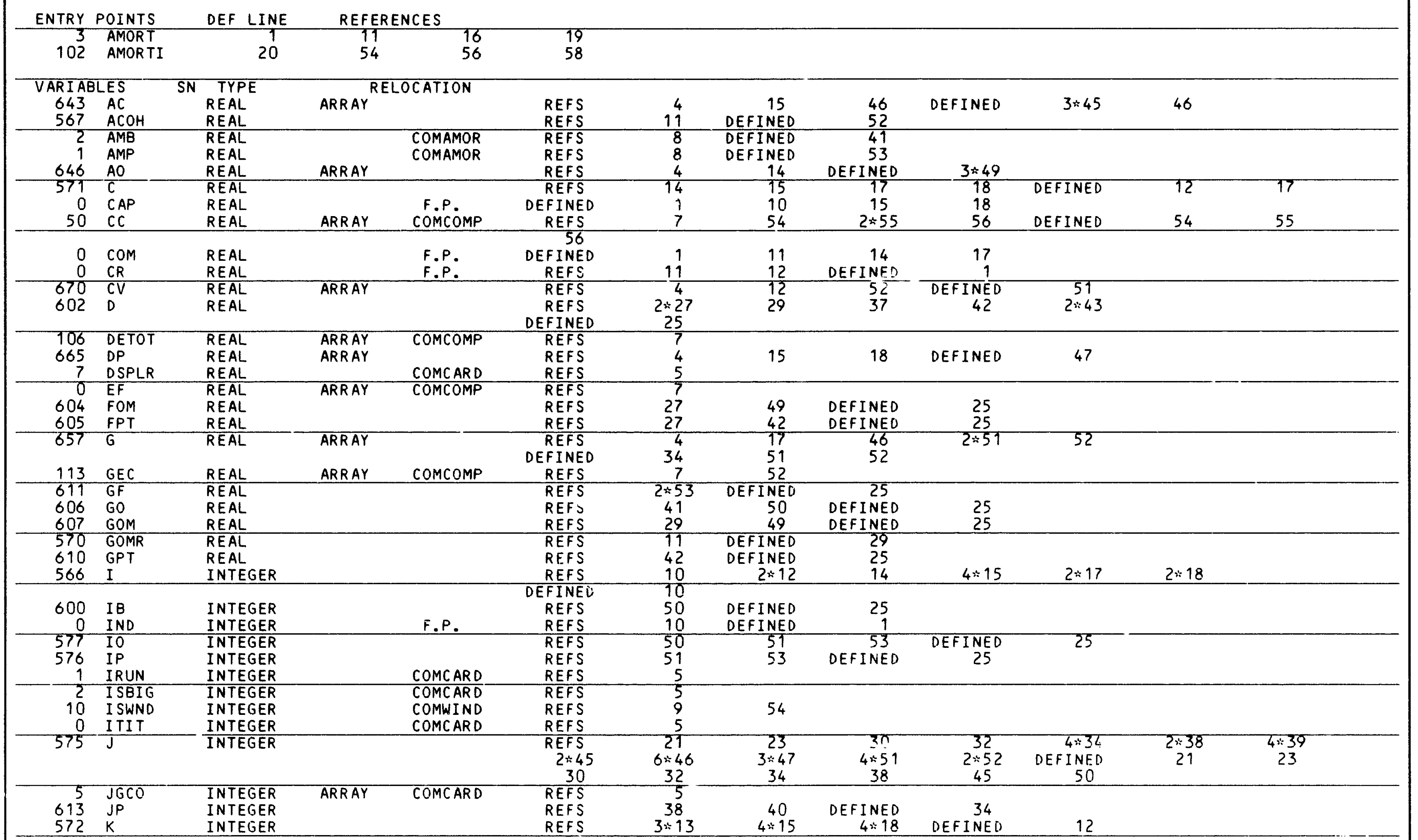




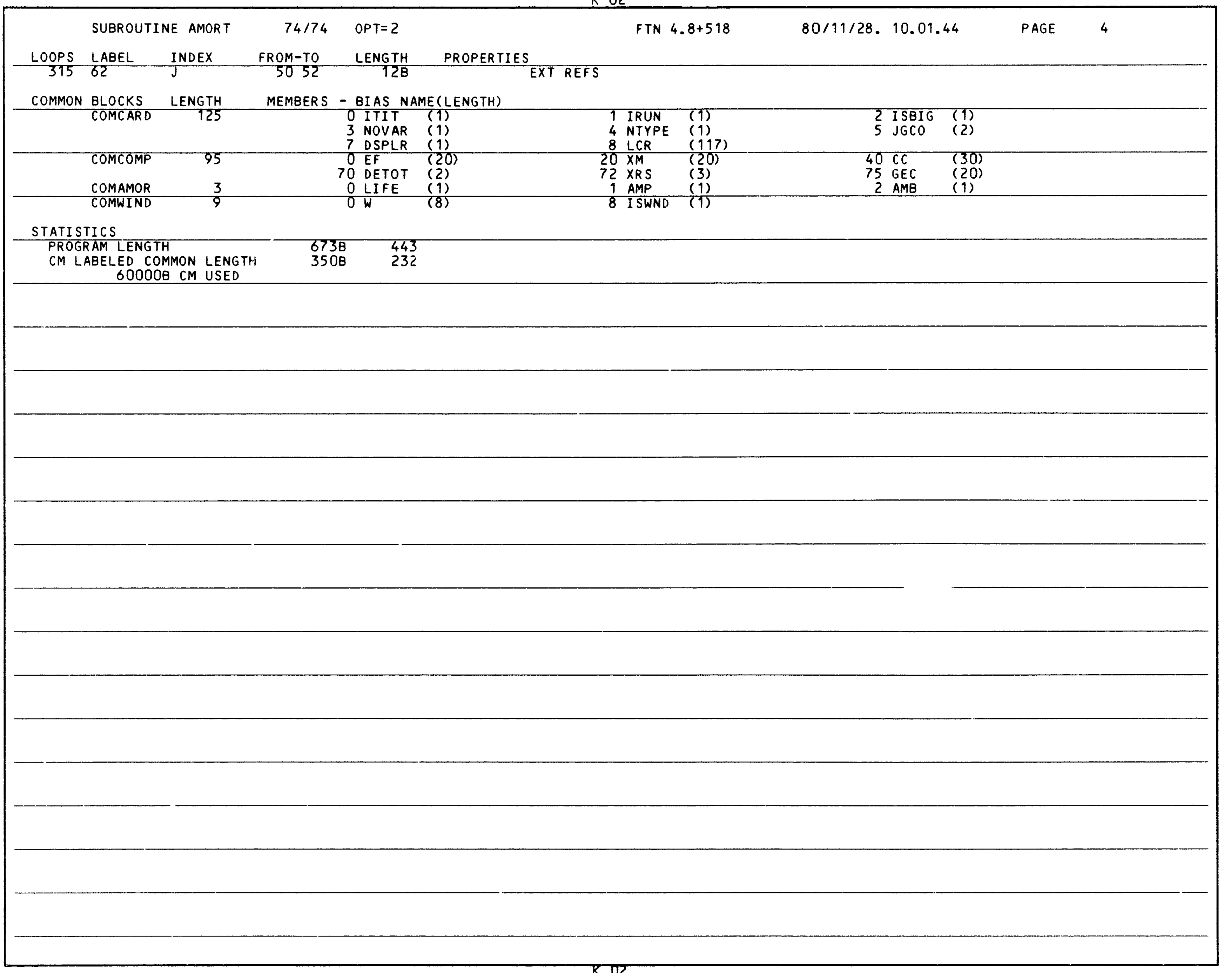




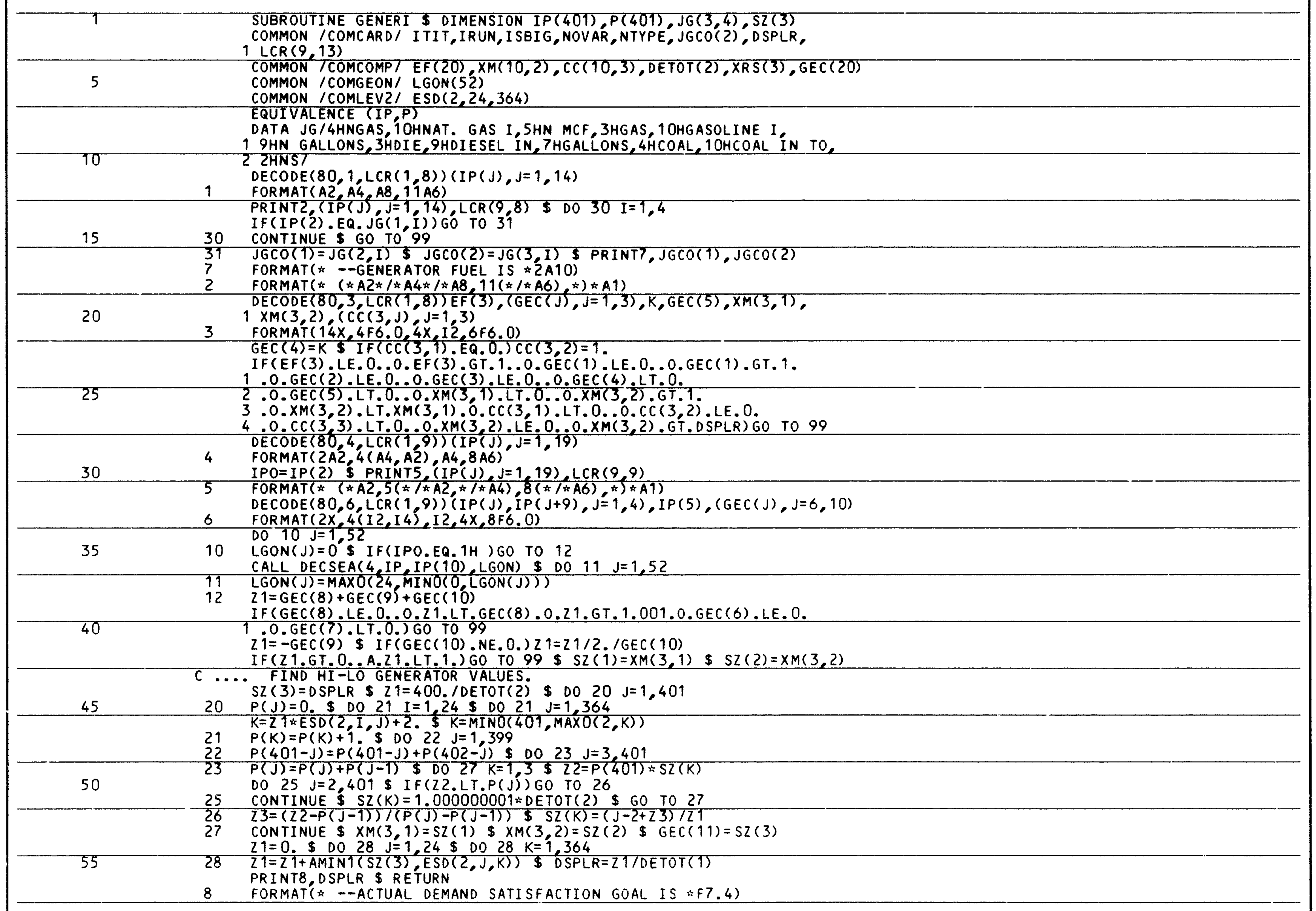


98 FORMAT(* GENERATOR (ARD ERROR*)

99 PRINT98 \$ CALL EXIT \$ END

\section{SYMBOLIC REFERENCE MAP $(R=3)$}

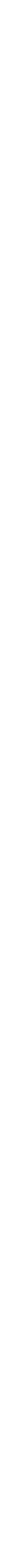




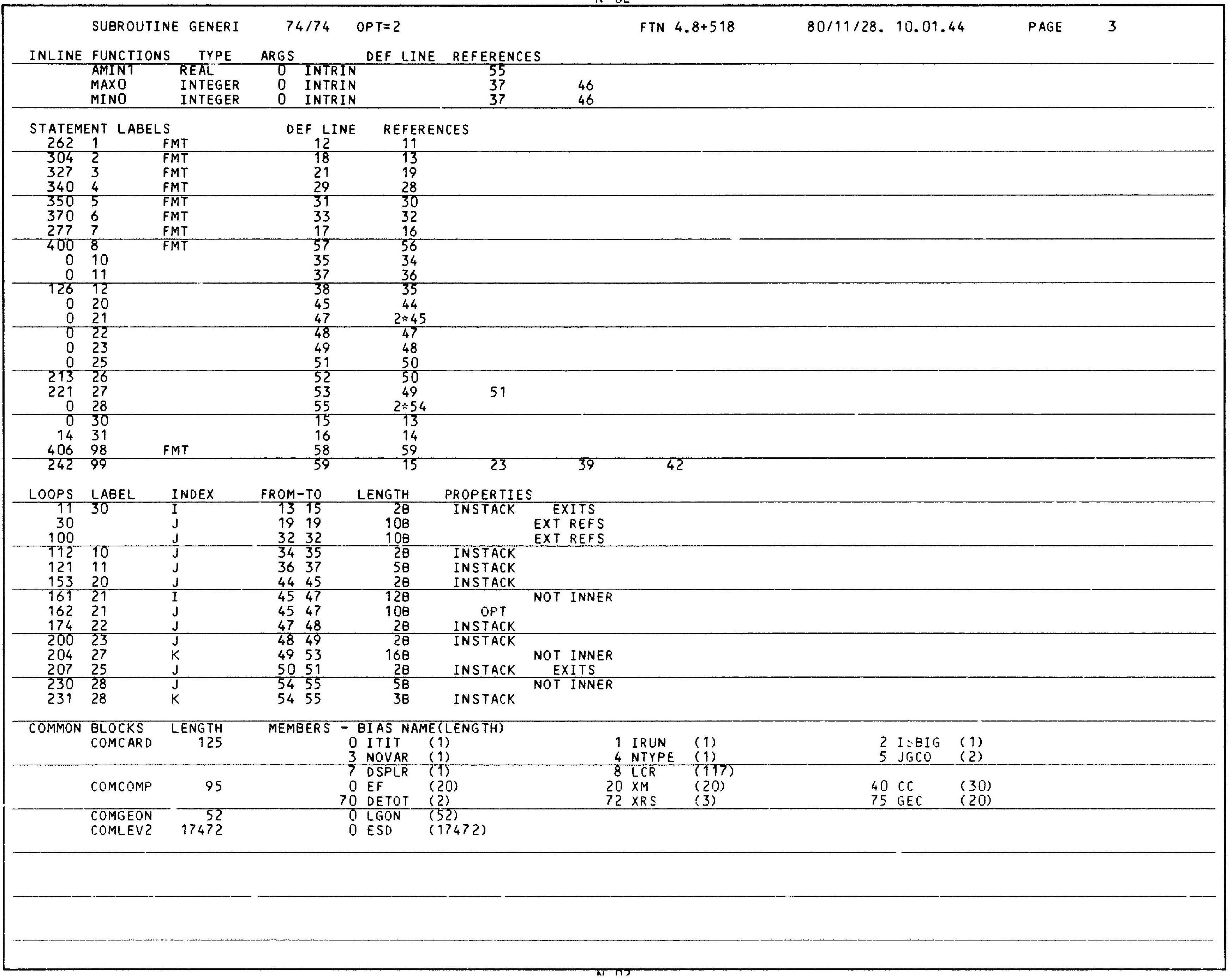




\section{EQUIV CLASSES LENGTH MEMBERS - BIAS NAME (LENGTH)

IP $401 \quad 0 \mathrm{P}$ (401)

STATISTICS

PROGRAM LENGTH

$2520 \mathrm{~B}$

7700

17744

$60000 B$ CM USED 


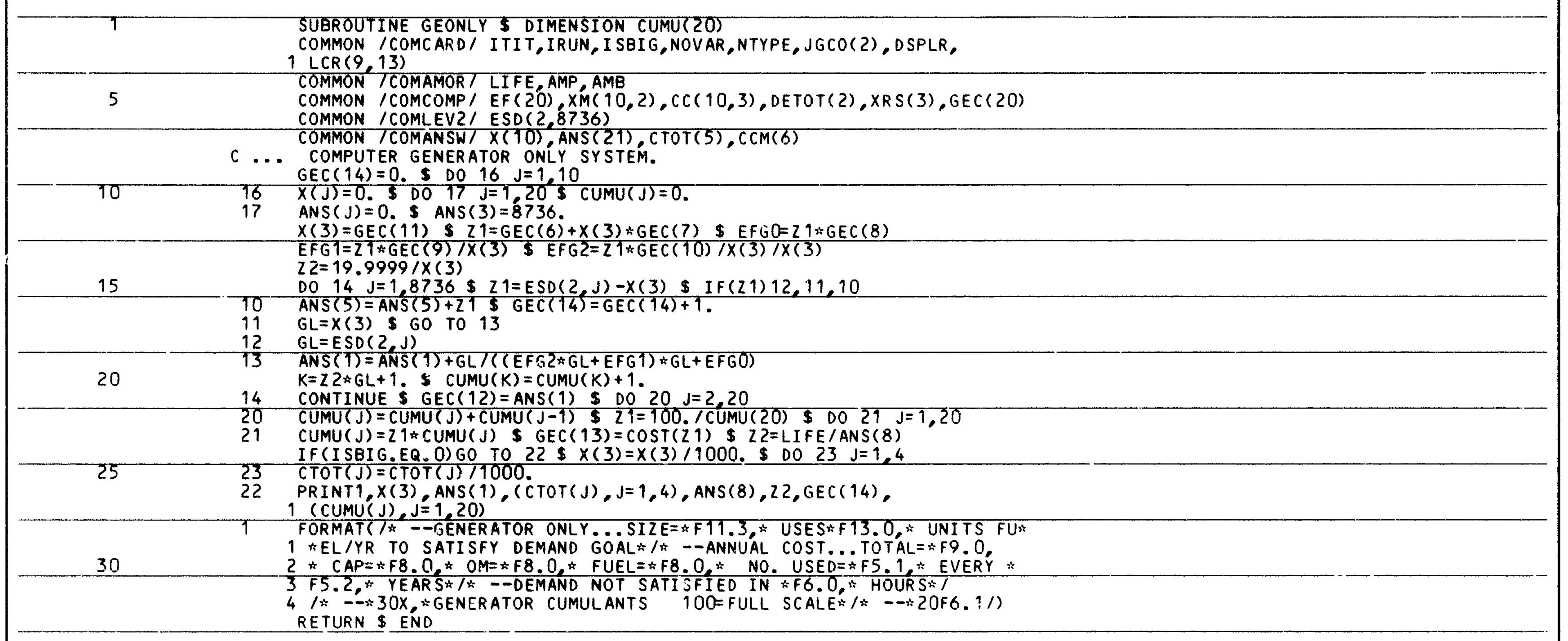

SYMBOLIC REFERENCE MAP $(R=3)$

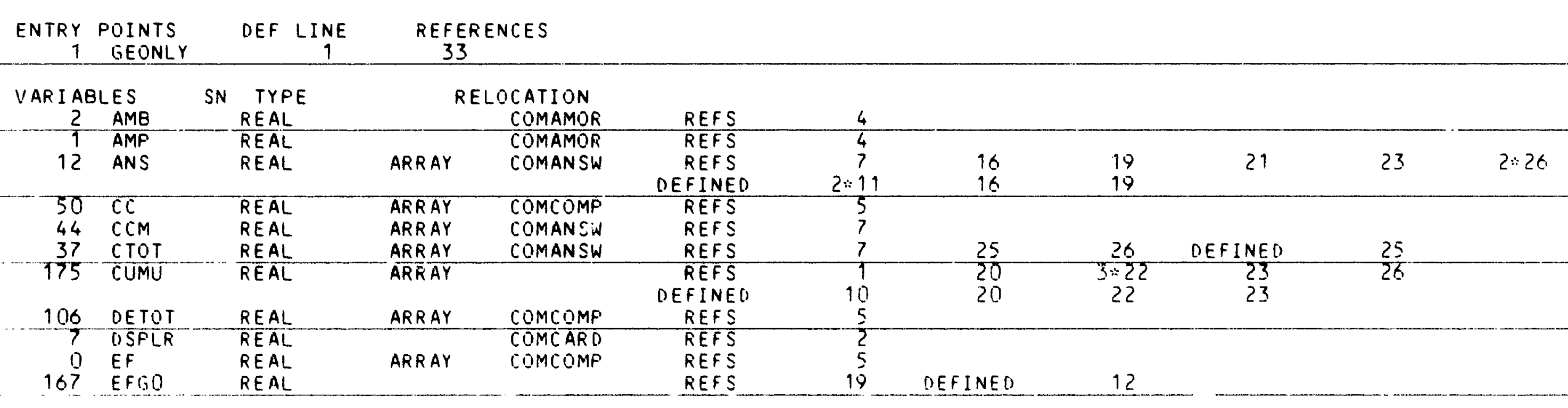


COMMON BLOCKS LENGTH MEMBERS - BIAS NAME (LENGTH)

\begin{tabular}{|c|c|c|c|}
\hline $\begin{array}{l}\text { COMAMOR } \\
\text { COMCOMP }\end{array}$ & $\begin{array}{r}3 \\
95\end{array}$ & $\begin{array}{l}7 \text { DSPLR } \\
0 \text { LIFE } \\
0 \text { EF }\end{array}$ & $\begin{array}{l}(1) \\
(1) \\
(20)\end{array}$ \\
\hline $\begin{array}{l}\text { COMLEVZ } \\
\text { COMANSW }\end{array}$ & $\begin{array}{r}17472 \\
42 \\
\end{array}$ & $\begin{array}{l}70 \text { DETOT } \\
0 \mathrm{ESD} \\
0 \mathrm{X}\end{array}$ & $\begin{array}{l}(2) \\
(17472) \\
(10)\end{array}$ \\
\hline
\end{tabular}

COMANSW

42

$\begin{array}{rll}8 & \text { LCR } & (117) \\ 1 & \text { AMP } & (1) \\ 20 & \text { XM } & (20) \\ 72 & \text { XRS } & (3) \\ 10 & \text { ANS } & (21)\end{array}$

2 AMB (1)

$\begin{array}{ll}40 C C & (30) \\ 75 & \text { CEC }\end{array}$

31 CTOT (5)

STATISTICS

PROGRAM LENGTH 221B 145

CM LABELED COMMON LENGTH $425118 \quad 17737$

$60000 B$ CM USED 
1 FUNCTION COST(7.222Z)

C $\ldots$ C CTOT $(1)=$ TOTAL COST, $2=$ CAP COST, $3=0 M$ COST, $4=F U E L$ COST

C.... 5=EXCESS UNSATISFÍIED DEMAND.

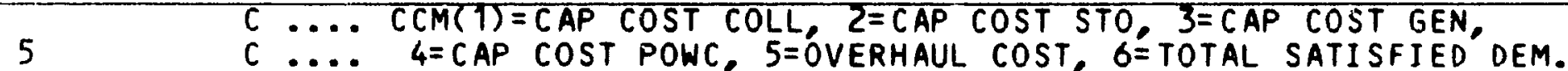

COMMON /COMCARD/ ITIT, IRUN, I SBIG, NÓVAR, NTYPE, JGCO(2) DSPLR,

1 LCR $(9,13)$

COMMON / COMCOMP/ EF(20),XM(10,2), CC(10,3), DETOT(2),XRS(3), GEC(20)

10 COMMON /COMAMOR/LIFE, AMP AMB

$\operatorname{CCM}(6)=0$. \$ DO $10 \mathrm{~J}=1,5$

$10 \operatorname{CTOT}(J)=\operatorname{CCM}(J)=0 . \$ \operatorname{CTOT}(4)=\operatorname{ANS}(1) * \operatorname{CEC}(2) * \operatorname{AMP}$

IF $(X(1)$. LE. O.) GO TO $11 \$ Z 1=C C(1,1) * X(1) * C C(1,2))+C C(1,3)$

15

CALL AMORT $(21,0, L$ IFE, $1, C C M(1), C T O T(3))$

11 IF $(X(4)$. LE. O. S GO TO 12

$Z T=C C(4,1) *((x(4) * E F(4)) * * C C(4,2))+C C(4,3)$

CALL AMORT $(21,0$, LIFE, 1, CCM(4),Z2) \& CTOT $(3)=\operatorname{CTOT}(3)+22$

C.... BATTERY COST

ANS $(7)=0 . \$$ IF $(X(2) \cdot$ LE. 0.) G0 TO 20 \& $P=$ ANS(2) *LIFE/XRS(3)

20

$Z 1=C C(2,1) *((X(2) * E F(2)) * C C(2,2))+C C(2,3) \$$ ANS $(1 ;:: 1$.

CALL AMORT(Z1, $0, L I F E, 2, C C M(2), Z 2)$ \& CTOT $(3)=C T O T(3)+2 i$

DO $14 \quad M=M 1, M 2 \$ 23=0$. \$ $24=M$ \$ XNR=LIFE $/ 24 \$ 28=21$

NR $=$ MAXO(1, INT $(X N R)) \$ D O 13 \mathrm{~J}=1, M$

25 CALL AMORT $(28, I N T(J-1) * X N R), N R, 2,24,25) \$ 28=21-C C(2,3)$

$13 \quad Z 3=23+Z 4$ \& IF $($ M.EQ.M1) $Z 6=Z 3$

$23=23+24 \$$ IF M.EQ.M1) $26=23$
CONTINUE $\$ C C M(2)=(23-26) *(P-M 1)+26$

CONTINUE $\$$ CCM(2)

C.. GENERATOR COST
20 ANS $(8)=$ ANS $(9)=0$. S IF $(X(3)$.LE.0.) GO TO 21

30

$P=A M A X 1(1$ ANS (3)*LIFE/GEC (5); $;$ ANS $(8)=P \quad$ ANS $(9)=P * G E C(4)$

$Z 1=C C(3,1) *(X(3) * C C(3,2))+C C(3,3) \frac{1}{5}$ NOV $=G E C(4)$

CALL AMÓRT $(21,0$, LIFE, $\}, 22,23) \$$ CTOT $(3)=$ CTOT $(3)+23$

$M 1=P$ \$ $Z 2=M 1 \$ X N R=L I F E / Z 2 \$ N R=M A X O(1, I N T(X N R))$

35 CALL AMORT $(28$, INT(TM), NR, 3, Z2, Z $\$) \$ 24=24+22 \$ 28=21-C C(3,3)$

$28=21 \$ 24=26=T M=0$, $\$ 0016 M=1 \% 1$

IF (NOV.LE. O)GO TO $16 \$$ DO $15 \mathrm{~J}=1$ NOV $\$ T Q=T M+J * X N R /(N O V+1)$

15 CONTINUE

$16 \quad T M=T M+X N R \$ 25=26 \$ 23=24 \$$ IF (P.LE 1.)GO TO 19

$40 \quad 16 \quad M M=T M+X N R \$ 25=26 \$ 23=24 \$$ IF $\$ P . L E .1 .960$ TO 19

$28=21$ \& $23=25=T M=0$. \$ DO 18 M $=1, M 2$

CALL AMORT $(28$, INT $(T M), N R, 3,22,2\}) \$ 23=23+22 \$ 28=21-\operatorname{CC}(3,3)$

IF(NOV.LE.0)GO TO $18 \$$ DO $17 \mathrm{~J}=1$ NOV $\$ T Q=T M+J: X N R /(N O V+1)$

45

CALL AMORT( 21, INT(TQ), NR, $0,22,27)^{\prime} \$ 25=25+27$

17 CONTINUE

$18 \quad T M=T M+X N R$

$19 \quad C C M(3)=(23-24) *(P-M 1)+Z 4 \$ C C M(5)=(25-Z 6) *(P-M 1)+26$

$21 \quad$ CTOT $(3)=$ CTOT $(3)+C C M(5)$ \& CTOT $(2)=C C M(1)+C C M(2)+C C M(3)+\operatorname{CCM}(4)$

50

CTOT $(1)=$ CTOT $(2)+$ CTOT $(3)+$ CTOT $(4)$

$C C M(6)=1 .-A N S(5) / D E T O T(1)$

CTOT $(5)=1$ E6:DETOT $(1): A M A X 1(0$. DSPLR $-C C M(6))$

$\operatorname{COST}=\overline{C T O T}(1)+\mathrm{CTOT}(5)$ \$ RETURN $\$$ END 
SYMBOLIC REFERENCE MAP ( $R=3)$

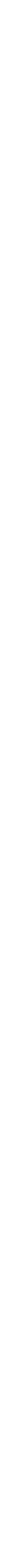




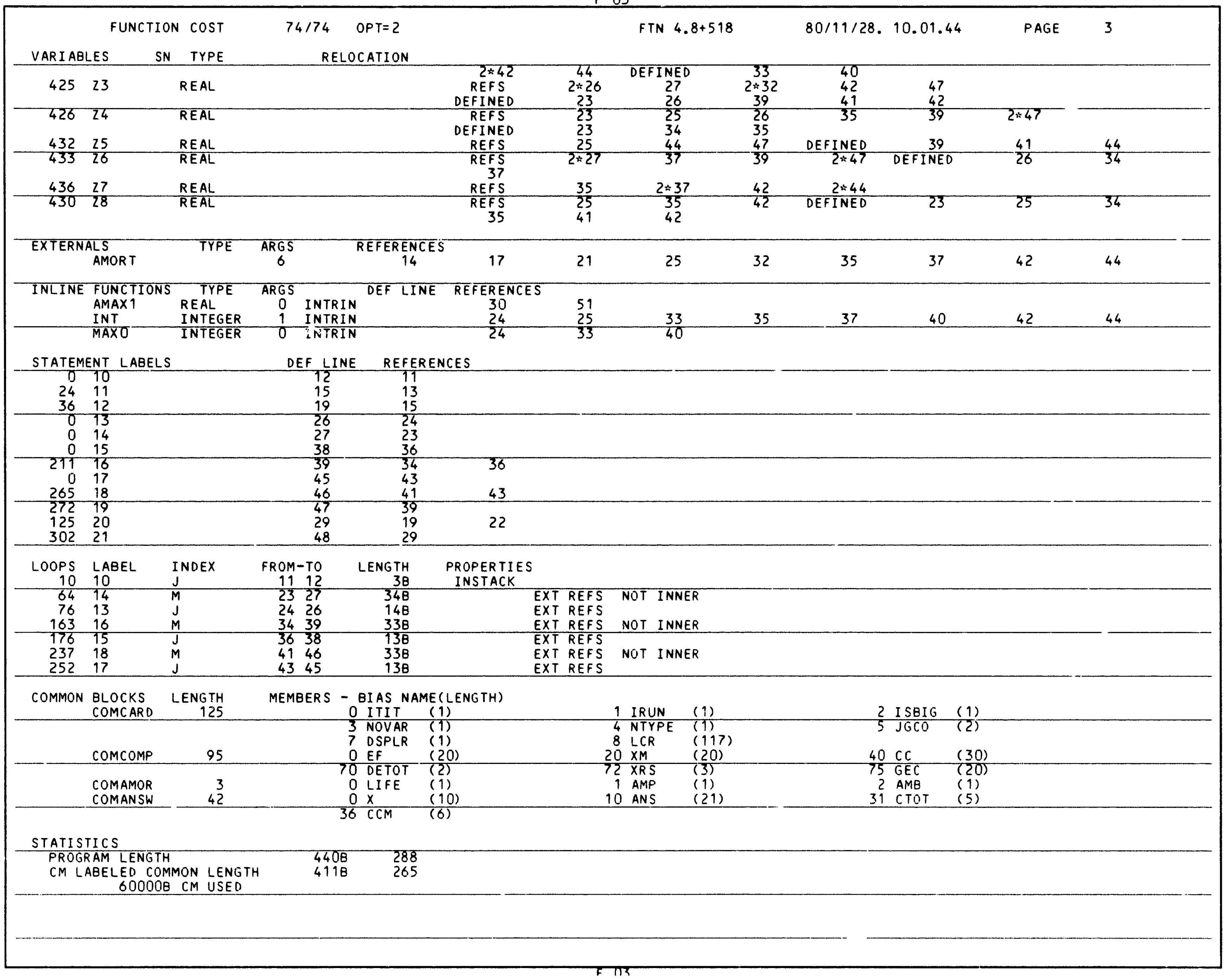




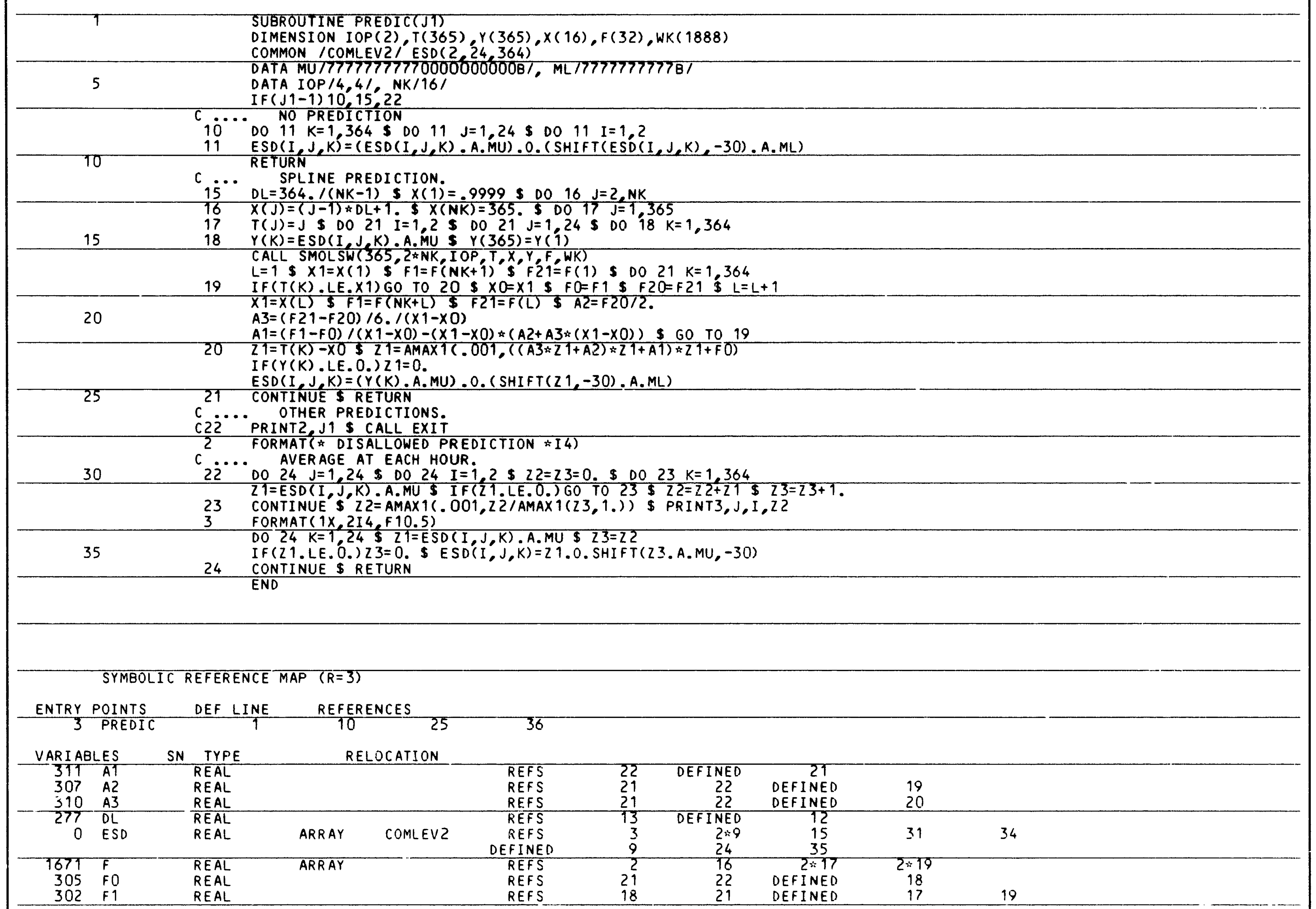




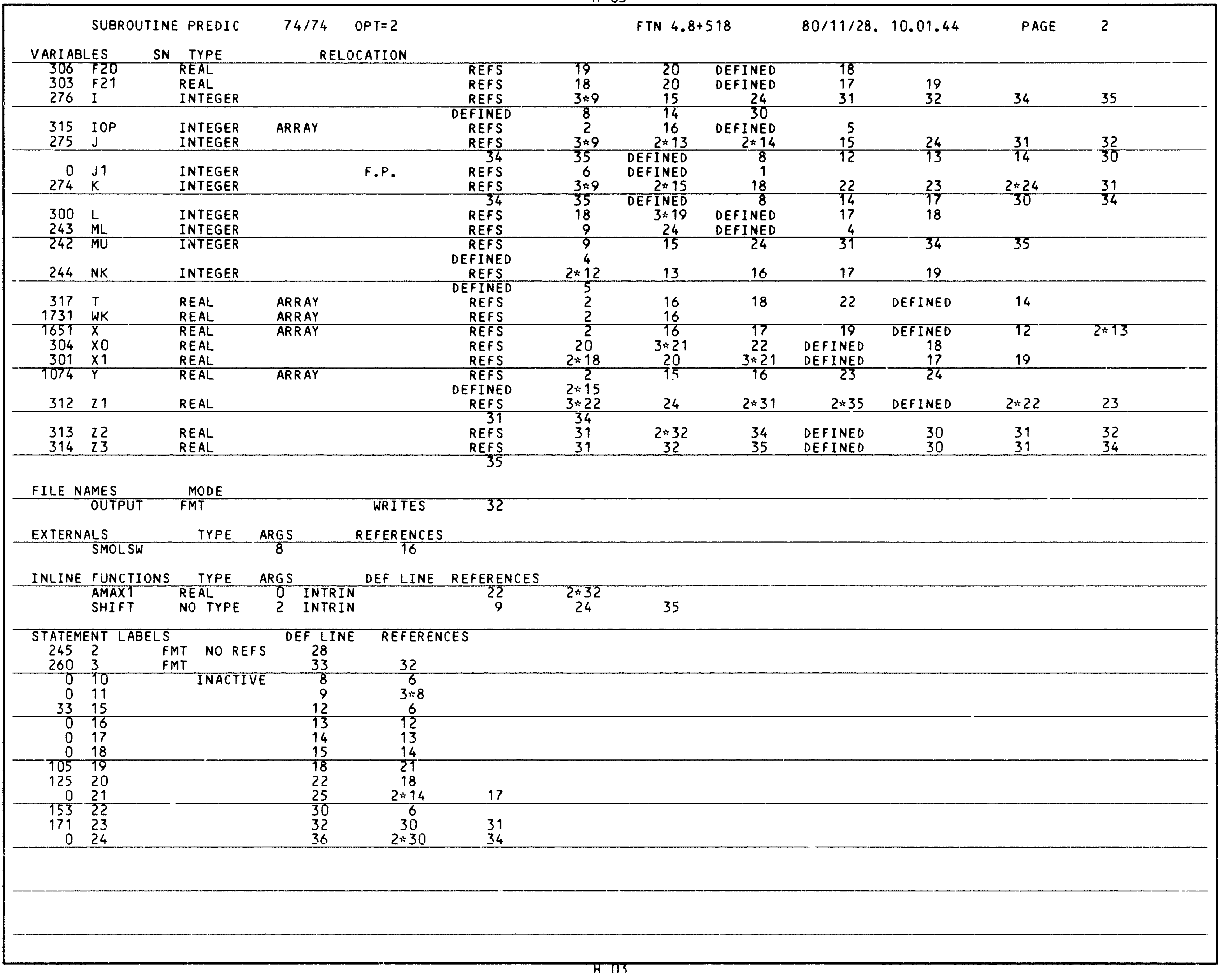




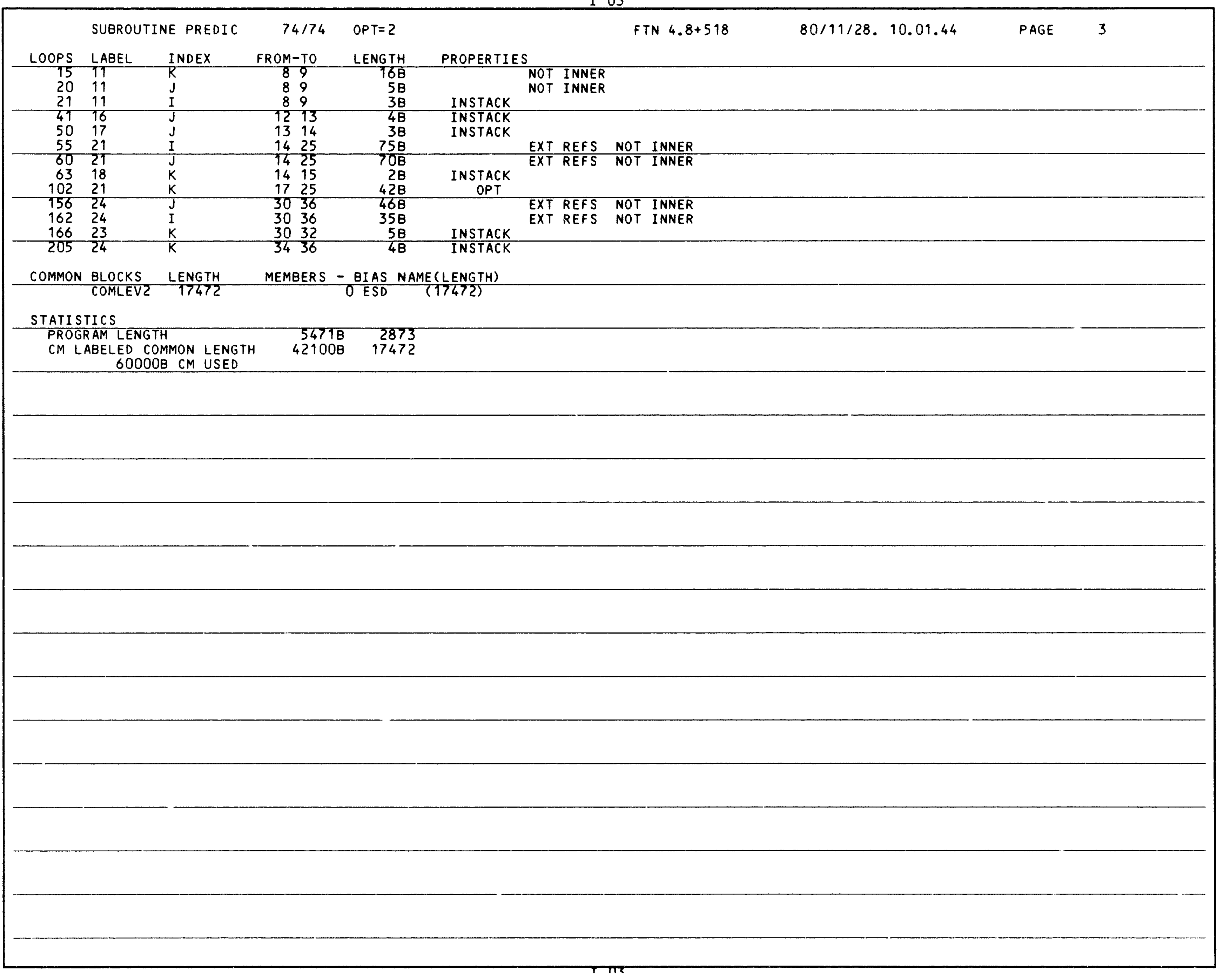




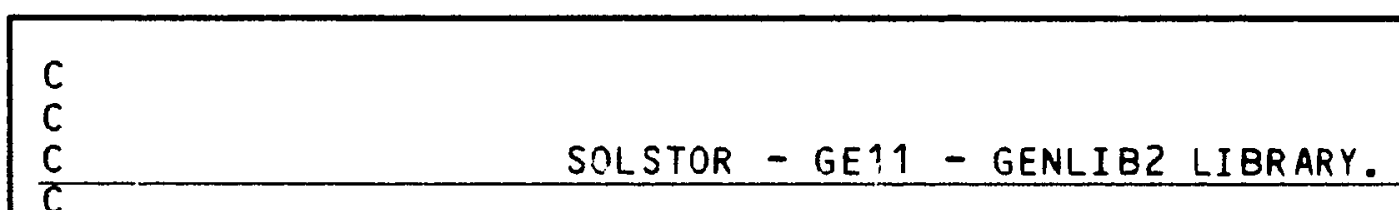




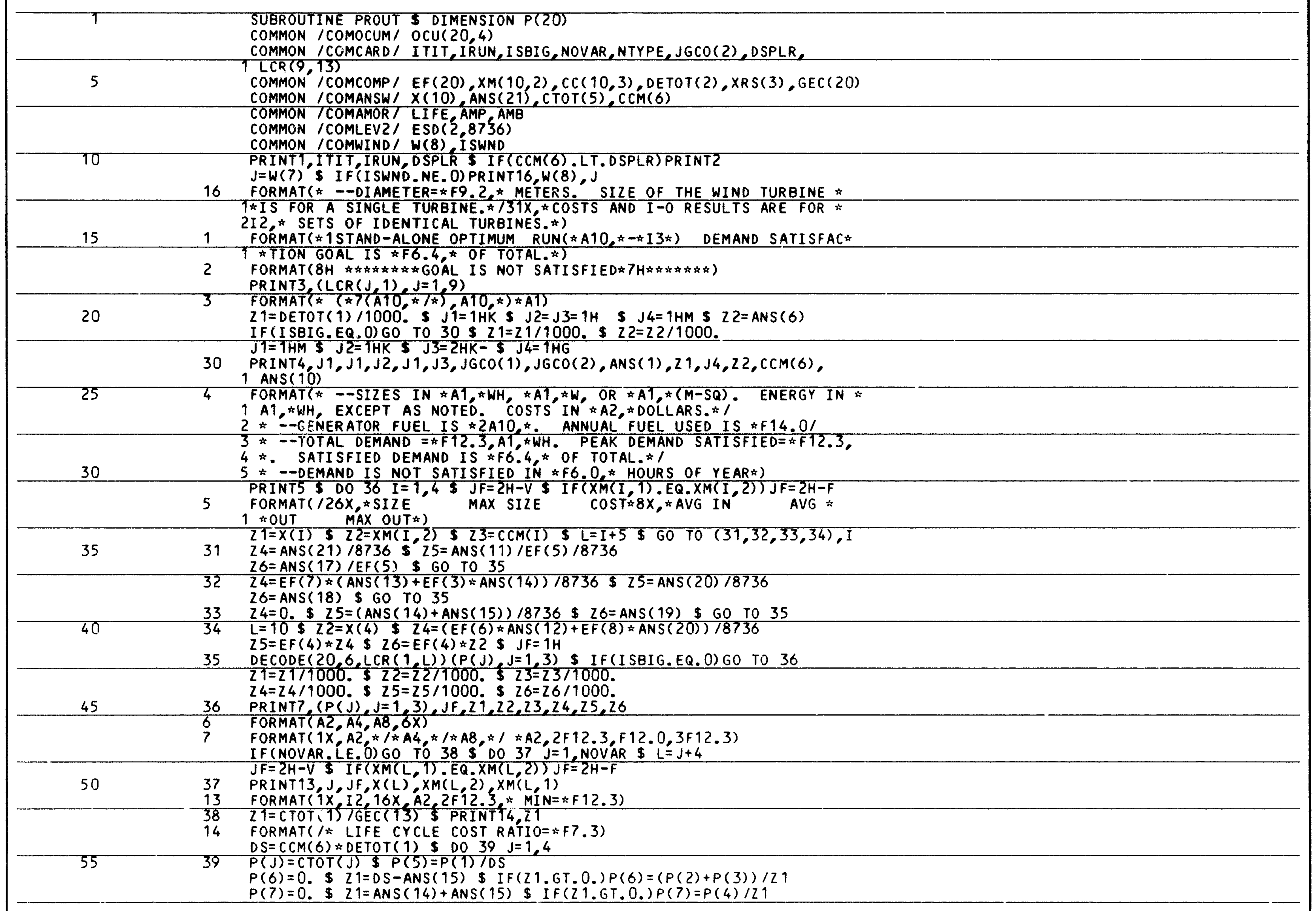




\section{$P(8)=P(5) * A M B \quad P(8)=P(6) * A M B$ \& $P(10)=P(7) * A M B$}

IF(ISBIG.EQ.0)GO TO $41 \$ D O 40 \mathrm{~J}=1,4$

60

$40 \quad P(J)=P(J) / 1000$.

41 PRINT8, $(P(J), J=1,10) \$ J 1=1 H M$ \$ $Z 1=1000$.

8 FORMAT $(19 X *$ *TOTAL*5X, * CAPITAL*8X, OM*8X *FUEL*/* ANNUAL COST *

$14 \mathrm{~F} 12.0 / *$ LEVEL COST *2F12.3, $12 X, F 12.3 / *$ INIT LEV COST *

$2 \frac{4 F 12.014}{2 F 12.3,12 X, F 12.3)}$

$65 \quad P(1)=A N S(11) \& P(2)=A N S(12) \& P(3)=A N S(13) \& P(4)=P(1)-P(2)-P(3)$

$P(5)=P(6)=A N S(20) \& P(7)=P(12)=0$. \& $P(8)=(1 .-E F(2)) * A N S(16)$

$P(9)=A N S(14)+A N S(15) \& P(10)=A N S(15) \$ P(11)=A N S(14)$

IF(ISBIG.EQ.0)GO TO 43 \& $1=1 \mathrm{HG} \$ 21=1000000$. \$ DO $42 \mathrm{~J}=1,12$

$42 \quad P(J)=P(J) / 21$

$70 \quad 43$ PRINT9,J1, (P(J),J=1,12)

FORMAT $/ *$ TOTAL $-\triangle A 1$, *WH NET OUTPUT TO DEMAND TO STORE *

$1 *$ WASTE* $/ *$ COLLECTOR $\# 4 F 12.1 /$ STORAGE $\approx 4 F 12.1 \%$

$2 *$ GENERATOR *4FT2.1)

75

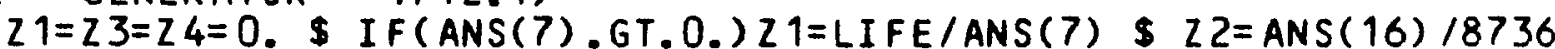

DO $15 \mathrm{~J}=1.8736$ \& $25=E S D(2, \mathrm{~J})$. A. $777777777770000000000 \mathrm{~B}$

$15 \quad 24=Z 4+A M I N 1(25, X(3)) \$ Z 4=24 / D E T O T(1)$

IF (ANS( 8 ).GT.0.) Z3=LIFE/ANS( 8 ) \$ I ( I SBIG. NE. 0) $Z 2=22 / 1000$

PRINT10, ANS(7), $Z 1$, ANS ( 2$), Z 2$, ANS (8), $Z 3$, ANS ( 9$),$ ANS ( 4$),$ ANS ( 3$), 24$

10 FORMAT( /12X,*NO. PURCH INTERVAL(YR) STO CYC/YR AVG LEVEL $\% 1$

1 * STORAGE *F9.2,F13.2,2F12.2/36X * NO. OVH NO. STARTS *

3 * HOURS/YR DSIZE* * GENERATOR *F9 $\{$ F13,2,F12.1,2F12.0,F7.4)

$Z 1=100 *(D S-A N S(15)$-ANS(14)) IDS $\$ Z Z=100-Z 1 \$ Z \xi=0$

IF (ANS ( 21$)$. GT. 0.) Z $3=21 * D S / A N S(21)$

$25=100$. *EF(4)*EF(8)*ANS(20)/DS

$85 \quad 24=100 * 21 .-$ ANS $(15) / 0 S)-25$

$26=100 * E F(8) * A N S(20) /($ ANS $(13)+$ ANS $(14))$

PRINT11,21,22,23,24,25,26

90 PRINT12, ( $\left.\left(O O_{C U}(I, J), I=1,20\right), J=1,2\right)$

PINT12, $((\operatorname{OCU}(I, J), I=1,20), J=1,2) \quad$ PDS AES* $11 X, 6 F 7.2$

FORMAT( $120 \mathrm{X}$ *CUMULANTS $100=$ FULL SCALE* $/ *$ ST $* 20 \mathrm{Fo} .1 \%$ GE *

P.ETURN \$ END

SYMBOLIC REFERENCE MAP $(R=3)$

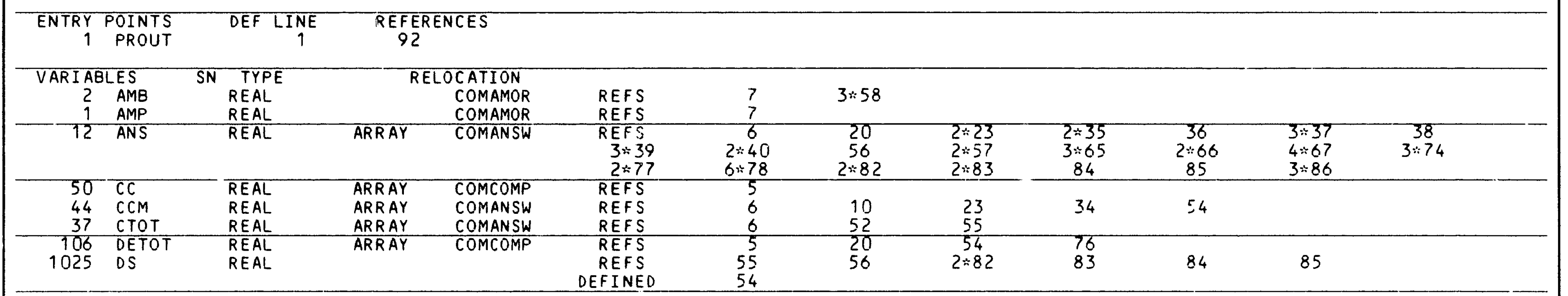




\begin{tabular}{|c|c|c|c|c|c|c|c|c|c|c|c|c|}
\hline & SUBROUTINE & $=$ PROUT & $74 / 74$ & $O P T=2$ & & & FTN $4.8+$ & 518 & $80 / 11 / 28$. & 10.01 .44 & PAGE & 3 \\
\hline VARIABL & LES & TYPE & RELO & OCATION & & & & & & & & \\
\hline $\begin{array}{l}7 \\
0\end{array}$ & $\begin{array}{l}\text { DSPLR } \\
\text { EF }\end{array}$ & $\begin{array}{l}\text { REAL } \\
\text { REAL }\end{array}$ & ARRAY & $\begin{array}{l}\text { COMCARD } \\
\text { COMCOMP }\end{array}$ & $\begin{array}{l}\text { REFS } \\
\text { REFS } \\
2 \approx 84\end{array}$ & $\begin{array}{r}3 \\
5 \\
86\end{array}$ & $\begin{array}{c}2 * 10 \\
35\end{array}$ & 36 & $2 * 37$ & $2 * 40$ & $2 \star 41$ & 66 \\
\hline $\begin{array}{r}0 \\
113 \\
1016\end{array}$ & $\begin{array}{l}\text { ESD } \\
\text { GEC } \\
\text { I }\end{array}$ & $\begin{array}{l}\text { REAL } \\
\text { REAL } \\
\text { INTEGER }\end{array}$ & $\begin{array}{l}\text { ARRAY } \\
\text { ARRAY }\end{array}$ & $\begin{array}{l}\text { COMLEV2 } \\
\text { COMCOMP }\end{array}$ & $\begin{array}{l}\text { REFS } \\
\text { REFS } \\
\text { REFS }\end{array}$ & $\begin{array}{c}8 \\
5 \\
2 \times 31\end{array}$ & $\begin{array}{c}75 \\
52 \\
5 \div 34\end{array}$ & 89 & DEFINED & 31 & 89 & \\
\hline $\begin{array}{r}1 \\
2 \\
10\end{array}$ & $\begin{array}{l}\text { IRUN } \\
\text { I SBIG } \\
\text { I SWND }\end{array}$ & $\begin{array}{l}\text { INTEGER } \\
\text { INTEGER } \\
\text { INTEGER }\end{array}$ & & $\begin{array}{l}\text { COMCARD } \\
\text { COMCARD } \\
\text { COMWIND }\end{array}$ & $\begin{array}{l}\text { REFS } \\
\text { REFS } \\
\text { REFS }\end{array}$ & $\begin{array}{l}3 \\
3 \\
9\end{array}$ & $\begin{array}{l}10 \\
21 \\
11\end{array}$ & 42 & 59 & 68 & 77 & \\
\hline $\begin{array}{r}0 \\
1007\end{array}$ & ITIT & $\begin{array}{l}\text { INTEGER } \\
\text { INTEGER }\end{array}$ & & COMCARD & $\begin{array}{l}\text { REFS } \\
\text { REFS } \\
2 \approx 60\end{array}$ & $\begin{array}{r}3 \\
11 \\
61\end{array}$ & $\begin{array}{c}10 \\
18 \\
2 * 69\end{array}$ & $\begin{array}{l}42 \\
70\end{array}$ & $\begin{array}{l}45 \\
75\end{array}$ & $\begin{array}{l}48 \\
89\end{array}$ & 50 & $2: 55$ \\
\hline 1017 & $J F$ & INTEGER & & & $\begin{array}{c}\text { DEFINED } \\
61 \\
\text { REFS }\end{array}$ & $\begin{array}{l}11 \\
68 \\
45\end{array}$ & $\begin{array}{l}18 \\
70 \\
50\end{array}$ & $\begin{array}{r}42 \\
75 \\
\text { DEFINED }\end{array}$ & $\begin{array}{c}45 \\
89 \\
2 \times 31\end{array}$ & $\begin{array}{l}\frac{1}{48} \\
41\end{array}$ & $\begin{array}{c}54 \\
2 \times 49\end{array}$ & 59 \\
\hline $\begin{array}{r}5 \\
1011 \\
1012\end{array}$ & $\begin{array}{l}\mathrm{JGCO} \\
\mathrm{J1} \\
\mathrm{J} 2\end{array}$ & $\begin{array}{l}\text { INTEGER } \\
\text { INTEGER } \\
\text { INTEGER }\end{array}$ & ARR AY & COMCARD & $\begin{array}{l}\text { REFS } \\
\text { REFS } \\
\text { REFS }\end{array}$ & $\begin{array}{c}3 \\
3 * 23 \\
23\end{array}$ & $\begin{array}{c}2 \$ 23 \\
70 \\
\text { DEFINED }\end{array}$ & $\begin{array}{c}\text { DEFINED } \\
20\end{array}$ & $\begin{array}{l}20 \\
22\end{array}$ & 22 & 61 & 68 \\
\hline $\begin{array}{l}1013 \\
1014 \\
1021\end{array}$ & $\begin{array}{l}\sqrt{3} \\
\sqrt{3} \\
\end{array}$ & $\begin{array}{l}\text { INTEGER } \\
\text { INTEGER } \\
\text { INTEGER }\end{array}$ & & & $\begin{array}{l}\text { REFS } \\
\text { REFS } \\
\text { REFS }\end{array}$ & $\begin{array}{l}23 \\
23 \\
42\end{array}$ & $\begin{array}{l}\text { DEFINED } \\
\text { DEFINED } \\
2 * 49\end{array}$ & $\begin{array}{c}20 \\
20 \\
3 \times 50\end{array}$ & $\begin{array}{r}22 \\
22 \\
\text { DEFINED }\end{array}$ & 34 & 40 & 48 \\
\hline $\begin{array}{r}10 \\
0 \\
3 \\
\end{array}$ & $\begin{array}{l}\text { LCR } \\
\text { LIFE } \\
\text { NOVAR }\end{array}$ & $\begin{array}{l}\text { INTEGER } \\
\text { INTEGER } \\
\text { INTEGER }\end{array}$ & ARRAY & $\begin{array}{l}\text { COMCARD } \\
\text { COMAMOR } \\
\text { COMCARD }\end{array}$ & $\begin{array}{l}\text { MERS } \\
\text { REFS } \\
\text { REFS } \\
\text { REFS }\end{array}$ & $\begin{array}{r}46 \\
3 \\
7 \\
3\end{array}$ & $\begin{array}{c}18 \\
74 \\
2 * 48\end{array}$ & $\begin{array}{c}320 \\
42 \\
77\end{array}$ & & & & \\
\hline $\begin{array}{r}4 \\
0 \\
1026\end{array}$ & $\begin{array}{l}\text { NTYPE } \\
\text { OCU } \\
P\end{array}$ & $\begin{array}{l}\text { INTEGER } \\
\text { REAL } \\
\text { REAL }\end{array}$ & $\begin{array}{l}\text { ARR AY } \\
\text { ARR AY }\end{array}$ & $\begin{array}{l}\text { COMCARD } \\
\text { COMOCUM }\end{array}$ & $\begin{array}{l}\text { REFS } \\
\text { REFS } \\
\text { REFS }\end{array}$ & $\begin{array}{l}3 \\
2 \\
1\end{array}$ & $\begin{array}{l}89 \\
45\end{array}$ & 55 & $2 * 56$ & 57 & $3 * 58$ & 60 \\
\hline 0 & $w$ & REAL & ARR AY & COMWIND & $\begin{array}{c}2 * 57 \\
\text { REFS }\end{array}$ & $\begin{array}{c}3 \div 65 \\
3 \div 58 \\
9\end{array}$ & $\begin{array}{c}69 \\
60 \\
2 * 11\end{array}$ & $\begin{array}{c}70 \\
4 \div 65\end{array}$ & $\begin{array}{r}\text { DEFINED } \\
5 \approx 66\end{array}$ & $\begin{array}{c}42 \\
3: 67\end{array}$ & $\begin{array}{c}2 * 55 \\
69\end{array}$ & $2 \div 56$ \\
\hline $\begin{array}{r}0 \\
24 \\
110\end{array}$ & $\begin{array}{l}x \\
X M \\
X R S\end{array}$ & $\begin{array}{l}\text { REAL } \\
\text { REAL } \\
\text { REAL }\end{array}$ & $\begin{array}{l}\text { ARR AY } \\
\text { ARR AY } \\
\text { ARR AY }\end{array}$ & $\begin{array}{l}\text { COMANSW } \\
\text { COMCOMP } \\
\text { COMCOMPP }\end{array}$ & $\begin{array}{l}\text { REFS } \\
\text { REFS } \\
\text { REFS }\end{array}$ & $\begin{array}{l}6 \\
5 \\
5\end{array}$ & $\begin{array}{c}34 \\
2 \div 31\end{array}$ & $\begin{array}{l}40 \\
34\end{array}$ & $\begin{array}{c}50 \\
2 * 49\end{array}$ & $\begin{array}{c}76 \\
2 * 50\end{array}$ & & \\
\hline 1010 & 21 & $\frac{M E A L}{R E A L}$ & & & $\begin{array}{r}\text { REFS } \\
69 \\
34 \\
\end{array}$ & $\begin{array}{l}21 \\
78 \\
43 \\
\end{array}$ & $\begin{array}{l}23 \\
82 \\
52 \\
\end{array}$ & $\begin{array}{l}43 \\
83 \\
56 \\
\end{array}$ & $\begin{array}{l}45 \\
87 \\
57 \\
\end{array}$ & $\begin{array}{c}52 \\
\text { DEFINED } \\
61 \\
\end{array}$ & $\begin{array}{c}2 \div 56 \\
20 \\
68\end{array}$ & $\begin{array}{r}2: 57 \\
21 \\
2: 74 \\
\end{array}$ \\
\hline 1015 & 22 & REAL & & & $\begin{array}{r}82 \\
\text { REFS } \\
87 \\
\end{array}$ & $\begin{array}{c}21 \\
\text { DEFINED } \\
\end{array}$ & $\begin{array}{l}23 \\
20 \\
\end{array}$ & $\begin{array}{r}41 \\
21 \\
\end{array}$ & $\begin{array}{l}43 \\
34 \\
\end{array}$ & $\begin{array}{l}45 \\
40 \\
\end{array}$ & $\begin{array}{l}77 \\
43 \\
\end{array}$ & $\begin{array}{l}78 \\
74 \\
\end{array}$ \\
\hline 1020 & 23 & REAL & & & $\begin{array}{r}77 \\
\text { REFS }\end{array}$ & $\begin{array}{l}82 \\
43 \\
77\end{array}$ & $\begin{array}{l}45 \\
87\end{array}$ & $\begin{array}{l}78 \\
83\end{array}$ & 87 & DEFINED & 34 & 43 \\
\hline 1022 & 24 & REAL & & & $\begin{array}{c}\text { REFS } \\
\text { DEFINED } \\
85\end{array}$ & $\begin{array}{l}41 \\
35\end{array}$ & $\begin{array}{l}44 \\
37\end{array}$ & $\begin{array}{l}45 \\
39\end{array}$ & $\begin{array}{c}2: 76 \\
40\end{array}$ & $\begin{array}{l}78 \\
44\end{array}$ & $\begin{array}{l}87 \\
74\end{array}$ & $2 * 76$ \\
\hline $\begin{array}{r}1023 \\
1024 \\
\end{array}$ & $\begin{array}{l}25 \\
26 \\
\end{array}$ & $\begin{array}{l}\text { REAL } \\
\text { REAL }\end{array}$ & & & $\begin{array}{c}\text { REFS } \\
\text { DEFINED } \\
\text { REFS }\end{array}$ & $\begin{array}{l}44 \\
35 \\
44 \\
\end{array}$ & $\begin{array}{l}45 \\
37 \\
45 \\
\end{array}$ & $\begin{array}{l}76 \\
39 \\
87 \\
\end{array}$ & $\begin{array}{c}85 \\
41 \\
\text { DEFINED } \\
\end{array}$ & $\begin{array}{l}87 \\
44 \\
36 \\
\end{array}$ & $\begin{array}{l}75 \\
38 \\
\end{array}$ & $\begin{array}{l}84 \\
39 \\
\end{array}$ \\
\hline & & & & & 41 & 44 & 86 & & & & & \\
\hline FILE N & AMES & MODE & & & & & & & & & & \\
\hline TLE N & OUTPUT & FMT & & $\begin{array}{c}\text { WRITES } \\
61\end{array}$ & $\begin{array}{c}2 * 10 \\
70\end{array}$ & $\begin{array}{l}11 \\
78\end{array}$ & $\begin{array}{l}18 \\
87\end{array}$ & $\begin{array}{l}23 \\
89\end{array}$ & 31 & 45 & 50 & 52 \\
\hline INLINE & $\begin{array}{l}\text { FUNCTIONS } \\
\text { AMIN1 }\end{array}$ & $\begin{array}{l}\text { TYPE } \\
\text { REAL }\end{array}$ & $\begin{array}{cc}\text { ARGS } & \\
0 & \text { INTRIN }\end{array}$ & $N^{\text {DEF LINE }}$ & $\begin{array}{c}\text { REFERENCES } \\
76\end{array}$ & & & & & & & \\
\hline
\end{tabular}




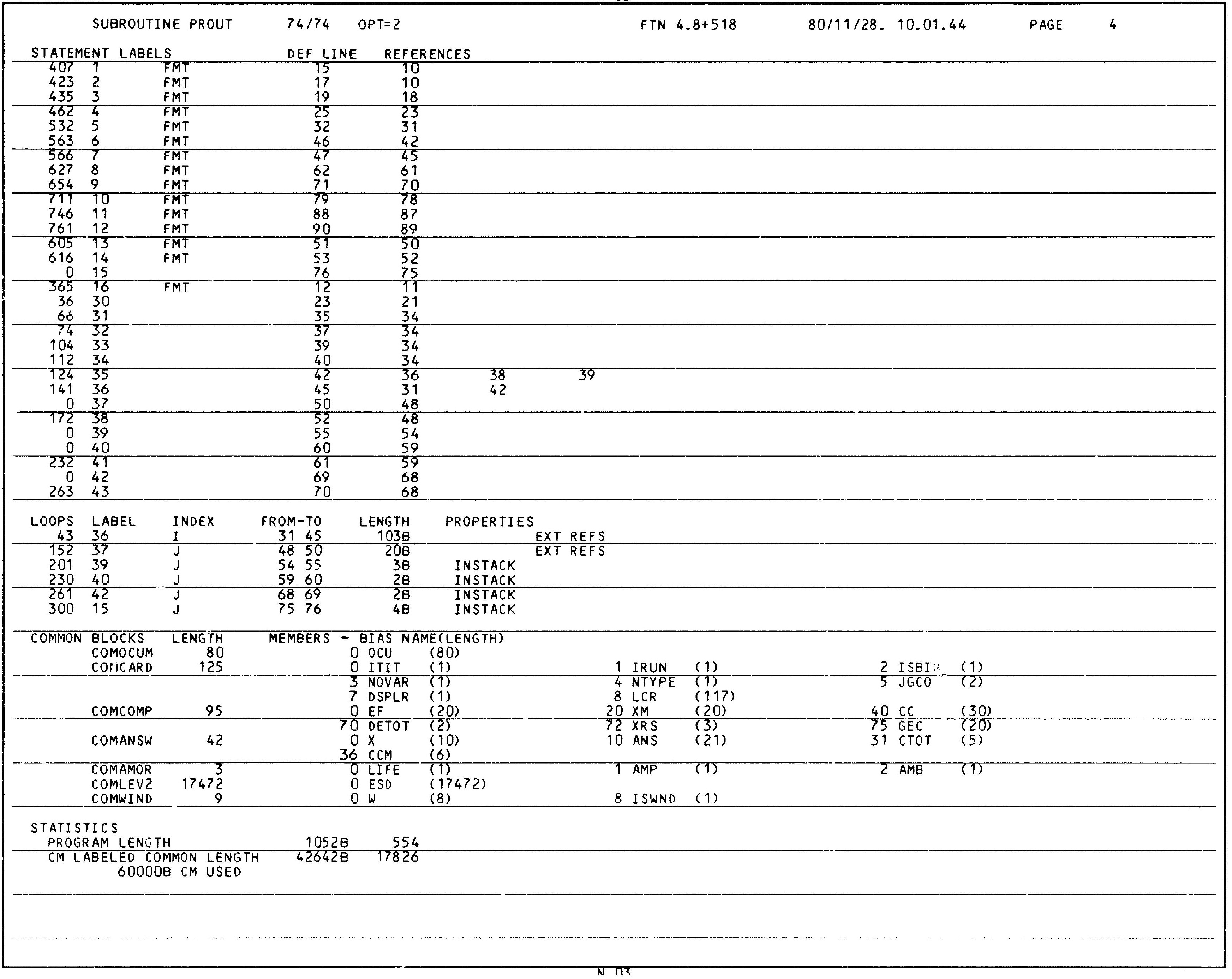


FUNCTION GETTAF $(X X X X)$

DIMENSI ON $X X X X(10), \operatorname{SAV}(8,24), B 5(4,48), X O L(10), J X O L(10)$

COMMON /COMWIND/ W(8), I SWND

5 COMMON /COMOCUM/ OCU $(20,4)$

COMMON / COMCOMP/ EF(20) XM(10,2) CC (10,3) DETOT(2) XRS(3), GEC(20)

COMMON /COMANSW/ $X(10)$, ANS(21), CTOT(5), $C \mathrm{CM}(6)$

COMMON /COMGEON/ LGON(52)

COMMON /COMSUDE/ SUDE $(24,4)$

10 COMMON /COMSXOL/ ISXOL

DATA XOL/10(-1.) /, ZERO/0.1

NITER $=$ NITER+1 1 DO $10 \mathrm{~J}=1.21$

10 ANS $(J)=0$. \$ DO $11 \mathrm{~J}=1,10$

$11 \quad x(J)=x \times x \times(J) \leqslant K G G=0 \& \quad x 2 L=x(5) * x(2)$

$X 2 U=(x(5)+x(6)-X(5) * x(6)) * x(2)$

15

$E S T=.5 * X(2) \$ X 7=X R S(1) * X(2) \$ X 8=X R S(2) * X(2)$

$E 46=E F(4) * E F(6) \$ E 48=E F(4) * E F(8)$ \$ $E 37=E F(3) * E F(7)$

$X 7 E 3=X 7 / E F(3) \& E 15 X=E F(1) * E F(5) * X(1)$ \& ETX7=EF(7)*X7

$2013 \quad 21=G E C(6)+X(3) * G E C(7) \quad \angle F G 0=21 * G E C(8)$

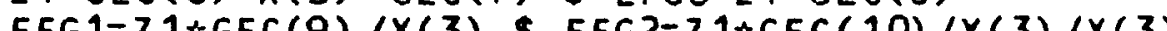

EFG1=Z1*GEC(9) /X(3) \& EFG2=21*GEC(10)/X(3)/X(3)

CALL GETSD(1) \$ IF(ISWND.EQ.0)GO TO 16
IF(NH.1 - 2) GO TO 80 \$ PRINTi \$ CALL EXIT

FORMAT (* PREDICTION NOT ALLOWED WITH WIND*)

$25 \quad 80$ DIA=SQRT(25 $7.7 * X(1) / W(3) /(W(5)+W(4)) * * 3) \$ E 15 X=W(7) * E 15 X$

$Q H T=((15.2+.5 * D I A) / W(2)) * 0.142857 \$ D 081 \mathrm{~J}=1,24$

$B 5(3, J)=\operatorname{SUDE}(J, 3)$ \& $B 5(1, j)=0, \$ \quad Z 3=0 H T \div \operatorname{SUDE}(J)-W(4)$

$\operatorname{IF}(Z \xi . L T . W(6)) B 5(1, J)=E 15 X * A M A X 1(0 ., A M I N 1(1 ., Z 3 / W(5)))$

$\begin{array}{lll}81 & \text { CONTINUE \$ W(8)=DIA } \$ \text { GO TO } 17 \\ 30 & 16 & \text { DO } 12 \quad J=1,24 \$ D O \quad 12 \quad I=3,4\end{array}$

$B 5(I-2, J)=E 15 X \div S U D E(J, I-2)$

$12 \quad B 5(I, J)=\operatorname{SUDE}(J, I) \& x^{\prime}(4)=0$

17 IF (IND EO. O) GO TO 20 \& WRITE(9) $(X(J) \quad J=1,10)$ \& $C U 1=C U 2=0$

$\operatorname{IF}(X(2) . G T .0$.$) CUT =19.9999 / X(2)$ \& $\operatorname{IF}(X(3) . G T .0) C U 2=.19.999 / X(3)$

DO $15 \mathrm{~J}=1,2$ \& $D 0$ 15 $\mathrm{i}=1,20$

$15 \quad \operatorname{OCU}(I, J)=0$

IF (I SWND.NE. O) QW $1=0.00385159 * W(7) * W(3) * D I A * D I A *(Q H T * 3)$

C.... MAIN LOOP.

DO 60 NWK $=152 \& L G O=L G O N(N W K) \$ N D Z=7 \approx N W K \$ N D 1=N D Z-6$

$40 \quad$ DO 59 ND=NDT. NN2 \$ CALL GETSD(ND+1) \$ IF(ISWND.EQ.0)GO TO 18

DO $82 \mathrm{~J}=1,24 \$ 85(3, \mathrm{~J}+24)=\operatorname{SUDE}(J, 3) \$ B 5(1, J+24)=0$

IF (IND.EQ.1) GANS $(21)=\operatorname{ANS}(21)+Q W 1 *{ }^{\prime}(\operatorname{SUDE}(J) \div 3 \xi 3)$

$Z 3=Q H T * \operatorname{SUDE}(J)-W(4)$

$\operatorname{IF}(23 . L T \cdot W(6)) B 5(1, J+24)=E 15 X: \operatorname{AMAX} 1(0 \ldots \operatorname{AMIN1}(1 \ldots 23 / W(5)))$

45

CONTINUE $\$$ GO TO 19

18 DO $21 \quad I=124 \$ 0021 \mathrm{~J}=1,2 \$ 85(\mathrm{~J}+2, \mathrm{I}+24)=\operatorname{SUDE}(\mathrm{I}, J+2)$

$21 \quad B 5(J, I+24)^{\prime}=\operatorname{SUDE}(I, J) * E 15 \dot{X}$

$19 \quad 0050 \quad I=1,24 \$ 85^{\prime}(2)=B 5(\hat{i}) \$ B 5(4)=85(3)$

$E E S=E F(2)$ मEST $\$$ IF(EES.GT.X2U) GO TO 37

50

IF(EES.LT.X2L.O.I.LE.LGO)GU TO $33 \$$ IF(NH.GT.0)60 TO 22

IF $(X(2)$.LE. O.) GO TO 22

C... MAINTAIN STATUS.

IF (KGG.EQ.0)GO TO $37 \$ G R M=X(3) \$ 60$ TO 34

C ... TEST FOR $N H=1$

$A D=A M I N T(B 5(3) / E 46, B 5(1))$ \& DUNS $=85(3)-E 46 \div A D$

$Z 1=B 5(1)-A D \$ \operatorname{IF}(Z 1 . G T .0) G$.0 TO $23 \$ A D S=A M I N 1 /$ DUNS / E 48, X8,EES)

$A S=0$. \$ EST $=E E S-A D S \$ D U N S=D U N S-E 48:$ ADS $\$ 00$ TO 24 
$23 A D S=0 . \quad A S=A M I N\{(21, X 7,(X(2)-E E S) / E F(7))$ EST=EES+EF $(7) * A S$

24 IF (DUNS.GT. .0001) GO TO 33 \$ IF (NH.GT.1)GO TO 26

$C$... SHUT OFF OR LEAVE OFF)

$25 \quad K G G=0 \$ G S=G D=G D S=0$. \$ $\$ O$ TO 40

C .... TEST FOR NH.GT. 1

$26^{\circ} \cdots$ TST=EST \& DO $29 \quad \mathrm{~K}=2$, NH \& TES $=E F(2) * T S T$

TD = AMIN $1(B 5(4, K) / E 46, B 5(2, K)) \$$ TUNS $=B 5(4, K)-E 46 * T D$

$65 \quad 21=85(2, K)-T D$ IF $(21 . G T .0$.) GO TO $27 \$$ TDS S AMIN1 (TUNS/E $48, X 8, T E S$ )

TST=TES-TDS S TUNS $=$ TUNS -E $48 *$ TDS $\$$ SO TO 28
TST

27 TST $=$ TES+AMINT $(E F(7) * 21, E 7 X 7, X(2)-T E S)$

IF (TUNS.GT...0001) GO TO' 33

29 CONTINUE S GO TO 25

$70-C \ldots$ TURN ON (OR LEAVE ON) GENERATOR.

$G R M=X(3)$ S IF (KGG.EQ.1) GO TO 34

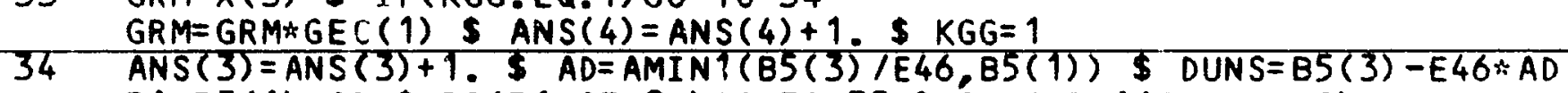

$21=B 5(1)-A D \&$ IF $(Z 1 . G T .0) G$.0 TO $35 \$ G D=A M I N 1$ (GRM, DUNS)

75 DUNS $=$ DUNS $-G D \$ A S=A D S=G S=0$. \$ Z2=GRM-GD \$ IF $(Z 2 . L E .0$.$) GO TO 41$

$G S=A M I N T(22, X 7 E 3,(X(2)-E E S) / E 37)$ \$ EST=EES+E37 $\div G S$ \$ 60 TO 36

41 ADS=AMIN1 (DUNS /E 48,EES) S DUNS=DUNS-E48*ADS

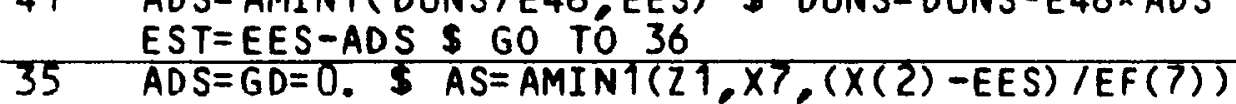

$80 \quad G S=A M I N 1\left(G R M_{\rho}(X 7-A S) / E F(3),(X(2)-(E E S+E F(7): A S)) / E 37\right)$

$E S T=(E E S+E F(7) * A S)+E 37 * G S$

$36 \quad G D S=G D+G S$

$\operatorname{ANS}(1)=\operatorname{ANS}(1)+G D S /((E F G 2 * G D S+E F G 1) * G D S+E F G 0)$ GO TO 40

85 C 37 GENERATOR OFF.

$37^{\circ} \mathrm{KGG}=0$ \$ $G S=G D=G D S=0$. \$ $A D=A M I N 1(B 5(3) / F 46, B 5(1))$

DUNS $=B 5(3)-E 46 * A D \& Z 1=B 5(1)-A D$ S IF (21.GT.0.)GO TO 38

$A D S=A M I N 1$ (DUNS $/ E 48, \times 8, E E S) \$ A S=0$. \$ EST $=E E S-A D S$

DUNS $=$ DUNS $-E 48 * A D S \$ G 0$ TO 40

90

38 ADS $=0$. \$ AS $=A M I N 1(Z 1, X 7,(x(2)-E E S) / E F(7)) \& E S T=E E S+E F(7) \div A S$

C $\cdots$. STATUS COMPLETE.

40 ANS $(2)=$ ANS $(2)+A D S S$ ANS $(5)=\operatorname{ANS}(5)+$ DUNS

$X(4)=A M A X 1(X(4), E F(6) * A D+E F(8) * A D S)$

95

IF (IND.EQ.0)GO TO 50 SAV $(1, I)=A D \$ S A V(5, I)=6 S \$ S A V(3, I)=A D S$

$\operatorname{SAV}(4, I)=A S$ S $\operatorname{SAV}(6, I)=E S T \& \operatorname{SAV}(2, I)=(G D . A .(-1)) .0 . \operatorname{KGG}$

$\operatorname{SAV}(7, I)=B 5(1)$ \& $\operatorname{SAV}(8, I)=B 5(3)$

ANS $(6)=$ AMAX $1($ ANS $(6), B 5(3)-D U N S)$

ANS $(11)=A N S(11)+B S(1) \$$ ANS $(12)=$ ANS $(12)+A D \$ A N S(13)=$ ANS $(13)+A S$

ANS $(14)=$ ANS $(14)+$ GS $\$$ ANS $(15)=$ ANS $(15)+$ GD $\$$ ANS $(16)=$ ANS $(16)+$ EST

$100-\operatorname{ANS}(17)=\operatorname{AMAXT}(\operatorname{ANS}(17), B 5(1)) \$$ ANS $(18)=\operatorname{AMAX1}($ ANS $(18)$ ADS $)$

$\operatorname{ANS}(19)=\operatorname{AMAX1}(\operatorname{ANS}(19)$, GDS) \$IF(DUNS.GT . 0001) ANS $(10)=\operatorname{ANS}(10)+1$

$L 1=C U 1$ \&EST+1. \& OCU $(L 1,1)=O C U(L 1,1)+1$

50 CALL MOVLEV $(\dot{B} 5(5), 85,188)$

IF (IND.EQ.0) GO TO 59

105

WRI TE $(9)((\operatorname{SAV}(J, I), J=1,8), Z$ ERO, ZERO $, I=1,24)$

59 CONTINUE

CONTINUE

ANS(20)=ANS(2) \$ IF (X(2).GT.0.) ANS(2) = ANS(2) /X(2)

110

GE TIAF $=$ COST(Z1) \$ IF(IND.EQ.0)GO TO 69

DO $62 \mathrm{I}=1,2 \mathrm{2}$ D0 $61 \mathrm{~J}=2,20$

$610 C U(J, I)=0 C U(J, I)+0 C U(J-1, I) \$ 0062 J=1,20$

$62 \operatorname{OCU}(\mathrm{J}, \mathrm{I})=100 . \cdots O C U(\mathrm{~J}, \mathrm{I}) / 0 C U(20$, I ) \& IF (ISWND. NE.0)60 TO 69

$23=E F(1): E F(5) \&$ ANS $(21)=0$. \$IF(23.6T.0.) ANS(21) $=$ ANS(11)/23 
69 IF(ISXOL.EQ.0)RETURN

DO $70 J=1,6 \$ J \times O L(J)=1 H \$ \operatorname{IF}(X(J)$. NE. XOL $(J)) J \times O L(J)=1 H:$

$70 \quad X O L(J)=X(j) \$$ PRINT71,GE11AF,CCM(6), $(X O L(J), J X O L(J), J=1,6)$

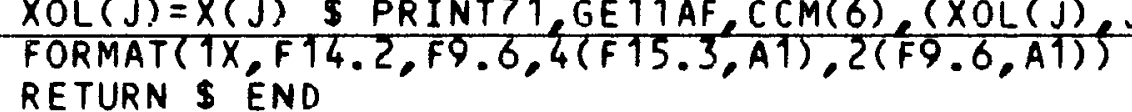

SYMBOLIC REFERENCE MAP $(R=3)$

\begin{tabular}{|c|c|c|c|c|c|c|c|c|c|c|c|}
\hline $\begin{array}{r}\text { ENTRY } \\
4\end{array}$ & $\begin{array}{l}\text { POINTS } \\
\text { GE11AF }\end{array}$ & DEF LINE & $\begin{array}{ll}\text { REFERENCES } \\
115 & 119\end{array}$ & & & & & & & & \\
\hline $\begin{array}{l}\text { VARIAB } \\
1044\end{array}$ & $\begin{array}{l}\text { LES } \\
A D\end{array}$ & $\begin{array}{c}\text { SN TYPE } \\
\text { REAL }\end{array}$ & RELOCATION & $\begin{array}{r}\text { REFS } \\
98\end{array}$ & DEFINED & $\begin{array}{l}56 \\
55\end{array}$ & $\begin{array}{l}73 \\
73\end{array}$ & $\begin{array}{l}74 \\
86\end{array}$ & $2 \div 87$ & 93 & 94 \\
\hline 1046 & $\overline{A O S}$ & $\overline{R E A L}$ & & $\begin{array}{r}\text { REFS } \\
94 \\
88\end{array}$ & $\begin{array}{c}2 \times 57 \\
100 \\
90\end{array}$ & DEFINED & $\begin{array}{l}78 \\
56\end{array}$ & $\begin{array}{l}88 \\
58\end{array}$ & $\begin{array}{l}89 \\
75\end{array}$ & $\begin{array}{l}92 \\
77\end{array}$ & $\begin{array}{l}93 \\
79\end{array}$ \\
\hline 12 & ANS & REAL & COMANISW & $\begin{array}{c}\text { REFS } \\
3 * 98 \\
\text { DEFINED }\end{array}$ & $\begin{array}{c}7 \\
3 \times 99 \\
13\end{array}$ & $\begin{array}{c}42 \\
2 * 100 \\
42\end{array}$ & $\begin{array}{c}72 \\
2 \times 101 \\
72 \\
\end{array}$ & $\begin{array}{c}73 \\
2 \times 109 \\
73\end{array}$ & $\begin{array}{r}83 \\
114 \\
83 \\
\end{array}$ & $\begin{array}{l}2: 92 \\
2: 92\end{array}$ & $\begin{array}{l}97 \\
97 \\
\end{array}$ \\
\hline 1047 & AS & REAL & & $\begin{array}{r}3 * 98 \\
\text { REFS } \\
\text { DEFINED } \\
\end{array}$ & $\begin{array}{c}3: 99 \\
58 \\
57 \\
\end{array}$ & $\begin{array}{c}2 \div 100 \\
2 \times 80 \\
58 \\
\end{array}$ & $\begin{array}{c}2 \div 101 \\
81 \\
75 \\
\end{array}$ & $\begin{array}{c}2 \div 109 \\
90 \\
79\end{array}$ & $\begin{array}{c}2 \div 114 \\
95 \\
88\end{array}$ & $\begin{array}{l}98 \\
90\end{array}$ & \\
\hline 1363 & 85 & REAL & ARRAY & $\begin{array}{c}\text { REFS } \\
74 \\
\text { DEFINED }\end{array}$ & $\begin{array}{c}2 \\
2 * 86 \\
2 * 27\end{array}$ & $\begin{array}{c}2: 48 \\
2: 87 \\
28\end{array}$ & $\begin{array}{c}3 \div 55 \\
2 \div 96 \\
31\end{array}$ & $\begin{array}{l}56 \\
97 \\
32 \\
\end{array}$ & $\begin{array}{c}3 \div 64 \\
98 \\
2 \div 41\end{array}$ & $\begin{array}{r}65 \\
100 \\
44 \\
\end{array}$ & $\begin{array}{c}3: 73 \\
2 * 104 \\
46\end{array}$ \\
\hline $\begin{array}{l}50 \\
44 \\
\end{array}$ & $\begin{array}{l}\mathrm{CC} \\
\mathrm{CCM} \\
\end{array}$ & $\begin{array}{l}\text { REAL } \\
\text { REAL }\end{array}$ & $\begin{array}{l}\text { COMCOMP } \\
\text { COMANSW }\end{array}$ & $\begin{array}{r}47 \\
R E F S \\
\text { REFS }\end{array}$ & $\begin{array}{c}2 \% 48 \\
6 \\
7 \\
\end{array}$ & 117 & & & & & \\
\hline $\begin{array}{r}37 \\
1032 \\
1033 \\
\end{array}$ & $\begin{array}{l}\text { CTOT } \\
\text { CU1 } \\
\text { CU2 }\end{array}$ & $\begin{array}{l}\text { REAL } \\
\text { REAL } \\
\text { REAL }\end{array}$ & COMANSW & $\begin{array}{l}\text { REFS } \\
\text { REFS } \\
\text { REFS } \\
\end{array}$ & $\begin{array}{r}7 \\
102 \\
103 \\
\end{array}$ & $\begin{array}{l}\text { DEF INED } \\
\text { DEF I NED }\end{array}$ & $\begin{array}{l}33 \\
33\end{array}$ & $\begin{array}{l}34 \\
34\end{array}$ & & & \\
\hline $\begin{array}{l}106 \\
1026 \\
1045\end{array}$ & $\begin{array}{l}\text { DETOT } \\
\text { DIA } \\
\text { DUNS }\end{array}$ & $\begin{array}{l}\text { REAL } \\
\text { REAL } \\
\text { REAL }\end{array}$ & COMCOMF & $\begin{array}{l}\text { REFS } \\
\text { REFS } \\
\text { REFS } \\
\end{array}$ & $\begin{array}{l}6 \\
26 \\
56 \\
\end{array}$ & $\begin{array}{l}29 \\
57\end{array}$ & $\begin{array}{c}2: 37 \\
59\end{array}$ & $\begin{array}{c}\text { DEFINED } \\
74\end{array}$ & $\begin{array}{l}25 \\
75 \\
\end{array}$ & $2 \times 77$ & 88 \\
\hline 1042 & EES & REAL & & $\begin{array}{r}89 \\
75 \\
\text { REFS } \\
\end{array}$ & $\begin{array}{l}92 \\
77 \\
49 \\
\end{array}$ & $\begin{array}{r}97 \\
87 \\
50 \\
\end{array}$ & $\begin{array}{r}101 \\
89 \\
56 \\
\end{array}$ & $\begin{array}{c}\text { DEF INED } \\
57\end{array}$ & $\begin{array}{c}55 \\
2 * 58 \\
\end{array}$ & $2 * 76$ & $\begin{array}{l}73 \\
77\end{array}$ \\
\hline 0 & $E F$ & REAL & COMCOMP & $\begin{array}{c}78 \\
\text { DEFINED } \\
\text { REFS }\end{array}$ & $\begin{array}{r}79 \\
49 \\
6 \\
\end{array}$ & $\begin{array}{r}80 \\
6 \div 17 \\
\end{array}$ & $\begin{array}{c}81 \\
4 * 18 \\
\end{array}$ & $\begin{array}{c}2: 88 \\
49\end{array}$ & $\begin{array}{l}2: 90 \\
2: 58\end{array}$ & 63 & 67 \\
\hline $\begin{array}{l}1023 \\
1024\end{array}$ & $\begin{array}{l}E F G 0 \\
E F G 1\end{array}$ & $\begin{array}{l}\text { REAL } \\
\text { REAL }\end{array}$ & & $\begin{array}{r}79 \\
\text { REFS } \\
\text { REFS }\end{array}$ & $\begin{array}{c}2 \% 80 \\
83 \\
83\end{array}$ & $\begin{array}{l}81 \\
\text { DEFINED } \\
\text { DEFINED }\end{array}$ & $\begin{array}{c}2590 \\
20 \\
21\end{array}$ & $2 \div 93$ & $2: 114$ & & \\
\hline $\begin{array}{l}1025 \\
1011\end{array}$ & $\begin{array}{l}\text { EFG2 } \\
\text { EST }\end{array}$ & $\begin{array}{l}\text { REAL } \\
\text { REAL }\end{array}$ & & $\begin{array}{c}\text { REFS } \\
\text { REFS } \\
\text { DEFINED }\end{array}$ & $\begin{array}{l}83 \\
49 \\
16 \\
\end{array}$ & $\begin{array}{c}\text { DEFINED } \\
63 \\
57 \\
\end{array}$ & $\begin{array}{l}21 \\
95 \\
58 \\
\end{array}$ & $\begin{array}{l}99 \\
76 \\
\end{array}$ & $\begin{array}{r}102 \\
78 \\
\end{array}$ & 81 & 88 \\
\hline 120 & E15X & REAL & & $\begin{array}{c}90 \\
\text { REFS } \\
\text { DEFINED }\end{array}$ & $\begin{array}{l}25 \\
18\end{array}$ & $\begin{array}{l}28 \\
25\end{array}$ & 31 & 44 & 47 & & \\
\hline $\begin{array}{l}1016 \\
1014\end{array}$ & $\begin{array}{l}E 37 \\
E 46\end{array}$ & $\begin{array}{l}\text { REAL } \\
\text { REAL }\end{array}$ & & $\begin{array}{c}\text { REFS } \\
\text { REFS } \\
\text { DEFINED }\end{array}$ & $\begin{array}{c}2: 76 \\
2: 55 \\
17\end{array}$ & $\begin{array}{c}80 \\
2 \div 64\end{array}$ & $\begin{array}{c}81 \\
2 * 73\end{array}$ & $\begin{array}{c}\text { DEFINED } \\
86\end{array}$ & $\begin{array}{l}17 \\
87\end{array}$ & & \\
\hline
\end{tabular}




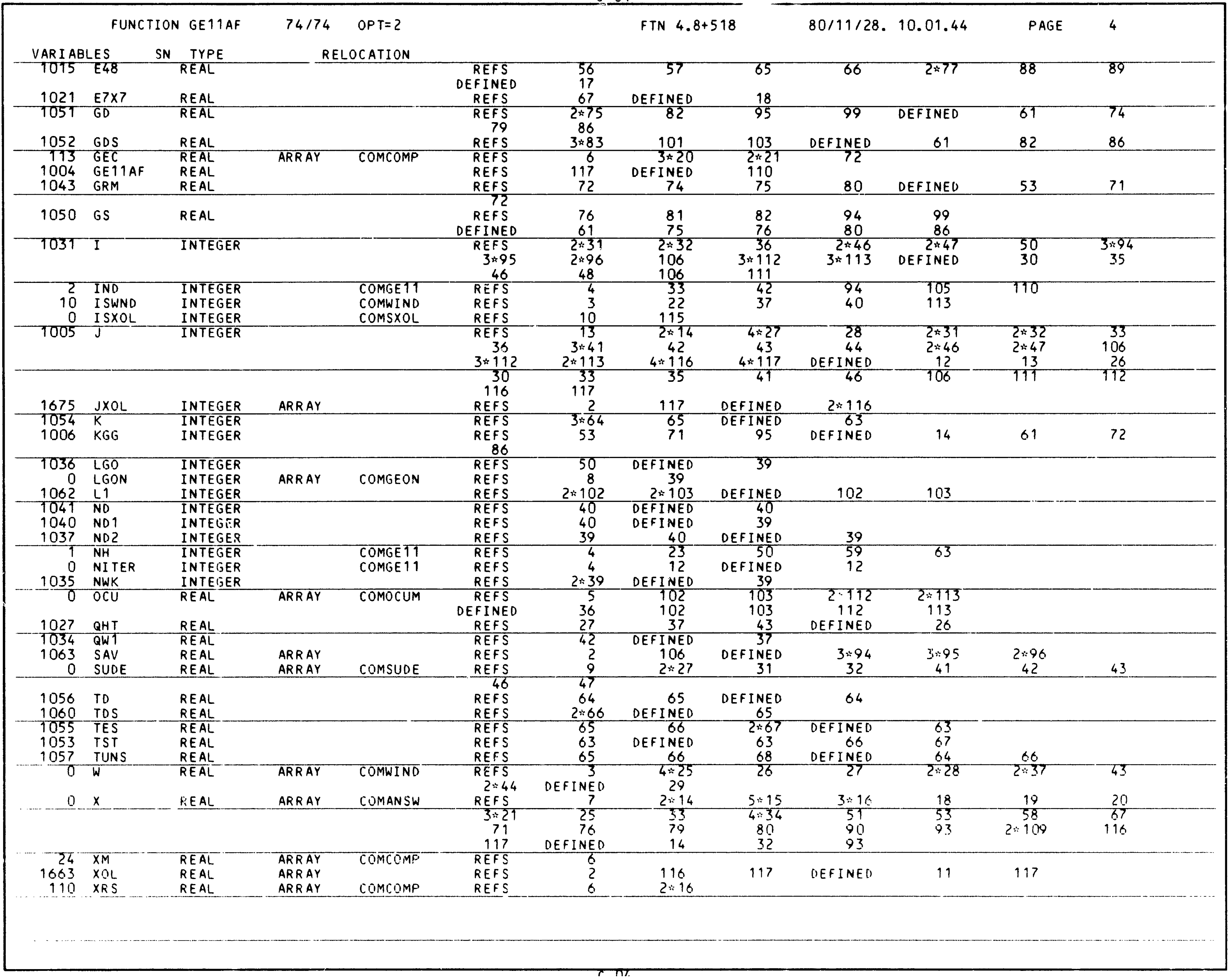




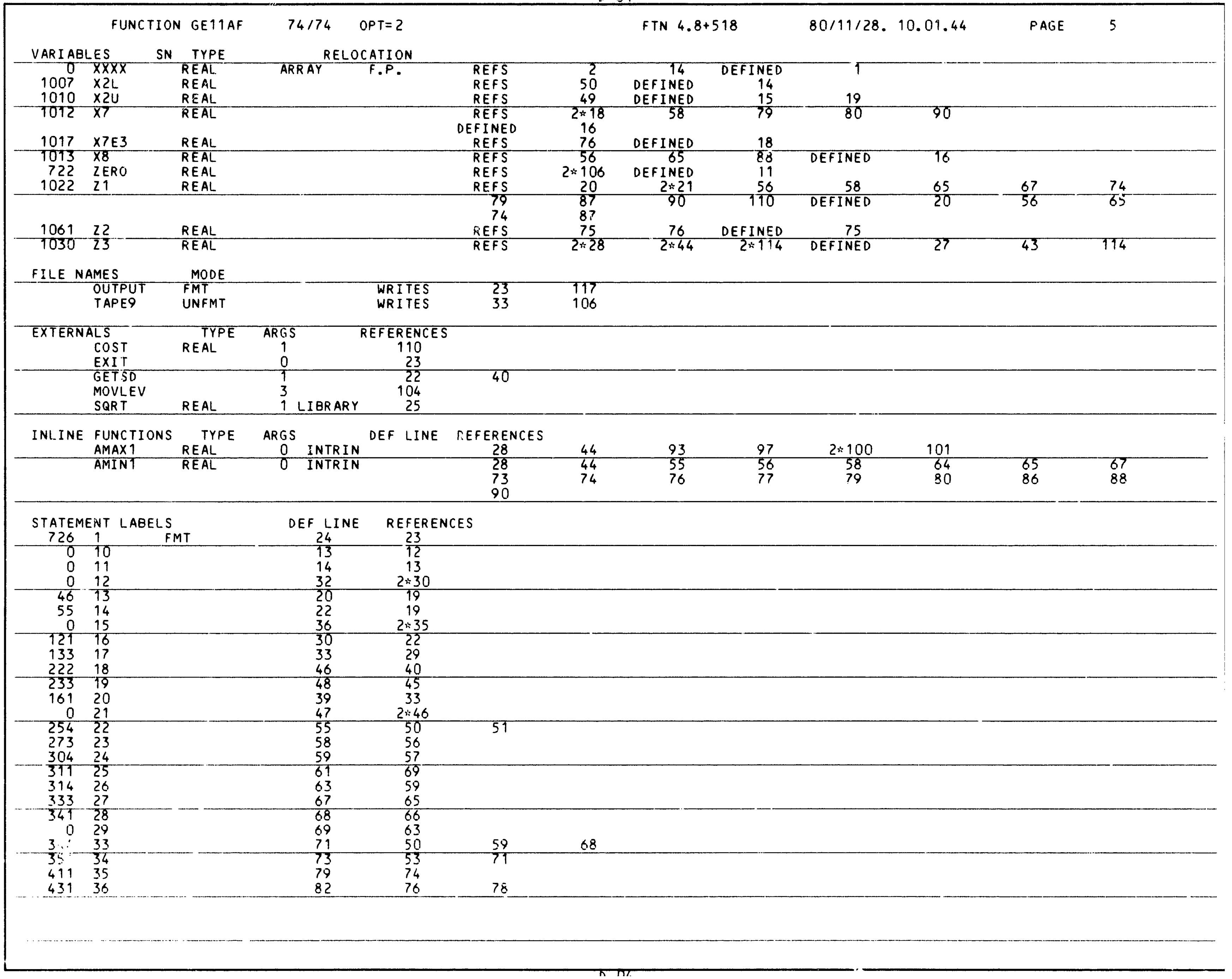




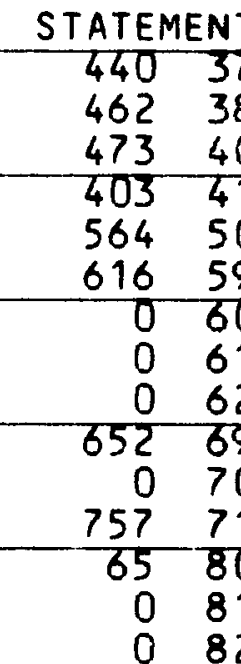

DEF LINE REFERENCES

$\begin{array}{ccc}\text { LINE } & \text { REFERENCES } & \\ 86 & 49 & 53 \\ 90 & 87 & \\ 92 & 61 & 84 \\ 77 & 75 & \\ 104 & 48 & 94 \\ 107 & 40 & 105 \\ 108 & 39 & \\ 112 & 119 & \\ 113 & 111 & 112 \\ 115 & 110 & 113 \\ 117 & 116 & \\ 118 & 117 & \\ 25 & 23 & \\ 29 & 26 & \\ 45 & 41 & \end{array}$

3

89 94
105

$\frac{112}{113}$

FMT

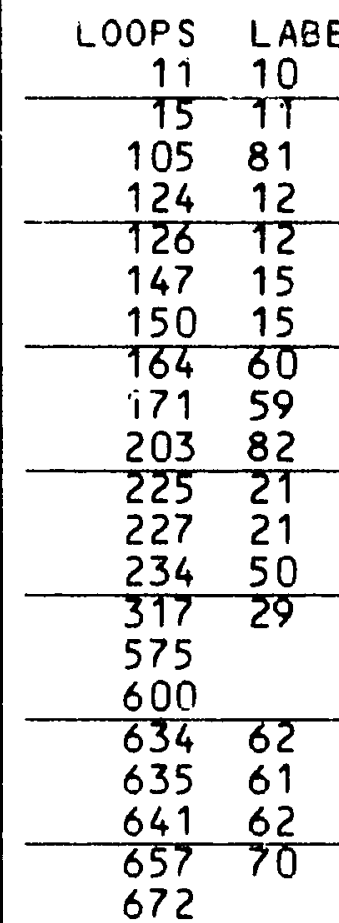

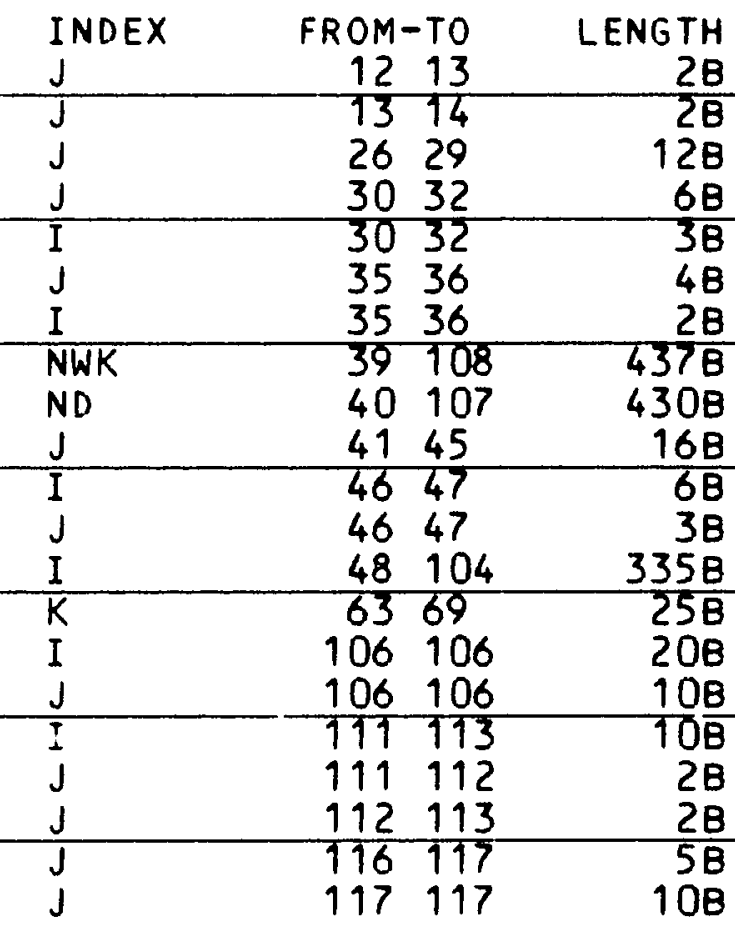

PROPERTIES

INSTACK

INSTACK

INSTACK NOT INNER

INSTACK NOT INNER

INSTACK

EXT REFS NOT INNER
EXT REFS NOT INNER

NOT INNER

INSTACK

EXT REFS NOT INNER

EXT REFS NOT INNER

EXT REFS

INSTACK

INSTACK

INS TACK

EXT REFS

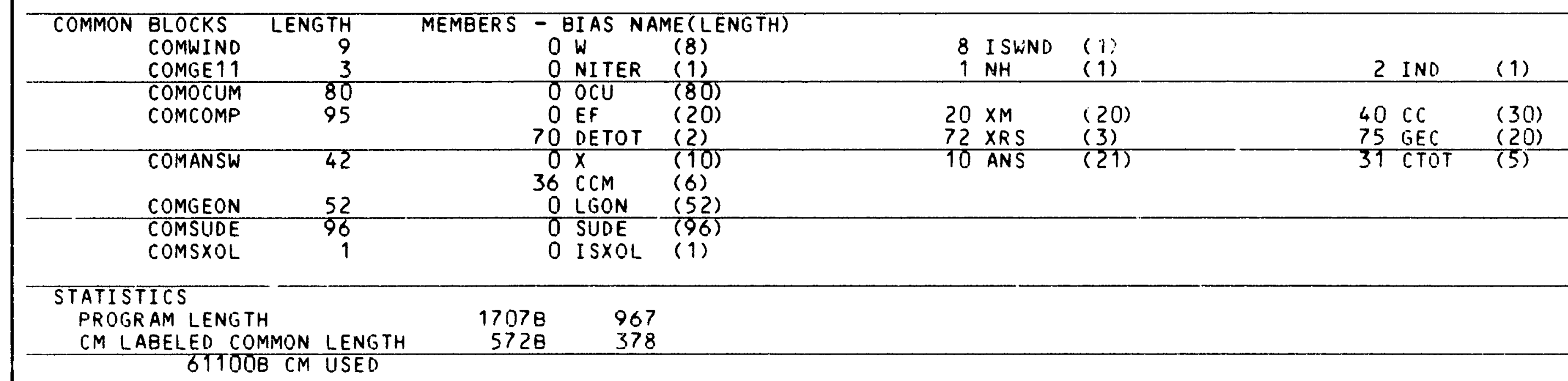


SUBROUTINE SMING (FCT,XO,FV)
DIMENSION XO(6), XN $(6), \operatorname{SV}(6,10), F F(10)$

COMMON I COMMINN' NMIN, DMIN,XL(10),XU(10), RR(10),XLU(10,2)

5 DXTERNAL FCT DV $/ 6 / 10$, NSM $/ 10 /$

$D=D M I N \& N S=N R=I D=1 \& D 010 \mathrm{~J}=1$, NV \& IF (RR (J).GT,O.)ID=0

$10 \quad S V(J, 1)=X O(J) \& F V=F F(1)=F Z=F C T(X O)$ IF (ID.NE.O)RETURN

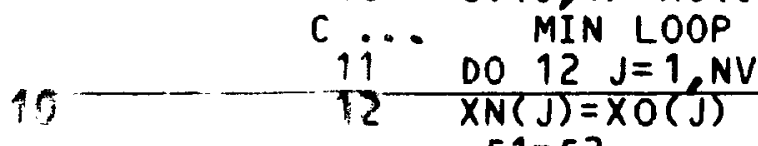

$F 1=F 2$
$13 \quad D O 17 \mathrm{~J}=1, \mathrm{NV}$

IF (XO(J).GE.XU(J))GO TO 14

$15 \quad \begin{aligned} X N(J) & =\operatorname{AMIN} 1(X O(J)+D * R R(J), X U(J)) \\ J U M P & =-1\end{aligned}$

24 IF (F3.LT.F2)GO TO 16

14 IF $(X O(J) \cdot L E \cdot X L(J)) G O$ TO 15

$X N(J)=A M A X T(X O(J)-D * R R(J), X L(J))$

$20 \quad$ JUMP $=0$

GO TO 30

GO TO 30
25 IF(F3.LT.FL)GO TO 16

$15 \quad X N(J)=X O(J)$

GO TO 17

$25 \quad 16 \quad F 2=F 3$

17 CONTINUE

I $S=1$

IF(F2.LT.FT)GO TO 18

30 IF (ID.GE.NMIN) 60 TO 35

$D=0 / D V J$

$I D=I D+1$

$18 \quad$ GO TO 13

I $C=0$

35 IF (IS.LT. 10)GO TO 19

$F A C=2$. $* F A C$

19 I $S=I S+1$

$I S=I S+1$
$0023 \mathrm{~J}=1, \mathrm{NV}$

$40 \quad \frac{D O 23 \quad J=1, N V}{X X=(X N(J)-X O(J)) \div F A C}$

$X O(J)=X N(J)$

If $(D X) \quad 20,21,22$

$20 X N(J)=\operatorname{AMAX} 1(X O(J)+D X X L(J))$

I $F(X N(J) \cdot L T \cdot X O(J))$ I $C=1$

$45 \quad$ GO TO 23

$51 \quad x N(J)=x O(j)$

GO TO 23

$22 \quad X N(J)=\operatorname{AMIN1}(X O(J)+D X, X U(J))$

5023 CONTINUE

IF (IC.EQ.O) GO TO 11

JUMP $=1$

GO TO 30

26 IF (F3.GE.F2) G0 TO 11

55

$F 2=F 3$

GO TO 18

C... TEST LOOP 


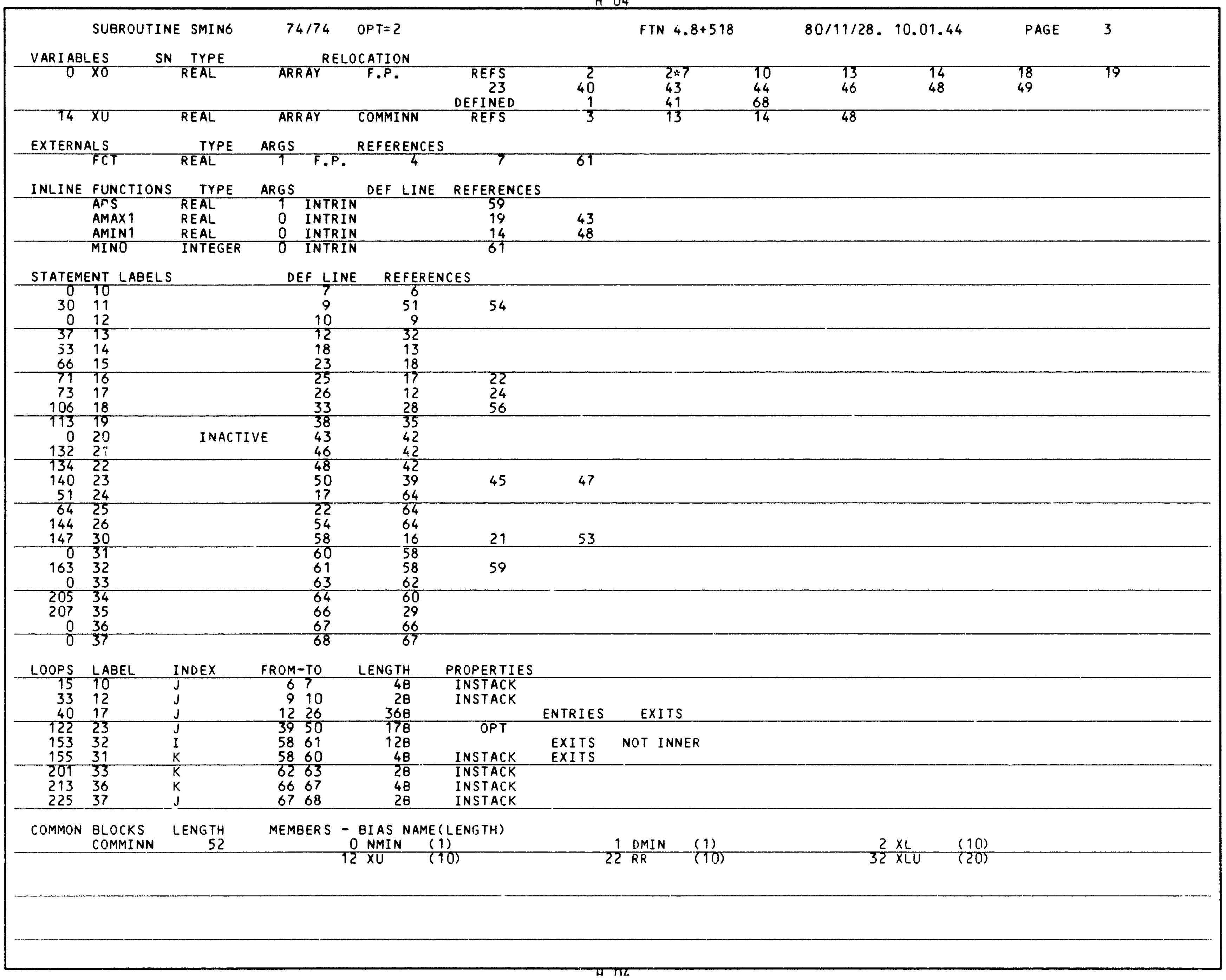




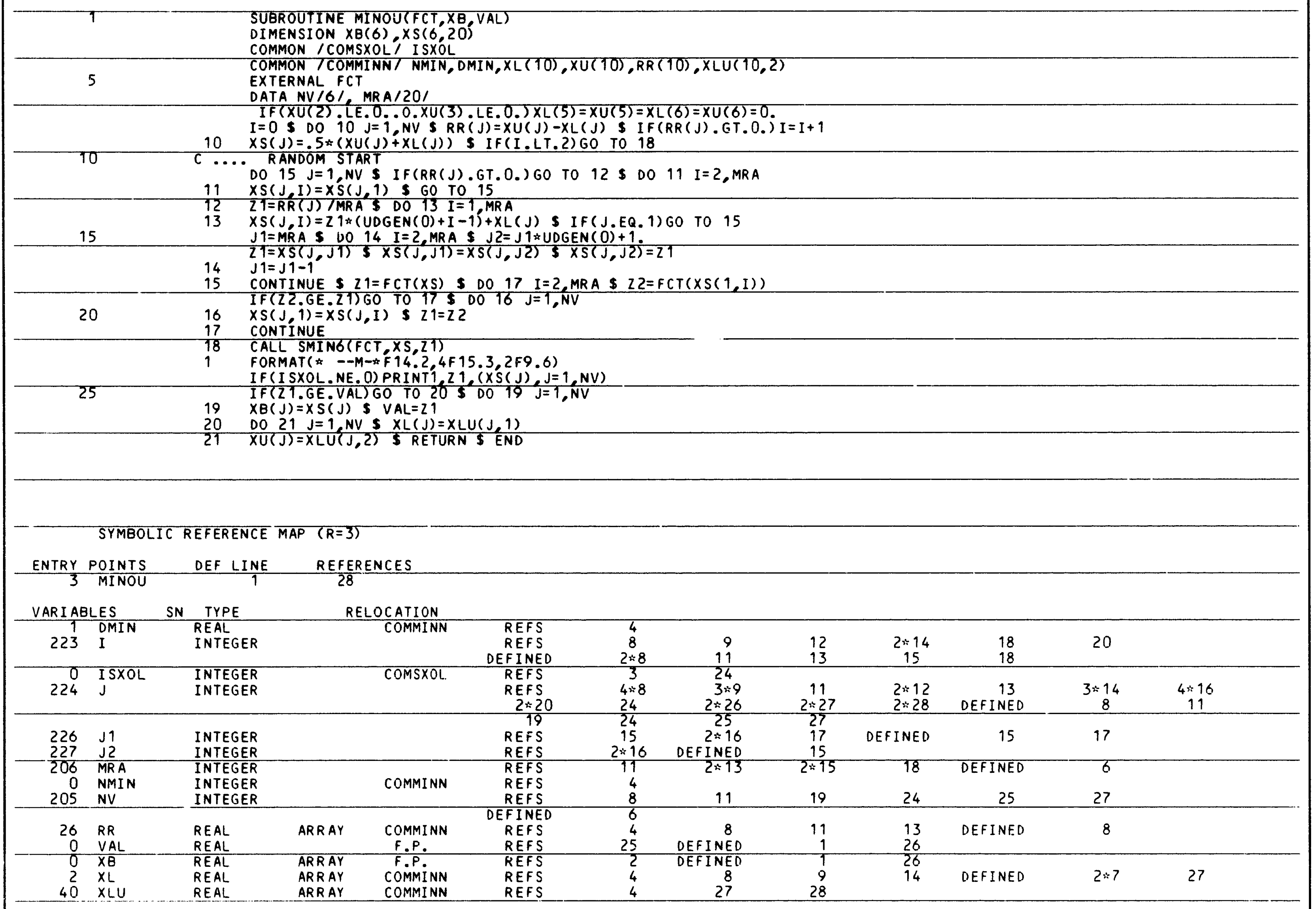




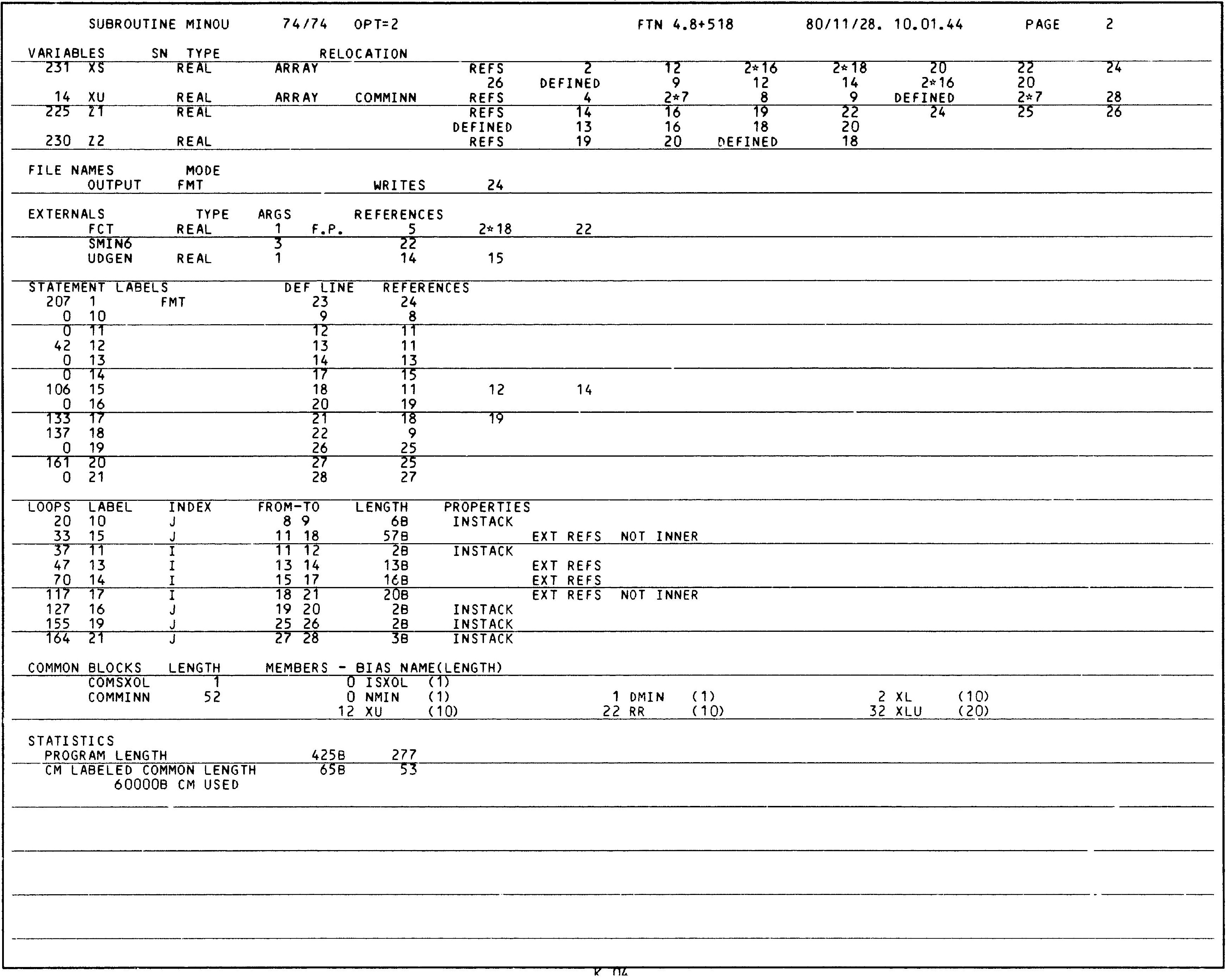




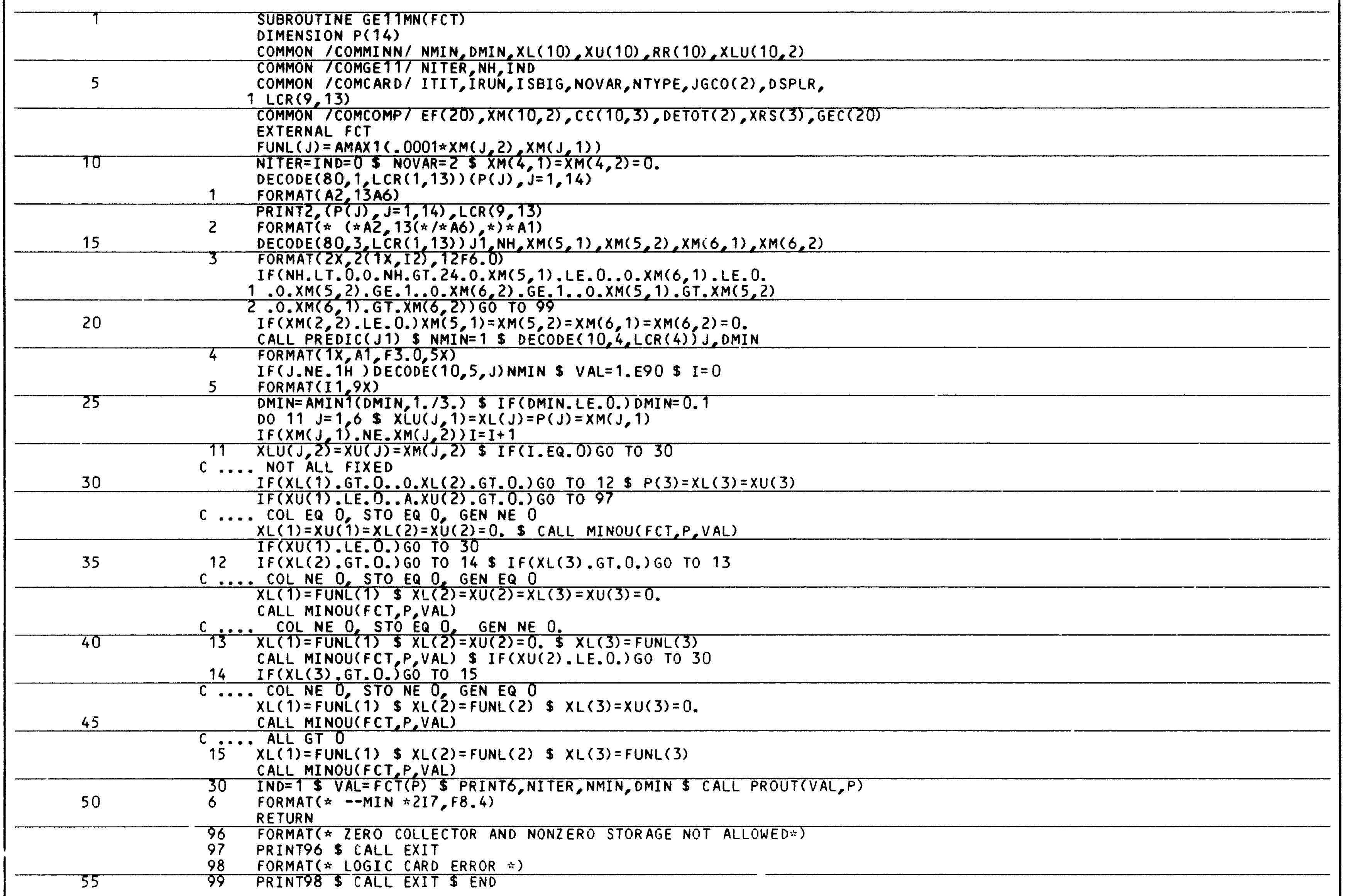




\section{SYMBOLIC REFERENCE MAP (R=3)}

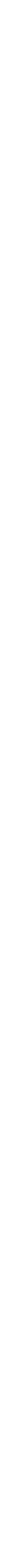




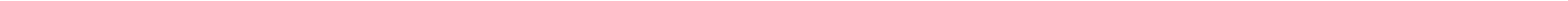


$c$
$c$
$c$
$c$ 


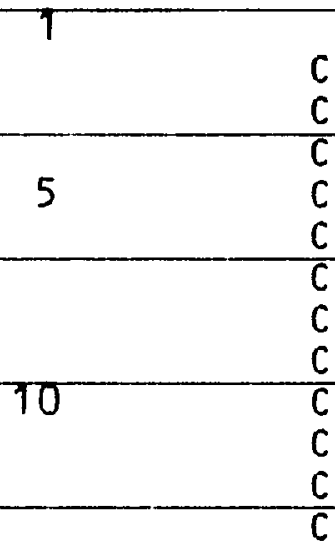

SUBROUTINE SMOLSW(JT,N2,IOP, $T, X, Y, F, A)$

WHERE J1=NUMBER OF DATA POINTS N $2=$ TWI CE THE NUMBER OF KNOTS

IOP= ARRAY OF DIMENSION 2 CONTAINING COMBINATIONS OF THE

INTEGERS 1 THRU 5 FOR SPECIFYING THE BOUNDARY CONDITIONS

$T=T$ TALL OF ABSCISSAS OF DATA POINTS $X=$ TABLE OF KNOTS

$Y=$ TABLE OF ORDINATES OF DATA POINTS

$W=$ WEIGHTS ARE REMOVED.

$F=A R R A Y$ OF DIMENSION N2 CONTAINING SECOND DERIVATIVES AND

FUNCTION VALUES UPON RETURN

$A=A R R A Y$ OF DIMENSION GE. N2*2 USED FOR TEMPORARY STORAGE

15

DIMENSION IOP(2), T(2), X(2), $Y(2), F(2), A(N 2, N 2), W(2)$

$N=N 2 / 2$

$\mathrm{KK}=\mathrm{N}-1$

$F 1=F(1)$

$F N=F(N)$

DO $100 \mathrm{I}=1, \mathrm{~N}$

20

$100 F(I)=0$.

$M 1=2 \div N$

$M 2=M 1-1$

$M 3=N+1$

$M 4=K K-1$

$25 \quad 0020 \mathrm{I}=2, K K$

$F L 1=X(I+1)-X(I)$

$F L=X(I+1)-X(I)$
$F L 2=X(I)-X(I-1)$

DO $20 \mathrm{~J}=1, \mathrm{~N}$

$\mathrm{M}=\mathrm{N}+\mathrm{J}$

IF $(J-(I-1))>0,40,30$

30 IF $(J-I) 50,60,50$

50 If $(J-(I+1))>70,80,70$

$70 A(I, J)=0$.

$35 \quad \begin{aligned} & A(I, M)=0 . \\ & \text { GO } T O 20\end{aligned}$

$40 A(I, J)=F L 2 / 6$.

$A(I, M)=-1 . / F L$

GO TO 20 $40 \quad 60 A(I, J)=(X(I+1)-X(I-1)) / 3$.

60 TO 20

$80 \mathrm{~A}(\mathrm{I}, \mathrm{J})=\mathrm{FL} 1 / 6$.

$A(I, M)=-1 . / F L 1$

45

20 CONTINUE

IF $(N-3) 111,112,111$

$11100110 \mathrm{I}=3, \mathrm{KK}$

$A(I, I)=A(I, I)-A(I, I-1) \div A(I-1, I) / A(I-1, I-1)$

$A(I, 1)=-A(I, I-1) \div A(I-1,1) / A(I-1, I-1)$

$110 A(I, J)=A(I, J)-A(I, I-1) * A(I-1, J) / A(I-1, I-1)$

$112 A(N-1,1)=A(N-1,1) / A(N-1, N-1)$

$A(N-1,1)=A(N-1$

$130 A(N-1, I)=A^{\prime}(N-1, I) / A(N-1, N-1)$

IF $(N-3) 113,114,113$

$11300 \quad 140 \mathrm{I}=2, \mathrm{M} 4$

$J=N-I$

$A(J, 1)=(A(J, 1)-A(J, J+1): A(J+1,1)) / A(J, J)$ 
DO $140 \mathrm{~K}=\mathrm{N}, \mathrm{M1}$

$140 A(J, K)=(A(J, K)-A(J, J+1) * A(J+1, K)) / A(J, J)$
114 DO $141 \quad I=2, K K$

DO $141 \mathrm{~J}=2, \mathrm{KK}$

IF (I-J) $142,143,142$

$143 A(I, J)=1$.

$65 \quad 142 A(I, J)=0$.

141 CONTINUE

DO $150 \quad I=M 3, M 1$

$F(I)=0$.

DO $150^{\circ} J=1, M 1$

70150 A(I,J) $=0$

IF $(\operatorname{IOP}(i)-5) 151,152,151$

152 DO $153 \quad I=1, M 1$

153 A(T, I $)=0$.

$75 \quad 151$ DO $149 \quad I=N, M 1$

$149 \quad A(1, I)=0$.

DO $154 \quad I=1, K K$

$160 \mathrm{MK}=\mathrm{IOP}(1)$

60 TO $(220,230,240,250), M K$

80

220 IF $(I-1) 221,222,221$

$A(1,1)=1$.

$F(1)=F 1$

GO TO 155

$221 \mathrm{BOB}=0$.

60 TO 155

230 If $(I-1) 231,232,231$

$232 \quad A(1,1)=1$.

231 If $(I-2) 233,233,234$

90

$233 B O B=-F 1$

GO TO 155

$234 \mathrm{BOB}=0$.

60 TO 155

95

IF $(I-1) 241,242,241$

$242 A(1,1)=(x(2)-x(1)) / 3$

$A(1, N+1)=1.1(x(2)-x(i))$

$A(1, N+2)=-A(1, N+1)$

$F(1)=-F 1$

GO TO 155

$100 \quad 241$ IF $(I-2) 243,243,244$

$243 \mathrm{BOB}=\left(x(2)-x^{\prime}(1)\right) 16$

60 TO 155

244 BOB $=0$.

GO TO 155

250 IF $(I-1) 251,252,251$

$252 A(1,1)=1$.

$A(1, N)=-i$.

$G 0$ TO 155

155 GO TO 155

$156 \quad A(1,1)=A(1,1)-B 0 B * A(1,1)$

$57 \quad A(1, J)=A(1, J)-B 0 B \div A(I, J)$ 
115154 CONINUE

DO $158 \mathrm{I}=\mathrm{N}, \mathrm{M} 1$

$158 \quad A(1, I)=A(1, I) / A(1,1)$

$F(1)=F(1) / A(1,1)$

120

DO $159 \mathrm{I}=2, \mathrm{KK}$

$F(I)=F(I)-A(I, 1) * F(1)$

DO $159 \mathrm{~J}=\mathrm{N}, \mathrm{MT}$

$159 \quad A(I, J)=A(I, J)-A(I, 1) * A(1, J)$

$A(1,1)=1$

$D O\{61 \quad I=2, K K$

125

$A(1, I)=0$.

$161 A(1,1)=0$.

200 IF (IOP(2) -5) 201,202,201

$20200203 \quad I=1, M 1$

$203 A(N, I)=0$.

201 DO $204 \mathrm{IO}=\mathrm{N}, \mathrm{M} 1$

$204 \quad A(N, I)=0$.

$A(N, 1)=0$.

DO $205 \quad I=1, K K$

$135 \quad 260 \mathrm{MK}=\mathrm{IOP}(2)$

GO TO $(310,320,330,340), M K$

310 If (I-1) $311,312,311$

$312 A(N, N)=1$.

$F(N)=F N$

$140 \quad$ GO TO 206

$311 \quad B O B=0$.

GO TO 206

320 IF (I - 1) $321,322,321$

$322 A(N, N)=1$.

321 If $(I-(N-1)) 323,324,323$

$324 B O B=-F N$

$\frac{B 0 B}{60}=-F N$

$323 \mathrm{BOB}=0$.

GO TO 206

150

(I - 1) $331,332,331$

$332 A(N, N)=(X(N)-X(N-1)) / 3$.

$A(N, M 2)=-1 . /(X(N)-X(N-i))$

$155 \quad \begin{array}{ll}A(N, M 1)=-A \\ F(N)=F N\end{array}$

$F(N)=F N$

-60 TO 206

(1) $(N-1)) 333,334,333$

$334 \mathrm{BOB}=(X(N)-X(N-1)) / 6$

GO TO 206

$160 \quad 333 \mathrm{BOB}=0$.

60 TO 206

340 If (I - I) $341,342,341$

$342 A(N, N)=(X(2)-X(1)+X(N)-X(N-1)) / 3$

$A(N, N+1)=1 . /(X(2)-X(1))$

$A(N, N+2)=-A(N, N+1)$

$A(N, M 2)=-1 . /(X(N)-X(N-1))$

$A(N, M 1)=-A(N, M 2)$

60 TO 206

341 IF (I - 2) $343,344,343$

343 If $(I-(N-1)\} 345,346,345$

$344 \quad 00 B=(x(2)-x(1)) 16$. 
GO TO 206

175

$346 \mathrm{BOB}=(X(N)-X(N-1)) / 6$.

GO TO 206

$345 \mathrm{BOB}=0$.

GO TO 206

206 If $(I-1) 207,205,207$

$207 F(N)=F(N)-B 0 B * F(I)$

180

$A(N, 1)=A(N, 1)-B O B * A(1,1)$

DO $208 \quad J=N, M 1$

$208 A(N, J)=A(N, J)-B 0 B * A(I, J)$

205 CONTINUE

DO $210 \quad I=M 3, M 1$

$210 A(N, I)=A(N, I) / A(N, N)$

$P(N)=F(N) / A(N, N)$

$A(N, 1)=A(N, 1) / A(N, N)$

$00\} 11 \mathrm{I}=1, \mathrm{KK}$

$F(I)=F(I)-A(I, N) * F(N)$

$A(I, 1)=A(I, 1)-A(I, N) * A(N, 1)$

190

$211 A(I, J)=A(I, J)-A(I, N) * A(N, J)$

$A(N, N)=1$.

$D O \sum 39 \quad I=2, K K$

195

$A(N, I)=0$.

$239 A(I, N)=0$.

$A(1, N)=0$.

300 GO TO 400

400 A1 N $=A(1, N)$

$A 1 N=A(1, N)$

DO $1000 \mathrm{~J}=1, J 1$
$\operatorname{IF}(T(\mathrm{~J})-X(1)) 77,77,66$

DO $1000 \mathrm{~J}=1, J 1$
$\operatorname{IF}(T(\mathrm{~J})-X(1)) 77,77,66$

66 IF $(T(J)$

GO TO 212

68 CALL SMOLS2(T(J), X, N,M,MFLAG)

If $(M-1) 76,77,76^{\circ}$

$77 I=1$

GO TO 212

76 If (MFLAG) $78,79,78$

210

$\frac{79=M-1}{G 0 \text { TO } 212}$

$78 \mathrm{I}=\mathrm{M}$

$212 A 1=X(I+1)-T(1)$

$F L I=X(I+1)-X(I)$

$215 \quad M B=N+I$

$M B=N+I$
$A Z=T(J)-X(I)$

AI $J=-((A 1+3) /(6 . * F L I)-F L I \div A 1 / 6$.

$B I J=-((A 2 * 3) /(6 . * F L I)-F L I * A 2 / 6 . ;$

$C I J=A 1 / F L I$

220

$D I J=A 2 / F L I$

IF $($ IOP $(1)-5) 401,402,401$

402 IF $(I-1) 403,404,403$

403 If $(I-(N-1)) 405,406,405$

404 EIJ $=-A I J+A(2,1): B I J$

GO TO 410

225

$406 E I J=A(N-1,1) * A I J+A N 1 \div B I J$

GO TO $410^{\circ}$

$405 E I J=A(I, 1) * A I J+A(I+1,1) * B I J$ 
$410 A(1, I)=A(1, I)-E I J * A I J$

$A(1, I+1)=A^{\prime}(1, I+1)-E I J \div B I J$

$A(1, M B)=A(1, M B)+E I J * C I J$

$A(1, M B+1)=A(1, M B+1)+E I J * D I J$

$F(1)=\bar{F}(1)+E I J$ \& $Y(J)$

$235 \quad 401$ IF (IOP(2)-5) 411,412,411

413 IF (I-T)413,414,413

413 IF $(\mathrm{I}-(\mathrm{N}-1)\} 415,416,415$

414 GIJ $=A 1 N * A I J+A(2, N) * B I J$

GO TO 420

240

$416 \mathrm{GIJ}=A(N-1$

GO TO $420, N) * A I J-B I J$

$415 G I J=A(I, N) * A I J+A(I+1, N) * B I J$

$420 A(N, I)=A(N, I)-G I J * A I J$

$A(N, I+1)=A^{\prime}(N, I+1)-G I J * B I J$

$A(N, M B)=A(N, M B)+G I J \star C I J$

$245 \quad \begin{array}{ll}A(N, M B+1)=A(N, M B+1)+G I J * D I J \\ F(N)=F(N)+G I J * Y(J)\end{array}$

$411001000 \mathrm{~K}=1, \mathrm{~N}$

$K 1=N+K$

IF $(I-1) 430,431,430$

$250 \quad 430$ IF $(I-(N-1)\} 432,433,432$

431 If (IOP(1)-5) 432, 435,432

$435 P K J I=A(2, K 1) * B I J$ GO TO 450

$255 \quad 433$ IF $(I O P(2)-5) 432,436,432$

GO TO 450

$432 P K J I=A(I, K 1) * A I J+A(I+1, K 1) * B I J$

450 IF $(K-I) 451,452,453$

453 IF $(K-(I+1)) 451,454,451$

452 PKJI $=P K J I+A 1 / \tilde{F} L I$

60 TO 451

454 PK $\sqrt{I=P K J I+A 2 / F L I}$

$451 A(K 1, I)=A(K 1, I)-P K J I * A I J$

$A(K 1, I+1)=A(K 1, I+1)-P K J I \div B I$

$A(K 1, M B)=A(K 1, M B)+P K J I * C I J$

$\begin{array}{ll}265 & A(K 1, M B)=A(K 1, M B)+P K J I * C I J \\ A(K 1, M B+1)=A(K 1, M B+1)+P K J I * D I J\end{array}$

$1000 \quad F(K 1)^{\prime}=F(K 1)+P K J I=Y(J)$

IF $($ IOP(1)-4)601,602,601

$270 \quad 602 D 0604 I=1, M 1$

$604 A(N+1, I)=0$.

$A(N+1, N+1)=1$.

$A(N+1, M 1)=-1$.

$F(N+1)=0$.

275

601 CALL SMOLS1(N2, 1, N2, A, F, DET)

RETURN

END 

\begin{tabular}{rrrr} 
ENTRY POINTS & DEF LINE & REFERENCES \\
\hline 3 & SMOLSW & 1 & 275
\end{tabular}

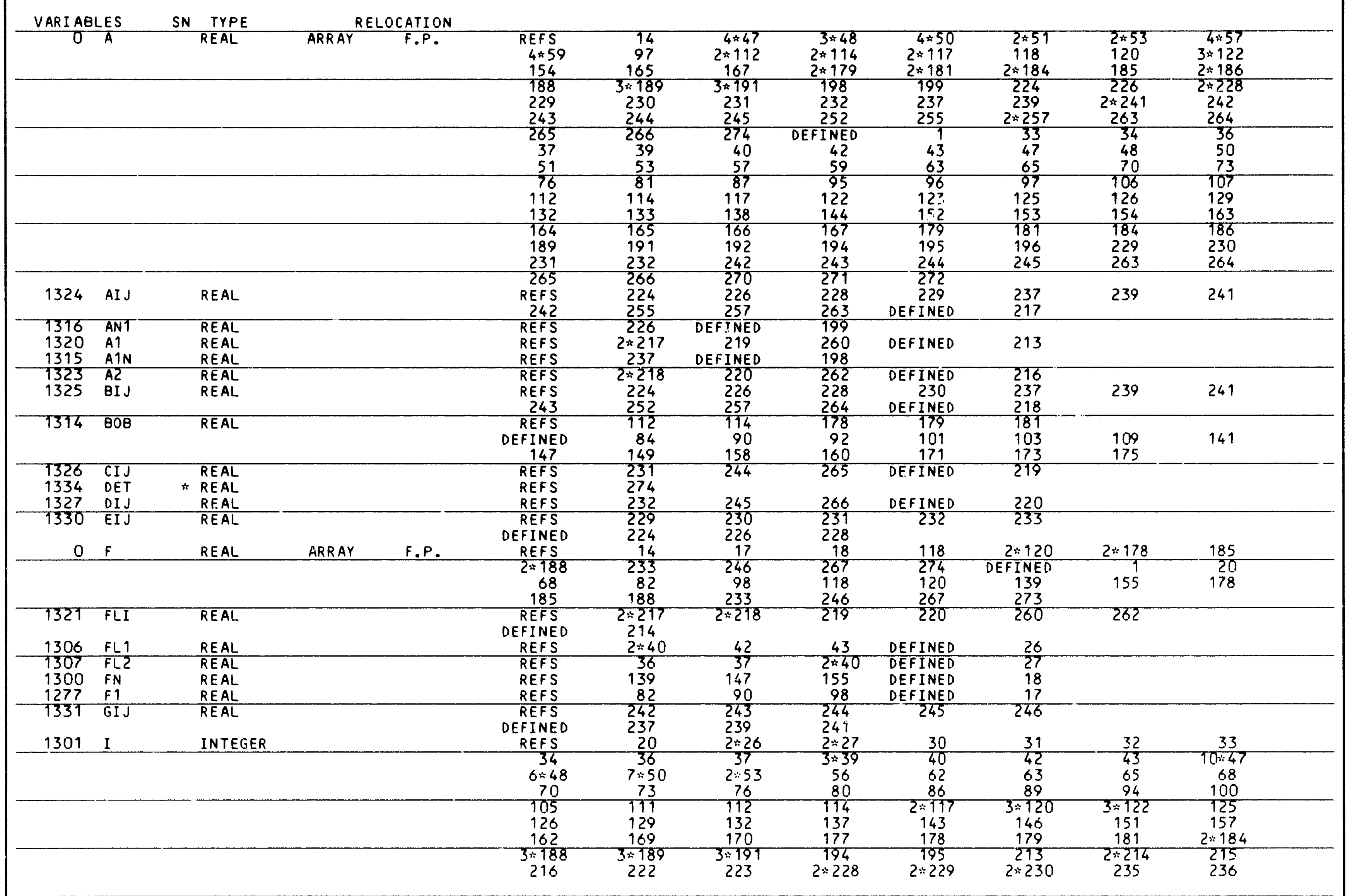




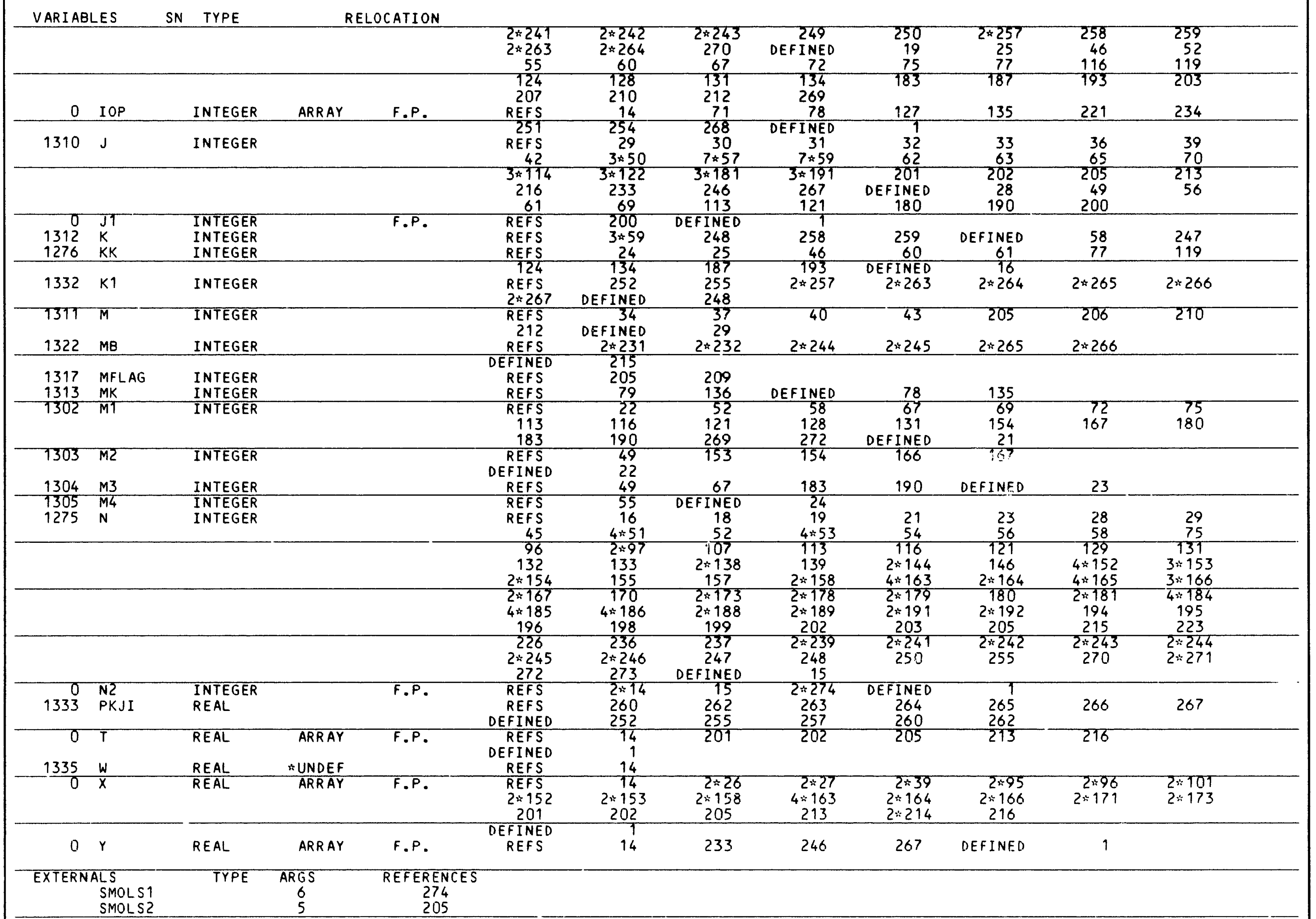




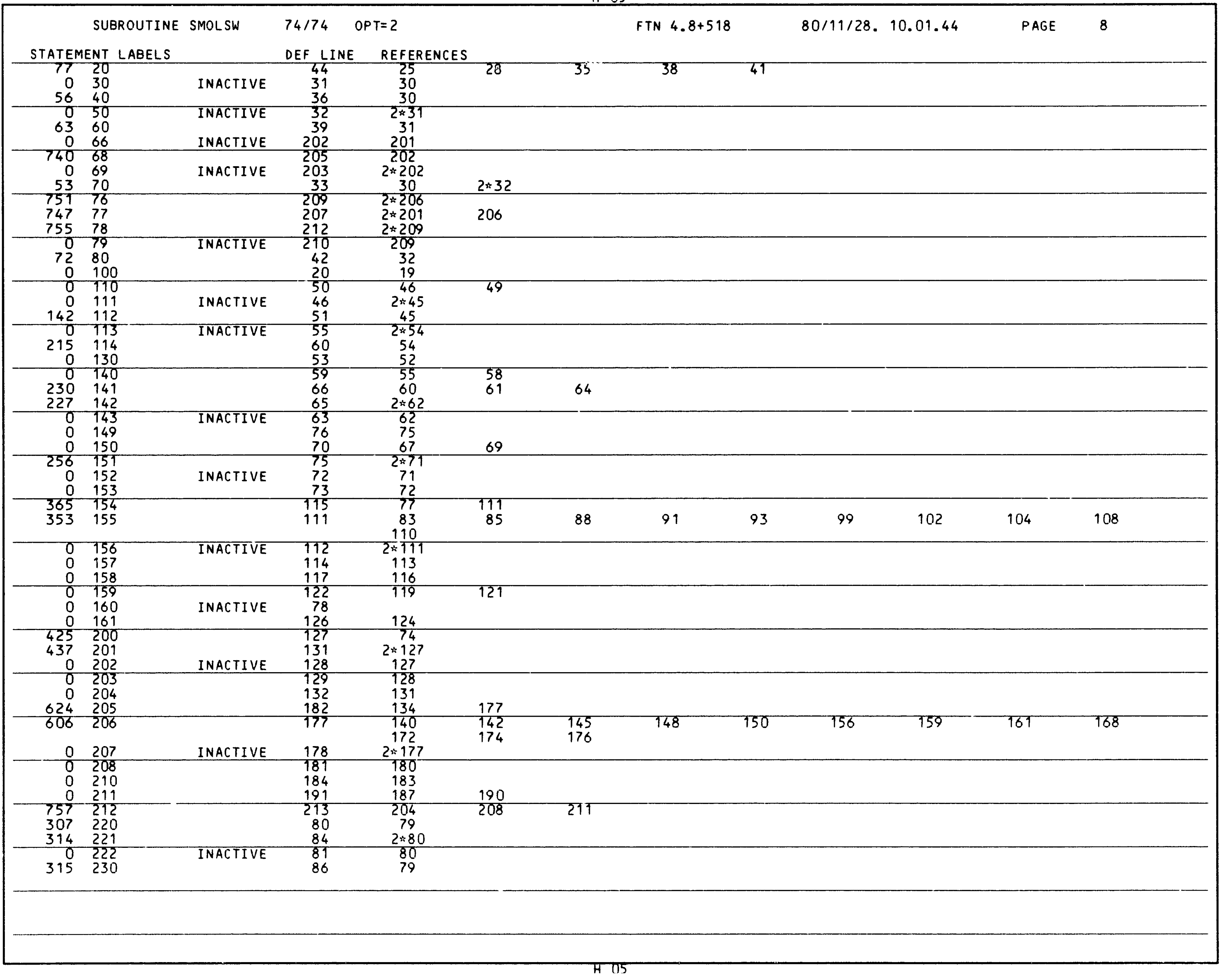




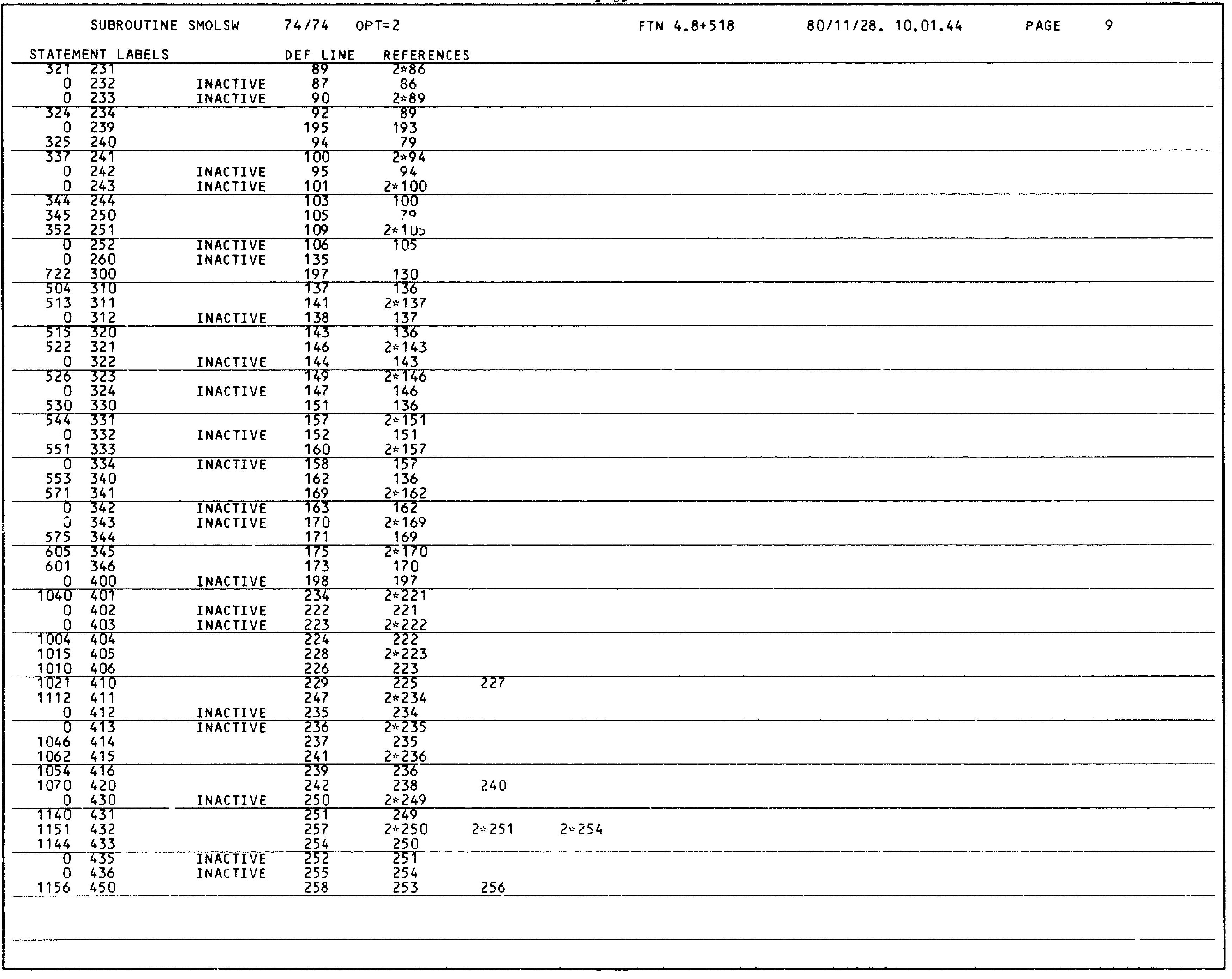




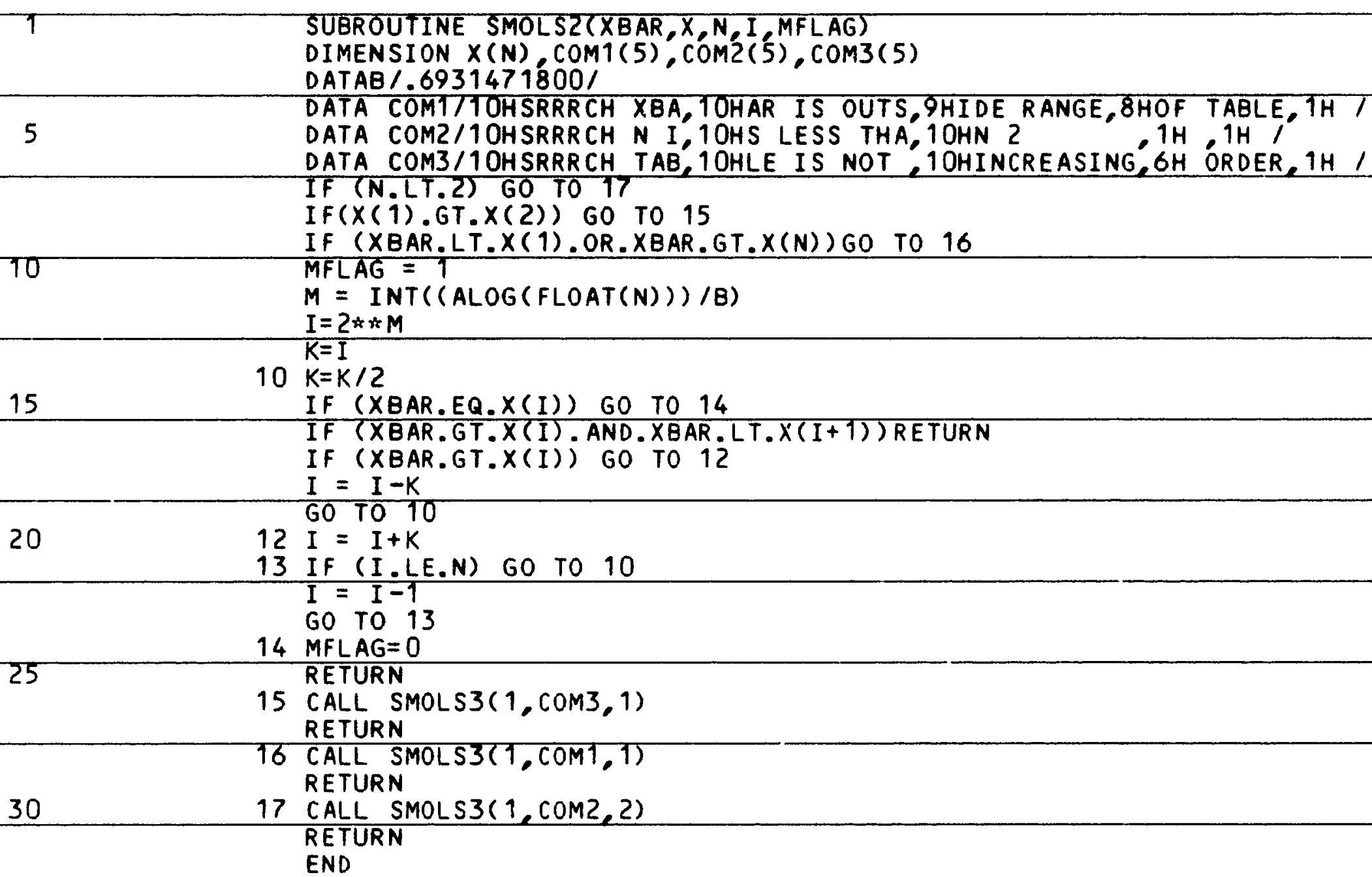

SYMBOLIC REFERENCE MAP $(R=3)$

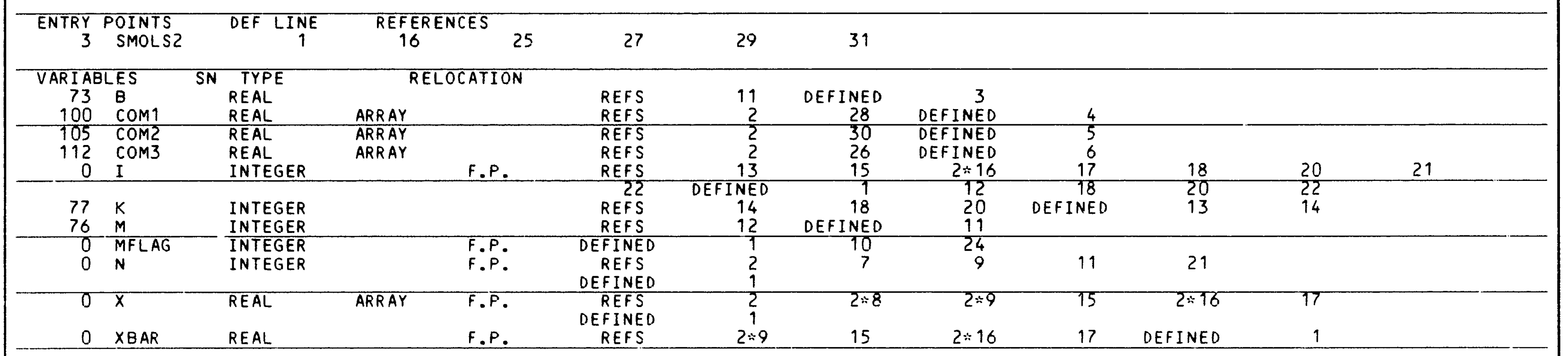




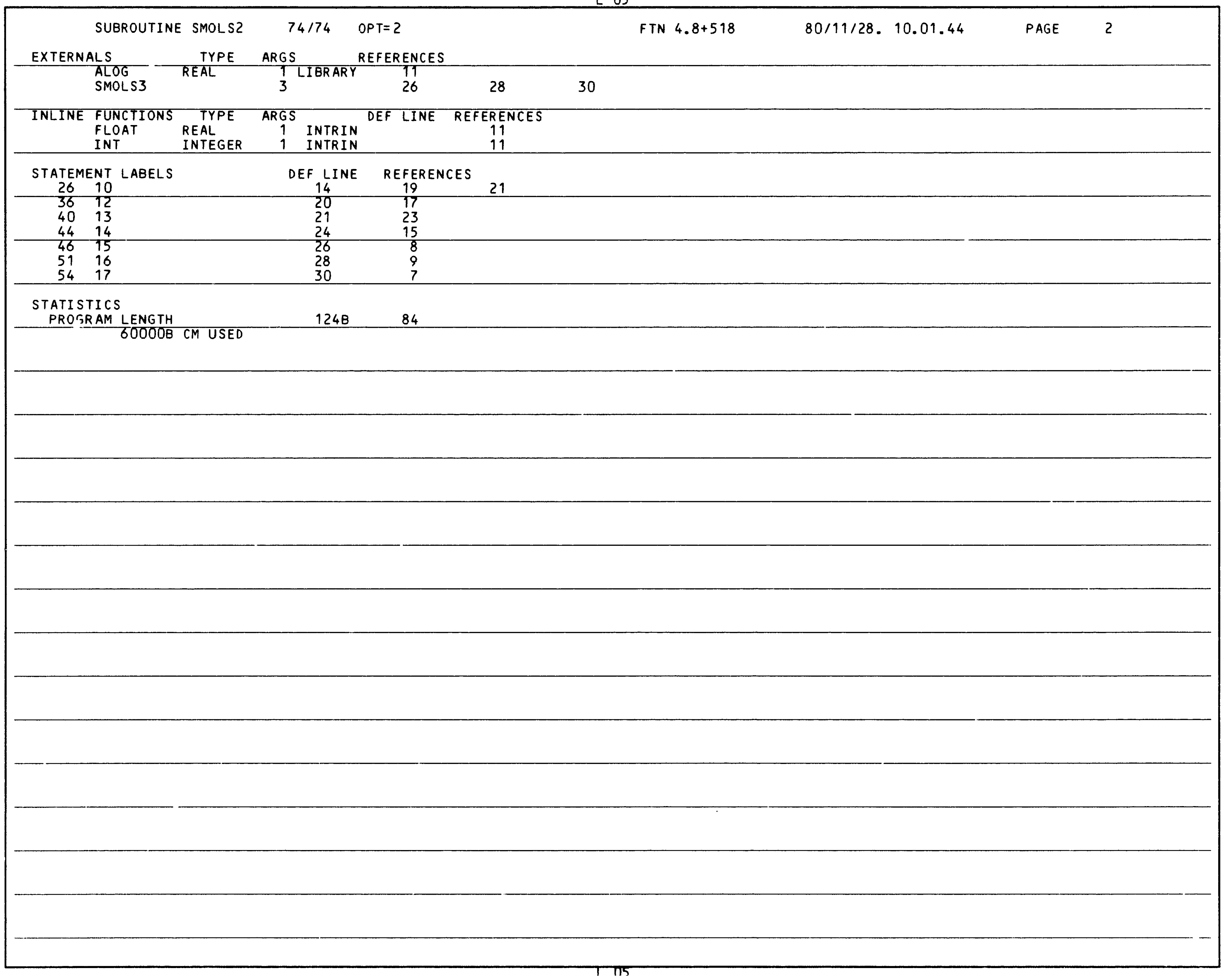




\section{1}

5

10

15

25

30

35

45

50

SUBROUTINE SMOLST(N,M,I,A,B, DET)

DIMENSION $A(I, N), B(I, M), \operatorname{COM} 1(5), \operatorname{COM} 2(5), \operatorname{COM} 3(5)$

DOUBLE PRECI SION 51,52, SMOLS4

DATA COMT/1OHLSS NEAR S, 1OHINGULAR SY, 10HSTEM. CALC, 1OHULATION CO, 11OHNTINUED

DATA COM2/10HLSS SINGUL, 10HAR SYSTEM., 10H NO RESULT, 10H. INPUT DE, TIOHSTROYED

N'IS 2,10 HERO. NO IN, 1OHPUT DATA H, 1OHAS BEEN DE,

DATA COM3/10HLSS $N$ IS $2,10 H E R O$. NO IN, 1OHPUT DATA H,10HAS BEEN DE,

$110 H S T R O Y E D$

$N N=N$

IF (NN.EQ.0) GO TO 20

$M M=M$

$X=0$

DO $1 \mathrm{~J}=1, \mathrm{NN}$

DO $1 K=1, N N$

$T=A B S(A(K, J))$

1 CONTINUE

IF (X.EQ.O.) GO TO 19

IF (X.GT.1.E-15) GO TO 2

CALL SMOLS3 $(1$, COM1, 1)

$2 S N=1$.

DO $14 j=1, N N$

$L=J-1$

IF (J.EQ.NN) GO TO 11

$T=A B S(A(J, J))$

$M 1=J$

$M 2=J+1$

DO $3 \mathrm{~K}=M 2, \mathrm{NN}$

$X=A B S(A(K, J))$

IF (X.LE.T) GO TO 3

$T=x$

$M 1=K$

3 CONTINUE

IF $(M 1 . E Q . J)$ GO TO 6

DO $4 \mathrm{~K}=1$, NN

$T=A(J, K)$

$A(J, K)=A(M 1, K)$

$4 A(M 1, K)=T$

DO $5 K=1, M M$

$T=B(J, K)^{\prime}$

$B(J, K)=B(M 1, K)$

$5 B(M T, K)=$

$S N=-S N$

6 IF $(A(J, J)$.EQ.0.) GO TO 19

DO $10 \mathrm{~K}=\mathrm{M} 2, \mathrm{NN}$

s1 $=0$.

$S 2=0$.

IF (L.EQ.O) G0 TO 8

$S 1=\operatorname{SMOLS4}(L, A(J, 1), I, A(1, K), 1)$

$8 A(J K)=(A(J, K)$

$S 2=S M O L S 4(J, A(K, I), I, A(1, M Z), 1)$

$10 A(K, M 2)=A(K, M Z)=S 2$

$11 \mathrm{DO} 13 \mathrm{~K}=1$, MM

$S 1=0$.

IF (L.EQ.0) GO TO 13

$S 1=S M O L S 4(L, A(J, 1), I, B(1, K), 1)$ 
60

$13 \mathrm{~B}(\mathrm{~J}, \mathrm{~K})=(\mathrm{B}(\mathrm{J}, \mathrm{K})-\mathrm{S} 1) / \mathrm{A}(\mathrm{J}, \mathrm{J})$

14 CONTINUE

$D E T=A(1,1) * S N$

IF (DET.EQ.O.) GO TO 19

IF (N.EQ.1) GO TO ?1

DO $15 \mathrm{~J}=2, \mathrm{NN}$

$65 \quad 15$ DET = DET*AC J O GC

IF (DET.EQ.0.) GC, 19

IF (MM.EQ.0) GO $T: 21$

$M 3=\mathrm{NN}-1$

DO $18 \mathrm{~J}=1, \mathrm{MM}$

DO $17 \mathrm{~L}=1, \mathrm{M3}$

$M 1=N N-L$

$\mathrm{s} 1=0$.

$M 2=M i+1$

$\mathrm{K}=\mathrm{NN}-\mathrm{M2}+1$

$S 1=S M O L S 4(K, A(M 1, M 2), I, B(M 2, J), 1)$

75

$17 B(M 1, J)=B(M 1, J)-S 1$

18 CONTINUE

GO TO 21

19 CALL SMOLS3 $(1$, COM2,2)

GO TO 21

80

20 CALL SMOLS $3(1, \operatorname{COM} 3,3)$

21 RETURN \$END

\section{SYMBOLIC REFERENCE MAP $(R=3)$}

\begin{tabular}{rrcc} 
ENTRY & POINTS & DEF LINE & REFERENCES \\
3 & SMOLS1 & 1 & 81 \\
\hline
\end{tabular}

\begin{tabular}{|c|c|c|c|c|c|c|c|c|c|c|c|c|}
\hline \multirow{2}{*}{$\begin{array}{c}\text { VARI ABLE } \\
0\end{array}$} & \multirow{2}{*}{$\begin{array}{l}E S \\
A\end{array}$} & \multirow{2}{*}{$\begin{array}{c}\text { SN TYPE } \\
\text { REAL } \\
\end{array}$} & \multicolumn{2}{|c|}{ RELOCATION } & \multirow[b]{2}{*}{ REFS } & \multirow[b]{2}{*}{2} & \multirow{3}{*}{$\frac{16}{2: 52}$} & \multirow[b]{2}{*}{26} & \multirow[b]{2}{*}{30} & \multirow[b]{2}{*}{37} & \multirow[b]{2}{*}{38} & \multirow[b]{2}{*}{45} \\
\hline & & & ARR AY & F.P. & & & & & & & & \\
\hline 0 & B & REAL & ARRAY & F.P. & $\begin{array}{c}2: 50 \\
74 \\
\text { REFS }\end{array}$ & $\begin{array}{r}2: 51 \\
\text { DEFINED } \\
2\end{array}$ & & $\begin{array}{l}53 \\
38 \\
42\end{array}$ & $\begin{array}{l}57 \\
39 \\
57\end{array}$ & $\begin{array}{l}58 \\
51 \\
58\end{array}$ & $\begin{array}{l}60 \\
53 \\
74\end{array}$ & $\begin{array}{l}64 \\
75\end{array}$ \\
\hline $\begin{array}{r}413 \\
420 \\
\end{array}$ & $\begin{array}{l}\text { COM1 } \\
\text { COM? }\end{array}$ & $\begin{array}{l}\text { REAL } \\
\text { REAL }\end{array}$ & $\begin{array}{l}\text { ARR AY } \\
\text { ARRAY }\end{array}$ & & $\begin{array}{c}\text { DEFINED } \\
\text { REFS } \\
\text { REFS } \\
\end{array}$ & $\begin{array}{r}1 \\
2 \\
2 \\
\end{array}$ & $\begin{array}{l}42 \\
21 \\
78 \\
\end{array}$ & $\begin{array}{c}43 \\
\text { DEFINED } \\
\text { DEFINED }\end{array}$ & $\begin{array}{r}58 \\
4 \\
6 \\
\end{array}$ & 75 & & \\
\hline $\begin{array}{r}425 \\
0 \\
0 \\
\end{array}$ & $\begin{array}{l}\operatorname{COM} 3 \\
D E T \\
I\end{array}$ & $\begin{array}{l}\text { REAL } \\
\text { REAL } \\
\text { INTEGER }\end{array}$ & ARRAY & $\begin{array}{l}\text { F.P. } \\
\text { F.P. }\end{array}$ & $\begin{array}{l}\text { REFS } \\
\text { REFS } \\
\text { REFS } \\
\end{array}$ & $\begin{array}{l}2 \\
61 \\
2 \times 2 \\
\end{array}$ & $\begin{array}{l}80 \\
64 \\
50 \\
\end{array}$ & $\begin{array}{c}\text { DEFINED } \\
65 \\
52 \\
\end{array}$ & $\begin{array}{c}8 \\
\text { DEFINED } \\
57\end{array}$ & $\begin{array}{r}1 \\
74 \\
\end{array}$ & 60 & 64 \\
\hline 403 & J & INTEGER & & & $\begin{array}{c}\text { DEFINED } \\
\text { REFS } \\
35 \\
\end{array}$ & $\begin{array}{r}1 \\
16 \\
37 \\
\end{array}$ & $\begin{array}{l}24 \\
38 \\
\end{array}$ & $\begin{array}{r}25 \\
41 \\
\end{array}$ & $\begin{array}{c}2 \div 26 \\
42 \\
\end{array}$ & $\begin{array}{c}27 \\
2 \div 45 \\
\end{array}$ & $\begin{array}{l}28 \\
50 \\
\end{array}$ & $\begin{array}{c}30 \\
4: 51 \\
\end{array}$ \\
\hline 404 & $\mathrm{~K}$ & INTEGER & & & $\begin{array}{c}52 \\
\text { DEFINED } \\
\text { REFS }\end{array}$ & $\begin{array}{l}57 \\
14 \\
16\end{array}$ & $\begin{array}{l}4 \div 58 \\
23 \\
30\end{array}$ & $\begin{array}{c}2 \div 64 \\
63 \\
33\end{array}$ & $\begin{array}{l}74 \\
68 \\
37 \\
\end{array}$ & $\begin{array}{l}2: 75 \\
2: 38\end{array}$ & 39 & 41 \\
\hline & & & & & $\begin{array}{c}2: 42 \\
74 \\
73\end{array}$ & $\begin{array}{c}43 \\
\text { DEFINED }\end{array}$ & $\begin{array}{l}50 \\
15\end{array}$ & $\begin{array}{c}2 \times 51 \\
29\end{array}$ & $\begin{array}{l}52 \\
36\end{array}$ & $\begin{array}{c}2: 53 \\
40\end{array}$ & $\begin{array}{l}57 \\
46\end{array}$ & $\begin{array}{c}2 * 58 \\
54\end{array}$ \\
\hline 407 & $L$ & INTEGER & & & $\begin{array}{c}\text { REFS } \\
\text { DEFINED }\end{array}$ & $\begin{array}{l}49 \\
24\end{array}$ & $\begin{array}{l}50 \\
69\end{array}$ & 56 & 57 & 70 & & \\
\hline 0 & $M$ & INTEGER & & F.P. & REFS & 2 & 12 & DEF INED & 1 & & & \\
\hline
\end{tabular}


SUBROUTINE SMOLS1

$74 / 74 \quad O P T=2$

FTN $4.8+518$

$80 / 11 / 28.10 .01 .44$

PAGE 3

\begin{tabular}{rll} 
VARI ABLES & SN & \multicolumn{1}{c}{ TYPE } \\
\hline 401 & $M M$ & INTEGER \\
410 & $M 1$ & \\
& & \\
\hline 411 & $M 2$ & INTEGER \\
412 & $M 3$ & INTEGER \\
0 & $N$ & INTEGER \\
400 & NN & INTEGER \\
406 & SN & REAL \\
374 & S1 & DOUBLE \\
376 & S2 & DOUBLE \\
405 & $\mathrm{~T}$ & REAL \\
402 & $X$ & REAL
\end{tabular}

RELOCATION

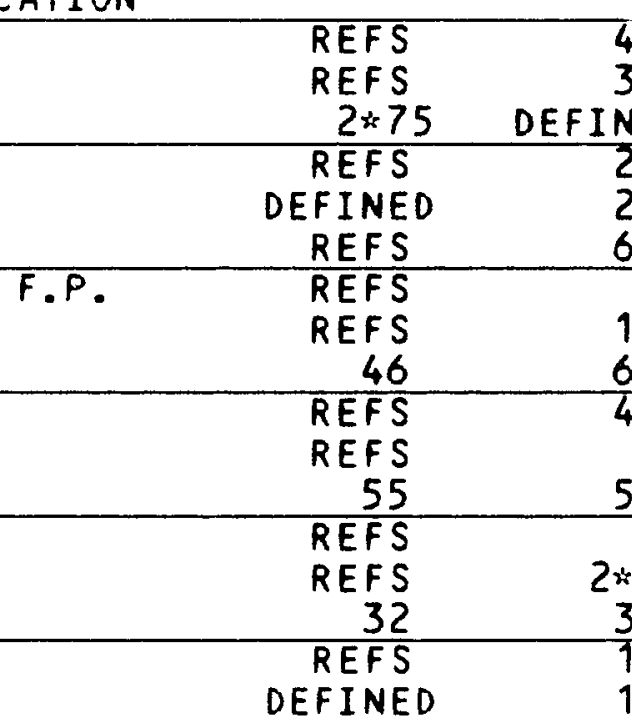

\begin{tabular}{ll}
40 & 54 \\
35 & 38 \\
NED & 27 \\
\hline 29 & 46
\end{tabular}

54
38
27
46
72

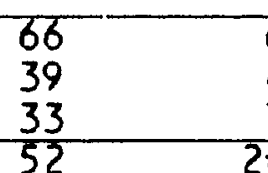

68 DEFINED

DEFINED

NED $\quad 67$

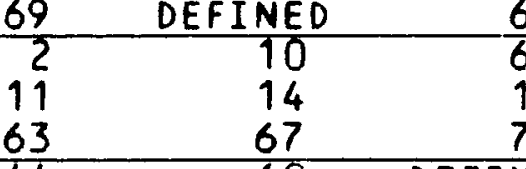

$67 \quad$ DEFINED

$\begin{array}{llll}42 & 43 & 72 & 74\end{array}$

SMOLS3
SMOLS4

TYPE ARGS

REFERENCES

REFNED 13

60 DEFIN

$\begin{array}{lcccc}15 & 1 & & \\ 70 & 23 & 25 & 29 & 36 \\ 73 & 73 & \text { DEFINED } & 10 & \end{array}$

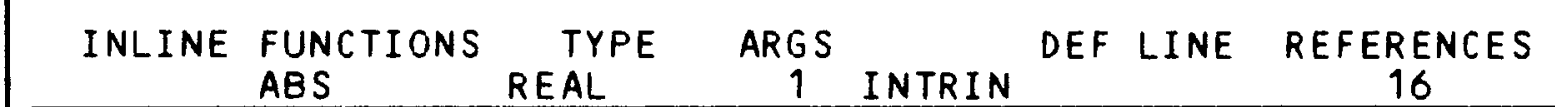

\begin{tabular}{rr} 
& \\
\hline & \\
STATEMENT & \\
0 & 1 \\
31 & 2 \\
56 & 3 \\
0 & 4 \\
\hline 0 & 5 \\
100 & 6 \\
123 & 8 \\
\hline 0 & 10 \\
152 & 11 \\
172 & 13 \\
\hline 0 & 14 \\
0 & 15 \\
0 & 17 \\
0 & 18 \\
303 & 19 \\
306 & 20 \\
\hline 310 & 21 \\
\hline
\end{tabular}

DEF LINE REFERENCES

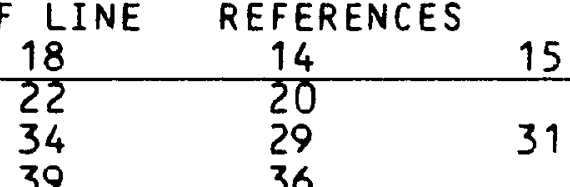

\begin{tabular}{rll} 
LOOPS & LABEL & INDEX \\
\cline { 1 - 3 } 20 & 1 & $\mathrm{~J}$ \\
21 & 1 & $\mathrm{~K}$ \\
41 & 14 & $\mathrm{~J}$ \\
\hline 54 & 3 & $\mathrm{~K}$ \\
64 & 4 & $\mathrm{~K}$ \\
74 & 5 & $\mathrm{~K}$ \\
\hline 116 & 10 & $\mathrm{~K}$ \\
161 & 13 & $\mathrm{~K}$ \\
224 & 15 & $\mathrm{~J}$ \\
\hline 241 & 18 & $\mathrm{~J}$ \\
251 & 17 & $\mathrm{~L}$
\end{tabular}

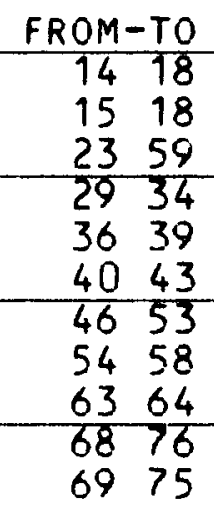

43

45

51

54

59

\begin{tabular}{l}
64 \\
75 \\
\hline
\end{tabular} 76

$\begin{array}{ll}78 & 19 \\ 80 & 11\end{array}$

81

15

56

DEFINED

$\begin{array}{lllll}72 & & 44 & & \\ 58 & 72 & \text { DEFINED } & 47 & 50\end{array}$

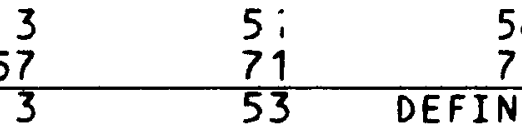

17

$31 \quad 39$

20

$48 \quad 52$

$\begin{array}{rr}43 & \text { DEFINED } \\ 31 & 32\end{array}$

16

26

40

35
49

25

$54 \quad 56$

69

$\begin{array}{llll}19 & 45 & 61 & 65\end{array}$

6975

LENGTH
58
38
1528
38
38
38
408
278
28
428
278

PROPERTIES

NOT INNER

EXT REFS EXITS NOT INNER

INSTACK

INSTACK

EXT REFS NOT INNER

EXT REFS 


\begin{tabular}{|c|c|}
\hline$T$ & $\begin{array}{l}\text { SUBROUTINE SMOLS3(I SW, LHOL, INX) } \\
\text { DIMENSI ON LHOL(5) } \\
\text { LOGICALPS, TS }\end{array}$ \\
\hline 5 & 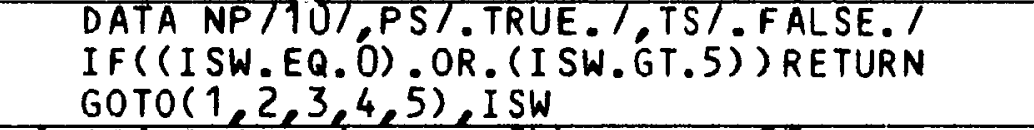 \\
\hline & $\begin{array}{l}\text { IF(PS.AND. (NP,GT,0) PRINT 27, LHOL, INX } \\
27 \text { FORMAT }(1 H O, 9 x, 5 A 10,3 x, 06) \\
\text { NP=NP-1 }\end{array}$ \\
\hline 10 & $\begin{array}{l}\text { IF(TS) CALLEXIT } \\
\text { RETURN } \\
2 \text { PS }=. \text { FALSE. }\end{array}$ \\
\hline 15 & $\begin{array}{l}\text { RETURN } \\
3 \text { PS=.TRUE. } \\
\text { NP }=\text { INX }\end{array}$ \\
\hline & $\begin{array}{l}\text { RETURN } \\
4 \text { TS=. TRUE. } \\
\text { RETURN } \\
\end{array}$ \\
\hline 20 & 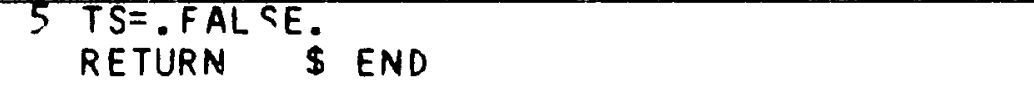 \\
\hline
\end{tabular}

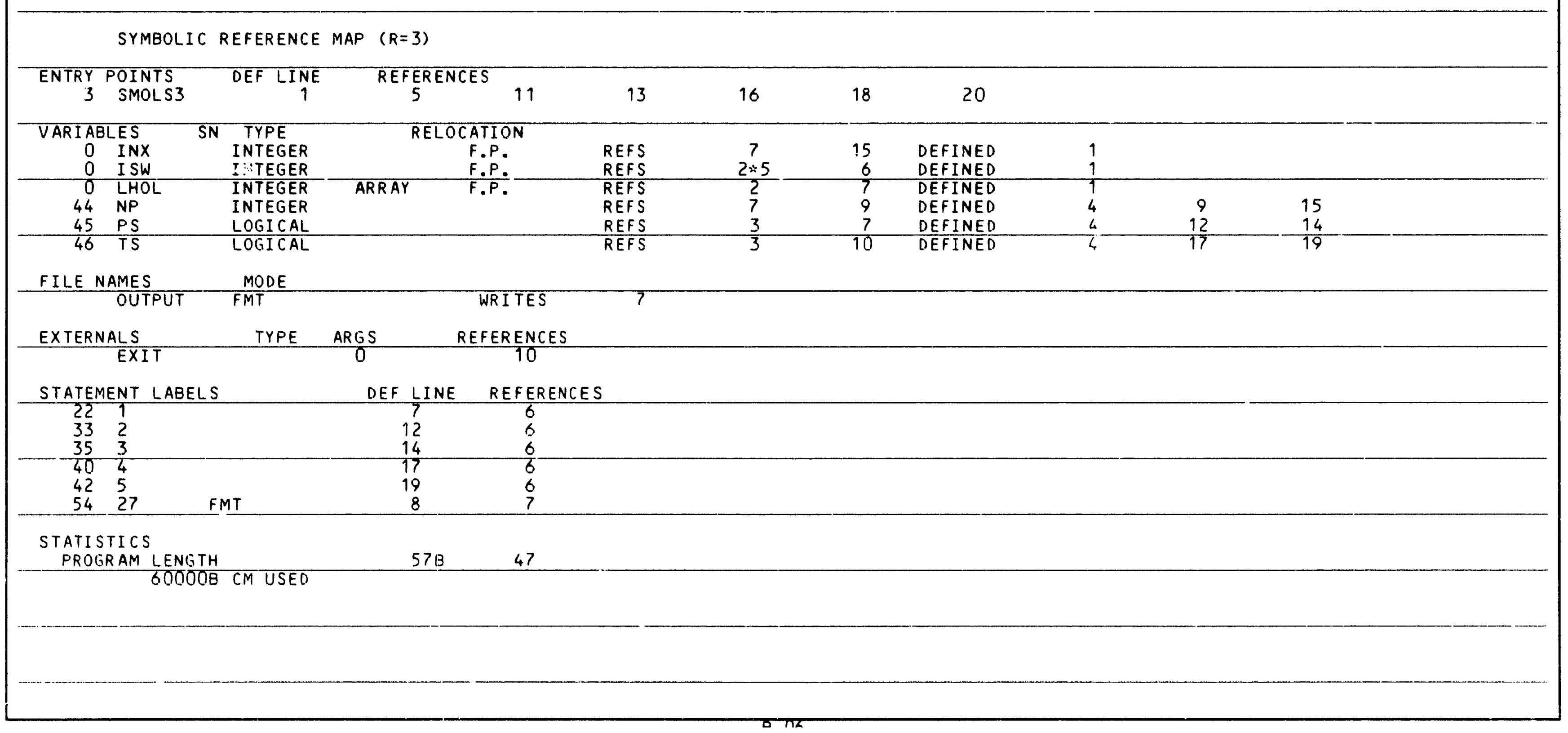




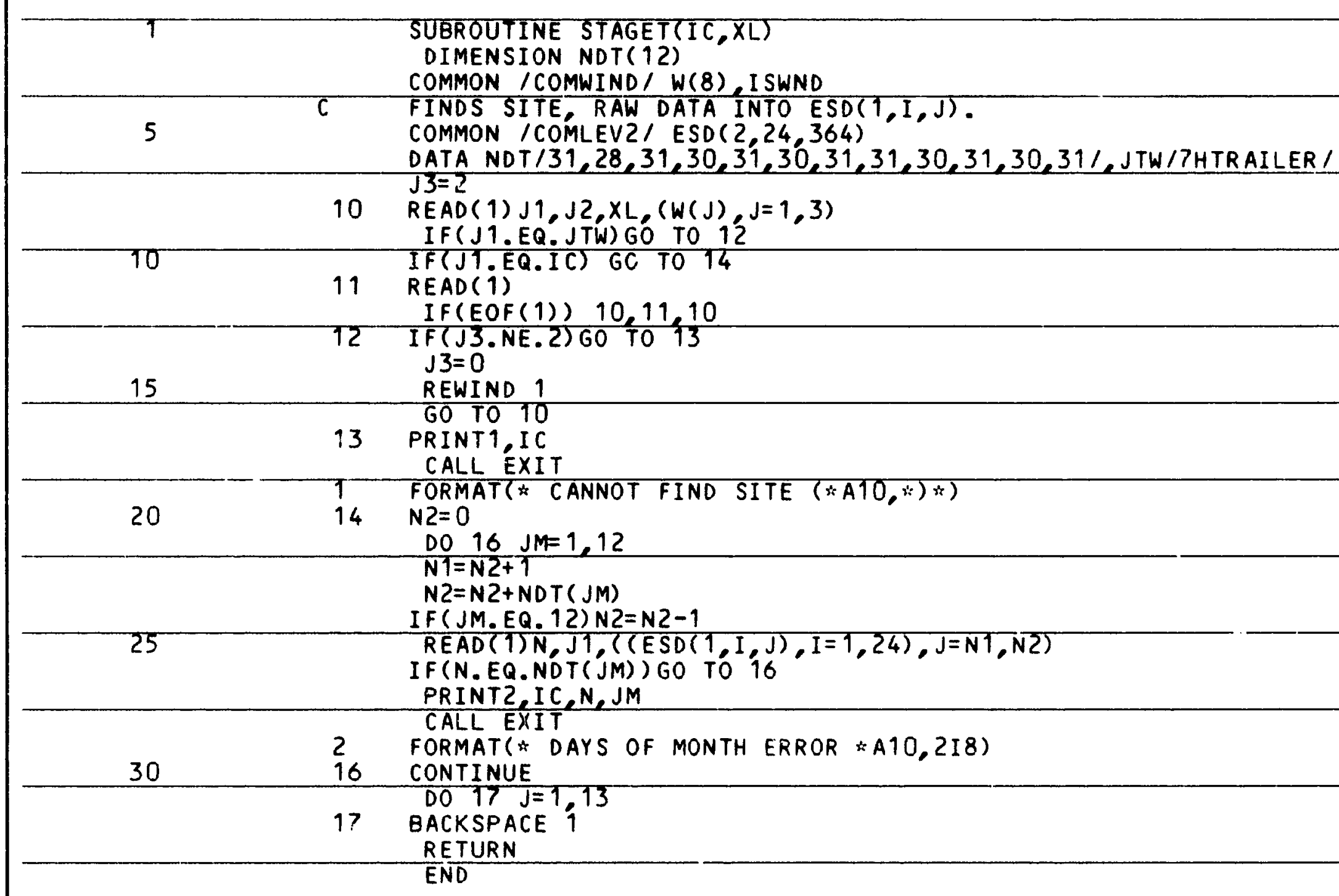

SYMBOLIC REFERENCE MAP ( $R=3)$

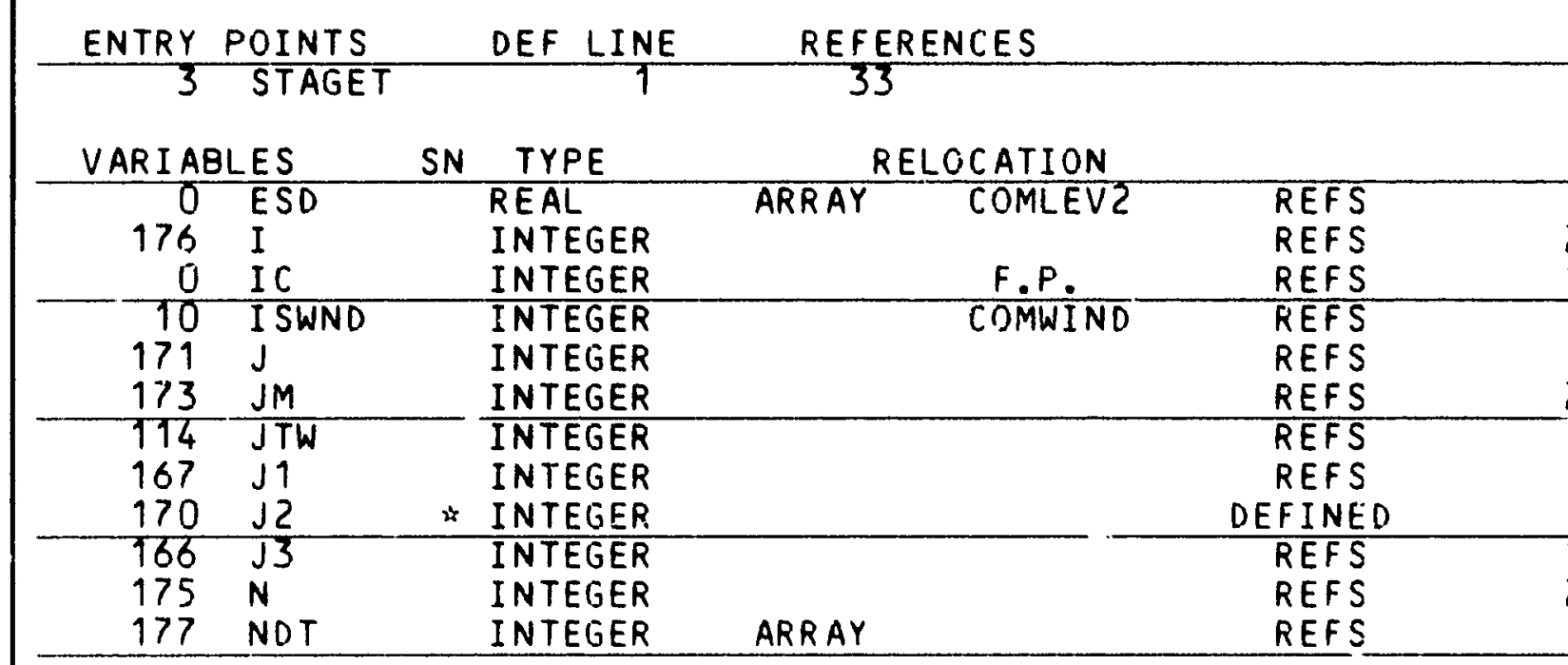

$\begin{array}{rrrrrr}5 & \text { DEFINED } & 25 & & & \\ 25 & \begin{array}{c}25 \\ \text { DEFINED } \\ 10\end{array} & 25 & \text { DEFINED } & 1 & \\ 3 & 17 & 27 & & \\ 8 & 25 & \text { DEFINED } & 8 & 25 & 31 \\ 23 & 24 & 26 & 27 & \text { DEFINED } & 21 \\ 9 & \text { DEFINED } & 6 & & \\ 9 & 10 & \text { DEFINED } & 8 & 25 & \\ 8 & & 7 & 14 & & \\ 13 & \text { DEFINED } & 27 & \text { DEFINED } & 25 & \\ 26 & 23 & \text { DEFINED } & 6 & \\ 2 & 23 & & & & \end{array}$




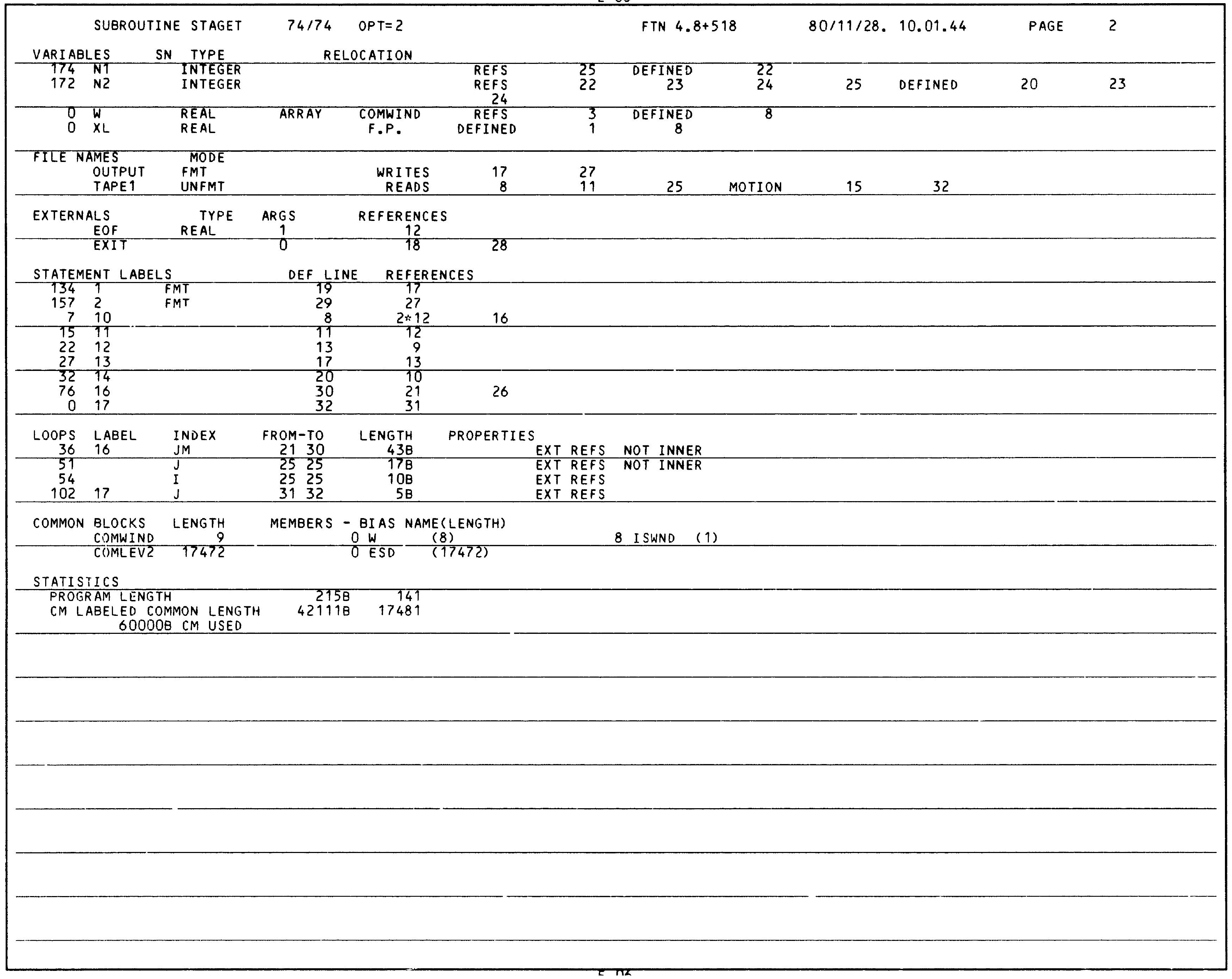


SUBROUTINE PIHI(SD)

DIMENSION R(2,24,14), $D(14), \operatorname{KF}(9,14), \operatorname{KE}(9,14), \operatorname{SD}(24,2)$

KA(I) $=$ SHIFT $(J 1, I) \cdot A \cdot 37777778$

5

REWIND 2

READ ( 2) J1

IF(J1.EQ. 1OHASHRAETABL) GO TO 13

PRINT1,J1

CALL EXIT

101 FORMAT(* NO ASHRAE DATA *A10)

$13 \operatorname{READ}(2) \times 2,(D(J),(\operatorname{KE}(I, J), I=1,9), J=2,13)$

IF (SD (1). LT.X2) GO TO $20^{\circ}$

$10 \times 1=x 2$

$\begin{array}{lll}\text { DO } & 11 & I=1,9 \\ \text { DO } & 11 & \mathrm{~J}=2,13\end{array}$

15

$11 \quad K F(I, J)=K E(I, J)$

$\operatorname{READ}(2) \times 2,\left(D^{\prime}(J),(\operatorname{KE}(I, J), I=1,9), J=2,13\right)$

IF(EOF (2) ) $20,12,20$

20 PRINT2,SD(1)

CALL EXIT

20

CALL EXIT

2 FORMAT(

IF (SD(1).GT.X2)GO TO 10
$D(1)=-10$.

$D(14)=386$

$25 \quad$ DO $14 \mathrm{~J}=19$

$\operatorname{KF}(J, 1)=K F(J, 13)$

$K F(j, 14)=K F(j, 2)$

$\operatorname{KE}(J, 1)=\operatorname{KE}(J, 1\})$

$30 \quad 14 \quad \operatorname{KE}(j, 14 !=\operatorname{KEE}(j, 2)$

$21=x 2-x 1$

$x 2=($ SD $(1)-x 1) / 21$

$x 1=1 .-x 2$

no $23^{\circ} k=1,14$

$35 \quad$ DO $21 \mathrm{~J}=1,24$

$21 \quad R(I, J, K)=0$.

N2 $=21$

DO $23 \mathrm{~J}=1,9$

$40 \quad J 1=K F(J, K)$

$J 2=K E(j, K)$

$K 1=K A(-40)$

$K 2=K B(-40)$

$21=\times 1 \div K 1+x 2 * K 2$

45

IF ( Z1.LE. O.) GO TO 22

$K^{4}=K A(-20)$

$K 2=K B(-20)$

$R(1, N 1, K)=R(1, N 2, K)=(\times 1: K 1+\times 2 \div K 2) / 21$

50

$K 2=K B(0)$

$R(2 N 1, K)=R(2 N 2 K)=(X 1 \div K 1+X 2 * K 2) / Z 1$

55

$N 2=N 2-1$

23 CONTINUE

$X=1$

$K 1=1$ 


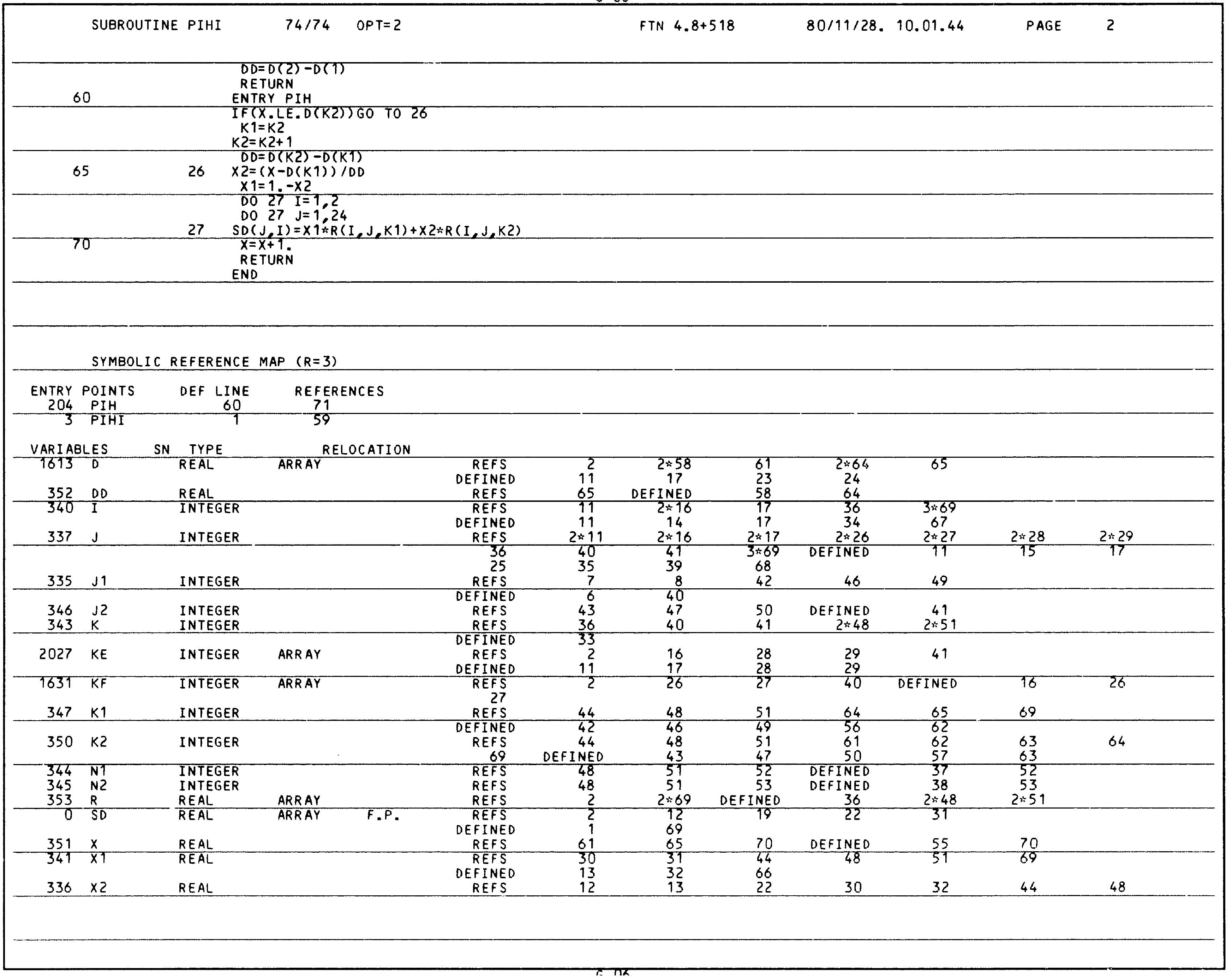




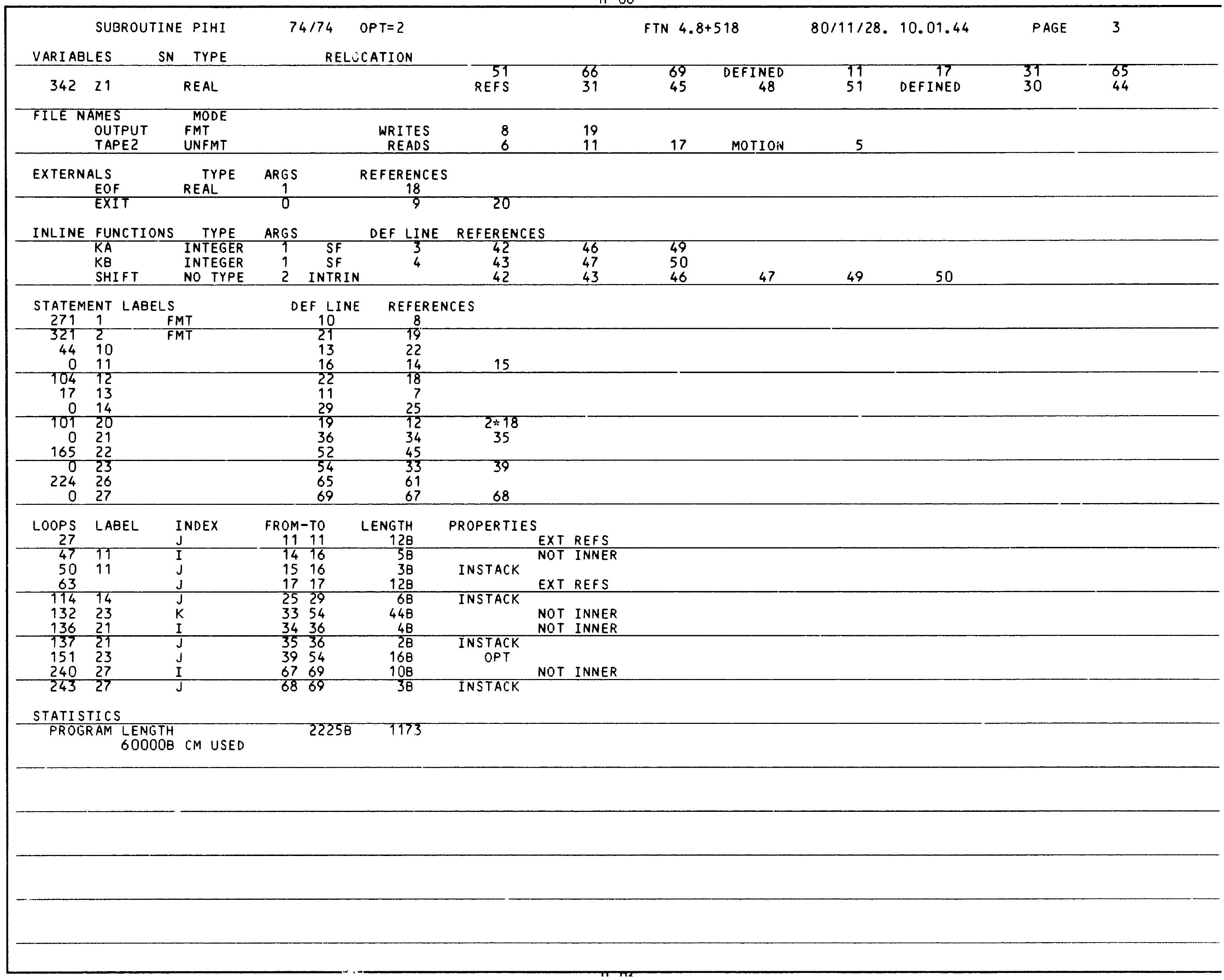


SUBROUTINE DECSEA(N,I $W, F, W)$ DIMENSION IW( 99$), F(99), W(52)$

C $\cdots$ DECODES SEASONAL INPUT.
IF(IW(1).LE.0.0.IW(1).GT.48)GO TO 99
DO $10 \mathrm{~K}=1$. S IF(IW(K+1).LE. IW(K)) G0 TO 99

DO $10 K=1$ I $\$$ I IF (IW(K+1), LE. IW
IF $(\operatorname{IW}(K+1)-\operatorname{IW}(1)-51) 10,11,99$

5

CONTINUE

98 FORMAT (* SEASONAL DECODE ERROR*)

99 PRINT98 \& CALL EXIT

$11 \quad J W=I W(1) \$ D O 13 \quad J=1, K$

$1012 \quad L W=J W \$$ IF (LW.GT.52) $L W=L W-52 \$ W(L W)=F(J)$

$L W=J W \$$
$J W=J W+1$

13 CONTINUE \$ RETURN \$ END

SYMBOLIC REFERENCE MAP $(R=3)$

\section{ENTRY POINTS DEF LINE REFERENCES}

$$
\begin{gathered}
V A R I A B \\
0 \\
\hline 0 \\
54 \\
53 \\
52 \\
55 \\
\hline 0 \\
0
\end{gathered}
$$$$
\begin{array}{cl}
0 & F \\
\hline 0 & \text { IW } \\
54 & \text { J } \\
53 & \text { JW } \\
52 & \text { K } \\
55 & \text { LW } \\
0 & N \\
0 & W
\end{array}
$$

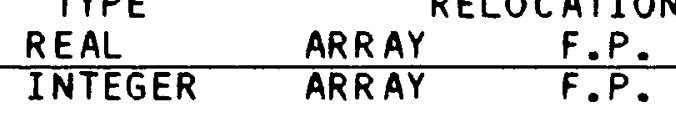

INTEGER

INTEGER

INTEGER

INTEGER

INTEGER

INTEGER

REAL

ARRAY F.P.

REFS

REFS

REFS

REFS

REFS
REFS

REFS

REFS

REFS

8

\begin{tabular}{lccc}
\hline $\begin{array}{c}\text { FILE NAMES } \\
\text { OUTPUT }\end{array}$ & $\begin{array}{c}\text { MODE } \\
\text { FMT }\end{array}$ & & WRITES \\
\hline EXTERNALS & TYPE & ARGS & REFERENCES
\end{tabular}

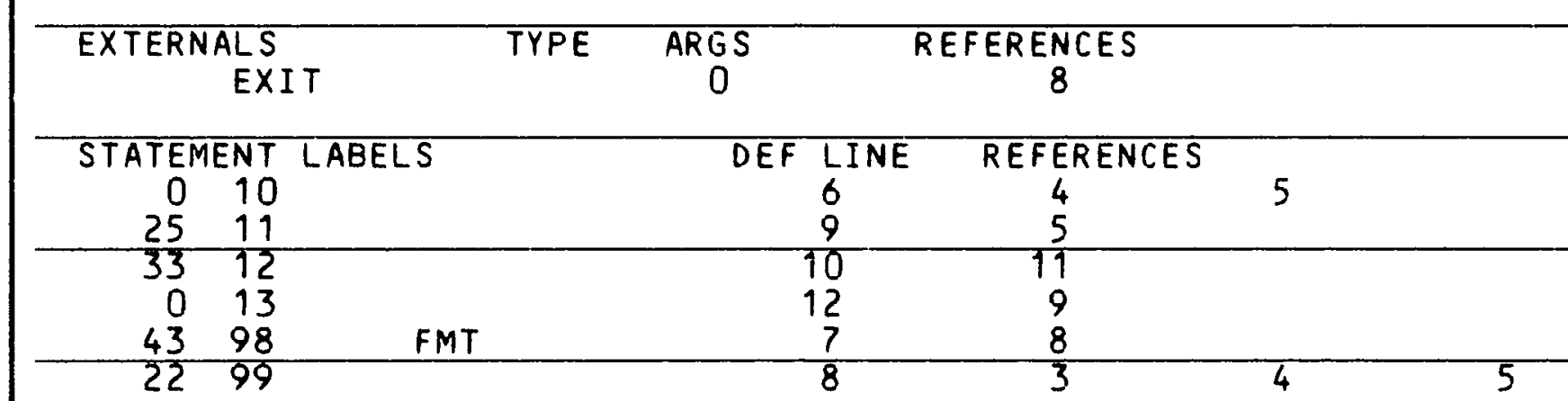

\begin{tabular}{ccccccc} 
LOOPS & LABEL & INDEX & FROM-TO & LENGTH & PROPERTIES & \\
\hline 14 & 10 & $\mathrm{~K}$ & 46 & $6 \mathrm{~B}$ & INSTACK & EXITS \\
32 & 13 & $\mathrm{~J}$ & 912 & $10 \mathrm{~B}$ & OPT &
\end{tabular}

STATISTICS

PROGRAM LENGTH $60000 B$ CM USED

$56 \mathrm{~B}$

46
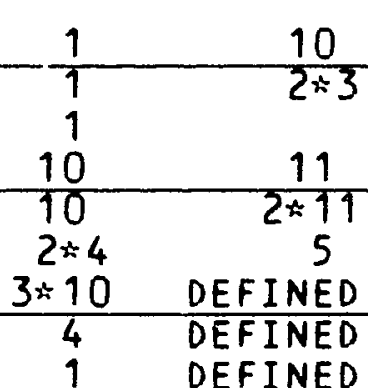

DEFINED

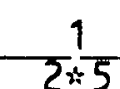

9

DEFINED

DEFINED

$2 * 90$

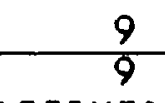

DEFINED

1

10

OPT 


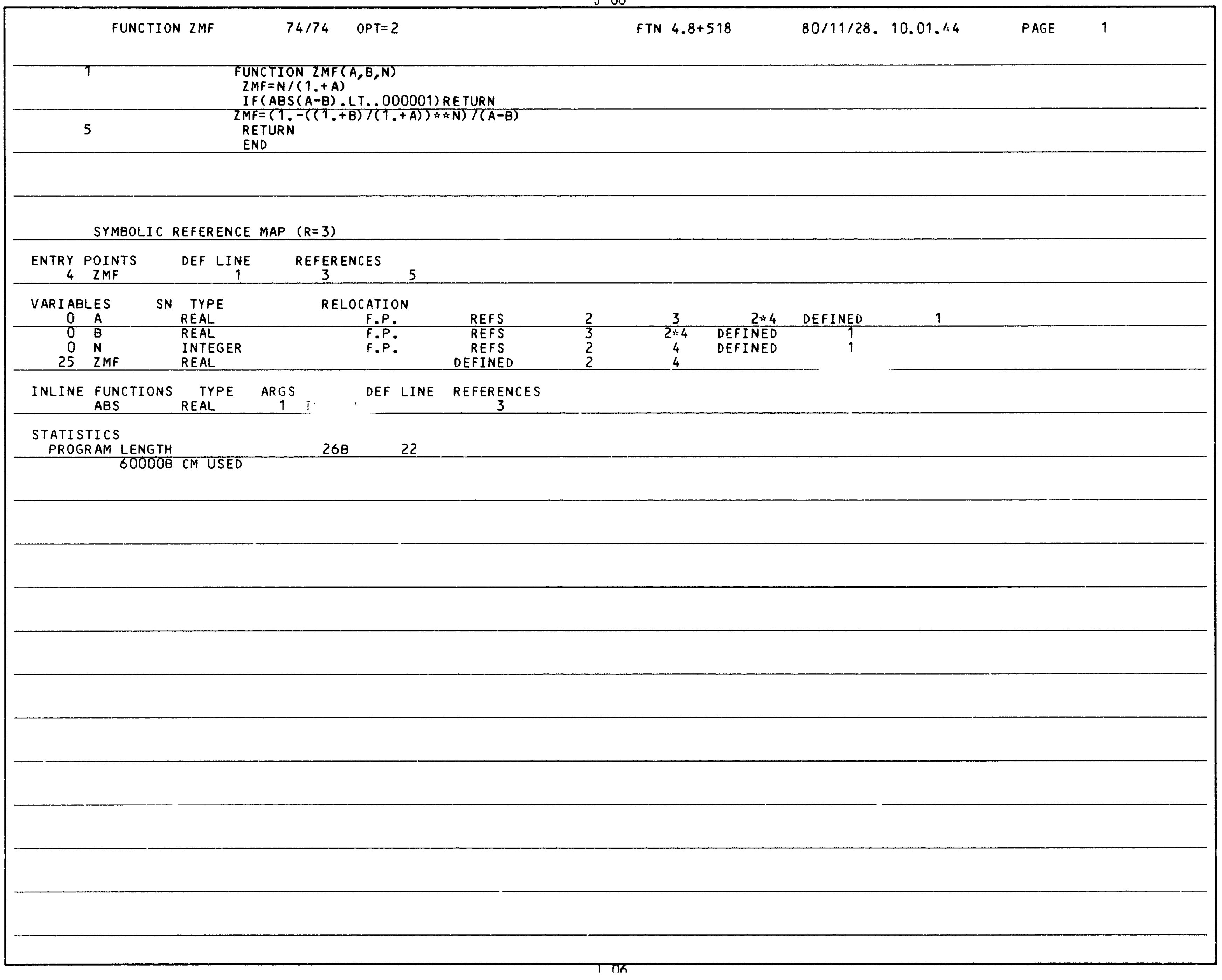


1 SUBROUTINE GETSD(ND)

C .... GETS SUPPLY AND DEMAND FOR ND DAY

C.... TRUE VALUES IN UPPER HALF, PREDICTED IN LOWER HALF OF ESD. COMMON TCOMSUDE/ SUDE $(24,4)$

5

COMMON /COMLEV2/ ESD $(2,24,364)$

DATA MU/77777777770000000000B/\& $N=N D$

10 IF (N.GT.O)GO TO TI\$ $N=N+364 \$$ GO TO 10 $\begin{array}{ll}11 & \text { I F }(N . L E .364) G O \\ 12 & \text { DO } 13 \text { IO } 12 \$ N=N-364 \$ \text { GO TO } 11\end{array}$

10 $D O 13 I=1,24 \$ \operatorname{SUDE}(I, 1)=E S D(1, I, N)$. A.MU

SUDE $(I, 3)=E S D(2, I, N)$.A.MU $\$$ SUDE $(I, 2)=\operatorname{SHIFT}(E S D(1, I, N), 30)$. A.MU

$13 \operatorname{SUDE}(I, 4)=\operatorname{SHIFT}(E S D(Z, I, N), 30)$. A.MÚ \$ RETURN \$ END́́

SYMBOLIC REFERENCE MAP $(R=3)$

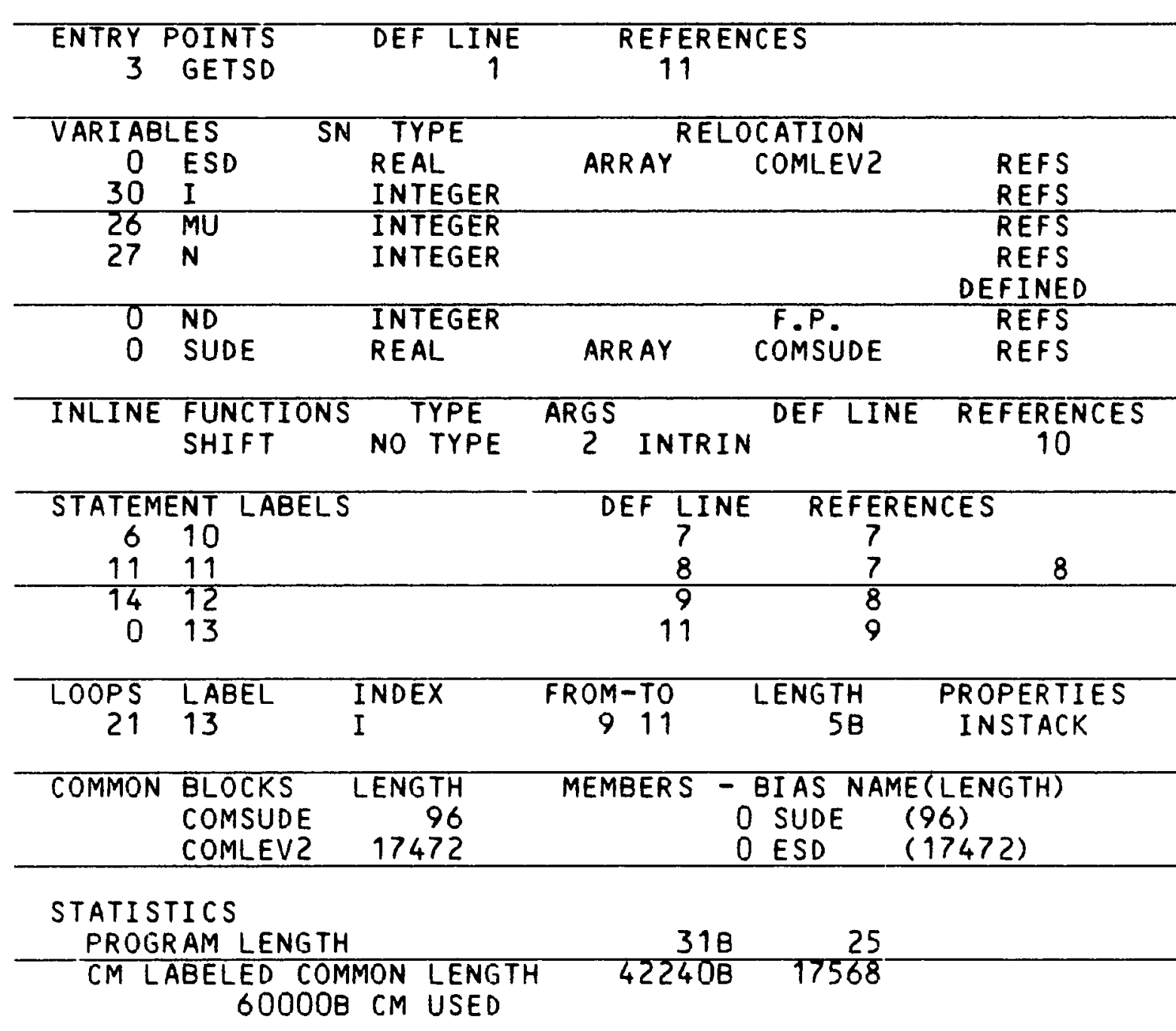




\begin{tabular}{|c|c|c|}
\hline 5 & & $\begin{array}{l}\text { SUBROUTINE DEMGET(IPR, ISBIG,FC,ESD) } \\
\text { DIMENSION ESD }(2,8736) \\
\text { DATA ISS } / 0 / \text { MU/77777777770000000000B/ } \\
\text { IF(FC.LE.0. SGO TO } 20 \\
\text { IF(IPR.EQ.8HFLATD-KW.0. IPR.EQ.8HFLATD-MW)GO TO } 21 \\
\text { IF(ISS.EQ.0)REWIND } 3\end{array}$ \\
\hline & 10 & $\begin{array}{l}\text { ISS }=2 \\
\operatorname{READ}(3) \mathrm{J} 1, \mathrm{~J} 2, \operatorname{ISBIG}(\operatorname{ESD}(\bar{c}, J), J=1,8736) \\
\operatorname{IF}(\operatorname{EOF}(3)) 11,13,11\end{array}$ \\
\hline 10 & 11 & $\begin{array}{l}\text { IF(ISS. EQ. T) GO TO } 12 \\
\text { REWIND } 3 \\
\text { ISS }=1\end{array}$ \\
\hline 15 & 12 & $\begin{array}{l}\text { GO TO } 10 \\
\text { PRINT I, IPR } \\
\text { CALL EXIT }\end{array}$ \\
\hline & 13 & $\begin{array}{l}\text { FORMAT(* CANNOT FIND DEMAND (*A10,*)*) } \\
\text { IF(J1.NE. IPR)GO TO } 10 \\
\text { BACKSPACE } 3 \$ \text { IF (ISBIG.NE. O) I SBIG=1 }\end{array}$ \\
\hline 20 & C & $\begin{array}{l}\text { IF (J2.NE. THE.A.J2.NE.2HEQ)GO TO } 20 \\
\text { ELECTRICAL ONLY } \\
\text { DO } 19 \quad \mathrm{~J}=1,8736\end{array}$ \\
\hline & 19 & $\begin{array}{l}Z 1=E S D(2, J) . A . M U \\
Z 1=Z 1 * F C \\
E S D(2, J)=Z 1 . A . M U\end{array}$ \\
\hline 25 & 20 & $\begin{array}{l}\text { RETURN } \\
\text { PRINT2, IPR, J2,FC } \\
\text { CALL EXIT }\end{array}$ \\
\hline 30 & $\begin{array}{l}2 \\
21\end{array}$ & $\begin{array}{l}\text { FORMAT(* FC OR E, EQ ERROR } \div A 10,1 X, A 10,1 X, E 10.2) \\
Z 1=1000 \text {. \$ I SBIG } 1 \\
\text { IF(IPR.EQ.8HFLATD-MW) GO TO } 22\end{array}$ \\
\hline & 22 & $\begin{array}{l}\text { ISBIG }=0 \\
Z 1=1 . \\
Z 2=2 i . A . M U \$ D O \quad 23 \mathrm{~J}=1,8736\end{array}$ \\
\hline 35 & 23 & $\begin{array}{l}\text { ESD }(2, J)=22 \\
\text { RETURN } \\
\text { END }\end{array}$ \\
\hline
\end{tabular}

SYMBOLIC REFERENCE MAP $(R=3)$

\begin{tabular}{|c|c|c|c|c|c|c|c|c|c|c|c|c|}
\hline $\begin{array}{r}\text { ENTRY } \\
3 \\
\end{array}$ & $\begin{array}{l}\text { PCINTS } \\
\text { DEMGET }\end{array}$ & & $\begin{array}{c}\text { DEF LINE } \\
1 \\
\end{array}$ & $\begin{array}{l}\text { REFERENCES } \\
25\end{array}$ & 35 & & & & & & & \\
\hline $\begin{array}{c}\text { VARI AE } \\
0\end{array}$ & $\begin{array}{l}\text { BLES } \\
\text { ESD }\end{array}$ & SN & $\begin{array}{l}\text { TYPE } \\
\text { REAL }\end{array}$ & ARRAY ${ }^{\text {RELOCATIO }}$ F.P. & REFS & 2 & 22 & DEFINED & 1 & 8 & 24 & 34 \\
\hline $\begin{array}{l}0 \\
0\end{array}$ & $\begin{array}{l}F C \\
I P R\end{array}$ & & $\begin{array}{l}\text { REAL } \\
\text { INTEGER }\end{array}$ & F.P & $\begin{array}{c}\text { REFS } \\
\text { REFS } \\
\text { DEFINED }\end{array}$ & $2 \div 5$ & 23 & $\begin{array}{l}26 \\
17\end{array}$ & $\begin{array}{c}\text { DEFINED } \\
26\end{array}$ & $\begin{array}{l}1 \\
30\end{array}$ & & \\
\hline $\begin{array}{r}0 \\
114 \\
170 \\
\end{array}$ & $\begin{array}{l}\text { ISBIG } \\
\text { ISS } \\
\mathrm{J}\end{array}$ & & $\begin{array}{l}\text { INTEGER } \\
\text { INTEGER } \\
\text { INTEGER }\end{array}$ & F.P. & $\begin{array}{l}\text { REFS } \\
\text { REFS } \\
\text { REFS }\end{array}$ & $\begin{array}{r}18 \\
6 \\
8 \\
\end{array}$ & $\begin{array}{c}\text { DEFINED } \\
10 \\
22\end{array}$ & $\begin{array}{c}1 \\
\text { DEFINED } \\
24\end{array}$ & $\begin{array}{r}8 \\
3 \\
34\end{array}$ & $\begin{array}{r}18 \\
7 \\
\text { DEF I NED }\end{array}$ & $\begin{array}{r}29 \\
12 \\
8\end{array}$ & $\begin{array}{l}31 \\
21\end{array}$ \\
\hline $\begin{array}{l}166 \\
167\end{array}$ & $\begin{array}{l}\mathrm{J} 1 \\
\mathrm{~J} 2\end{array}$ & & $\begin{array}{l}\text { INTEGER } \\
\text { INTEGER }\end{array}$ & & $\begin{array}{r}33 \\
\text { REFS } \\
\text { REFS }\end{array}$ & $\begin{array}{c}17 \\
2 * 19\end{array}$ & $\begin{array}{c}\text { DEFINED } \\
26\end{array}$ & $\begin{array}{c}8 \\
\text { DEFINED }\end{array}$ & 8 & & & \\
\hline
\end{tabular}




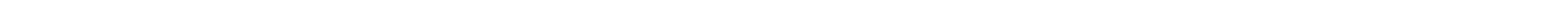




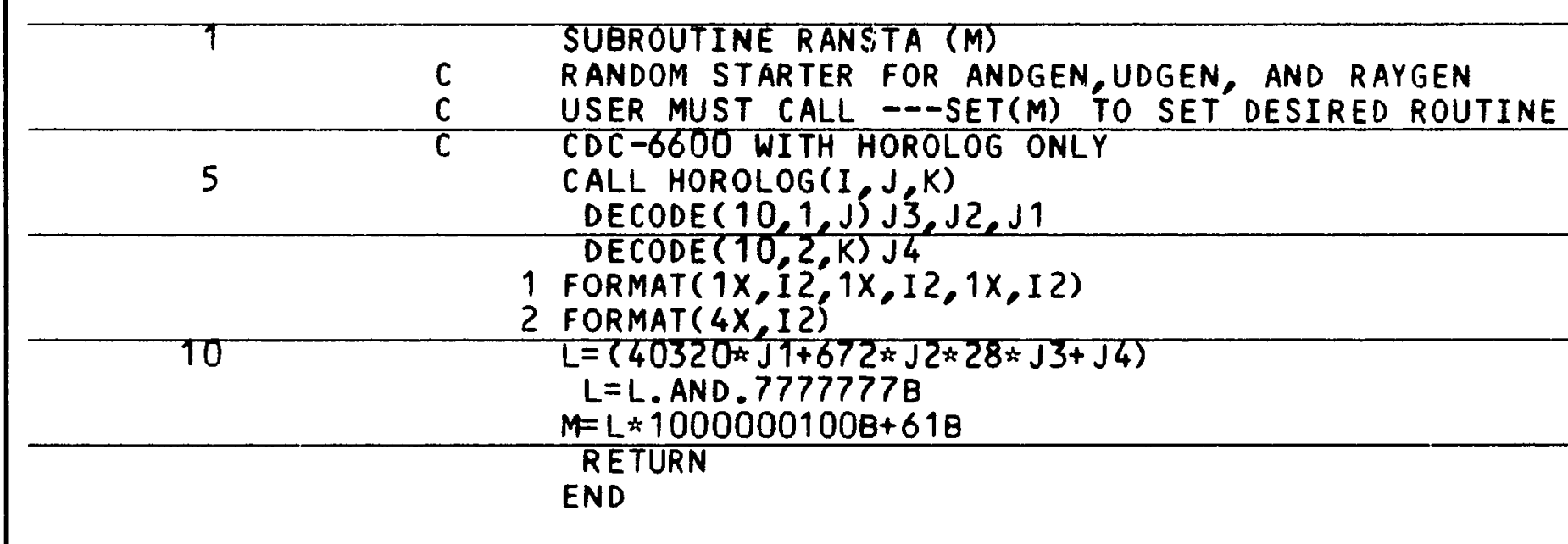

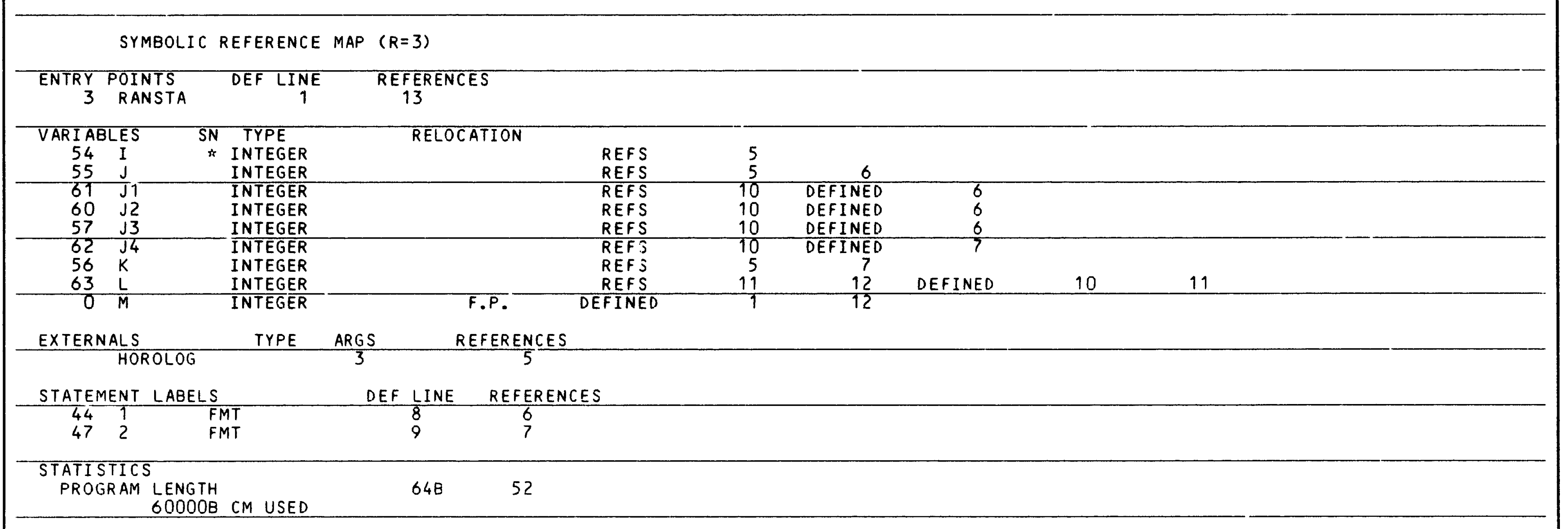

